\title{
Understanding Ridership Trends in Transit
}

CUTR

Follow this and additional works at: https://scholarcommons.usf.edu/cutr_nctr

\section{Recommended Citation}

"Understanding Ridership Trends in Transit," National Center for Transit Research (NCTR) Report No. CUTR-NCTR-RR-2018-05, Center for Urban Transportation Research, University of South Florida, 2018. DOI: https://doi.org/10.5038/CUTR-NCTR-RR-2018-05

Available at: https://scholarcommons.usf.edu/cutr_nctr/15

This Technical Report is brought to you for free and open access by the National Center for Transit Research (NCTR) Archive (2000-2020) at Scholar Commons. It has been accepted for inclusion in Research Reports by an authorized administrator of Scholar Commons. For more information, please contact scholarcommons@usf.edu. 


\title{
Understanding Ridership Trends in Transit
}

\author{
Final Report
}

Report prepared for: Florida Department of Transportation, Freight Logistics and Passenger Operations, Transit Office
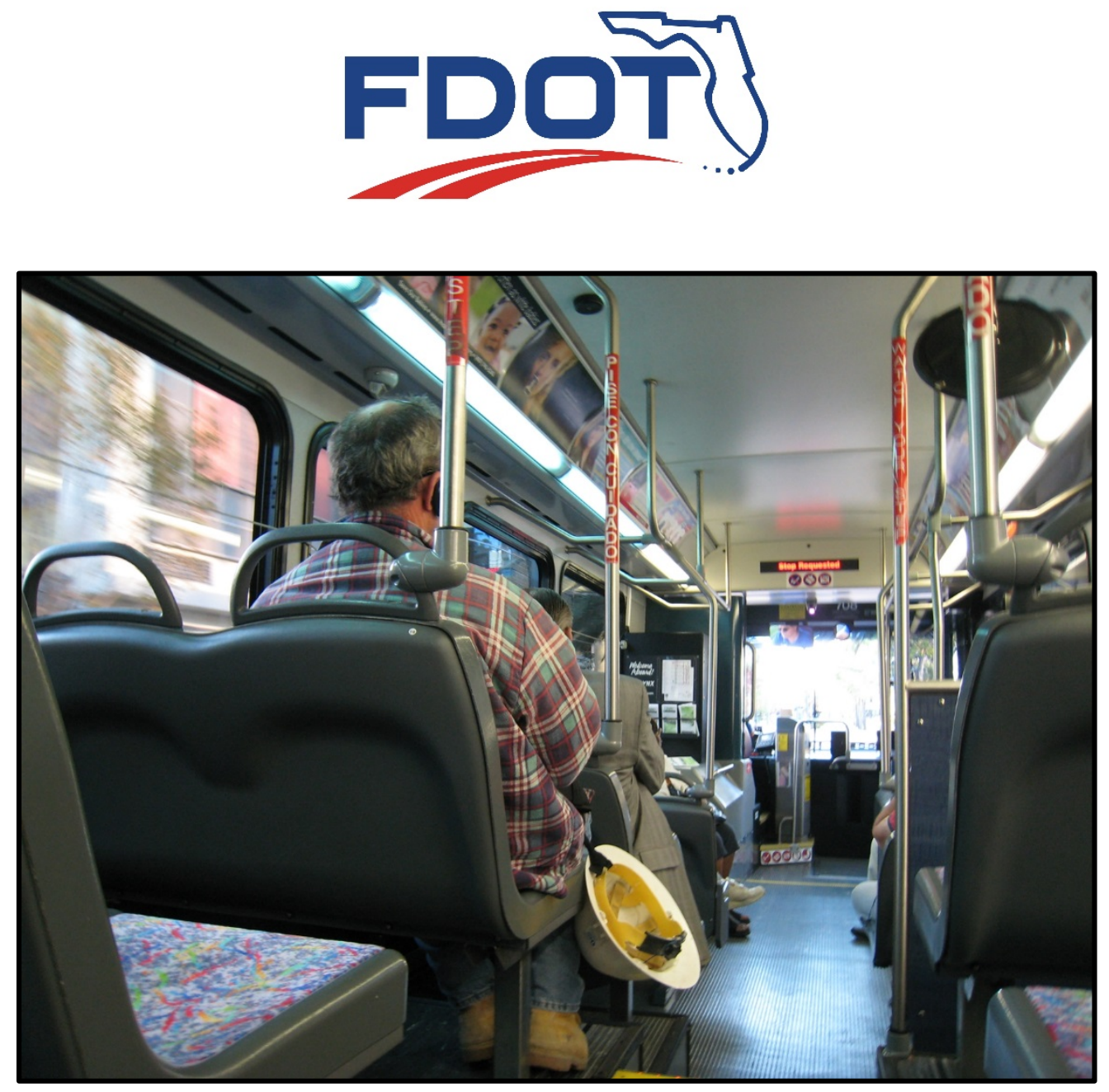

February 2019
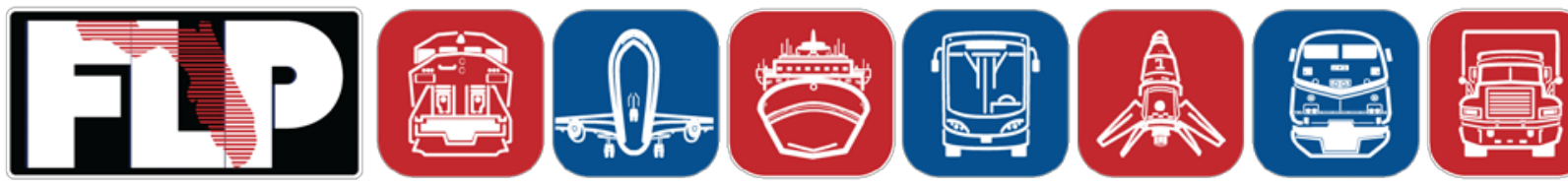


\title{
Understanding Ridership Trends in Transit
}

\section{Task 8 Deliverable: Final Report}

\author{
BDV25 977-45 \\ Report prepared for: \\ Florida Department of Transportation, Freight Logistics and \\ Passenger Operations, Transit Office

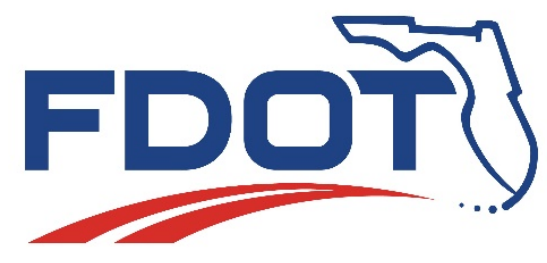 \\ By: \\ Steven E. Polzin and Jodi Godfrey \\ Center for Urban Transportation Research \\ University of South Florida \\ Project Manager: \\ Gabrielle Matthews \\ Office of Public Transportation \\ Florida Department of Transportation \\ gabrielle.matthews@dot.state.fl.us
}

(850)414-4803

February 2019 
"The opinions, findings, and conclusions expressed in this publication are those of the authors and not necessarily those of the State of Florida Department of Transportation." 


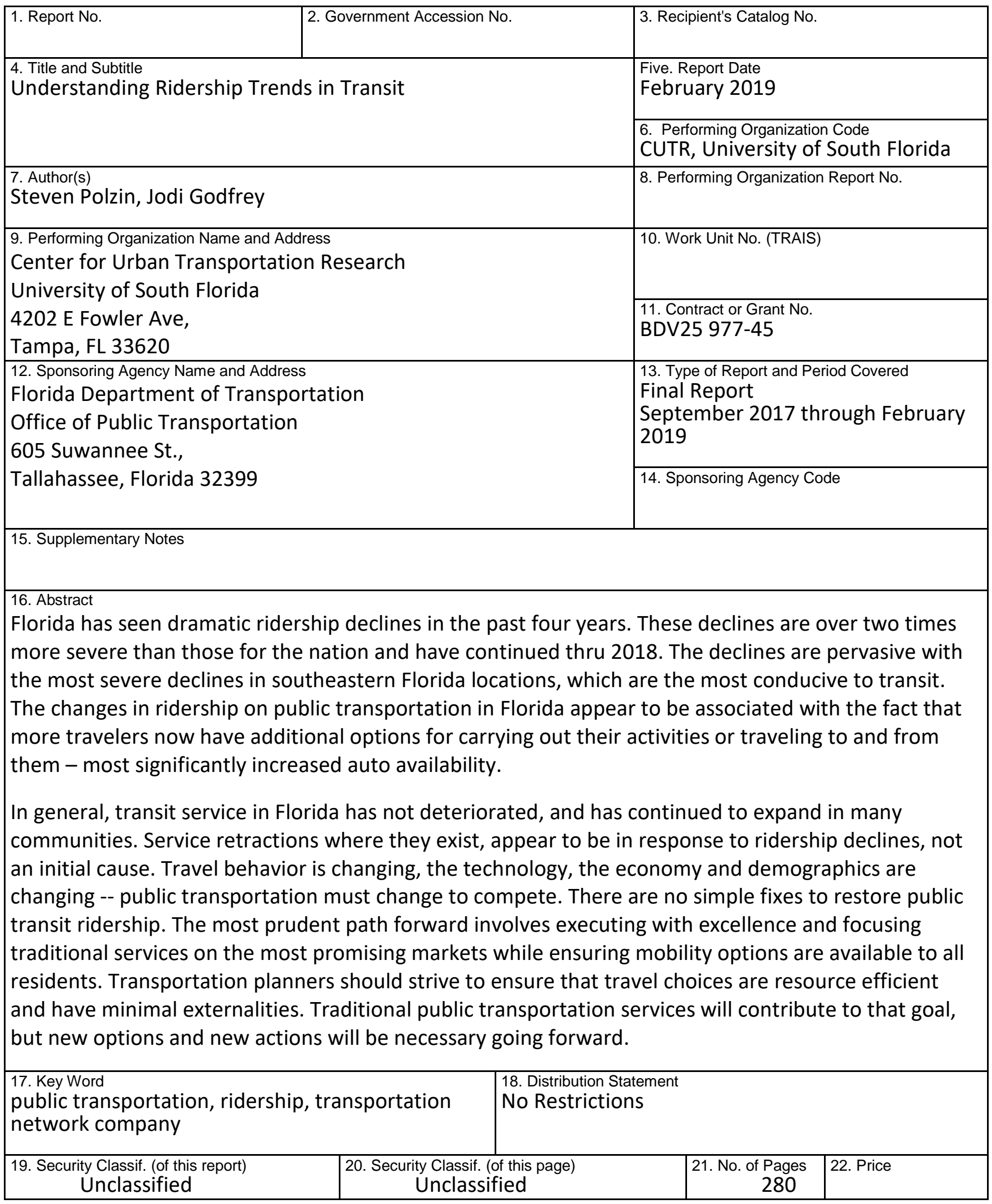

Form DOT F 1700.7 (8-72) Reproduction of completed page authorized 


\section{Executive Summary}

Both in Florida and nationally, transit ridership was generally on a positive trend between approximately 1995 and 2013. Growing population, expanded services and facilities, increased urbanization, higher fuel prices, and other factors were credited with this positive trend. In 2013, the industry was hitting ridership totals that had not been witnessed since the 1950s. Florida was reporting transit ridership growth percentages twice the level of population growth. Per capita ridership nationally was stable to slightly declining. In approximately 2013, trends changed dramatically. Public transportation entered a period of ridership declines in spite of an improving economy, growing population and generally increasing levels of service. As the decline accelerated and affected virtually every metropolitan area in the country, the public transportation industry took notice and began to seek to understand these new trends. In Florida, the trends were broad-based and more pronounced than industry averages.

The significant decline in transit ridership, coupled with the prospect that ongoing technology changes and demographic and economic trends will continue to challenge traditional public transportation going forward, has given rise to questions about what is causing the change and how public transportation stakeholders should respond. Both the magnitude and pervasiveness of the declines in transit ridership have made it increasingly apparent that this ridership downturn is unlike many other ridership fluctuations. This research effort, supported by the Florida Department of Transportation, explores the issue of declining transit ridership in greater detail. While the motivation for understanding and responding to ridership declines for public transportation is self-evident, it is important to fully understand the nature of changes in travel behavior, explore the factors that may be underlying the changes and provide insights and perspectives on what responses might be appropriate.

Florida has seen dramatic ridership declines in the past four years. These declines are over two times more severe than those for the nation, on average, and have continued well into 2018. The declines are relatively pervasive with no areas escaping the pressures on transit ridership. Of concern, the most severe declines have been in those locations, like southeastern Florida, that are the most conducive to transit. The magnitude of the declines exceeds those observed in prior economic cycles and have been traced to a set of conditions, some of which have not been witnessed previously. The conditions that have contributed to changes in travel behavior have not necessarily fully played themselves out.

The changes in ridership on public transportation in Florida appear to be associated with the fact that more travelers now have additional options for carrying out their activities or traveling to and from them. In general, transit service in Florida has not deteriorated, and in fact has continued to expand in many communities. Unlike some other communities across the country, 
high profile safety, service reliability or chronic substance abuse and homeless loitering issues are not key causes for declining ridership. Service reductions, where they exist, appear to be in response to ridership declines, not an initial cause.

Housing patterns and origin-destination travel patterns which change relatively slowly over time preclude attributing short-term ridership declines to changes in land use patterns. While Florida's land-use and activity patterns are acknowledged as not conducive to cost-effective high-quality public transportation services, the patterns have not changed meaningfully in the past few years.

However, in light of having new options, more trips made by the growing population are opting for alternatives to transit. Transit is losing in the competition for attracting customers. Some travelers are replacing travel with communication, for example working at home and shopping via e-commerce. Many others have added household vehicles offering an alternative for individuals who were previously inclined to use public transportation. Still others are using transportation network companies as an alternative to transit for some trips.

Transit has not gotten worse; the other options have gotten better. Accordingly, the challenge facing transit is not one of undoing actions that hurt ridership but rather finding new ways to be more competitive. This challenge is complicated by the fact that declining ridership creates financial pressures for agencies and undermines the productivity and efficiency of public transportation in ways that diminish its potential benefits in areas such as congestion reduction, air quality, and energy use. This undermines both the justification for services as well as the political and public support for them. There is no simple formula or lookup table as to what transit agencies should do. The answers are complex, context specific, and may include rethinking the role of public transportation as we currently know it and finding additional multimodal ways to pursue the fundamental objectives of providing resource efficient mobility opportunities for travelers.

Transit's role in many communities is still critical and will be for the foreseeable future. Growing population, and in some areas increased density, have historically suggested a need for an expanded role for transit. Florida faces a dilemma, growth is still robust and decision makers aspire for the growth that provides employment and economic opportunities. There is often an unwillingness or inability to meet mobility needs by expanding roadway capacity despite demand, but the hoped-for public embrace of public transit is not materializing. Individuals' travel decisions are not growing transit ridership. The challenge facing transportation planning and operations is profound.

To craft a constructive role for public transportation will require agencies to fully understand their markets and the needs of travelers who may find transit an attractive alternative. It will be 
critical to refine our understanding of activity patterns in terms of origins and destinations with a high propensity to support public transportation services so that services can be correctly targeted to travel patterns that can support public transportation. Similarly, it will be important to recognize that as more options have become available to travelers and activity patterns continue to disperse as metropolitan areas in Florida grow, we may see increasing areas where markets may not justify fixed route services. Meanwhile, meaningful numbers of travelers still need assistance in meeting their mobility needs.

Many citizens and policymakers still do not realize the significance of what has been going on. Some presume the ridership decline is a cyclical phenomenon. Others assume it is a result of underinvestment and can be reversed with more money. Still others are reticent to talk about the issue, as they worry it might undermine the public support for public transportation. Segments of the public transportation planning community realize there are no easy answers. Service reconfigurations, new investment in service and amenities, and other actions, while certainly supportive, are unlikely to quickly reverse the trend of the past several years nor enable public transportation to return to the productivity levels it has enjoyed in the past.

Other communities may see an intensification of development in select areas. With proper planning, these areas may be increasingly supportive of public transit services. Where communities plan to have intense urban developments, careful design and coordinated transportation investments such that transit's competitive position is not undermined by actions such as underpriced parking or poor intermodal integration, can support robust public transportation. If communities want public transportation to be successful, they need both the physical and policy environment to support it.

Stakeholders beyond the transit operating agencies will need to be engaged as many of the conditions that influence public transit use are influenced by broader community, state, and federal actions. Public transportation stakeholders will need to be facilitators of mobility in their communities. In this role, the responsibility will be to ensure mobility options are available and that basic elements of safety, accessibility, reliability, equity, and other quality parameters meet community standards. This may involve integrating public and private sector operators, ensuring modal integration, enabling convenient travel information and fare payment, and potentially providing user side subsidies to ensure access to market priced services. Land-use planning, transportation pricing, and transportation investment and coordination are responsibilities that require all stakeholders to be engaged. Solutions and strategies may vary across areas as local travel needs and priorities influence actions. The pace of change may be influenced by the pace of technological progress with respect to vehicle automation and customer acceptance and its influence on travel choices available to the public. 
The nature of changes in ridership and the prospect of their continuation suggests the need to review and modify transportation planning activities as they relate to planning for public transportation. The planning data sets, tools, and processes should reflect, to the extent possible, the recent changes in travel behavior. The uncertainty inherent in travel behavior and technology change indicate a need for planning processes that more fully embrace evaluations of different scenarios with respect to future conditions and demand for transportation.

Travel behavior is changing, the technology, economy and demographics are changing -- public transportation must change as well. There are no simple fixes to restore public transit ridership. Rather than hoping to restore public transportation, the most prudent path forward involves ensuring mobility options are available to all residents and striving to ensure that travel choices are resource efficient and have minimal externalities. Traditional public transportation services can contribute to that goal, but new options and new actions will be necessary going forward.

In its simplest form, the path forward for public transportation includes the following steps:

- Acknowledge the magnitude and complexity of the changes and engage stakeholders in exploring responses going forward.

- Aggressively monitor changing transit ridership and travel behavior characteristics to make sure planners and policymakers are aware of and understand changing trends.

- Execute the delivery of public transportation with excellence - make sure the basic elements important to travelers are delivered to the extent possible. Vehicles should be clean and safe, personnel competent and professional, communications with customers should be enhanced and responsive, service plans should be responsive to evolving land-use and activity patterns, amenities should be provided where prudent, and safety in both accessing and using public transportation should remain a critical priority.

- Other public policies should be sensitive to their consequence on transit ridership. Drivers should be required to have insurance. Parking should be priced in a manner that does not subsidize auto travel. Where possible, public transportation and multi occupant vehicles should be given priority treatment. Land use decisions should take into account the ability of development to support public transit.

- New technologies should be leveraged by public transportation to enhance its competitiveness. This will include convenient customer information, trip planning, fare payment, vehicle and station safety systems, driver assistance features, preferential treatment capabilities, and integration with first-mile, last-mile and interregional travel options.

- Revisit transportation planning and public transportation planning practices in light of the nature of changes that have been occurring and are anticipated to continue. 
- Where traditional public transportation cannot be competitive, or cannot be competitive in a cost-effective manner, other options should be explored. Spending resources without commensurate levels of utilization do not accomplish the goals of public transportation.

- Identify opportunities were emerging modes and business models as characterized by transportation network companies, short-term vehicle rental, bike and scooter sharing services etc., may be opportunities for connecting with transit and/or substituting for transit in a fashion that is both cost-effective and responsive to customer needs.

- Watch the emergence of automated transportation services carefully so the industry can position itself to both embrace automation where appropriate and relinquish the role of traditional big vehicle fixed route public transportation services if mobility-as-aservice options render them uncompetitive in some markets. 


\section{Table of Contents}

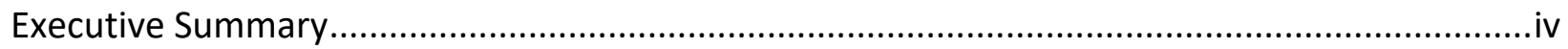

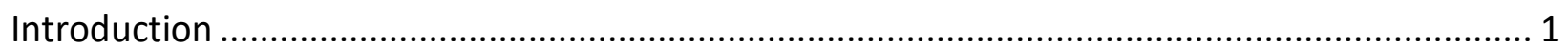

Chapter 1. Transit Ridership Trends in Florida and Nationwide............................................. 2

What Is Happening to Transit Ridership? ......................................................................... 2

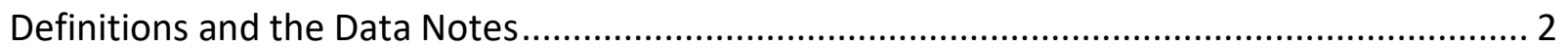

Descriptive Portrait of Transit Use and Associated Trends ..................................................... 3

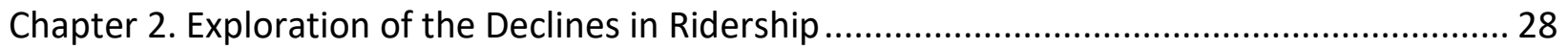

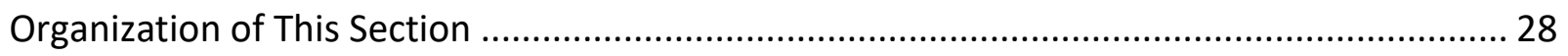

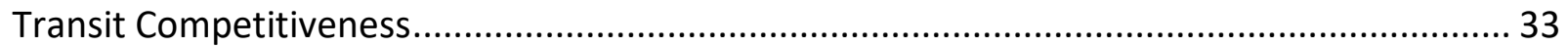

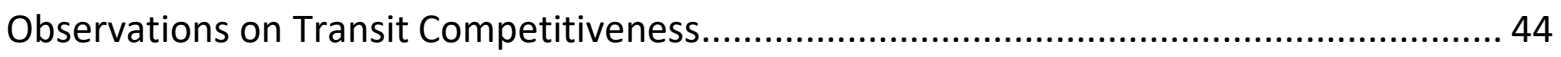

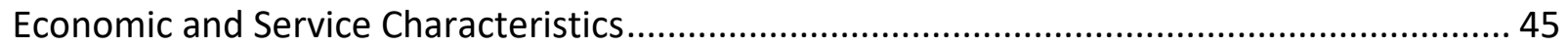

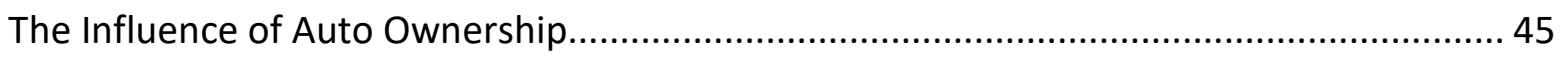

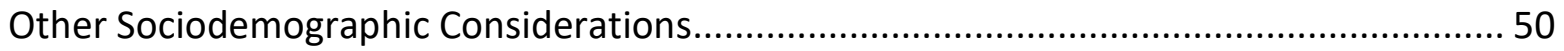

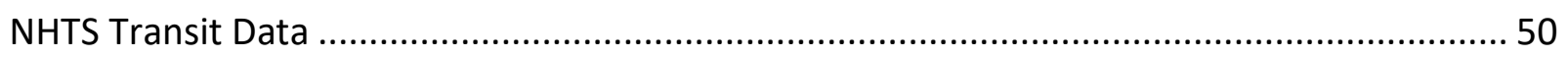

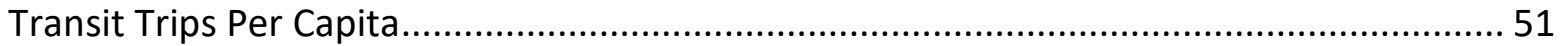

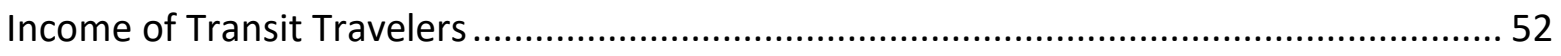

Average Age of Transit Travelers (years) ....................................................................... 52

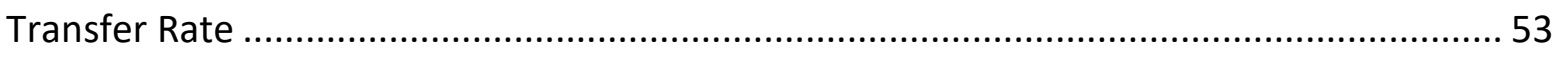

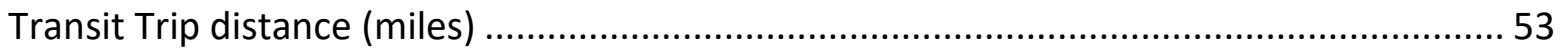

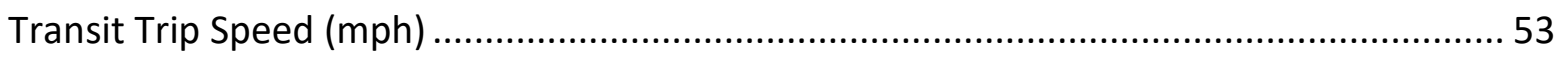

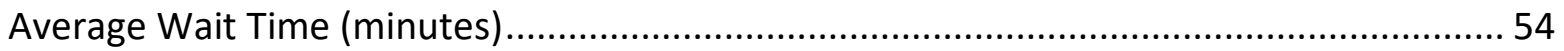

Household Vehicle Availability (Average Vehicles per Household) ..................................... 54

Household Vehicle Availability (Share of Zero-Vehicle Households) .................................... 54

Persons who use Public Transit with Zero Vehicles Available............................................... 54

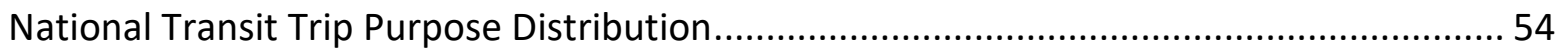

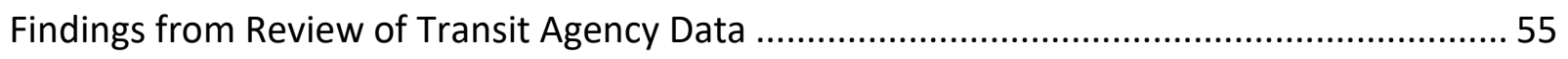

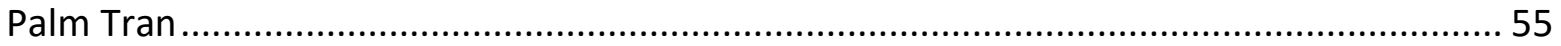

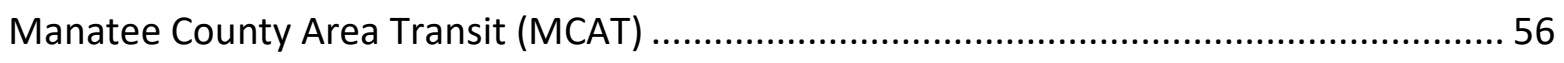




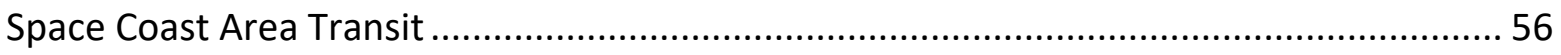

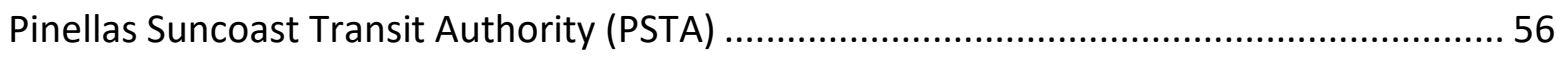

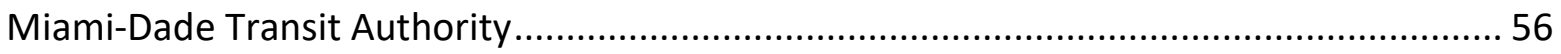

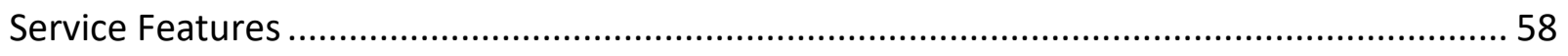

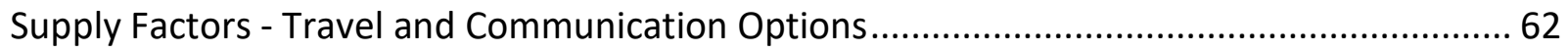

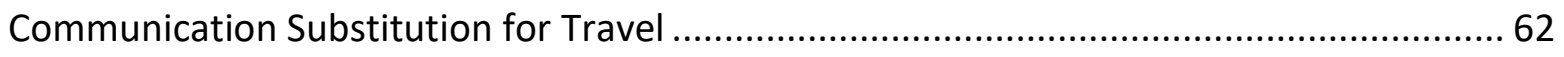

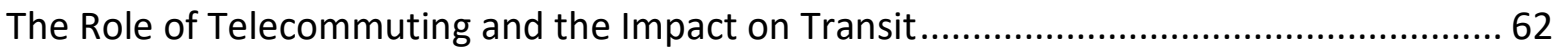

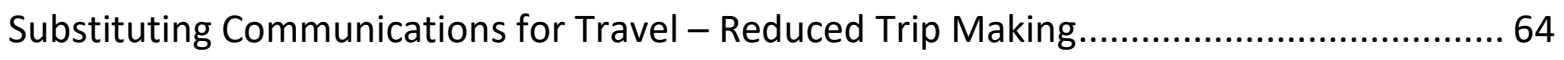

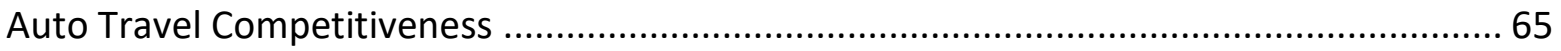

Ridership Impact of Communication and Transportation Options - Transportation Network

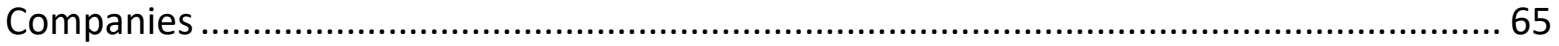

Observations and Recommendations regarding TNC and Transit in Florida ........................ 75

Summary Observations on Exploration of the Declines in Ridership ........................................ 76

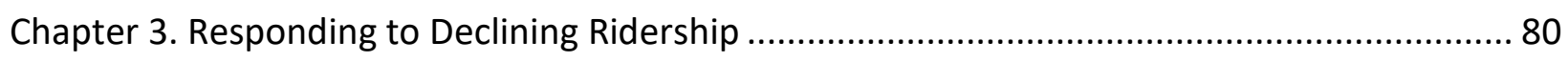

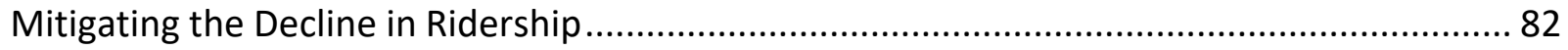

Paratransit and Demand Responsive Services ................................................................. 86

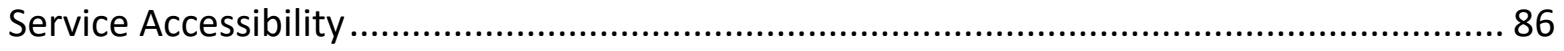

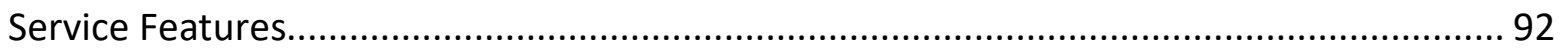

The Trend toward Service Reconfiguration....................................................................... 93

Demographic, Economic and Land Use Market Factors ...................................................... 95

Travel and Communication Options .................................................................................... 99

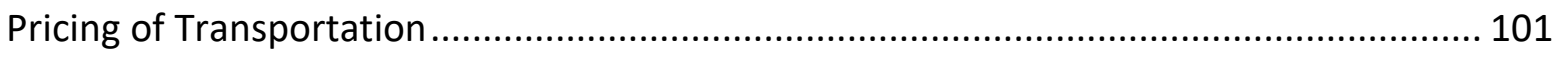

Mitigate or Offset the Impacts of Declining Ridership .......................................................... 101

Positioning Public Transportation for the Evolving World of Personal Mobility .................... 102

The Future of Public Transit as a Social Service ............................................................ 104

The Future of Public Transit as a Resource-Efficient Means of Moving People ................. 106

Public Transit as a Tool to Stimulate Economic Activity and Influence Land-Use .............. 107

Modifying Transportation Planning to Reflect Changing Ridership Propensity ..................... 109

Evaluating travel demand forecasting data sets and tools ................................................ 110

Rethinking plan update cycles ................................................................................... 111 
Evaluate plan actions or strategies against future scenarios

Design service investment strategies that offer near-term benefits

Continued monitoring of key trends

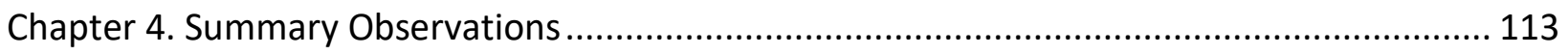

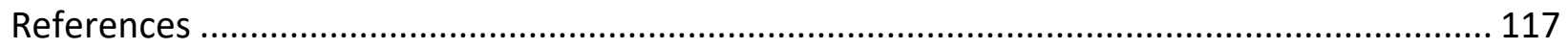

Appendix A - Profiles of Florida Transit Operating Agencies.............................................. 121

Listed in order of Ridership. See Table of Contents for direct links to each property. ......... 121

Miami-Dade County (Miami-Dade Transit) ....................................................................... 121

Broward County (Broward County Transit Division, BCT) ............................................... 126

Central Florida RTA (Central Florida Regional Transportation Authority, LYNX).................. 130

Hillsborough County (Hillsborough Area Regional Transit Authority, HART) ...................... 135

Jacksonville (Jacksonville Transportation Authority, JTA)............................................. 139

Pinellas County (Pinellas Suncoast Transit Authority, PSTA) ............................................ 143

Jolley Trolley (Jolley Trolley Transportation of Clearwater, Inc.)...................................... 146

Looper Group (The Looper Group, Inc.) ............................................................... 147

Palm Beach County (Board of County Commissioners, PalmTran) ................................... 148

Gainesville (Gainesville Regional Transit System, RTS) ................................................. 152

South Florida RTA (South Florida Regional Transportation Authority, SFRTA).................... 156

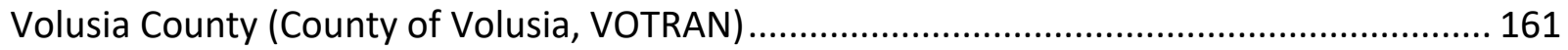

Tallahassee (City of Tallahassee, StarMetro) .................................................................. 165

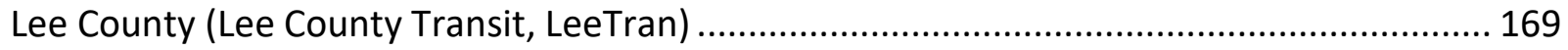

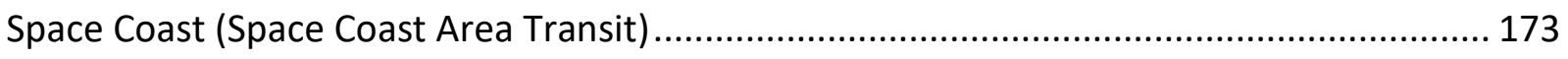

Sarasota County (Sarasota County Area Transit, SCAT) .............................................. 177

Escambia County (Escambia County Area Transit, ECAT) ............................................... 181

Manatee County (Manatee County Area Transit, MCAT) ............................................... 186

Lakeland (Lakeland Area Mass Transit District, CitrusConnection) .................................... 190

Indian River County (Indian River County, GoLine) ........................................................ 194

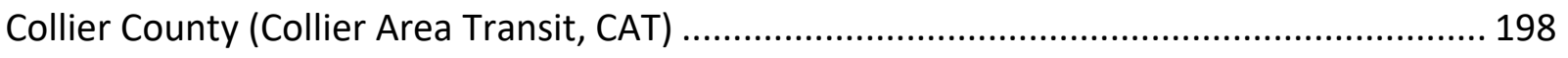

Pasco County (Pasco County Public Transportation, PCPT) ............................................... 202 
Central Florida CR (Central Florida Commuter Rail, SunRail) .......................................... 206

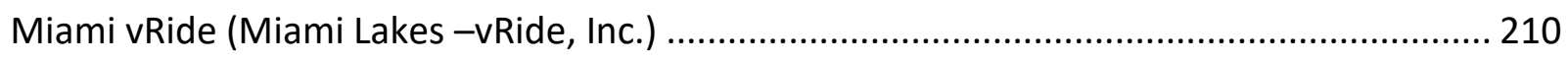

Lake County (Lake County Board of County Commissioners, Lake Transit) ......................... 213

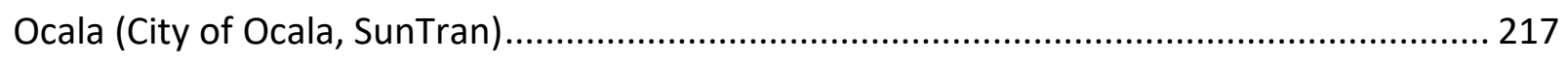

St. Lucie County (Council on Aging of St. Lucie, Inc., Treasure Coast Connector) ................. 221

Fort Lauderdale (City of Fort Lauderdale Transit) ....................................................... 225

Okaloosa County (Okaloosa County Board of County Commissioners, EC Rider) ................. 229

TBARTA (Tampa Bay Area Regional Transportation Authority) ........................................ 233

Bay County (Bay County Transportation Planning Organization, Transit Division) ............... 236

Charlotte County (Charlotte County Transit) ............................................................. 240

Clay County (Clay County Council on Aging, Inc., Clay Transit) ......................................... 243

Flagler County (Flagler County Public Transportation, FCPT) ........................................ 247

Martin County (Martin County Transit, Marty) .............................................................. 250

Polk County (Polk County Transit Services Division) .................................................... 255

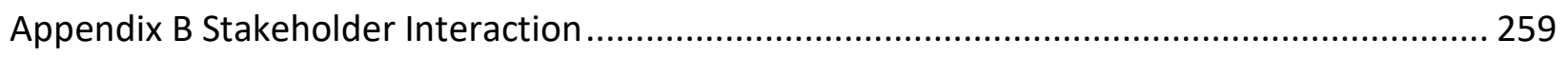




\section{List of Figures}

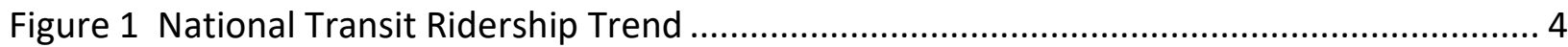

Figure 2 National Trend in VMT and VMT Per Capita, Rolling 12 Month Total......................... 8

Figure 3 Florida Trend in VMT and VMT Per Capita .......................................................... 8

Figure 4 Florida and U.S. Trend in 12 Month Rolling Fixed Route Ridership Levels................... 9

Figure 5 Florida and U.S. Trend in 12 Month Rolling Fixed-Route Ridership Losses Since 2012 .. 9

Figure 6 U.S. Fixed Route Transit Ridership and Service Trend .......................................... 10

Figure 7 Florida Fixed Route Transit Ridership and Service Trend ......................................... 10

Figure 8 Top 40 UZAs by 2017 Transit Ridership, Change 2014-2017 (Millions)....................... 13

Figure 9 Top 10 Florida Operators by 2017 Transit Ridership, Change 2014-2017 (Millions) .... 14

Figure 10 Florida Agencies Share of Ridership Total and Losses, 2013-2017.......................... 15

Figure 11 Commuting Mode Choice Trends in Florida ........................................................ 16

Figure 12 National Commuting Mode Choice Trends............................................................ 16

Figure 13 Zero-Vehicle Household Trend, U.S. and Florida................................................ 17

Figure 14 National Transit Trip Purpose Distribution ............................................................. 21

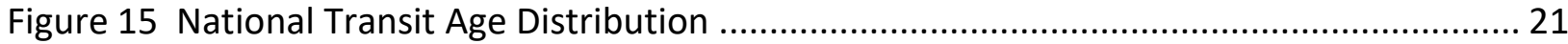

Figure 16 12-Month Rolling Average U.S. Transit Ridership and Service, All Modes................ 22

Figure 17 12-Month Rolling Average U.S. Transit Ridership and Service, Fixed Route............... 22

Figure 18 12-Month Rolling Average U.S. Transit Ridership and Service, Bus ........................ 22

Figure 19 12-Month Rolling Average U.S. Transit Ridership and Service, Heavy Rail ................ 23

Figure 20 12-Month Rolling Average U.S. Transit Ridership and Service, Light Rail .................. 23

Figure 21 12-Month Rolling Average U.S. Transit Ridership and Service, Commuter Rail.......... 23

Figure 22 National Gas Price and Transit Ridership Trends................................................. 24

Figure 23 Florida Gas Price and Transit Ridership Trends ................................................. 25

Figure 24 Percent Change U.S. Transit Ridership and SNAP Enrollment.................................. 25

Figure 25 Percent Change FL Transit Ridership and SNAP Enrollment.................................. 26

Figure 26 Average Fare Revenue per Passenger Trip and Passenger Mile (in 2017 Dollars) ...... 27

Figure 27 Framework for Exploring Factors Influencing Public Transit Ridership Levels ............ 28

Figure 28 Components of Transit Travel Time.................................................................... 34

Figure 29 Florida Fixed Route Transit Ridership and Service Trend ...................................... 35

Figure 30 Ridership vs. Service percent Change 2014-2017................................................ 37

Figure 31 Trend in Florida Population Served by Transit (2002-2016) .................................... 37

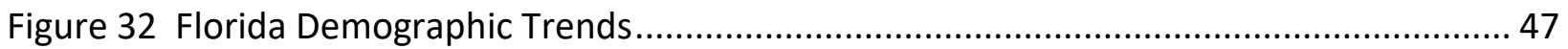

Figure 33 Income Distribution of National Transit Trips .................................................... 52

Figure 34 Age Distribution of National Transit Trips ............................................................ 53

Figure 35 National Distribution of Transit Trips by Purpose .............................................. 55 
Figure 36 Total Monthly an Average Weekday Ridership MDTA, Year-Over-Year Comparisons,

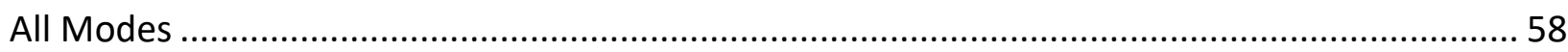

Figure 37 Commuting by U.S. Workers by Usual Commuting Mode, 2013, 2017, (000) ........... 63

Figure 38 Change in Florida Workers by Usual Commuting Mode, 2013-2017 (000)............... 63

Figure 39 Trends in Person Trips by Purpose, US, 1990 to 2017 ........................................... 65

Figure 40 Trend in Number of Receipts of Livery Operators in Florida ................................... 68

Figure 41 Trend in Number of Non-employer Livery Drivers in Florida ...................................6 69

Figure 42 Trend in Number of Non-employer Livery Driver Receipts in Florida ....................... 70

Figure 43 Characterization of the Changing Choice Set Facing Many Travelers Who Previously

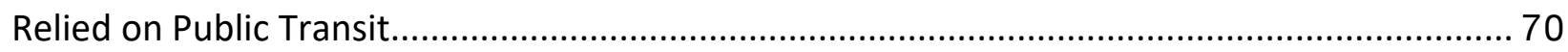

Figure 44 Conceptual Interrelationships between Transit Use and Contributing Factors .......... 78

Figure 45 Probability of Using Transit Versus Service Frequency for Captive and Choice

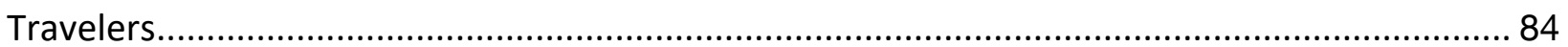

Figure 46 Probability of Using Transit versus Surface Frequency for Choice Travelers ............. 94 


\section{List of Tables}

Table 1 National Trends in Travel and Contributory Factors.................................................... 6

Table 2 Florida Trends in Travel and Contributory Factors ................................................ 7

Table 3 Transit Ridership and Service Summary by Mode, Florida and U.S............................ 11

Table 4 Zero-Vehicles Household Trends for Florida Geographies ........................................ 18

Table 5 Population Trend for Florida Transit Service Areas ................................................ 19

Table 6 Transit Trip and Travel Characteristics from the National Household Travel Survey..... 20

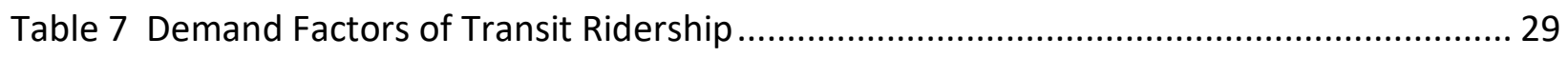

Table 8 Supply Factors of Transit Ridership, Transit Service Characteristic ............................. 30

Table 9 Supply Factors of Transit Ridership, Travel and Communications Options ................... 31

Table 10 Transit Ridership and Service Summary by Mode, Florida ....................................... 36

Table 11 Ridership and Service Change 2017-2014 .............................................................. 38

Table 12 Service Accessibility Factors That Impact Transit Ridership ..................................... 39

Table 13 Service Intensiveness for All Florida Transit Agencies ............................................ 41

Table 14 Florida Fixed Route Agencies Average Speed ......................................................... 41

Table 15 Comparisons of Transit Accessibility in Major U.S. Metropolitan Areas .................... 43

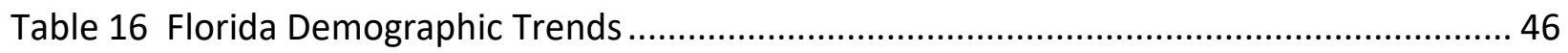

Table 17 Fixed Route Ridership and Service Trends in Florida ................................................ 47

Table 18 Trips Per Person (5 and older) Per Year Using Transit ............................................. 48

Table 19 Florida Population by Household Vehicle Availability, 5 and Older.......................... 48

Table 20 Sample Sizes of 2009 and 2017 NHTS Surveys...................................................... 51

Table 21 Florida \& National Travel Characteristics, 2009 VS 2017 (NHTS) .............................. 51

Table 22 Service Features Factors That Impact Transit Ridership .......................................... 59

Table 23 Supply Factors That Impact Transit Ridership, Travel and Communication Options ... 61

Table 24 Census Data Trend by Florida County for Nonemployee Livery Driver Count and

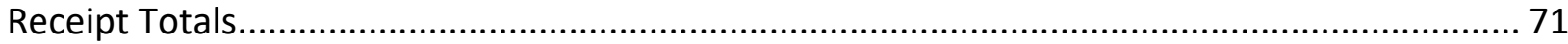

Table 25 Scenario on the Impact of TNC on Transit Ridership, Miami-Dade, 2016 ................. 73

Table 26 Service Productivity Implications of Public Transportation Trends ............................. 82

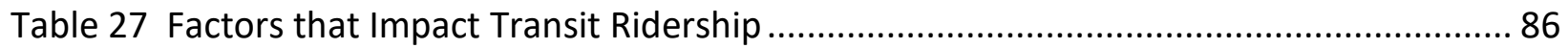

Table 28 Target Markets for the Service Improvements ................................................... 89

Table 29 Factors that Impact Changes in Transit Ridership................................................... 96

Table 30 Factors that Impact Transit Ridership .................................................................. 100 


\section{Introduction}

The purpose of this report is to document the research activities and findings associated with the investigation of Florida transit ridership. This specifically provides the Final Report for project BDV25 977 - 45 for the Florida Department of Transportation Public Transit Office. This deliverable summarizes the research carried out in prior tasks and the information delivered in prior deliverables. This final report summarizes, integrates, and updates this information into a single summary document.

Through this effort, the project team had an opportunity to explore ridership trends across Florida transit properties and develop an understanding of how Florida trends compared across properties and with respect to national trends. These trends are described based on extensive empirical data analyzed in an effort to discern causality, and interpreted such that stakeholders can formulate responses based on the data and insights developed during this research.

This report is organized into four major sections. Beyond this introductory section, the report provides a descriptive summary of trends, which are supported by a detailed appendix with agency specific data. The next section describes an analysis carried out to discern causality and reports those findings. The subsequent section discusses implications and stakeholder responses. An additional appendix details communication activity with industry stakeholders. A bibliography provides a list of resources for those interested in further exploration of this topic. 


\title{
Chapter 1. Transit Ridership Trends in Florida and Nationwide
}

\author{
What Is Happening to Transit Ridership?
}

The significant decline in transit ridership, coupled with the prospect that ongoing technology changes and demographic and economic trends will continue to challenge traditional public transportation going forward, has given rise to questions about what is causing the change and how public transportation stakeholders should respond. It has become increasingly apparent that this ridership downturn is unlike many other ridership fluctuations in response to economic trends or fluctuations in service availability. Both the magnitude and pervasiveness of the declines in transit ridership in the context of a strengthening economy and growing overall travel levels, coupled with rapid innovations in technology enabling more travel choices, have motivated several research initiatives across the country. This research effort, supported by the Florida Department of Transportation, explores the issue of declining transit ridership in greater detail. While the motivation for understanding and responding to ridership declines for public transportation is self-evident, it is important to fully understand the nature of changes in travel behavior, explore the factors that may be underlying the changes, and provide insights and perspectives on what responses might be appropriate.

\section{Definitions and the Data Notes}

This analysis is based on analysis of ridership and service data reported by the individual transit operators to the U.S. Department of Transportation (USDOT) Federal Transit Administration (FTA) through the National Transit Data (NTD) program. This mandatory agency reporting is a prerequisite of receipt of federal formula funds and provides information for oversight of financial, service, safety, and other aspects of transit operations that utilize federal resources.

In using the data set, we identified several cases where data was missing and/or appeared erroneous. In some cases, we worked with the agencies and/or reported the errors to the NTD program. There are also cases of missing data where agencies did not report during particular time periods or for other reasons data was not available. In some instances, agencies lag in the timeliness of the reporting, therefore, the project team used slightly different dates as the reference point for comparative trends. It is quite common for agencies to retroactively update data, sometimes for several months beyond the initial reporting, to reflect refinements in methodology, corrections of errors, or other factors. Therefore, anyone attempting to carry out similar analyses or extend the analysis period should use the most current available data.

The analysis in this report focuses on calendar year and monthly trends, which means it differs from some other data analyses that FDOT or other entities use that reference agency fiscal years. Because fiscal years vary across agencies and we wanted to capture the most current data possible, the project team chose to focus on calendar year and monthly trend data. 
Users of this information should review the data carefully to understand nuances and context specific conditions. In general, the data set was very adequate for meeting the purposes of this aspect of the research project, that being to understand temporal and modal trends across geographies in Florida.

Definitions and abbreviations used in the report are detailed below for readers' reference. The ordering of the reporting on agencies in Appendix A is based on calendar year 2017 total transit ridership.

According to the NTD monthly raw data download file, "After the close of a month, transit properties have one month to compile and submit data to the NTD; therefore, there is a 30-day lag from the end of the month to the time the data is submitted."

Additionally, the NTD monthly raw data download states, "FTA requires properties to report a 100 percent count of unlinked passenger trips if the data is available and reliable; however, there are many properties that do not have the technology, or the means required to perform a 100 percent count. In these cases, FTA allows reporting based on sampling. Unlike unlinked passenger trips, service supplied data must be reported based on a 100 percent count."

A multitude of other data sources are used throughout the report and referenced accordingly.

\begin{tabular}{|l|l|l|l|}
\hline \multicolumn{4}{|c|}{ Acronyms for Public Transit Modes Monitored with NTD Data } \\
\hline Abr. & Term & Abr. & Term \\
\hline AG & Automated Guideway & MG & Monorail/Automated Guideway \\
\hline CB & Commuter Bus & MO & Monorail \\
\hline CC & Cable Car & OR & Other \\
\hline CR & Commuter Rail & PB & Publico \\
\hline DR & Demand Response & RB & Bus Rapid Transit \\
\hline DT & Demand Response Taxi & SR & Street Car \\
\hline FB & Ferryboat & TB & Trolleybus \\
\hline HR & Heavy Rail & TR & Aerial Tramway \\
\hline IP & Inclined Plane & VP & Vanpool \\
\hline JT & Jitney & YR & Hybrid Rail \\
\hline LR & Light Rail & AR & Alaska Railroad \\
\hline MB & Motorbus & & \\
\hline
\end{tabular}

\section{Descriptive Portrait of Transit Use and Associated Trends}

In both Florida and nationally, transit ridership has generally been on a positive trend since approximately 1995. Growing population, expanded services and facilities, increased urbanization, higher fuel prices, and other factors were credited with this positive trend. In 
2013, the industry was hitting ridership totals that had not been witnessed since the 1950 s (Figure 1). Even with the recession that handicapped funding available to support public transportation, ridership levels were robust and service productivity improved. Florida was reporting transit ridership growth percentages twice the level of population growth. Per capita ridership nationally was generally stable.

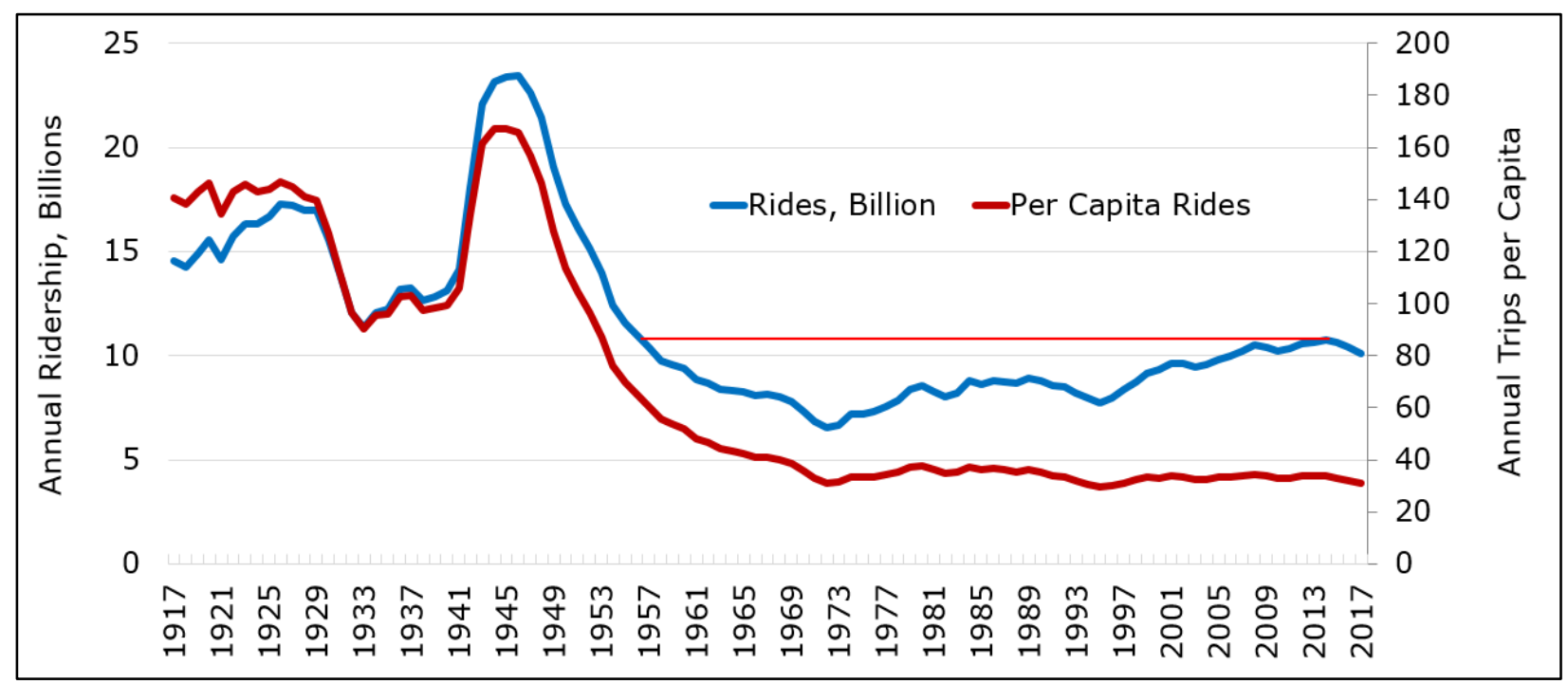

Figure 1 National Transit Ridership Trend

Sources: American Public transportation Association (APTA) historical data, NTD data and Census data.

Many communities were expanding investment in public transportation with a record of positive results for a majority of funding referendum nationally, modest increases in federal investments, and growing private sector support for transit-oriented development, and transit access as a critical factor in economic development for urban areas. There was evidence that millennials were more urban centric than prior generations and less attached to automobiles. Transportation network companies (TNC), those entities using smartphone apps to solicit vehicles for personal transportation such as Uber and Lyft, were seen as complementary to public transportation by enhancing first-mile/last-mile connections. The economic recession had pressured transit agency funding levels, but it had stimulated ridership and heightened interest in transit as a tool to stimulate development.

As the economic recovery gained steam, conditions for transit deteriorated quickly. While efforts such as this research were and continue to be directed to fully understanding what's happening with changing travel behavior and transit use, the empirical evidence accumulated that transit ridership levels were weakening across the state and country. Initial reactions placed blame on softening of fuel prices and a residual effect of some service reductions during the depth of the recessionary years. Early results of various investigations suggest a far more complex set of factors impacting ridership - perhaps most significant, expanded auto 
availability for previously zero-vehicle households as the economy improved. In various parts of the country, other factors appeared significant. Some systems were struggling with on-time performance and operating safety. In other locations, system condition/cleanliness, homelessness, and other urban conditions deterred ridership. Increases in telecommuting (working at home) and continued growth in e-commerce (shopping from home instead of making a trip), proliferation of delivery services, and the ability to do everything from take courses to banking and document delivery online, dampened the need to travel. Technology also contributed to the growing proliferation of TNC services and it became apparent that while complementary in some contexts, TNC services were also competing for travelers in some situations. The millennial generation, who had been impacted severely by reaching adulthood during an economic recession, were beginning to evidence behaviors more typical of prior young adults with increased household formation, auto ownership, and migration to suburban and lower density southern and western metropolitan areas where environments are less conducive to transit use. As economic activities ramped up, improved economic conditions and increased time pressures on working residents weigh against transit use.

The future of public transportation began to get attention motivated both by what was generally an unanticipated downward ridership trend for the industry and increasing questions regarding the viability of public transportation services as they exist today. Planners and analysts began to question how public transportation would be able to compete in the future given the growing expectations of automated vehicles and mobility-as-a-service (MaaS) business models providing attractive options that could compete with transit in many contexts. Simultaneously, rising costs for providing transit with pressures from employee health care cost increases, maintenance expenditures, and increased roadway congestion impacting service reliability/productivity, and select disappointments as budget, schedule, and ridership expectations failed to materialize for some high-profile transit initiatives, further undermined confidence in the future of public transportation.

In approximately 2013, ridership trends changed and began declining with the rate of decline accelerating through early 2018. Most recently, transit ridership remains under pressure and below year ago levels although there is some evidence ridership declines are bottoming out.

Table 1 reports on national trends for critical factors that influence travel behavior and for several metrics of travel behavior change. Table 2 presents the same information for Florida. The tables display the population growth, employment growth, and economic growth that underlie the demand for travel. They also indicate gas price changes and information on vehicle availability, two critical factors in understanding travel. Of the travel demand data included, shaded in green, the metrics are positive except for public transportation. Vehicle miles of travel (VMT) grew particularly robustly in 2015 and 2016 and continued a positive trend in 
2017, outpacing population growth before slowing in 2018. One should note the softness in transit ridership in Florida was over two times greater than in the country as a whole, despite having a faster population growth rate and similarly strong economic performance.

Table 1 National Trends in Travel and Contributory Factors

\begin{tabular}{|c|c|c|c|c|c|c|}
\hline & $\begin{array}{c}2015 \text { vs } \\
2014\end{array}$ & $\begin{array}{c}2016 \text { vs } \\
2015 \\
\end{array}$ & $\begin{array}{c}2017 \text { vs } \\
2016 \\
\end{array}$ & $\begin{array}{c}2018 \text { YTD } \\
\text { vs } 2017 \\
\end{array}$ & Months & Source \\
\hline U.S. Population & $0.8 \%$ & $0.7 \%$ & $0.7 \%$ & $0.7 \%$ & 8 & Census \\
\hline Total Employment & $1.7 \%$ & $1.7 \%$ & $1.3 \%$ & $1.3 \%$ & 8 & $\begin{array}{l}\text { Bureau of } \\
\text { Labor Statistics }\end{array}$ \\
\hline Real GDP & $2.9 \%$ & $1.6 \%$ & $2.2 \%$ & $2.9 \%$ & 6 & $\begin{array}{l}\text { Bureau of } \\
\text { Economic } \\
\text { Analysis }\end{array}$ \\
\hline Gas Price & $-29.3 \%$ & $-14.8 \%$ & $15.1 \%$ & $18.2 \%$ & 8 & $\begin{array}{l}\text { Energy } \\
\text { Information } \\
\text { Agency }\end{array}$ \\
\hline Registered Vehicles & $2.1 \%$ & $2.4 \%$ & $2.4 \%$ & $2.1 \%$ & 9 & Hedges Co. \\
\hline Light Vehicle Sales & $5.8 \%$ & $0.1 \%$ & $-1.8 \%$ & $-1.1 \%$ & 8 & $\begin{array}{l}\text { Bureau of } \\
\text { Economic } \\
\text { Analysis }\end{array}$ \\
\hline $\begin{array}{l}\text { Count of Zero-Vehicle } \\
\text { households }\end{array}$ & $-1.0 \%$ & $-1.9 \%$ & $-0.7 \%$ & - & - & Census \\
\hline VMT & $2.3 \%$ & $2.4 \%$ & $1.2 \%$ & $0.4 \%$ & 8 & $\begin{array}{l}\text { Federal } \\
\text { Highway } \\
\text { Administration }\end{array}$ \\
\hline Public Transit Ridership & $\begin{array}{c}-1.4 \% \text { to }- \\
2.2 \% \\
\end{array}$ & $\begin{array}{c}-2.1 \% \text { to }- \\
1.8 \% \\
\end{array}$ & $\begin{array}{c}-2.7 \% \text { to }- \\
2.5 \% \\
\end{array}$ & $\begin{array}{c}-3.9 \% \text { to }- \\
3.3 \% \\
\end{array}$ & $3-7$ & APTA and NTD \\
\hline Amtrak Ridership (FY) & $-0.3 \%$ & $1.9 \%$ & $1.9 \%$ & $-0.4 \%$ & 7 & Amtrak \\
\hline Airline Passengers & $5.3 \%$ & $3.9 \%$ & $3.5 \%$ & $5.0 \%$ & 6 & $\begin{array}{l}\text { US Department } \\
\text { of } \\
\text { Transportation, } \\
\text { Bureau of } \\
\text { Transportation } \\
\text { Statistics }\end{array}$ \\
\hline
\end{tabular}


Table 2 Florida Trends in Travel and Contributory Factors

\begin{tabular}{|c|c|c|c|c|c|c|}
\hline & $\begin{array}{c}2015 \text { vs } \\
2014\end{array}$ & $\begin{array}{c}2016 \text { vs } \\
2015 \\
\end{array}$ & $\begin{array}{c}2017 \text { vs } \\
2016\end{array}$ & $\begin{array}{c}2018 \text { YTD } \\
\text { vs } 2017\end{array}$ & Months & Source \\
\hline Florida Population & $1.9 \%$ & $1.7 \%$ & $1.8 \%$ & - & - & Census \\
\hline Total Employment & $1.4 \%$ & $2.9 \%$ & $3.3 \%$ & $1.8 \%$ & 8 & $\begin{array}{l}\text { BLS Bureau of } \\
\text { Labor Statistics }\end{array}$ \\
\hline Real GDP & $4.2 \%$ & $2.4 \%$ & $2.2 \%$ & - & - & $\begin{array}{l}\text { Bureau of } \\
\text { Economic } \\
\text { Analysis (3rd } \\
\text { estimate) }\end{array}$ \\
\hline Gas Price & $-30.3 \%$ & $-10.1 \%$ & $12.5 \%$ & $16.3 \%$ & 8 & $\begin{array}{l}\text { Energy } \\
\text { Information } \\
\text { Agency }\end{array}$ \\
\hline Registered Vehicles & $4.1 \%$ & $-5.1 \%$ & $7.4 \%$ & $-11.9 \%$ & 8 & $\begin{array}{l}\text { Florida } \\
\text { Highway } \\
\text { Statistics and } \\
\text { Motor Vehicles }\end{array}$ \\
\hline Light Vehicle Sales & - & - & - & - & - & BEA \\
\hline $\begin{array}{l}\text { Count of Zero-Vehicle } \\
\text { households }\end{array}$ & +0.40 & -2.07 & -2.25 & - & - & Census \\
\hline VMT & $5.5 \%$ & $2.0 \%$ & $1.5 \%$ & $3.1 \%$ & 7 & $\begin{array}{l}\text { Federal } \\
\text { Highway } \\
\text { Administration }\end{array}$ \\
\hline Public Transit Ridership & $-4.4 \%$ & $-7.9 \%$ & $-7.1 \%$ & $-8.5 \%$ & 7 & NTD \\
\hline Amtrak Ridership (FY) & $-5.3 \%$ & $-7.5 \%$ & $-2.8 \%$ & - & - & Amtrak \\
\hline $\begin{array}{l}\text { Airline Passengers (nine } \\
\text { major airports) }\end{array}$ & $8.0 \%$ & $3.8 \%$ & $4.5 \%$ & $7.4 \%$ & 3 & $\begin{array}{l}\text { US Department } \\
\text { of } \\
\text { Transportation, } \\
\text { Bureau of } \\
\text { Transportation } \\
\text { Statistics }\end{array}$ \\
\hline
\end{tabular}

Figure 2 presents national data on roadway travel as measured by vehicle miles of travel (VMT). This figure characterizes the recessionary impact on vehicle travel and the robust recovery coincident with the economic recovery. VMT growth has slowed in early 2018. Figure 3 presents similar data for Florida. Given Florida's more rapid population growth, one would expect more rapid VMT growth if trends were tracking national norms. Florida VMT slowed between 2016 and 2017 and Florida VMT per capita declined in 2017. 


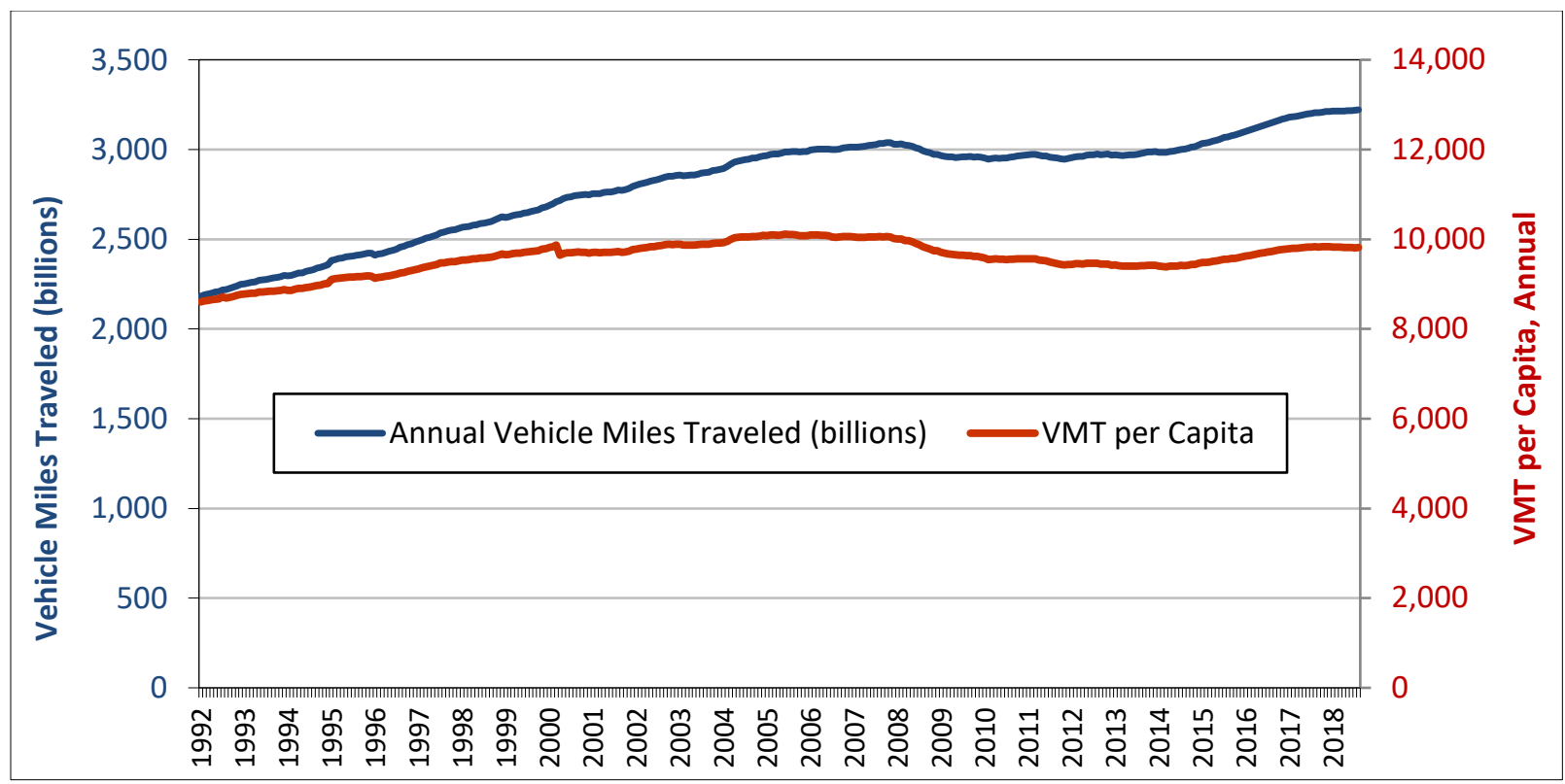

Figure 2 National Trend in VMT and VMT Per Capita, Rolling 12 Month Total

Source: Federal Highway Administration (FHWA)

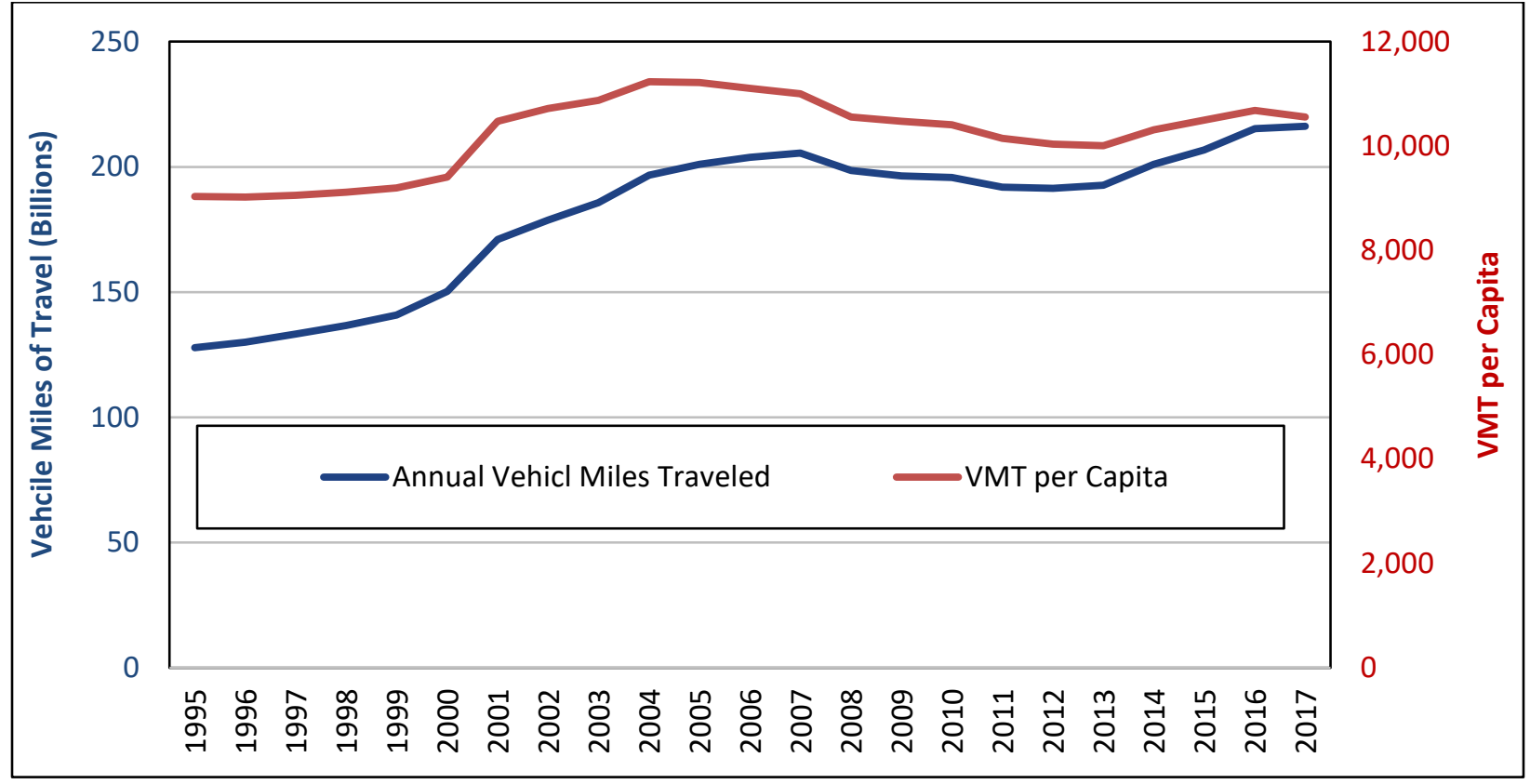

Figure 3 Florida Trend in VMT and VMT Per Capita

Source: FDOT, FHWA. Note: 2017 VMT data for Florida relies on FHWA estimates whereas prior year numbers are based on Florida Sourcebook data.

Figure 4 compares the U.S. and Florida fixed route transit ridership trends. This trend shows average monthly ridership on a rolling 12-month basis. Fixed route ridership levels in Florida are more sensitive to changing economic conditions than is the case for the national total. Ridership in Florida grew faster as the recession took hold but declined faster as the recovery 
strengthened. Figure 5 processes ridership data to report a trend for average monthly riders lost since 2012.

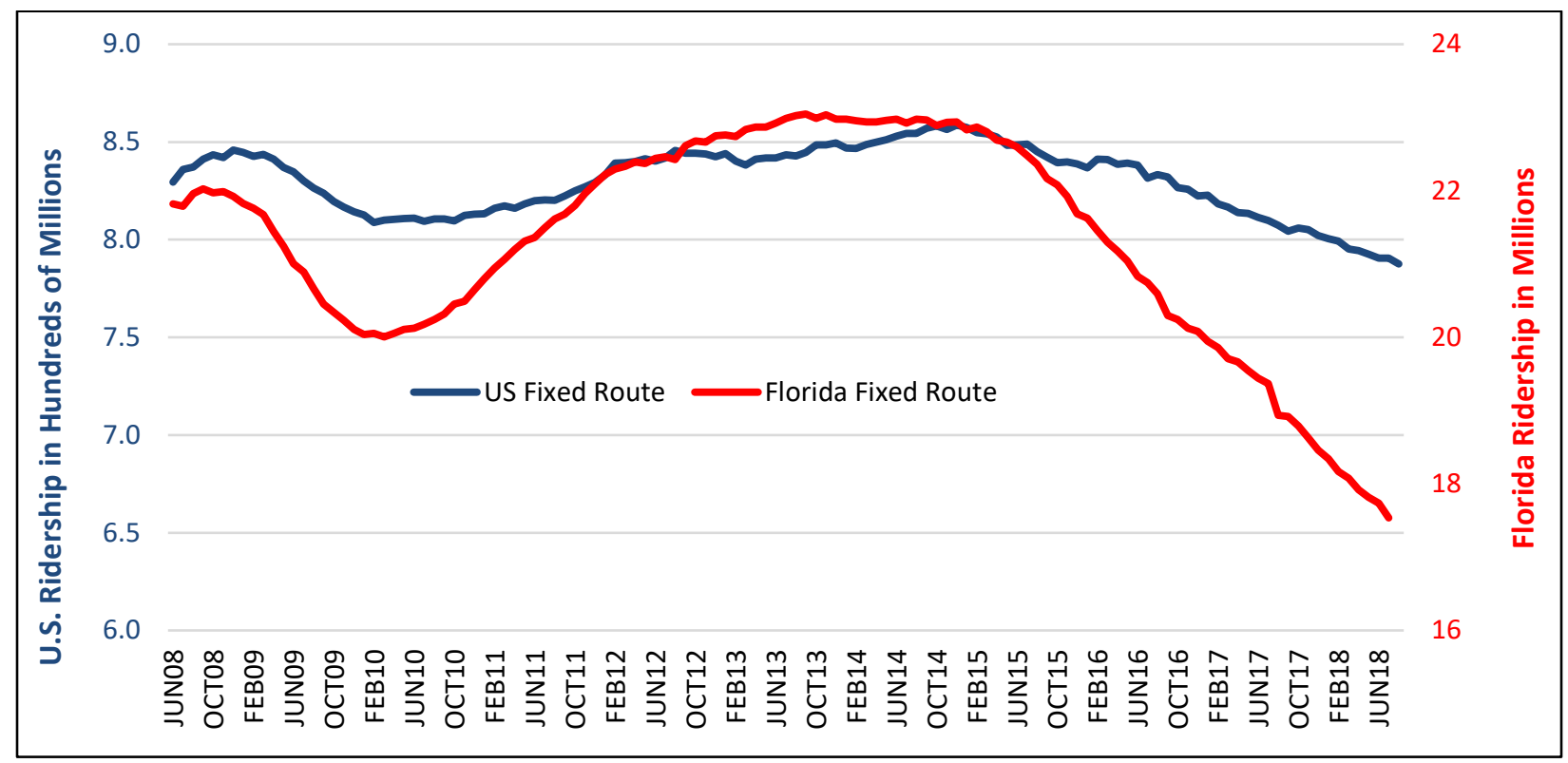

Figure 4 Florida and U.S. Trend in 12 Month Rolling Fixed Route Ridership Levels Source: NTD

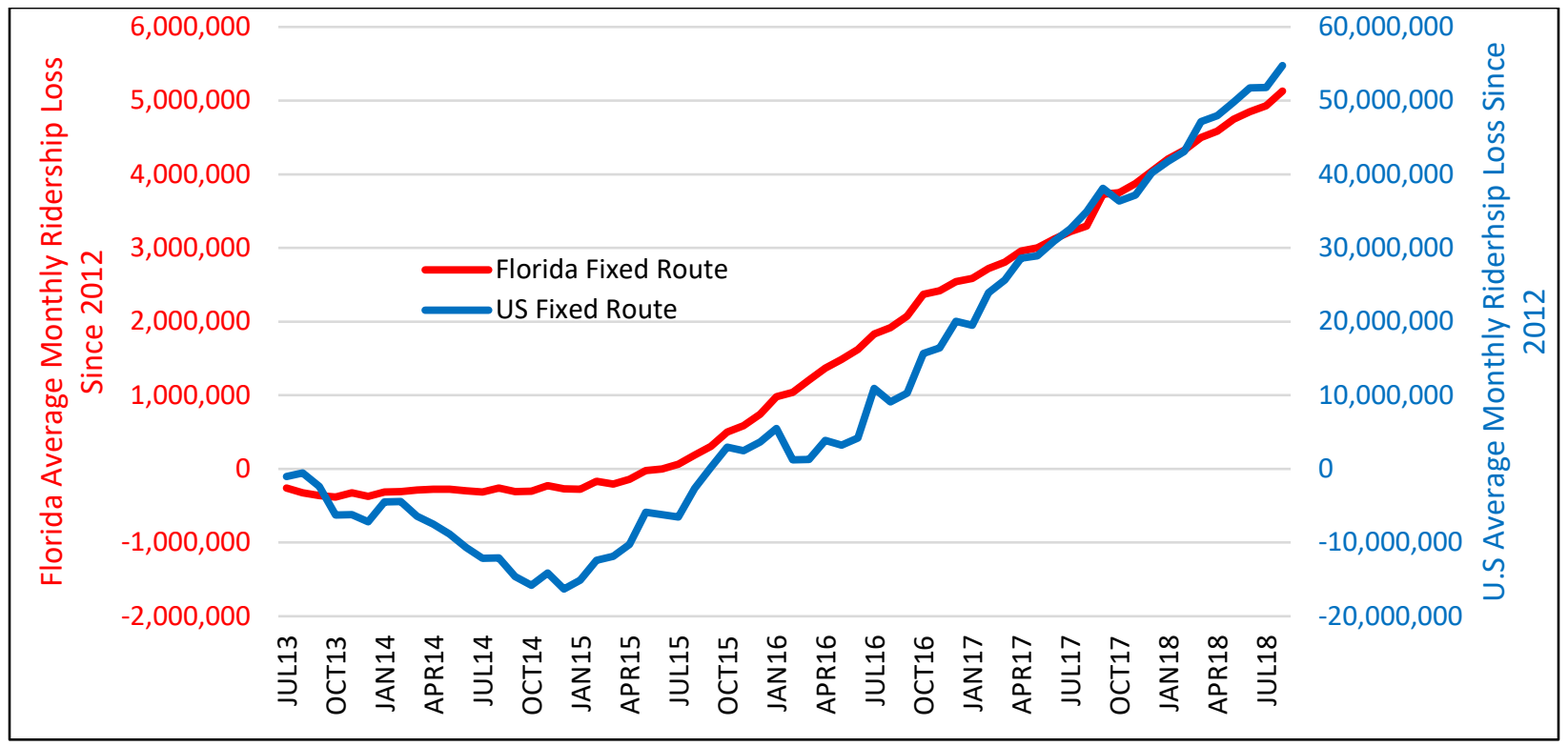

Figure 5 Florida and U.S. Trend in 12 Month Rolling Fixed-Route Ridership Losses Since 2012 Source: NTD

Figure 6 presents the U.S. trend in transit total fixed route ridership and service levels, expressed in vehicle miles of revenue service. What is readily apparent is that service declines occurred during the recession in the 2010-2012 time period, but service levels have generally grown modestly since then. Ridership dipped as the economy weakened and gradually 
strengthened until approximately 2013-2014 when declines became apparent. Service cuts occurred coincident with the recession, since then, on average, service levels have grown modestly. The situation in individual communities may vary. Figure 7 displays the same ridership and service information for Florida. Florida fixed-route transit service trends followed a similar, yet less pronounced decrease in service around the recession. The changes in Florida ridership trends reveal a decrease in ridership at the onset of the recession, with ridership increasing annually from 2009 through 2013. However, since 2013 Florida fixed-route transit ridership has decreased continuously.

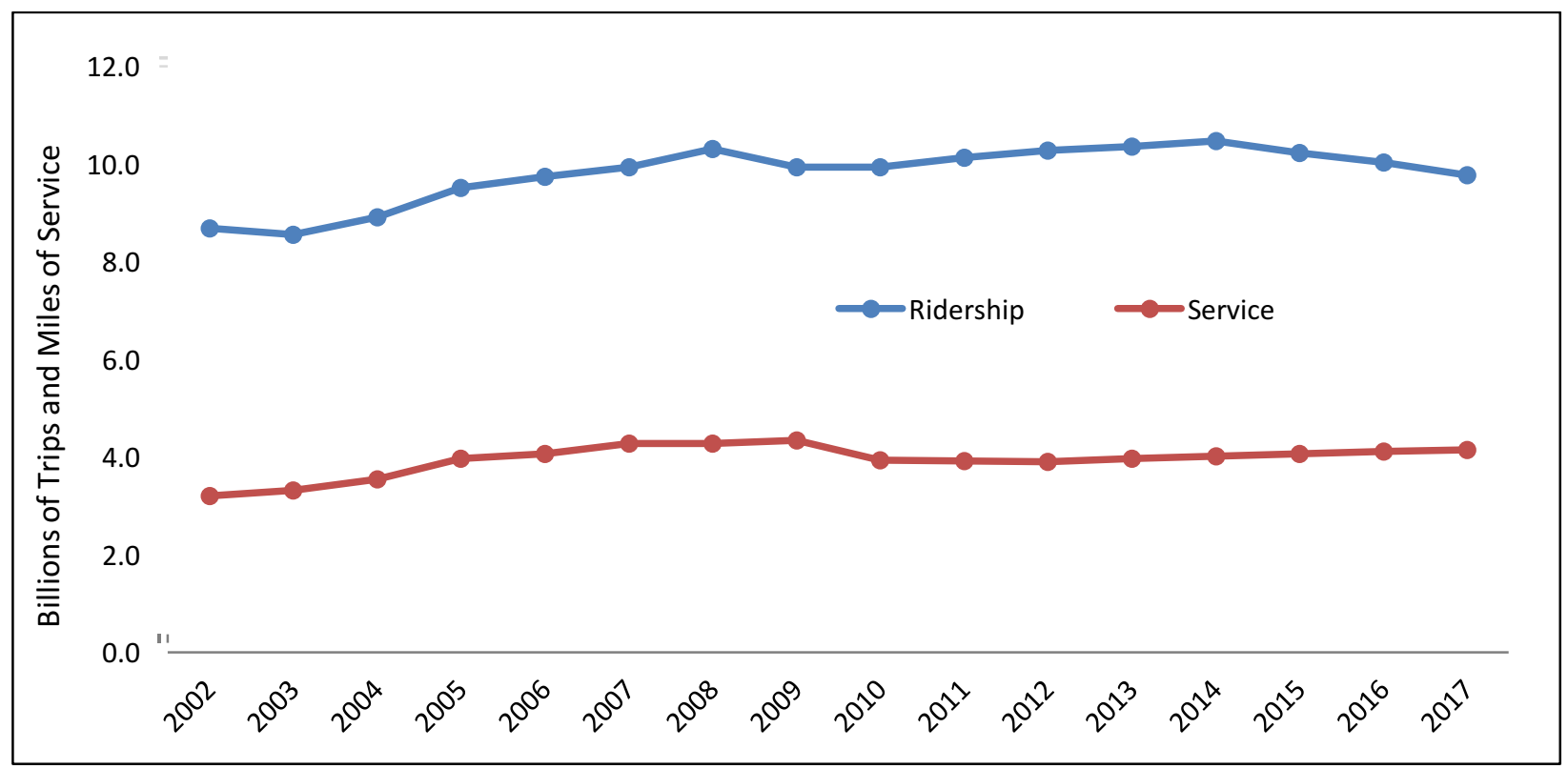

Figure 6 U.S. Fixed Route Transit Ridership and Service Trend Source: NTD

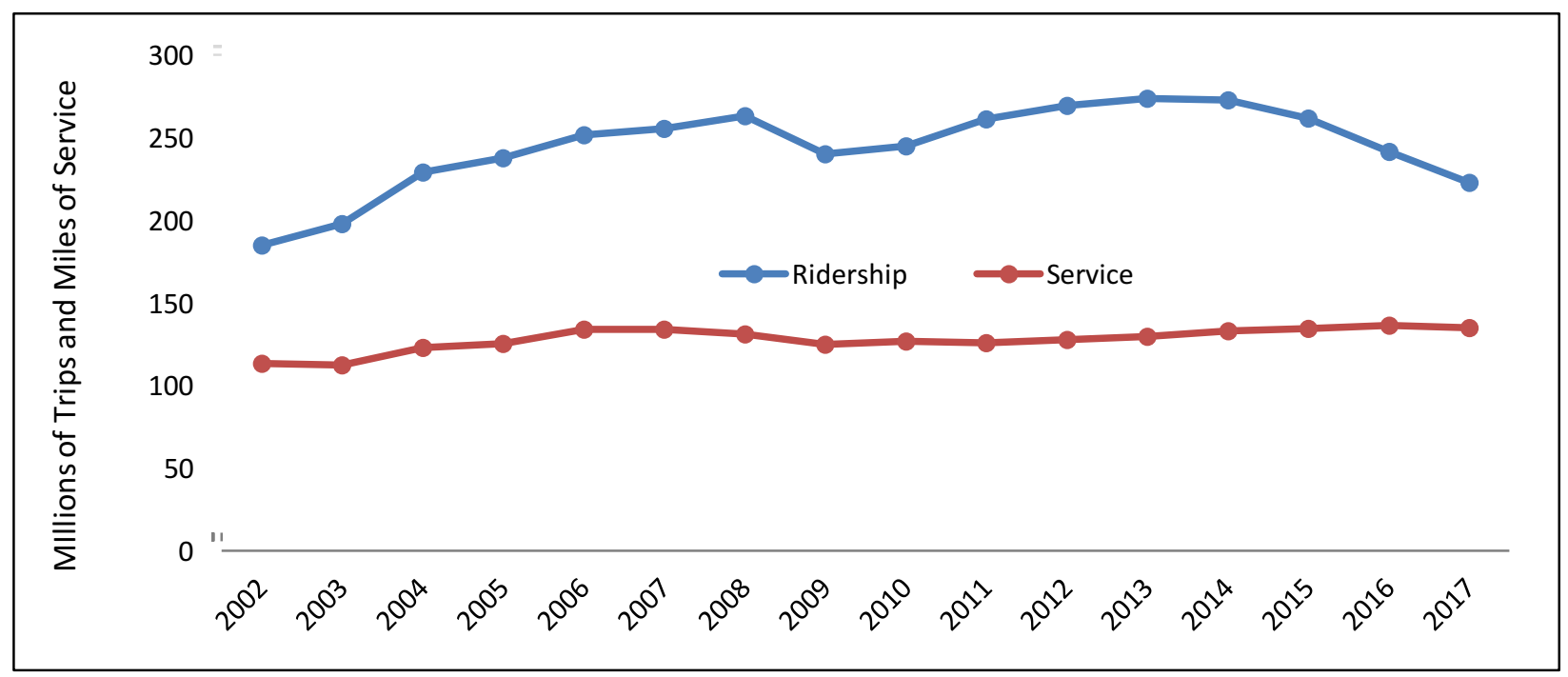

Figure 7 Florida Fixed Route Transit Ridership and Service Trend Source: NTD 
Table 3 presents a summary of transit ridership and service trends by mode for different time periods. The purpose of analyzing the information this way is to discern both differences in trend across modes and to further analyze the temporal distribution of changes, specifically whether the downward trend is moderating.

Table 3 Transit Ridership and Service Summary by Mode, Florida and U.S.

\begin{tabular}{|c|c|c|c|c|c|c|}
\hline & & & $\begin{array}{c}10 \text { year trend - } \\
2017-2007\end{array}$ & $\begin{array}{c}\text { 3-year trend - } \\
\text { 2017-2014 }\end{array}$ & $\begin{array}{c}1 \text { year trend - } \\
2017-2016\end{array}$ & $\begin{array}{l}\text { Trending - Q4 } \\
2017 \text { - Q4 } 2016\end{array}$ \\
\hline \multirow{12}{*}{$\begin{array}{l}\bar{\pi} \\
\frac{0}{2} \\
\frac{0}{\pi} \\
\frac{\pi}{2}\end{array}$} & \multirow{5}{*}{$\frac{\frac{2}{\frac{1}{n}}}{\frac{0}{\frac{1}{0}}}$} & All bus & $-15.2 \%$ & $-11.3 \%$ & $-5.1 \%$ & $-3.4 \%$ \\
\hline & & Light rail (LR \& SR) & $20.7 \%$ & $1.4 \%$ & $-0.8 \%$ & $-3.6 \%$ \\
\hline & & Commuter rail & $5.6 \%$ & $-1.3 \%$ & $-1.7 \%$ & $-1.3 \%$ \\
\hline & & Heavy rail & $9.8 \%$ & $-3.8 \%$ & $-0.4 \%$ & $1.2 \%$ \\
\hline & & Demand Response (DR-DT) & $10.4 \%$ & $-1.3 \%$ & $-0.5 \%$ & $0.2 \%$ \\
\hline & & Total & $-3.4 \%$ & $-7.1 \%$ & $-2.8 \%$ & $-1.4 \%$ \\
\hline & \multirow{5}{*}{ 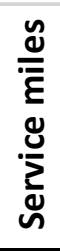 } & All bus & $-3.5 \%$ & $3.7 \%$ & $0.5 \%$ & $0.3 \%$ \\
\hline & & Light rail & $54.9 \%$ & $17.4 \%$ & $6.8 \%$ & $5.2 \%$ \\
\hline & & Commuter rail & $16.5 \%$ & $1.1 \%$ & $0.9 \%$ & $1.3 \%$ \\
\hline & & Heavy rail & $7.8 \%$ & $3.0 \%$ & $1.8 \%$ & $0.7 \%$ \\
\hline & & Demand Response & $15.5 \%$ & $1.2 \%$ & $0.1 \%$ & $0.8 \%$ \\
\hline & & Total & $4.7 \%$ & $3.2 \%$ & $0.9 \%$ & $0.7 \%$ \\
\hline \multirow{12}{*}{$\begin{array}{l}\frac{\pi}{0} \\
\frac{0}{2} \\
\frac{0}{4}\end{array}$} & \multirow{5}{*}{$\frac{\frac{0}{c}}{\frac{n}{\frac{1}{2}}}$} & All bus & $-18.4 \%$ & $-20.5 \%$ & $-7.6 \%$ & $-5.6 \%$ \\
\hline & & Light rail & $-50.0 \%$ & $2.5 \%$ & $-4.1 \%$ & $2.7 \%$ \\
\hline & & Commuter rail & $22.4 \%$ & $-2.4 \%$ & $2.0 \%$ & $6.5 \%$ \\
\hline & & Heavy rail & $15.3 \%$ & $-9.4 \%$ & $-6.7 \%$ & $-3.8 \%$ \\
\hline & & Demand Response & $-0.2 \%$ & $6.6 \%$ & $4.3 \%$ & $6.4 \%$ \\
\hline & & Total & $-15.1 \%$ & $-18.6 \%$ & $-7.0 \%$ & $-4.9 \%$ \\
\hline & \multirow{5}{*}{ 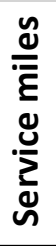 } & All bus & $-4.6 \%$ & $1.2 \%$ & $-0.8 \%$ & $-1.9 \%$ \\
\hline & & Light rail & $-20.2 \%$ & $2.4 \%$ & $-1.7 \%$ & $-16.6 \%$ \\
\hline & & Commuter rail & $270.2 \%$ & $1.9 \%$ & $1.1 \%$ & $7.7 \%$ \\
\hline & & Heavy rail & $-9.0 \%$ & $-7.5 \%$ & $-8.9 \%$ & $-18.8 \%$ \\
\hline & & Demand Response & $9.1 \%$ & $17.1 \%$ & $5.8 \%$ & $5.7 \%$ \\
\hline & & Total & $0.8 \%$ & $5.7 \%$ & $1.0 \%$ & $5.7 \%$ \\
\hline
\end{tabular}

Source: NTD

Several findings can be gleaned from Table 3. With respect to transit sub mode, bus ridership has been weakest, and the weakness started earlier than for other modes. A modest share of bus decline is associated with expansion of rail systems replacing prior bus services. However, data to quantify that affect is not available at the aggregate level. Bus ridership declines were steeper in the past year than on average over the three-year period at both the U.S. and Florida level, evidence of an accelerating decline into 2017, as shown in Table 1, has continued into 2018. Also, at both the state and national level, ridership declines in the last quarter of the 
calendar year were less severe than the annual average, suggesting some moderation of the pace of decline, but that has not materialized in the first half of 2018.

Heavy rail was the second most impacted mode in the past three years and, like bus, tends to be urban core centric. Light rail service, impacted by significant expansion of service in the three-year period, had ridership levels hold up relatively well until more recently. Demand responsive services were modestly impacted, as the factors influencing their utilization appear to be mostly independent of those factors influencing fixed route service demand. Also, by virtue of the nature of the service, demand responsive supply and demand track relatively closely. Florida showed one-year increases in commuter rail service, a result of the presence of a full year of service on the SunRail system.

It is important to remember that 2017 transit ridership in Florida was impacted by Hurricane Irma, which resulted in dramatic ridership declines for the month following the storm, particularly in South Florida. Agency specific impacts are apparent in the data presented in Appendix A. The composite effect of this storm may have contributed as much as $2 \%$ or $3 \%$ of the reported 7\% annual ridership decline in 2017.

Figure 8 shows changes in transit ridership amongst the top 40 urban areas in the U.S. These 40 urban areas make up $85.2 \%$ of the U.S. ridership decline from 2014 through 2017. Thirty-six of the 40 urban areas showed ridership declines. There is no obvious pattern as the declines occur across geography, urban area size, urban area growth rate, and economic conditions. The outliers, for example Seattle and Houston, each had a set of relatively unique characteristics that can be credited with explaining differential behavior. Amongst the top 40 Metro areas, Orlando, Tampa Bay, and the Miami area represented Florida. It is noteworthy that the Miami Metropolitan Area had the largest percent decline in transit ridership of any of the 40 Metropolitan areas.

Figure 9 shows ridership changes for the top 10 transit operators in Florida. These 10 agencies account for $90.4 \%$ of the ridership decline in Florida over the past three years. Broward County had the highest percentage decrease among the top 10, and Jacksonville the least significant decline in percentage terms.

Figure 10 portrays the contribution of agencies to total ridership and change in ridership. It is disheartening that the southeastern area in Florida comprised of Miami Dade, Broward, and West Palm Beach counties suffered the greatest ridership losses despite this area having the densest settlement pattern, the most substantial transit level of service, and rapid population growth. 


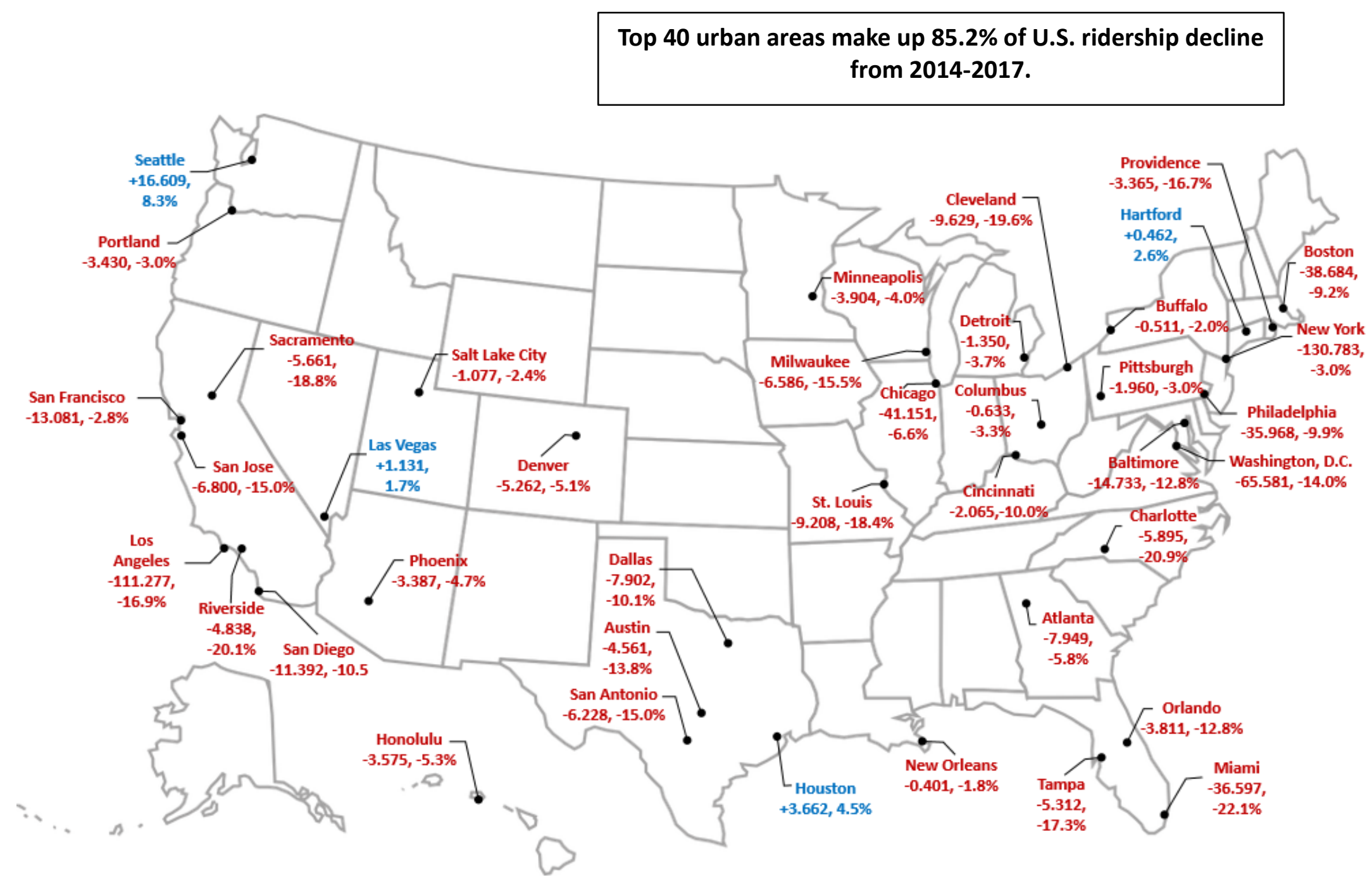

Figure 8 Top 40 UZAs by 2017 Transit Ridership, Change 2014-2017 (Millions) 


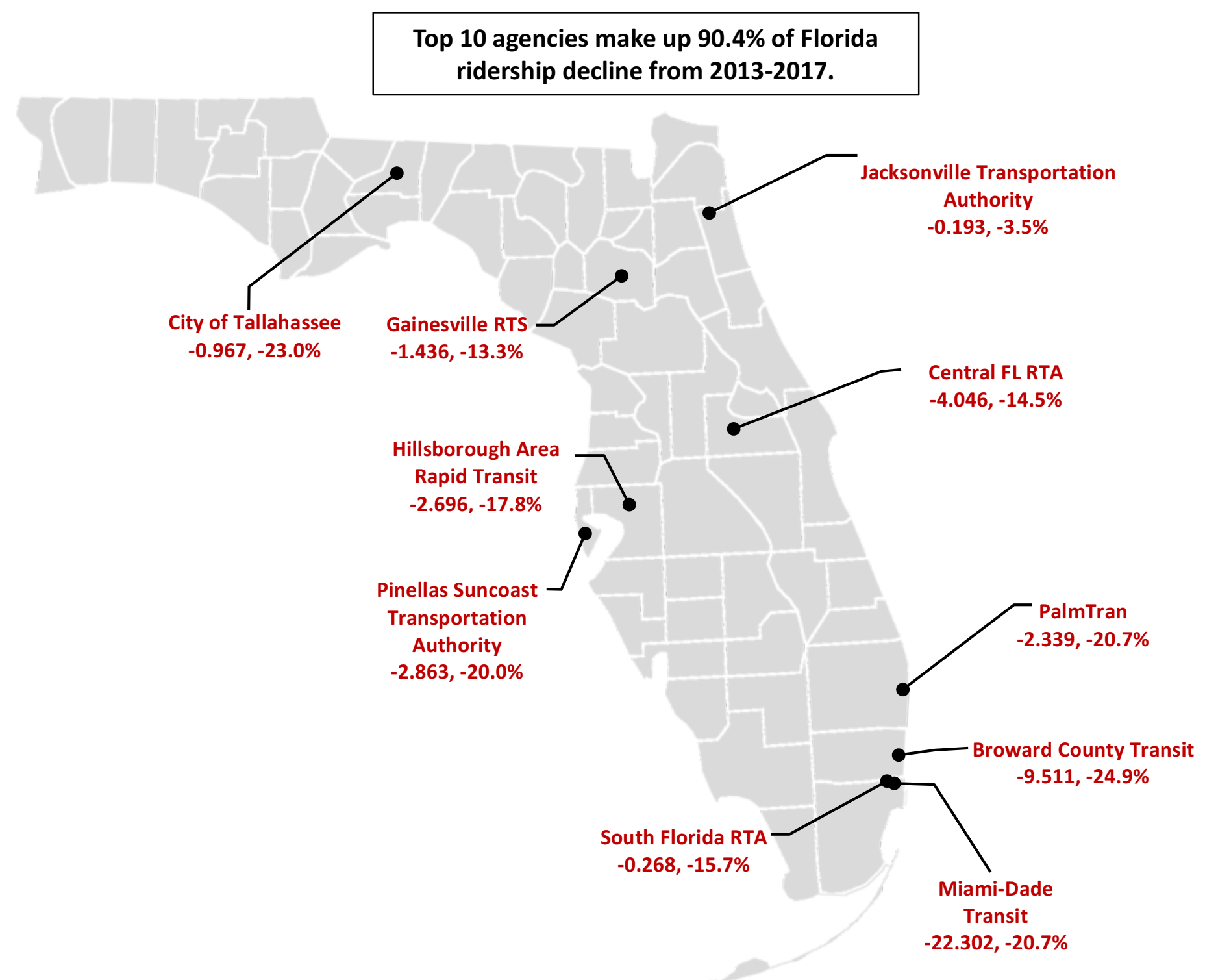

Figure 9 Top 10 Florida Operators by 2017 Transit Ridership, Change 2013-2017 (Millions) 


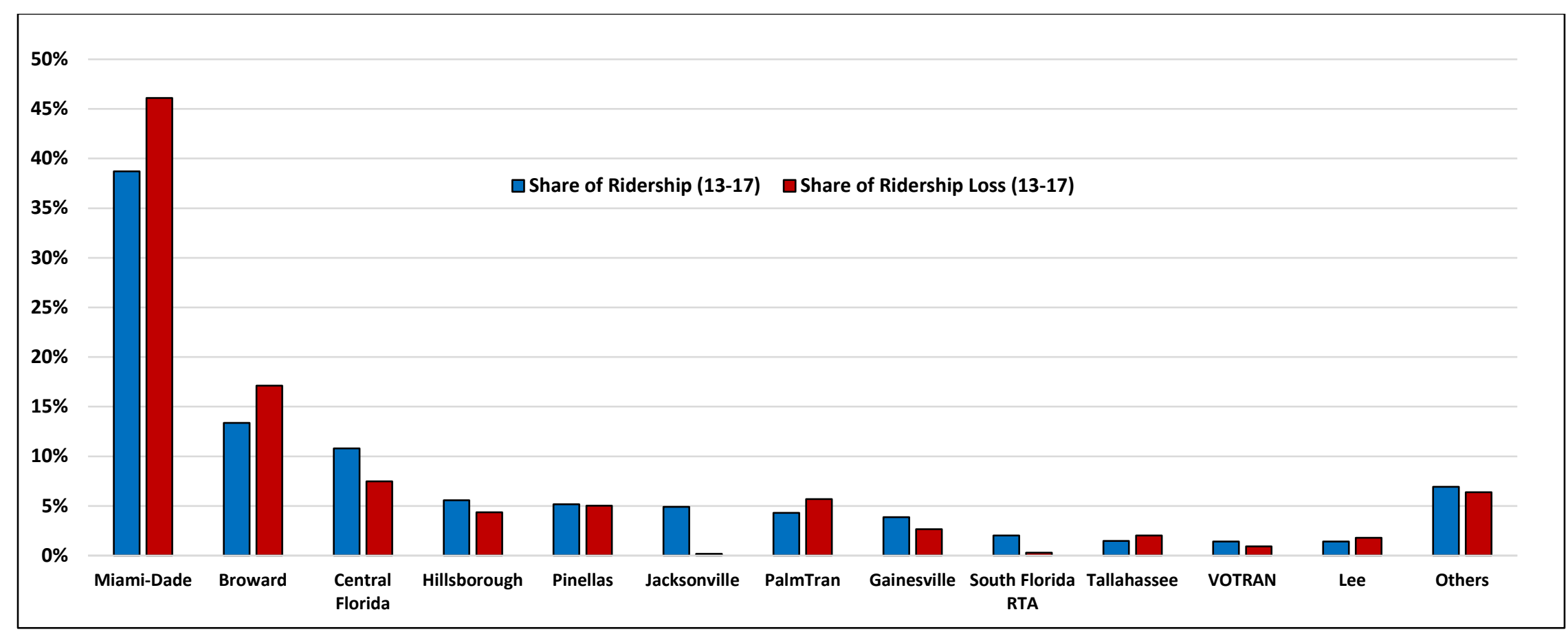

Figure 10 Florida Agencies Share of Ridership Total and Losses, 2013-2017

Source: NTD

The data presented above have been developed based on transit ridership count information. Information in Figure 11 and Figure 12 are derived from survey information. The annual American Community Survey (ACS) conducted by the Census Bureau samples households regarding their means of travel to work. Work is typically estimated to be approximately $40 \%$ of all transit trips. This figure pair indicate that the transit commuting share has remained relatively stable at both the state and national levels, but a modest decline was evident in 2016. The 2017 data will be available in September 2018. Work at home is growing meaningfully and is among those factors that have impacted transit ridership. Historically carpooling has been declining. This lends further credence to the hypothesis that travelers prefer travel means that are not constrained by scheduling requirements. Throughout the past decade, the share of commuting by driving alone has remained virtually constant between $79 \%$ and $80 \%$ in Florida and between $76 \%$ and $77 \%$ nationally. 


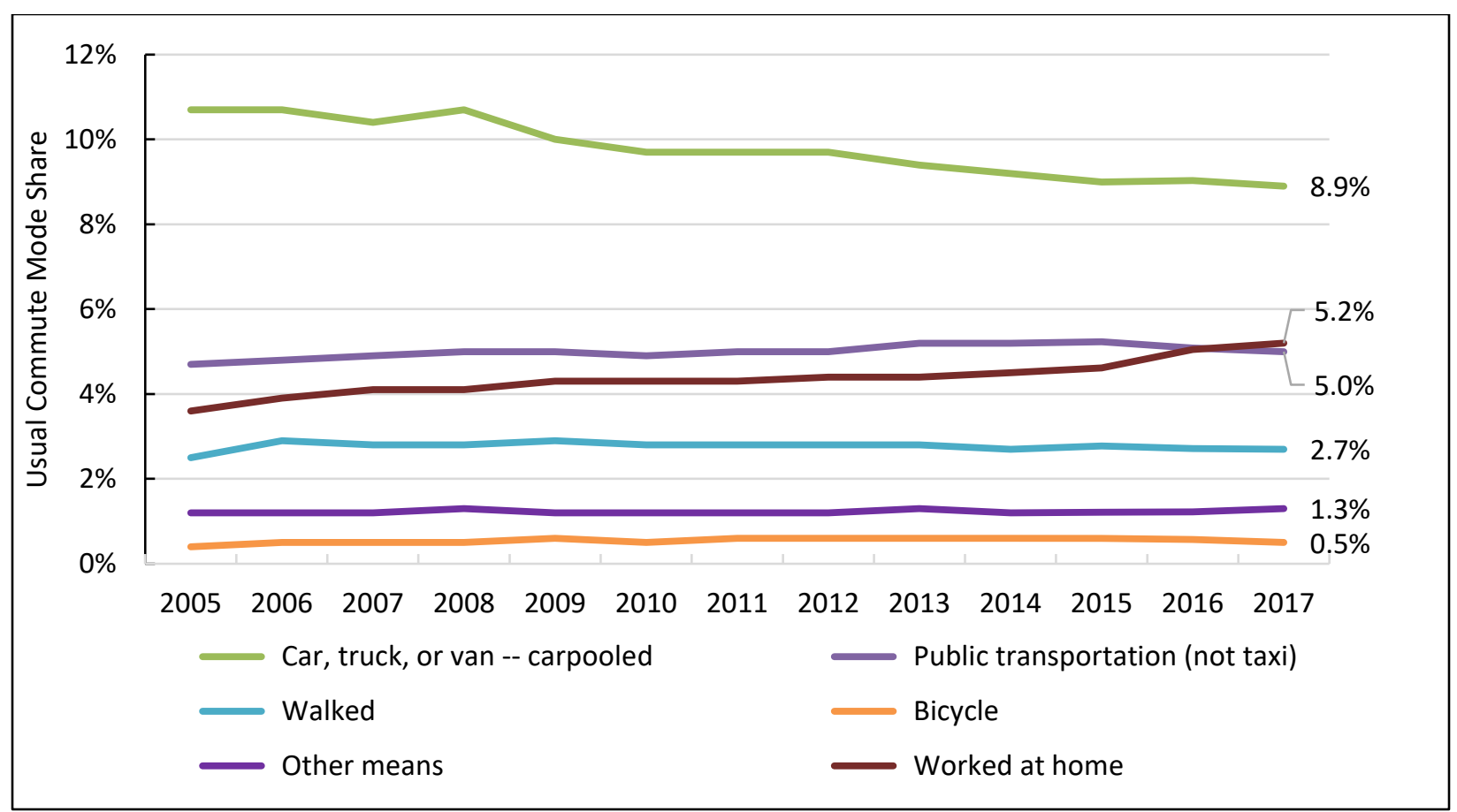

Figure 11 Commuting Mode Choice Trends in Florida

Source: ACS, drive-alone not shown

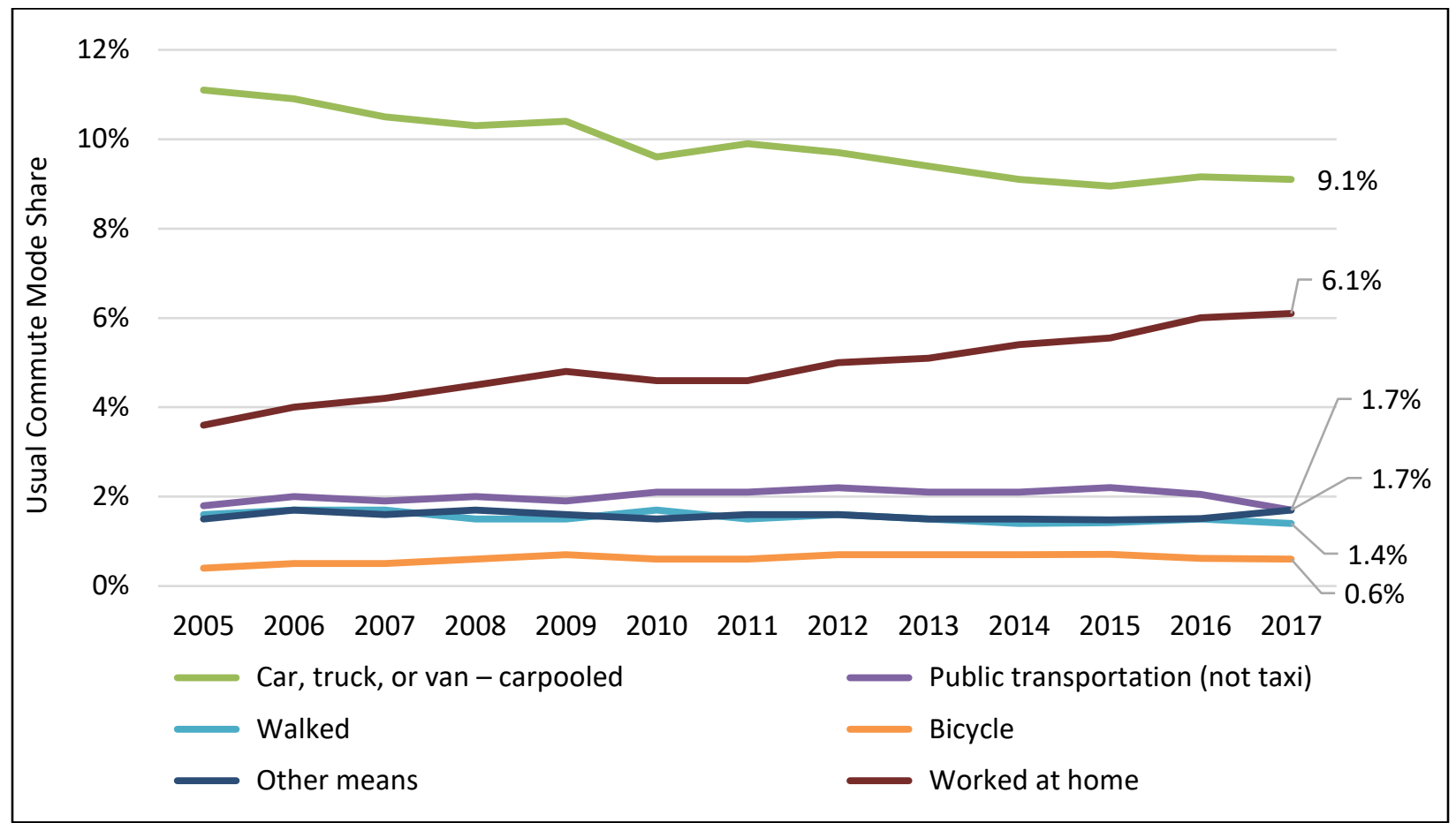

Figure 12 National Commuting Mode Choice Trends

Source: ACS, drive-alone not shown

Another critical factor in understanding transit use involves zero-vehicle households. National survey data indicates that the absence of a household vehicle has a dramatic impact on 
utilization of transit by household members. For example, 2016 National Household Travel Survey (NHTS) data indicate that individuals living in zero-vehicle households make 227 transit trips annually, whereas individuals living in one-vehicle households make 40 transit trips annually, and individuals living in households with two or more vehicles make 11 transit trips annually. Thus, understanding trends in zero-vehicle households is important to understanding transit ridership trends. Figure 13 shows the U.S. and Florida trend in the number of households with zero vehicles. In Florida, the number of zero-vehicle households peaked in 2012 at approximately 530,000 households and declined to approximately 486,000 zero-vehicle households in 2017. Thus, there were approximately 43,000 fewer zero-vehicle households in Florida in 2017 , despite a growth of 492,000 households.

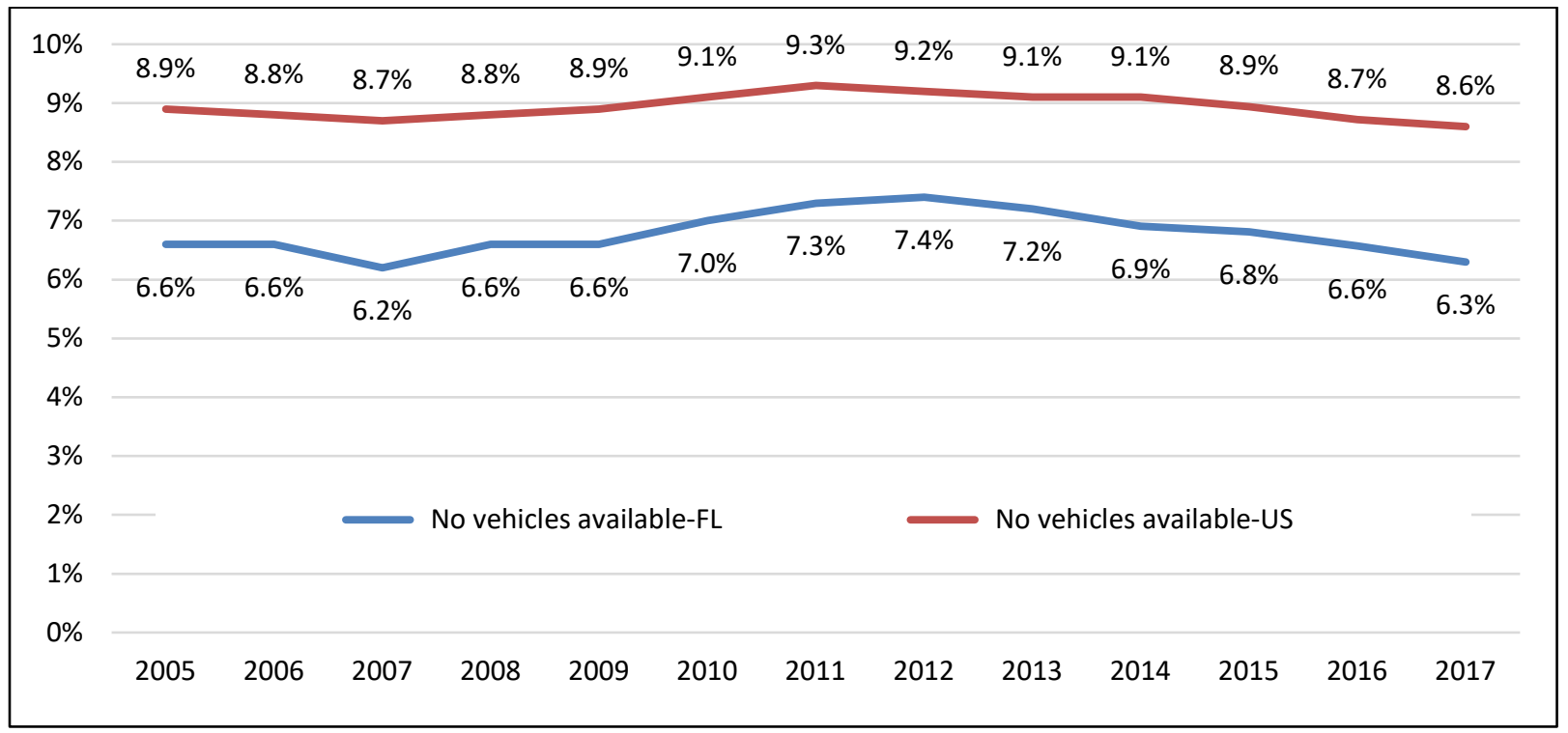

Figure 13 Zero-Vehicle Household Trend, U.S. and Florida

Source: ACS

Table 4 presents trend data for zero-vehicle households for various Florida geographies. As one would expect, areas that are more metropolitan had larger shares of households with zero vehicles. Several counties in Florida showed significant declines in zero-vehicle households including Broward County, Hillsborough County, Pinellas County, and Miami Dade County locations that showed significant ridership declines. 
Table 4 Zero-Vehicles Household Trends for Florida Geographies

\begin{tabular}{|c|c|c|c|c|c|c|c|c|c|c|c|c|c|c|c|}
\hline Agency & Geography & Geography Name & 2005 & 2006 & 2007 & 2008 & 2009 & 2010 & 2011 & 2012 & 2013 & 2014 & 2015 & 2016 & 2017 \\
\hline Gainesville & County & Alachua & $6.2 \%$ & $7.3 \%$ & $8.3 \%$ & $6.8 \%$ & $7.1 \%$ & $7.3 \%$ & $9.4 \%$ & $8.9 \%$ & $10.2 \%$ & $7.4 \%$ & $7.3 \%$ & $8.5 \%$ & $7.4 \%$ \\
\hline Bay & County & Bay & $4.9 \%$ & $4.6 \%$ & $4.8 \%$ & $6.2 \%$ & $4.5 \%$ & $6.3 \%$ & $6.1 \%$ & $6.5 \%$ & $5.5 \%$ & $6.6 \%$ & $7.1 \%$ & $6.3 \%$ & $7.2 \%$ \\
\hline Space Coast & County & Brevard & $4.7 \%$ & $4.6 \%$ & $4.2 \%$ & $4.8 \%$ & $4.7 \%$ & $4.7 \%$ & $4.3 \%$ & $5.4 \%$ & $6.3 \%$ & $6.6 \%$ & $5.8 \%$ & $4.9 \%$ & $4.9 \%$ \\
\hline Broward & County & Broward & $7.6 \%$ & $7.1 \%$ & $6.6 \%$ & $7.4 \%$ & $7.4 \%$ & $7.8 \%$ & $7.9 \%$ & $8.0 \%$ & $8.1 \%$ & $7.3 \%$ & $7.5 \%$ & $6.9 \%$ & $7.1 \%$ \\
\hline Charlotte & County & Charlotte & $4.1 \%$ & $3.9 \%$ & $4.0 \%$ & $4.2 \%$ & $6.2 \%$ & $5.4 \%$ & $5.8 \%$ & $5.6 \%$ & $5.0 \%$ & $4.4 \%$ & $4.6 \%$ & $5.1 \%$ & $4.8 \%$ \\
\hline Jacksonville & County & Duval & $7.6 \%$ & $8.3 \%$ & $7.3 \%$ & $7.5 \%$ & $8.1 \%$ & $7.7 \%$ & $8.2 \%$ & $8.8 \%$ & $8.1 \%$ & $9.2 \%$ & $8.2 \%$ & $8.4 \%$ & $8.2 \%$ \\
\hline Escambia & County & Escambia & $6.2 \%$ & $8.1 \%$ & $7.1 \%$ & $7.0 \%$ & $8.1 \%$ & $9.1 \%$ & $8.0 \%$ & $6.3 \%$ & $6.5 \%$ & $6.5 \%$ & $5.6 \%$ & $5.9 \%$ & $6.3 \%$ \\
\hline Hillsborough & County & Hillsborough & $7.0 \%$ & $6.3 \%$ & $6.6 \%$ & $6.4 \%$ & $6.6 \%$ & $6.9 \%$ & $7.4 \%$ & $7.1 \%$ & $7.4 \%$ & $7.0 \%$ & $7.4 \%$ & $6.9 \%$ & $6.4 \%$ \\
\hline Lee & County & Lee & $4.2 \%$ & $4.4 \%$ & $4.8 \%$ & $5.7 \%$ & $4.3 \%$ & $5.1 \%$ & $5.2 \%$ & $5.9 \%$ & $5.1 \%$ & $5.1 \%$ & $4.4 \%$ & $4.9 \%$ & $4.7 \%$ \\
\hline Manatee & County & Manatee & $3.7 \%$ & $4.6 \%$ & $4.4 \%$ & $4.7 \%$ & $4.8 \%$ & $4.8 \%$ & $5.7 \%$ & $6.1 \%$ & $4.6 \%$ & $5.2 \%$ & $5.8 \%$ & $4.7 \%$ & $4.6 \%$ \\
\hline Martin & County & Martin & $4.7 \%$ & $4.7 \%$ & $3.8 \%$ & $4.7 \%$ & $5.1 \%$ & $4.7 \%$ & $3.8 \%$ & $6.6 \%$ & $3.5 \%$ & $3.8 \%$ & $5.1 \%$ & $5.4 \%$ & $5.6 \%$ \\
\hline Miami-Dade & County & Miami-Dade & $11.4 \%$ & $11.4 \%$ & $10.7 \%$ & $11.3 \%$ & $11.1 \%$ & $11.4 \%$ & $11.6 \%$ & $11.6 \%$ & $12.0 \%$ & $10.3 \%$ & $10.5 \%$ & $10.8 \%$ & $10.2 \%$ \\
\hline Okaloosa & County & Okaloosa & $5.3 \%$ & $3.8 \%$ & $3.2 \%$ & $3.7 \%$ & $3.6 \%$ & $4.2 \%$ & $5.0 \%$ & $5.0 \%$ & $5.2 \%$ & $5.1 \%$ & $6.0 \%$ & $4.1 \%$ & $5.6 \%$ \\
\hline Palm Beach & County & Palm Beach & $6.9 \%$ & $6.4 \%$ & $6.1 \%$ & $6.0 \%$ & $6.6 \%$ & $6.2 \%$ & $6.5 \%$ & $6.9 \%$ & $7.1 \%$ & $6.4 \%$ & $6.7 \%$ & $6.3 \%$ & $5.8 \%$ \\
\hline Pasco & County & Pasco & $4.5 \%$ & $5.1 \%$ & $4.0 \%$ & $4.9 \%$ & $4.6 \%$ & $5.0 \%$ & $5.9 \%$ & $5.4 \%$ & $6.6 \%$ & $5.8 \%$ & $6.1 \%$ & $5.8 \%$ & $5.0 \%$ \\
\hline Pinellas & County & Pinellas & $8.2 \%$ & $7.4 \%$ & $8.2 \%$ & $7.8 \%$ & $7.5 \%$ & $9.0 \%$ & $9.4 \%$ & $10.0 \%$ & $8.3 \%$ & $8.7 \%$ & $8.3 \%$ & $8.0 \%$ & $8.3 \%$ \\
\hline Lakeland & County & Polk & $5.5 \%$ & $6.3 \%$ & $4.4 \%$ & $6.4 \%$ & $6.0 \%$ & $6.2 \%$ & $7.1 \%$ & $7.4 \%$ & $7.0 \%$ & $6.8 \%$ & $5.7 \%$ & $5.1 \%$ & $5.7 \%$ \\
\hline St. Lucie & County & St. Lucie & $4.2 \%$ & $5.2 \%$ & $3.7 \%$ & $4.8 \%$ & $4.4 \%$ & $5.2 \%$ & $7.0 \%$ & $6.2 \%$ & $7.0 \%$ & $7.1 \%$ & $5.6 \%$ & $4.3 \%$ & $4.2 \%$ \\
\hline Sarasota & County & Sarasota & $4.9 \%$ & $6.1 \%$ & $5.3 \%$ & $6.1 \%$ & $5.7 \%$ & $6.6 \%$ & $6.2 \%$ & $5.9 \%$ & $5.3 \%$ & $5.3 \%$ & $5.1 \%$ & $4.5 \%$ & $6.1 \%$ \\
\hline Volusia & County & Volusia & $6.7 \%$ & $5.2 \%$ & $5.3 \%$ & $5.8 \%$ & $6.8 \%$ & $6.9 \%$ & $8.6 \%$ & $7.0 \%$ & $5.3 \%$ & $6.0 \%$ & $7.2 \%$ & $5.9 \%$ & $5.2 \%$ \\
\hline $\begin{array}{l}\text { Central } \\
\text { Florida RTA } \\
\end{array}$ & MSA & Orlando-Kissimmee-Sanford & & & & & & & & & $5.9 \%$ & $6.0 \%$ & $5.5 \%$ & $5.8 \%$ & $5.2 \%$ \\
\hline $\begin{array}{l}\text { South } \\
\text { Florida RTA }\end{array}$ & MSA & $\begin{array}{l}\text { Miami-Fort Lauderdale- } \\
\text { West Palm Beach }\end{array}$ & & & & & & & & & $9.5 \%$ & $8.3 \%$ & $8.5 \%$ & $8.4 \%$ & $8.0 \%$ \\
\hline Tallahassee & City & Tallahassee & $6.6 \%$ & $7.3 \%$ & $8.1 \%$ & $7.2 \%$ & $7.8 \%$ & $9.0 \%$ & $7.1 \%$ & $9.6 \%$ & $6.9 \%$ & $9.5 \%$ & $8.4 \%$ & $6.9 \%$ & $6.9 \%$ \\
\hline
\end{tabular}

Source: ACS

Table 5 presents the trend in the population growth for transit service areas in Florida. These data are those reported by agencies that reflect their service area population as defined by the Federal Transit Administration (FTA). Service area growth has been running at approximately $1.4 \%$ per year. Agencies do not have route buffer area level population estimates updated on a regular basis, so updates are not necessarily annual. 
Table 5 Population Trend for Florida Transit Service Areas

Florida Transit Service Area Population Trend

\begin{tabular}{|c|c|c|c|c|c|c|c|c|c|c|c|c|c|c|c|c|}
\hline Service Area & & & & & & & & & & & & & & & & \\
\hline Population & 2002 & 2003 & 2004 & 2005 & 2006 & 2007 & 2008 & 2009 & 2010 & 2011 & 2012 & 2013 & 2014 & 2015 & 2016 & 2017 \\
\hline Miami-Dade & $1,900,000$ & $1,900,000$ & $2,345,932$ & $2,379,818$ & $2,379,818$ & $2,402,208$ & $2,402,208$ & $2,402,208$ & $2,500,625$ & $2,496,435$ & $2,496,435$ & $2,496,435$ & $2,496,435$ & $2,496,435$ & $2,496,435$ & $2,496,435$ \\
\hline Broward & $1,623,018$ & $1,623,018$ & $1,623,018$ & $1,623,018$ & $1,623,018$ & $1,787,636$ & $1,787,636$ & $1,751,234$ & $1,766,476$ & $1,748,066$ & $1,780,172$ & $2 \quad 1,815,137$ & $7 \quad 1,838,844$ & $1,869,235$ & $1,869,425$ & $1,909,632$ \\
\hline Central Florida RTA & $1,434,033$ & $1,536,900$ & $1,536,900$ & $1,536,900$ & $1,536,900$ & $1,536,900$ & $1,811,366$ & $1,811,366$ & $1,805,921$ & $1,837,359$ & $1,837,359$ & $1,920,488$ & $1,959,812$ & $2,005,728$ & $2,134,411$ & $2,134,41$ \\
\hline Hillsborough & 578,252 & 578,252 & 578,252 & 578,252 & 578,252 & 578,252 & 821,306 & 821,306 & 821,306 & 822,404 & 822,404 & 822,404 & 875,598 & 875,598 & 875,598 & 875,598 \\
\hline Jacksonville & 882,295 & 899,992 & 817,480 & 817,480 & 827,453 & 827,453 & 827,453 & 827,453 & 853,300 & 874,673 & 838,815 & 827,481 & 985,050 & $1,001,311$ & $11,021,375$ & $1,036,907$ \\
\hline Pinellas & 862,076 & 877,996 & 896,651 & 881,868 & 881,705 & 858,947 & 863,796 & 883,631 & 871,480 & 922,616 & 922,616 & 922,616 & 850,758 & 944,553 & 985,625 & 980,147 \\
\hline Palm Beach & 908,485 & 900,386 & 915,000 & 930,100 & 958,582 & 982,900 & 982,900 & 982,900 & 982,900 & $1,268,782$ & $1,268,782$ & $1,268,782$ & $1,268,782$ & $1,268,782$ & $1,268,782$ & $1,268,782$ \\
\hline Gainesville & 140,000 & 144,164 & 144,164 & 144,164 & 149,173 & 149,173 & 149,173 & 151,294 & 151,294 & 187,781 & 160,000 & 160,000 & 160,000 & 163,990 & 163,990 & 163,990 \\
\hline South Florida & $4,919,036$ & $4,919,036$ & $4,919,036$ & $5,448,962$ & $5,448,962$ & $5,448,962$ & $5,448,962$ & $5,448,962$ & $5,448,962$ & $5,448,962$ & $5,502,379$ & $5,502,379$ & $5,502,379$ & $5,502,379$ & $5,502,379$ & $5,502,379$ \\
\hline Volusia & 43,343 & 454,581 & 468,663 & 468,670 & 468,670 & 468,670 & 468,670 & 468,670 & 468,670 & 468,670 & 468,670 & 468,670 & 494,593 & 494,593 & 494,593 & 494,593 \\
\hline Lee & 440,888 & 280,707 & 373,498 & 399,023 & 429,057 & 451,153 & 451,153 & 444,837 & 443,696 & 443,696 & 459,381 & 463,224 & 470,588 & 479,489 & 490,070 & 437,570 \\
\hline Tallahassee & 156,703 & 162,310 & 62,310 & 162,310 & 162,310 & 162,310 & 162,310 & 162,310 & 162,310 & 162,310 & 162,310 & 162,310 & 162,310 & 162,310 & 162,310 & $162,31 \mathrm{C}$ \\
\hline Sarasota & 308,043 & 308,043 & 310,714 & 337,474 & 389,000 & 398,854 & 398,854 & 398,854 & 393,826 & 393,826 & 388,474 & 388,474 & 388,559 & 393,807 & 404,312 & 400,867 \\
\hline Space Co & 499,180 & 499,360 & 499,360 & 504,891 & 504,891 & 551,030 & 554,560 & 554,698 & 554,354 & 554,354 & 554,354 & 554,354 & 554,354 & 55 & 568,701 & 579,130 \\
\hline Manatee & 278,144 & 285,486 & 231,450 & 296,385 & 103,000 & 103,000 & 103,000 & 103,000 & 103,000 & 103,000 & 322,833 & 322,833 & 322,833 & 322,833 & 322,833 & 368,782 \\
\hline Escambia & 294,410 & 294,410 & 294,410 & 307,220 & 307,220 & 307,220 & 307,220 & 307,220 & 307,220 & 340,067 & 341,765 & 341,765 & 341,765 & 341,765 & 241,661 & 241,661 \\
\hline Lakeland & 110,000 & 110,000 & 110,000 & 110,000 & 110,000 & 110,000 & 110,000 & 110,000 & 110,000 & 110,000 & 97,497 & 145,000 & 145,000 & 312,388 & 312,388 & 312,388 \\
\hline Pasco & 362,658 & 371,245 & 388,906 & 406,857 & 424,355 & 434,425 & 437,846 & 462,715 & 471,709 & 464,697 & 464,697 & 470,391 & 475,502 & 475,502 & 475,502 & 488,310 \\
\hline Bay & 132,419 & 132,419 & 85,458 & 85,458 & 85,458 & 85,458 & 85,458 & 85,458 & 85,458 & 105,192 & 105,192 & 105,192 & 105,192 & 105,192 & 105,192 & 105,192 \\
\hline St. L & 202,000 & 212,000 & 12,000 & 12,000 & 241,305 & 49,300 & 241,305 & 265,108 & 266,502 & 280,379 & 280,379 & 283,866 & 195,823 & 291,028 & 298,563 & 306,507 \\
\hline Okaloosa & 170,498 & 170,498 & 170,498 & 170,498 & 170,498 & 170,498 & 170,498 & 170,498 & 170,498 & 170,498 & 180,822 & 180,822 & 191,917 & 196,512 & 196,512 & 196,512 \\
\hline Charlo & 122,421 & 122,421 & 8,679 & 2,900 & 00 & 38 & 45 & 163 & 45 & 169,541 & 169,541 & 169,541 & 169,541 & 173,115 & 173,115 & 173,11 \\
\hline Martin & 270,774 & 270,774 & 270,774 & 137,956 & 137,956 & 137,956 & 137,956 & 137,956 & 137,956 & 137,956 & 146,000 & 146,000 & 146,000 & 149,806 & 149,806 & 150,870 \\
\hline $\begin{array}{l}\text { Total for Flo } \\
\text { Reporters ( }\end{array}$ & $17,038,676$ & $17,053,998$ & $17,503,153$ & $18,102,204$ & $18,074,583$ & $18,256,743$ & $18,886,875$ & $18,914,923$ & $19,040,708$ & 19,5 & $419,770,877$ & $19,938,164$ & 20,10 & $20,580,705$ & $20,713,57$ & $20,786,088$ \\
\hline $\begin{array}{l}\text { Total for Florida } \\
\text { Reporters (2002-2016) - } \\
\text { South Florida RTA }\end{array}$ & $12,119,64 \mathrm{C}$ & $12,134,962$ & $12,584,117$ & $712,653,242$ & $12,625,621$ & $12,807,781$ & $13,437,913$ & $13,465,961$ & $13,591,746$ & $14,062,302$ & $14,268,498$ & $14,435,785$ & $14,599,256$ & $15,078,326$ & $15,211,19$ & $915,283,709$ \\
\hline $\begin{array}{l}\text { Percent Growth in Service } \\
\text { Area Population }\end{array}$ & & & & & & & & & & & & & & & & $20.70 \%$ \\
\hline $\begin{array}{l}\text { Average Annual Growth } \\
\text { Rate }\end{array}$ & & & & & & & & & & & & & & & & $1.56 \%$ \\
\hline State of Florida (BEBR) & $16,634,256$ & $16,979,706$ & $17,374,824$ & $17,778,156$ & $18,154,475$ & $18,446,768$ & $18,613,905$ & $18,687,425$ & $18,801,310$ & $18,905,048$ & $19,074,434$ & $19,259,543$ & $19,507,369$ & $19,815,183$ & $320,148,654$ & $20,484,142$ \\
\hline $\begin{array}{l}\text { Average Annual Growth } \\
\text { Rate }\end{array}$ & & & & & & & & & & & & & & & & $1.40 \%$ \\
\hline $\begin{array}{l}\text { State of Florida } \\
\text { Population in Service } \\
\text { Areas }\end{array}$ & $72.9 \%$ & $71.5 \%$ & $72.4 \%$ & $71.2 \%$ & $69.5 \%$ & $69.4 \%$ & $72.2 \%$ & $72.1 \%$ & $72.3 \%$ & $74.4 \%$ & $74.8 \%$ & $75.0 \%$ & $74.8 \%$ & $76.1 \%$ & $75.5 \%$ & $74.6 \%$ \\
\hline
\end{tabular}


Table 6 presents data from the NHTS. This nationwide sample of travel behavior provides a comprehensive resource on travel behavior and characteristics of travelers. While the sample size is modest for transit trips in Florida, the data set provides useful information regarding the nature of transit travel at the U.S. and state level as well as differences in behavior between 2008 and 2016, the years the respective data was collected. The new 2017 data set is still being analyzed, and questions have arisen regarding the purported increase in transit mode share in contrast to empirical data from transit ridership counts, thus, users of this data should exercise caution in making interpretations. In Florida, transit use is markedly more modest than at the national level. Vehicle availability in terms of share of zero-vehicle households is better, average wait times are longer, and use per capita is accordingly far lower than national averages. Income levels appear to be significantly higher for national transit riders compared to Floridians. This would be attributable to quality transit services serving high density central business districts with white-collar jobs in locations such as New York, Washington DC, Boston, San Francisco, Seattle, Chicago, etc.

The comparisons between the nation and Florida observations are logically consistent with travel behavior theory and consistent with other data sources and historical data sets. Figure 14 shows the national transit trip purpose distribution. Work is the top non-home destination followed by shopping and errands.

Table 6 Transit Trip and Travel Characteristics from the National Household Travel Survey

\begin{tabular}{|l|c|c|c|c|}
\hline \multicolumn{5}{|c|}{ Transit Trip Characteristics from NHTS } \\
\hline \multicolumn{1}{|c|}{ Characteristic } & Florida 2009 & $\begin{array}{c}\text { National } \\
\mathbf{2 0 0 9}\end{array}$ & Florida 2017 & $\begin{array}{c}\text { National } \\
\mathbf{2 0 1 7}\end{array}$ \\
\hline Transit mode share & $1.10 \%$ & $2.00 \%$ & $0.95 \%$ & $2.54 \%$ \\
\hline Transit trips per capita & 13.27 & 26.57 & 11.40 & 31.32 \\
\hline Average Income of Transit Traveler & $\$ 26,786$ & $\$ 45,000^{*}$ & $\$ 36,138$ & $\$ 70,000^{*}$ \\
\hline $\begin{array}{l}\text { Average age of Transit Travelers } \\
\text { (years) }\end{array}$ & 42.4 & 38.4 & 52.5 & 41.1 \\
\hline Transfer rate & -- & -- & 1.30 & 1.55 \\
\hline Transit Trip distance (miles) & 10.17 & 8.83 & 10.88 & 11.01 \\
\hline Transit Trip speed (mph) & 11.95 & 10.94 & 11.04 & 12.02 \\
\hline Average wait time (minutes) & 14.28 & 9.63 & 14.32 & 9.56 \\
\hline $\begin{array}{l}\text { Household vehicle availability } \\
\text { (average vehicles/household) }\end{array}$ & 1.68 & 1.86 & 1.77 & 1.88 \\
\hline $\begin{array}{l}\text { Household vehicle availability (share } \\
\text { 0 vehicle) }\end{array}$ & $6.7 \%$ & $8.7 \%$ & $5.3 \%$ & $8.9 \%$ \\
\hline $\begin{array}{l}\text { Persons who use public transit with 0 } \\
\text { vehicles available }\end{array}$ & $36.1 \%$ & $39.6 \%$ & $40.8 \%$ & $43.0 \%$ \\
\hline *Due to aggregate data and unknown top range means, these numbers were estimated. & \\
\hline
\end{tabular}

Source: NHTS 2009, 2017

Note: NHTS data is referred to as the 2017 NHTS, but the data was collected predominately in 2016. 


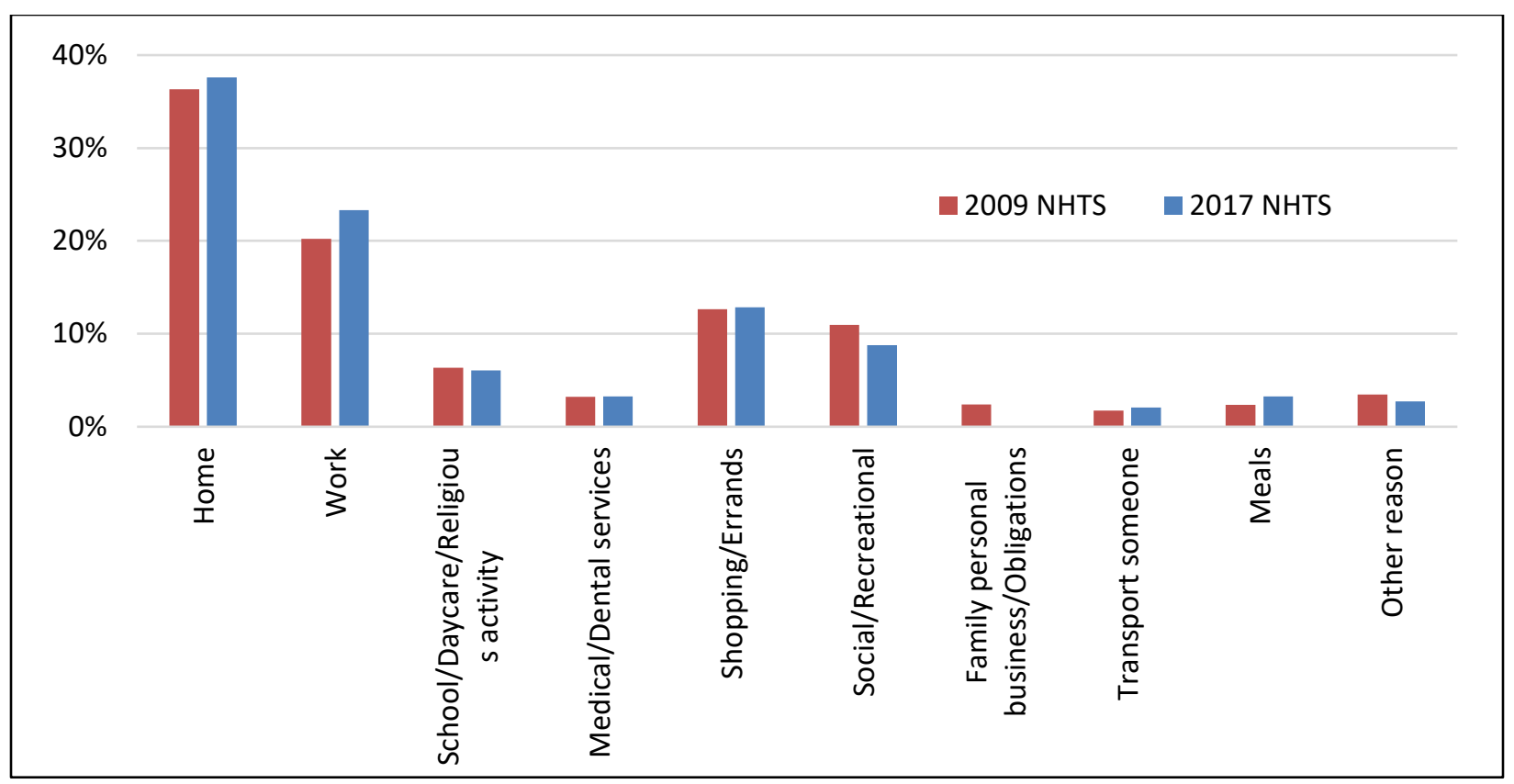

Figure 14 National Transit Trip Purpose Distribution

Source: 2009 and 2017 NHTS

Figure 15 shows the age distribution of transit Travelers according to NHTS data. This data indicates that transit use has declined among the young population but is growing amongst the older population.

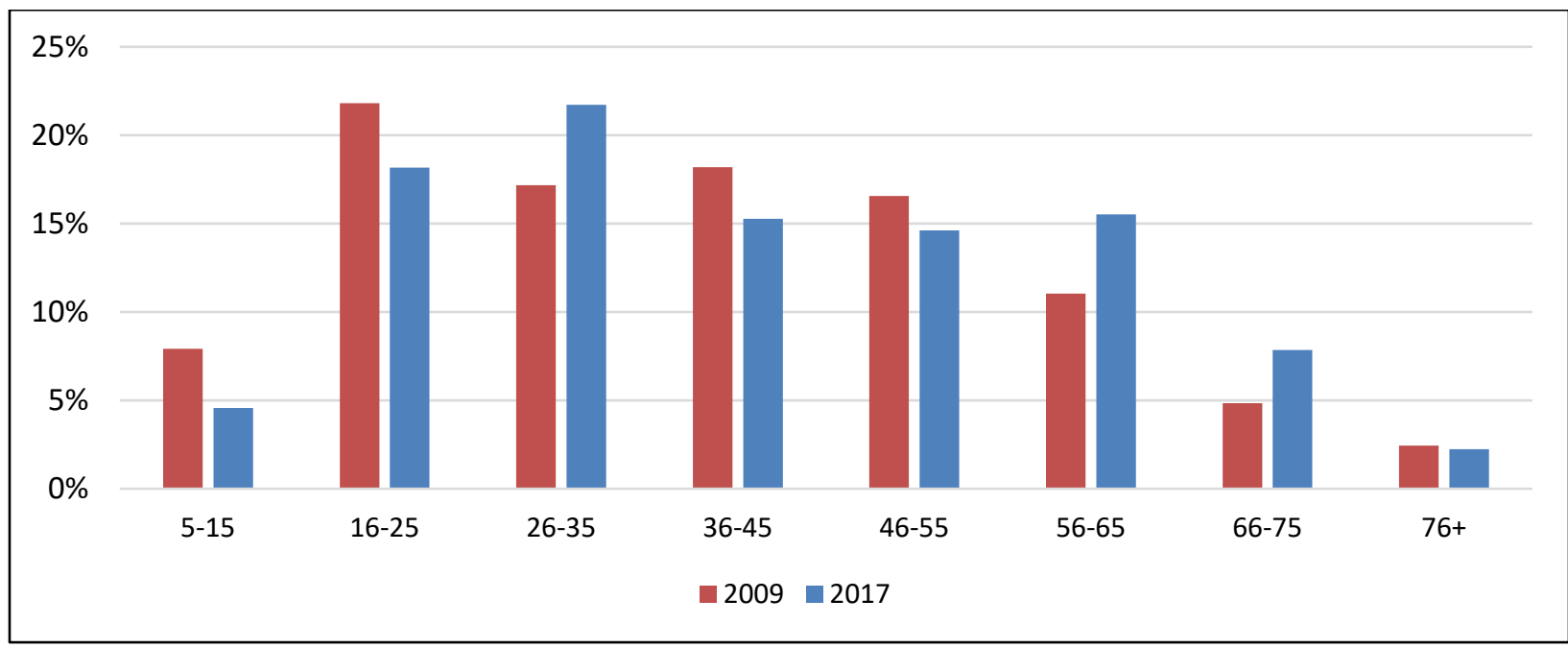

Figure 15 National Transit Age Distribution

Source: 2009 and 2017 NHTS

Figure 16 through Figure 21 present ridership and service trends for various modes and mode combinations using monthly NTD. These images give a visual representation of the relationship between supply and demand and the differences in transit across modes with respect to both the timing and magnitude of changes. 


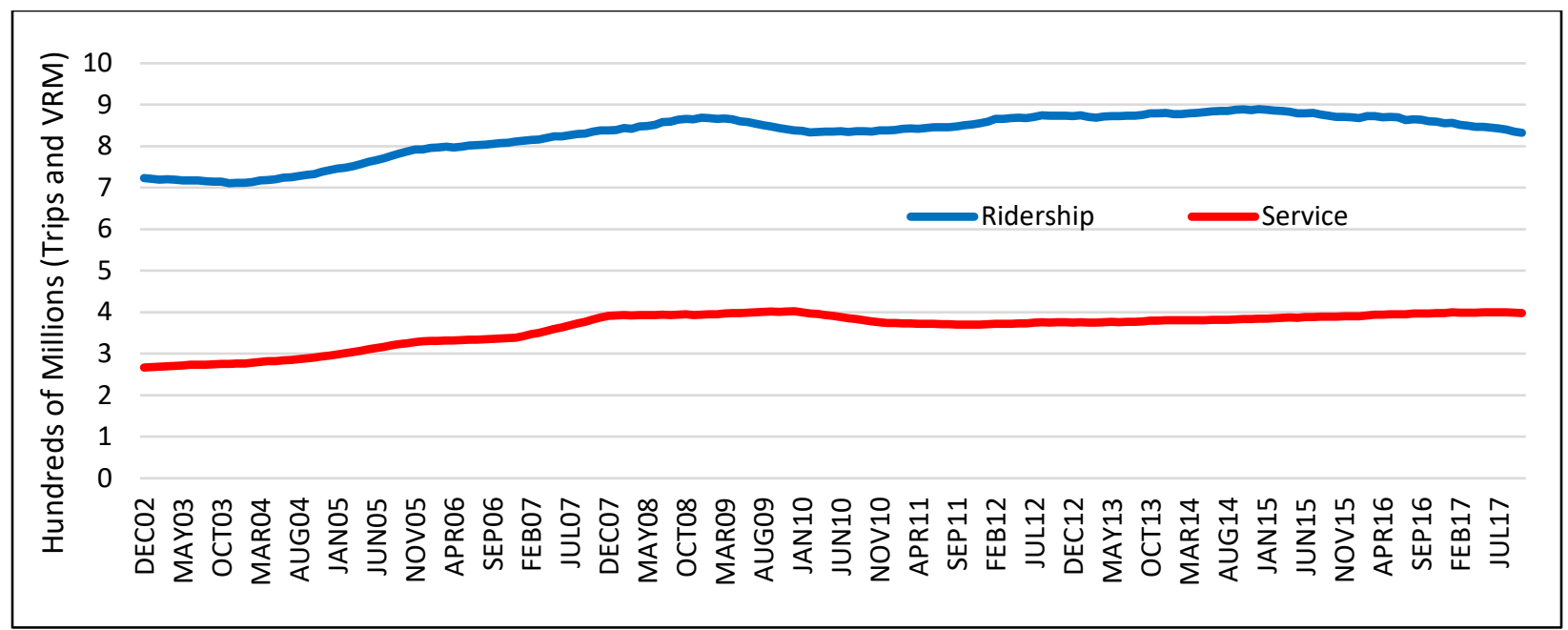

Figure 16 12-Month Rolling Average U.S. Transit Ridership and Service, All Modes

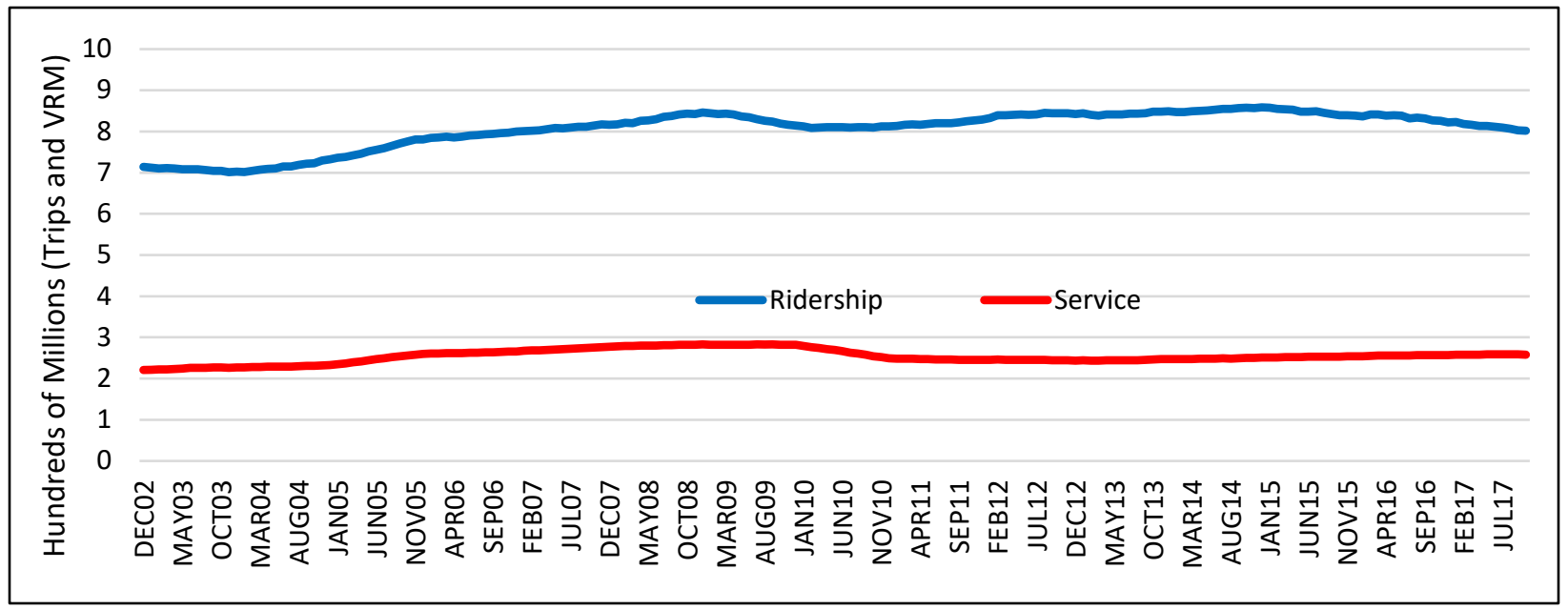

Figure 17 12-Month Rolling Average U.S. Transit Ridership and Service, Fixed Route

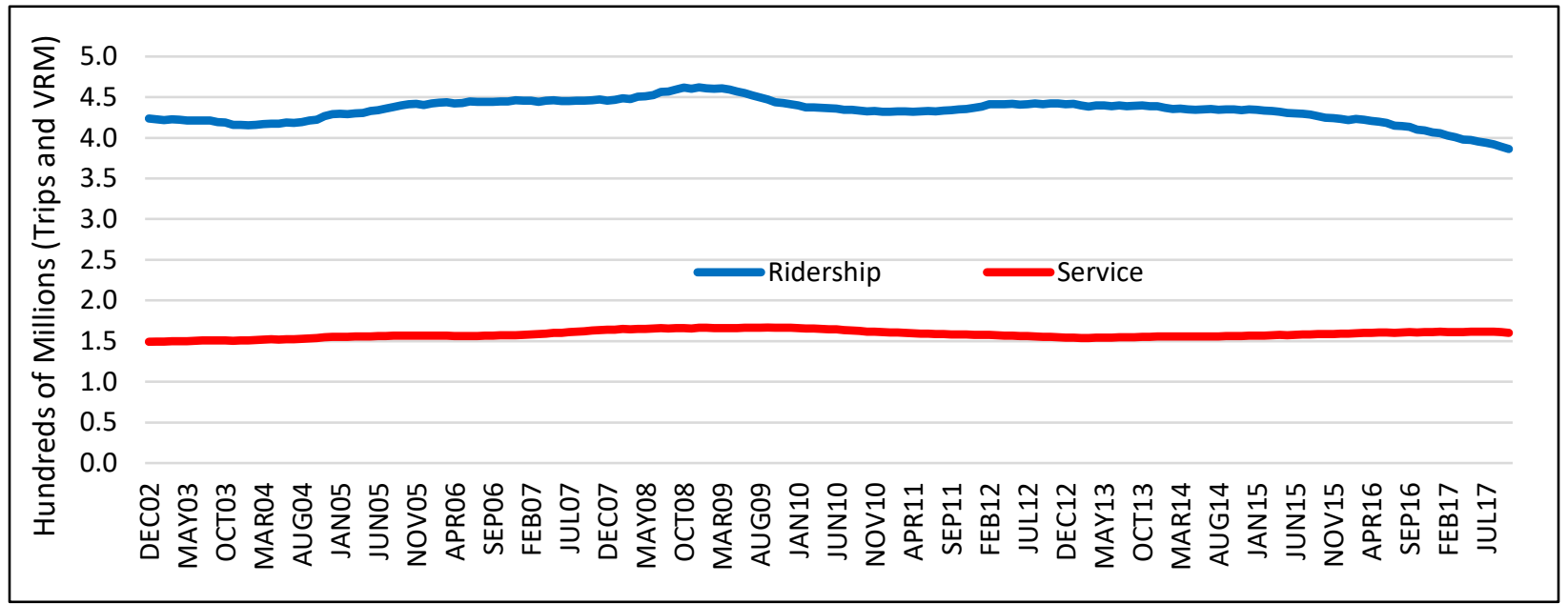

Figure 18 12-Month Rolling Average U.S. Transit Ridership and Service, Bus 


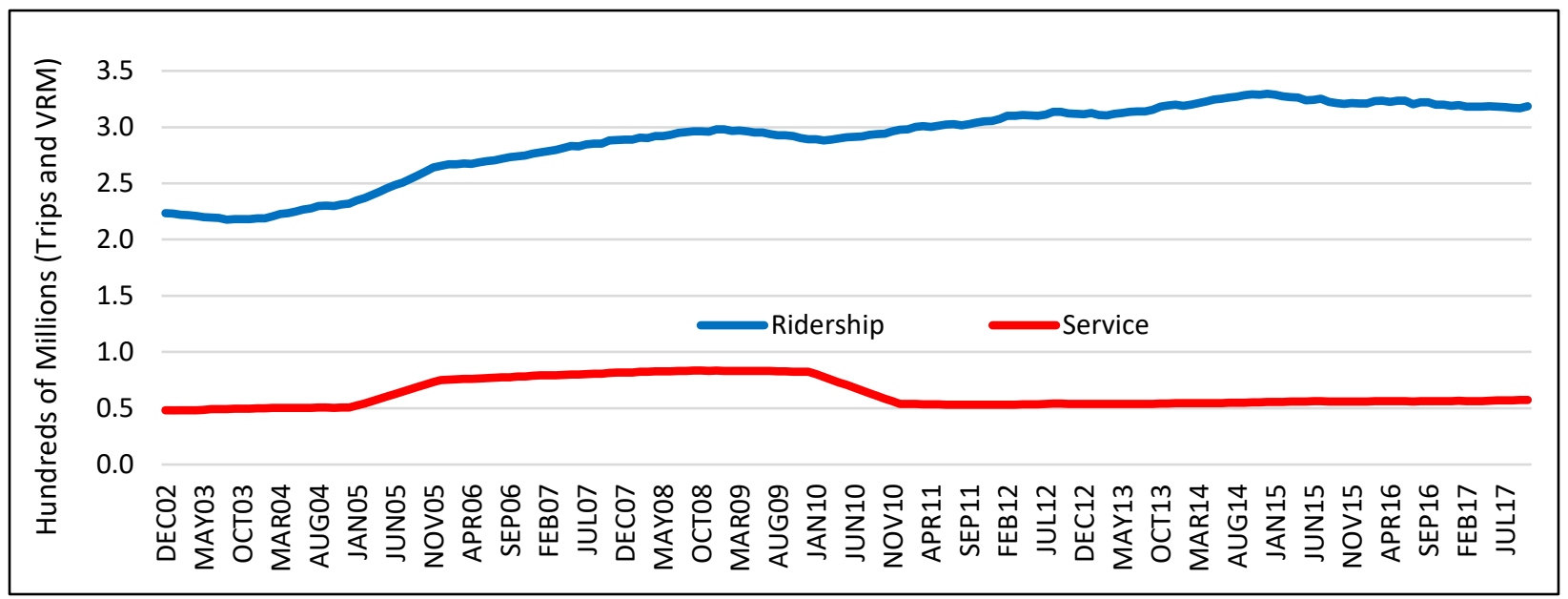

Figure 19 12-Month Rolling Average U.S. Transit Ridership and Service, Heavy Rail

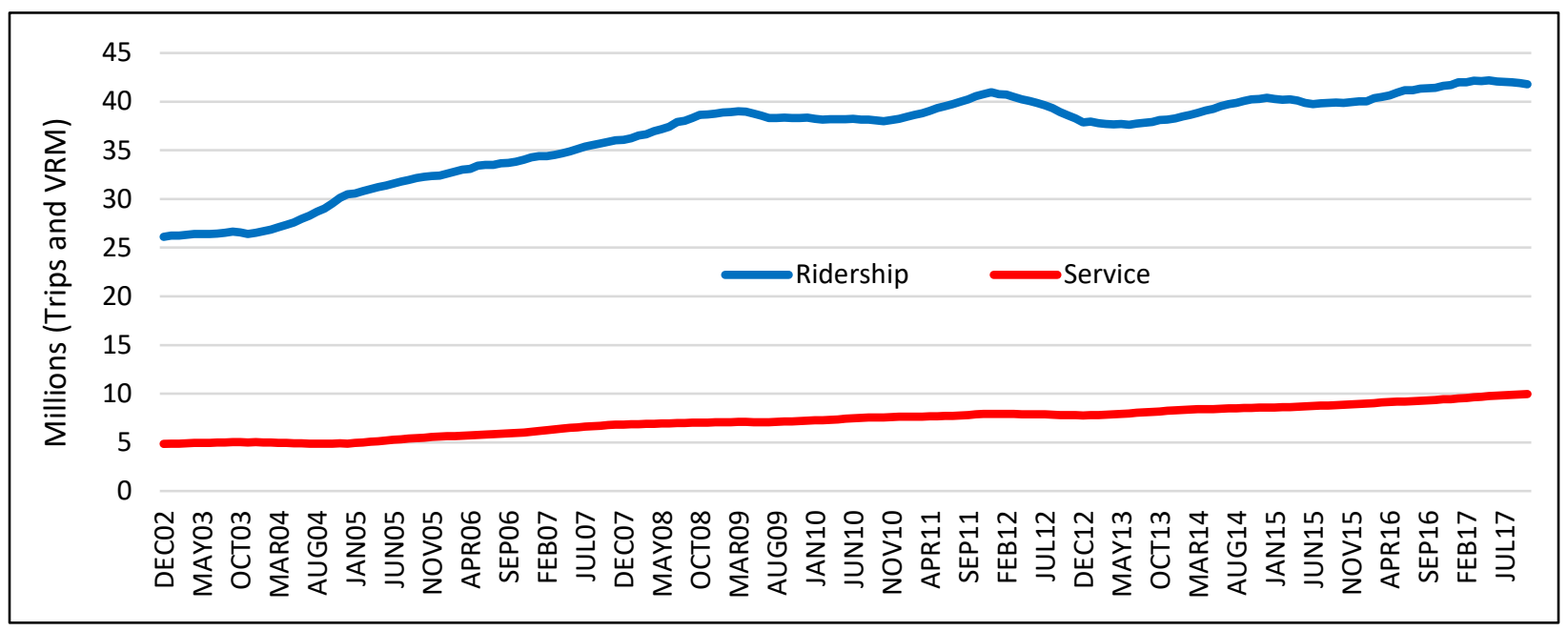

Figure 20 12-Month Rolling Average U.S. Transit Ridership and Service, Light Rail

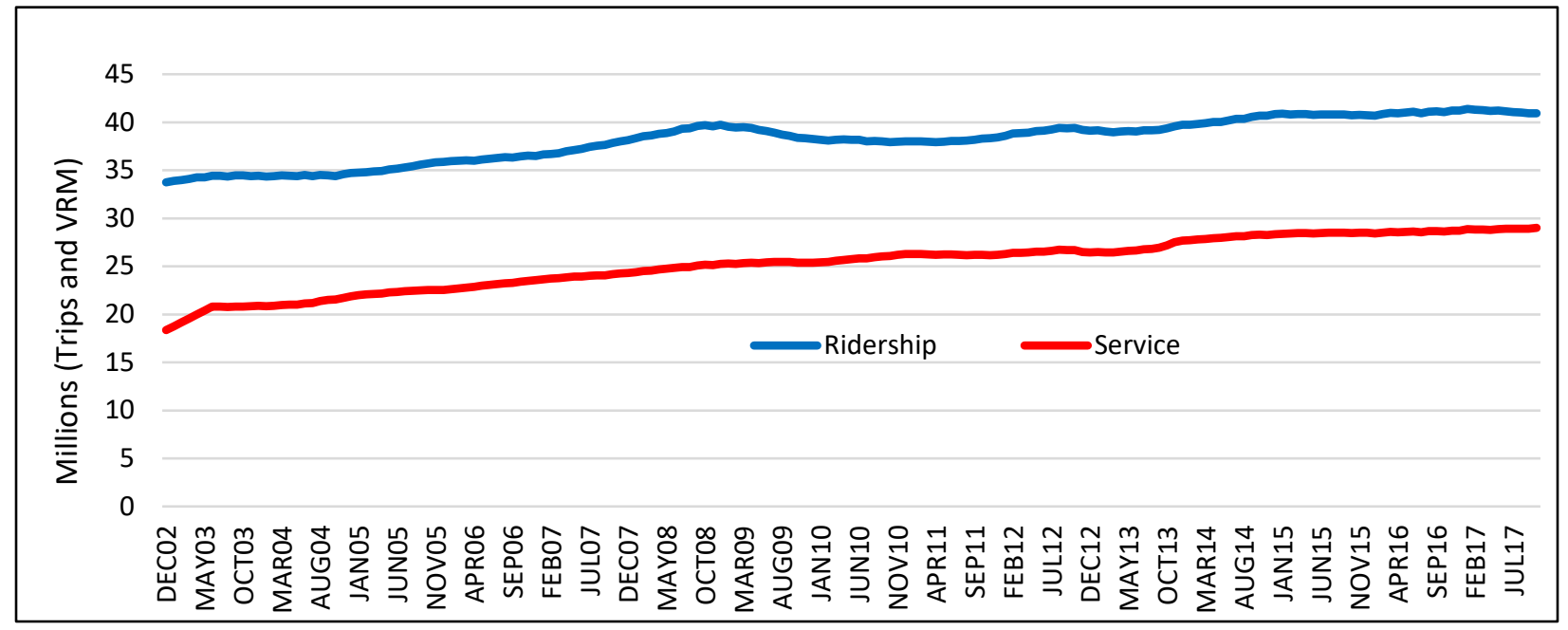

Figure 21 12-Month Rolling Average U.S. Transit Ridership and Service, Commuter Rail 
Several observations are relevant:

- $\quad$ Subsequent to the dip in service supply in the 2009 - 2011 timeframe, transit service supply has generally grown and at the aggregate level is not a significant explanatory factor in understanding ridership declines.

- $\quad$ Overall ridership declines are somewhat dampened by the fact that non-fixed route service - primarily paratransit type services - have not been subject to the same ridership pressures as have fixed route services.

- $\quad$ Bus service shows the most pronounced decline in ridership and those declines date back the furthest, beginning in 2012.

- $\quad$ Heavy rail ridership declines became apparent in fall 2014. They were more modest but persisted through 2017.

- $\quad$ Light rail ridership declines were more modest and began later. Growth in light rail service may have played a factor in buffering light rail from ridership declines experienced by other modes. In 2017, aggregate light rail ridership showed declines.

- $\quad$ Commuter rail ridership also showed strength until 2017. Commuter rail ridership was also supported by improvements in service availability.

Figure 22 shows the relationship between gas prices and transit ridership (Urban Passenger Trips - UPT). Figure 23 shows similar data for Florida. At the national level, the relationship is modest as portrayed graphically. Data in Figure 23 suggests that there is a stronger relationship between fuel prices and transit use in Florida.

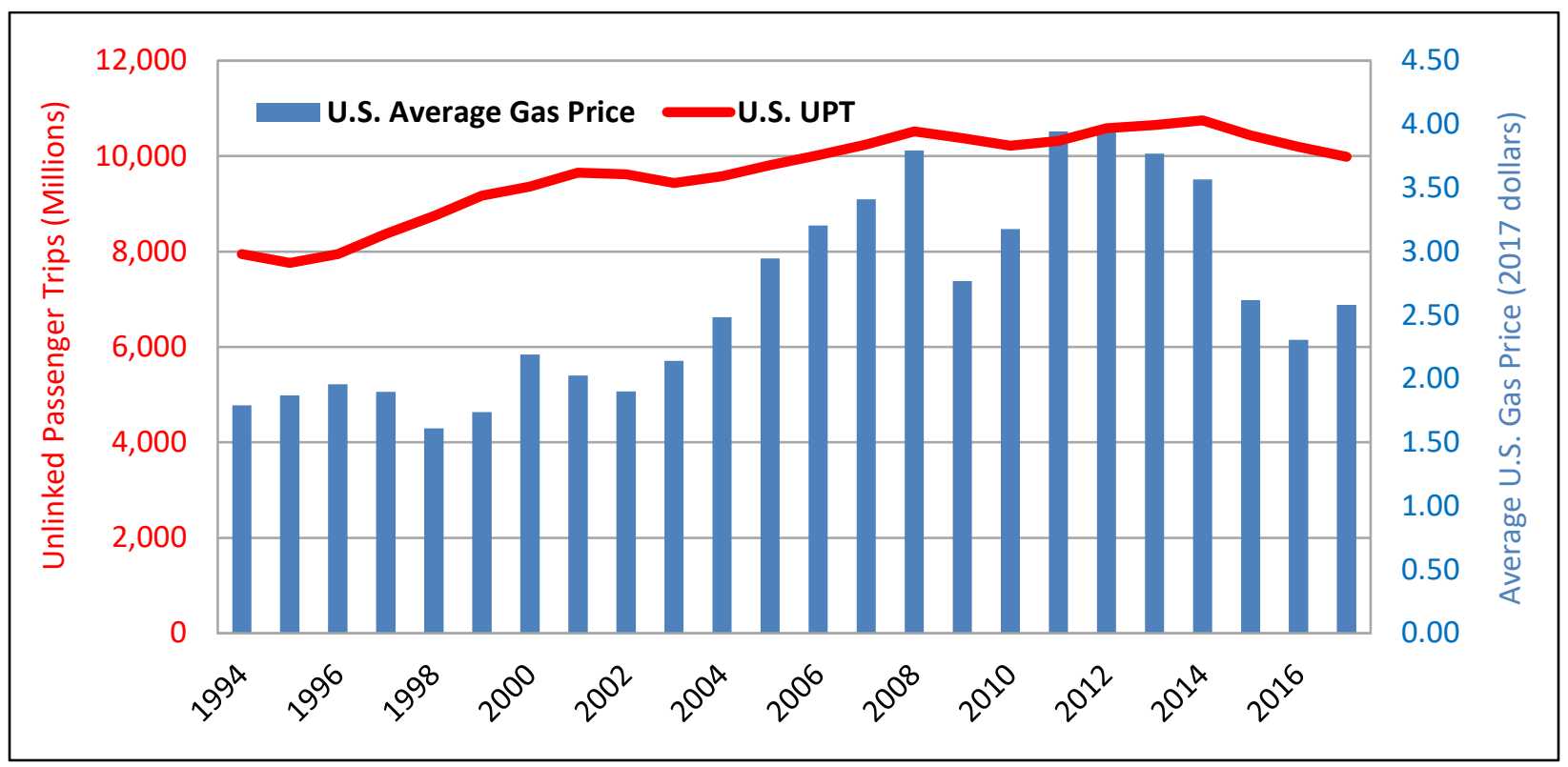

Figure 22 National Gas Price and Transit Ridership Trends Sources: EIA, APTA, BTS 


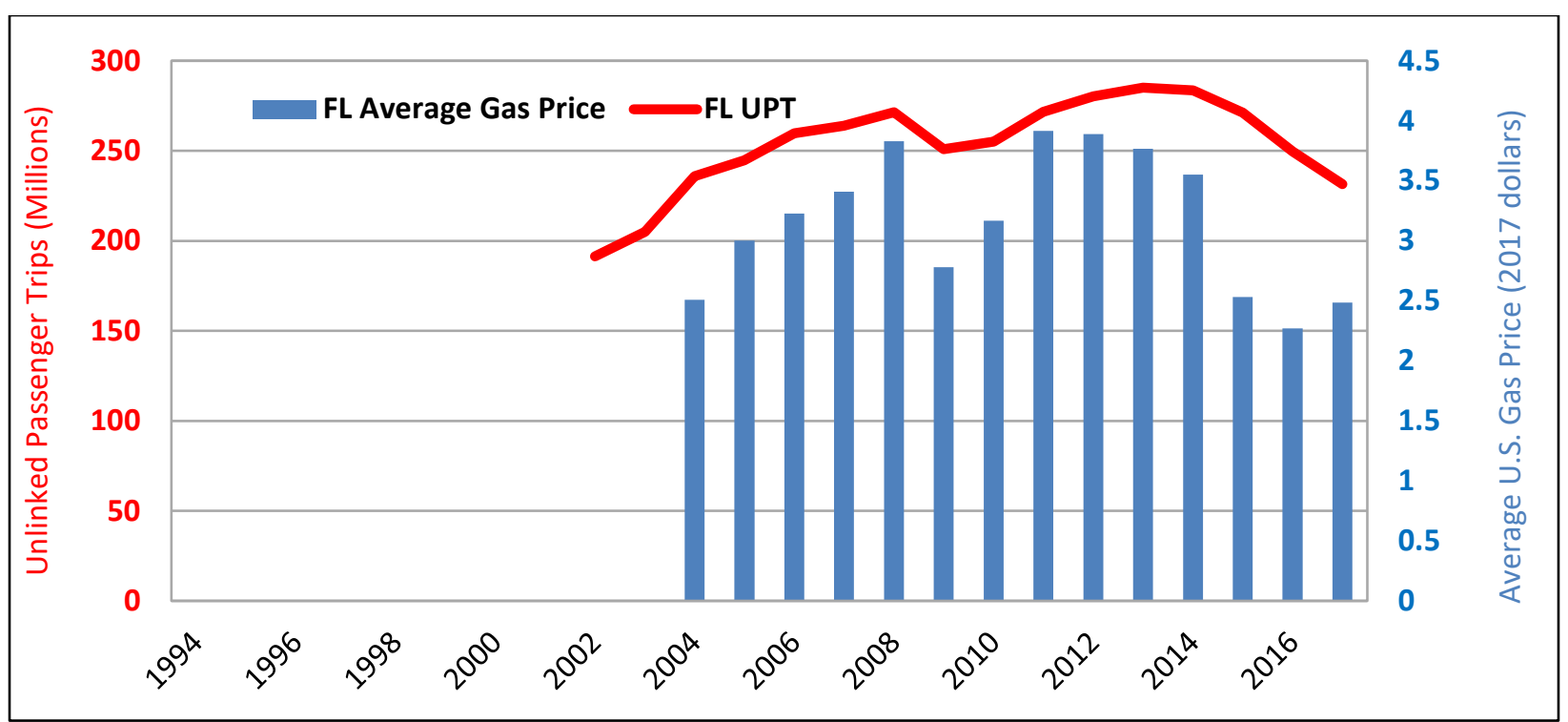

Figure 23 Florida Gas Price and Transit Ridership Trends

Sources: EIA, APTA, BTS

Figure 24 and Figure 25 present information on the relationship between transit ridership and use of Supplemental Nutrition Assistance Programs (SNAP) by persons at the national and state level. As a significant share of transit ridership is comprised of people of limited means, it is helpful to understand if transit use tracks with use of other programs to help individuals in need. The SNAP program has undergone changes in administration and eligibility, so the utilization levels are not strictly a reflection of economic conditions. The graphic relationships suggest softness in transit ridership in recent years is coincident with a general decline in participation in the SNAP program.

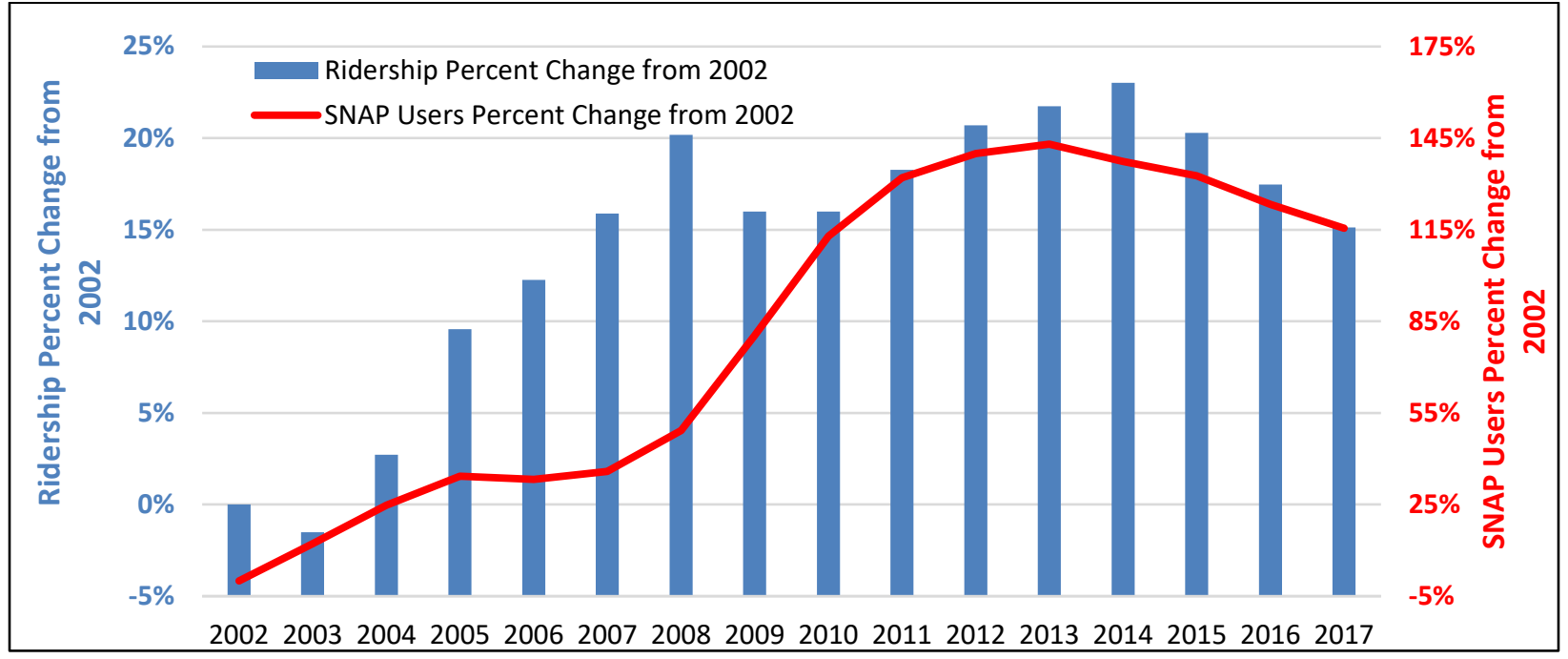

Figure 24 Percent Change U.S. Transit Ridership and SNAP Enrollment

Sources: NTD, U.S. Department of Agriculture 


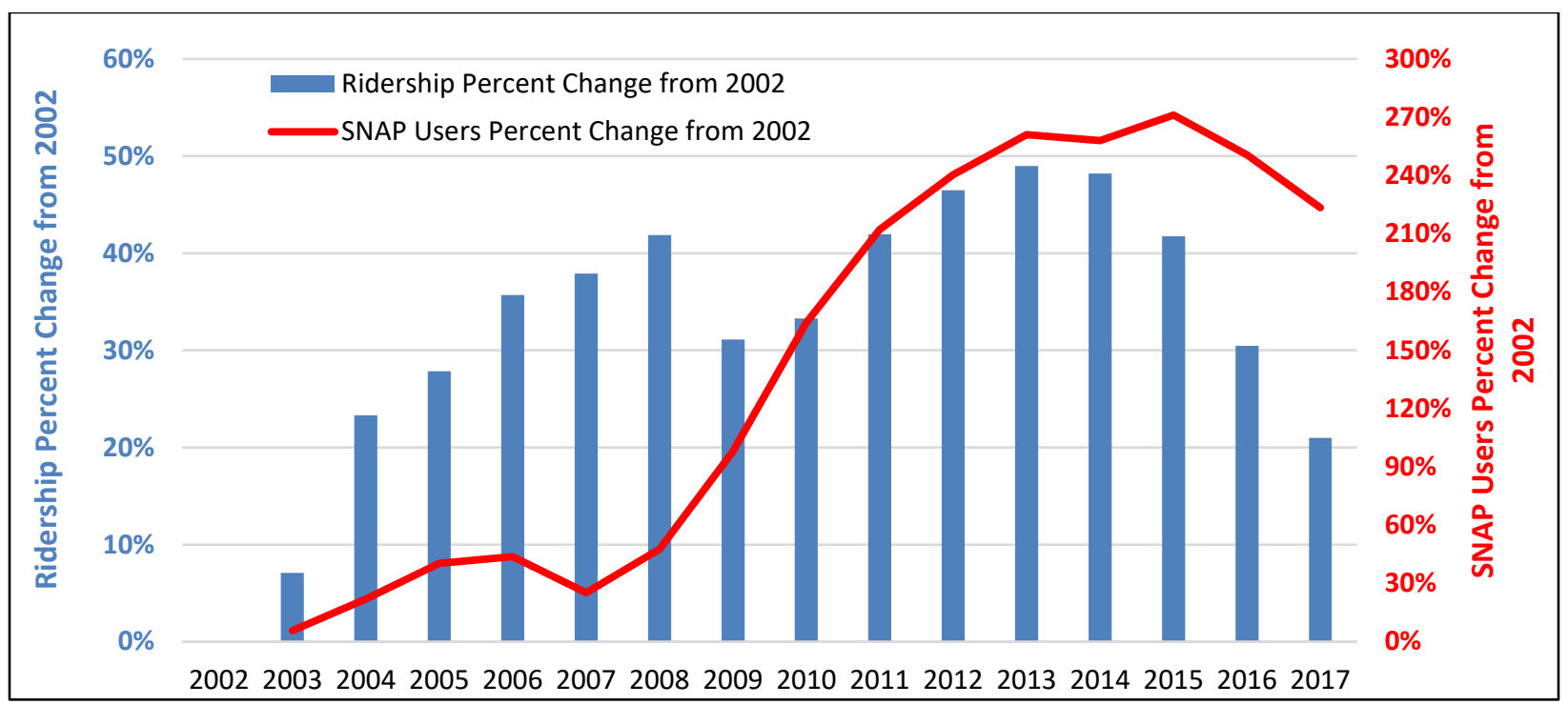

Figure 25 Percent Change FL Transit Ridership and SNAP Enrollment

Sources: NTD, U.S. Department of Agriculture

Figure 26 presents information on transit fares. Cost is one factor in ridership decision-making and has been hypothesized as a consideration impacting declining ridership. Fare levels expressed in 2017 dollars have risen modestly. Note, the 2015 and 2016 data source is different, hence, shown in a different color on the graph. When fares are adjusted for average trip length, the data indicate that on average fares have remained nearly constant in the $\$ .25$ $\$ .30$ per mile range. One should note that agencies increasingly have a variety of pricing strategies for fares, many of which mitigate the impact for low-income travelers. In addition, third-party subsidies from social service agencies can offset the cost for travel for some eligible populations.

Rail systems with the explicit stations and more sophisticated billing systems are perpetuating the growth in the ability of transit agencies to implement distance-based fare systems. For these systems, longer distance trips as services penetrate outlying areas can become expensive and some agencies nationally have reported soft ridership for longer trips. 


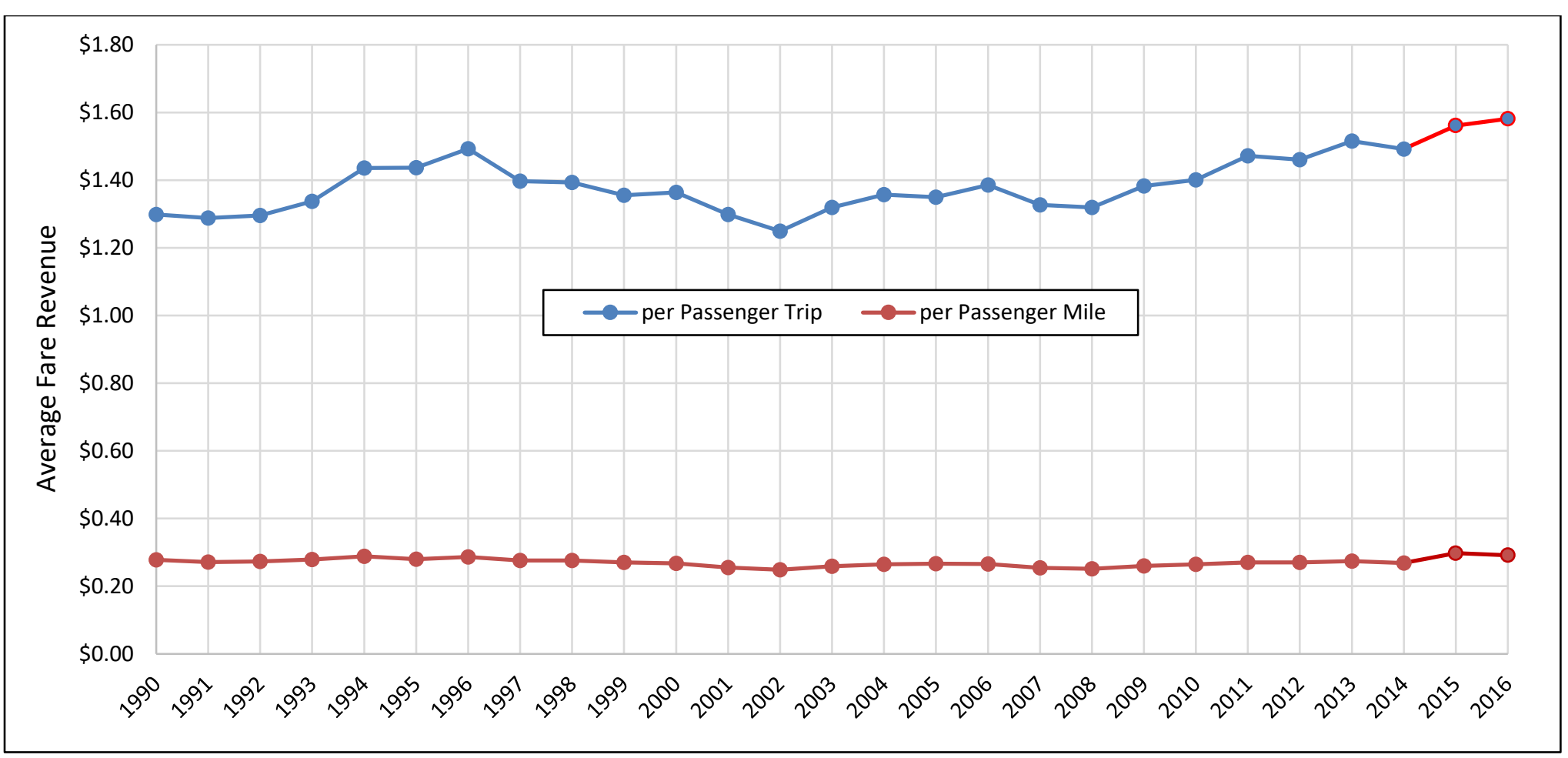

Figure 26 Average Fare Revenue per Passenger Trip and Passenger Mile (in 2017 Dollars)

Source: APTA Transit Fact Book, NTD

Detailed data on the changes in ridership for individual Florida transit operators are shown in Appendix A. 


\section{Chapter 2. Exploration of the Declines in Ridership}

The prior materials have presented aggregate data for Florida and the nation with respect to transit ridership trends and the trends in the underlying factors known to influence transit use. This section looks in more detail at the causes for the declines in ridership.

As revealed throughout this report, the dynamics of changing context conditions, limited detailed data, and the inherent complexity associated with human decision making, make it difficult to explicitly attribute causality to the various factors influencing transit ridership. The factors influencing ridership not only change across geography with different factors having different affects in different transit operating environments, but the factors influencing transit use may be changing over time. The factors that impacted transit declines in the 2014-2015 period may not be the same as those factors that impacted transit ridership before or after that period.

Despite the complexity and uncertainty, the project team is confident that the breadth of data reviewed and the in depth understanding of travel behavior from decades of monitoring trends provide significant insight that can be of assistance as stakeholders seek to counter and respond to the ridership trends.

\section{Organization of This Section}

There are several possible ways one could organize this section. As a point of reference, Figure 27 frames a general outline of how various factors influence travel behavior and subsequently transit ridership.

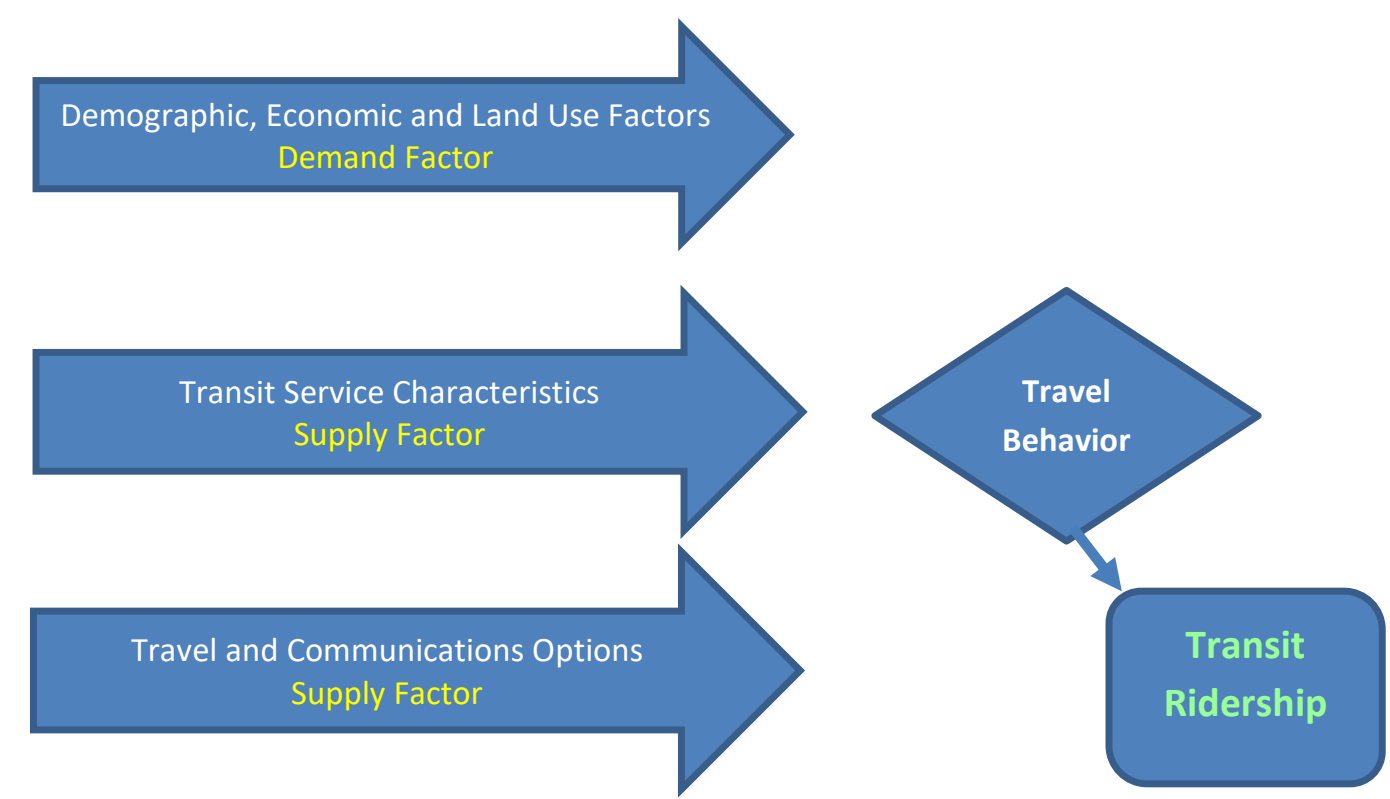

Figure 27 Framework for Exploring Factors Influencing Public Transit Ridership Levels 
The first set of factors (Table 7) are indicators of the demand for travel and transit use. The second set of factors (Table 8) are characteristics of transit supply, and the third set of factors (Table 9) are characteristics of the alternative means of travel and/or accomplishing the activities one engages in. As one would expect, these factors interact in ways that ultimately influence travel. The subsequent tables detail those categories.

Table 7 Demand Factors of Transit Ridership

\begin{tabular}{|c|c|}
\hline \multicolumn{2}{|r|}{ Demand Factors - Demographic, Economic and Land Use } \\
\hline $\begin{array}{l}\stackrel{\mathscr{N}}{د} \\
\overline{0} \\
\stackrel{\Xi}{\Xi}\end{array}$ & $\begin{array}{l}\text { Geographic distribution of population/activity with respect to transit service areas } \\
\text { Urban, suburban or rural - low versus high service areas (regional scale) } \\
\text { Geographic activity distribution within transit service areas } \\
\text { Concentration near higher quality service locations (neighborhood/stop scale, TOD) } \\
\text { Geographic activity patterns } \\
\text { Clustering/concentration, origin-destination balancing }\end{array}$ \\
\hline 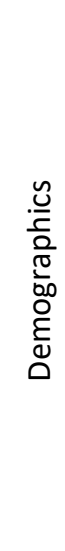 & $\begin{array}{l}\text { Age, household composition/structure, employment status } \\
\text { Factors that influence travel levels, preferences and available choices } \\
\text { Income, wealth, home ownership status, vehicle ownership status } \\
\text { Factors that influence travel levels and options/preferences } \\
\text { Race, Ethnicity, gender, citizenship status } \\
\text { Factors that may influence travel options and preferences } \\
\text { Changes in core values (safety, reliability, flexibility, convenience, image, autonomy, etc.) } \\
\text { Changes in culture or preferences (independent of socio-demographic changes) that influence choices }\end{array}$ \\
\hline 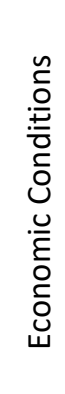 & $\begin{array}{l}\text { Economic activity } \\
\text { Employment, disposable income, job security, consumer confidence - factors that affect activity levels } \\
\text { Fuel prices } \\
\text { Impacts mode choice and household disposable income } \\
\text { Interest costs/availability } \\
\text { Factors that affect home/vehicle ownership decisions and subsequently impact travel decisions }\end{array}$ \\
\hline
\end{tabular}


Table 8 Supply Factors of Transit Ridership, Transit Service Characteristic

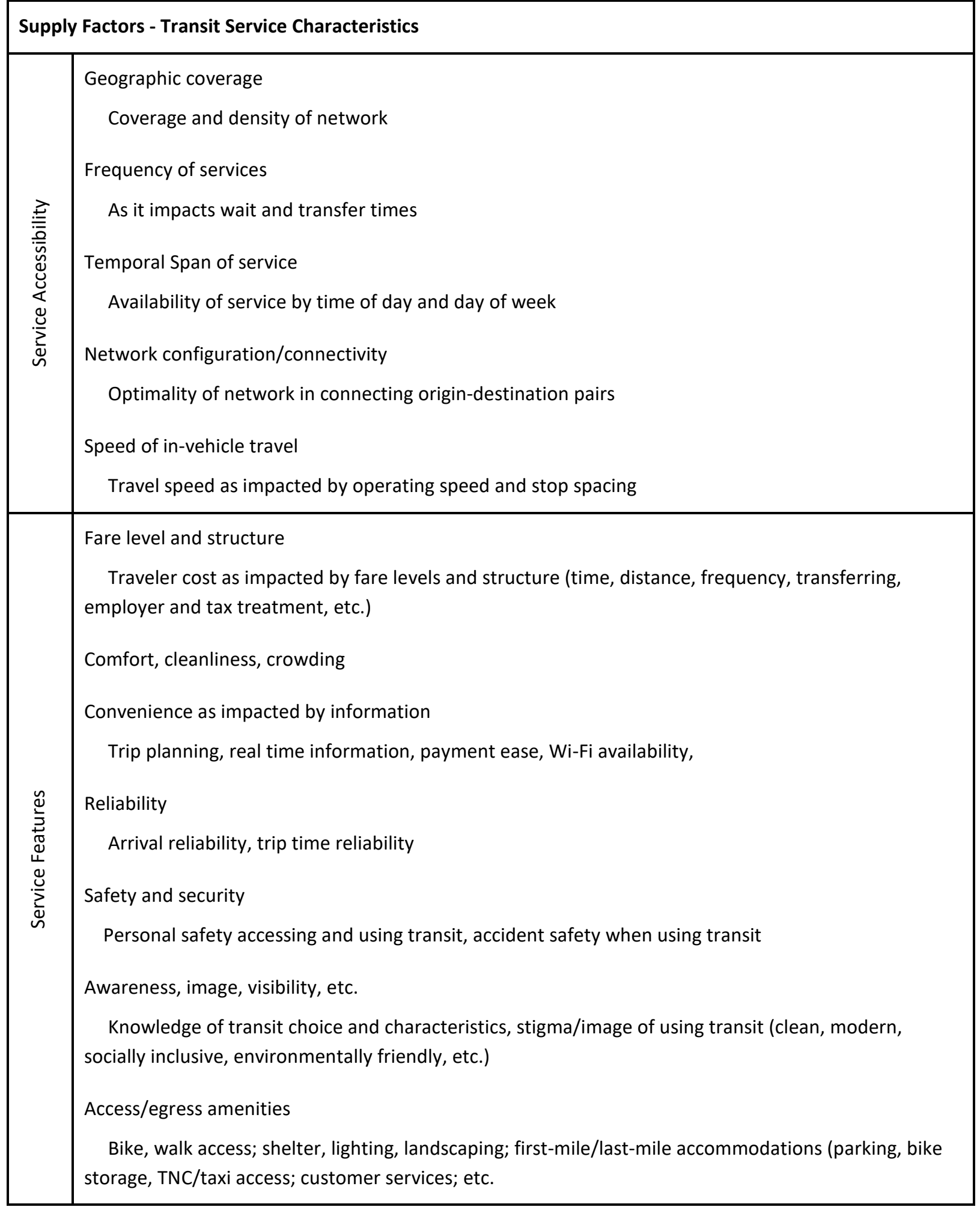


Table 9 Supply Factors of Transit Ridership, Travel and Communications Options

\begin{tabular}{|c|c|}
\hline \multicolumn{2}{|c|}{ Supply Factors - Travel and Communication Options } \\
\hline 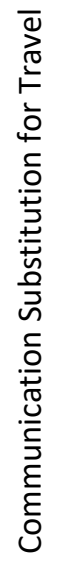 & $\begin{array}{l}\text { Telecommuting/work-at-home } \\
\text { Changes in commuting travel levels } \\
\text { E-Commerce } \\
\text { Foregone travel via online shopping } \\
\text { Electronic communications of video, audio, and document materials in lieu of travel } \\
\text { E-learning, online banking, electronic document transfer, video and music streaming, etc. } \\
\text { Social Networking } \\
\text { Electronic interaction in lieu of in-person social interaction (text, tweet, skype, Facebook, } \\
\text { Instagram, video gaming, etc.) }\end{array}$ \\
\hline 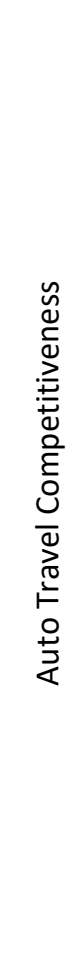 & $\begin{array}{l}\text { Vehicle cost and availability } \\
\text { New/used vehicle prices, interest cost and financing availability, vehicle reliability/maintenance } \\
\text { Licensure/Insurance considerations } \\
\text { Costs, government policies (age, immigration status, etc.) } \\
\text { Parking cost and availability } \\
\text { Travel time/speed and reliability } \\
\text { Congestion, incident frequency, mechanical reliability } \\
\text { Safety and security } \\
\text { Change in features and amenities } \\
\text { Comfort/convenience features (Wi-Fi, navigation, toll/parking payment connectivity, vehicle } \\
\text { telematics, etc.) } \\
\text { Fuel Cost } \\
\text { Stigma, Image } \\
\text { Perceptions of environmental impacts, social impacts, status, etc. }\end{array}$ \\
\hline 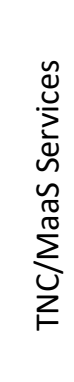 & $\begin{array}{l}\text { TNC Availability } \\
\text { Temporal and geographic availability, arrival time } \\
\text { TNC Access } \\
\text { Banking arrangement, smartphone availability, vehicle accessibility for mobility limited, etc. } \\
\text { TNC Cost } \\
\text { Bikeshare, scooter share, short term auto rental - availability, accessibility, and cost }\end{array}$ \\
\hline
\end{tabular}


This framework collectively enumerates numerous factors, each of which has been hypothesized to have been a factor in influencing the demand for public transportation. Several of them were addressed in the prior section and some will be discussed here. Others remain speculative due to the expectation that their significance is minor, data to address the factor is not available, or there is no research methodology readily available to discern their significance. It is important to note that a multitude of factors act in concert to influence ridership trends. The interaction between supply and demand ultimately influence behavior. Human decisionmaking is complex such that in many cases multiple factors influence the ultimate decision. For example, prior research has reported that auto ownership trends are a significant factor explaining ridership declines. The decision of a household to secure a vehicle or an additional vehicle could quite logically be influenced by a host of factors. A recovering economy may have helped provide resources, as might have lower used-car costs and the availability of low-cost financing options. Changes in household structure, changes in the destination choice set for the travelers (for example a new job in a different location), lower gas prices, and perhaps changes in satisfaction with existing transit services might collectively influence vehicle ownership decisions and subsequent mode choice decisions.

Research methods can help to inform our knowledge base but are seldom able to fully diagnose the range and relative significance of the multitude of factors involved. The American Public Transportation Association (APTA) has chosen to categorize factors that influence ridership levels into four main characteristics ${ }^{1}$ : erosion in time competitiveness, reduced affinity, erosion in cost competitiveness, and external factors. Other studies have used different approaches, for example work by the Washington Metropolitan Area Transit Authority (WMATA) focused on internal factors, factors that might be able to be influenced by the agency, and external factors unlikely to be able to be impacted by the agency.

For this analysis, we have chosen to focus on the interplay of transit supply and demand in a section titled Transit Competitiveness. This addresses the demographic and land use characteristics shown in the framework above and the level of service accessibility considerations shown in the transit service characteristics framework table. The subsequent section discusses other economic and service characteristics and is followed by a section that addresses the influence of emerging technologies and business models.

${ }^{1}$ Understanding Recent Ridership Changes, Trends and Adaptations, APTA, April 2018 


\section{Transit Competitiveness}

This section looks at the levels of service provided by transit and addresses factors associated with changes in transit's relative competitiveness with alternative means of travel. This includes addressing speed, cost, and accessibility to and from public transportation. This discussion integrates characteristics of the transit market with characteristics of transit service.

Figure 28 is a representation of the national and Florida average transit trip travel time components based on the 2017 NHTS (data collected from April 2016 through March 2017). These components are portrayed to provide a framework for discussion of travel time competitiveness. The average national trip on transit totals 54.9 minutes and the Florida transit trip averages 59.1 minutes. Of the national transit travel time, 19.6 minutes, or $36 \%$, is consumed in access or egress to and from transit stops. 9.4 minutes, or $17 \%$, is consumed in waiting for the vehicle to arrive with the remaining 25.9 minutes, or $45 \%$, comprised of in vehicle travel time. It is notable that less than half of travel time is consumed by in-vehicle travel.

Florida, which generally has more modest transit levels than the national average as well as a smaller share of transit travel on guideway facilities, has longer average total travel time and wait time, but access and egress are slightly lower. Less dense networks tend to increase access and egress time, and lower frequencies tend to result in greater wait times. In-vehicle travel time may be somewhat longer for bus dominated transit services that are slower, but this may be offset by shorter trip lengths. Considerations such as parking cost, perceptions of transit service quality, and other factors also influence the propensity to use transit, which can influence the magnitude of the trip components. For perspective, the 55-minute average national transit trip involves travel of 11 miles. In that same 55 minutes, the average urban auto traveler would travel approximately 27 miles $^{2}$. There is not data available to capture the auto access or egress times for auto trips. On average, these times may be nearly insignificant but for urban core trips in larger metropolitan areas time consumed finding parking and walking to and from that parking to the ultimate destination might be significant.

\footnotetext{
${ }^{2}$ Based on analysis of 2017 NHTS data.
} 


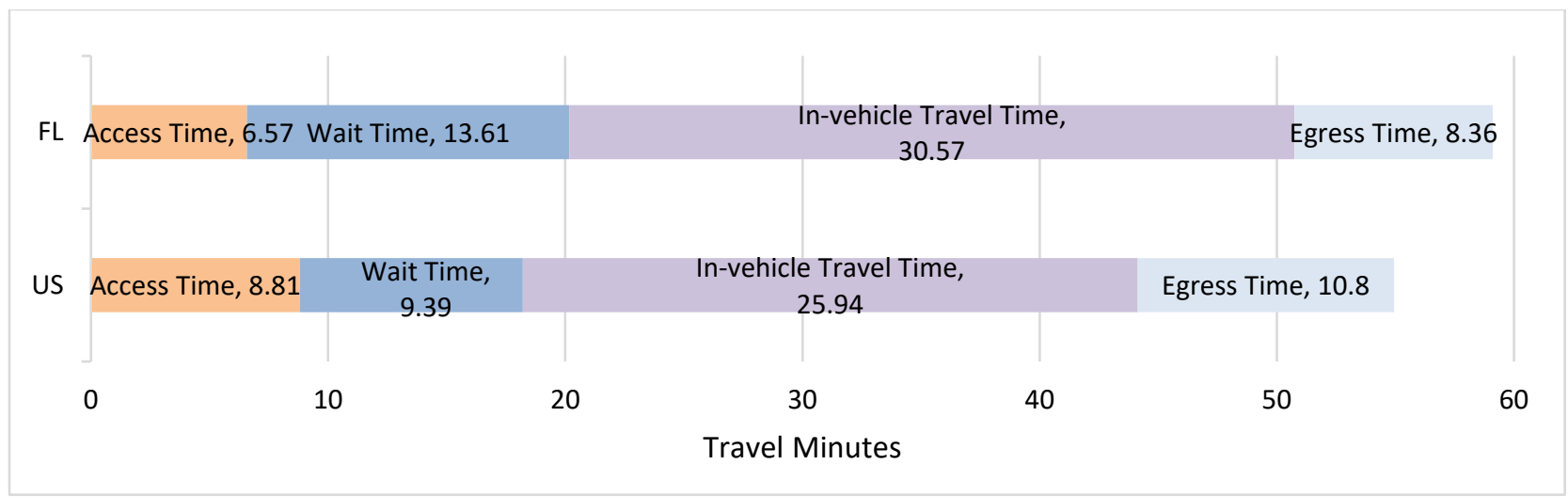

\section{Figure 28 Components of Transit Travel Time}

Source: 2017 NHTS

The data in Figure 28 applies to transit trips as reported by NHTS respondents and does not explicitly acknowledge the fact that approximately half of transit trips involve a transfer. Accordingly, if respondents provided accurate details, the wait time shown represents an average of initial waits for all travelers and second waits for individuals making a transfer.

The first element regarding the competitiveness of transit and its potential influence on transit ridership changes relates to the accessibility of transit to the population, both at the residential trip end and with respect to travel destinations. To the extent that there are changes over time in access to transit for potential travelers and access via transit to destinations, transit's competitiveness and hence transit ridership might change.

As noted in the framework table above, service accessibility or availability is characterized by five traits: geographic coverage, temporal span of service, service frequency, connectivity or network configuration, and in-vehicle speeds. Collectively, these traits comprise what is frequently referred to as level of service for public transportation. These traits are generally characteristics that are controlled by the operating agency, and subject to resource and policy decisions made by a host governmental entity. These level of service factors are the variables that transit service planners utilize as they evaluate services and make decisions on allocating service to markets. These are also variables that are influenced by resources available to the transit agency, hence, they are subject to change as economic conditions and other factors influence the available resources to support public transportation.

In its most aggregate form, service accessibility is often characterized as the revenue vehicle miles of service offered by the agency in its market area. This single measure can reflect whether service levels are changing over time. As shown in Figure 29 below, and as detailed for each fixed route operator in Florida in Appendix A, Florida fixed route transit service levels have 
remained relatively stable over the past decade. These statewide trends by sub mode and time period are shown in Table 10 below.

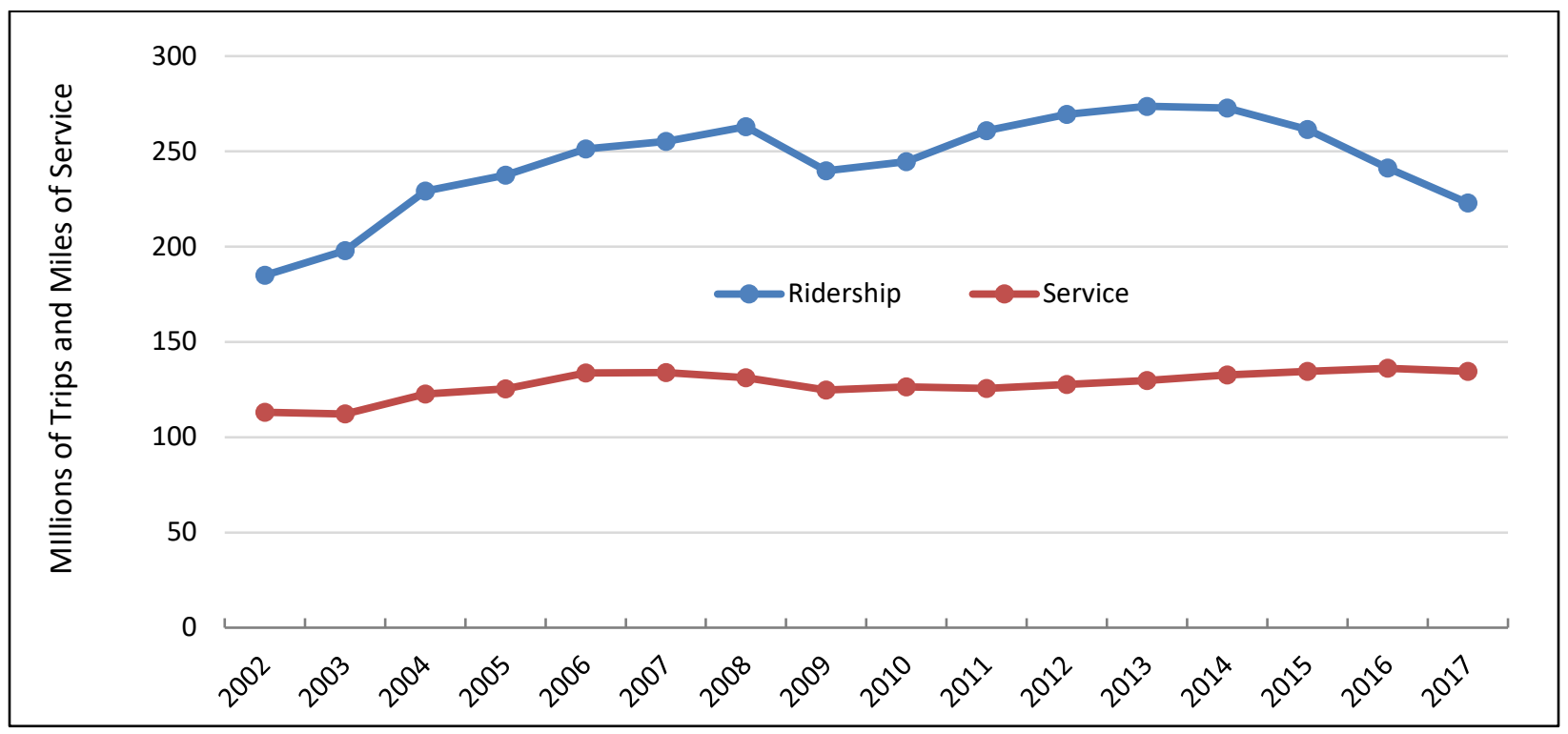

Figure 29 Florida Fixed Route Transit Ridership and Service Trend

Source: NTD

As shown in Figure 29, fixed route service levels peaked in the 2006-07-time period, showed a decline to 2009 when economic conditions sapped resources, and then steadily increased through 2016. A modest decline in 2017 reflects some service adjustments in response to declining ridership and the impacts of Hurricane Irma, on several transit properties. Most vehicle miles of service in Florida are fixed route bus services. Fluctuations in other modes are principally the result of distinct, context specific service modifications. Over 10 years, bus service levels have declined $4.6 \%$. Light rail services - which consist exclusively of services on the TECO streetcar in Tampa, declined $20 \%$ reflecting resource constraints and soft ridership. The dramatic increase in commuter rail service levels reflects both enhanced Tri-Rail service and the addition of SunRail service in Orlando. Heavy rail service declines reflect resource constraints and supply demand balancing in Miami-Dade County. Demand response service levels respond to demand as influenced by policy and pricing decisions and service quality as well as demographic trends. The three-year trend in service supply is positive for all sub modes except for heavy rail. The one-year trend is mixed with relatively modest changes except for heavy rail and demand response. The quarterly trend is neutral. 
Table 10 Transit Ridership and Service Summary by Mode, Florida

\begin{tabular}{|c|c|c|c|c|c|c|}
\hline \multicolumn{7}{|c|}{ Transit Ridership and Service Summary } \\
\hline & & & $\begin{array}{c}10 \text { year trend - } \\
2017-2007\end{array}$ & $\begin{array}{c}\text { 3-year trend - } \\
\text { 2017-2014 }\end{array}$ & $\begin{array}{c}1 \text { year trend - } \\
2017-2016\end{array}$ & $\begin{array}{l}\text { Trending - Q4 } \\
2017 \text { - Q4 } 2016\end{array}$ \\
\hline \multirow{12}{*}{$\begin{array}{l}\frac{\pi}{0} \\
\frac{0}{0} \\
\frac{0}{4}\end{array}$} & \multirow{5}{*}{$\begin{array}{l}\frac{0}{\frac{1}{n}} \\
\frac{1}{d} \\
\frac{0}{\frac{0}{x}}\end{array}$} & All bus & $-18.4 \%$ & $-20.5 \%$ & $-7.6 \%$ & $-5.6 \%$ \\
\hline & & Light rail & $-50.0 \%$ & $2.5 \%$ & $-4.1 \%$ & $2.7 \%$ \\
\hline & & Commuter rail & $22.4 \%$ & $-2.4 \%$ & $2.0 \%$ & $6.5 \%$ \\
\hline & & Heavy rail & $15.3 \%$ & $-9.4 \%$ & $-6.7 \%$ & $-3.8 \%$ \\
\hline & & Demand Response & $-0.2 \%$ & $6.6 \%$ & $4.3 \%$ & $6.4 \%$ \\
\hline & & Total & $-15.1 \%$ & $-18.6 \%$ & $-7.0 \%$ & $-4.9 \%$ \\
\hline & \multirow{5}{*}{ 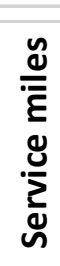 } & All bus & $-4.6 \%$ & $1.2 \%$ & $-0.8 \%$ & $-1.9 \%$ \\
\hline & & Light rail & $-20.2 \%$ & $2.4 \%$ & $-1.7 \%$ & $-16.6 \%$ \\
\hline & & Commuter rail & $270.2 \%$ & $1.9 \%$ & $1.1 \%$ & $7.7 \%$ \\
\hline & & Heavy rail & $-9.0 \%$ & $-7.5 \%$ & $-8.9 \%$ & $-18.8 \%$ \\
\hline & & Demand Response & $9.1 \%$ & $17.1 \%$ & $5.8 \%$ & $5.7 \%$ \\
\hline & & Total & $0.8 \%$ & $5.7 \%$ & $1.0 \%$ & $0.0 \%$ \\
\hline
\end{tabular}

Source: NTD

What is clear in reviewing these aggregate measures is that service supply has not been a significant factor in explaining declining ridership. By virtue of the fact that ridership declined while service levels have grown, there is no basis for the argument that service declines explain the ridership trends in the aggregate. As noted in the data in Appendix A, service changes appear to be a consideration in some Florida properties. Figure 30 below, shows a scatter diagram of the percent changes in ridership and service for Florida operators over the past three years. Table 11 includes the source data and reports the respective percent changes in service levels. The positive ridership changes are generally unique situations with new services or reconfigurations. No properties had positive ridership trends with declining service.

While there is certainly variation across transit properties, the general downward trend in ridership relative to service levels suggest a systematic set of phenomena that are impacting consistently across transit properties.

The next analysis test was applied to look more closely at the population served by public transportation. To address that in the most aggregate terms, the share of Florida's population within transit service areas was enumerated and was shown in Table 5 which reports the trend data for transit agencies reporting service area populations within the NTD. As the table indicates, the population reported in transit service areas has been growing. The growth in transit served areas averaged $1.6 \%$ per year, a rate slightly ahead of the overall state 
population growth rate of $1.4 \%$. This growth is consistent with the general trend of increased urbanization, as rural areas tend to be losing population and growth tends to be concentrated in urban areas. One should note that this is not necessarily the case uniformly across the country. Some strong transit markets, for example Chicago, have seen absolute declines in population.

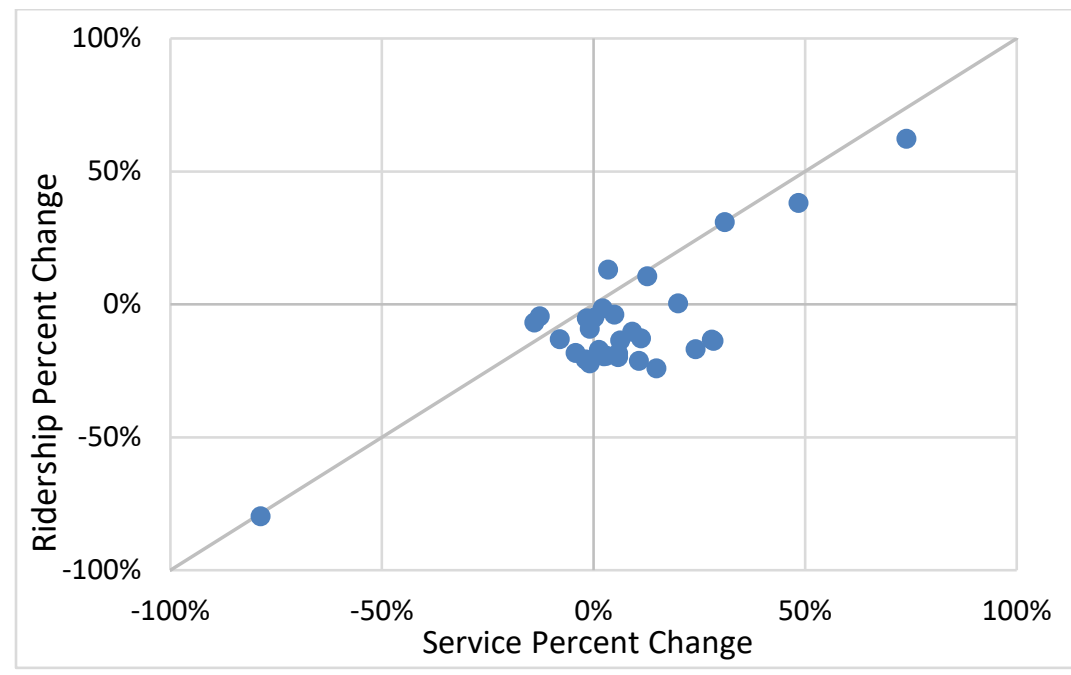

Figure 30 Ridership vs. Service percent Change 2014-2017

Source: CUTR analysis of NTD

At the national level, population growth has been faster in areas (the South and West) that generally have more modest levels of transit than the slow or no growth areas in the Northeast and Midwest. Florida, a fast growth state, has a lower level of transit use per capita than the national average.

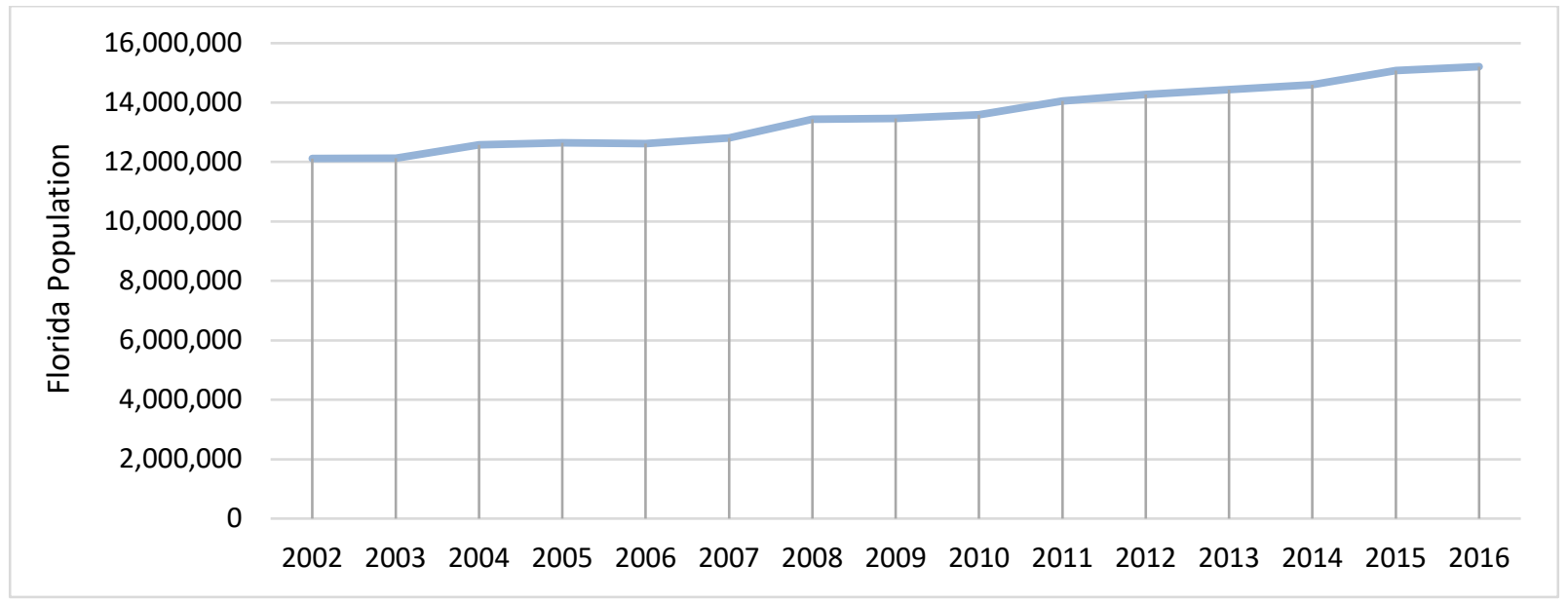

Figure 31 Trend in Florida Population Served by Transit (2002-2016)

Source: CUTR analysis of NTD 
Table 11 Ridership and Service Change

2017-2014

\begin{tabular}{|c|c|c|}
\hline Geography & $\begin{array}{l}\text { Ridership } \\
\text { (UPT) }\end{array}$ & $\begin{array}{c}\text { Service } \\
\text { (VRM) }\end{array}$ \\
\hline Martin & $62 \%$ & $74 \%$ \\
\hline Central FL CR & $38 \%$ & $48 \%$ \\
\hline St. Lucie & $31 \%$ & $31 \%$ \\
\hline Charlotte & $13 \%$ & $3 \%$ \\
\hline Indian River & $11 \%$ & $13 \%$ \\
\hline Escambia & $0 \%$ & $20 \%$ \\
\hline Jacksonville & $-2 \%$ & $2 \%$ \\
\hline TBARTA & $-4 \%$ & $5 \%$ \\
\hline Clay* & $-4 \%$ & $-13 \%$ \\
\hline SFRTA & $-5 \%$ & $0 \%$ \\
\hline Ocala & $-5 \%$ & $-2 \%$ \\
\hline Lake County & $-7 \%$ & $-14 \%$ \\
\hline MiamivRide & $-9 \%$ & $-1 \%$ \\
\hline Volusia & $-10 \%$ & $9 \%$ \\
\hline Gainesville & $-13 \%$ & $11 \%$ \\
\hline Space Coast & $-13 \%$ & $-8 \%$ \\
\hline Okaloosa & $-13 \%$ & $28 \%$ \\
\hline CF RTA & $-14 \%$ & $6 \%$ \\
\hline Pasco & $-14 \%$ & $28 \%$ \\
\hline Lakeland & $-17 \%$ & $24 \%$ \\
\hline HART & $-17 \%$ & $1 \%$ \\
\hline Sarasota & $-18 \%$ & $-4 \%$ \\
\hline Manatee & $-18 \%$ & $6 \%$ \\
\hline PSTA & $-19 \%$ & $3 \%$ \\
\hline Palm Beach & $-20 \%$ & $2 \%$ \\
\hline Lee & $-20 \%$ & $6 \%$ \\
\hline Miaimi-Dade & $-21 \%$ & $-2 \%$ \\
\hline Collier & $-21 \%$ & $11 \%$ \\
\hline Tallahassee & $-22 \%$ & $-1 \%$ \\
\hline Broward & $-24 \%$ & $15 \%$ \\
\hline Bay & $-80 \%$ & $-79 \%$ \\
\hline \multicolumn{2}{|c|}{ * data for $2017-2015$} & \\
\hline
\end{tabular}

What this market area-based analysis does not address is the micro-scale orientation of people and destinations with respect to the orientation of transit service. Unfortunately, the data sets necessary to evaluate the accessibility of service to the population is more challenging to assemble. Transit service level information is available via the General Transit Feed System (GTFS) but the socio-demographic data is more challenging to work with as it is a massive data set and, most critically, generally is not updated with a frequency appropriate for monitoring year-to-year trends in service accessibility. The process of evaluating access to transit is complex with significant data and computing/programming challenges associated with measuring level of service given varying temporal availability of service, transferring opportunities, assumptions regarding access/egress, etc.

This issue is very relevant in the discussion of transit ridership trends particularly over longer durations of time. This issue embraces several factors enumerated in the insert below that influence the competitiveness of transit as characterized by the information in Figure 27. 


\section{Table 12 Service Accessibility Factors That Impact Transit Ridership}

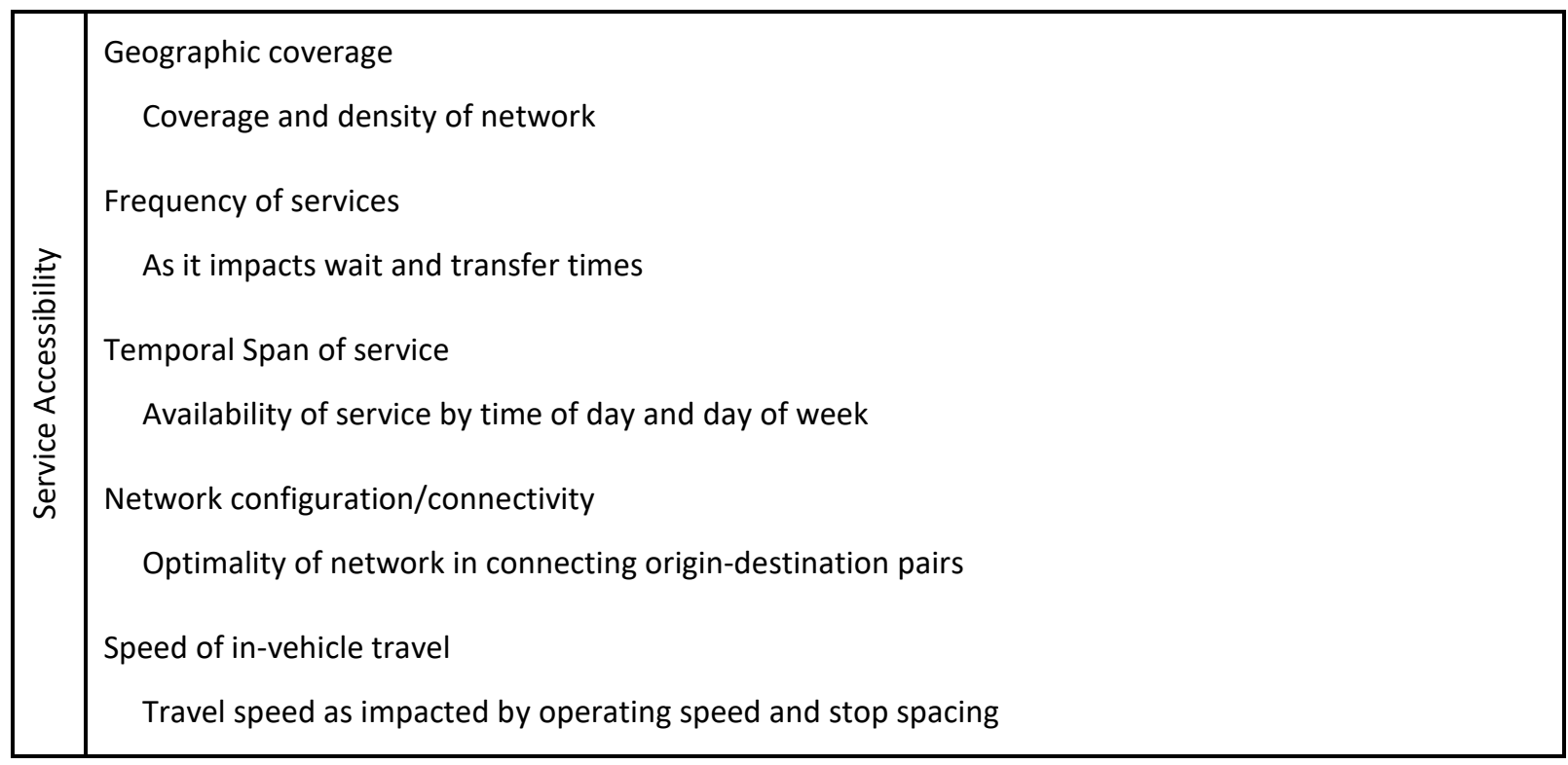

The proximity of both origins and destinations to service determines the access and egress time to transit. This is influenced both by the coverage of the network (share of regional population and activities within walk or other access mode distance from a transit stop or station), which is a function of the physical extent of the network beyond the core of the urban area, the density of the routes, and the stop spacing. In addition to physical access to service, there is the issue of temporal availability of service. This addresses the temporal coverage of service relative to travel activity levels. For example, transit service tends to be concentrated in the peak periods, which are strong markets and less robust in midday, evenings, overnight, and weekends when the overall share of travel demand tends to be lower.

In addition to the geographic and temporal availability as influenced by the span of service, the frequency of service is another factor impacting the accessibility of activities via public transportation. Most specifically, this influences the wait time duration for travelers. While individuals may time their departures to access transit initially, minimizing their wait time, they are captive to the schedules if their trip involves a transfer, as their arrival at the transfer point is governed by the schedule on the arriving route, leaving them captive to the scheduled wait between arriving and departing vehicles. In addition to these factors that influence the accessibility to activities via public transportation, the fourth factor is the circuity of the route network.

Transportation planners strive to develop a pattern of service routes that best accommodate the origin destination patterns of travelers, subject to the nature of the roadway system for bus services, and the ability to build or operate connections for rail, ferry, or other transit options. This configuration attempts to optimize the quality of service for the largest number of 
potential passengers subject to policy or other factors that may override what might be a mathematical optimal solution to this network problem. Several communities across the country, including HART in Hillsborough County and JTA in Duval County, have recently comprehensively reviewed their transit route networks with the goal of adapting them to the best understanding of current travel patterns. It is not uncommon for agencies to conduct major route reviews every 5 to 10 years or when a significant change in context occurs (new level of funding, new investment in fixed guideway option, major roadway restructuring, etc.). Not to mention, continuous monitoring of service can often result in modifications to a single or smaller number of routes annually or more frequently.

The final element influencing accessibility via transit is the speed of operation of the respective services. Speed of operation is influenced by several factors including stop spacing, extent of exclusive right away and/or priority treatment crossings, boarding/alighting volumes, the nature of fare collection, the extent to which bicycles on buses or mobility aids or other factors impact boarding times, the vehicle design (number of doors and door width, floor height, etc.), vehicle performance specifications (acceleration and deceleration capabilities), and other factors. Aside from investments in priority lanes or priority crossing treatments, the single most typical strategy to influence speed involves changing stop spacing and/or reassigning route alignments to remove circuity and/or operate on higher functional classification (and typically higher speed) roadways.

The composite impact of the five factors discussed above can be evaluated via measures of market accessibility. These measurement strategies are complex and subject to interpretation, as various metrics are available, and analysts can focus on various demographic market segments or various strategies for counting and weighting accessibility opportunities.

Table 13 indicates that directional route miles of service in Florida, a measure of route coverage, has increased modestly over the past several years, but as of 2016, were at levels slightly below those in 2014 and 2015. Revenue vehicle miles per directional route mile was at the highest level in 2016, indicating that service frequencies have been increasing slightly. Revenue vehicle miles has increased continuously since 2010. 
Table 13 Service Intensiveness for All Florida Transit Agencies

\begin{tabular}{|c|c|c|c|c|c|}
\hline & Vehicle Miles & $\begin{array}{c}\text { Vehicle Rev } \\
\text { Miles }\end{array}$ & $\begin{array}{l}\text { Directional } \\
\text { Route Miles }\end{array}$ & VRM/VM & VRM/DRM \\
\hline 2016 & $234,686,207$ & $208,998,950$ & 15,383 & $89.10 \%$ & 13,586 \\
\hline 2015 & $230,225,775$ & $206,346,836$ & 15,551 & $89.60 \%$ & 13,269 \\
\hline 2014 & $222,856,983$ & $204,319,915$ & 15,809 & $91.70 \%$ & 12,924 \\
\hline 2013 & $227,524,013$ & $204,187,184$ & 15,325 & $89.70 \%$ & 13,324 \\
\hline 2012 & $224,641,871$ & $200,696,728$ & 14,992 & $89.30 \%$ & 13,387 \\
\hline 2011 & $220,067,823$ & $197,507,461$ & 14,628 & $89.70 \%$ & 13,502 \\
\hline 2010 & $218,477,997$ & $195,301,735$ & 14,505 & $89.40 \%$ & 13,464 \\
\hline
\end{tabular}

Source: NTD annual data

Table 14 indicates the average speed for Florida fixed route transit services. This speed is a passenger volume weighted average speed observed by travelers on Florida fixed route systems. Declines in average speed are generally consistent with overall declines in roadway travel speeds, associated with growth in demand exceeding new capacity and creating additional congestion. Changes in passenger volume are not significant enough to be an important factor in operating speed, but, given the declines in demand, stop or station dwell times should not have increased.

Given the information available on levels of service, the remaining factor to assess level of service for public transportation is to explore the orientation of services with respect to travel demand. Specifically, this refers to the population, employment, or activity trip ends that are accessible to the transit stops and stations. This is an important factor that has been raised
Table 14 Florida Fixed Route Agencies Average Speed

\begin{tabular}{|cc|}
\hline Year & Average Speed \\
2016 & 13.83 \\
2015 & 14.00 \\
2014 & 13.99 \\
2013 & 14.10 \\
2012 & 14.20 \\
2011 & 14.08 \\
2010 & 14.31 \\
\hline
\end{tabular}

Source: NTD Annual Data, passenger volume weighted 
in discussions of changes in ridership associated with land use and population redistribution. Several hypotheses have been suggested:

- Economic conditions, and to some extent policy, have favored dispersion of lower income residents away from the core of urban areas which typically moves them to locations in the urban area with less robust transit service. This includes accelerating housing prices that force lower income or transit dependent travelers to seek lower-cost housing more distant from the urban core.

- While there has been some high visibility central business district residential growth in Florida, there has been continued dispersion of employment and public services that serve riders (hospitals, schools, retail, etc.) which have continued outward migration as metropolitan areas have grown.

- Transit oriented development can concentrate activity in the proximity of transit stops and stations. However, transit-oriented development has been modest in Florida, and the extent of concentration and quality of service necessary to stimulate ridership may be at levels below those most optimal for generating significant mode changes.

- Growth in employment in central business districts with high quality transit and in locations where parking is expensive or difficult to find have been important factors in growing transit ridership in locations such as Seattle, where the Amazon headquarters facility has grown dramatically over the past several years in the central business area. Employment growth in Florida's central business districts, the focal point for significant shares of transit service, does not appear to have been robust.

The best measure of the composite impact of activity distribution and levels of service are measures of transit accessibility. The University of Minnesota Accessibility Laboratory analyzes accessibility to employment for Metropolitan areas for both transit and roadways. Table 15 presents that data for 49 Metropolitan areas across the country for which data is available. 
Table 15 Comparisons of Transit Accessibility in Major U.S. Metropolitan Areas

\begin{tabular}{|c|c|c|c|c|c|c|}
\hline $\begin{array}{c}\text { Metro } \\
\text { Rank by } \\
\text { Jobs }\end{array}$ & Metro Area & $\begin{array}{c}\text { Employment } \\
2017\end{array}$ & $\begin{array}{c}\text { Jobs Accessible by } \\
\text { Transit in } 60 \text { Mins } \\
\text { (Access Across } \\
\text { America: } \\
\text { Transit 2017) }\end{array}$ & 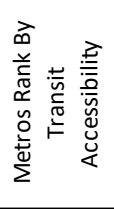 & $\begin{array}{l}\text { Jobs Accessibile by } \\
\text { Auto in } 60 \text { Minutes } \\
\text { (Access Across } \\
\text { America Auto 2017) }\end{array}$ & 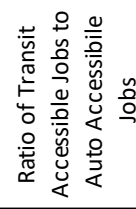 \\
\hline 1 & New York & $8,654,470$ & $1,287,186$ & 1 & $5,165,184$ & $24.9 \%$ \\
\hline 11 & San Francisco & $2,164,298$ & 415,289 & 2 & $2,414,867$ & $17.2 \%$ \\
\hline 7 & Washington DC & $2,776,148$ & 357,510 & 4 & $2,555,148$ & $14.0 \%$ \\
\hline 23 & Portland & $1,093,778$ & 156,682 & 11 & $1,130,378$ & $13.9 \%$ \\
\hline 45 & Salt Lake City & 576,320 & 144,560 & 14 & $1,044,810$ & $13.8 \%$ \\
\hline 15 & Seattle & $1,709,920$ & 185,318 & 8 & $1,421,132$ & $13.0 \%$ \\
\hline 33 & Las Vegas & 897,183 & 110,821 & 23 & 856,257 & $12.9 \%$ \\
\hline 10 & Boston & $2,401,512$ & 275,182 & 5 & $2,261,287$ & $12.2 \%$ \\
\hline 47 & Buffalo & 529,252 & 70,219 & 24 & 582,827 & $12.0 \%$ \\
\hline 37 & Milwaukee & 771,322 & 139,321 & 12 & $1,172,274$ & $11.9 \%$ \\
\hline 3 & Chicago & $4,389,339$ & 342,635 & 3 & $3,012,464$ & $11.4 \%$ \\
\hline 18 & Denver & $1,356,387$ & 180,478 & 10 & $1,617,550$ & $11.2 \%$ \\
\hline 32 & San Jose & 909,053 & 203,107 & 9 & $2,163,277$ & $9.4 \%$ \\
\hline 27 & San Antonio & 986,091 & 86,468 & 26 & 949,332 & $9.1 \%$ \\
\hline 14 & Minneapolis & $1,794,806$ & 146,905 & 13 & $1,754,122$ & $8.4 \%$ \\
\hline 6 & Philadelphia & $2,793,982$ & 205,692 & 7 & $2,542,247$ & $8.1 \%$ \\
\hline 17 & San Diego & $1,363,986$ & 113,058 & 18 & $1,433,964$ & $7.9 \%$ \\
\hline 48 & New Orleans & 513,830 & 48,220 & 30 & 616,252 & $7.8 \%$ \\
\hline 29 & Austin & 917,901 & 81,826 & 22 & $1,051,765$ & $7.8 \%$ \\
\hline 22 & Pittsburgh & $1,100,915$ & 76,673 & 21 & $1,000,173$ & $7.7 \%$ \\
\hline 2 & Los Angeles & $5,636,421$ & 341,437 & 6 & $4,517,360$ & $7.6 \%$ \\
\hline 40 & Louisville & 627,630 & 52,872 & 37 & 720,647 & $7.3 \%$ \\
\hline 30 & Sacramento & 915,759 & 72,932 & 28 & $1,063,577$ & $6.9 \%$ \\
\hline 31 & Columbus & 911,367 & 74,521 & 25 & $1,093,480$ & $6.8 \%$ \\
\hline 9 & Miami & $2,412,346$ & 113,542 & 16 & $1,737,359$ & $6.5 \%$ \\
\hline 13 & Phoenix & $1,865,829$ & 109,972 & 19 & $1,739,291$ & $6.3 \%$ \\
\hline 20 & Baltimore & $1,291,995$ & 111,707 & 15 & $1,926,759$ & $5.8 \%$ \\
\hline 46 & Oklahoma City & 574,561 & 35,139 & 44 & 619,587 & $5.7 \%$ \\
\hline 28 & Cleveland & 955,181 & 74,528 & 29 & $1,372,782$ & $5.4 \%$ \\
\hline 19 & St. Louis & $1,310,349$ & 64,119 & 33 & $1,200,988$ & $5.3 \%$ \\
\hline 41 & Jacksonville & 626,060 & 32,651 & 48 & 634,122 & $5.1 \%$ \\
\hline 39 & Virginia Beach & 707,752 & 33,168 & 46 & 659,585 & $5.0 \%$ \\
\hline 35 & Charlotte & 877,360 & 55,578 & 34 & $1,137,958$ & $4.9 \%$ \\
\hline 42 & Richmond & 617,617 & 33,016 & 42 & 697,915 & $4.7 \%$ \\
\hline 34 & Indianapolis & 886,380 & 52,705 & 35 & $1,115,194$ & $4.7 \%$ \\
\hline 5 & Houston & $2,888,073$ & 114,960 & 17 & $2,520,388$ & $4.6 \%$ \\
\hline 43 & Hartford & 593,012 & 64,698 & 27 & $1,443,504$ & $4.5 \%$ \\
\hline 25 & Kansas city & $1,023,563$ & 47,330 & 40 & $1,087,996$ & $4.4 \%$ \\
\hline 38 & Povidence & 757,913 & 53,339 & 31 & $1,279,767$ & $4.2 \%$ \\
\hline 26 & Cincinnati & $1,018,914$ & 48,793 & 39 & $1,197,690$ & $4.1 \%$ \\
\hline 36 & Nashville & 801,589 & 34,390 & 43 & 847,287 & $4.1 \%$ \\
\hline 8 & Atlanta & $2,416,397$ & 72,599 & 32 & $1,791,972$ & $4.1 \%$ \\
\hline 21 & Tampa & $1,227,356$ & 52,728 & 38 & $1,328,760$ & $4.0 \%$ \\
\hline 24 & Orlando & $1,050,065$ & 48,584 & 41 & $1,323,827$ & $3.7 \%$ \\
\hline 4 & Dallas & $3,206,364$ & 100,304 & 20 & $2,941,638$ & $3.4 \%$ \\
\hline 44 & Raleigh & 583,916 & 36,321 & 47 & $1,070,759$ & $3.4 \%$ \\
\hline 12 & Detroit & $1,869,538$ & 64,677 & 36 & $1,975,248$ & $3.3 \%$ \\
\hline 49 & Birmingham & 476,681 & 17,858 & 49 & 582,467 & $3.1 \%$ \\
\hline 16 & Riverside & $1,635,100$ & 39,302 & 45 & $1,815,028$ & $2.2 \%$ \\
\hline
\end{tabular}


The data in Table 15 are ranked according to the ratio of transit accessible jobs to auto accessible jobs - shown in the right-hand column. This table includes data for the 49 cities that the accessibility laboratory analyzes by using detailed information on the roadway and transit networks, the levels of service, and the population and employment demographic information at the census tract level for these metropolitan areas. The transit and auto accessibility measures were calculated with 2017 data. The four Florida metropolitan areas included in the study are shown in red.

The most telling information in the table is the right-hand column, which shows the relative comparability of employment access via transit compared to auto. For the Miami metropolitan area, the highest-ranked Florida metropolitan area, the analysis indicates that for the average resident, only 5.9\% as many employment opportunities are accessible via transit within a onehour travel time as would be accessible by auto. This data reveals the rather dramatic substantial competitive disadvantage of public transit in terms of access to job opportunities. This disadvantage is pervasive across all urban areas; however, the performance of the Florida metropolitan areas is below the national average and consistent with the below average transit utilization levels in Florida. The lack of clustering of job opportunities and their dispersion over significant geography, combined with a modest to poor level of transit service compared to some other metropolitan areas contributes to this performance.

The infrequent availability of tract level Census Bureau population count data coupled with the modest sample size of the annual ACS preclude evaluating transit accessibility on a year-to-year basis. This coupled with the fact that housing patterns and origin-destination travel patterns change relatively slowly over time, preclude attributing changes in travel market and transit level of service as being primary factors in explaining the market decline in transit ridership since 2013. These factors may be significant over longer periods of time and may be playing a role in influencing ridership, but changes are simply not fast enough to be dominant influences in recent ridership changes.

\section{Observations on Transit Competitiveness}

Several overall observations can be drawn from the information presented above and in the prior technical memorandum:

- The Florida population having public transportation services available has continued to grow steadily as urban population has increased and service has expanded modestly over time.

- Service level changes do not explain changes in ridership in Florida over the past several years. 
- Service quality has not changed meaningfully with respect to speed, average frequency, or changes in coverage.

- The declines in ridership for growing service levels mitigate the possibility that crowding was impacting transit demand.

- Transit fares have remained relatively consistent in constant dollars; thus, fare levels do not explain changing ridership levels.

While changes in transit level of service, in conjunction with changing demographic and land use patterns, are ultimately critical to the attractiveness of public transportation and will be relevant in understanding longer-term trends in transit ridership, they are not dynamic enough to explain recent trends in ridership. However, the composite factor of the land-use and activity patterns in Florida metropolitan areas, coupled with the levels of transit service available in Florida metropolitan areas, are nonetheless critical factors, in the opinion of this author, as it characterizes the vulnerability of Florida transit operations. Florida transit operators suffer ridership declines if other factors impact the availability of alternative means of mobility. In simple terms, as the accessibility metrics in Table 15 reveal, public transportation is not a time competitive means of travel for huge segments of the Florida population. Using Orlando as an example, the average resident can only reach 3.5\% as many employment opportunities within one hour of travel time via transit as they can by auto travel. Thus, a traveler would have 28 times as many employment opportunities available with a one-hour commute time if they had an automobile available.

While travel decisions embrace more than just modal accessibility, the dramatic employment accessibility disparity results in Florida travelers being highly incentivized to avail themselves of automobile travel if other conditions (financial, legal, physical/mental, etc.) do not constrain the availability of that opportunity. The balance of this report explores some of those factors in more detail.

\section{Economic and Service Characteristics}

The Influence of Auto Ownership

It has long been known that economic conditions play a significant role in influencing mode choice. Resource constraints influence the ability of individuals to participate in activities and the ability to pay for the travel necessary to get to and from activities. For lower income individuals, the ability to afford a personal vehicle, with its relatively high initial purchase cost and/or relatively high fixed cost for payments and insurance, impact the affordability of vehicle ownership for many individuals and households. The presence of a household vehicle obviously influences the availability of an auto choice for travel. In Florida, as in many other locations, a significant share of transit travelers are individuals with no vehicle available. NHTS data 
indicates nearly half of all national transit trips are made by residents of zero-vehicle households $-44.6 \%$ in 2001, 48.1\% in 2009, and 43.0\% in 2017. In Florida, the 2009 data (when additional sampling in Florida gave a robust sample of transit trips) indicated that $45.0 \%$ of transit trips were taken by persons from zero-vehicle households. The Florida share was $40.1 \%$ in 2017.

Table 16 reports basic demographic trends for Florida. Of importance are the trends between 2013 and 2016, the period during which transit ridership fell significantly. As noted in the bottom line of the table, during the 2013 to 2016 period population grew $5.42 \%$, employment grew $8.96 \%$, households grew $5.02 \%$ and household vehicles increased by $8.2 \%$. Vehicle growth outpaced population and households, and trended very close to growth in employment. Thus, vehicle availability was increasing. Figure 32 portrays these trends graphically.

Table 16 Florida Demographic Trends

\begin{tabular}{|ccccc|}
\hline Year & Population & $\begin{array}{c}\text { Employed } \\
\text { Persons }\end{array}$ & Households & $\begin{array}{c}\text { Household } \\
\text { Vehicles Est. }\end{array}$ \\
\hline 2006 & $18,089,889$ & $8,350,076$ & $7,106,042$ & $11,942,942$ \\
2007 & $18,251,243$ & $8,371,485$ & $7,088,960$ & $11,977,849$ \\
2008 & $18,328,340$ & $8,399,763$ & $7,057,285$ & $11,723,276$ \\
2009 & $18,537,969$ & $7,994,791$ & $6,987,647$ & $11,509,305$ \\
2010 & $18,843,326$ & $7,970,551$ & $7,035,068$ & $11,482,763$ \\
2011 & $19,057,542$ & $8,099,212$ & $7,106,283$ & $11,473,800$ \\
2012 & $19,317,568$ & $8,271,006$ & $7,197,943$ & $11,573,647$ \\
2013 & $19,552,860$ & $8,462,255$ & $7,211,584$ & $11,700,291$ \\
2014 & $19,893,297$ & $8,741,509$ & $7,328,046$ & $11,989,656$ \\
2015 & $20,271,272$ & $8,985,706$ & $7,463,184$ & $12,303,027$ \\
2016 & $20,612,439$ & $9,220,896$ & $7,573,456$ & $12,659,935$ \\
2016 vs. 2006 & $13.94 \%$ & $10.43 \%$ & $6.58 \%$ & $6.00 \%$ \\
2016 vs. 2013 & $5.42 \%$ & $8.96 \%$ & $5.02 \%$ & $8.20 \%$ \\
\hline & & & & \\
\hline
\end{tabular}

For reference, Table 17 portrays ridership trends for Florida. During the 2013 to 2017 period, ridership decreased $18.8 \%$. Based on the strong relationship between transit use and vehicle availability, a Florida specific analysis was carried out to gauge the influence of changing vehicle availability on ridership using survey data reporting transit trip rates as a function of vehicle availability. 


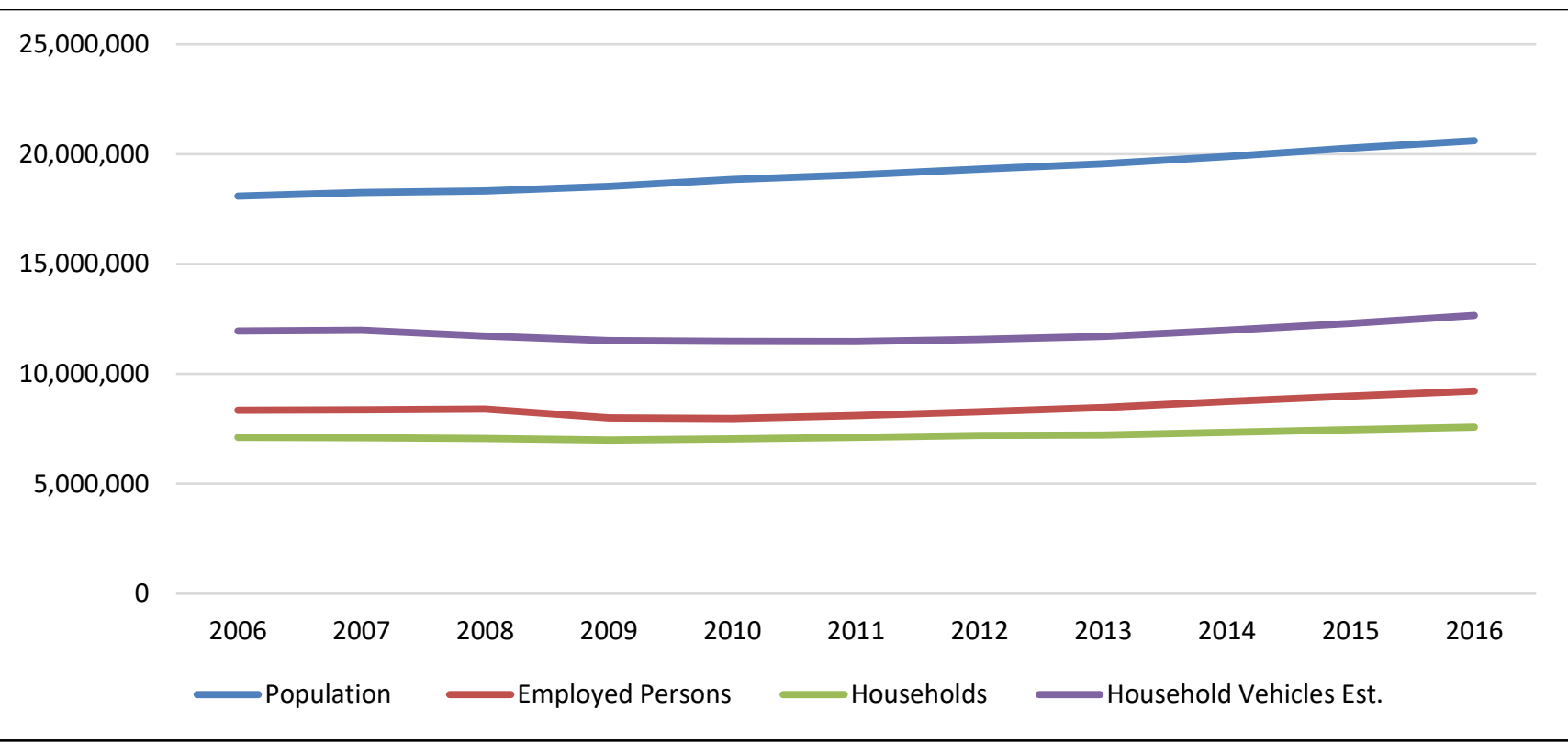

Figure 32 Florida Demographic Trends

Source: ACS

Table 17 Fixed Route Ridership and Service Trends in Florida

\begin{tabular}{|c|c|c|c|c|}
\hline Year & $\begin{array}{c}\text { Fixed } \\
\text { Route } \\
\text { Ridership }\end{array}$ & $\begin{array}{c}\text { Change } \\
\text { from } \\
\text { Previous } \\
\text { Year }\end{array}$ & Service & $\begin{array}{c}\text { Change } \\
\text { from } \\
\text { Previous } \\
\text { Year }\end{array}$ \\
\hline 2002 & $191,355,730$ & & $169,289,376$ & \\
\hline 2003 & $204,925,565$ & $7.1 \%$ & $168,100,828$ & $-0.7 \%$ \\
\hline 2004 & $235,975,856$ & $15.2 \%$ & $179,539,981$ & $6.8 \%$ \\
\hline 2005 & $244,661,590$ & $3.7 \%$ & $187,608,846$ & $4.5 \%$ \\
\hline 2006 & $259,660,356$ & $6.1 \%$ & $201,188,721$ & $7.2 \%$ \\
\hline 2007 & $263,926,396$ & $1.6 \%$ & $201,589,977$ & $0.2 \%$ \\
\hline 2008 & $271,492,158$ & $2.9 \%$ & $198,496,393$ & $-1.5 \%$ \\
\hline 2009 & $250,902,392$ & $-7.6 \%$ & $194,890,561$ & $-1.8 \%$ \\
\hline 2010 & $255,059,771$ & $1.7 \%$ & $194,018,644$ & $-0.4 \%$ \\
\hline 2011 & $271,642,257$ & $6.5 \%$ & $195,575,780$ & $0.8 \%$ \\
\hline 2012 & $280,313,492$ & $3.2 \%$ & $199,404,810$ & $2.0 \%$ \\
\hline 2013 & $285,084,731$ & $1.7 \%$ & $203,551,956$ & $2.1 \%$ \\
\hline 2014 & $283,630,356$ & $-0.5 \%$ & $205,243,261$ & $0.8 \%$ \\
\hline 2015 & $271,256,168$ & $-4.4 \%$ & $206,492,950$ & $0.6 \%$ \\
\hline 2016 & $249,653,837$ & $-8.0 \%$ & $209,670,618$ & $1.5 \%$ \\
\hline 2017 & $231,493,278$ & $-7.3 \%$ & $211,281,350$ & $0.8 \%$ \\
\hline $5045 c:$ & & & \\
\hline
\end{tabular}

Source: NTD 
Table 18 Trips Per Person (5 and older) Per Year Using Transit

\begin{tabular}{|l|cccc|}
\hline & $\begin{array}{c}\text { Year, Data } \\
\text { Source }\end{array}$ & $\begin{array}{c}\mathbf{0} \\
\text { Vehicles }\end{array}$ & $\begin{array}{c}\mathbf{1} \\
\text { Vehicle }\end{array}$ & $\begin{array}{c}\mathbf{2 +} \\
\text { Vehicles }\end{array}$ \\
\hline \multirow{2}{*}{ National } & 2008,2009 NHTS & 211.0 & 36.2 & 8.2 \\
& 2016,2017 NHTS & 226.5 & 39.7 & 10.7 \\
\hline \multirow{2}{*}{ Florida } & 2008,2009 NHTS & 130.9 & 17.9 & 3.7 \\
& 2016,2017 NHTS & 147.6 & 18.6 & 2.3 \\
\hline
\end{tabular}

The data in Table 18 indicates the annual transit trip rates per person based on the number of vehicles available to the households. This is for individuals aged 5 and older based on the NHTS. The pronounced changes in travel behavior as a function of vehicle availability have persisted over multiple survey periods and the comparisons of Florida to national data appear logical given demographic and service availability comparisons. Vehicle availability is slightly less significant in Florida, which is hypothesized to be attributable to the fact that transit service levels are modest forcing zero-vehicle households to find alternative travel options, and the fact that many Florida zero-vehicle households are older citizens with modest travel requirements or are dependent on assisted mobility.

Table 19 shows the population by household vehicle status in Florida. It is important to note that despite growing population, there was a decline in households with zero vehicles between 2013 and 2016, and there was also a decline in households with one vehicle, but a pronounced increase of more than 1,000,000 households with two or more vehicles. Performing the calculations and adjusting for unlinked transit trips, the changes in vehicle availability given the presumed travel behavior shown in the NHTS survey data, would result in approximately $71 / 2$ million fewer transit trips in 2016. That explains approximately $20 \%$ of the 35 million decline in transit trips in Florida between those years. Of interest, scenarios run at the national level suggest that vehicle availability changes may explain half or more of the decline in transit ridership over the 2014 through 2016-time frame.

Table 19 Florida Population by Household Vehicle Availability, 5 and Older

\begin{tabular}{|c|c|c|c|}
\hline & 0 vehicles & 1 vehicle & 2+ vehicles \\
\hline 2008 & 766,110 & $5,045,241$ & $11,435,616$ \\
\hline 2013 & 913,141 & $5,498,887$ & $11,987,214$ \\
\hline 2016 & 866,657 & $5,472,770$ & $13,056,877$ \\
\hline 2017 & 886,993 & $5,771,880$ & $14,327,341$ \\
\hline
\end{tabular}

Source: CUTR analysis of ACS 
Data in Table 19 indicates that there were nearly 1,000,000 more household vehicles in 2016 while the number of households increased about 360,000. Accordingly, many households beyond those that converted from zero cars to one car or one car to $2+$ cars also had increases in vehicle availability, which for multi-person households, could further influence mode choice. Looked at another way, each of the million additional vehicles were associated with a decline of approximately 35 transit trips per year.

After this analysis, the 2017 ACS data became available as shown in Table 19. The phenomenon and trends referenced in the example above continue in 2017 with virtually all the population growth in households with vehicle availability.

The data in Table 4 provided earlier shows information on changes in zero-vehicle household shares for the various transit market areas in Florida. It's important to note that the southeastern part of the state where transit ridership declines were most severe, also had the most significant declines in zero-vehicle households.

When evaluating the influence of enhanced auto availability one quite logically wonders if the extent of auto availability can continue to increase with improvements in the economy. Auto availability in some counties has exceeded its previous peak, while in others it remains below prior years. At the national level, the share of zero-vehicle households has matched the level in 2007, at the lowest levels since annual ACS data commenced in 2005. For the state of Florida, zero-vehicle household levels totaled $6.3 \%$ in 2017 , the second lowest ever, nearly matching the prior low of $6.2 \%$ in 2007.

We do not know what share of zero-vehicle households are zero-vehicle by choice, what share have physical or mental medical conditions that preclude residents from having/using a vehicle, what share have legal constraints on operating a vehicle, or what share have income constraints that preclude them from having a household vehicle. For perspective, the share of zero-vehicle households ranges from $4.0 \%$ in Utah to $12.6 \%$ in Massachusetts, then $29.0 \%$ in New York and $37.3 \%$ in DC. The critical question going forward is understanding the extent to which continuing strength in the economy and employment growth, including the emerging signs that wage growth and hours worked are increasing, might result in continued growth in vehicle availability at the household level.

Historically, transit use has fluctuated in response to changes in economic conditions, however, the degree of ridership changes is more pronounced than in prior cycles. Part of this might be attributable to fuel price fluctuations, with high prices in the depths of the recession putting more pressure on household budgets, and declining fuel prices coincident with the recovery. While fuel prices affect the competitiveness of the auto (and will be discussed below) the magnitude of the change in fuel costs was significant enough that it has been argued to have 
affected the economic conditions of the household. To give perspective, according to the 2017 NHTS the average household accumulates approximately 57,000 miles per year. Assuming an attained fuel efficiency of 20 miles per gallon and applying the 2012 and 2016 average fuel prices, \$3.94 and \$2.31 (EIA), the change in fuel price would result in a spending difference of approximately $\$ 1,500$ per year. Given not all households have vehicles, the actual savings from lower fuel prices would be higher for auto owning households. This dollar amount, and this is after-tax dollars, is approximately $2.5 \%$ of average household expenditures, an amount coincidentally equal to the increase in average household consumer spending between 2015 and 2016. Increases in available household resources of this magnitude have been hypothesized to be significant in the context of household vehicle ownership decisions.

Other Sociodemographic Considerations

Other sociodemographic considerations beyond auto ownership influence the use of transit. For example, a traveler may choose to commute by transit in order to save the cost of parking at the destination but with an improved economy may choose to incur that cost for the convenience of driving a personal vehicle. Similarly, a traveler without access to a vehicle may be more inclined to use a taxi or provide gas money to a friend than use transit when resources are less scarce. Part of the analysis carried out to understand changing ridership explores changes in demographic profile of transit travelers. This was carried out in two ways. First, the NHTS data was reviewed for 2009 and 2017 to see if there were any changes that give insight into changing profiles of transit users. Second, on-board surveys for Florida transit properties were examined at four agencies that had two successive surveys over the past half dozen years to see if there were changes of significance. This information is reported in the sections below.

\section{NHTS Transit Data}

The NHTS is a survey of non-commercial travel by all modes and is conducted by the U.S. Department of Transportation's Federal Highway Administration (FHWA). The survey collects data related to travel, including characteristics of the people who travel, their households, and their vehicles. The NHTS survey series originated as the Nationwide Personal Transportation Survey (NPTS) in 1969. In 2001, the NHTS replaced the NPTS. This NHTS survey series affords one the ability to analyze trends in person and household travel over time, with data for 2001, 2009 , and now 2017. The reader should note that the transit sample in the 2017 NHTS is still under review as of fall 2018. The transit mode share derived from survey results appears to overstate the empirical data on transit ridership by a significant amount. Hence, some of the observations below may be modified slightly if modifications in data weighting are developed. Nonetheless, the data offers insight into changes in sociodemographic characteristics and other aspects of transit travel. 
The 2009 NHTS interviews were conducted from March 17, 2008 through May 7, 2009. The first assigned travel day was March 28, 2008 and the last assigned travel date was April 30, 2009. The 2017 NHTS survey was conducted from March 31, 2016 through May 8, 2017. The first assigned Travel Day was April 19, 2016 and the last assigned travel date was April 25, 2017.

Table 20 shows the sample size for both households and persons in Florida and nationally, for the 2009 and 2017 survey data. It is worth noting that Florida purchased additional samples in the 2009 survey as an add-on state. In 2017, Florida did not purchase additional samples, making the 2017 Florida data less robust, leading to the inability to make detailed comparisons at the transit trip level, which only constitutes $0.95 \%$ of all trips in Florida.

Table 20 Sample Sizes of 2009 and 2017 NHTS Surveys

\begin{tabular}{|l|c|c|c|c|}
\hline \multirow{2}{*}{} & \multicolumn{2}{|c|}{ Florida } & \multicolumn{2}{c|}{ National } \\
\cline { 2 - 5 } & $\mathbf{2 0 0 9}$ & $\mathbf{2 0 1 7}$ & $\mathbf{2 0 0 9}$ & $\mathbf{2 0 1 7}$ \\
\hline Households & 15,884 & 1,423 & 150,147 & 129,696 \\
\hline Persons & 30,952 & 2,773 & 308,901 & 264,234 \\
\hline
\end{tabular}

Table 21 shows Florida and national travel characteristics for 2009 and 2017.

Table 21 Florida \& National Travel Characteristics, 2009 VS 2017 (NHTS)

\begin{tabular}{|l|c|c|c|c|}
\hline \multicolumn{1}{|c|}{ Characteristic } & Florida 2009 & $\begin{array}{c}\text { National } \\
\mathbf{2 0 0 9}\end{array}$ & Florida 2017 & $\begin{array}{c}\text { National } \\
\mathbf{2 0 1 7}\end{array}$ \\
\hline Transit mode share & $1.10 \%$ & $2.00 \%$ & $0.95 \%$ & $2.54 \%$ \\
\hline Transit trips per capita & 13.27 & 26.57 & 11.40 & 31.32 \\
\hline Average income of transit travelers & $\$ 26,786.87$ & & $\$ 36,138.55$ & \\
\hline Average age of transit travelers (years) & 42.4 & 38.4 & 52.5 & 41.1 \\
\hline Transfer rate & -- & -- & 1.30 & 1.55 \\
\hline Transit Trip distance (miles) & 10.17 & 8.83 & 10.88 & 11.01 \\
\hline Transit Trip speed (mph) & 11.95 & 10.94 & 11.04 & 12.02 \\
\hline Average wait time (minutes) & 14.28 & 9.63 & 14.32 & 9.56 \\
\hline $\begin{array}{l}\text { Household vehicle availability (avg. } \\
\text { vehicle/household) }\end{array}$ & 1.68 & 1.86 & 1.77 & 1.88 \\
\hline $\begin{array}{l}\text { Household vehicle availability (share 0 } \\
\text { vehicle }\end{array}$ & $6.7 \%$ & $8.7 \%$ & $5.3 \%$ & $8.9 \%$ \\
\hline $\begin{array}{l}\text { Persons with 0 vehicle available who } \\
\text { use pub trans }\end{array}$ & $36.1 \%$ & $39.6 \%$ & $40.8 \%$ & $43.0 \%$ \\
\hline
\end{tabular}

\section{Transit Trips Per Capita}

The transit trips per capita were calculated as the number of person trips that used transit divided by the number of persons for Florida and the U.S. These are annualized totals, so for 
example, each person in Florida took an average of 11.40 transit trips in 2017, compared to 13.27 average transit trips taken per Floridian in 2009. The annual transit trips per capita increased nationally from 26.57 in 2009 to 31.32 average annual transit trips in 2017.

Income of Transit Travelers

Assuming the median value of each income bracket, the average income of transit travel day person trips was calculated by summing the product of the number of transit trips in each income bracket by the median value of the income bracket, divided by the total number of transit trips. This is a rough estimate, and comparative data does not account for inflation. There were no transit trips taken by persons in the highest open-ended income bracket in Florida, so there was no need to assume an upper limit value. That was not the case for the national data. Additionally, the national data had significantly different upper bounds by income, making the national comparisons void. Figure 33 below displays the national distribution of transit trips by income bracket, with no inflation considerations incorporated.

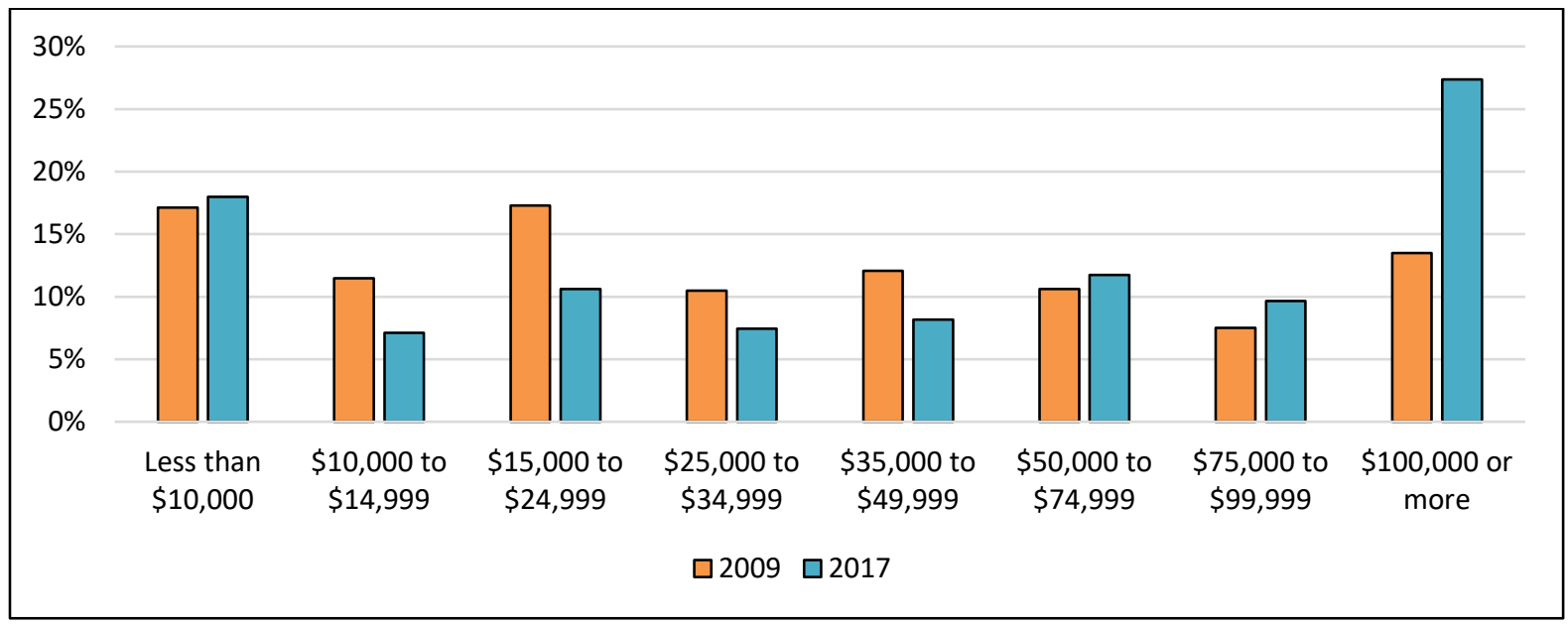

Figure 33 Income Distribution of National Transit Trips

Source: NHTS

Average Age of Transit Travelers (years)

Using a similar approach as the average income of transit travelers approach, the average age of transit travelers was calculated by first assuming the median age in each age bracket. The median age was then multiplied by the number of transit trips taken by individuals in that age bracket. The products were then summed and divided by the total number of transit trips to obtain the average age of transit trips. For the upper bound of 89+, the age 91 was assumed. The 2009 data provided the age in each year, rather than an age bracket, leaving no need to assume an upper age. Using the approach for both Florida and the U.S., the average age of each transit person trip increased at both geographic levels. It is important to note that the Florida sample was sufficiently small to require an average age calculation as opposed to an age 
distribution figure. The number of transit trips in the Florida sample size by age was 50, compared to 514 trips in that same category in 2009 when Florida purchased additional samples. The age distribution at the national level is presented in Figure 33 below. Obvious increases are displayed in the share of transit trips in the 26-35 and 56-65 age groups.

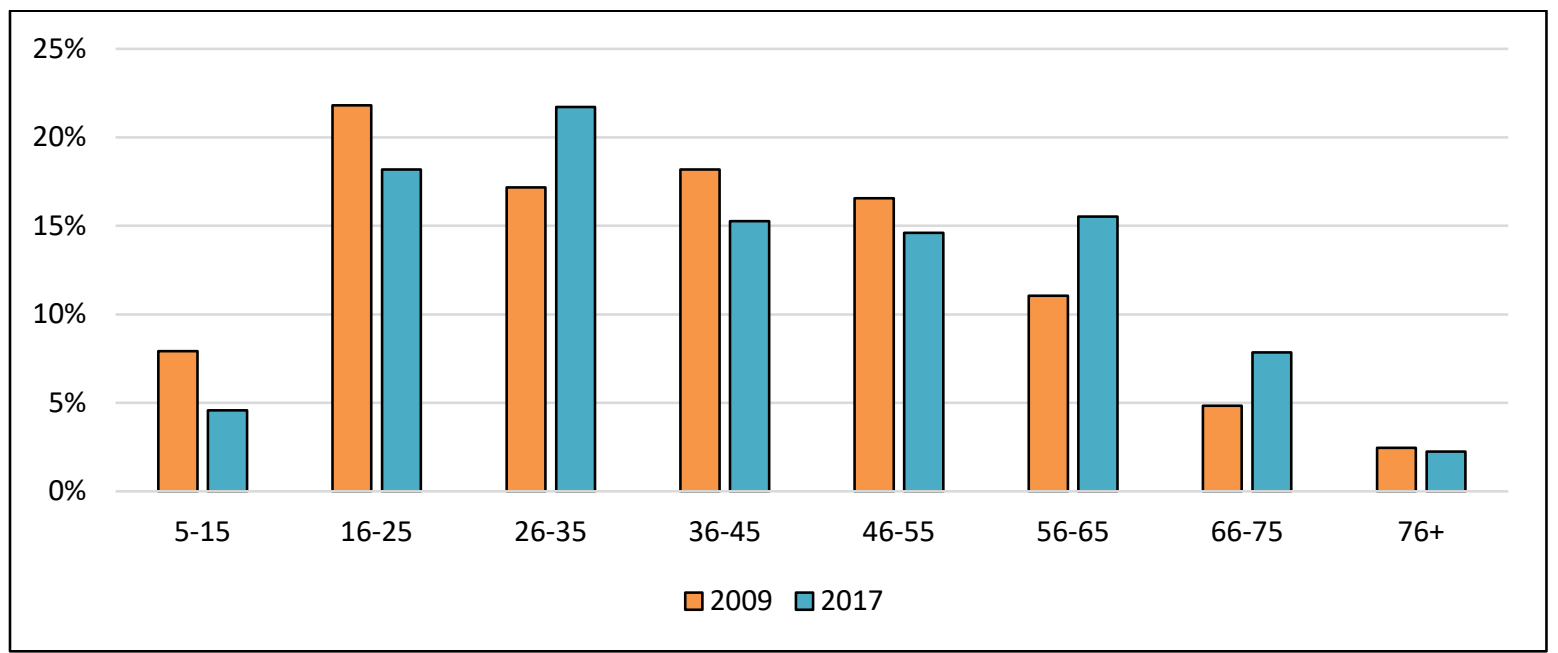

\section{Figure 34 Age Distribution of National Transit Trips}

Source: NHTS

Transfer Rate

The average transfer rate was calculated for 2017 by summing the product of the number of transfers by the number of travel day person trips on transit, divided by the total number of travel day transit person trips. Florida averaged slightly less transfers at 1.30 transfers per transit trip, compared to the national average of 1.55 transfers per transit trip.

Transit Trip distance (miles)

Transit trip distance is directly provided in NHTS data as the average person trip length by public transit use. The average transit trip distance has increased both for Florida and nationally, at $7.0 \%$ and $24.7 \%$ respectively. The national average transit trip is approximately 11 miles as of 2017.

\section{Transit Trip Speed (mph)}

The average transit trip speed was calculated by dividing the average person trip length for person trips that used public transit by the hourly equivalent of the average person trip duration for person trips that used public transit, both at the state of Florida and at the national geography. The average transit trip speed decreased by $7.6 \%$ in Florida to an average of 11.04 miles per hour in 2017. On the other hand, nationally the average transit trip speed increased 9.9\% from 2009, to reach an average of 12.02 miles per hour in 2017. 
Average Wait Time (minutes)

The average wait time was calculated using a weighted average of all derived length of wait for public transit of travel day person trips for trips that used public transit. The average transit wait time increased slightly in Florida between 2009 and 2017 from 14.28 minutes to 14.32 minutes. Alternatively, the national average transit wait time decreased slightly from 9.63 minutes in 2009 to 9.56 minutes in 2017, a 0.7\% improvement.

Household Vehicle Availability (Average Vehicles per Household)

The household vehicle availability was estimated by calculating the weighted average of all households by the number of vehicles available in that household, for both 2009 and 2017. The average number of vehicles per household increased $5.7 \%$ in Florida from 1.68 vehicles per household in 2009 to 1.77 vehicles per household in 2017, which remains below the national average. Nationally, the average number of vehicles per household increased $1.0 \%$, reaching 1.88 vehicles per household in 2017.

Household Vehicle Availability (Share of Zero-Vehicle Households)

The share of households with no vehicles available was calculated by dividing the number of households with no vehicles by the total number of households. The share of households in Florida with no vehicles available decreased from $6.7 \%$ in 2009 to $5.3 \%$ in 2017 . Conversely, the national share of households with no vehicles available increased slightly from $8.7 \%$ in 2009 to $8.9 \%$ in 2017.

Persons who use Public Transit with Zero Vehicles Available

The share of persons who use public transit with no household vehicles available was calculated by dividing the number of people who used public transit on their travel day and have no household vehicles available by the total number of persons who used public transit on their travel day. It is important to note that it is persons, not person trips represented by this percentage value. This same analysis was done at the national and state of Florida geography level. The share of people that use public transit who have no household vehicles has increased both for Florida and nationally. In Florida in 2009, 36.1\% of people who used public transit on their travel day had no vehicles available, while nationally that share was $39.6 \%$. As of 2017 , the share of Floridians that used public transit on their travel day and have no household vehicles available increased to $40.8 \%$, an increase of 4.6 percentage points. The share also increased nationally by 3.5 percentage points, reaching $43.0 \%$ in 2017 .

National Transit Trip Purpose Distribution

The national transit trip purpose distribution was calculated by dividing annualized travel day person trips by purpose by the total number of annualized travel day person trips taken on 
transit. This analysis is not applicable at the state of Florida geography level due to the small sample size of travel day transit person trips. The national distribution is displayed in Figure 35.

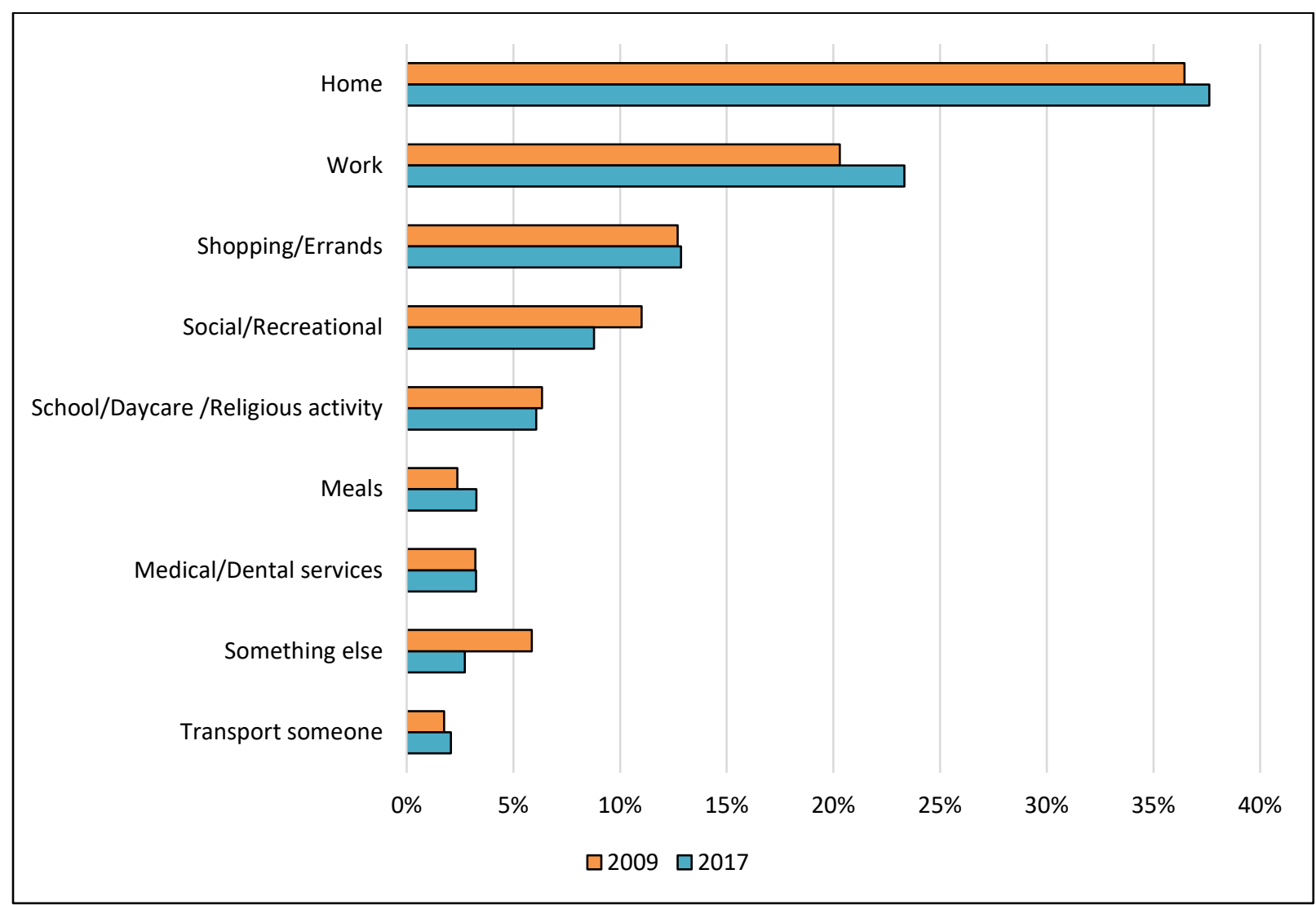

\section{Figure 35 National Distribution of Transit Trips by Purpose}

Source: NHTS

\section{Findings from Review of Transit Agency Data}

As part of the search for an understanding of how the transit ridership market may be changing that would give insight on the ridership decline, the project team sought data from transit authority onboard surveys in order to screen for changes in traveler characteristics over time that would give insight into traveler changes. Agencies where multiple onboard surveys were conducted within the last several years were selected to identify survey pairs that could be reviewed. Each of those available survey pairs are noted and described below followed by insights. More detailed reviews were provided in a prior technical memorandum. In addition, ridership trends for select agencies were reviewed.

Palm Tran

Palm Tran performed a 2015 onboard survey and some data was compared to a similar survey conducted in 2011. While only limited data was available, it provided some insight. The tenure 
of riders was somewhat typical of public transit with a significant share of passengers having been customers or one year or less. In the case of Palm Tran, 35\% of customers fell in this category and it was reported as being like the 2011 survey. At the other end of the spectrum, $30 \%$ of riders reported being customers more than five years.

Palm Tran is like many Florida transit properties in that a large percent, (52\%) of the reported reasons for not riding identified the lack of car availability as a reason for their decision to use public transportation, and an additional 7\% reported they did not know how to drive. Perhaps insightful as to ridership trends, the percentage of riders indicating the level of satisfaction with Palm Tran was 55\%, a decrease from 70\% in the 2011 survey. In all measured areas, satisfaction decreased.

Manatee County Area Transit (MCAT)

MCAT performed a 2018 onboard survey. Their question regarding transit use tenure indicated that $38.4 \%$ of respondents had been using the service for less than one year. An estimated $51.6 \%$ of respondents indicated that they did not have a driver's license. The ridership profile is slightly older, lower income, and more diverse than in prior surveys.

Space Coast Area Transit

Space Coast conducted a 2016 survey and provided comparative results with surveys in 2012 and 2008 . The vast majority, $81.1 \%$ of respondents, indicated they did not have access to a vehicle. The demographic profile was similar but slightly more diverse.

Pinellas Suncoast Transit Authority (PSTA)

PSTA regularly monitors customer preferences and customer satisfaction. The surveys provide good data on traveler preferences with findings that are reflective of many transit properties in Florida. Florida's transit travelers are generally more dependent on transit than is the case in areas with higher incomes and higher quality public transportation services that are more competitive for choice travelers. In general, Florida transit users desire better transit service, which most often means more service - longer hours, more frequency, and better coverage. On-time arrival is also important. In general service attributes such as bus shelters, Wi-Fi, cleanliness attributes, and other amenities are nice but are subordinate to core service quality characteristics where basic levels of service are not attractive to choice travelers and frustrating for transit dependent travelers.

Miami-Dade Transit Authority

Miami-Dade data was examined to gain insight on emerging trends and insights on market response to various transit services. Miami-Dade is particularly important, as the largest transit property in Florida, it offers the most comprehensive array of public transportation services and 
yet has suffered sustained severe ridership declines. There are some distinctive lessons that can be drawn from information from Miami-Dade Transit. Figure 36 shows a recent ridership trend by month for Miami-Dade. There is a very significant message in this data. The ridership declines have not relented for this system with the exception that year over year trends have been positive in September - mostly attributable to Hurricane Irma, in 2017. While nationally, there is some evidence that declines in ridership are bottoming out in terms of national aggregate totals, there are certain markets including Miami where ridership has continued to decline significantly. This continued decline reinforces the need to understand consumer choices and make serious strategic reflections on strategies and investment priorities for public transportation. The data reaffirms that this is not just a cyclical anomaly, but rather a more profound change in travel behaviors. This consideration will be discussed more in subsequent sections.

Information on ridership trends by service type for Miami-Dade Transit Authority was also reviewed. It is the judgment of this author that the respective fluctuations in ridership changes by service type are indicative of the nature of transit traveler decision-making in this era of declining transit ridership. Specifically, the best services, those that have a larger share of travelers who choose them as a preferred mode of travel in situations where they have other choices including auto availability, tend to be less significantly impacted by the ridership declines. In simple terms, for travelers who are dependent on poor services, technology economic or other changes that then provide them options (for example auto ownership, telecommuting, or using a transportation network company service) become more attractive, resulting in a decision to abandon transit use. In situations where the mode choice set already included auto ownership, the recent changes may have incented them to use TNCs or perhaps drive because of reduced fuel prices, but the magnitude of change in their choice set is more modest and fewer have chosen to abandon higher-quality transit services. More discussion of this hypothesis will be presented later. 

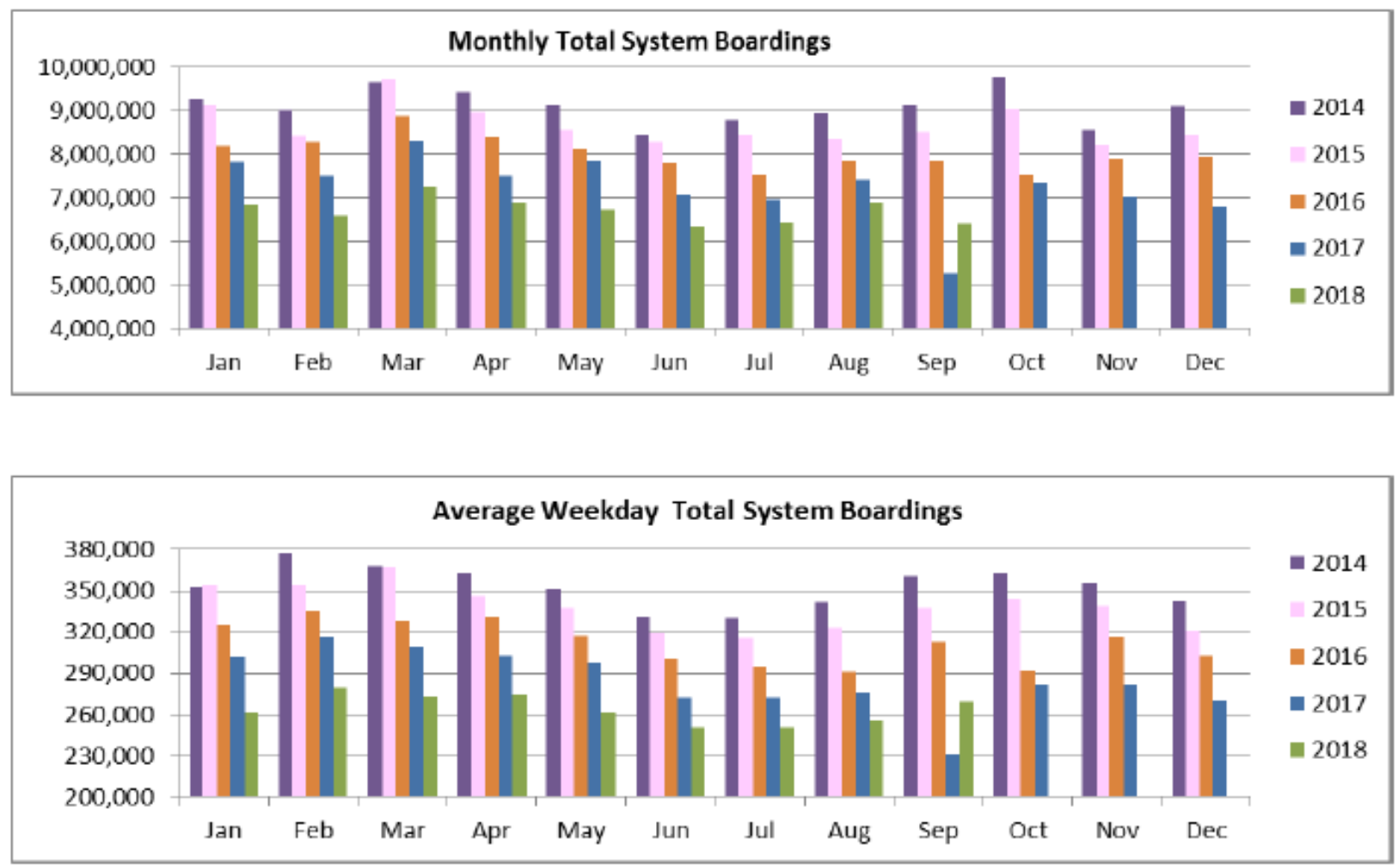

Figure 36 Total Monthly an Average Weekday Ridership MDTA, Year-Over-Year Comparisons,

\section{All Modes}

Source: September 2018 Ridership Technical Report, Miami-Dade County, Transportation and Public Works

Service Features

The final consideration to discuss under transit service characteristics is service features. Table 22 below categorizes and summarizes those features. Many of these factors have complex relationships with transit ridership. Onboard surveys frequently rank agency performance with respect to these various characteristics, and perceptions fluctuate depending upon context and agency execution. Some of these characteristics are within or partially within the influence of the transit agency (vehicle cleanliness) while others are governed more by broader community considerations (personal safety when walking to transit). 


\section{Table 22 Service Features Factors That Impact Transit Ridership}

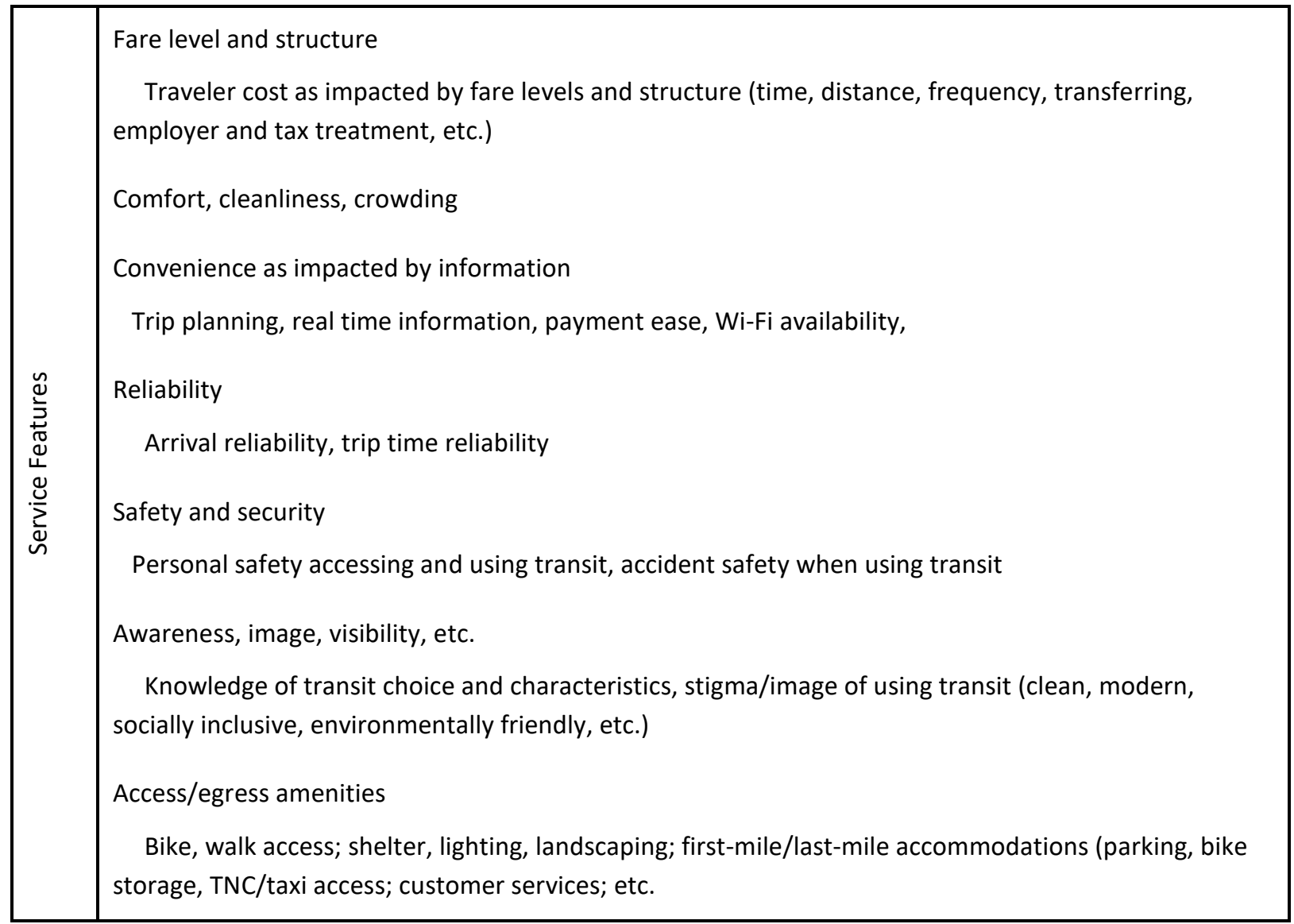

As noted earlier, fare levels for transit have remained relatively stable. Some analysts have argued that lower frequency of use by travelers - specifically those individuals who now might be telecommuting one or two days per week or substituting transportation network companies or communications for some transit trips might not be leveraging fixed-price monthly passes to the same extent, thus, in effect increasing their fare cost per trip. Other systems with distancebased pricing, generally rail systems, have received some customer pushback on higher-priced long-distance trips as systems have expanded farther into outlying areas. There is no evidence that these factors have been significant in Florida.

Other service features addressing reliability, cleanliness, perceptions of security, and others are monitored in transit development planning and onboard survey data collection. As noted previously, these are factors that may be important to travelers. In general, travel time reliability has been challenged over the past four years as roadway travel volumes have increased creating additional urban congestion. This congestion impacts both transit travel speed for mixed operation services as well as travel time reliability. Again, there is no compelling case to be made that deterioration in this performance characteristic is a significant 
explanatory factor in Florida transit ridership trends and auto travel times have also been subject to increased congestion.

Often traveler transit use decision-making is governed first by a litmus test or tolerance threshold type characteristics (Is it available? Will I be safe?), then focuses on cost, service availability (hours of operation and frequency) and travel speed, and finally considers amenities and convenience features. In addition, given the relatively low penetration of transit use amongst Florida travelers, public perceptions as to the characteristics of transit are often very modestly informed and/or perceptions may significantly lag actual current performance characteristics. In certain systems across the country, there have been highly visible conditions that have influenced ridership. Travel reliability and safety has impacted ridership in Washington D.C. on the rail system. Service reliability and station cleanliness/conditions have been widely recognized as impacting ridership in New York and difficulties with station cleanliness and intimidation by homeless individuals have negatively impacted the image of the San Francisco systems. In Florida, there has been no high-profile public perception of changing conditions for transit services.

Many transit agencies are moving forward with a host of features that will enhance customer convenience and awareness. Increasingly available trip planning and real-time trip information, electronic fare payment, web access, and in-travel information such as stop annunciation enhance services and improve competitiveness over time. These features enhance the attractiveness of services but do not solve problems of service availability and travel time competitiveness. Additionally, many of these same types of features are simultaneously changing the convenience and amenities of travel options (in vehicle telematics, electronic toll payment, electronic parking payment, etc.).

While many of the remaining service features itemized in the insert above are being continuously addressed by Florida transit agencies and communities as opportunities and resources permit, these conditions are not changing dramatically and in general are improving over time, thus are not necessarily factors that can be described as causes for transit ridership declines in Florida. While progress in these areas will enhance the appeal of public transportation and help attract current non-users, there is not a data-driven basis for assuming they have contributed to declining transit ridership.

There is one caveat with respect to this discussion that merits inclusion. As ridership declines, it can change the profile of transit travelers, the resources available to the system operator, and the sense of comfort and security that comes from being with a group of travelers. To the extent that declining ridership in some markets and locations has resulted in travelers with the resources to avail themselves of alternatives such as driving or using transportation network companies in lieu of transit use, the remaining travelers may be fewer and more disadvantaged 
and this factor may be a deterrent to some travelers. Travelers have a sense of security traveling with a group of people. As volumes decline individuals may feel more isolated at transit stops or in almost empty vehicles and may be less comfortable using public transportation. This concern can be exacerbated if the remaining passengers are less like one's self.

\section{Table 23 Supply Factors That Impact Transit Ridership, Travel and Communication Options}

\begin{tabular}{|c|c|}
\hline 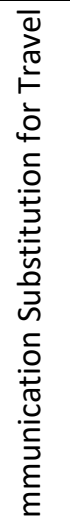 & $\begin{array}{l}\text { Telecommuting/work-at-home } \\
\text { Changes in commuting travel levels } \\
\text { E-Commerce } \\
\text { Foregone travel via online shopping } \\
\text { Electronic communications of video, audio, and document materials in lieu of travel } \\
\text { E-learning, online banking, electronic document transfer, video and music streaming, etc. } \\
\text { Social Networking } \\
\text { Electronic interaction in lieu of in-person social interaction (text, tweet, skype, Facebook, Instagram, } \\
\text { video gaming, etc.) }\end{array}$ \\
\hline 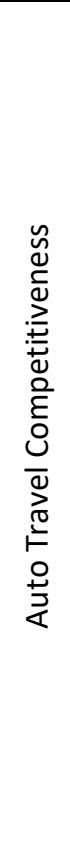 & $\begin{array}{l}\text { Vehicle cost and availability } \\
\text { New/used vehicle prices, interest cost and financing availability, vehicle reliability/maintenance cost } \\
\text { Licensure/Insurance considerations } \\
\text { Costs, government policies (age, immigration status, etc.) } \\
\text { Parking cost and availability } \\
\text { Travel time/speed and reliability } \\
\text { Congestion, incident frequency, mechanical reliability } \\
\text { Safety and security } \\
\text { Change in features and amenities } \\
\text { Comfort/convenience features (Wi-Fi, navigation, toll/parking payment connectivity, vehicle } \\
\text { telematics, etc.) } \\
\text { Fuel Cost } \\
\text { Stigma, Image } \\
\text { Perceptions of environmental impacts, social impacts, status, etc. }\end{array}$ \\
\hline 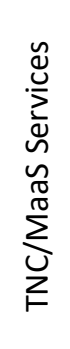 & $\begin{array}{l}\text { TNC Availability } \\
\text { Temporal and geographic availability, arrival time } \\
\text { TNC Access } \\
\text { Banking arrangement, smartphone availability, vehicle accessibility for mobility limited, etc. } \\
\text { TNC Cost } \\
\text { Bikeshare, scooter share, short term auto rental - availability, accessibility, and cost }\end{array}$ \\
\hline
\end{tabular}




\section{Supply Factors - Travel and Communication Options}

This third and final item of this section addresses how changes in the set of choices as alternatives to using transit may have influenced ridership. As alluded to in prior information, the most pronounced change in conditions over the past few years, during which we have witnessed significant changes in transit use, have been in the range of alternatives to transit travel. Three specific conditions have changed. Opportunities to substitute communications for travel continue to proliferate, auto availability has increased markedly as noted in prior discussion and, transportation network company service availability and consumer awareness has changed dramatically in urbanized areas. Each of these subjects is discussed in more detail.

Unlike some of the sociodemographic and land use changes that occur quite slowly, and unlike the transit supply levels and service characteristics which can change rapidly but have also been documented to have changed quite slowly, changes in the ability to substitute communication for travel, changes in auto availability and changes in transportation network company service availability have been changing relatively fast over the past few years.

Communication Substitution for Travel

The proliferation of technology, specifically high-speed computing, wireless internet connections, smart phone capabilities, and high-powered software for processing and transmitting massive amounts of information instantaneously have dramatically altered virtually every business and government function. These capabilities have resulted in dramatic changes in the way business, government, social interaction and other functions are carried out and subsequently meaningfully changed transportation. These changes, and the prospect of their continued deployment and evolution, are impacting public transportation and influencing transit ridership.

Understanding the magnitude and nature of these consequences is challenging and dynamic. Some scenarios are presented below that add perspective and give a sense of how these phenomena may be impacting transit and accordingly, what share of the changes in transit might be attributable to these factors.

The Role of Telecommuting and the Impact on Transit

As shown in Figure 37, ACS survey results indicate that telecommuting is the fastest changing "mode" for commuting to work. The 2017 Florida data indicated that work at home was the commute mode for $6.1 \%$ of commuters. As ACS reports individuals who reported this as their "usual" means of travel, it understates the total number of individuals who work from home some or all the time. Figure 38 shows the change in commuting by mode in Florida between 2013 and 2016. 


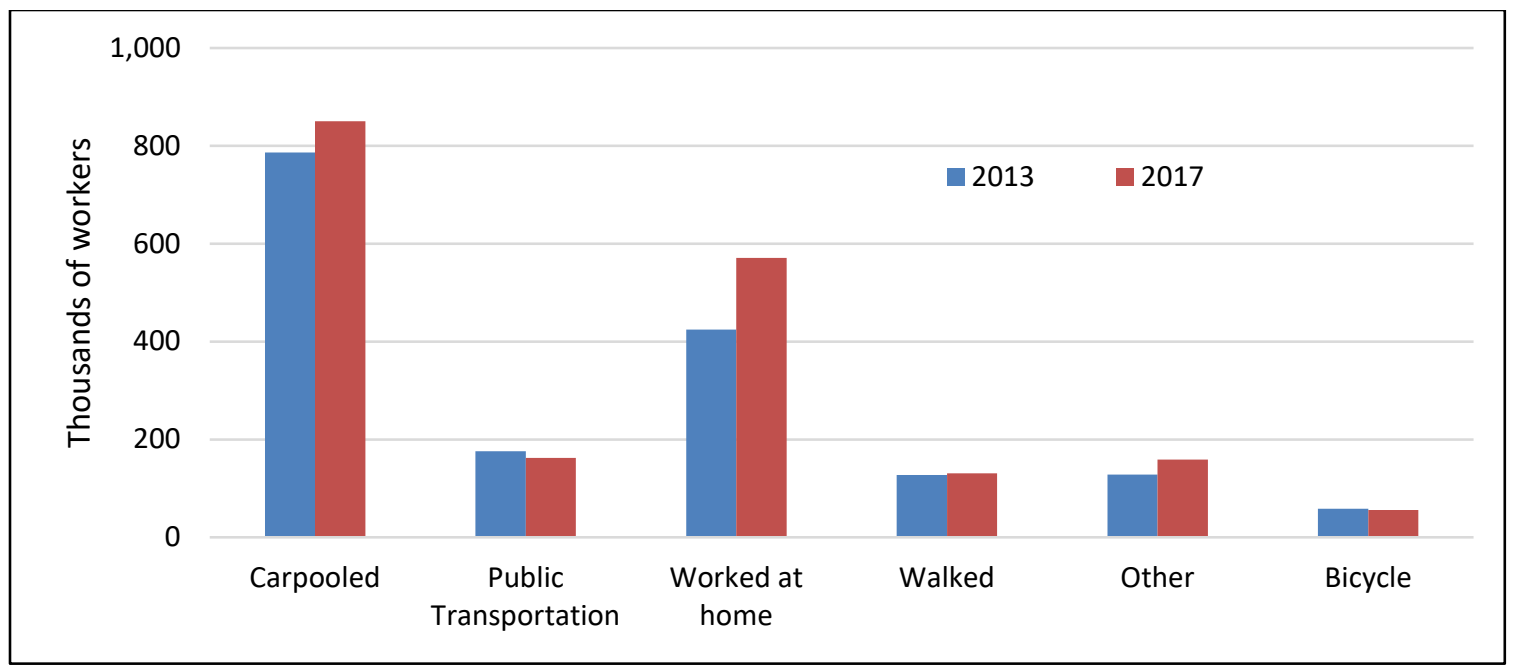

Figure 37 Commuting by U.S. Workers by Usual Commuting Mode, 2013, 2017, (000) Source: ACS

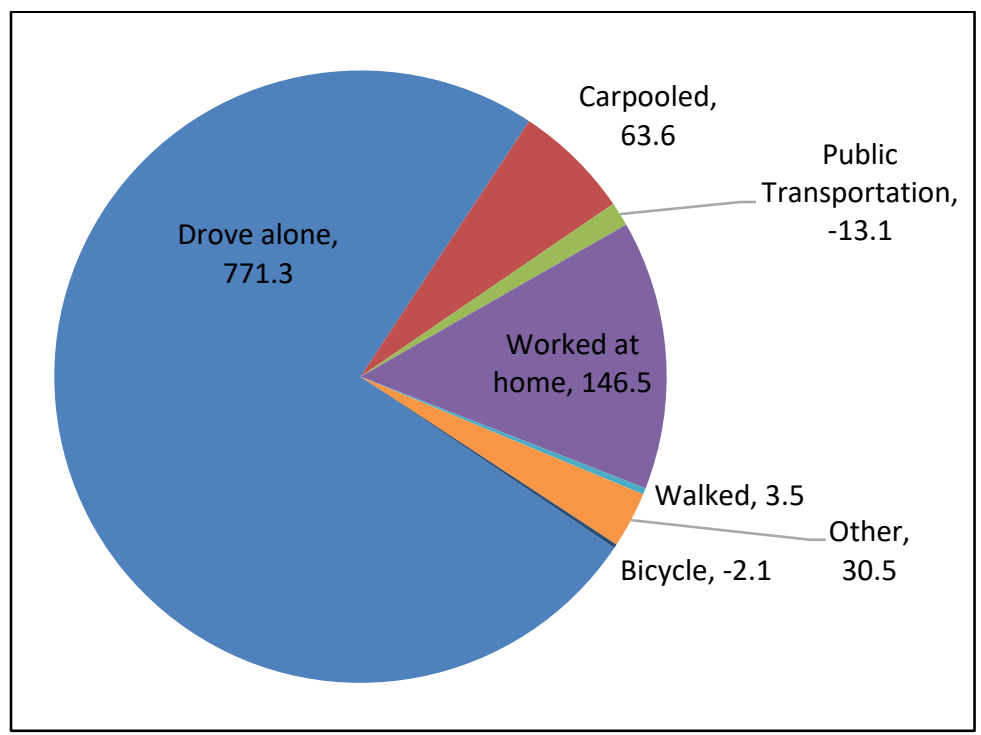

Figure 38 Change in Florida Workers by Usual Commuting Mode, 2013-2017 (000) Source: ACS

To give some insight as to the potential significance of telecommuting on transit ridership a hypothetical scenario is presented. We do not know what the prior mode of travel was for people who switched to telecommuting. One might presuppose that these were information intensive jobs more conducive to higher skills and less likely to be transit travelers. However, one might also presume that the burdensomeness of transit travel relative to auto travel might motivate transit travelers to pursue telecommuting options whenever available. In this fouryear period, Florida had 146,500 additional persons telecommuting. If these persons would have alternatively used travel modes in proportion to the overall population, approximately $1.7 \%$ would have been transit travelers. Had these individuals each commuted 220 days per year, made round-trips, and had approximately $30 \%$ of them required transfers as is reported in 
NHTS data for Florida, it would have resulted in approximately 712,000 fewer annual transit trips. As noted in Table 11 previously, transit ridership in Florida declined approximately $53,500,000$ trips between 2013 and 2017. Thus, increases in telecommuting could arguably explain $1.3 \%$ of the decline in transit ridership.

Substituting Communications for Travel - Reduced Trip Making

Communication substitution for travel has implications well beyond work trips. E-commerce has been acknowledged as significantly changing travel behavior. E-commerce constitutes approximately $10 \%$ of retail activity, and that number is increasing in excess of $1 \%$ per year ${ }^{3}$.

In addition, distance learning, electronic information transmittal, online banking, and a host of other technology enabled activities to replace personal business errands and other activities. Collectively, this results in diminished trip making. While there is no data that associates the relationship between communication substitution for travel and transit use explicitly, one can create some scenarios based on available data to communicate a sense of the potential impact on transit ridership associated with diminished household serving travel activities. One might note that household local travel has been observed to be declining for the past several years, at least partially attributable to communication substitution. For perspective, we have developed a scenario where transit travelers showed reductions in trip making proportional to reductions in overall trip making.

Figure 39 reports national per person trip rates and shows how they have declined over time. The data suggest that non-work trip making has declined by 0.05 trips per person per day per year. If one assumed that the $\mathbf{2 1 . 5}$ million Floridians older than age 5 had similar declines in trip making and that $1 \%$ of those trips were on transit, the approximate transit mode share for all trip purposes in Florida, one can estimate the ridership impact of declining trip rates between 2013 and 2017. This calculation, when adjusted for transferring, suggests that approximately $20,400,000$ fewer trips annually would be made on transit due to declining trip rates. This 20.4 million fewer trips is approximately $38 \%$ of the reported decline in ridership.

${ }^{3}$ https://www.statista.com/statistics/379112/e-commerce-share-of-retail-sales-in-us/ 


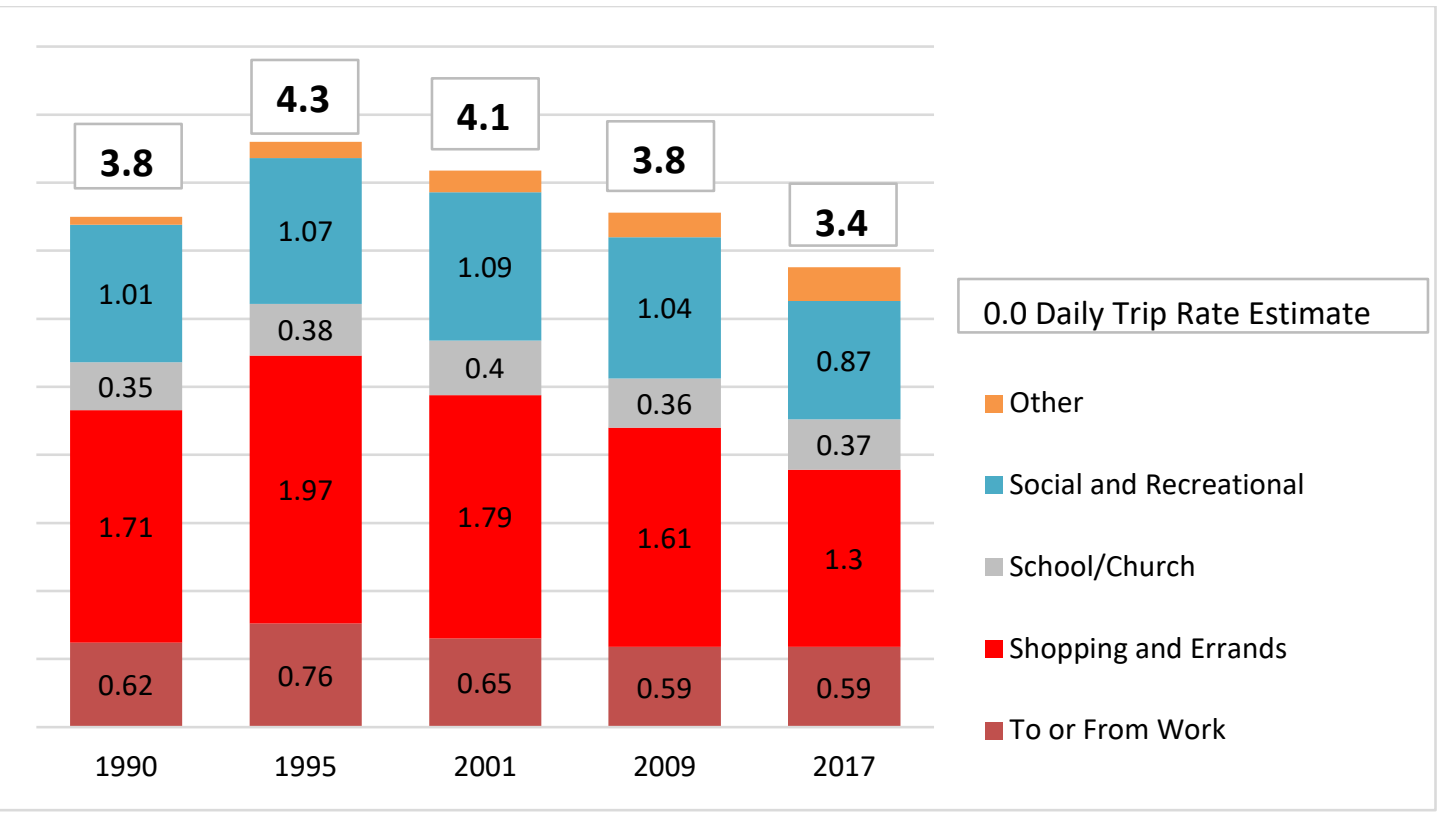

Figure 39 Trends in Person Trips by Purpose, US, 1990 to 2017

Source: NHTS data, Analysis by Nancy McGuckin

Auto Travel Competitiveness

In evaluating transit ridership, one would logically want to understand the level of service and characteristics of the travel alternatives to public transportation. Most obviously, this would include the level of service and cost of auto travel. The most pronounced characteristic of the auto travel option is the availability of autos for travel and the cost of their use. Auto availability was discussed extensively above. This availability was certainly influenced by a host of economic conditions including household employment and income levels, fuel prices, credit availability and vehicle price. A full discussion of these factors is available in Understanding Recent Ridership Changes: Trends and Adaptations, a report by the American Public Transportation Association released in April 2018.

Ridership Impact of Communication and Transportation Options - Transportation Network Companies

The presence of transportation network companies (TNCS) are frequently cited or hypothesized to be a factor in the declines in transit ridership. In some cases, that is based on a reference to the coincident rise in TNCs simultaneous with the declines in transit ridership, often with an inexplicit implication as to the causal relationship. For example, Randle O'Toole recently reported,

The latest blow to transit is ride-hailing. A recent study estimated that ride-hailing companies such as Uber and Lyft carried 710 million more riders in 2017 than 2016, 
while another study estimates that a third of ride-hailing users would otherwise have taken transit.

Since transit ridership dropped by 255 million trips in 2017, ride-hailing may be responsible for more than 90 percent of the decline in transit. ${ }^{4}$

This followed by another report a few weeks later that added perspective on the impact and nature of TNC's.

1) TNCs have more than doubled the overall size of the for-hire ride services sector since 2012, making the for-hire sector a major provider of urban transportation services that is projected to surpass local bus ridership by the end of 2018.

- TNCs transported 2.61 billion passengers in 2017, a 37 percent increase from 1.90 billion in 2016.

- Together with taxicabs, the for-hire sector is projected to grow to 4.74 billion trips (annual rate) by the end of 2018, a 241 percent increase over the last six years, surpassing projected ridership on local bus services in the United States (4.66 billion).

2) TNC ridership is highly concentrated in large, densely populated metro areas. Riders are relatively young and mostly affluent and well-educated.

- 70 percent of Uber and Lyft trips are in nine large, densely populated metropolitan areas (Boston, Chicago, Los Angeles, Miami, New York, Philadelphia, San Francisco, Seattle and Washington DC.)

- People with a bachelor's degree, over \$50,000 in household income, and age 25 to 34 use TNCs at least twice or even three times as often as less affluent, less educated and older persons. ${ }^{5}$

These observations give a different impression than do some recently released research results. For example, a comprehensive Transportation Research Board (TRB) study came to the following conclusions related to this issue.

3. There is no clear relationship between the level of peak-hour TNC use and longer term changes in the study regions' public transit usage. From 2010 to 2016, Seattle, San Francisco, and Nashville-representing high, medium, and low

\footnotetext{
${ }^{4}$ Subsidies can't save transit from its death spiral, THE HILL, BY RANDAL O'TOOLE, OPINION CONTRIBUTOR 08/16/18 05:00 PM EDT

${ }^{5}$ The New Automobility: Lyft, Uber and the Future of American Cities, July 25, 2018, SCHALLER CONSULTING
} 
peak-hour TNC usage, respectively—all saw transit ridership increase. Meanwhile transit ridership in Chicago and Los Angeles (high and medium peak-hour TNC use, respectively) decreased, and Washington, D.C.'s (high peak-hour TNC use) fell by the greatest percentage. The changes in transit ridership between 2010 and 2016 in these regions do not appear to be related to the regions' levels of peak hour TNC usage. ${ }^{6}$.

\begin{tabular}{|c|c|c|c|c|}
\hline & BART $^{15}$ & MARTA & NJ Transit & WMATA \\
\hline $\begin{array}{l}\text { TNC connecting } \\
\text { to transit }\end{array}$ & $16 \%$ & $6 \%$ & $8 \%$ & $3 \%$ \\
\hline $\begin{array}{l}\text { TNC instead of } \\
\text { transit }\end{array}$ & $11 \%$ & $16 \%$ & $17 \%$ & $39 \%$ \\
\hline $\begin{array}{l}\text { Transit not an } \\
\text { option (reason) }\end{array}$ & $\begin{array}{r}32 \% \\
(26 \% \text { hour, } 6 \% \\
\text { route) }\end{array}$ & $\begin{array}{r}16 \% \\
(8 \% \text { hour, } 8 \% \\
\text { route })\end{array}$ & $\begin{array}{r}19 \% \\
\text { (no data for } \\
\text { reason) }\end{array}$ & $\begin{array}{r}13 \% \\
\text { (4\% hour, } 9 \% \\
\text { route) }\end{array}$ \\
\hline $\begin{array}{l}\text { Haven't used } \\
\text { TNC in region }\end{array}$ & $41 \%$ & $62 \%$ & $56 \%$ & $45 \%$ \\
\hline
\end{tabular}

Survey results included in that same report gave insight into both diversion from transit and TNC use being complementary to transit.

Other newer data from a study in Boston, FARE CHOICES: A SURVEY OF RIDE-HAILING PASSENGERS IN METRO BOSTON, suggests a much more pronounced relationship between TNC's and public transportation ridership changes.

While the services are justifiably popular, their growing use may result in negative outcomes for traffic congestion, transit use, and active transportation. When asked how they would have made their current trip if ride-hailing hadn't been an option, 12\% said they would have walked or biked, and over two-fifths (42\%) of respondents said they would have otherwise taken transit. Some of this "transit substitution" takes place during rush hours. Indeed, we estimate that $12 \%$ of all ride-hailing trips are substituting for a transit trip during the morning or afternoon commute periods; an additional $3 \%$ of riders during these times would have otherwise walked or biked. ${ }^{7}$

The survey-based data on the prior or alternative mode of current TNC users remains limited to a small number of studies in generally high profile TNC cities, generally in locations where there are high quality transit services, and a significant share of higher-

\footnotetext{
${ }^{6}$ TCRP RESEARCH REPORT 195, Broadening Understanding of the Interplay Among Public Transit, Shared Mobility, and Personal Automobiles, Sharon Feigon, Colin Murphy, Shared-Use Mobility Center, Chicago, 2018.

${ }^{7}$ FARE CHOICES: A SURVEY OF RIDE-HAILING PASSENGERS IN METRO BOSTON, Report \#1: February 2018, A Metropolitan Area Planning Council Research Brief.
} 
income choice travelers on transit. These are characteristics of a market segment more inclined to be able to take advantage of the convenience of TNCs. Very limited disaggregate data on TNC use, particularly in Florida, limits the extent to which one can develop geographic specific profiles of TNC users, or highly confident knowledge regarding their influence on public transportation.

There is one source of data that can shed some light on TNC use by county level geography. The Census reports the number of non-employer businesses and their receipts annually by county. The Livery Operations job category covers TNC operators and independent/selfemployed taxi operators, and is a reasonable surrogate source of information on the magnitude of independent livery operations. Figure 39 shows the trend in the number of non-employer livery operators in Florida. Given the overall TNC industry growth, one would expect the accelerating trend to continue into 2017 and possibly beyond.

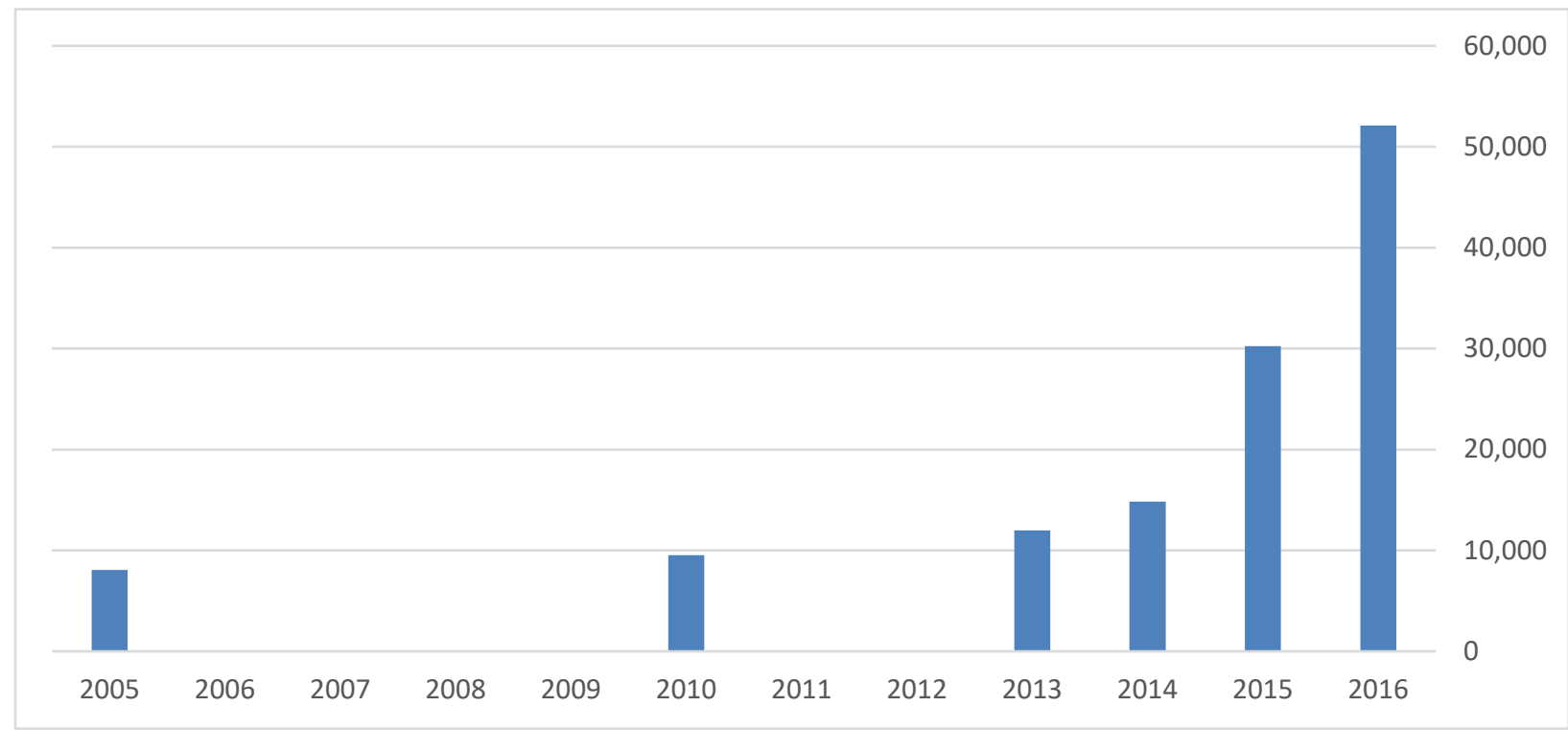

Figure 40 Trend in Number of Non-employer Livery Operators in Florida Source: Census, Non-employer Statistics 2016

Figure 40 uses the same data source and presents receipts. This trend, while also increasing significantly since 2013 , is less steep. This reflects the fact that increasingly livery drivers are part time employees. Receipts per operator have declined 50\% since 2013. Total annual receipts in 2016 is in excess of $\$ 735$ million. If an average TNC trip were \$15 this would represent approximately 50,000,000 annual trips. For context, Florida reported approximately $250,000,000$ annual fixed route transit trips in fiscal year 2016 . However, if a TNC trip had multiple occupants or if that trip replaced a transit trip that involved a transfer, one could envision the mobility provided by TNC trips being equivalent to 75 
million transit boardings. This should not imply that these trips would have alternatively been made on transit, but rather gives perspective.

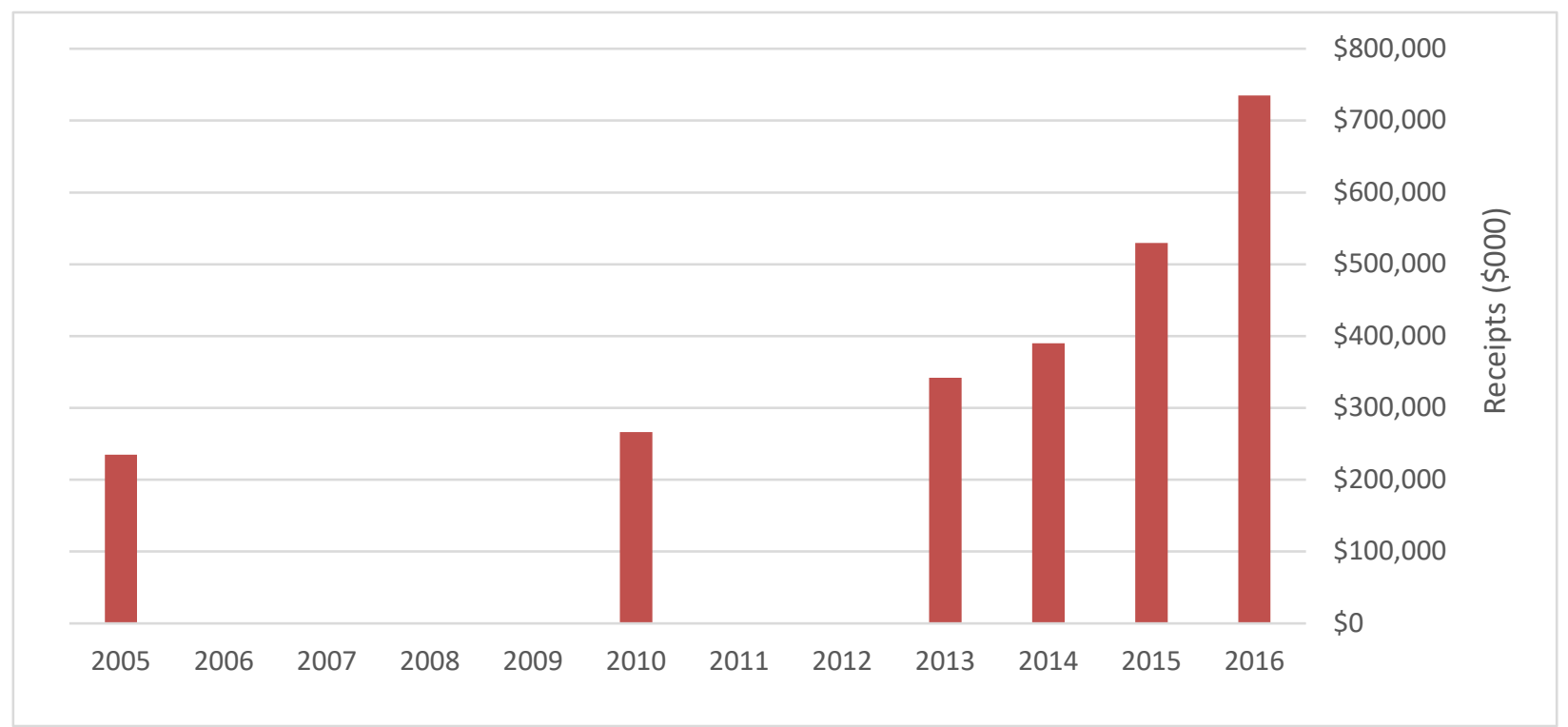

Figure 41 Trend in Number of Receipts of Livery Operators in Florida

Source: Census, Non-employer Statistics 2016

If one third of the TNC trips increase between 2015 and 2016 (23.5 million new TNC trips in Florida) would have been alternatively made by transit, and if the boarding group size had been 1.2 persons with half the trips involving a transfer (approximately half of national and $30 \%$ of Florida transit trips involve a transfer), then approximately 11,250,000 of the 20 million transit passenger trip decline between 2015 and 2016 could be explained by growth in TNC ridership. Unfortunately, available data does not support more robust analysis of this potential. Because both the TNC market and the transit market in Florida are less robust than in locations like Boston and San Francisco where data on transit trip diversion has been collected, it is this author's opinion that TNC influences in Florida is less pronounced than might be the case in these other locations. However, both transit and TNC services are more mature in the Miami area, and this area has suffered a significant decline in transit ridership. A county specific scenario of possible diversion is presented later in this section.

Figure 41 and Figure 42 present data on drivers and receipts for Florida counties for select years. This data in tabular form is included in Table 24. Livery driver activity is concentrated in the larger more urban counties. Miami-Dade, Broward, and Orange County collectively comprise approximately half of the activity for the State of Florida. The nature of TNC activity geographic concentration is not meaningfully different than is the case for transit ridership. 


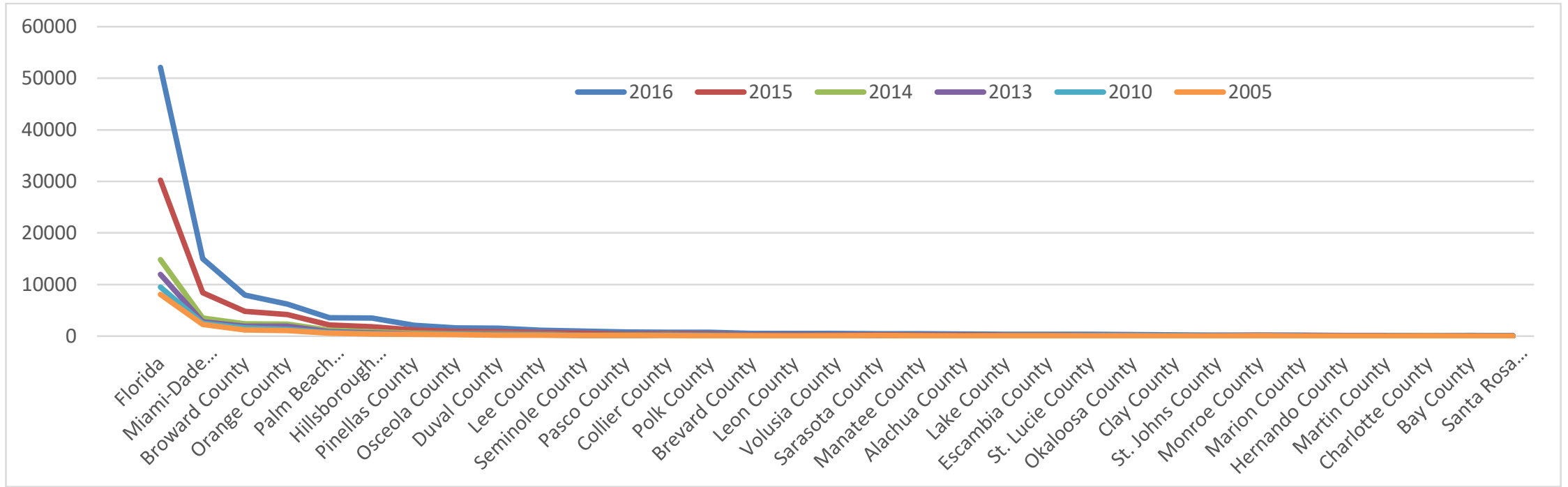

Figure 42 Trend in Number of Non-employer Livery Drivers in Florida

Source: Census, Non-employer Statistics 2016. Counties with over 100 reports in 2016.

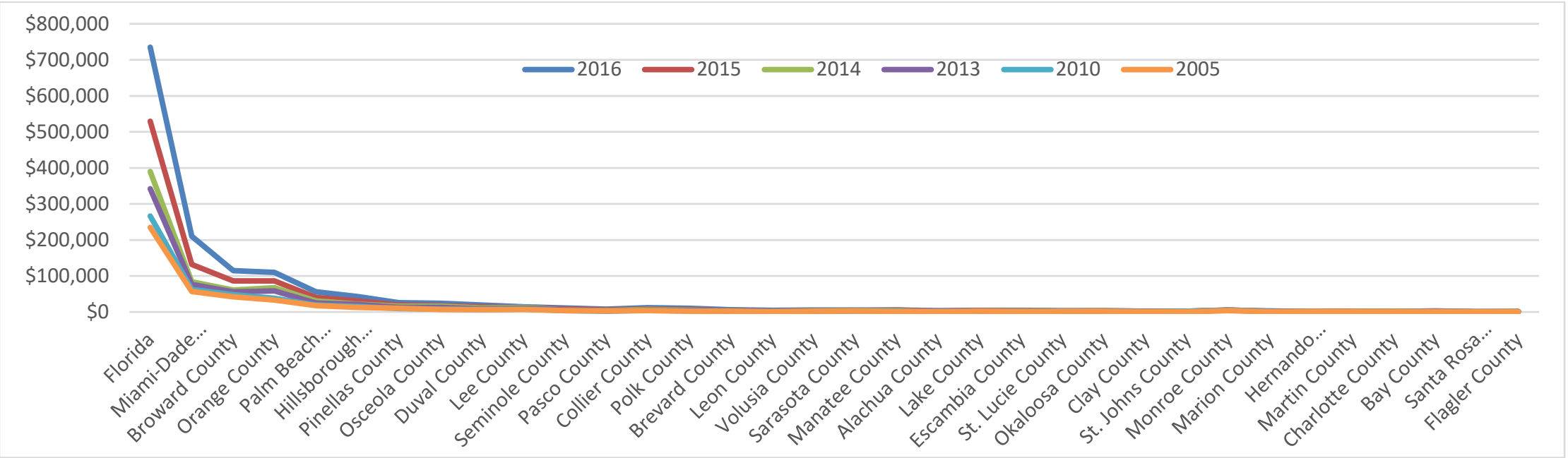

Figure 43 Trend in Number of Non-employer Livery Driver Receipts in Florida

Source: Census, Non-employer Statistics 2016. Counties with over 100 reports in 2016. 
Table 24 Census Data Trend by Florida County for Nonemployee Livery Driver Count and Receipt Totals

\begin{tabular}{|c|c|c|c|c|c|c|c|c|c|c|c|c|}
\hline & \multicolumn{6}{|c|}{ Number of Nonemployer Establishments } & \multicolumn{6}{|c|}{ Receipts $(\$ 1,000)$} \\
\hline & 2016 & 2015 & 2014 & 2013 & 2010 & 2005 & 2016 & 2015 & 2014 & 2013 & 2010 & 2005 \\
\hline Florida & 52096 & 30238 & 14828 & 11971 & 9512 & 8085 & 735005 & 529432 & 389773 & 342084 & 266288 & 234773 \\
\hline Miami-Dade County & 14981 & 8402 & 3530 & 2787 & 2482 & 2255 & 209962 & 131519 & 83961 & 76027 & 62729 & 56610 \\
\hline Broward County & 7955 & 4797 & 2365 & 1947 & 1600 & 1206 & 114379 & 86109 & 60564 & 55569 & 48069 & 42276 \\
\hline Orange County & 6216 & 4158 & 2353 & 1936 & 1297 & 1111 & 109950 & 86429 & 67417 & 58120 & 38323 & 32968 \\
\hline Palm Beach County & 3564 & 2157 & 1120 & 864 & 698 & 594 & 56206 & 40474 & 30363 & 25058 & 19495 & 17372 \\
\hline Hillsborough County & 3493 & 1827 & 842 & 632 & 473 & 389 & 43159 & 30906 & 21373 & 21181 & 14737 & 12709 \\
\hline Pinellas County & 2111 & 1211 & 571 & 416 & 326 & 340 & 25884 & 19138 & 15725 & 12658 & 9828 & 9864 \\
\hline Osceola County & 1573 & 916 & 548 & 457 & 333 & 279 & 24138 & 17725 & 16127 & 12672 & 7543 & 7241 \\
\hline Duval County & 1518 & 835 & 468 & 341 & 242 & 178 & 18829 & 14316 & 11336 & 8926 & 7101 & 5975 \\
\hline Lee County & 1138 & 690 & 405 & 360 & 240 & 202 & 14443 & 11478 & 12490 & 10604 & 8010 & 6616 \\
\hline Seminole County & 973 & 600 & 198 & 178 & 118 & 132 & 11323 & 8272 & 5339 & 5606 & 3457 & 3619 \\
\hline Pasco County & 808 & 381 & 161 & 128 & 89 & 107 & 8146 & 5483 & 3683 & 3017 & 2294 & 3189 \\
\hline Collier County & 774 & 468 & 301 & 261 & 210 & 141 & 11530 & 8758 & 7030 & 5321 & 4561 & 3426 \\
\hline Polk County & 767 & 409 & 202 & 158 & 114 & 69 & 10333 & 7280 & 5024 & 4180 & 3107 & 2318 \\
\hline Brevard County & 524 & 243 & 138 & 113 & 98 & 87 & 5865 & 3919 & 3123 & 2677 & 2127 & 1982 \\
\hline Leon County & 515 & 301 & 116 & 65 & 45 & 35 & 4503 & 2914 & 1722 & 1363 & 795 & 802 \\
\hline Volusia County & 515 & 228 & 105 & 91 & 72 & 77 & 5584 & 3562 & 2778 & 3278 & 2506 & 1991 \\
\hline Sarasota County & 468 & 240 & 100 & 93 & 105 & 101 & 5508 & 3627 & 3346 & 2722 & 2914 & 2787 \\
\hline Manatee County & 459 & 247 & 115 & 84 & 82 & 51 & 5700 & 5544 & 3464 & 2872 & 2787 & 1567 \\
\hline Alachua County & 408 & 246 & 48 & 40 & 29 & 29 & 3842 & 2147 & 723 & 1055 & 446 & 924 \\
\hline Lake County & 380 & 212 & 105 & 65 & 62 & 66 & 4673 & 3381 & 2878 & 2360 & 1597 & 1779 \\
\hline Escambia County & 343 & 205 & 118 & 94 & 92 & 63 & 4817 & 3860 & 3020 & 2595 & 2484 & 1210 \\
\hline St. Lucie County & 332 & 154 & 96 & 100 & 87 & 56 & 4098 & 2438 & 2325 & 2303 & 2372 & 1785 \\
\hline Okaloosa County & 275 & 128 & 77 & 70 & 69 & 61 & 3652 & 3252 & 2754 & 1820 & 2018 & 2020 \\
\hline Clay County & 230 & 90 & 46 & 36 & 27 & 22 & 2258 & 1784 & 925 & 1040 & 712 & 644 \\
\hline St. Johns County & 210 & 114 & 59 & 59 & 39 & 23 & 2139 & 2080 & 1606 & 1390 & 1733 & 712 \\
\hline Monroe County & 174 & 158 & 140 & 138 & 116 & 90 & 4775 & 5342 & 5132 & 5100 & 4231 & 3369 \\
\hline Marion County & 173 & 104 & 51 & 50 & 43 & 34 & 2731 & 2117 & 1651 & 1543 & 1241 & 739 \\
\hline Hernando County & 130 & 55 & & & 25 & 30 & 1267 & 971 & & & 572 & 1017 \\
\hline Martin County & 130 & 80 & 43 & 39 & 23 & 26 & 2044 & 1799 & 1455 & 791 & 404 & 1304 \\
\hline Charlotte County & 126 & 63 & 46 & 48 & 54 & 47 & 1719 & 1436 & 1317 & 1200 & 1417 & 1531 \\
\hline Bay County & 111 & 109 & 84 & 76 & 40 & 29 & 2314 & 2758 & 2396 & 1641 & 474 & 267 \\
\hline Santa Rosa County & 108 & 50 & 27 & 25 & 22 & 15 & 941 & 683 & 679 & 612 & 639 & 336 \\
\hline Flagler County & 98 & 51 & 25 & 20 & 22 & 21 & 1291 & 1087 & 998 & 616 & 813 & 641 \\
\hline Indian River County & 91 & 63 & 31 & 26 & 16 & 12 & 1394 & 1114 & 1033 & 1413 & 447 & 246 \\
\hline Nassau County & 52 & 34 & 24 & 17 & & 7 & 506 & 938 & 1063 & 676 & & 452 \\
\hline
\end{tabular}


To add perspective on the magnitude of changes in TNC use relative to the magnitude of changes in transit ridership, a specific scenario was developed for Miami-Dade County. This scenario integrates some additional considerations not readily apparent in some of the other discussions of the relationship between TNC's and transit ridership.

- TNC use, like all travel, is subject to different size travel parties. To a certain extent, use of TNC relative to transit has a competitive advantage for a larger group size where the fixed cost of the TNC trip can offset the need to incur transit fares for multiple members of a group traveling together. In the absence of empirical data on TNC trip group size, 1.2 persons (beyond the driver) were assumed for the scenario.

- Nationally, data indicates that approximately half of transit trips to a destination involve needing to transfer between transit vehicles and recent Florida NHTS data suggest a $30 \%$ transfer rate in Florida. This can be something as simple as cross platform transfers - for example between Metrorail and Metromover, to transfers between intersecting or nearby bus routes. There is no data regarding what types of transit trips might be foregone considering the availability of the TNC option. While many TNC trips are urban core centric, growing use for airport access and other purposes coupled with the fact that travelers might be more inclined to switch to TNC's if they were facing a transit trip that involved at least one transfer, has resulted in the decision to assume 1.5 foregone transit boardings for each TNC diverted trip passenger for a scenario for Miami-Dade County.

The scenario in Table 25 below suggests that over $30 \%$ of the change in ridership on transit in Miami-Dade in 2016 could have been as a result of diversion of trips to TNC. One might be able to assess with greater confidence the extent to which this diversion is reasonable in the context of comparing the sociodemographic profiles of TNC travelers with those of transit users. Similarly, if one had year-over-year comparisons of transit rider demographics one might be able to discern what market segments were changing travel behavior.

Table 25 itemizes a scenario estimation of the relationship between TNC ridership and transit use for Miami-Dade County. 
Table 25 Scenario on the Impact of TNC on Transit Ridership, Miami-Dade, 2016

\begin{tabular}{|l|r|}
\hline 2015 Miami transit ridership & $102,889,956$ \\
2016 Miami transit ridership & $94,969,988$ \\
2016 - 2015 change & $-7,919,968$ \\
\hline 2016 TNC operator receipts & $\$ 209,962,000$ \\
2015 TNC operator receipts & $\$ 131,519,000$ \\
2016 - 2015 change & $\$ 78,443,000$ \\
\hline Guesstimated TNC trips assuming a \$15 average fare of which & $6,972,711$ \\
\$11.25 would be driver receipts & \\
Number of transit trip equivalents assuming group size of 1.2 and & $12,550,880$ \\
50\% of trips would have required a transfer & $2,510,176$ \\
Assuming 20\% would have been made on transit & $31.7 \%$ \\
Share of transit ridership decline potentially explained by & \\
diversion to TNC travel & \\
\hline
\end{tabular}

Source: CUTR scenario

After looking at the disparity of observations in prior research and the Florida data presented, several observations arise.

- The impact of TNCs on transit ridership may be very different across time and across geography. Early TNC growth appears to have targeted the off-peak/evening and weekend time periods and grown fastest amongst younger higher income individuals with smart phone and banking relationships and higher awareness of emerging technology applications. As awareness of TNCs grew, the profile of TNC riders may have changed. Similarly, the relative availability of TNC travel options has changed at different paces in different metropolitan areas.

- TNCs have expanded geographically quite dramatically over the past few years. The user profile of TNC users and the impact on transit, both as a complementary and competitive mode, is inevitably changing over time and across geography. It is entirely possible that TNCs were not powerful in explaining changes in transit ridership in 2013 2015 but have become more significant factors in 2016 and 2017.

- There may be a difference in the influence of TNCs dependence upon context factors. For example, the convenience and speed of TNCs might be particularly attractive in offpeak time periods for larger group sizes and in situations where the transit option requires a transfer. Similarly, shorter TNC trips might have a more acceptable cost comparison in situations where travel costs are shared across the group and fixed-price transit had a higher cost per mile as might be the case for a short trip on a fixed price system. 
- TNC as an access mode to transit makes the most sense in situations where the total trip length is relatively long and TNC enables access to (or egress from) a high-quality transit mode that offers an efficient and competitive means of travel for a longer distance commute or access to an airport or special event. This is particularly true if parking costs at the destination are a deterrent to using auto travel for the whole trip (i.e. airport access, special event venue, etc.).

- The fixed minimum trip cost for TNCs will discourage their use for very short trips and induce travelers to complete the whole trip in the TNC if the overall trip is short to modest in length.

Going forward, it's important to recognize that the competitive situation is continuing to change. TNC service options, pricing, and other level of service factors are changing quickly. TNC fare costs are significantly above levels that existed two to three years ago when operators were trying to increase awareness and grow market. Average costs are extremely difficult to discern. TNC costs are comprised of several elements many of which have changed and are likely to continue to change.

TNC typical fare structure:

Base Fare $+(($ Cost per minute $x$ time of the ride $)+($ cost per mile $x$ ride distance $) x$ surge boost multiplier) + booking fee + Tip = Passengers Ride Fare

In addition, there are often several choice options related to sharing and/or the nature of the vehicle and cancellation fees and vehicle cleaning fees as relevant. Recently, there have been several additional factors that are changing TNC pricing. New York and Boston have added per mile taxes to TNC rates to support various transportation related programs. Other communities and states are considering similar fees. Fixed fees for airport trips are being implemented across the country, and New York capped the number of ride hail vehicles for one year and imposed a minimum wage for drivers - factors that are likely to impact future prices. ${ }^{8} \mathrm{Higher}$ fuel prices, strong employment trends dampening the competitiveness of driver jobs, and greater transparency of the compensation levels of TNC drivers ${ }^{9}$, coupled with the prospect that TNC companies may desire to show increased revenues to support initiatives to become publicly held companies, might change the cost and subsequent financial competitiveness of TNC travel relative to transit and personal vehicle use going forward.

\footnotetext{
${ }^{8}$ https://www.cnbc.com/2018/08/08/new-york-city-votes-to-cap-uber-and-lyft-vehicles.html

${ }^{9}$ https://www.mercurynews.com/2018/05/17/uber-drivers-wages-revisited-how-much-do-they-make/, https://www.ridesharingdriver.com/survey-data-how-much-uber-drivers-really-make-share/, http://time.com/money/4845407/uber-drivers-really-make-per-hour/
} 
Observations and Recommendations regarding TNC and Transit in Florida

Based on the information available, it is difficult to determine with any degree of confidence, the impact of TNCs on individual transit properties in Florida. There is compelling evidence, however, that TNCs are impacting travel behavior, and that includes both complementary and competitive interactions with public transportation. The weight of the evidence suggests that TNCs are capturing some share of trips that might otherwise be made on public transportation services. Survey data from other locations suggests that customer convenience is the compelling factor in motivating TNC use. Door to door travel, coupled with minimum wait times - often in low to middle single-digit number of minutes in larger Metropolitan areas, and moderate fares particularly if shared amongst a travel group, are appealing to travelers. A stronger sense of personal security, weather protection, personal/more private travel environment and other factors may be influencing decisions.

The prospect of utilizing TNCs for complementary connections with public transportation would appear to be most promising in situations where long distance commutes or special-purpose trips, on high level of service transit options, may offer some opportunities. However, park-andride and longer distance commute services are relatively modest in Florida (particularly outside of southeastern Florida) as dispersed employment and relatively small central business district employment concentrations weigh against the competitiveness of high quality, longer distance commute markets.

Continued monitoring and analysis of the interaction of TNCs and transit in Florida merit attention. The Census data on TNC driver and receipt information as well as any locally available data on TNC market penetration and user profiles that might become available over time may help discern a stronger understanding of the market interactions of public transportation and TNCs in Florida. Based on the data available, it is the opinion of this author that TNCs are responsible for a meaningful part of the decline in transit ridership, particularly in the southeastern part of Florida and perhaps some other select markets. The data collectively suggest that a double-digit share of the recent year declines in transit ridership may be diversion to TNC travel. It would not be surprising if 5\% to $30 \%$ of the most recent declines in transit ridership were attributable to diversion to TNCs.

One should note that there is also a secondary effect associated with diversion of travel to TNCs. To the extent that declining transit ridership and the associated loss of fare revenues contributes to policy decisions to reduce transit level of services, this could further undermine transit ridership going forward. While this cause-and-effect relationship is unlikely to be explicit, TNC diversion may contribute to what is characterized in the public transportation industry as the downward spiral associated with declining ridership. 
It is also important to note that analysts have speculated that the presence of TNC options may be contributing to increased polarization in the profile of transit travelers. To the extent that TNCs attract higher income travelers away from transit, it may undermine public support of transit. Reduced ridership by individuals matching the profile of TNC riders may undermine political support for public transportation by those individuals no longer inclined to use it.

This polarization in riders may itself diminish motivation for some additional travelers to use public transportation if changes in the sociodemographic profile of fellow passengers contributes to decisions by some travelers to change travel behavior if they are no longer as comfortable with the social interaction with fellow passengers.

Finally, most of the analyses of TNC use and its impact on travel behavior are short-term measures and do not necessarily reflect longer-term changes in behaviors that influence travel behavior. Specifically, the presence of TNC services, particularly over time in conjunction with quality transit, can influence both vehicle ownership and decisions regarding where to live, work and participate in other activities. As these still very young and dynamic services mature and stabilize, people may make different decisions about vehicle ownership and residential and work locations based on travel options. Should TNC pricing stabilize and availability prove itself to be reliable over a multi-year period, then households may be more willing to relinquish a household vehicle as they rely more on TNCs and public transportation. Such a scenario may offset the current situation where TNCs appear to be cannibalizing more trips by virtue of providing a more convenient and faster option than they are inducing by virtue of enhancing first-mile, last-mile connections.

\section{Summary Observations on Exploration of the Declines in Ridership}

The project team sought to quantify and characterize the impacts of various factors on public transit ridership. As noted, complex decision-making, data availability, and the extensive set of factors as enumerated in the introductory section of this report, preclude sophisticated analytical analysis in a manner that could precisely attribute causality either for individual properties and/or the collective set of transit operators in Florida. The relatively rapid change over a very recent short period of time (4 years) impede data availability on critical factors such as current sociodemographic conditions at the transit stop level of geography (level of precision and currency of data), and quantification of transportation supply characteristics (system accessibility to destinations on an annual or more frequent basis) over the past few years. Nonetheless, robust aggregate data on transit service supply and demand is available. Numerous other data elements are available and have been reviewed by the project team to discern and interpret trends and causes. As a result, many of the observations reflect the collective review of information across the numerous data sources consulted during the study, 
but use professional judgment seasoned with extensive public transportation experience as the fundamental basis for synthesizing conclusions.

As noted, the magnitude, speed, and pervasiveness of changes in transit use are pronounced compared to recent history. They indicate both significant changes in economic conditions, and factors beyond changes in economic conditions, have occurred and may be continuing. The spectrum of travel choices is changing, and travelers are making decisions to forgo public transportation. The performance characteristics of transit travel options are perceived by many travelers as being inferior to the alternative mobility choices now available. In most situations, transit ridership declines do not appear to be attributable to deterioration in the levels of service offered by Florida public transit operators, but rather by the emergence of options that offer more utility to travelers.

While a small number of individuals consider environmental impacts, social/cultural benefits of using transit, or other indirect costs and consequences when they make their travel decisions, the vast majority make their decisions based on the direct costs and benefits that they incur as consumers given the choice features that confront them as travelers. The cost in time and money, flexibility, reliability, safety, comfort, and related factors drive consumer decisions. These characteristics are certainly influenced by the characteristics and quantity of transit service delivered by Florida transit operators, but their ability to deliver services are influenced by the spectrum of community characteristics that influence the competitiveness of public transportation. Of critical importance is the land-use/activity pattern of communities which influences the extent to which public transportation can attract travelers and deliver resource efficient services. Similarly, the public's willingness to support public transportation services, or require auto travelers to bear the financial burden of the direct costs of auto travel (fully funding roadway maintenance and capacity expansion, charging travelers with the cost of parking, charging travelers with the cost of safety consequences of auto travel, etc.), will influence travel decisions.

The reality of current conditions, and how travelers perceive and value them, has resulted in a four-year decline in transit ridership that, while perhaps slowing, appears to be continuing at least in some important markets. The conditions that have contributed to changes in travel behavior have not necessarily fully played themselves out. The economy remains strong and automobile ownership remains affordable. Employment is growing faster than population and incomes are rising. Technology that enables foregoing travel continues to be deployed, refined, and leveraged in new business models (for example GrubHub for food delivery, and Docusign for document transmittal). Transportation network company growth continues with expansion in geographic coverage and travel choice options producing large double-digit year-over-year growth trends. 
The ridership declines exacerbate the challenge of transit trying to improve, sustain, or improve their competitiveness with other travel choices. Reduced ridership itself is a deterrent as riders are ambassadors of the service and increase the awareness of transit options to individuals they interact with. Declining ridership can influence perceptions of security and can undermine political support for public transportation. Perhaps as relevant, declining ridership undermines the ability of public transportation to accomplish some of its resource efficiency objectives. Underutilized services are not able to capture benefits in terms of energy efficiency, reduced emissions, improve travel safety, reduce congestion, transportation infrastructure cost savings, etc. that have helped justify public transportation investments and motivated public support. To the extent that these benefits are diminished, or are no longer accruing, public transit is left with the goal of providing a mobility opportunity for those with no alternatives. While a meritorious goal, garnering public support is easier when credible arguments can be made for additional benefits.

It is the opinion of this project team that the softness in ridership in Florida, relative to other transit markets, is attributable to the fact that transit ridership in Florida has been more dependent upon individuals who have not had other travel options. The conditions observed in the last few years, specifically increased household auto availability, increased options to substitute communication for travel, and increased options to utilize transportation network company services and in some cases bikeshare or other emerging travel options, has resulted in substantial shares of this group of travelers now having a travel option that did not previously exist. These new choices are a superior option particularly with respect to speed, convenience, and flexibility compared to public transit in Florida, and many have chosen these options.

To characterize this change in choice set Figure 43 symbolizes the situation for travelers who did not have an auto travel option in the past.

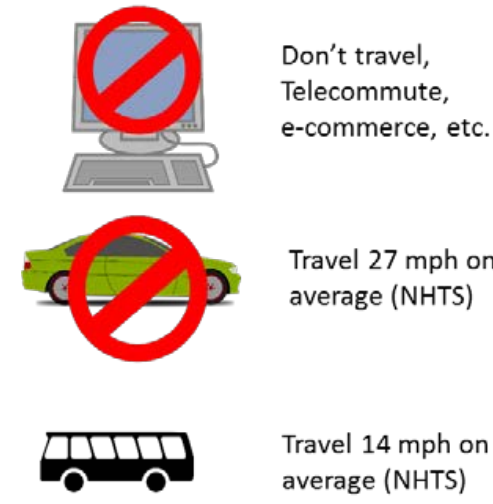

2013 Choice set for many Florida Transit travelers

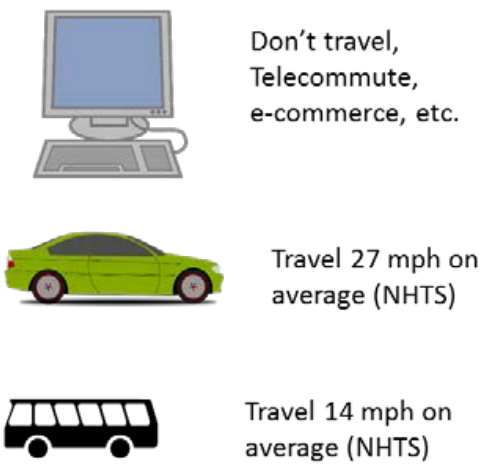

2018 Choice set for growing share of Florida travelers

Figure 44 Characterization of the Changing Choice Set Facing Many Travelers Who Previously Relied on Public Transit 
Individuals who have always had the choice of auto travel have made decisions to use transit based on their comparative utility. For various reasons, perhaps expensive downtown parking, a chance to relax and work on a lengthy commute from a distant location, the presence of a speed competitive transit option for their particular trip, accident safety concerns, or perhaps other factors; their choice set has not changed as significantly and, with the exception of an enhanced opportunity to substitute communication for travel or use TNC services, their probable change in choice is more modest. Thus, premium transit services that attract more choice riders have seen lower declines in ridership.

While these are believed to be the most significant factors that have systematically impacted transit ridership in the past four years, it is recognized that conditions vary across different areas, and changes in numerous of the myriad factors that influence ridership - as pointed out in earlier sections of this report - may be factors in explaining differential ridership trends across agencies. 


\section{Chapter 3. Responding to Declining Ridership}

The significant decline in transit ridership, coupled with the prospect that ongoing technology changes and demographic and economic trends that will challenge traditional public transportation going forward, have given rise to questions about how public transportation stakeholders should respond. This section explores that issue in more detail. While the motivation for understanding and responding to ridership declines for public transportation is self-evident, exploring the core motivations for providing public transportation in more detail helps reveal additional considerations that merit attention when contemplating appropriate responses. Accordingly, this discussion is broken into four main sections: 1) strategies to mitigate the decline in ridership, 2) strategies to offset the impacts of declining ridership, 3) positioning public transportation for a changing world and, 4) modifying transportation planning to address changing ridership. The initial discussion focuses most specifically on the data and information generated during this study. Part two focuses on identifying possible strategies public transportation stakeholders may consider for mitigating the consequences of declining ridership such that the goals associated with providing public transportation are not undermined. The third part focuses on strategic issues that stakeholders should be considering as public transportation positions itself in the evolving world of personal mobility. The last section notes some changings in how planning for public transportation might be carried out to reflect the changing world.

Translating the findings from the research tasks into guidance to public transit stakeholders is both the most challenging and the most critical aspect of this research. If the declines in ridership could be cleanly related to changes in service levels, fares, reliability or other factors within the control of transit agencies, it would be relatively easy to prescribe a matrix of actions that would be responsive to the various conditions across properties. However, there is compelling evidence that the current spectrum of conditions is unique. Technology is changing the travel options for travelers, in effect, increasing the competition for transit. This is compounded by a confluence of conditions that have enabled a significant increase in auto availability, allowing still more persons to have a fundamentally different travel choice set, and complicated by demographic and land use pattern changes. Many of these significant changes are modestly, or not at all, influenced by the transit levels of service and quality. Thus, sustaining and restoring transit ridership cannot depend wholly on undoing agency actions or fixing specific service problems. While ensuring quality services can diminish the ridership impact of the external changes by making transit more competitive, it may not undo or stop the ridership declines absent more aggressive actions to insure transit's competitiveness.

In practical terms, this might mean that an agency may not be able to attract the lost riders but may find ways to target new markets segments to increase transit use. Beyond what can be accomplished by that strategy, it also means that transit may have to move out of the comfort zone for many agencies and do two things that move beyond traditional operations. The 
reference to stakeholders in the introductory paragraph of this section was intentional as the entities that will need to be involved in responding to the challenges for public transportation going forward extend beyond the traditional transit operating agencies. First, it means that transit agencies may have to play a larger role in educating and advocating for actions regarding general governmental policies that impact the competitiveness of transit. This includes everything from funding levels to urban design policies, land use planning, transportation and parking pricing and policies that can shape the markets and their conduciveness to being served by transit. Second, it means that agencies may have to redefine their roles focusing on ensuring mobility opportunities for those who are unable to personally avail themselves of such opportunities, by influencing a spectrum of mobility options and partnerships. This may leverage public and private operations and involve roles as facilitators of partnerships, brokers of information, coordinators of service, regulators of safety, insurers of equity and, providers of user side subsidies, etc. Simultaneously, agencies will have to ensure continued productivity of traditional services in markets where volumes empower them to capture the resource efficiencies enabled by group travel and where high-capacity public transit services enable them to support the dense development patterns that are not sustainable if dependent upon low occupancy vehicle travel.

The consequences of declines in public transportation ridership extend beyond the simple loss of customers. Declines in ridership without proportionate reductions in service result in declining productivity or efficiency of public transportation services. This is particularly true in cases where services increase simultaneously with ridership declines, and is exacerbated if cost increases more than service supply changes. As Table 26 below reveals, the compounding of these trends can result in steep declines in public transportation performance metrics relevant to transportation policy making.

For example, the $7.4 \%$ decline in public transportation ridership in Florida between 2015 and 2016 , when coupled with the $1.8 \%$ increase in service supply, results in the $9.1 \%$ decline in ridership per revenue mile of service. Similarly, the ridership decline coupled with a $3.4 \%$ increase in operating cost results in an operating expense per passenger trip increase of $11.8 \%$. While certain response strategies might target the declining ridership, others might attempt to mitigate the consequences in terms of service efficiency or productivity, or attempt to offset unwanted changes in other performance metrics. 
Table 26 Service Productivity Implications of Public Transportation Trends

\begin{tabular}{|lrrc|}
\hline & 2015 & 2016 & Percent Change \\
Ridership & $270,776,337$ & $250,683,439$ & $-7.4 \%$ \\
Revenue miles & $145,701,039$ & $148,297,591$ & $+1.8 \%$ \\
Operating expense & $\$ 1,191,866,309$ & $\$ 1,232,858,715$ & $+3.4 \%$ \\
$\begin{array}{l}\text { Ridership per revenue } \\
\text { mile }\end{array}$ & 1.86 & 1.69 & $-9.1 \%$ \\
$\begin{array}{l}\text { Operating expense per } \\
\text { passenger trip }\end{array}$ & $\$ 4.40$ & $\$ 4.92$ & $+11.8 \%$ \\
\hline
\end{tabular}

Source: FDOT 2017 Florida Transit Information and Performance Handbook

Note: This data was used to include financial data which is fiscal year based. It represents the most currently available data. Ridership, service and cost trends for 2017 are likely to show even more pronounced impacts on service productivity.

In addition to traditional measures of service and cost effectiveness one could similarly expand the analysis to show that public transportation's consequences with regard to energy use, emissions, congestion mitigation, etc. would similarly show pronounced negative trends, which collectively undermine the motivations for public transportation investment or challenge the current model of delivering service.

Examples of strategies to offset the impacts of ridership declines might include efforts to scale service levels to match demand, reduce costs where possible to offset declining financial efficiency, or mitigate the deteriorating energy efficiency of bus public transportation by substituting smaller more fuel-efficient vehicles. While these efforts do not reverse the ridership trend, they nonetheless offset some of the negative impacts.

The recent ridership declines coupled with the impacts on travel from technology deployment (telecommuting, e-commerce, transportation network companies, and the prospect of mobility as a service and automated vehicles) indicate a need for public transportation stakeholders to comprehensively review how the goals and expectations historically addressed with public transportation services are best accomplished going forward.

Mitigating the Decline in Ridership

Considering the service and infrastructure investments in public transportation, a critical first step is to address the extent to which ridership improvements can be encouraged by leveraging 
the opportunities to influence travel behavior decisions. Accordingly, one should consider the full spectrum of known levers of influence over transit ridership. For example, the full spectrum of mechanisms for improving the availability and quality of transit service would merit consideration for increasing ridership. However, given what is known about ridership declines, one might attempt to focus attention on the prospect of reversing conditions with respect to those variables that have been shown to explain ridership declines witnessed over the past three to four years. For example, if service levels or fare levels were deemed to be significant contributors to ridership declines in a given market, one might strategize on ways to reverse service level declines or fare increases.

Such a strategy suggests one would want to map what is known about factors that contributed to ridership declines against factors or conditions known to influence transit ridership. With that mapping, one would then have insight into relative priorities or significance of various strategies. Several factors complicate this overall strategy:

1. These efforts, and others, have suggested that the phenomenon surrounding declining ridership are multifaceted and the ability to comprehensively diagnose and attribute causality in a quantitative sense is challenged by data availability and the inherent complexity of multifactor decision-making.

2. A growing body of research findings confirm that ridership declines are attributable to different factors in different markets. In some locations demographic changes, service changes, safety, or other factors have been shown to be significant factors, whereas in other markets different conditions apply.

3. Many of the phenomenon that have contributed to changing ridership are factors that are beyond the control of transit agencies and other stakeholders in a position to deploy policies and investments targeted at increasing transit ridership.

4. Finally, in an era of limited resources, one may seek out the most effective mechanisms for increasing ridership irrespective of their contribution to recent ridership declines. For example, policy makers would not aspire to undo the economic recovery that has enabled increased auto ownership, nor to impede the improvements to mobility enabled by transportation network companies (TNC). Thus, addressing ridership declines does not necessarily Addressing ridership declines does not necessarily mean undoing the changes in conditions that contributed to those declines.

mean undoing the changes in conditions that contributed to those declines.

This discussion of factors influencing public transit ridership relies on a framework to array the various factors and provides a table of contents for discussing possible responses to ridership 
declines. Several different frameworks are possible. For purposes of this project, the categorization of factors outlined earlier in this document is used to frame the discussion. Figure 44 portrays the factors that are known to influence individual travel behaviors. Hosts of economic, demographic, technological, cultural and other factors influence the respective attributes of travel options and traveler conditions that ultimately lead to travel decisions. Historically, travel time and cost have been the dominant factors in our understanding of travel behavior and the factors that we have been most able to quantify and model in transportation planning. However, it's increasingly recognized that travel decisions are influenced by a host of factors. New business models such as transportation network companies (Uber, Lyft, etc.), new features such as electronic fare, parking, or toll payment, and new options to substitute communication for travel (telecommuting, e-commerce, distance learning, etc.) fundamentally change the flexibility, image, convenience, safety, and other attributes that influence individuals' travel decisions.

Collectively, this set of factors in the context of considerations that travelers have when making travel decisions, shape our thinking regarding influencing future transit ridership.

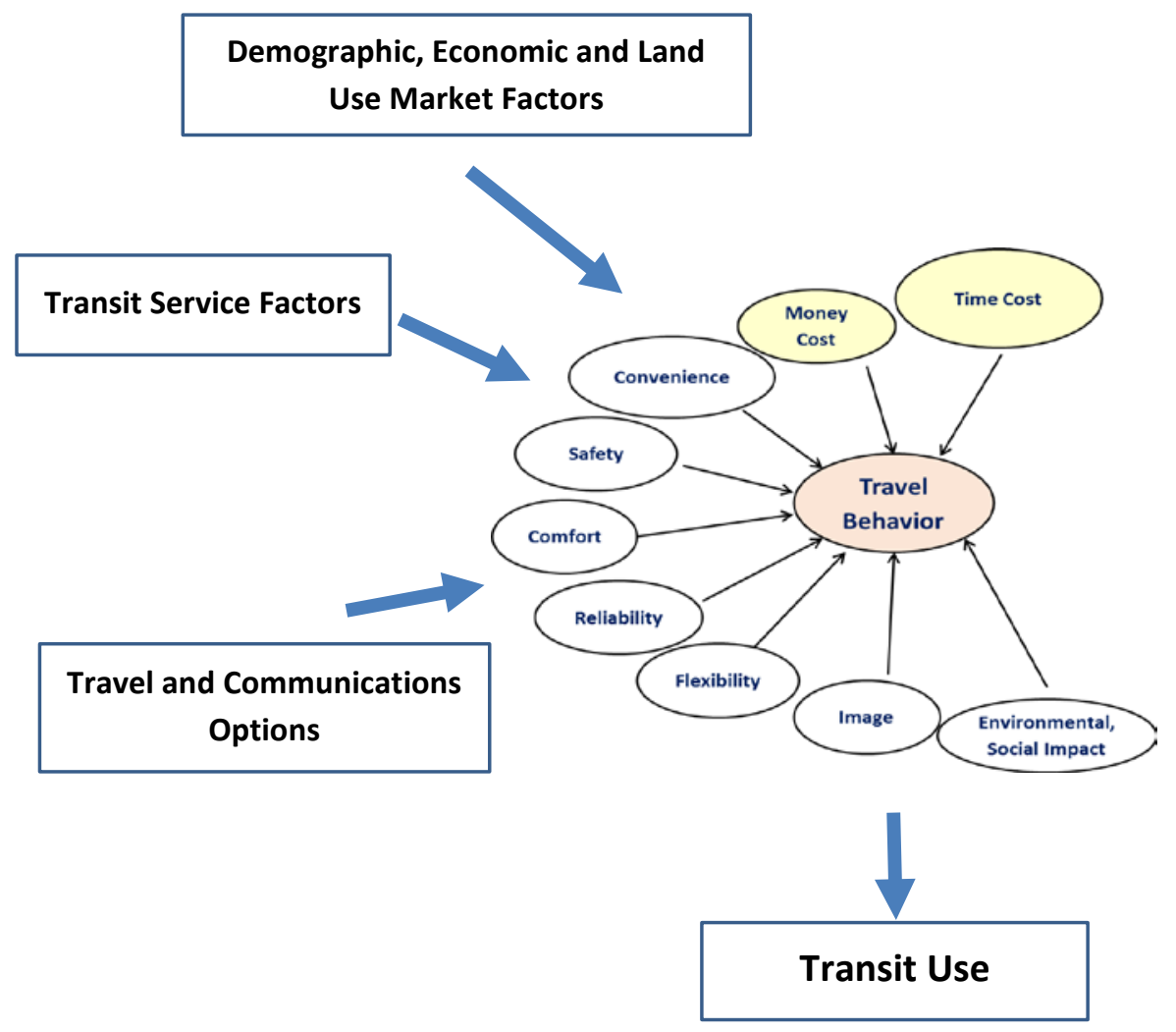

Figure $\mathbf{4 5}$ Conceptual Interrelationships between Transit Use and Contributing Factors Source: CUTR

Before delving into specific strategies, it's important to recognize that the ridership trend through September 2018 still seems to be intact for many transit properties. Nationally, 
ridership through July 2018 continued down at an accelerating rate. Within Florida, Miami ridership, as noted, has remained weak. Other properties are having different experiences, some having stabilized ridership. The absence of a disruptive hurricane in strong transit markets this year should favor more positive year-over-year ridership trends for September and October. However, some of the fundamental underlying trends, increasing car ownership, growing market penetration of transportation network companies, and continued population and employment growth in areas more distant from the highest quality transit service, will continue to impact public transportation. Somewhat higher fuel prices may provide modest incentives for greater transit use. In addition, transit agencies, having suffered significant ridership declines, are modifying services to optimize routes and in some cases reducing service to more appropriately correspond with demand. Service reductions will inevitably hurt ridership. However, efforts to restructure and reprioritize service may help to mitigate ridership impacts of service changes. Thus, the discussion of restoring ridership should be prefaced with a recognition that in many cases a near-term goal is to stop the ridership declines.

The first element of this discussion will focus on transit service factors. These are the actions that are most within the control of transit agencies and the actions that have gotten the most attention within the transit community, as they can be influenced by transit agencies and may be changed relatively quickly. The list of relevant variables is characterized in Table 27. 
Table 27 Factors that Impact Transit Ridership

\begin{tabular}{|c|c|}
\hline & Supply Factors - Transit Service Characteristics \\
\hline & Geographic coverage: Coverage and density of network \\
\hline$\underline{\underline{\underline{\underline{Z}}}}$ & Frequency of services: As it impacts wait and transfer times \\
\hline 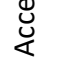 & Temporal span of service: Availability of service by time of day and day of week \\
\hline$\sum_{\frac{1}{2}}^{0}$ & Network configuration/connectivity: Optimality of network in connecting origin-destination pairs \\
\hline & Speed of in-vehicle travel: Speed as impacted by operating speed and stop spacing \\
\hline \multirow{7}{*}{ 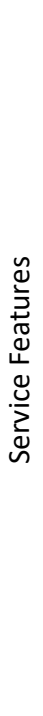 } & $\begin{array}{l}\text { Fare level and structure: Fare levels and structure (time, distance, frequency, transferring, employer and } \\
\text { tax treatment, etc.) }\end{array}$ \\
\hline & Comfort, cleanliness, crowding: \\
\hline & $\begin{array}{l}\text { Convenience as impacted by information: Trip planning, real time information, payment ease, Wi-Fi } \\
\text { availability, }\end{array}$ \\
\hline & Reliability: Arrival reliability, trip time reliability \\
\hline & Safety and security: Personal safety accessing and using transit, accident safety when using transit \\
\hline & $\begin{array}{l}\text { Awareness, image, visibility, etc.: Knowledge of transit choice, stigma/image (modern, socially inclusive, } \\
\text { environmentally friendly, etc.) }\end{array}$ \\
\hline & $\begin{array}{l}\text { Access/egress amenities: Shelter, lighting, landscaping; first-mile/last-mile accommodations, customer } \\
\text { services/amenities; etc. }\end{array}$ \\
\hline
\end{tabular}

\section{Paratransit and Demand Responsive Services}

The bulk of the discussion in the subsequent narrative will focus on fixed route transit services. Paratransit services and other services designed for specific market segments are fundamentally different in terms of supply and demand characteristics as well as ridership trends. The declines in ridership have focused on fixed route services. Paratransit service demands are most typically associated with market characteristics and supply characteristics. The quality, availability, and pricing of service in combination with the size of the market segment that is eligible for these services determines demand. The fundamental economic and technology trends that have been discussed have not fundamentally impacted the competitiveness of highly publicly subsidized paratransit services relative to personal and private sector alternatives. Hence, ridership volatility of paratransit services has not been meaningfully impacted.

\section{Service Accessibility}

The term service accessibility as used in this report embraces service supply factors for public transportation as noted in the top section of Table 27 above. Historically, service supply has 
focused on geographic coverage, temporal span of service, and service frequency. The concept of network configuration/connectivity is added to reflect the fact that accessibility to activities is also influenced by the fundamental nature of the network (for example, grid versus radial versus hybrid) relative to the distribution of trip ends. In-vehicle speed is also added as speed influences travel time and travel accessibility.

At the most basic level, public transit accessibility changes if some of these service accessibility features change or if the activity patterns/market characteristics change. As activity patterns and market characteristics change more slowly, this discussion first focuses on service characteristics. In response to ridership changes, many agencies systematically evaluate service performance and seek to modify service traits to optimize ridership. The magnitude of ridership changes has resulted in agencies more comprehensively scrutinizing their service characteristics. Jacksonville, Tampa, Sarasota, and others have comprehensively reviewed service in light of changing ridership.

There are some fundamental principles of transit service that need to be considered in the context of understanding how ridership demand will respond to changes in service. Subject to some political or equity constraints, transit agencies try to focus their service on the most promising markets both geographically and temporally. This has historically resulted in service in high-density corridors and focusing on rush hour time periods. Increases in service, be it serving new geographies, increasing the hours of operation, or increasing the frequency, almost by definition serve less promising markets unless the initial service is miss-targeted. Thus, expanded services tends to attract, on average, fewer customers per unit of service provided relative to the pre-existing base service. This phenomenon is borne out in empirical data as reported in TCRP $95^{10}$. Expanded service can attract additional customers and certainly benefits customers, but typically results in declining service productivity.

The second challenge associated with growing transit ridership relates to the inherent challenge associated with expanding ridership in a market that is highly dependent on "captive" travelers. For purposes of discussion, the term captive as it refers to transit riders is associated with individuals who cannot drive and/or do not have vehicles available for providing their own mobility. These individuals are captive to transit in that their choice set for traveling is far more limited than individuals who have vehicles available, thus, their probability of using public transportation is far higher. Captivity is subjective and influenced by the spectrum of household characteristics and trip characteristics. Someone whose activities are within walking distance is

\footnotetext{
${ }^{10}$ Traveler Response to Transportation System Changes Handbook, Third Edition: Chapter 9, Transit Scheduling and Frequency
} 
not captive to transit nor is someone who has access to vehicles from other households or other household members who can assist them in providing their mobility. Similarly, a household with multiple travelers and only one vehicle may leave certain individuals in situations where their travel is captive to public transportation but not all their travel is. Individuals with a limited choice set are far more likely to choose transit. The data bears this out with dramatically higher transit use for individuals in zero-vehicle households and half or more of transit trips in Florida being made by individuals who could be characterized as captive based on NHTS or onboard survey data.

The relevance of this characteristic is that those travelers who are categorized as captive arguably are currently using transit service to a significant extent, to accommodate their travel needs. Improvements in service may induce additional trips or may result in some mode shift, for example, no longer begging rides from neighbors but rather using the improved transit service but is unlikely to result in meaningful increases in transit use amongst that market segment. Geographic service expansion to serve more individuals who might be characterized as captive may increase ridership, but individuals previously without service likely have found some means of meeting their travel needs prior to service expansion thus, the increased ridership may be moderate. Given that phenomenon, the ridership response to service expansion would need to attract additional choice travelers, where choice travelers are defined as those individuals who have travel options including auto availability but now might find the transit choice more attractive. The challenge for public transportation is being able to design service improvements that are sufficiently attractive to enough new choice riders to create a meaningful improvement in transit ridership. Unfortunately, in many markets, the level of competitiveness of public transportation is such that marginal improvements are not sufficient to make public transportation a competitive option for choice travelers.

Table 28 below identifies target market segments for transit service improvement. It acknowledges a continuum between individuals who are highly dependent on public transportation to those who have numerous choices and only use public transportation when it offers a competitive advantage relative to their values set. Each market segment is discussed below. 
Table 28 Target Markets for the Service Improvements

\section{Transit Dependent $\rightarrow \rightarrow \rightarrow \rightarrow \rightarrow \rightarrow \rightarrow \rightarrow \rightarrow \rightarrow \rightarrow \rightarrow \rightarrow \rightarrow$ Transit}

Stabilize Transit Dependent Market

Improve hours, frequency, coverage, connectivity, and speed to discourage transit dependent from seeking alternatives (auto ownership, TNC use, etc.).

\section{Induce Transit Dependent Trips}

Improve hours, frequency, coverage, connectivity, and speed to induce greater use by transit dependent.

Target Transit Dependent in New Geographies

Improve coverage, hours, frequency, connectivity, and speed to target transit dependent in new areas where gentrification or dispersion has resulted in concentrations beyond traditionally strong core urban areas.
Target Choice Travelers to Special Generators

Target service improvements to areas where parking cost and availability, site congestion, or other features make transit potentially competitive. (Airports, convention centers, arenas, major intermodal facilities, etc.

Target Premium Services to Longer Distance Trips Where Transit Can Be Time Competitive

Longer distance trips allow travelers to amortize the access and egress times over a longer invehicle time where they may garner time savings.

Target High-Quality Services to Transit Friendly Areas Where High Activity Levels Enable Productive Service and an Opportunity for "captive by choice" Markets

Some communities have dense areas where high quality transit service could be operated productively and competitively enabling persons who favor an auto free or auto light lifestyle.

Stabilize Transit Dependent Market - as transit ridership has continued to decline, a priority for many transit professionals has been to stabilize existing markets. As noted previously, the list of factors that have contributed to declining ridership are context specific. Also, many of those factors are beyond the immediate control of transit agencies. However, most ridership decisions influenced by multiple considerations. For example, while improved economic conditions may have enabled more households to purchase additional vehicles, part of the motivation for such decisions is inevitably partially attributed to the quality of transit service available. Nationally, headlines regarding such things as service disruptions, crime and homelessness creating a hostile environment, deteriorated physical conditions impacting comfort and safety, and related factors may be contributory. In Florida, there are no highly visible compelling factors to suggest service quality deterioration has been a meaningful explanatory factor in ridership declines.

Nonetheless, excellence in execution and a disciplined focus on the most promising services will continue to be transit agency priorities. This might include relatively modest refinements in 
routes and schedules to make sure that service is best meeting the needs as activity patterns change in a given market. One of the strategies toward this and has been to expand hours of operation with better evening and weekend service levels. This recognizes that individuals have activities beyond traditional workday schedules and accommodating these needs lessens the motivation of these individuals to become vehicle owners.

Nonetheless, the magnitude of the increase in accessibility and convenience in travel for new owners of autos versus those dependent on transit is so compelling that modest improvements in transit may have modest or no impact on the motivation of individuals to attain vehicles if changes in economic situations enable that possibility. The research team is unaware of any literature that explores the sensitivity of vehicle ownership decisions for captive travelers to the level of transit service available.

Induced Transit Dependent Trips - improved services for existing transit target markets can enhance ridership by virtue of attracting additional trips to transit from those customers. Better frequency and/or expanded hours, for example, may encourage travelers to utilize public transportation more frequently. This might mean switching from bike and walk trips, using public transportation in lieu of riding with somebody else, or simply making new additional trips due to the convenience of better transit service. While these can increase transit ridership, the market response is likely to be modest as this market segment already uses transit substantially.

Target Transit Dependent in New Geographies - this strategy refers to targeting frequent transit users, often transit dependent persons, in geographies beyond those traditionally associated with transit dependents. This strategy is an outgrowth of the realization that residential settlement patterns have changed in recent years due to significant changes in real estate markets. Specifically, re-gentrification of many core urban areas coupled with housing shortages has led to housing rent and ownership costs in core urban areas - long the focus of high-quality transit service - becoming unaffordable for the transit dependent population. Policies encouraging the dispersion of public housing have contributed to transit ridership changes as low-income households that have long been clustered in dense urban housing, increasingly are moving to more dispersed lower density housing in city fringe and inner ring suburban communities. Changes in settlement patterns of immigrants as well as changes in locations for entry-level employment opportunities are altering the traditional patterns of travel for low-income households who are most conducive to using public transportation. It behooves public transportation agencies to closely monitor demographic trends in the respective communities to fully understand how travel patterns are changing. Adapting service patterns to accommodate travel needs of markets with a high propensity to use public transportation provides an opportunity to restore or mitigate declines in ridership in some 
markets. However, to the extent that high propensity transit users are more dispersed, service expansion to reach these markets are likely less productive than in dense areas.

Target Choice Travelers to Special Generators - this strategy relates to identifying specific market segments where transit may provide a competitive option for choice travelers. This would apply to situations where there is unique situation such as high-priced parking, significant congestion, venues where travelers may want to consume alcohol and not drive, situations where the individual does not have access to their vehicle (after airline travel to an away from home destination) and similar situations where transit can compete. Examples would include access to and from airports or other intermodal terminals, access to arenas, stadiums, convention centers or similar venues. Often these services can attract both the workforce at these venues as well as customers who might not be motivated to use public transportation for more traditional trips.

Target Premium Services to Longer Distance Trips Where Transit Can Be Time Competitive choice travelers tend to use faster transit services because these services are more competitive and because these travelers are often traveling long distances, for example from a suburb to a central business district job, where the longer trip length is conducive to higher speed express or exclusive guideway public transportation options. As the sum of access time, egress time, and wait time for a transit trip exceed in-vehicle travel time; longer distance trips enable the access, egress and wait time to, in effect, be amortized over a longer in-vehicle travel time where this longer block of time offers the benefits of using that time more productively than if one were driving. To the extent that the transit may be faster than driving during the line haul portion of the trip if it has an exclusive travel way, it provides an opportunity to make up for some of the time spent in access, wait, and egress.

These situations tend to occur in larger Metropolitan areas where high concentrations of destinations such as a strong central business district can support premium services from distant locations. Unfortunately, the dispersion of employment in many metropolitan areas in Florida make it difficult to support high-quality premium services to these destinations as there is often not sufficient trip density to support the capital investment to enable premium services.

Target High-Quality Services to Transit Friendly Areas Where High Activity Levels Enable Productive Service and an Opportunity for "captive by choice" Markets - some communities or geographies within communities have traits that make them conducive to public transportation services being successful. These characteristics would include substantial densities and traits supportive of public transportation, including strong pedestrian and bicycle access opportunities, amenities to complement transit (shelters, bike storage and vehicle drop off, attractive facilities, etc.), and other features often characteristic of a transit-oriented 
development (TOD). These geographies might be characterized by difficulty finding parking or parking costs at both the home and the destination end of trips. Such areas might have mixed land uses, the probability of strong market penetration by transportation network companies and perhaps bikeshare, scooter, short-term car rental opportunities. In addition, such areas might attract concentrations of individuals who support the social and environmental benefits of public transportation and are more conducive to use such services. In some instances, communities may work to develop one or more of these areas to offer that type of community environment, often appealing to millennial's, amongst the portfolio of community types in the broader metropolitan area. Public transit services in these areas might accommodate trips for a variety of purposes and might consist of circulator services as well as strong public transit connections to other major destinations in the region.

Such markets are relatively unique across metropolitan areas and as such, policies for service provision would have to enable special treatment of communities that have features that offer a promise of meaningful ridership response.

\section{Service Features}

Table 27 references a host of service features that would influence various factors in the mode choice decision. Transit agencies are continuing to pursue numerous initiatives designed to increase the visibility, convenience, comfort, reliability and other characteristics of public transportation service in an effort to make it more attractive. These ongoing initiatives offer promise particularly in making transit more attractive to choice travelers. While these features can each individually influence some travelers, none are considered transformative. In general, these features can attract marginal travelers if the core service attributes are sufficiently attractive such that transit travel is a viable option in the choice set. More specifically, the service must access the desired destinations, be available at the time desired and offer a travel speed that doesn't dramatically impede the competitiveness of transit. These preface conditions are most often the constraint to greater transit use.

It's also important to note that several of the service features referenced in Table 27 are influenced by factors well beyond the control of the transit agency. The perceived and actual personal safety accessing and using the service as well as certain aspects of the comfort are associated with broader social cultural phenomenon. Homeless persons, persons with mental health and other disabilities, and persons who suffer from extreme poverty often congregate at transit facilities and use transit services - sometimes as a respite from hot or cold weather. This phenomenon, which is associated with broader governmental policies on how to deal with untreated social and public health problems, undermines the desire of some travelers to utilize public transit services. Transit agencies can play a role in addressing these problems, but such actions typically incur costs and require collaboration with other governmental entities. 


\section{The Trend toward Service Reconfiguration}

Several transit agencies across the country have reconfigured their transit networks in response to ridership changes. The general trend has been to focus on simplifying networks, speeding up services by eliminating circuity and reducing stop frequency, and expanding hours of operation and frequencies to make transit a more robust choice. Such initiatives have met with varying success and are currently the subject of a Transit Cooperative Research Program analysis. Some caution is in order for agencies considering this strategy. The fundamental premise is that these modifications result in more competitive services such that new customers attracted to the service by faster operating speed and better service availability would outnumber those lost due to service declines in certain geographies, or the necessity of longer walk access in situations where stop frequency was reduced and circuity was diminished which de facto resulted in some customers having longer access and egress trips. Markets that are highly dependent on captive travelers, and whose levels of service and market conditions are such that marginal improvements are unlikely to attract choice travelers, may not benefit as much from this service modification strategy.

Figure 45 portrays the relationships between service frequency and probability of taking transit for transit captive and choice markets. These lines characterize possible behavioral responses. They are not based on hard empirical data, but they are informed by extensive review of travel behavior information. In areas with high quality transit service the probability of using transit becomes considerably higher for choice travelers. The purpose of differentiating between captive and choice travelers is to suggest that the sensitivity of these market segments to service quality is very different. Only when service becomes highly available as represented by very high frequencies, is it likely that choice travelers will find service attractive. Obviously unique situations such as commuter rail services to large central business districts may deviate from these relationships, but in general, they characterize historical data on travel behavior. 


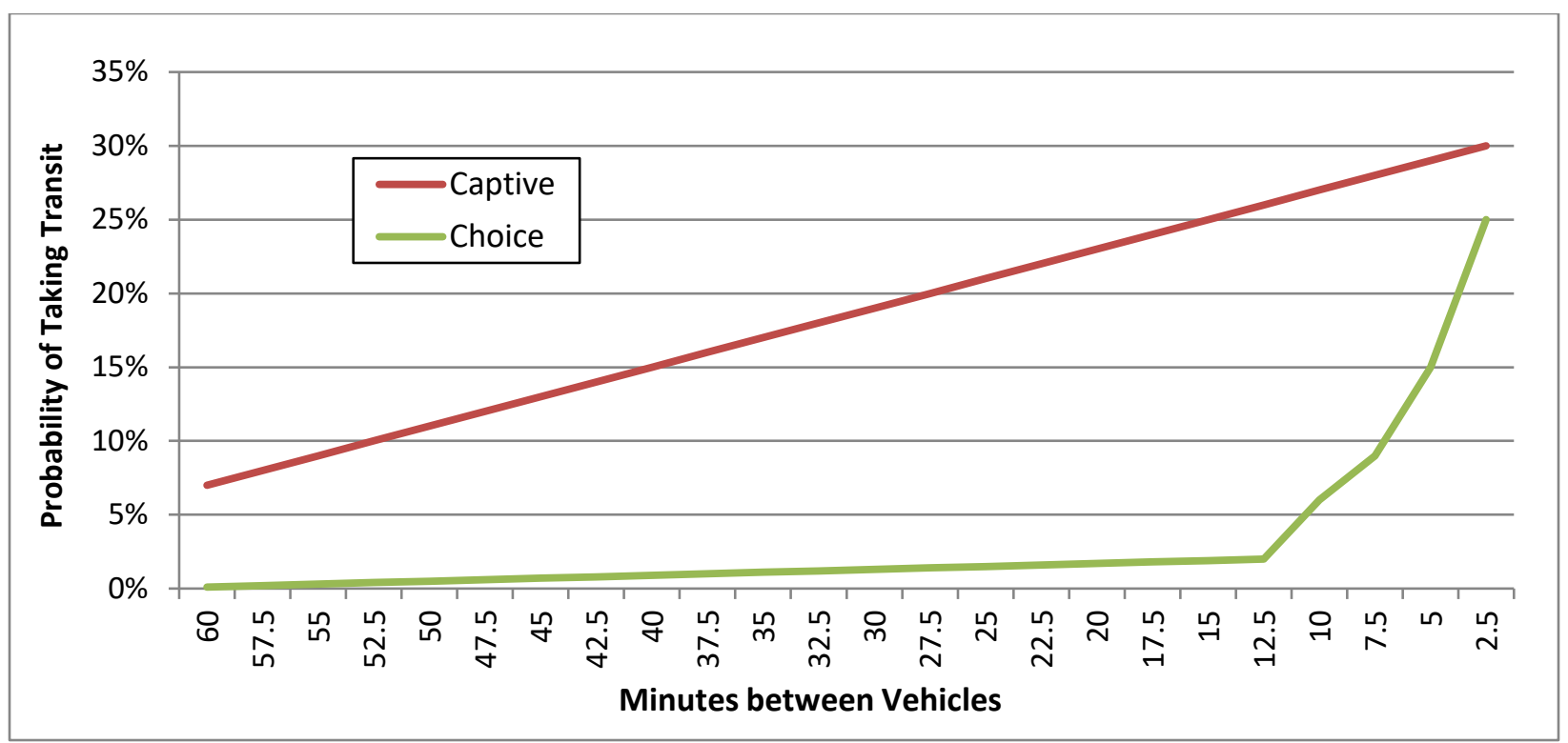

Figure 46 Probability of Using Transit Versus Service Frequency for Captive and Choice Travelers

Figure 46 builds on this by focusing specifically on the relationship for choice travelers. As the graphic portrays, the challenge with providing the high frequencies that are attractive for choice travelers is that unless the development pattern is very dense, the volume of trips generated that can potentially be attracted to transit is not sufficient to enable that frequency of transit to be productive. The challenge in many Florida communities is that activity density is not high enough to justify the qualities of service that become attractive to choice travelers. Good service is a prerequisite to higher mode share for choice travelers, but intense development is a prerequisite to having sufficient demand to make high-quality services economically sustainable. 


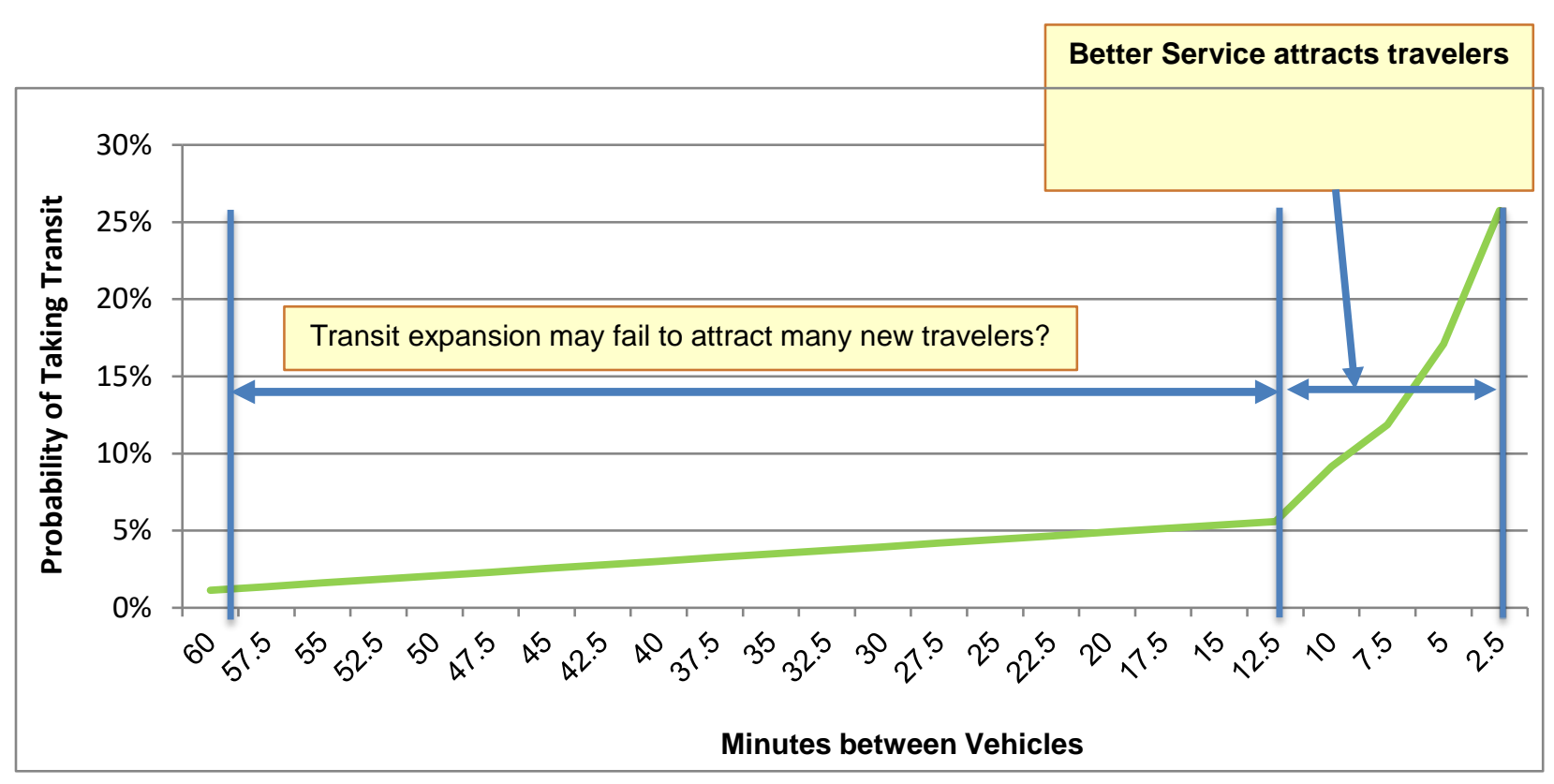

Figure 47 Probability of Using Transit versus Surface Frequency for Choice Travelers

This discussion is not intended to discourage service reconfigurations, but rather to encourage transit planners to understand and evaluate the market carefully to enhance the probability that service modifications offer a meaningful opportunity to expand ridership.

\section{Demographic, Economic and Land Use Market Factors}

Table 29 itemizes several factors regarding demographic, economic and land use conditions that influence transit ridership. These factors generally are beyond the direct influence of transit operators. Absent catastrophic events, land use patterns change relatively slowly, and accordingly cannot be dominant factors in rapid changes in transit ridership trends. Similarly, most demographic factors also change slowly as aging, household structure shifts, immigration and migration patterns, and other factors shift population profiles in neighborhoods and regions.

Economic conditions can change more rapidly as the economy cycles. Certain elements, for example fuel prices, can fluctuate quickly and significantly in response to international events. However, these factors are generally beyond the influence of transit agencies.

While these conditions do not appear to be significant in explaining the past four-year trend in ridership in Florida or nationally, various research has linked these phenomena to longer-term trends in transit ridership. At the national level, work carried out by CUTR traced the influence 
of aging population and migration shifts on transit ridership trends ${ }^{11}$. As people age, they tend to travel less and the probability of using public transportation declines. The peak years for transit use are young adults. Young adults are less likely to own automobiles, more likely to be cost sensitive, and may disproportionately have other traits such as urban living preferences and schedule independence that enable them to use public transportation more easily than might be the case for older adults with parental time constraints. As the mean age of the population continues to increase, it has a subtle negative effect on transit use.

Table 29 Factors that Impact Changes in Transit Ridership

\begin{tabular}{|c|c|}
\hline \multicolumn{2}{|r|}{ Demand Factors - Demographic, Economic and Land Use } \\
\hline \multirow{3}{*}{ 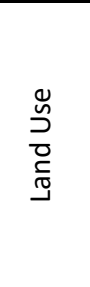 } & $\begin{array}{l}\text { Geographic distribution of population/activity with respect to transit service areas: Urban versus rural, in } \\
\text { low versus high service areas (regional scale). }\end{array}$ \\
\hline & $\begin{array}{l}\text { Geographic activity distribution within transit service areas: Concentration near higher quality service } \\
\text { locations (neighborhood/stop scale, TOD) }\end{array}$ \\
\hline & Geographic activity patterns: Clustering/concentration, origin-destination balancing \\
\hline \multirow{4}{*}{$\begin{array}{l}\frac{\tilde{c}}{\frac{1}{2}} \\
\frac{0}{0} \\
\frac{0}{00} \\
0 \\
0 \\
\frac{\varepsilon}{0} \\
0\end{array}$} & $\begin{array}{l}\text { Age, household composition/structure, employment status: } \\
\text { Factors that influence travel levels, preferences and available choices }\end{array}$ \\
\hline & $\begin{array}{l}\text { Income, wealth, home ownership status, vehicle ownership status: Factors that influence travel levels and } \\
\text { options/preferences }\end{array}$ \\
\hline & Race, Ethnicity, gender, citizenship status: Factors that may influence travel options and preferences \\
\hline & $\begin{array}{l}\text { Changes in core values (safety, reliability, flexibility, convenience, image, autonomy, etc.): Changes in } \\
\text { culture or preferences (independent of socio-demographic changes) that influence choices }\end{array}$ \\
\hline \multirow{3}{*}{ 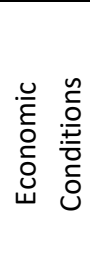 } & $\begin{array}{l}\text { Economic activity: Employment, disposable income, job security, consumer confidence - factors that } \\
\text { affect activity levels }\end{array}$ \\
\hline & Fuel prices: Impacts mode choice and household disposable income \\
\hline & $\begin{array}{l}\text { Interest costs/availability: Factors that affect home/vehicle ownership decisions and subsequently impact } \\
\text { travel decisions }\end{array}$ \\
\hline
\end{tabular}

Several characteristics of the geographic distribution of populations have also garnered the attention of transportation planners. Longer-term migration trends have resulted in shifts in population from Northeastern and Midwestern geographies that were denser and more richly served with public transportation than are the common destinations such as Florida, Arizona, Texas, and California where transit services are not as mature and land-use/activity patterns

11 (With Kurt Lehman, Richard Driscoll, Jodi Godfrey) "The effects of Demographic Changes on Transit Ridership Trends," Conference Proceedings, Presentation, TRB Annual Meeting Session 697 - Integrating the Data into Public Transportation Service Planning Process, Washington DC, January 9, 2018. 
are generally not as conducive to public transit use. The population has been becoming more urban which is conducive to transit use.

In addition to broader national population distribution trends, planners are increasingly paying attention to the distribution of populations in urban areas, particularly those population segments most conducive to the use of public transportation. The past ten years has seen substantial interest in the CBD centric residential development highly visible by virtue of the presence of condominium and apartment towers in central business districts - many of which had not seen new office employment buildings for several years to decades. Contemporary media was flooded with stories about millennial residential preferences for urban areas with characteristics conducive to public transportation - walkability, transit service availability, dense activity patterns, and often bike, TNC, and other travel options that make auto ownership less attractive and less necessary. More recently, evidence is suggesting that as millennials age and the economy improves, housing location preferences are more closely mirroring prior generations where affordability and space favor suburban locations for young families. Perhaps more critical, researchers are beginning to hypothesize that the millennial generation priced many people with a high transit use propensity out of urban core residential locations. These new residents, often with more resources than those they replaced, do use transit but not to the same extent as individuals who have sought lower-cost housing at a farther distance from neighborhoods traditionally well served by public transportation. The consequence is hypothesized to be that these displaced, previously transit dependent households are now more motivated to become auto owners in light of diminished transit accessibility in their new residential locations. Researchers and institutions such as UCLA and Georgia Tech are beginning to explore the hypothesis that traditional transit captive residents are dispersing.

In addition to residential location trends, employment and activity location trends are equally relevant in terms of understanding changing transit accessibility. Employment continues to disperse with central business districts comprising a declining share of total regional employment in virtually every Metropolitan area. The absence of a standardized definition for central business districts precludes systematic assessment of this phenomenon across geographies absent reliance upon individual Metropolitan areas self-determining geographic boundaries and employment levels in their central business districts. Many strong employment growth areas; high-tech industries, healthcare, tourism and other related services, continue to grow across metropolitan areas. Fulfillment centers, for example, tend to employ large numbers of low- and moderate-income individuals and are located in suburban or fringe locations - often areas where public transit service is not robust.

It is well recognized in public transportation that transit use is greatest among younger persons who often do not have the resources to have automobiles and live in environments where transit use is a viable alternative. It is not uncommon that young people age out of using public transportation as their circumstances change such that they are less likely to use transit. This 
phenomenon results in transit having to cultivate new riders among the young population on a continuous basis to replace those that are transitioning away from public transportation. The post-millennial young person cohort is markedly smaller than the millennial cohort, thus challenging transit agencies. In addition, the pace of immigration, often another source of young workers with an inclination to use public transportation, may be moderating. Data indicates that the educational levels, source country, and settlement destinations of immigrant populations might be shifting. Historically, moderate- and low-income immigrants settled in some of America's largest cities and were able to take advantage of robust public transportation systems. It is less clear that the same trend is continuing. A rich understanding of immigration trends is limited due to data availability associated with confidentiality and undocumented immigrants being unwilling to provide data. This hypothesis provides further validation of the need to monitor emerging demographic trends and settlement patterns.

Many of the economic conditions that influence travel behavior are beyond the control of the transit agencies, and in many cases beyond the control of local and even state policymakers. However, there are some specific economic considerations that do influence transit use and are subject to policy decisions. Two elements of transportation cost are influenced by public policy, auto insurance and fuel costs. Auto insurance is a meaningful component of overall auto ownership and use costs, and occasionally a barrier to entry into auto ownership. Florida is regularly ranked amongst states with the highest shares of uninsured motorists. The most recent data show Florida as having the highest share, $26.7 \%$ of uninsured motorists. These are individuals whose cost of driving is lower than it should be while simultaneously increasing insurance and driving cost for those responsible individuals who have insurance. While it is disheartening to think of pricing people out of auto availability by virtue of enforcing insurance requirements, the practical reality is that enabling people to drive without adequate financial resources burdens others and may be undermining public transit use.

About one in eight drivers on the road in 2015 was uninsured, according to the latest data from the Insurance Research Council (IRC). The nationwide uninsured motorist (UM) rate increased from 12.3 percent in 2010 to 13 percent in 2015. Uninsured motorist rates varied substantially among individual states, ranging from 4.5 percent in Maine to 26.7 percent in Florida.

\section{Uninsured Motorists, 2017 Edition, Insurance Research Council (IRC)}

The second element of public policy relates to energy pricing and policy. Fuel costs are a significant share of vehicle operating costs, often in the range of $15 \%$ to $20 \%$ of total vehicle ownership costs. These costs fluctuate over time depending upon fuel price and the basis of estimating auto ownership costs. Energy pricing and taxing are influenced by local state and particularly national policy. For example, the relative affordability of fuel in the U.S. compared to Europe is a significant factor in vehicle ownership and use differences across these geographies. The run-up in fuel prices during the recession 
contributed to constraints on vehicle affordability during that time period. As fuel prices decreased simultaneously with the improvements in the economy, households had significant additional discretionary funds, some of which were used towards increasing vehicle ownership and use. Should environmental or other considerations including market forces, result in meaningfully different energy prices, it could influence vehicle ownership and use in the future.

Travel and Communication Options

As noted in the prior section, perhaps the most unique characteristic of the current trend in declining transit ridership is the fact that there has been a significant change in travel choices for consumers. Table 30 reviews factors that are changing the choice set for travelers. This change in choices has been empowered by several advances in technology that have enabled the substitution of communication for travel as well as enabling new technologies and business models to significantly change the choice set of travel options. Most obvious amongst these is the opportunity to utilize smart phones to hail transportation network company vehicles with convenient payment, strong logistics and attractive pricing. These technologies have enabled the sharing of transportation assets and a fundamental break from the auto ownership model of transportation where high fixed costs and low variable costs shape travel decisions, versus a cost structure where full costs are amortized and priced by trip or trip distance.

At the national level, the media took notice when the share of workers who reported working at home in the American Community Survey in 2017 surpassed the share that reported public transportation as their usual mode to work. This trend is indicative of the enhanced capabilities of substituting communications for travel for many purposes. In addition to work, growth in e-commerce, distance learning, socialization via software platforms and Internet connectivity, and rapid communication of video, audio, and document materials have enabled diminished travel, which can impact the extent of transit use. Public transportation agencies and stakeholders are not in a position to influence the extent of communication substitution for travel on public transit, nor is there a compelling motivation to do so, as communication substitution for travel is environmentally benign, cost-effective, and not associated with other negative externalities. There is not a knowledge base with respect to understanding the extent to which transit users are substituting communications for travel. Public transportation stakeholders should support efforts to more fully understand these travel behavior trends. 
Table 30 Factors that Impact Transit Ridership

\begin{tabular}{|c|c|}
\hline \multicolumn{2}{|c|}{ Supply Factors - Travel and Communication Options } \\
\hline \multirow{4}{*}{ 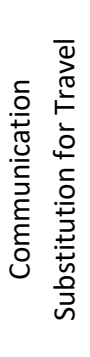 } & Telecommuting/work-at-home: Changes in commuting travel levels \\
\hline & E-Commerce and banking: Foregone travel via online shopping and banking \\
\hline & $\begin{array}{l}\text { Electronic communications of video, audio, and document materials in lieu of travel: E-learning, online } \\
\text { banking, electronic document transfer, video and music streaming, etc. }\end{array}$ \\
\hline & $\begin{array}{l}\text { Social Networking: Electronic interaction in lieu of in-person social interaction (text, tweet, skype, Facebook, } \\
\text { Instagram, etc.) }\end{array}$ \\
\hline \multirow{8}{*}{ 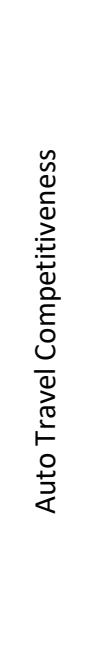 } & $\begin{array}{l}\text { Vehicle cost and availability: New/used vehicle prices, interest cost and financing availability, vehicle } \\
\text { reliability/maintenance cost }\end{array}$ \\
\hline & Licensure/Insurance considerations: Costs, government policies (age, immigration status, etc.) \\
\hline & Parking cost and availability: \\
\hline & Travel time/speed and reliability: Congestion, incident frequency, mechanical reliability \\
\hline & Safety and security: \\
\hline & $\begin{array}{l}\text { Change in features and amenities: Comfort/convenience features (Wi-Fi, navigation, toll/parking payment } \\
\text { connectivity, vehicle telematics, etc.) }\end{array}$ \\
\hline & Fuel Cost: \\
\hline & Stigma, Image: Perceptions of environmental impacts, social impacts, status, etc. \\
\hline \multirow{4}{*}{ 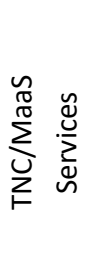 } & TNC Availability: Temporal and geographic availability, arrival time \\
\hline & TNC Access: Banking arrangement, smartphone availability, vehicle accessibility for mobility limited, etc. \\
\hline & TNC Cost: \\
\hline & Bikeshare, scooter share, short term auto rental, etc. - availability, accessibility, and cost \\
\hline
\end{tabular}

With respect to changes in the competitiveness of automobiles, public transportation stakeholders should recognize that many of the technologies that benefit public transportation, for example onboard cameras, in vehicle Wi-Fi, convenient navigation and fare payment, have analogies in auto travel where Wi-Fi hotspots, navigation, electronic parking and toll collection and other features mean the competitors to public transportation continue to improve. Similarly, ongoing improvements in safety related technologies are enabling auto travel to become safer. While the continued addition of amenities and features to public transportation can support increased ridership, planners need to recognize that characteristics of other travel choices are also improving over time. 
Pricing of Transportation

At the local, state and federal level, there is a strong consensus that our infrastructure is inadequate in both condition and capacity. Direct, transparent, user-based fees for providing transportation infrastructure are best positioned to influence travelers' mode choice and other travel behavior decisions. At the federal level, general revenue funds are subsidizing transportation investments and underinvestment is widely recognized by the public and policymakers. Arguably, underinvestment and the associated reluctance to increase user fees via fuel taxes or other means at the state and local level, further result in underpricing of auto use for travelers. Florida's gas price is among the lower priced across states, currently ranked $17^{\text {th }}$ lowest (https://www.gasbuddy.com/USA). The collective consequence of this underpricing vehicle travel's direct costs, say nothing of pricing in the externalities of auto use, contribute to its relative affordability - a factor that undermines transit use.

Public transportation stakeholders are, as they should be, involved in policy making relative to the deployment of emerging modes. These modes or technologies such as transportation network companies, bikeshare, scooter rental, short-term car rental, etc. influence travel behavior and can compete with and complement public transportation. The greatest opportunities to leverage these emerging technologies in ways that are complementary to public transportation include taking advantage of their logistics and cost structure characteristics to support affordable paratransit services and leverage these modes as first-mile last-mile connectors for markets where that can help transit's competitiveness. Actions will include integrating information, and perhaps payment system, such that travelers can move seamlessly between service providers. In addition, public transportation stakeholders should make sure these services do not impede public transportation's ability to operate, as it may impact curb space for bus stops, and localized congestion at major trip generators. Longer-term relationships between public transportation and transportation network companies and other emerging modes is addressed below.

\section{Mitigate or Offset the Impacts of Declining Ridership}

The second major discussion area relates to initiatives to mitigate or offset the impacts of declining ridership for public transit operators. The challenge with declining ridership is that it undermines the ability of public transportation to accomplish some of its goals relating to capturing the economies of scale of a mass mode of transportation. Historically, public transportation's benefits have included reduced emissions, reduced energy use, and reduced physical space requirements enabling land to be dedicated to productive economic activities. To the extent that declining ridership undermines the ability of public transportation to accomplish these purposes, it diminishes the benefits of public transportation and diminishes political will to continue to support public transportation. Buses with low load factors do not 
save energy, reduce air pollution, or save transportation infrastructure space. Public transportation operators should make changes where possible to ensure that the services delivered remain efficient with respect to these characteristics. Responses and actions towards that end can include operating vehicle sizes consistent with the magnitude of market demands, striving to have the most efficient logistics possible (minimize circuity and deadhead mileage), and operating vehicles with state of the practice propulsion systems to ensure energy and emissions efficiencies.

Public transportation operators are in the best position to determine the most effective actions towards that purpose. It is acknowledged that declining ridership challenges agencies to maintain efficiency. While steps can be taken to offset the consequences of declining ridership, public transportation stakeholders need to acknowledge this challenge. Declining ridership undermines the ability of the industry to attain some of its purported goals relating to transportation efficiency. An honest assessment of the ability of public transportation to impact air quality, influence roadway congestion, and reduce energy use, need to be evaluated with information reflective of actual operations. Only with an honest assessment, can the industry position itself to address these issues.

To a certain extent, the inability of transit to accomplish efficiency goals, makes transit more reliant on accomplishing social service objectives as a basis of securing public and policymaker support. It behooves public transportation to be able to articulate the role it plays in meeting the mobility needs of those individuals who do not have alternative means of transportation. Public transportation's ability to enhance the quality of life and provide upward mobility and opportunity for individuals who cannot avail themselves of an automobile becomes a more critical goal, and one that stakeholders must understand and be able to articulate to garner public and policymaker support.

\section{Positioning Public Transportation for the Evolving World of Personal Mobility ${ }^{12}$}

The third and perhaps most critical aspect of positioning public transportation for the future involves making strategic decisions such that the fundamental goals associated with public transportation can continue to be accomplished going forward. The logic of this discussion involves moving beyond discussions of preserving the ridership numbers for traditional public transportation services and technologies or even institutional structures for delivering services, to a broader look at discerning how best to ensure that public transportation's fundamental

\footnotetext{
12 This section borrows some content from the author's recent publication, "Just Around the Corner: The Future of U.S. Public Transportation", Journal of Public Transportation, 21 (1): 43-52. http://scholarcommons.usf.edu/jpt/vol21/iss1/5/, February 2018.
} 
goals can continue to be accomplished going forward in a world where demographics, economics, and technology are changing.

The comments are bound by thinking about public transportation from the perspective of three key goals that underlie the provision of public transportation:

1. Provide transportation to enable upward mobility and enhanced quality of life for those unable to provide their own mobility.

2. Provide a resource-efficient means of moving people.

3. Stimulate economic development and influence land use.

These are, by no means, the full set of motivations that underlie the provision of public transportation infrastructure and services, but they do capture the core motivations that have led to the public's willingness to invest resources in public transportation. This discussion attempts to frame strategic actions in the context of how various goals can be pursued rather than focusing exclusively on preserving or restoring ridership counts. Indeed, the challenge and opportunity for public transit is to transition such that the core motivations for providing public transportation continue to be aspirations for those individuals planning for and making decisions regarding the future of transportation.

This acknowledges that public transit as we know it today may not remain the same in many communities in the future. What will remain is the need to have transportation options that meet the needs of those who are unable to provide mobility for themselves, options that offer resource-efficient means of moving volumes of people, and options that complement other collective aspirations of our society such as economic opportunity and productive deployment of capital and human talents. Today's governance and funding arrangements for public transportation may change markedly, and the technologies (bus, heavy rail, light rail, streetcar, etc.) that characterize public transportation today may no longer dominate the public perceptions of what public transportation is.

Several decades in the future, some elements of our current public transportation infrastructure are likely to still be in use. Many exclusive guideway corridors likely will still be in service with trains of vehicles, perhaps still running on rails, continuing to provide high-volume services to major travel markets. Vehicles will have automated operation. Shorter-life, roadway-based transportation technologies for moving public travelers are likely to evolve faster with the very real prospect that myriad different-sized technology-enhanced vehicles will provide mobility options for travelers. Who owns, operates, and regulates these services remains to be seen, although government is likely to remain a significant stakeholder. There may well be a continuum of vehicle sizes and ownership/operations/governance frameworks that are responsible for ensuring the availability of mobility options. The governance and funding silos that differentiate public transit from personal vehicle use today may disappear as 
historic technology, funding, and governance aspects of modal definitions are no longer distinguishable or so diverse as to be difficult to categorize. Technology changes-but not just technology changes-guarantee that the future will be different from the present.

The Future of Public Transit as a Social Service

Arguably, the most important role for public transportation in Florida is to provide mobility options for those without the ability to otherwise secure transportation at market rates. The 2017 American Community Survey (ACS) indicates that, on average, 8.6\% of U.S. households and $6.3 \%$ of Florida households do not have a personal auto available. An unknown share of these are carless by choice, but the majority are a result of physical or mental health conditions, financial considerations, or legal constraints. National Household Travel Survey (NHTS) data indicates that over $40 \%$ of transit trips are made by persons from households with no vehicle available. Onboard survey data compiled by the American Public Transportation Association (APTA) indicates that $33 \%$ of all transit trips and $46 \%$ of bus transit trips are made by individuals whose household incomes are below \$25,000 annually (American Public Transportation Association, January 2017, page 36). Thus, the availability of public transportation enables a significant share of the population to have the mobility that supports their quality of life as a result of local, state, and federal government investments in public transit services and facilities.

Looking ahead, technology offers several possible changes in transportation access and affordability. Automated self-driving vehicles, for example, offer the potential opportunity to make travel options available to persons with mental and physical disabilities who are currently unable to operate a personal vehicle. Individuals who may not be constrained by resources but are transit travelers by virtue of their inability to operate vehicles would have a new travel opportunity, and thus no longer be dependent on traditional fixed-route or paratransit service providers. Even today, the presence of TNCs such as Uber and Lyft offer greater convenience and a lower price point than previously had been available by taxi services. Transit agencies are experimenting with various TNC partnerships serving paratransit trips, transit access and egress, and target area circulation markets. The independence of being able to solicit a vehicle in real time, via an app, offers a pronounced enhancement in personal mobility for many.

Another segment of individuals who use public transportation because personal vehicle use is financially challenging may have a lower-cost travel opportunity by virtue of technologyenabled vehicle sharing and/or ridesharing. Various speculative analyses suggest that perpassenger-mile costs for use of shared automated vehicles might be well below current levels of operating cost for personal vehicles. U.S. average auto operating costs in the range of \$0.50$\$ 0.60$ per passenger mile are higher than various predictions of costs for automated mobility services that have been estimated to be able to deliver transportation for $\$ 0.20-\$ 0.50$ per 
passenger mile or less if shared. Additionally, mobility service costs are structured as marginal per-trip costs and, thus, are more palatable than the fixed-cost nature and lumpiness of the vehicle purchase, registration, and insurance costs that characterize auto ownership and can drive personal vehicle use costs to very high levels, particularly for individuals who incur these fixed costs but travel modest amounts over which to amortize the costs in expensive urban markets. The extent to which mobility services emerge that can provide per-trip costs in a price range below auto ownership costs would open the opportunity for additional individuals to rely on market-based transportation options and implicitly reduce the market for traditional fixedroute transit services.

However, the poorest of the poor still may need some mechanism of financial support to avail themselves of mobility. This mobility is critical to health care, educational opportunity and employment and, thus, is critical to the quality of life and upward mobility opportunity. Historically, this has meant reliance on publicly operated or publicly-procured transit services and reliance on low or subsidized fares. In the future, this might mean continued reliance on traditional transit services or, alternatively, accommodating this markets' mobility needs via user side subsidies for publicly- or privately-operated mobility services. For example, analogous to the Supplemental Nutrition Assistance Program (SNAP), eligible individuals might be provided a mobility subsidy that could be used to purchase market-priced mobility services.

The public sector role might be one of providing user side subsidies to individuals deemed eligible and enabling and encouraging efficient logistics and trip sharing to increase the efficiency and affordability of various MaaS strategies.

Several transit properties have already begun to address the challenge of meeting mobility needs of dependent populations in areas that can no longer support traditional fixed route public transportation services. There is a growing body of data on how flexible route circulators, demand response services, TNC partnerships, and other strategies might be helpful in addressing the needs of individuals no longer having convenient access to traditional services. There is an acknowledged challenge associated with attempting to find financially sustainable and effective ways of providing mobility for individuals who clearly benefit from that mobility but who do not live in locations with enough density or that generate sufficient travel volumes to enable efficient fixed route services.

This challenge is most visible in instances where pre-existing services have been withdrawn, but has, and will continue to exist in areas without publicly supported services. It begs the issue of determining the public responsibility and/or public benefit of meeting mobility needs of all individuals irrespective of location decisions and activity patterns that they may have chosen. If ridership declines continue by virtue of more individuals having alternative choices to accomplish their activities, it is possible that a larger share of the population will reside in 
geographies that are no longer viable for traditional public transportation services. There is no obvious solution to this dilemma, as policy makers will have to make decisions appropriate to their context and values. Nonetheless, the emergence of new technologies may be helpful in making mobility options more affordable and efficient as electrification, automation and shared mobility may produce travel options that can be sustainable and efficient in a broader set of market conditions.

The Future of Public Transit as a Resource-Efficient Means of Moving People The fact that economic conditions have reduced the number of those who need transit, and technology enhancements have enabled alternative travel options at lower price points has cannibalized the market for traditional public transportation and challenges the second fundamental goal of public transportation-providing a resource-efficient means of moving people. For transit to accomplish its goal of resource efficiency generally requires a high volume and high utilization of assets and services such that critical resources of fuel, infrastructure, labor, and urban space are used productively. More modest demand from those dependent on public transportation jeopardizes the prospect that the market will be able to support the levels of service that are sufficiently attractive to appeal to significant numbers of travelers who have choices. Collectively this makes it difficult to provide the highly productive services that enable the resource efficiencies of mass modes of transportation.

The relative modal efficiency in terms of energy utilization has shifted over time and may continue to do so. As a result of modest utilization in U.S. operations, bus-based public transportation has consumed more BTUs per passenger mile than has automobile travel for several years (Oak Ridge National Laboratory, 2016). Another aspect of resource efficiency is physical space requirements for providing mobility. Public transportation large-vehicle modes have always had a competitive advantage in terms of being able to deliver higher volumes of people with more modest requirements for both travel way space and vehicle storage/parking. The prospect of automated shared vehicles dramatically reduces the space requirements for vehicle storage and allows that space to be shifted from locations where it consumes valuable land, such as in the cores of central business districts. Various scenarios envision substantial urban space being freed up by reduced parking requirements enabling a significant intensification of development should markets materialize to take advantage of that space. Additionally, various scenarios of deployment of automated vehicles envision substantial increases in the throughput of travel ways by automation of vehicles. Engineers envision throughput increases as a result of several characteristics of technology-enhanced vehicles, including reductions in incident delays as a result of less incident prone vehicles, increased capacity via smoother vehicle flow, optimized dynamic intersection operation, reduced following distances enabled by technology, narrower lanes enabled by smaller vehicles and precise travel path management, and potentially reduced vehicle numbers by technology- 
enabled ridesharing (higher vehicle occupancies). Although these considerations will be unlikely to produce throughput per lane comparable to the high-volume peak-period heavily-utilized exclusive guideway corridors, they could significantly increase corridor capacity in many urban corridors.

Another critical resource to consider is cost. The magnitude of changes in system efficiencies, infrastructure requirements, and scale economies of various elements of transportation infrastructure and technology may be altered significantly by the host of changes anticipated. There is the prospect of scaling vehicle sizes to match demands and optimizing vehicle capacity to meet market needs. Similarly, there is the prospect of controlling vehicle operations such that high-performance services can be offered to public transit or multi-occupant vehicles integrated within a travel way that also carries personal vehicles and commercial vehiclesreducing the need for exclusive infrastructure to ensure congestion-free operation and enabling greater utilization and infrastructure cost-sharing across market segments (automobiles, trucks, transit vehicles). A fundamental determinant of cost-per-unit of mobility provided is highly dependent on the utilization of the infrastructure. For transit to remain competitive going forward, it will require a great deal of sensitivity to scaling the investments to market size such that the cost per unit of mobility delivered is competitive.

Public Transit as a Tool to Stimulate Economic Activity and Influence Land-Use

An increasingly frequently-cited goal of public transportation is its ability to influence land-use and stimulate economic activity in a corridor or region. The current decline in transit ridership and the prospect that emerging modes will challenge growth in public transportation going forward, creates uncertainties regarding the prospect that public transportation can be a powerful tool in influencing land-use. Public transportation can improve mobility that can be leveraged through lower time and money transportation costs and agglomeration economies realized by businesses by access to a larger labor force, which can optimize staffing and workforce synergies and, hence, enhance productivity. The improved mobility is accomplished both by the investment in transportation capacity, and by the fact that public transportation can encourage densification along corridors, thus minimizing travel distances.

Looking ahead, changes in technology as applied to transportation may influence the magnitude and value of economic development associated with transportation investment. As noted, the prospect of enhanced capacity on existing transportation infrastructure systems, including such things as freeing up space devoted to parking, may enable society to capture the benefits of agglomeration if market forces alter land development patterns to either use freedup parking space, or increase development intensity to take advantage of increased capacity in roadway systems enabled by self-driving vehicles. In addition, continued improvements in communication and the prospects of things such as drone deliveries and trends such as growing 
participation in work-at-home, may alter the fundamental relationship between productivity and activity concentration.

High-capacity public transportation modes will continue to be required to sustain the activity levels in the most intensively developed geographies. While one might challenge the ability of public transit to induce development in the future, it will remain important to sustaining the economic functioning of existing extensively developed areas.

The downward trend in ridership coupled with the magnitude of technology and other changes underway suggests that an alternative focus of public transportation stakeholders may be necessary to ensure that the core motivations for today's transit services are well-articulated and advocated, to remain critical considerations in the future of mobility. Specifically, enhancing mobility, particularly for those who are unable to provide it themselves, should remain a critical consideration as we move toward a new frontier in transportation. Irrespective of institutional structure and technologies, society will benefit by ensuring that travel options are available and affordable for all segments of society. Indeed, technology may help us more effectively attribute cost to beneficiaries and target subsidies to those truly in need. The mechanism or mechanisms by which these services are delivered may change substantially, and the model of the service operator may change over time. The public interest may be in ensuring that mobility options are available and ensuring that those most in need have the resources to take advantage of these options. That may or may not mean today's transit agencies directly operating or procuring those services.

Similarly, historical perceptions of the resource-intensiveness of various means of travel need to be revisited considering changes in ridership and technologies. Technology potentially neutralizes differential safety benefits across modes. Electrification with the prospect of sustainable electric production in the future, and a spectrum of vehicle sizes targeted to market needs, will neutralize emissions and energy-consumption differences across modes, and minimize the relevance of this factor in transportation policy and investment considerations. Other impacts such as noise, environmental, and social disruption caused by the physical presence of transportation facilities similarly might be altered as technologies change the features and externalities of transportation, and technology enables significantly higher capacity within existing transportation corridors.

Finally, the ability of transportation capacity to influence land-use, be it some version of public transportation or other emerging modes, will continue to merit attention going forward. The sensitivity of development to accessibility may be changing, and the ability of various modes to enable more intense development is also changing. More direct strategies for influencing landuse may be more effective than dependence on transportation investments whose impact may be less significant in the future. 


\section{Modifying Transportation Planning to Reflect Changing Ridership Propensity}

Beyond the broader industry responses to declining ridership in the form of changes to service planning and delivery, and strategic changes of public transportation stakeholders to position transportation policy to continue to accomplish the core goals of public transportation, there remains some specific issues that relate to public transportation planning.

It is important to remember that nobody, including public transportation planning professionals, were anticipating a multiyear decline in transit ridership as the economy recovered. The multi-year steep decline in public transit ridership both across the country, and especially within Florida, were not anticipated and incorporated in planning documents. Virtually every planning and analysis effort envisions public transportation use growing in proportion to population and service levels. While some seasoned professionals were aware that a stronger economy does not necessarily induce additional transit ridership, nobody was publicly forecasting successive broad-based declines in transit ridership. Transit development plans, long-range transportation plans, corridor studies, and fleet replacement plans have not been developed in the context of declining transit ridership. The recent, and generally unanticipated, change in transit ridership reinforces the uncertainty about future transit ridership levels and suggests that public transportation planning may need to be reevaluated in the context of this uncertainty.

Such uncertainty regarding future public transit demand, and our ability to anticipate it, might suggest several changes in how we plan for public transportation. As a first step, this means a reevaluation of our understanding of the factors that influence transit ridership. Questions the planning community should be addressing include things such as:

- What additional variables need to be in our forecasting methods/models to capture the witnessed changes?

- To what extent are the phenomenon that are hypothesized to have contributed to these changes understood sufficiently well to develop quantitative relationships that can be used in future forecasting?

- Even if an understanding of the influence of various factors on ridership can be determined, can planners predict future levels for these causal variables? For example, if the influence of transportation network company availability on transit ridership are determined - is it possible to predict the availability of transportation network company services and their characteristics?

- Does future uncertainty suggest fundamental rethinking about the nature of long-term strategies? Should we be looking at initiatives that have a shorter-term payback and/or can be adapted to changes over time should demand or other factors change? 
- Is it practical or politically tenable to forecast negative trends or plan for negative scenarios for stakeholders who generally have a strong advocacy bias toward the public transportation industry and the motivations for supporting public transportation? Are there lessons from other industries or professions that have addressed planning for decline?

- What basic planning strategies dealing with developing scenarios, addressing risk, evaluating uncertainty, and related tactics can be adapted by public transportation planners?

- Are there new data items that should be collected to monitor trends associated with declining transit ridership? Are there changes to our modeling or planning processes? Should concepts like dealing with flexibility, adaptability, or robustness be translated into activity or investment evaluation criteria? Should the timeframe and frequency cycle for planning change to reflect the dynamics of what is going on in technology development and behavior and demographic trends?

- Finally, do we need a different set of levers or policies to influence travel choice should there be the public will to take actions to increase transit use beyond the passive strategies that exist today?

Clearly, there are opportunities to adapt planning to reflect the reality that there are factors influencing public transit use, and consequently public transit performance and productivity that go beyond traditional cyclical considerations and merit serious reflection and substantial changes in planning activities.

Turning to more specific guidance, there are specific activities that the Florida Department of Transportation and other entities involved in transit planning can engage in to adapt planning in the context of declining transit ridership. Specific ideas are noted below:

Evaluating travel demand forecasting data sets and tools

The magnitude of changes in ridership merit sensitivity testing of current forecasting tools, both regional travel forecasting models, the TBEST model and other forecasting tools including STOPS, to determine how the noted changes in economic conditions (median income, zero car households, etc.) and other factors (gas prices, service levels, household trip rates, etc.) might influence transit ridership forecasts. The rapid changes in conditions may suggest a need for more frequent model validation and or ensuring more current sociodemographic and other information is utilized in modeling activities. In addition, sensitivity testing with respect to relevant variables might give insight into the adaptability of the models to incorporate or respond to changes that underlie the current change in transit ridership. 
Declines in fixed route ridership approaching $20 \%$ over a three-year period in Florida bring into question the veracity of long-range forecasts and raise questions about the sensitivity of decisions that utilize forecasts whose data foundation predated the recent change in transit ridership. The Florida Department of Transportation and entities using transit forecasts for planning purposes need to be able to understand the implications of empirical data on declining transit ridership in the context of the forecast information they are using in evaluating project merit. Decision-makers should be appraised of the change in transit utilization between the model validation year and present and be given some guidance as to how changes might influence ridership forecasts inherent in the model (based on the best understanding of sensitivities to available causal variables and/or based on how the forecasts might change if the models were revalidated to current conditions). While normal cyclical variations in demand attributable to economic cycles would not command this level of attention, the magnitude of the observed actual trends is significant in the context of investment cost effectiveness and hence merits attention.

Rethinking plan update cycles

The dynamics of current trends coupled with the expectation that emerging technologies will continue to significantly alter travel behavior and the competitive position of public transportation, suggest there be a reconsideration of plan update cycles and/or other aspects of planning to ensure that the most current information is reflected in planning documents. Historically, fundamental phenomenon that influence travel changed rather modestly and mode choice trends, as well as total travel levels, changed in relatively predictable fashions. Now, however, the pace of change has been more rapid and the underlying causal factors more complex and multifaceted. One logical response would be to increase the frequency of plan update cycles to incorporate the most current information. Admittedly, this is an expensive and burdensome task and does not fully mitigate the fact that long-range forecasts have less credibility in an era of rapid change.

\section{Evaluate plan actions or strategies against future scenarios}

Another strategy to adapt planning to the dynamics of change involves testing alternatives or recommended planned strategies against various scenarios of future conditions including scenarios that involve continued softness or decline in transit ridership. Thus, decision-makers would understand how various decisions and actions would function in future scenarios that may differ from the consensus scenario. Decision-makers would then be in a position to value an option that performed well under various conditions versus one that excelled for a given scenario. Adaptations of planning might include prescribing evaluation against multiple future scenarios and perhaps developing specific measures of "robustness" or "adaptability" that would measure performance given probabilities of various future scenarios materializing. 
Among the strategies might be developing measures of the present value of the time stream of costs and benefits associated with an action. This allows the decision maker to appropriately value the costs and benefits by applying appropriate discounts that reflect their timing. This can dampen the motivation for premature investment and discount investments whose productive life may be limited by developing technologies or other changes.

Design service investment strategies that offer near-term benefits

In addition to being able to assess uncertainty and risk in evaluating actions, it behooves transportation planners to prescribe amongst their set of actions, strategies whose benefits are realized in the near term.

This mitigates the risk that future conditions will undermine the value derived from a recommended action should transit supportive conditions deteriorate for example, as automated mobility services challenge fixed route transit operation in low and moderate density environments. In its simplest form, this means focusing on projects that can be deployed quickly such that they can began capturing benefits in the near term and it would suggest that initiatives with elements that can be adapted or fully amortized faster will have less risk. An example of this would be in evaluating the merits of a bus rapid transit investment versus a rail investment. Traditionally rail can take dramatically longer to implement and has components (track, vehicles, stations, etc.) whose lives can be 25 to 50 years. Alternatively, bus rapid transit would have shorter life components enabling adaptation sooner. For example, a 12-year bus life would allow the operating entity to change the fleet size and/or update the technology, amenities and characteristics on a relatively near-term timeframe thus accommodating possible changes in market size or conditions/preferences.

Continued monitoring of key trends

Future planning will be supported with close monitoring of emerging travel behavior trends including transit ridership. This monitoring should go beyond just looking at aggregate ridership numbers, to more fully understand trends in underlying factors including rates of person trip making (as influenced by factors such as telecommuting, e-commerce, distance learning and other technology enabled substitutions for travel), rates of utilization of alternative modes, differential changes in travel behavior as a function of demographic characteristics, different changes in travel behavior as a function of urban development characteristics, etc. 


\section{Chapter 4. Summary Observations}

Florida has seen dramatic ridership declines in the past four years. These declines are over two times more severe than those for the nation on average, and have continued well into 2018. The declines are relatively pervasive with no areas escaping the pressures on transit ridership. Of concern, the most severe declines have been in those locations, like southeastern Florida, that are the most conducive to transit. The magnitude of the declines exceeds those observed in prior economic cycles and have been traced to a set of conditions, some of which have not been witnessed previously. The conditions that have contributed to changes in travel behavior have not necessarily fully played themselves out.

The changes in ridership on public transportation in Florida appear to be primarily associated with the fact that more travelers now have additional options for carrying out their activities or traveling to and from them. In general, transit service in Florida has not deteriorated, and in fact, has continued to expand in many communities. Unlike some other communities across the country, high profile safety, service reliability or overwhelming drug abuse and homeless loitering issues are not key causes for declining ridership. Service retractions, where they exist, appear to be in response to ridership declines, not an initial cause.

Housing patterns and origin destination travel patterns that change relatively slowly over time, preclude attributing much of the ridership declines to changes in land use patterns. While Florida's land-use and activity patterns are acknowledged as not conducive to cost-effective high-quality public transportation services, patterns have not changed meaningfully in the past few years. Changes in the transit level of service are similarly not a primary factor in explaining the decline in transit ridership since 2013. These factors may be significant over longer periods of time and may be playing a role in influencing ridership, but changes are simply not fast enough to be dominant influences in recent ridership changes.

However, in light of having new options, more trips made by the growing population are opting for alternatives to transit. Transit is losing in the competition for attracting customers. Some travelers are replacing travel with communication, for example working at home and shopping via e-commerce. Many others have added household vehicles offering an alternative for individuals who were previously inclined to use public transportation. Still others are using transportation network companies as an alternative to transit for some trips.

Transit has not gotten worse, but the other options have gotten better. Accordingly, the challenge facing transit is not one of undoing actions that hurt ridership but rather finding new ways to be more competitive. This challenge is complicated by the fact that declining ridership creates financial pressures for agencies and undermines the productivity and efficiency of public transportation in ways that diminish its potential benefits in areas such as congestion 
reduction, air quality, and energy use. This undermines both the justification for services as well as the political and public support for them. As the narrative above suggests, there is no simple formula or lookup table as to what transit agencies should do. The answers are complex, and context specific, and may include rethinking the role of public transportation as we currently know it, and finding additional multimodal ways to pursue the fundamental objectives of mobility opportunity for travelers and resource efficient means of moving people.

Transit's role in many communities is still critical and will be for the foreseeable future. Growing population, and in some areas increased density, have historically suggested a need for an expanded role for transit. Florida faces a dilemma, growth is still robust and decision makers aspire for the growth that provides employment and economic opportunities. There is often an unwillingness or inability to meet mobility needs by expanding roadway capacity despite demand, but the hoped-for public embrace of public transit is not materializing. Individuals' travel decisions are not growing transit ridership. The challenge facing transportation planning and operations is profound.

To craft a constructive role for public transportation will require agencies to fully understand their markets and the needs of travelers who may find transit an attractive alternative. It will be critical to refine our understanding of activity patterns in terms of origins and destinations with a high propensity to support public transportation services so that services can be correctly targeted to travel patterns that can support public transportation. Similarly, it will be important to recognize that as more options have become available to travelers and activity patterns continue to disperse as metropolitan areas in Florida grow, we may see increasing areas where markets may not justify fixed route services, but meaningful numbers of travelers still need assistance in meeting their mobility needs.

A meaningful share of the public and policymakers are oblivious to the significance of what has been going on. Some presume it's a cyclical phenomenon. Others assume it's a result of underinvestment and can be reversed with more money. Still others are reluctant to even talk about the issue as they are afraid it will undermine the public support for public transportation. Segments of the public transportation planning community are even reluctant to admit that there are no easy answers. Service reconfigurations, new investment in service and amenities, and other actions, while certainly supportive, are unlikely to reverse the trend of the past several years nor enable public transportation to return to the productivity levels it has enjoyed in the past.

Other communities may see an intensification of development in select areas. With proper planning these areas may be increasingly supportive of public transit services. Where communities aspire to intense urban developments, careful design and coordinated transportation investments such that transit's competitive position is not undermined by 
actions such as underpriced parking or poor intermodal integration, can support robust public transportation. If communities want public transportation to be successful, they need both the physical and policy environment to support it.

Stakeholders beyond the transit operating agencies will need to be engaged as many of the conditions that influence public transit use are influenced by broader community, state, and federal actions. Public transportation stakeholders will need to be facilitators of mobility in their communities. In this role, the responsibility will be to ensure mobility options are available and that basic elements of safety, accessibility, reliability, equity, and other quality parameters meet community standards. This may involve integrating public and private sector operators, ensuring modal integration, enabling convenient travel information and fare payment, and potentially providing user side subsidies to ensure access to market priced services. Land-use planning, transportation pricing, and transportation investment and coordination are responsibilities that require all stakeholders to be engaged. Solutions and strategies may vary across areas as local travel needs and priorities influence actions. The pace of change may be influenced by the pace of technological progress with respect to vehicle automation and customer acceptance and its influence on travel choices available to the public.

The nature of changes in ridership and the prospect of their continuation suggests the need to review and modify transportation planning activities as they relate to planning for public transportation. The planning data sets, tools, and processes should reflect, to the extent possible, the recent changes in travel behavior. The uncertainty inherent in travel behavior and technology change indicate a need for planning processes that more fully embrace evaluation of different scenarios with respect to future conditions and demand for transportation.

Travel behavior is changing, the technology, economy and demographics are changing -- public transportation must change as well. There are no simple fixes to restore public transit ridership. Rather than hoping to restore public transportation, the most prudent path forward involves ensuring mobility options are available to all residents and striving to ensure that travel choices are resource efficient and have minimal externalities. Traditional public transportation services can contribute to that goal, but new options and new actions will be necessary going forward.

In its simplest form the path forward for public transportation includes the following steps:

- Acknowledge the magnitude and complexity of the problem and engage stakeholders in exploring responses going forward.

- Aggressively monitor changing transit ridership and travel behavior characteristics to make sure planners and policymakers are aware of and understand critical trends.

- Execute the delivery of public transportation with excellence - make sure the basic elements important to travelers are delivered to the extent possible. Vehicle should be 
clean, personnel competent and professional, communications with customers should be enhanced and responsive, service plans should be responsive to evolving land-use and activity patterns, amenities should be provided where prudent, and safety in both accessing and using public transportation should remain a critical priority.

- Other public policies should be sensitive to their consequence on transit ridership. Drivers should be required to have insurance, parking should be priced in a manner that does not subsidize auto travel, where possible public transportation and multi occupant vehicles should be given priority treatment.

- New technologies should be leveraged by public transportation to enhance its competitiveness. This will include convenient customer information, trip planning, fare payment, vehicle and station safety systems, driver assistance features, preferential treatment capabilities, and integration with integration with first-mile, last-mile and interregional travel options.

- Revisit transportation planning practices and public transportation planning practices in light of the nature of changes that have been occurring.

- Where traditional public transportation cannot be competitive or cannot be competitive in a cost-effective manner, other options should be explored. Spending resources without commensurate levels of utilization do not accomplish the goals of public transportation.

- Identify opportunities were emerging modes and business models as characterized by transportation network companies, short-term vehicle rental, bike and scooter sharing services etc., may be opportunities for connecting with transit and/or substituting for transit in a fashion that is both cost-effective and responsive to customer needs.

- Watch the emergence of automated transportation services carefully so the industry can position itself to both embrace automation where appropriate and relinquish the role of traditional big vehicle fixed route public transportation services if MaaS options render them uncompetitive. 


\section{References}

A. Singhal, C. Kamga and A. Yazici, "Impact of Weather on Urban Transit Ridership," Transportation Research Part A, vol. 69, pp. 379-391, 2014. https://ac.els-cdn.com/S0965856414002195/1s2.0-S0965856414002195-main.pdf? tid=4d53465e-ebf9-11e7-a93600000aab0f26\&acdnat $=1514484344$ 06df2836fb6df724952e714b4127315f

A. Small, "How Seattle Bucked a National Trend and Got More People to Ride the Bus." Citylabe. 2017. Seattle. https://www.citylab.com/transportation/2017/10/how-seattle-bucked-anational-trend-and-got-more-people-to-ride-the-bus/542958/

American Public Transportation Association. "A Profile of Public Transportation Passenger Demographics and Travel Characteristics Reported in On-Board Surveys." Washington, DC, May, 2007.

http://www.apta.com/resources/statistics/Documents/transit passenger characteristics text $5 \quad 29$ 2007.pdf

APTA. "Understanding Recent Ridership Changes: Trends and Applications." Policy Development and Research. Nov. 2017. http://www.apta.com/DocumentMember/APTA-UnderstandingRecent-Ridership-Changes-2017.pdf

B. D. Taylor and C. N. Fink, "The Factors Influencing Transit Ridership: A Review and Analysis of the Ridership Literature," UCLA Institute of Transportation Studies, Los Angeles, March 2003. http://www.reconnectingamerica.org/assets/Uploads/ridersipfactors.pdf

D. C. Vock, "Why Transit Ridership Is Falling (Hint: It's Not Just Uber)." Governing, 2018. http://www.governing.com/topics/transportation-infrastructure/gov-los-angeles-transitridership-study.html

D. Grisby, "Fair Treatment: Commuters and Tax Reform," APTA, Washington, D.C., 2017. http://www.commuterbenefitsworkforus.com/APTA-Fair-Treatment-Report.pdf

F. Sharon and C. Murphy, "Broadening Understanding of the Interplay between Public Transit, Shared Mobility, and Personal Automobiles." Pre-publication draft of TCRP Research Report 195. Transportation Research Board, Washington, D.C, 2018. https://www.nap.edu/catalog/24996/broadening-understanding-of-the-interplay-betweenpublic-transit-shared-mobility-and-personal-automobiles

F. Siddiqui, "Here's what happens when a key Metro station - National Airport - halts train service," The Washington Post, 17 October 2017. [Online]. Available: https://www.washingtonpost.com/news/dr-gridlock/wp/2017/10/17/heres-what-happenswhen-a-key-metro-station-national-airport-halts-train-service/?utm term=.eef713e8db23 
G. Thompson, J. Brown, and T. Bhattacharya, "What Really Matters for Increasing Transit Ridership: Understanding the Determinants of Transit Ridership Demand in Broward County, Florida," Urban Studies, 49(15), 3327-3345, 2012.

http://journals.sagepub.com/doi/pdf/10.1177/0042098012443864

H M. Kohn, "Factors Affecting Urban Transit Ridership."

http://www.statcan.gc.ca/pub/53f0003x/4225128-eng.pdf

J. A. Gomez-Ibanez, "Big-City Transit Rider Snips, Deficits, and Politics: Avoiding Reality in Boston," Journal of the American Planning Association, vol. 62, no. 1, pp. 30-50, 1996.

http://www.tandfonline.com/doi/abs/10.1080/01944369608975669

J. D. Hall, C. Palsson and J. Price, "Is Uber a Substitute or Complement for Public Transit?"

University Of Toronto Department of Economics, 2017.

https://www.economics.utoronto.ca/public/workingPapers/tecipa-585.pdf

J. F. Kain and Z. Liu, "Secrets of success: assessing the large increases in transit ridership achieved by Houston and San Diego transit providers," Transportation Research Part A, vol. 33, no. 7-8, pp. 601-624, 1999. http://www.sciencedirect.com/science/article/pii/S0965856499000099

J. Mattson, "Effects of Rising Gas Prices on Bus Ridership for Small Urban and Rural Transit Systems," North Dakota State University, 2008. https://www.ugpti.org/pubs/pdf/DP201.pdf

J. Morrall and D. Bolger, "The Relationship Between Downtown Parking Supply and Transit Use," Institute of Transportation Engineers Journal, vol. 66, pp. 32-36, 1996. http://citeseerx.ist.psu.edu/viewdoc/download?doi=10.1.1.417.4242\&rep=rep1\&type=pdf

J. Sale, "Increasing Transit Ridership: The Experience of Seven Cities," USDOT, 1976.

J. Walker, "Should Transit Agencies Panic?" Citylab, 2018. https://www.citylab.com/transportation/2018/01/should-transit-agenciespanic/550811/?utm source=SFTwitter

K. Wang and M. Woo, "The relationship between transit rich neighborhoods and transit ridership: Evidence from the decentralization of poverty," Applied Geography, vol. 86, pp. 183-196, 2017. https://www.sciencedirect.com/science/article/pii/S0143622817307166

L. Bliss, "What's Behind Declining Transit Ridership?" Citylab, 2017. https://www.citylab.com/transportation/2017/02/whats-behind-declining-transit-ridershipnationwide/517701/ 
L. Ecola and M. Grant, "Impacts of Transit Benefits Programs on Transit Agency Ridership, Revenues, and Costs," Journal of Public Transportation, vol. 11, no. 2, pp. 1-18, 2008. https://www.nctr.usf.edu/ipt/pdf/JPT11-2Ecola.pdf

M. J. Bianco, K. J. Dueke and J. G. Strathman, "Parking Strategies to Attract Auto Users to Public Transportation," Portland State University, 1997. https://www.pdx.edu/sites/www.pdx.edu.cus/files/DP97-5.pdf

M. Lewyn, “Why is Transit Ridership Declining?” Planetizen. 16 Jan. 2018. https://www.planetizen.com/blogs/96692-why-transit-ridership-declining

M. Manville, E. Blumenberg and B. Taylor, "Falling Transit Ridership: California and Southern California." UCLA Institute of Transportation Studies. Dec. 2017.

M. S. McLeod, K. J. Flannelly, L. Flannelly and R. W. Behnke, "Multivariate Time-Series Model of Transit Ridership Based on Historical, Aggregate Data: The Past, Present and Future of Honolulu," Transportation Research Record, no. 1297, pp. 76-84, 1991. http://journals.sagepub.com/doi/abs/10.1177/0042098010379280

M. Tinoco, "Metro's Declining Ridership, Explained," Curbed Los Angeles, Los Angeles, 2017. https://la.curbed.com/2017/8/29/16219230/transit-metro-ridership-down-why

Miami-Dade Office of the Commission Auditor. "Public Transit Systems Response to Ridership Decrease." 10 May 2017. http://www.miamidade.gov/auditor/library/public-transit-systemsresponse-to-ridership-decrease.pdf

National Academies of Sciences, Engineering, and Medicine. "Broadening Understanding of the Interplay Between Public Transit, Shared Mobility, and Personal Automobiles," 2018, Washington, DC: The National Academies Press. https://doi.org/10.17226/24996.

R. R. Clewlow and G. S. Mishra, "Disruptive Transportation: The Adoption, Utilization, and Impacts of Ride-Hailing in the United States," UC Davis, 2017. https://assets.documentcloud.org/documents/4107733/UCD-Study.pdf

R. O'Toole, "The Coming Transit Apocalypse." Cato Institute, 824. 2017. https://object.cato.org/sites/cato.org/files/pubs/pdf/pa 824-updated.pdf

S. J. Peterson, "Seattle's Transportation Transformation." Urban Land Institute. 10 Apr. 2017. https://urbanland.uli.org/industry-sectors/infrastructure-transit/seattles-transportationtransformation/

S. J. Syed and A. M. Khan, "Factor Analysis for the Study of Determinants of Public Transit Ridership," Journal of Public Transportation, vol. 3, no. 3, pp. 1-17, 2000. https://www.nctr.usf.edu/wp-content/uploads/2013/07/3.3 Syed.pdf 
S. R. Gehrke, A. Felix, and T. Reardon, "Fare Choices: A Survey of Ride-Hailing Passengers in Metro Boston. Report 1," 2018, Metropolitan Area Planning Council, Boston. http://www.mapc.org/wp-content/uploads/2018/02/Fare-Choices-MAPC.pdf

Transit Center, Who's on Board? Riders Explain Why They're Using Transit Less - And How to Win Them Back, Feb 13, 2019, http://transitcenter.org/2019/02/13/whos-on-board-riders-explainwhy-theyre-using-transit-less-and-what-it-will-take-to-win-them-back/

T. Mills and M. Steele, "In Portland, Economic Displacement May Be A Driver of Transit Ridership Loss," TransitCenter, 2017. http://transitcenter.org/2017/11/14/in-portland-economicdisplacement-may-be-a-driver-of-transit-ridership-loss/

T. Misra, "The Newest Americans, Getting Off the Bus," Citylab, Charlotte, 2017. https://www.citylab.com/transportation/2017/01/the-newest-americans-getting-off-thebus/512048/

Washington Metropolitan Area Transit Authority, "Understanding Rail and Bus Ridership: Increasing Our Understanding of a Changing Travel Landscape," WMATA Finance Committee, Washington, D.C., 2017. https://www.wmata.com/about/board/meetings/board-pdfs/upload/3AUnderstanding-Ridership-TO-POST.pdf

Y. Freemark, "Getting Transit Right," in Presentation at the Remix 2017 Conference, Atlanta, 2017. https://www.youtube.com/watch?v=jotxesBt38M 


\section{Appendix A - Profiles of Florida Transit Operating Agencies}

Listed in order of Ridership. See Table of Contents for direct links to each property.

Miami-Dade County (Miami-Dade Transit)

Ridership on Miami-Dade transit has declined $22 \%$ since its near-term peak calendar year of 2013. Vehicle revenue miles of service has declined $18.4 \%$ since its peak level in 2006. As borne out in the figure, service has remained relatively stable for the past several years while the ridership decline has accelerated since 2013. Ridership per County resident has declined $30.9 \%$ from its peak in 2008, a result of both

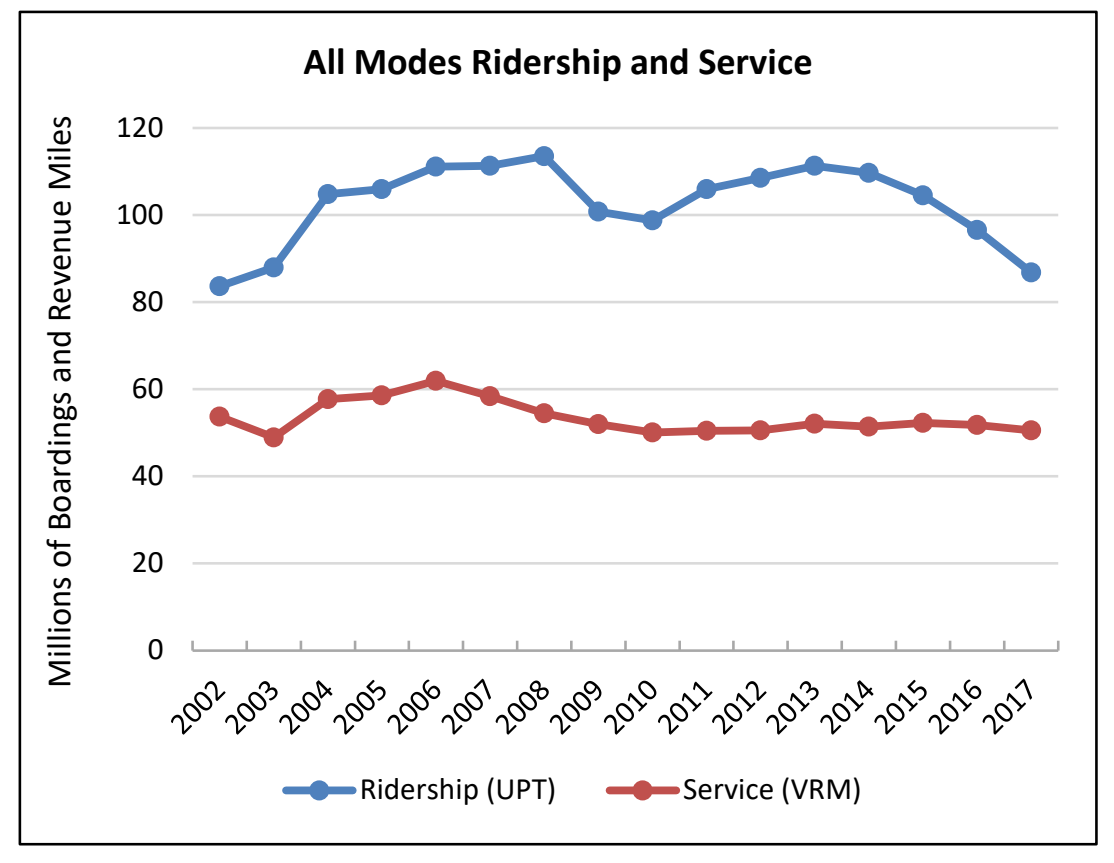
declining ridership and increasing population. The downward ridership trend in Miami Dade County is among the most severe in the state and country.

\begin{tabular}{|c|c|c|c|c|c|c|c|c|}
\hline \multicolumn{9}{|c|}{ Annual Trend Data, All Modes } \\
\hline Year & Ridership (UPT) & Service (VRM) & $\begin{array}{l}\text { Boardings per } \\
\text { Revenue Mile }\end{array}$ & $\begin{array}{l}\text { AVG Fixed- } \\
\text { Route } \\
\text { Speed } \\
\text { (mph) }\end{array}$ & $\begin{array}{c}\text { County } \\
\text { Population }\end{array}$ & $\begin{array}{l}\text { Trips per } \\
\text { Capita }\end{array}$ & $\begin{array}{c}\text { Passenger } \\
\text { Miles of } \\
\text { Travel }\end{array}$ & $\begin{array}{c}\text { Average } \\
\text { Trip } \\
\text { Length }\end{array}$ \\
\hline 2002 & $83,662,302$ & $53,712,765$ & 1.56 & 18.33 & $2,312,478$ & 36.2 & $386,328,780$ & 4.62 \\
\hline 2003 & $87,987,871$ & $48,944,451$ & 1.80 & 14.19 & $2,345,932$ & 37.5 & $395,020,789$ & 4.49 \\
\hline 2004 & $104,782,778$ & $57,703,153$ & 1.82 & 14.36 & $2,379,818$ & 44.0 & $426,622,569$ & 4.07 \\
\hline 2005 & $105,970,262$ & $58,558,459$ & 1.81 & 13.97 & $2,422,075$ & 43.8 & $468,529,569$ & 4.42 \\
\hline 2006 & $111,090,702$ & $61,936,045$ & 1.79 & 13.92 & $2,437,022$ & 45.6 & $487,682,644$ & 4.39 \\
\hline 2007 & $111,265,857$ & $58,417,492$ & 1.90 & 13.45 & $2,462,292$ & 45.2 & $595,143,090$ & 5.35 \\
\hline 2008 & $113,555,718$ & $54,448,426$ & 2.09 & 13.34 & $2,477,289$ & 45.8 & $599,371,183$ & 5.28 \\
\hline 2009 & $100,786,861$ & $51,980,097$ & 1.94 & 13.22 & $2,472,344$ & 40.8 & $549,269,506$ & 5.45 \\
\hline 2010 & $98,742,114$ & $50,089,007$ & 1.97 & 13.29 & $2,505,379$ & 39.4 & $537,970,307$ & 5.45 \\
\hline 2011 & $105,948,316$ & $50,451,506$ & 2.10 & 13.09 & $2,516,537$ & 42.1 & $575,160,471$ & 5.43 \\
\hline 2012 & $108,529,122$ & $50,526,578$ & 2.15 & 13.24 & $2,551,290$ & 42.5 & $613,211,863$ & 5.65 \\
\hline 2013 & $111,324,151$ & $52,083,750$ & 2.14 & 13.10 & $2,582,375$ & 43.1 & $628,696,613$ & 5.65 \\
\hline 2014 & $109,667,693$ & $51,470,645$ & 2.13 & 13.10 & $2,613,692$ & 42.0 & $640,050,014$ & 5.84 \\
\hline 2015 & $104,534,007$ & $52,239,714$ & 2.00 & 13.16 & $2,653,934$ & 39.4 & $629,554,837$ & 6.02 \\
\hline 2016 & $96,608,527$ & $51,784,540$ & 1.87 & 12.96 & $2,700,794$ & 35.8 & $559,919,373$ & 5.80 \\
\hline 2017 & $86,859,282$ & $50,540,318$ & 1.72 & 12.81 & $2,743,095$ & 31.7 & & \\
\hline
\end{tabular}


As noted in the monthly ridership trend, the ridership decline had accelerated through 2017. Of particular note, hurricane Irma in early September resulted in a yearover-year September ridership decline of $32 \%$, a large enough decline to account for approximately $3 \%$ of the 2017-2016 year-overyear decline of $10.1 \%$. However, ridership in the first third of 2018 was running behind the prior year by approximately $12 \%$.

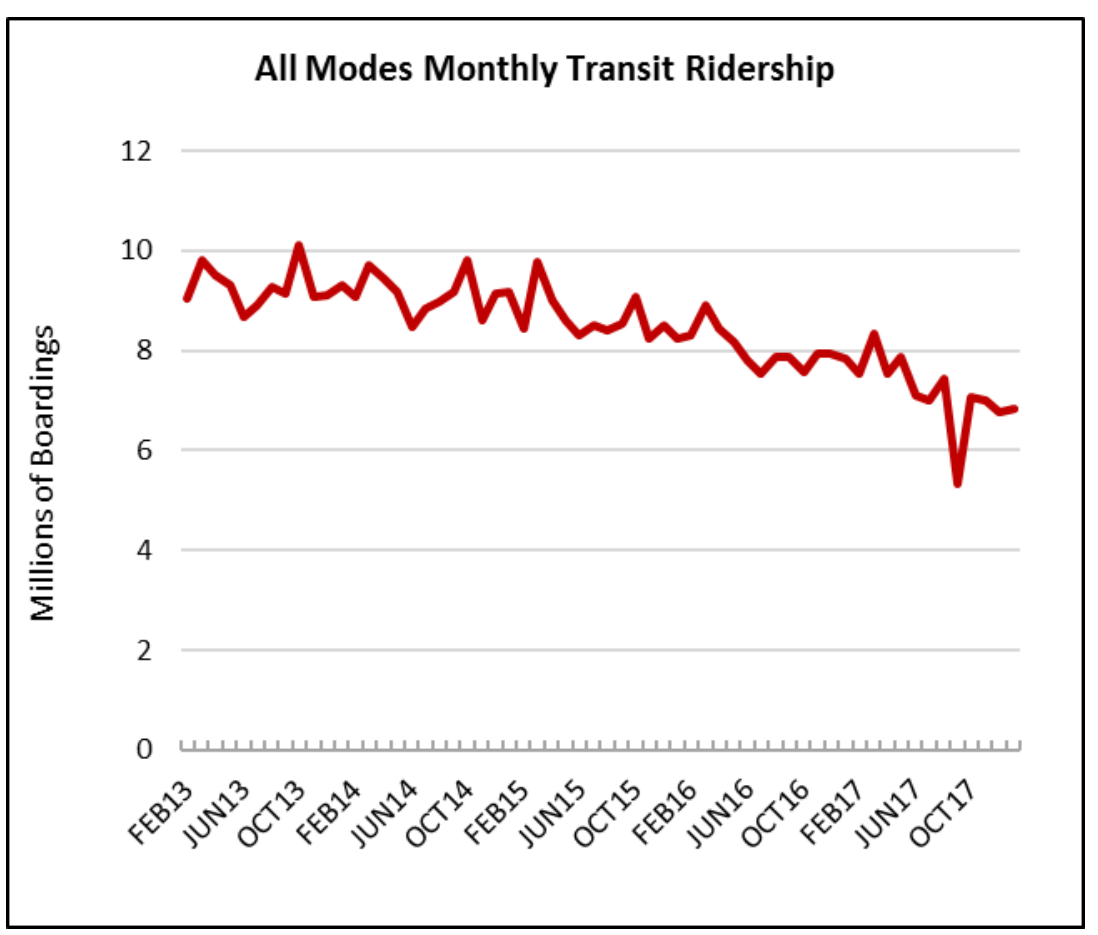

Average operating speed, defined as vehicle revenue miles divided by vehicle revenue hours, declined from over $14 \mathrm{mph}$ early in the century to under $13 \mathrm{mph}$ in 2016 and 2017. This decline in speed is presumably attributed to increased roadway congestion but should have been partially mitigated by shorter dwell times associated with lower ridership. Route alignment decisions also influence operating speed, however, there is not a basis for discerning that impact from aggregate data.

The subsequent graphic shows service productivity. While it has declined the past three

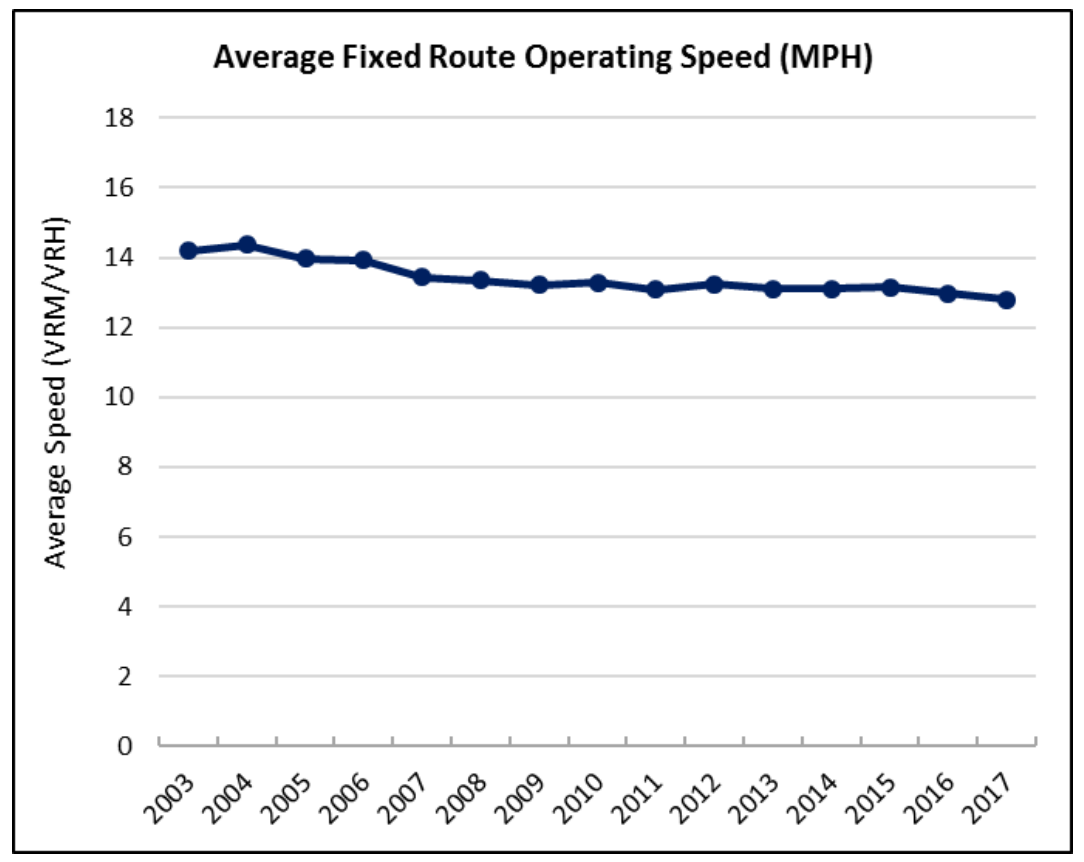
years, it remains above the prior low in 2002. 
The figures below provide the ridership trend and service supply trends by sub mode. This allows one to understand how the various component modes are performing. As visibly apparent, bus ridership has had the most pronounced decline in ridership and comprises the largest share of all transit ridership. Bus ridership has declined approximately $13 \%$ for the one year. Ending in March 2018 and approximately 29\% for the three-year period with that end date.

In 2017 service utilization as measured by boardings per revenue mile was the lowest it has been since 2002. Average trip length on transit has increased over the years. Longer distance trips tend to be on higher speed modes increasing their competitive advantage.

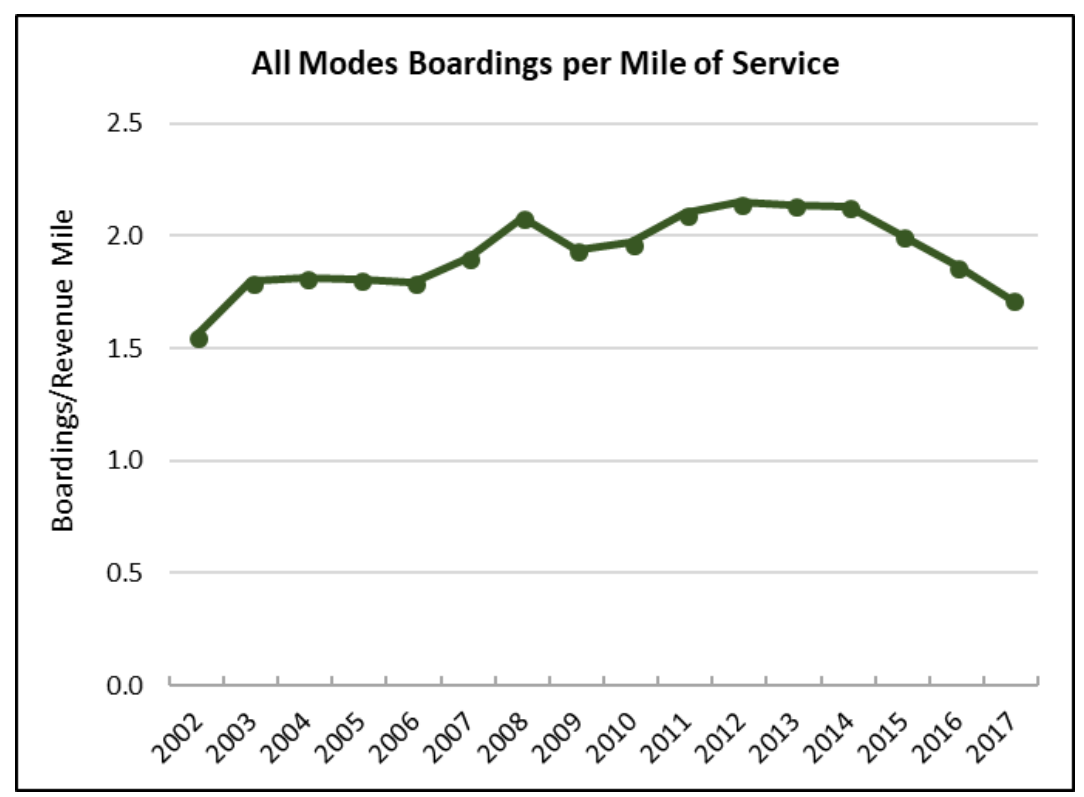


Alternatively, heavy rail has declined approximately $8 \%$ in the past year and $12 \%$ in the three year period. Demand responsive service grew $1 \%$ in the past year and has remained virtually unchanged over the three-year period. Automated transit had an $11 \%$ decline over the past year and a $10 \%$ decline over the three-year period. Commuter bus, a very small share of total ridership, as had a $19 \%$ one your decline but remains nearly $70 \%$ above the levels three years ago. Declines in non-bus modes are far more recent than the decline in bus ridership which dates back to 2013.
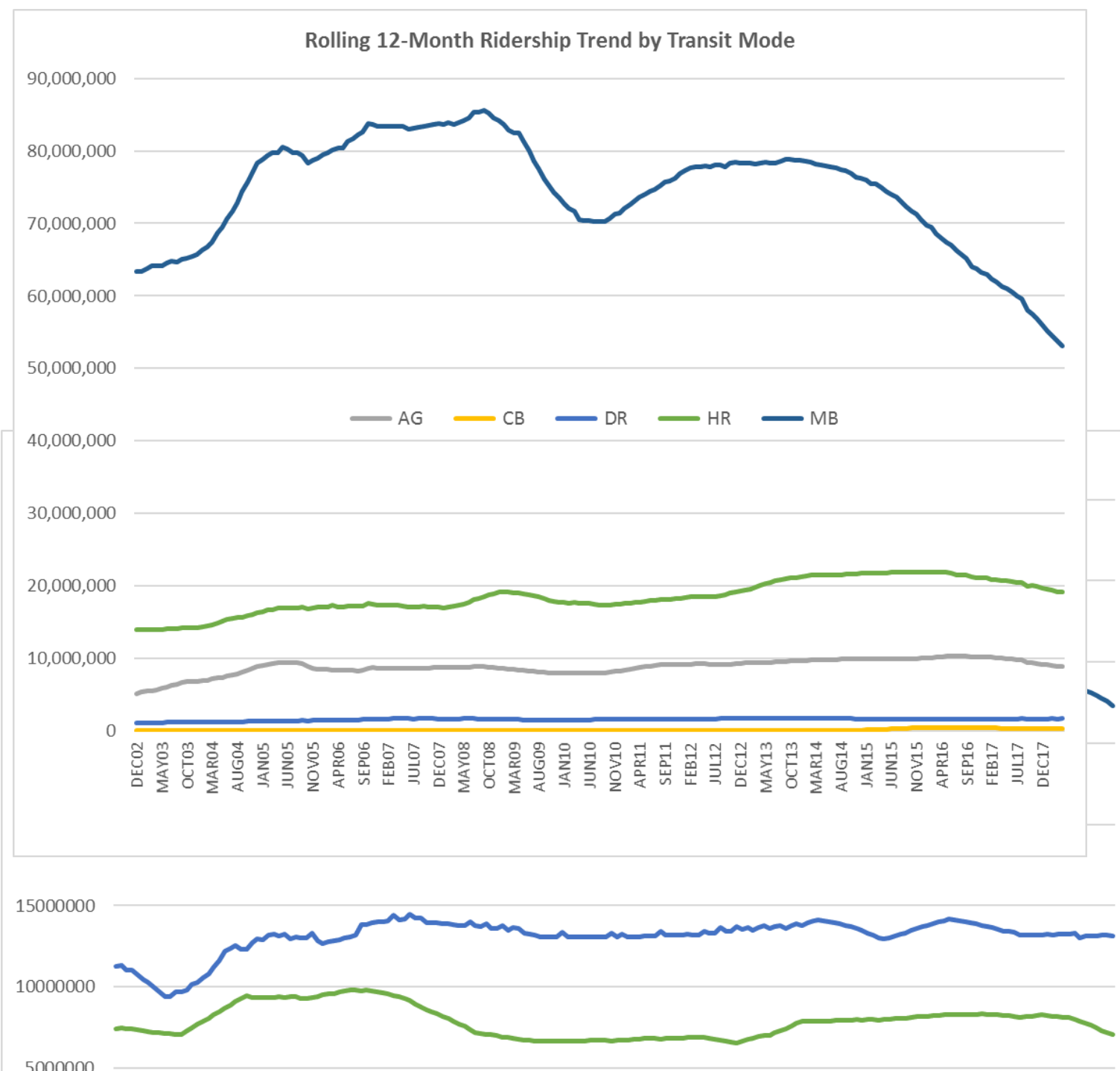

5000000

0

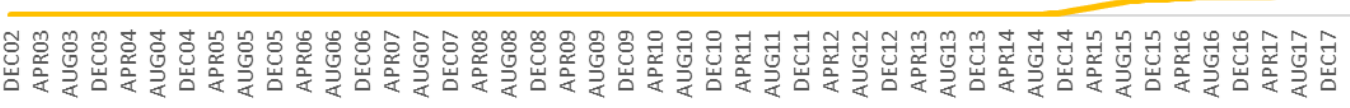

The final graphic shows service supply as measured by revenue vehicle miles of service, as the graphical data communications, service supply has remained relatively stable over time until 
more recently. In the past few years increases in commuter bus service offset some of the declines in regular bus service. More recently, both bus service and heavy rail service have shown some reductions in service. Bus service levels are approximately $4 \%$ below one year ago and at similar levels or below three year ago levels. The rail service levels are down over $14 \%$ in the past year and approximately $13 \%$ over a three-year period. Automated guideway service levels are down $11 \%$ in the prior year and $14 \%$ over three years. Demand response miles of service are stable in the past year and down 3\% over three years. 
Broward County (Broward County Transit Division, BCT)

Ridership on Broward County transit has declined $24 \%$ since 2014. Vehicle revenue miles of service has increased $15 \%$ in that same time period. This combination results in a steep drop in service productivity. Boardings per revenue mile has dropped 35\% since 2012. Ridership per County resident has declined $34 \%$ from its peak in 2008. The downward ridership trend in in Broward County is similar to that in Dade County and among the

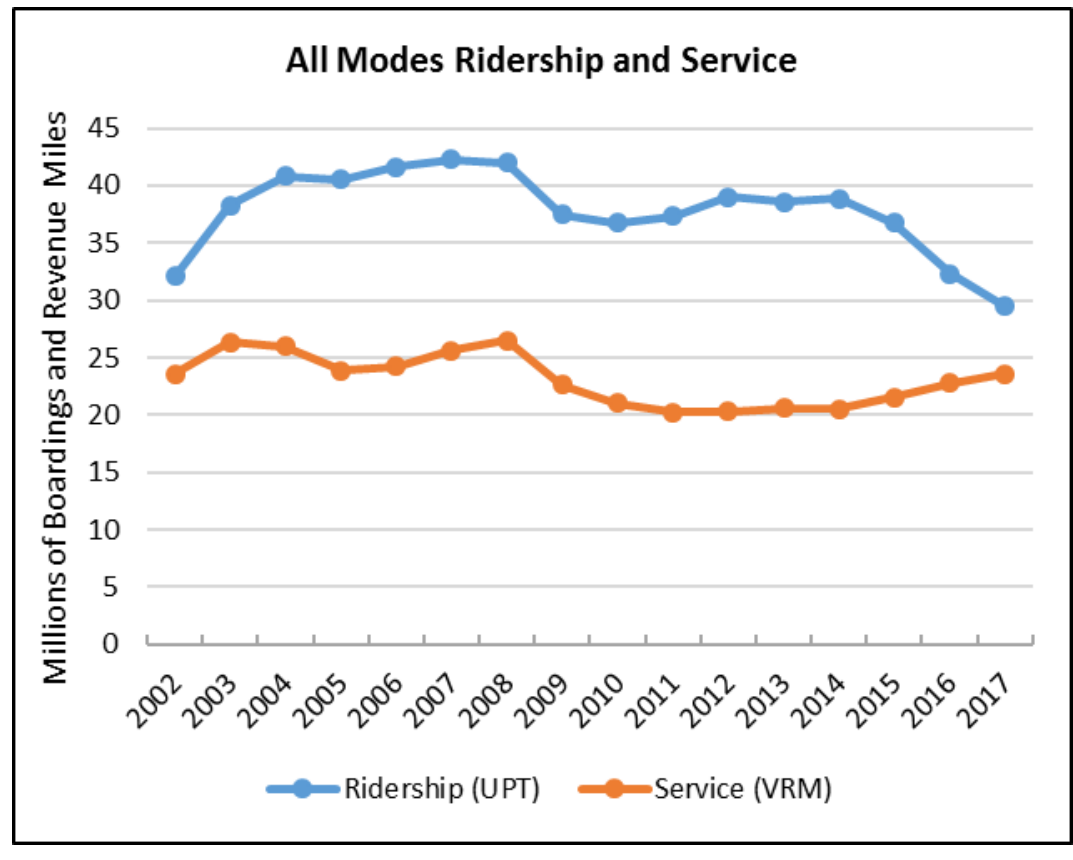
most severe in the state and country.

In 2017 service utilization as measured by boardings per revenue mile was lower than any prior year in the reference data. Average trip length on transit has increased modestly but fluctuates.

\begin{tabular}{|c|c|c|c|c|c|c|c|c|}
\hline \multicolumn{9}{|c|}{ Annual Trend Data, All Modes } \\
\hline Year & Ridership (UPT) & Service (VRM) & $\begin{array}{c}\text { Boardings } \\
\text { per Revenue } \\
\text { Mile }\end{array}$ & $\begin{array}{l}\text { AVG Fixed- } \\
\text { Route } \\
\text { Speed } \\
\text { (mph) }\end{array}$ & County Pop & $\begin{array}{l}\text { Trips per } \\
\text { Capita }\end{array}$ & $\begin{array}{c}\text { Passenger } \\
\text { Miles of Travel }\end{array}$ & $\begin{array}{c}\text { Average } \\
\text { Trip } \\
\text { Length }\end{array}$ \\
\hline 2002 & $32,085,247$ & $23,588,349$ & 1.36 & 13.55 & $1,669,153$ & 19.2 & $153,117,517$ & 4.77 \\
\hline 2003 & $38,272,651$ & $26,326,273$ & 1.45 & 12.91 & $1,698,425$ & 22.5 & $165,005,134$ & 4.31 \\
\hline 2004 & $40,800,271$ & $25,940,959$ & 1.57 & 13.29 & $1,723,131$ & 23.7 & $175,434,864$ & 4.30 \\
\hline 2005 & $40,532,076$ & $23,842,985$ & 1.70 & 13.32 & $1,740,987$ & 23.3 & $175,854,195$ & 4.34 \\
\hline 2006 & $41,644,624$ & $24,209,235$ & 1.72 & 13.67 & $1,753,162$ & 23.8 & $177,700,608$ & 4.27 \\
\hline 2007 & $42,283,946$ & $25,639,853$ & 1.65 & 13.61 & $1,765,707$ & 23.9 & $188,385,552$ & 4.46 \\
\hline 2008 & $41,978,913$ & $26,489,227$ & 1.58 & 13.64 & $1,758,494$ & 23.9 & $188,541,068$ & 4.49 \\
\hline 2009 & $37,501,661$ & $22,615,998$ & 1.66 & 13.72 & $1,744,922$ & 21.5 & $176,472,666$ & 4.71 \\
\hline 2010 & $36,728,982$ & $21,059,772$ & 1.74 & 13.70 & $1,753,578$ & 20.9 & $179,497,947$ & 4.89 \\
\hline 2011 & $37,359,103$ & $20,204,170$ & 1.85 & 13.66 & $1,753,162$ & 21.3 & $176,644,533$ & 4.73 \\
\hline 2012 & $38,982,462$ & $20,323,572$ & 1.92 & 13.87 & $1,771,099$ & 22.0 & $187,637,811$ & 4.81 \\
\hline 2013 & $38,554,060$ & $20,588,392$ & 1.87 & 13.96 & $1,784,715$ & 21.6 & $193,462,959$ & 5.02 \\
\hline 2014 & $38,825,211$ & $20,542,107$ & 1.89 & 13.56 & $1,803,903$ & 21.5 & $176,490,422$ & 4.55 \\
\hline 2015 & $36,730,852$ & $21,525,772$ & 1.71 & 13.28 & $1,827,367$ & 20.1 & $173,667,897$ & 4.73 \\
\hline 2016 & $32,296,475$ & $22,738,797$ & 1.42 & 13.21 & $1,854,513$ & 17.4 & $163,565,194$ & 5.06 \\
\hline 2017 & $29,466,675$ & $23,588,990$ & 1.25 & 13.07 & $1,873,970$ & 15.7 & & \\
\hline
\end{tabular}


As noted in the monthly ridership trend below, the ridership decline was impacted by Hurricane Irma with a $22 \%$ year-over-year decline in the month of September but ridership levels appears to have stabilized in recent months. Ridership in the first third of 2018 was running behind the prior year by approximately $6 \%$.

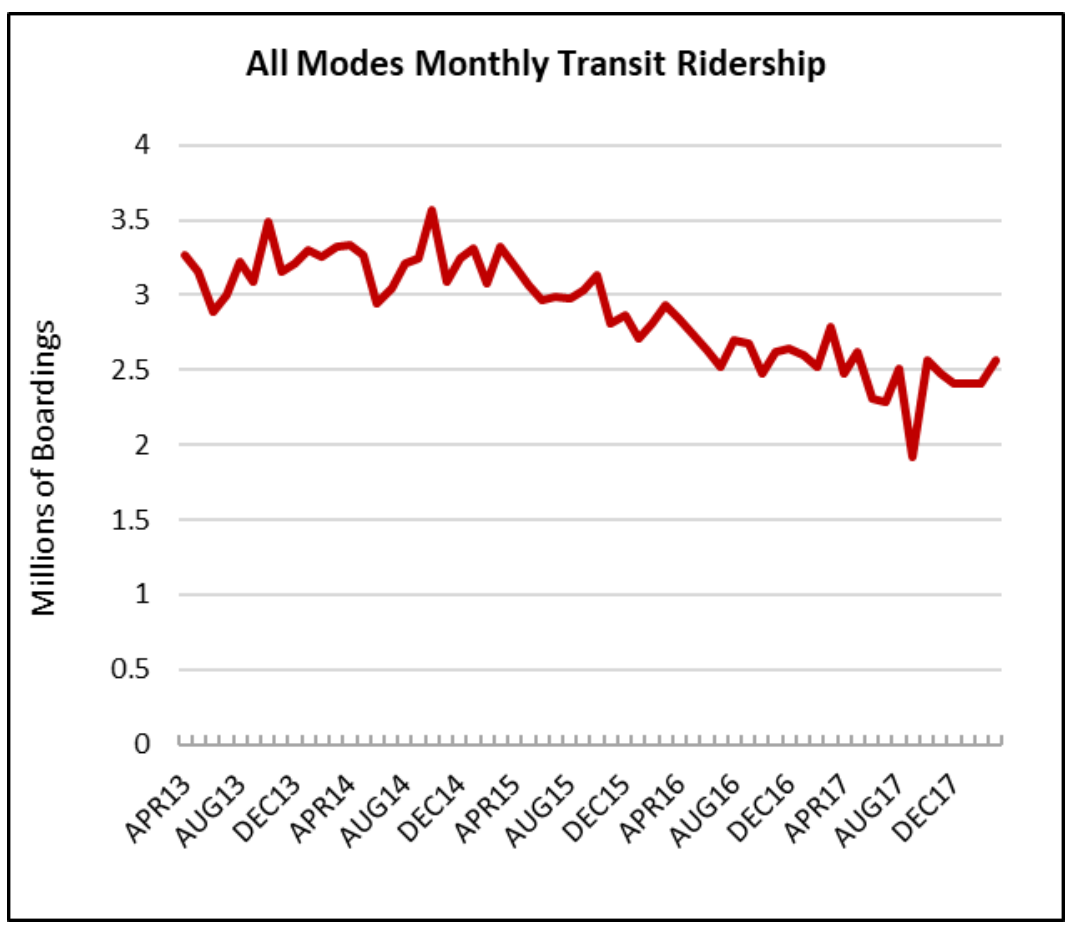

Average operating speed defined as vehicle revenue miles divided by vehicle revenue hours, has remained relatively stable in the $13 \mathrm{mph}$ range since 2003 . There has been a slight downward trend in speed through the economic recovery, presumably a consequence of greater congestion.

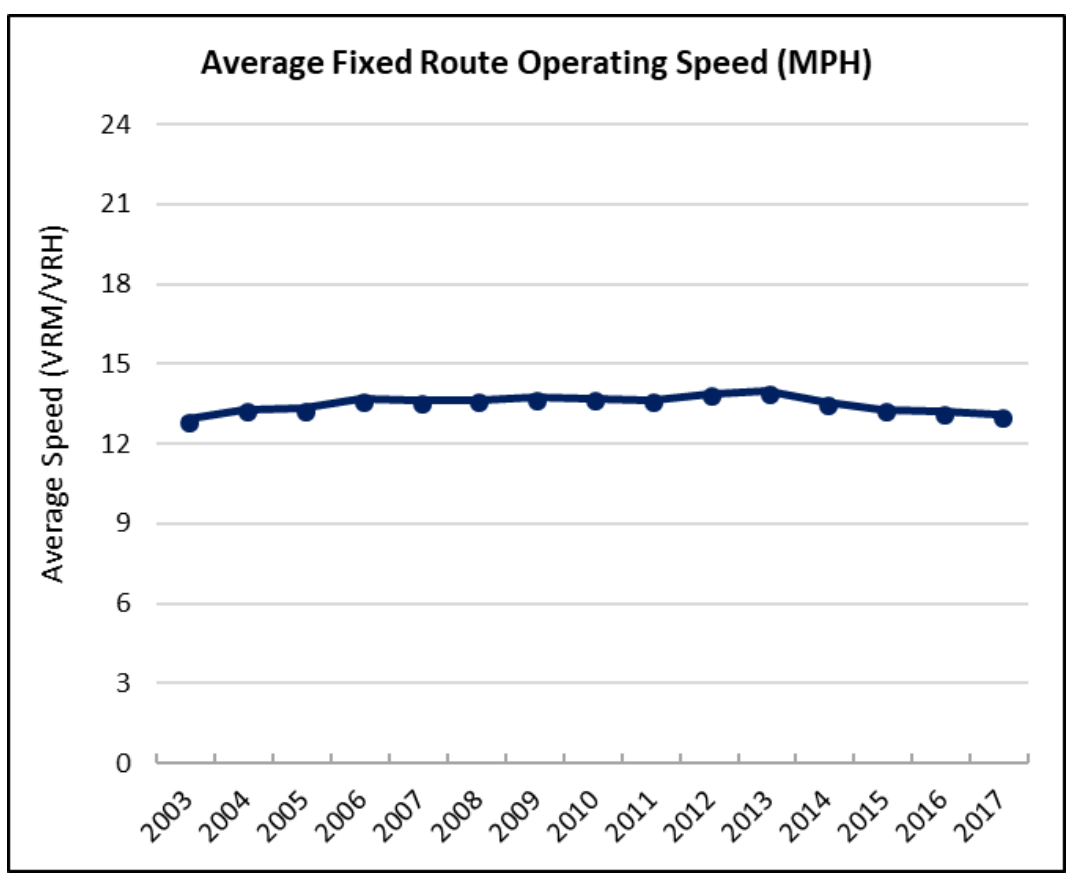


The subsequent graphic shows service productivity. It has declined the past three years, and is now below the prior low in 2002.

The figures below provide the ridership trend and service supply trends by sub mode. This allows one to understand how the various component modes are performing. As visibly apparent, bus ridership dominates and has had the most pronounced decline in ridership. Bus ridership has declined approximately $9 \%$ for the one year period ending in March 2018 and

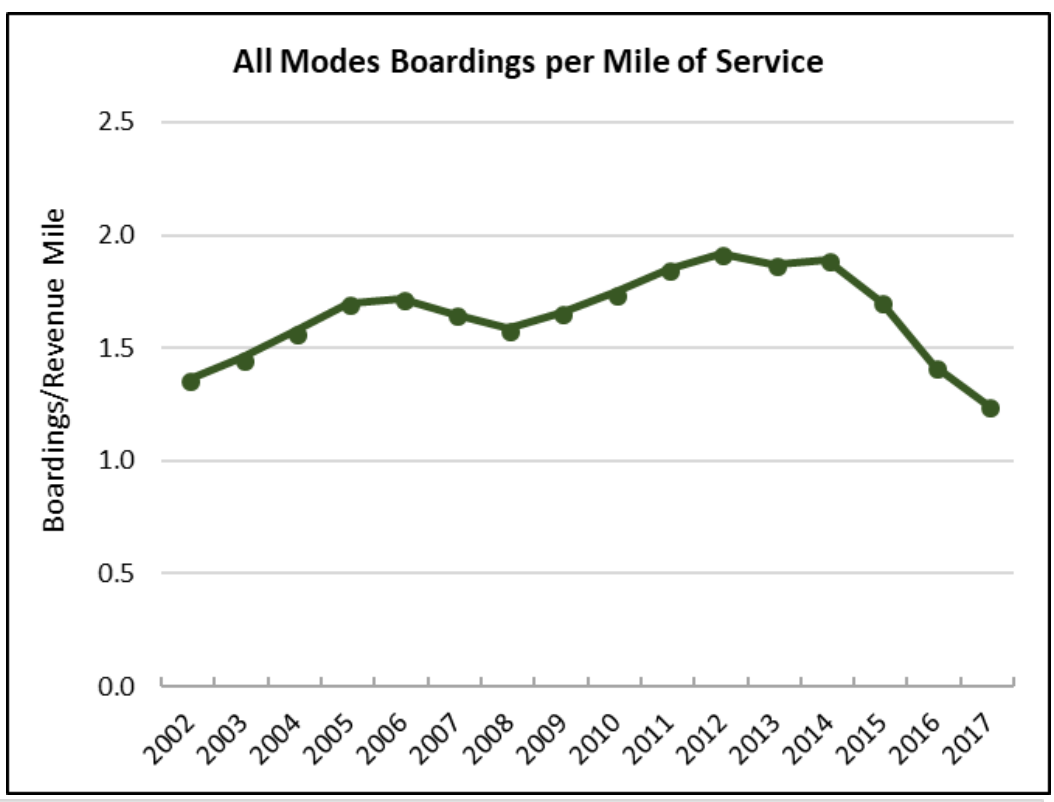

Rolling 12-Month Ridership Trend by Transit Mode

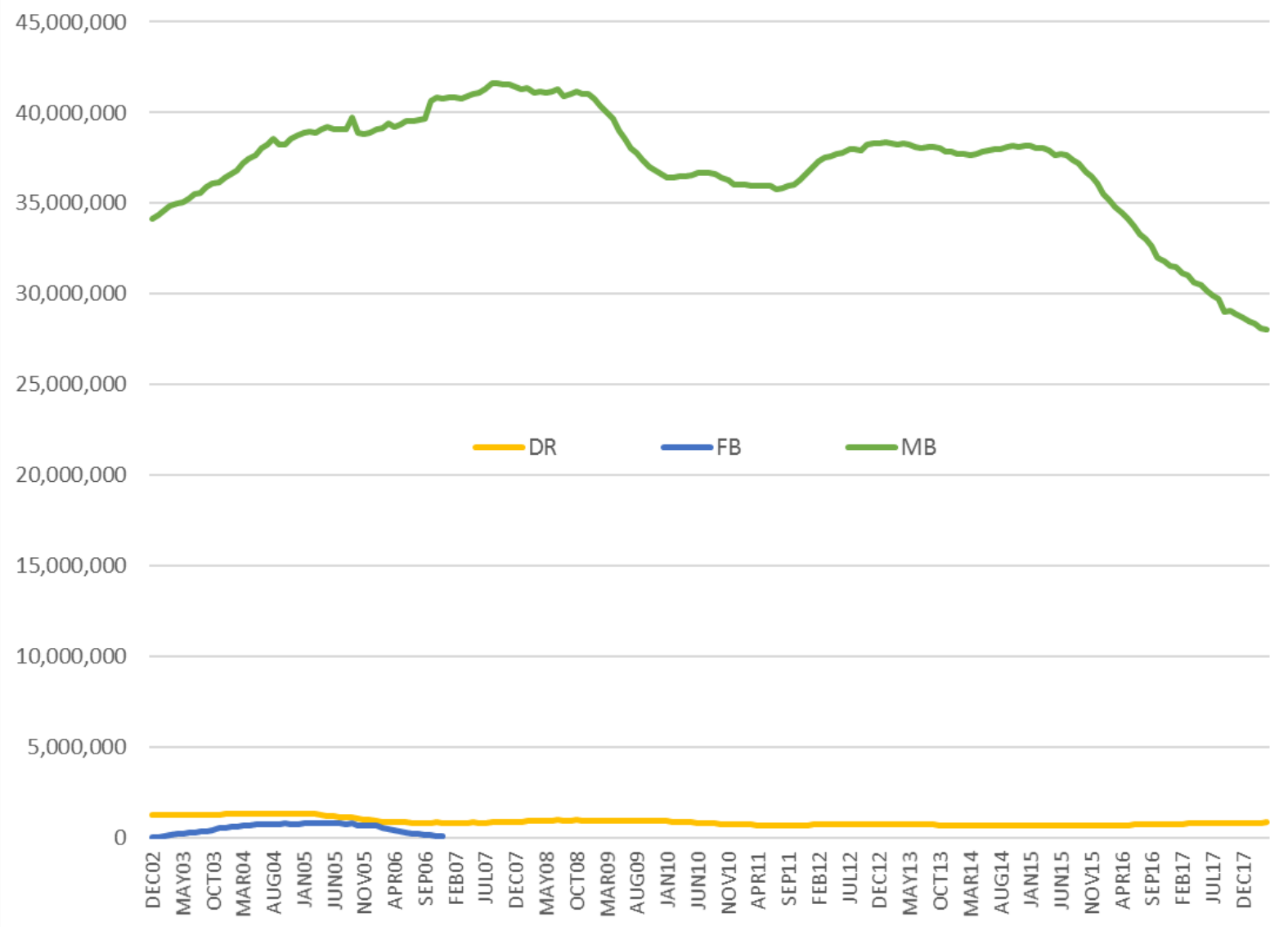


approximately $26 \%$ for the three-year period with that end date. Demand responsive service grew $8 \%$ in the past year and $26 \%$ over the three-year period. Ferry bus service was previously operated in Broward County but is no longer reported.

The final graphic shows service supply as measured by revenue vehicle miles of service, as the graphical data communicates, service supply has remained relatively stable over time. In the past few years increases in commuter bus service offset some of the declines in regular bus service. More recently, bus service has shown some reduction in service. Bus service levels are approximately $2 \%$ below one year ago and a similar level below three year ago levels. Demand response miles of service are up 11\% in the past year and up 51\% over three years.

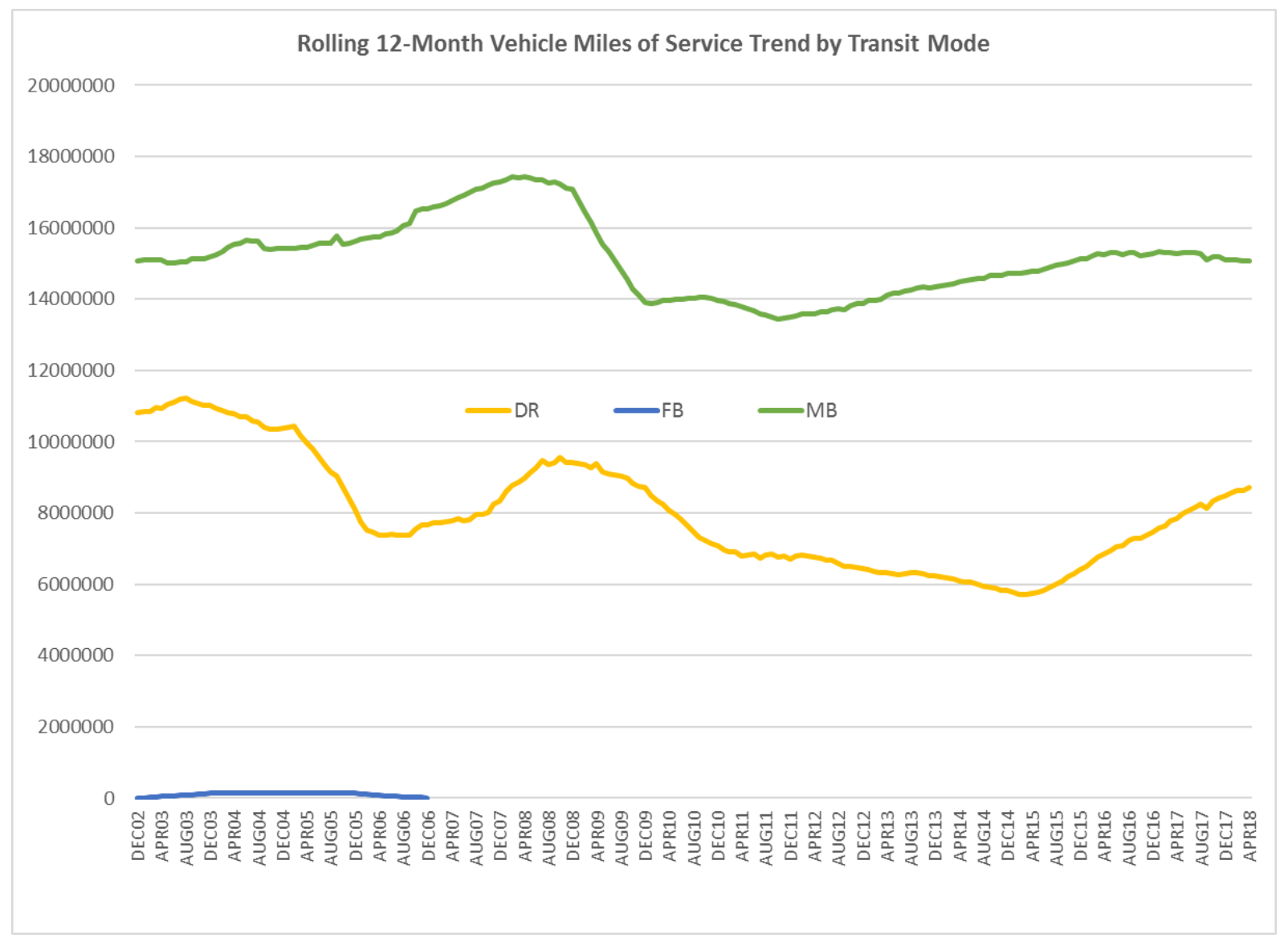


Central Florida RTA (Central Florida Regional Transportation Authority, LYNX)

Ridership on the Central

Florida RTA has declined 13\% since a peak in 2014. Vehicle revenue miles of service has increased nearly $9 \%$ in that same time period. This combination results in a drop in service productivity. Boardings per revenue mile has dropped $28 \%$ since its peak in 2006. Ridership per County resident has declined 21\% from its peak in 2012. The downward trend in ridership has been muted by

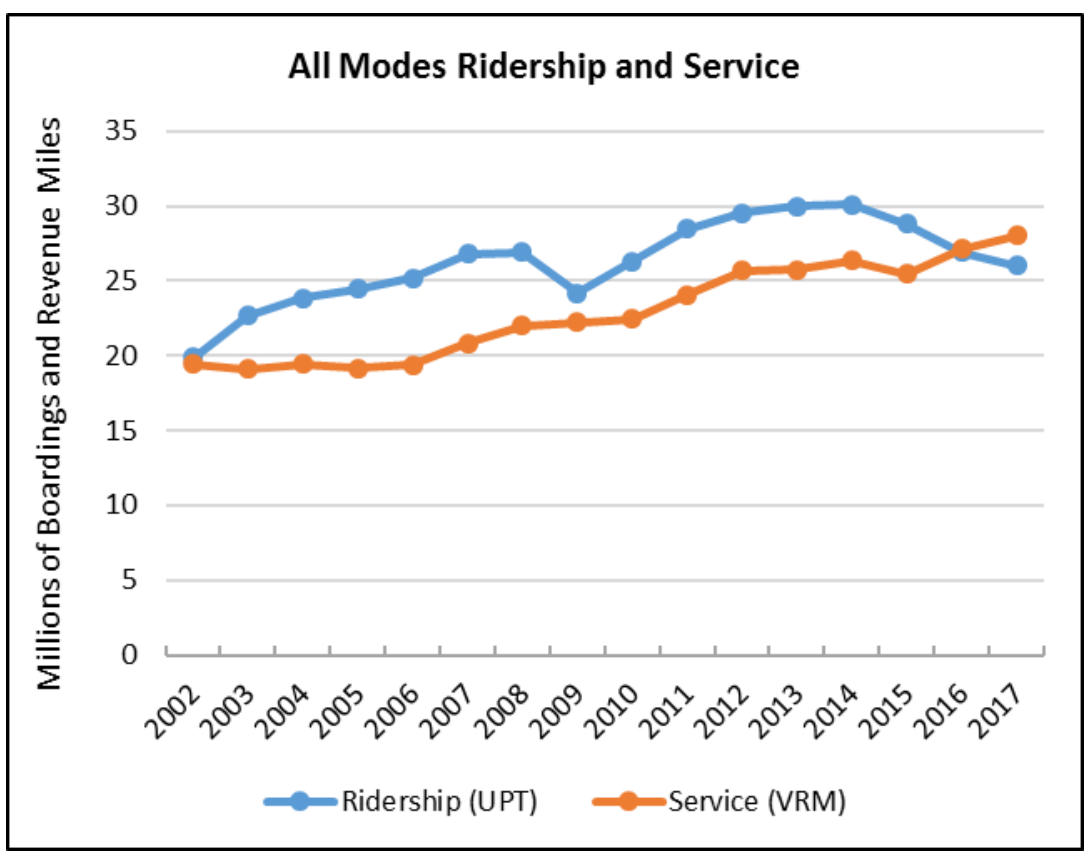
the service expansion. 
In 2017 service utilization as measured by boardings per revenue mile was lower than any prior

\begin{tabular}{|c|c|c|c|c|c|c|c|c|}
\hline \multicolumn{9}{|c|}{ Annual Trend Data, All Modes } \\
\hline Year & Ridership (UPT) & Service (VRM) & $\begin{array}{c}\text { Boardings } \\
\text { per Revenue } \\
\text { Mile }\end{array}$ & $\begin{array}{l}\text { AVG Fixed- } \\
\text { Route } \\
\text { Speed } \\
\text { (mph) }\end{array}$ & County Pop & Trips per Capita & $\begin{array}{l}\text { Passenger } \\
\text { Miles of } \\
\text { Travel }\end{array}$ & $\begin{array}{l}\text { Average } \\
\text { Trip } \\
\text { Length }\end{array}$ \\
\hline 2002 & $19,891,640$ & $19,421,667$ & 1.02 & 13.93 & 1536846 & 12.9 & $144,252,157$ & 7.25 \\
\hline 2003 & $22,668,289$ & $19,114,073$ & 1.19 & 14.01 & 1588503 & 14.3 & $147,099,769$ & 6.49 \\
\hline 2004 & $23,873,273$ & $19,420,121$ & 1.23 & 14.08 & 1643114 & 14.5 & $144,207,156$ & 6.04 \\
\hline 2005 & $24,469,835$ & $19,173,560$ & 1.28 & 14.31 & 1690337 & 14.5 & $160,205,605$ & 6.55 \\
\hline 2006 & $25,216,948$ & $19,384,621$ & 1.30 & 14.10 & 1756094 & 14.4 & $162,837,682$ & 6.46 \\
\hline 2007 & $26,790,330$ & $20,826,600$ & 1.29 & 13.94 & 1797424 & 14.9 & $159,324,353$ & 5.95 \\
\hline 2008 & $26,898,347$ & $21,987,849$ & 1.22 & 13.77 & 1815101 & 14.8 & $166,769,628$ & 6.20 \\
\hline 2009 & $24,213,617$ & $22,211,261$ & 1.09 & 13.80 & 1805429 & 13.4 & $151,389,724$ & 6.25 \\
\hline 2010 & $26,281,263$ & $22,486,235$ & 1.17 & 14.36 & 1842845 & 14.3 & $148,294,757$ & 5.64 \\
\hline 2011 & $28,487,964$ & $24,063,763$ & 1.18 & 14.19 & 1855796 & 15.4 & $156,697,957$ & 5.50 \\
\hline 2012 & $29,530,845$ & $25,694,400$ & 1.15 & 14.58 & 1884911 & 15.7 & $164,408,315$ & 5.57 \\
\hline 2013 & $30,005,027$ & $25,777,371$ & 1.16 & 13.68 & 1922413 & 15.6 & $167,299,657$ & 5.58 \\
\hline 2014 & $30,105,716$ & $26,368,202$ & 1.14 & 13.60 & 1960634 & 15.4 & $178,129,638$ & 5.92 \\
\hline 2015 & $28,800,407$ & $25,495,211$ & 1.13 & 13.62 & 2003626 & 14.4 & $169,531,611$ & 5.89 \\
\hline 2016 & $26,930,409$ & $27,172,249$ & 0.99 & 13.49 & 2052373 & 13.1 & $152,609,519$ & 5.67 \\
\hline 2017 & $26,039,274$ & $28,014,457$ & 0.93 & 13.50 & 2106251 & 12.4 & & \\
\hline
\end{tabular}

year in the reference data. Average trip length on transit has declined modestly but fluctuates under six miles.

As noted in the monthly ridership trend, the ridership decline impact from Hurricane Irma was more moderate than in southeast Florida. Ridership in the first quarter of 2018 was running behind the prior year by approximately $6 \%$.

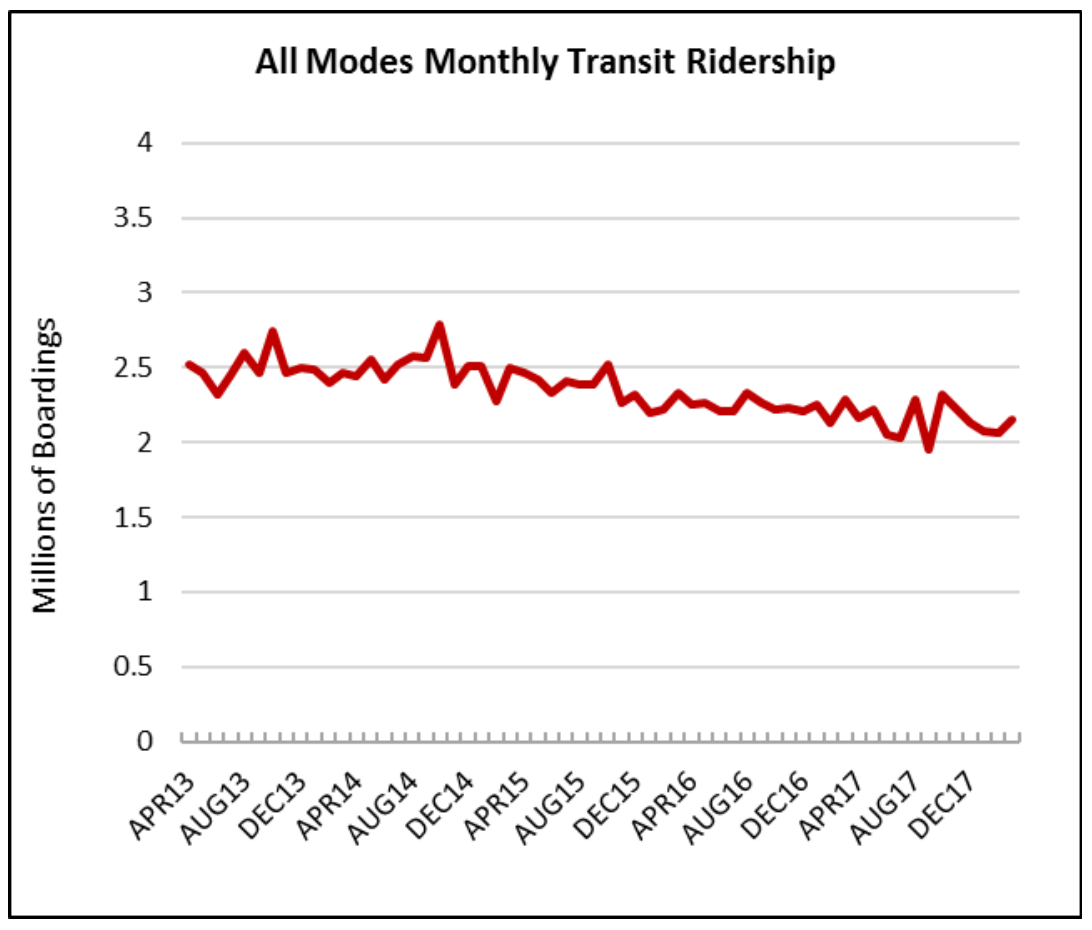


Average operating speed defined as vehicle revenue miles divided by vehicle revenue hours, has remained relatively stable in the $14 \mathrm{mph}$ range since 2002. There has been a slight downward trend in speed through the economic recovery, presumably a consequence of greater congestion.

The subsequent graphic shows service productivity. It has been declining since

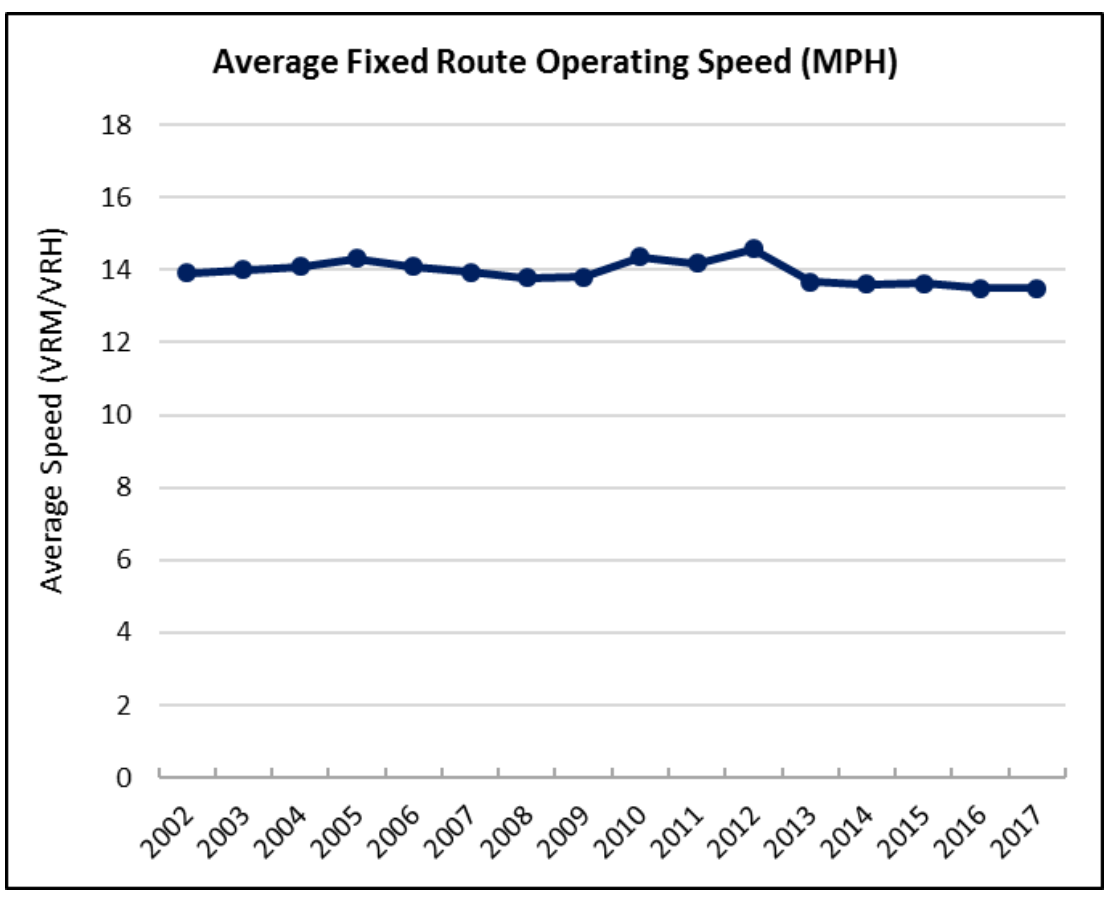
2011 and is below the prior low in 2002.

The figures below provide the ridership trend and service supply trends by sub mode. This allows one to understand how the various component modes are performing. As visibly apparent, bus ridership dominates and has had the most pronounced decline in ridership. Bus ridership has declined approximately $4 \%$ for the one year and $15 \%$ over three years. Demand responsive ridership declined

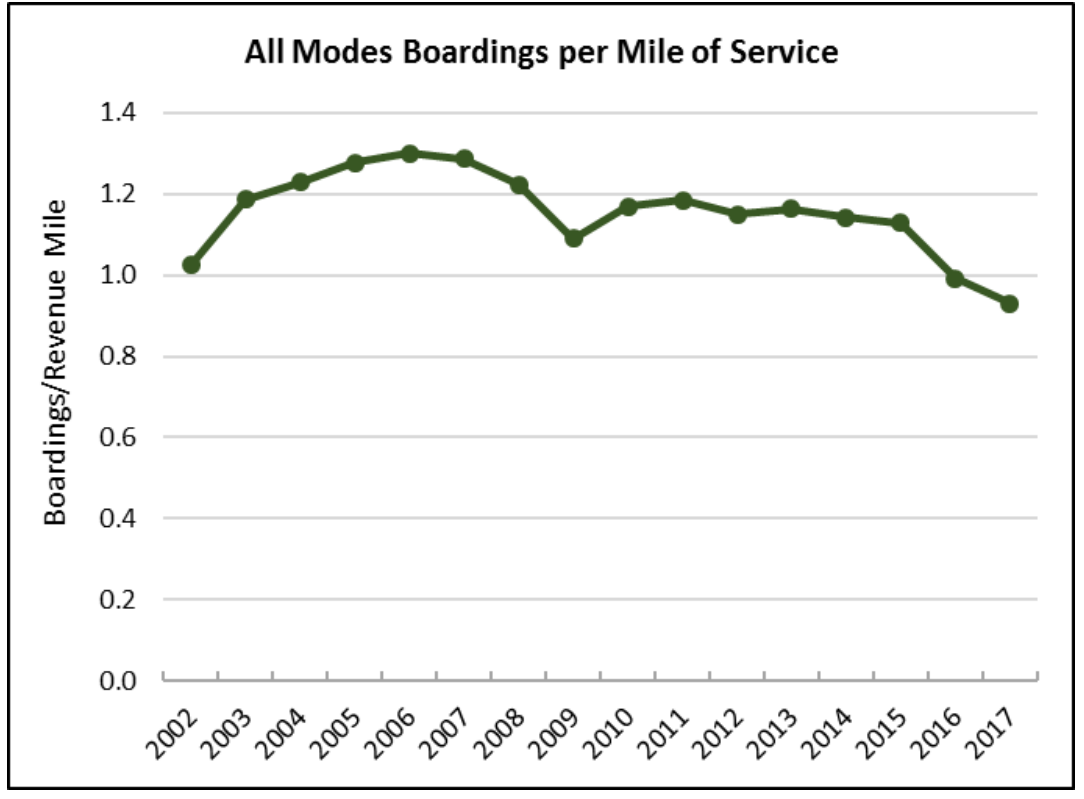
$1 \%$ in the past year and $12 \%$ over the three-year period. 
Rolling 12-Month Ridership Trend by Transit Mode

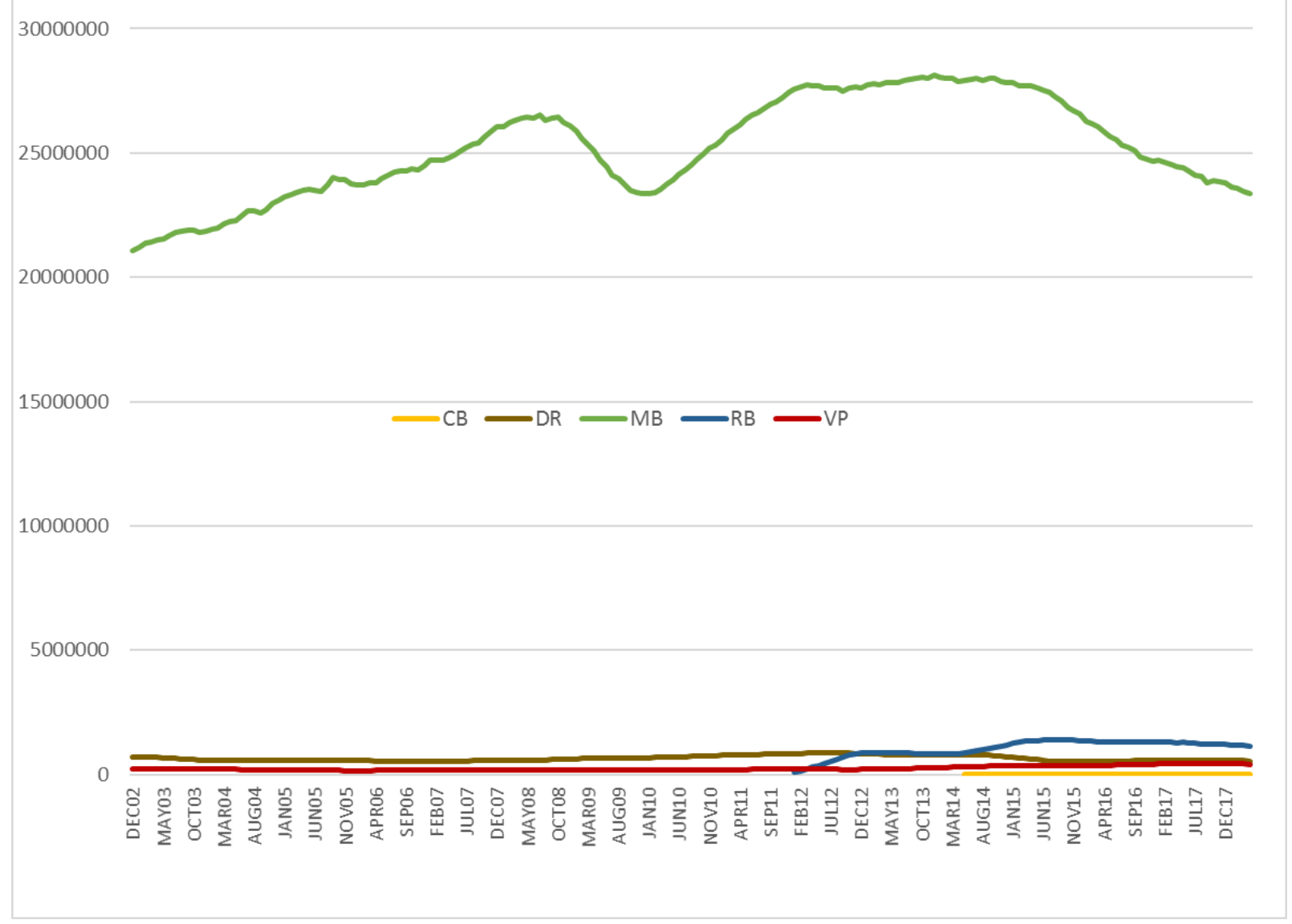

The final graphic shows service supply as measured by revenue vehicle miles of service, as the graphical data communicates, service supply has generally grown over time. Rapid bus and commuter bus service have been added/enumerated over the past few years. Bus service levels are approximately level with last year and 3\% above three year ago levels. Demand response and vanpool services have trended upward with fluctuations including downward fluctuations over the past half year. 
Rolling 12-Month Revenue Miles of Service Trend by Transit Mode

18000000
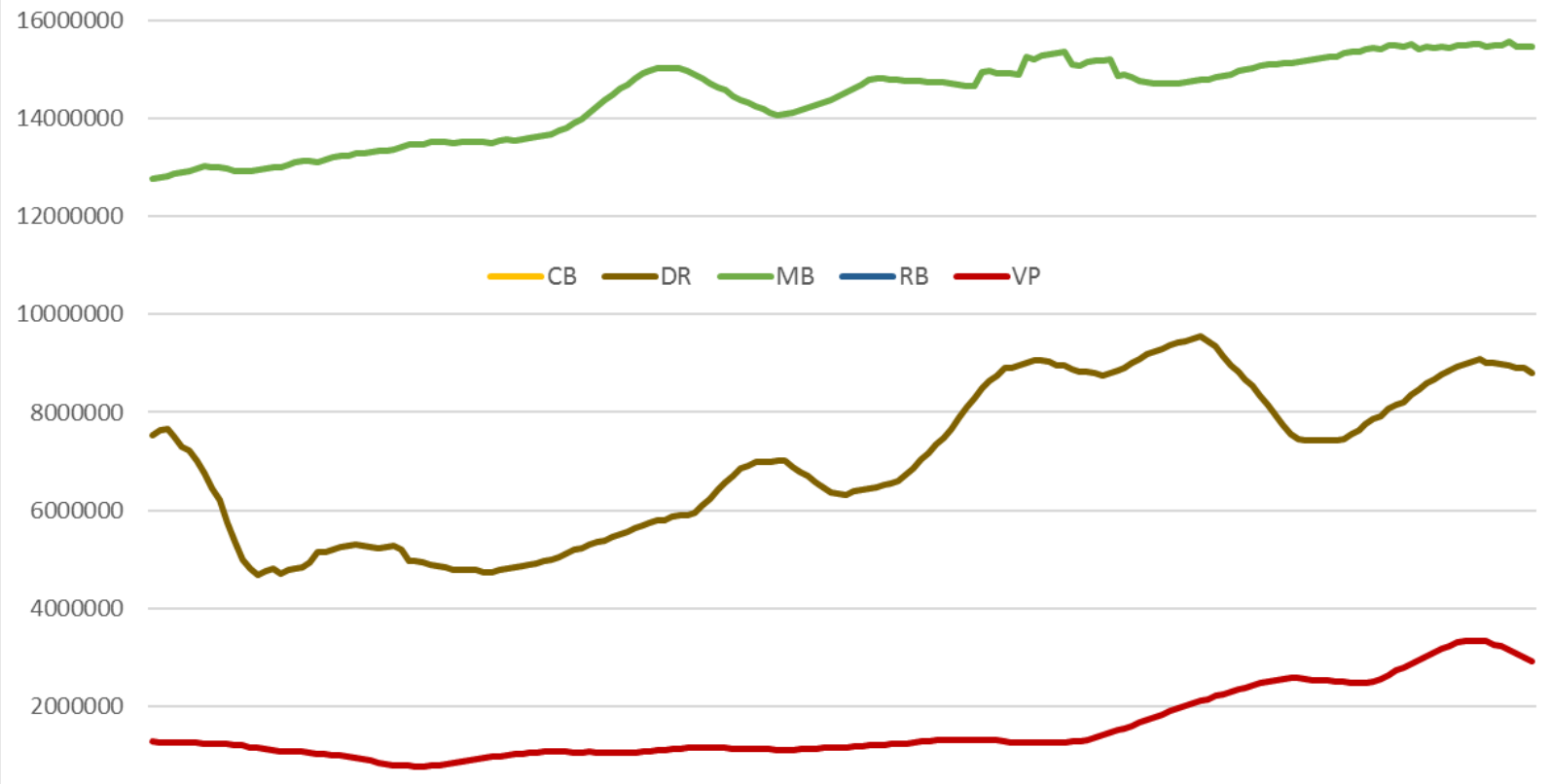

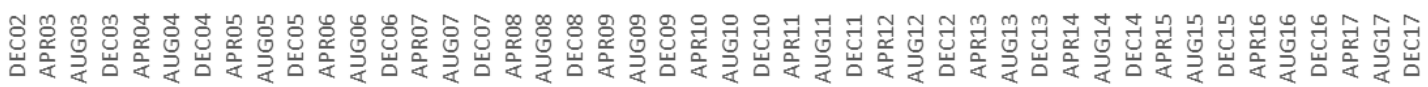




\section{Hillsborough County (Hillsborough Area Regional Transit Authority, HART)}

Ridership on the Hillsborough has declined $17 \%$ since a peak in 2014. Vehicle revenue miles of service has increased $1 \%$ in that same time period. This combination results in a drop in service productivity. Boardings per revenue mile has dropped $21 \%$ since its peak in 2012. Ridership per County resident has declined $21 \%$ from its peak in 2014.

Average trip length on transit Area Regional Transit system

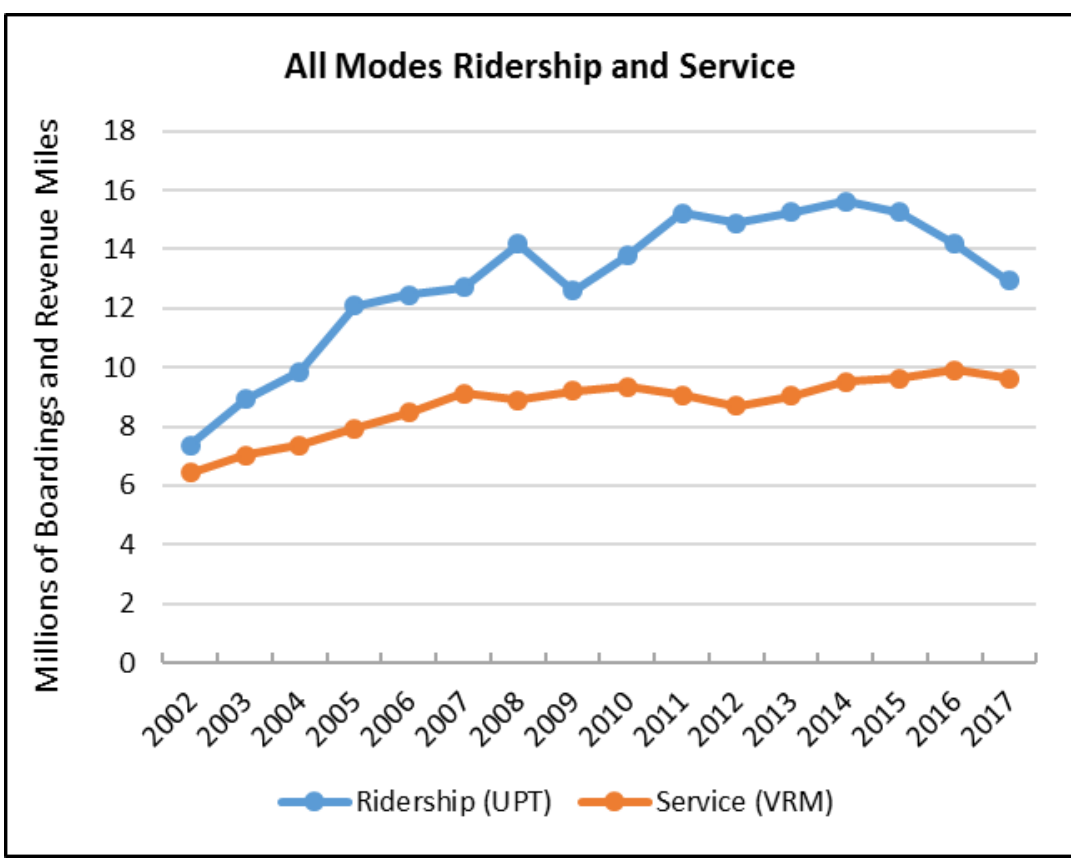

\begin{tabular}{|c|c|c|c|c|c|c|c|c|}
\hline \multicolumn{9}{|c|}{ Annual Trend Data, All Modes } \\
\hline Year & Ridership (UPT) & Service (VRM) & $\begin{array}{c}\text { Boardings } \\
\text { per Revenue } \\
\text { Mile }\end{array}$ & $\begin{array}{l}\text { AVG Fixed- } \\
\text { Route } \\
\text { Speed } \\
\text { (mph) }\end{array}$ & County Pop & Trips per Capita & $\begin{array}{c}\text { Passenger } \\
\text { Miles of } \\
\text { Travel }\end{array}$ & $\begin{array}{l}\text { Average } \\
\text { Trip } \\
\text { Length }\end{array}$ \\
\hline 2002 & $7,367,965$ & $6,426,542$ & 1.15 & 12.22 & $1,055,617$ & 7.0 & $42,180,572$ & 5.72 \\
\hline 2003 & $8,934,988$ & $7,028,278$ & 1.27 & 11.95 & $1,079,587$ & 8.3 & $46,077,352$ & 5.16 \\
\hline 2004 & $9,867,362$ & $7,367,533$ & 1.34 & 12.61 & $1,108,435$ & 8.9 & $51,603,922$ & 5.23 \\
\hline 2005 & $12,081,482$ & $7,933,295$ & 1.52 & 12.16 & $1,131,546$ & 10.7 & $56,991,258$ & 4.72 \\
\hline 2006 & $12,450,064$ & $8,465,558$ & 1.47 & 12.27 & $1,164,425$ & 10.7 & $64,639,403$ & 5.19 \\
\hline 2007 & $12,721,548$ & $9,110,247$ & 1.40 & 12.39 & $1,192,861$ & 10.7 & $66,604,762$ & 5.24 \\
\hline 2008 & $14,183,168$ & $8,902,930$ & 1.59 & 12.38 & $1,200,541$ & 11.8 & $72,728,454$ & 5.13 \\
\hline 2009 & $12,590,661$ & $9,196,118$ & 1.37 & 12.58 & $1,196,892$ & 10.5 & $68,543,371$ & 5.44 \\
\hline 2010 & $13,797,508$ & $9,338,914$ & 1.48 & 12.59 & $1,233,846$ & 11.2 & $64,276,461$ & 4.66 \\
\hline 2011 & $15,220,438$ & $9,067,216$ & 1.68 & 12.56 & $1,238,951$ & 12.3 & $75,504,604$ & 4.96 \\
\hline 2012 & $14,879,977$ & $8,694,894$ & 1.71 & 12.40 & $1,256,118$ & 11.8 & $74,524,583$ & 5.01 \\
\hline 2013 & $15,258,647$ & $9,024,905$ & 1.69 & 12.47 & $1,276,410$ & 12.0 & $75,239,499$ & 4.93 \\
\hline 2014 & $15,638,626$ & $9,503,831$ & 1.65 & 12.35 & $1,301,887$ & 12.0 & $75,717,224$ & 4.84 \\
\hline 2015 & $15,244,489$ & $9,628,944$ & 1.58 & 12.41 & $1,325,563$ & 11.5 & $82,522,556$ & 5.41 \\
\hline 2016 & $14,187,301$ & $9,915,228$ & 1.43 & 12.56 & $1,352,797$ & 10.5 & $78,068,659$ & 5.50 \\
\hline 2017 & $12,950,147$ & $9,625,324$ & 1.35 & 12.35 & $1,379,302$ & 9.4 & & \\
\hline
\end{tabular}

fluctuates on average over 5 miles. 
As noted in the monthly ridership trend, the ridership decline impact from Hurricane Irma is evident. Ridership in the first third of 2018 was running behind the prior year by approximately $13 \%$.
Average operating speed, defined as vehicle revenue miles divided by vehicle revenue hours, has remained relatively stable in the $12 \mathrm{mph}$ range since 2002.

The subsequent graphic shows
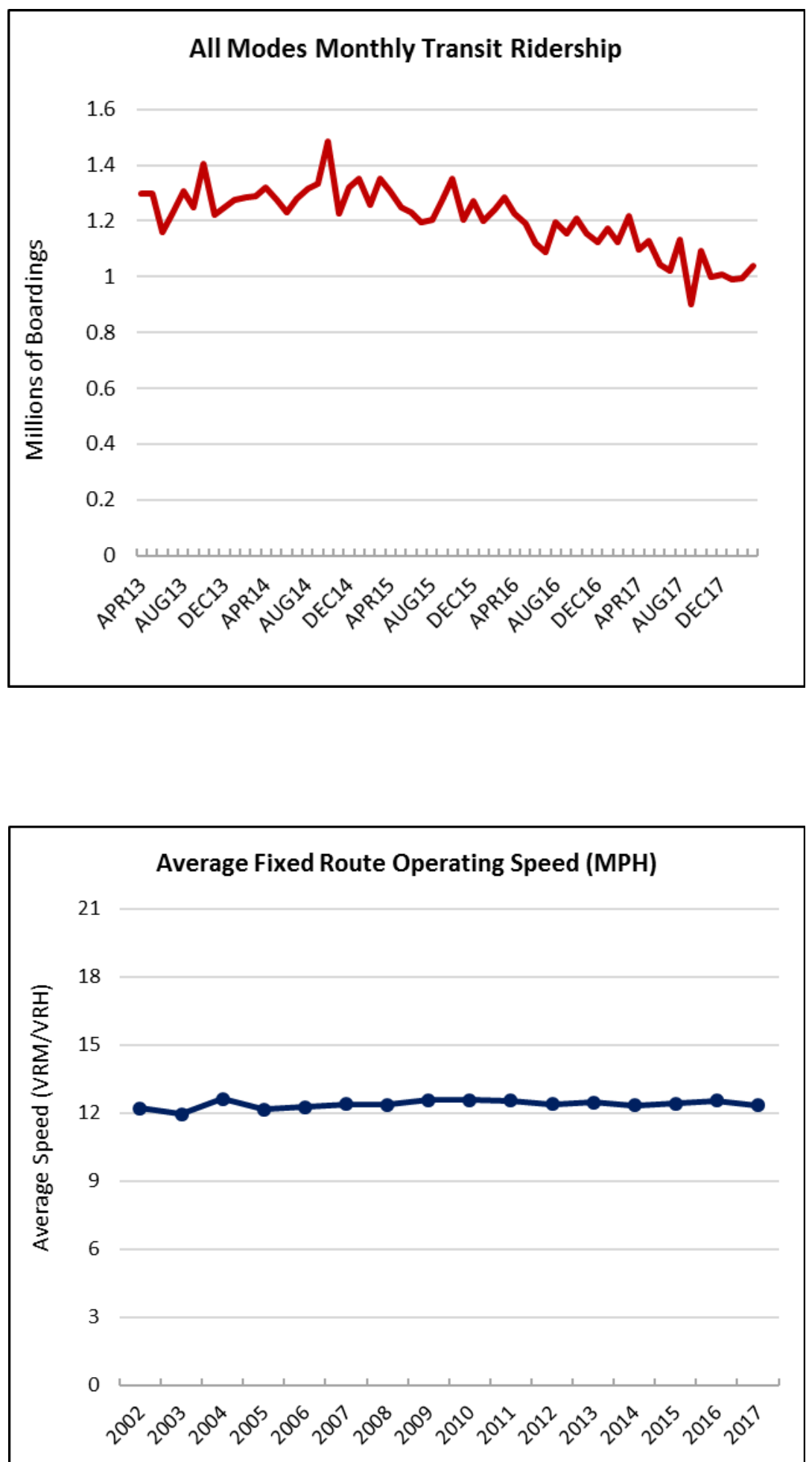
service productivity. It has been declining since 2012 but remains above levels in 2002 and 2003. 
The figures below provide the ridership trends and service supply trends by sub mode. This allows one to understand how the various component modes are performing. As visibly apparent, bus ridership dominates and has had the most pronounced decline in ridership. Bus ridership has declined approximately $11 \%$ for the one year and $21 \%$ over three years. Demand responsive ridership has grown

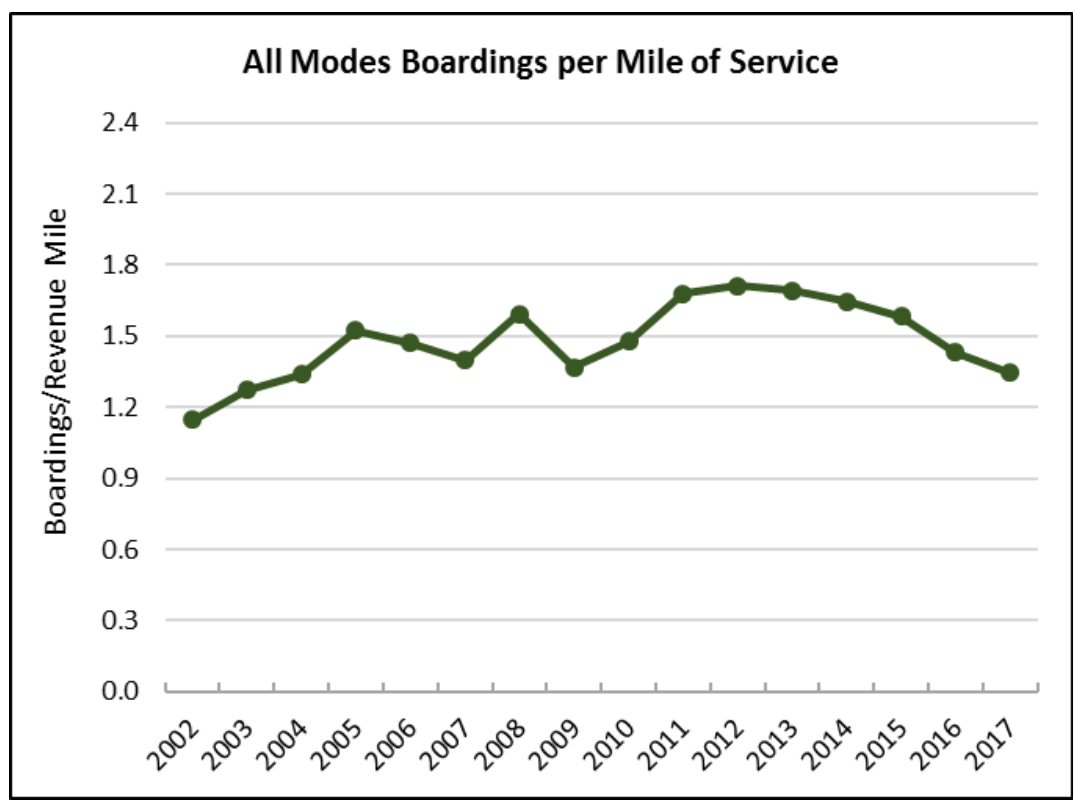
$4 \%$ in the past year and $5 \%$ over the three-year period. Vanpool service that was previously

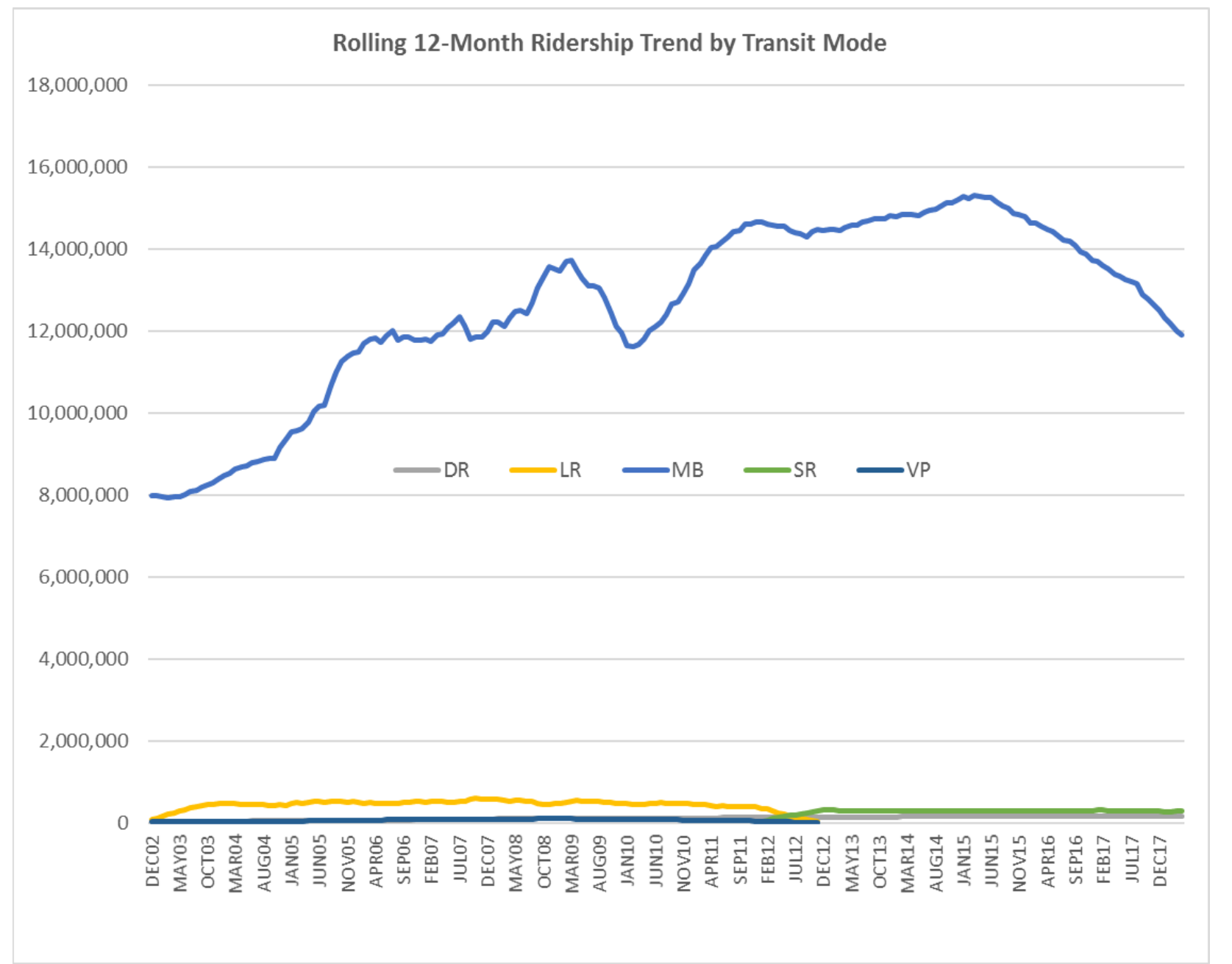


operated by HART has transition to operation by TBARTA several years ago. TECO streetcar service was previously categorized for data collection purposes as light rail but in more recent years is categorized as street rail. Ridership has declined $7 \%$ in the past year and $3 \%$ over a three-year period.

The final graphic shows service supply as measured by revenue vehicle miles of service, as the graphical data communicates, service supply has generally grown over time until 2017 where a major service redesign resulted in significant service cuts. Demand response services have trended upward. More bus service has declined $7 \%$ in the past year and 3\% over three years. Streetcar service has declined $12 \%$ in the past year and 3\% over three years. Demand responsive service has increased $3 \%$ in the past year and $5 \%$ over three years

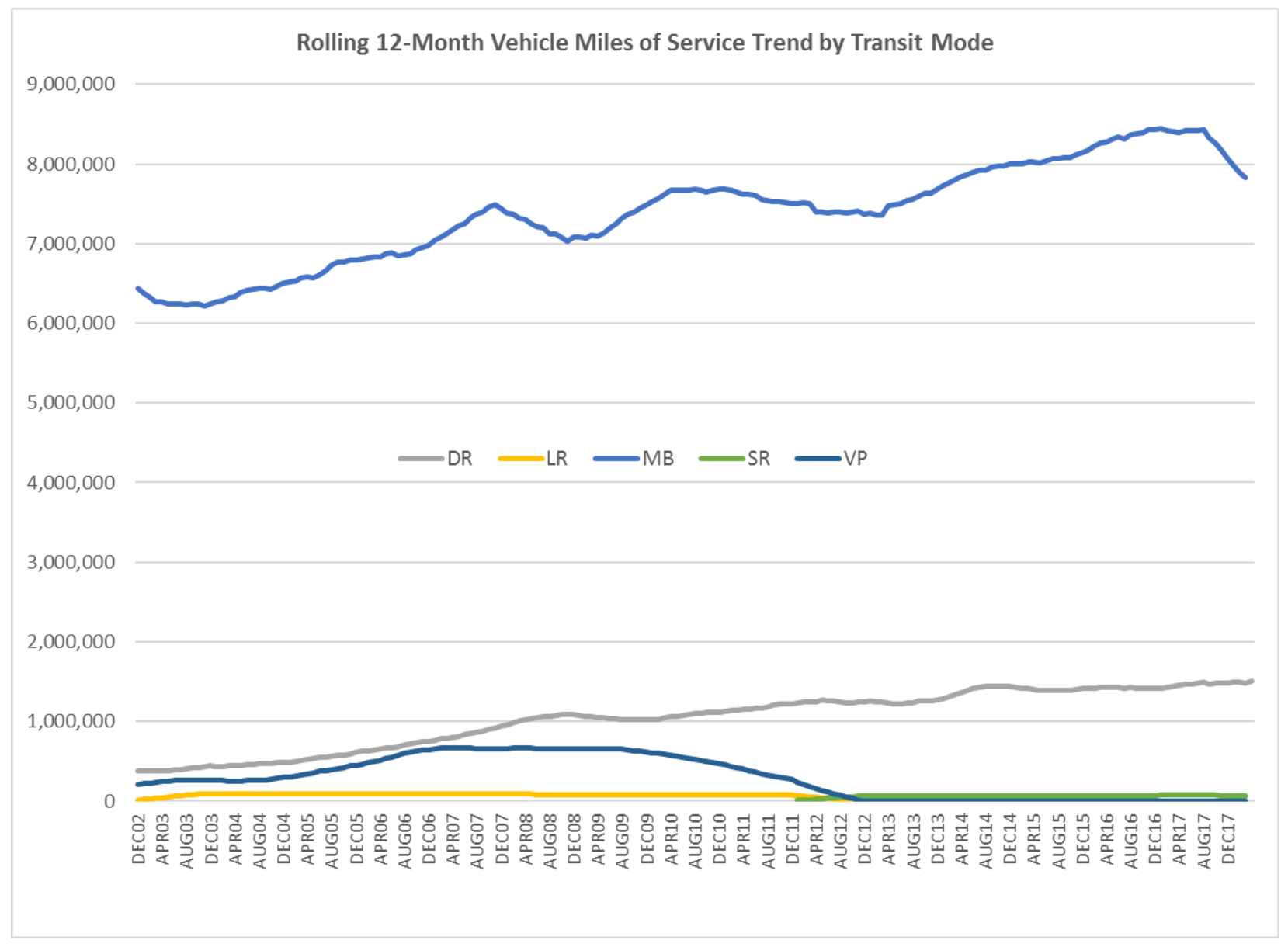


Jacksonville (Jacksonville Transportation Authority, JTA)

Ridership on the Jacksonville transit system has declined $6 \%$ since a peak in 2015. Vehicle revenue miles of service has increased $3 \%$ in that same time period. Jacksonville was among the top performing transit properties in Florida and the country during the past few years. Boardings per revenue mile has dropped $9 \%$ since its peak in 2014.

Ridership per County resident has declined $10 \%$ from its peak in 2011.

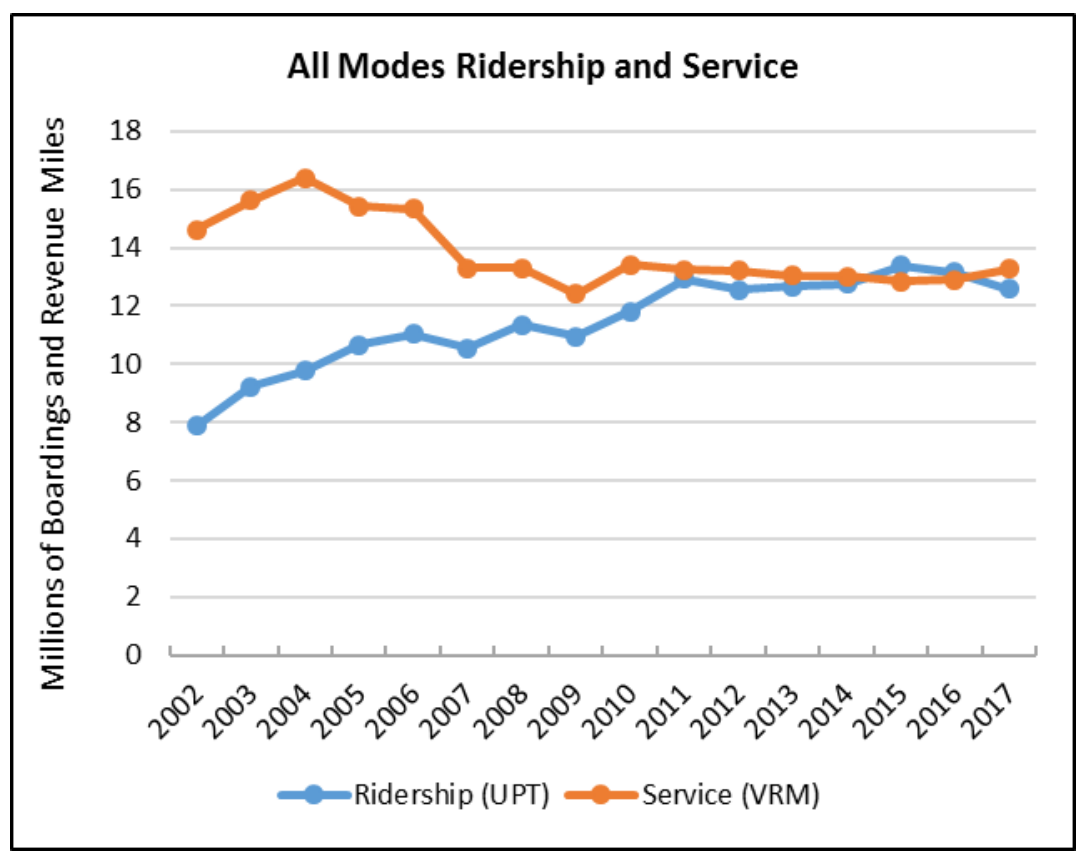

Average trip length on transit has declined through that period with some fluctuations.

\begin{tabular}{|c|c|c|c|c|c|c|c|c|}
\hline \multicolumn{9}{|c|}{ Annual Trend Data, All Modes } \\
\hline Year & Ridership (UPT) & Service (VRM) & $\begin{array}{c}\text { Boardings } \\
\text { per Revenue } \\
\text { Mile }\end{array}$ & $\begin{array}{l}\text { AVG Fixed- } \\
\text { Route } \\
\text { Speed } \\
\text { (mph) }\end{array}$ & $\begin{array}{c}\text { County } \\
\text { Population }\end{array}$ & $\begin{array}{c}\text { Trips per } \\
\text { Capita }\end{array}$ & $\begin{array}{c}\text { Passenger } \\
\text { Miles of } \\
\text { Travel }\end{array}$ & $\begin{array}{l}\text { Average } \\
\text { Trip } \\
\text { Length }\end{array}$ \\
\hline 2002 & $7,863,030$ & $14,618,631$ & 0.54 & 16.17 & 809,394 & 9.7 & $59,103,681$ & 7.52 \\
\hline 2003 & $9,219,333$ & $15,619,206$ & 0.59 & 16.51 & 826,279 & 11.2 & $68,247,806$ & 7.40 \\
\hline 2004 & $9,767,889$ & $16,392,535$ & 0.60 & 18.03 & 840,474 & 11.6 & $65,765,969$ & 6.73 \\
\hline 2005 & $10,653,814$ & $15,415,206$ & 0.69 & 17.55 & 861,150 & 12.4 & $66,968,618$ & 6.29 \\
\hline 2006 & $11,046,036$ & $15,328,079$ & 0.72 & 17.22 & 879,235 & 12.6 & $68,315,820$ & 6.18 \\
\hline 2007 & $10,541,775$ & $13,295,939$ & 0.79 & 16.52 & 897,597 & 11.7 & $63,897,191$ & 6.06 \\
\hline 2008 & $11,345,892$ & $13,313,590$ & 0.85 & 16.58 & 904,971 & 12.5 & $57,857,188$ & 5.10 \\
\hline 2009 & $10,936,822$ & $12,421,673$ & 0.88 & 16.70 & 900,518 & 12.1 & $58,419,887$ & 5.34 \\
\hline 2010 & $11,802,138$ & $13,402,289$ & 0.88 & 16.04 & 865,876 & 13.6 & $66,037,029$ & 5.60 \\
\hline 2011 & $12,935,662$ & $13,234,759$ & 0.98 & 14.65 & 864,601 & 15.0 & $74,227,588$ & 5.74 \\
\hline 2012 & $12,549,430$ & $13,212,330$ & 0.95 & 14.55 & 869,729 & 14.4 & $75,757,926$ & 6.04 \\
\hline 2013 & $12,664,444$ & $13,045,971$ & 0.97 & 14.65 & 876,075 & 14.5 & $79,384,669$ & 6.27 \\
\hline 2014 & $12,766,307$ & $13,000,450$ & 0.98 & 14.06 & 890,066 & 14.3 & $80,165,368$ & 6.28 \\
\hline 2015 & $13,387,495$ & $12,835,668$ & 1.04 & 13.76 & 905,574 & 14.8 & $75,960,507$ & 5.67 \\
\hline 2016 & $13,144,270$ & $12,901,815$ & 1.02 & 13.82 & 923,647 & 14.2 & $73,662,800$ & 5.60 \\
\hline 2017 & $12,572,015$ & $13,278,698$ & 0.95 & 13.88 & 936,811 & 13.4 & & \\
\hline
\end{tabular}


The monthly ridership decline impact from Hurricane Irma is evident in the monthly trend data. Ridership in the first quarter of 2018 was running behind the prior year by approximately $9 \%$.

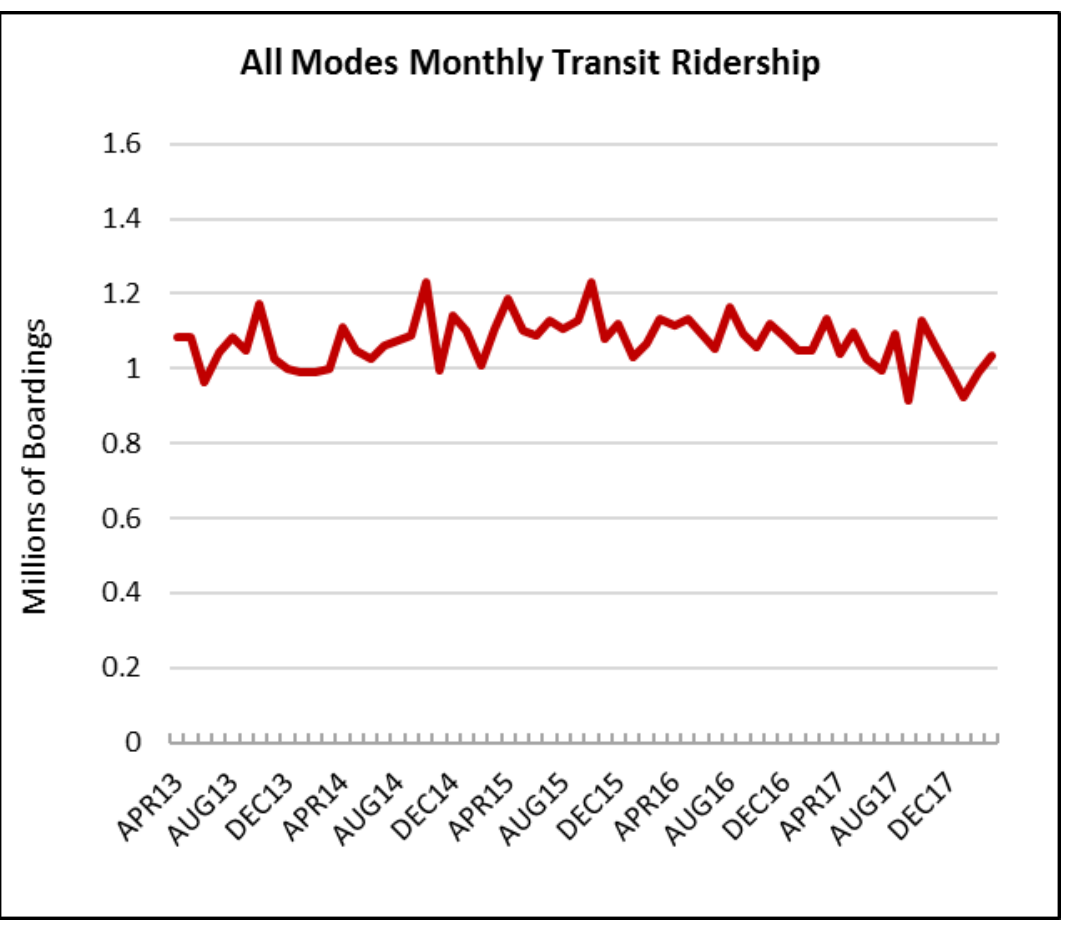

Average operating speed, defined as vehicle revenue miles divided by vehicle revenue hours, has declined almost steadily since 2003 but still remains faster that most urban systems with a speed of nearly $14 \mathrm{mph}$.

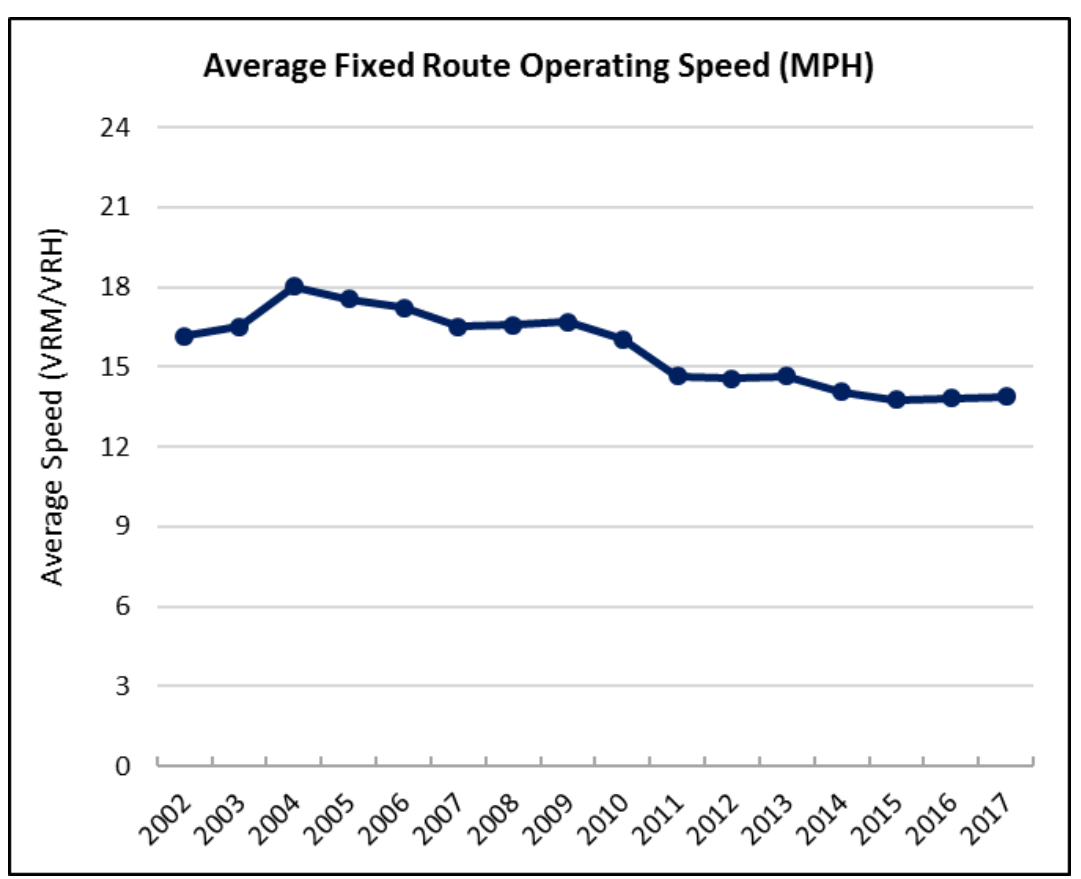

The subsequent graphic shows service productivity. It has been increasing since 2002 until the recent two year dip. 
The figures below provide the ridership trends and service supply trends by sub mode. This allows one to understand how the various component modes are motorbus service levels are up $2 \%$ in the past year and $4 \%$ over three years. Sky train services were level over the past year and down $7 \%$ over three years.

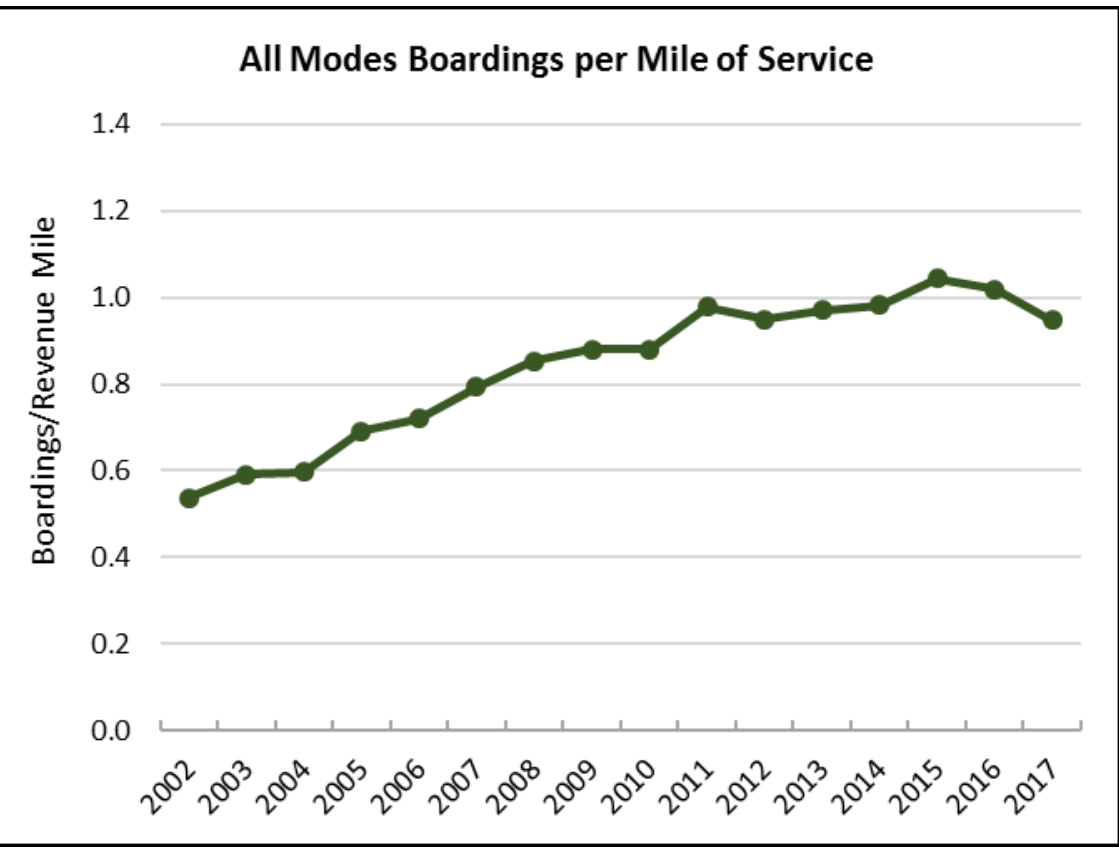

Rolling 12-Month Ridership Trend by Transit Mode

$14,000,000$

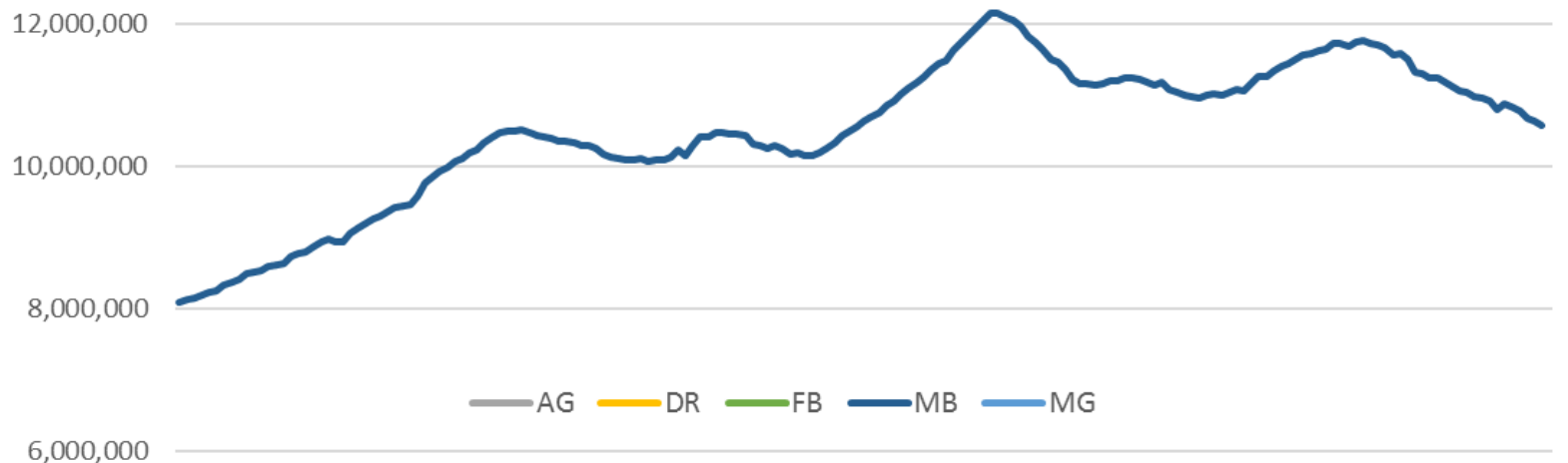

$6,000,000$

$4,000,000$

$2,000,000$

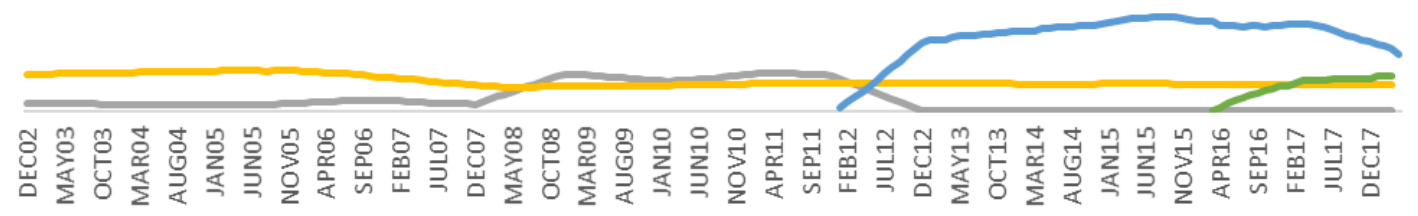


As visibly apparent, bus ridership dominates and has had the most pronounced decline in ridership. Bus ridership has declined approximately $5 \%$ for the one year and $7 \%$ over three years.

The final graphic shows service supply as measured by revenue vehicle miles of service, as the graphical data communicates, service supply has generally grown over time until early 2017 where a major service redesign resulted in significant service reductions. Demand response services have trended stable. Demand responsive ridership been steady in the past year and declined 3\% over the three-year period. The Skytran system (shown as AG and MG in the data set) has declined $28 \%$ in ridership in the past year and $31 \%$ over a three-year period.

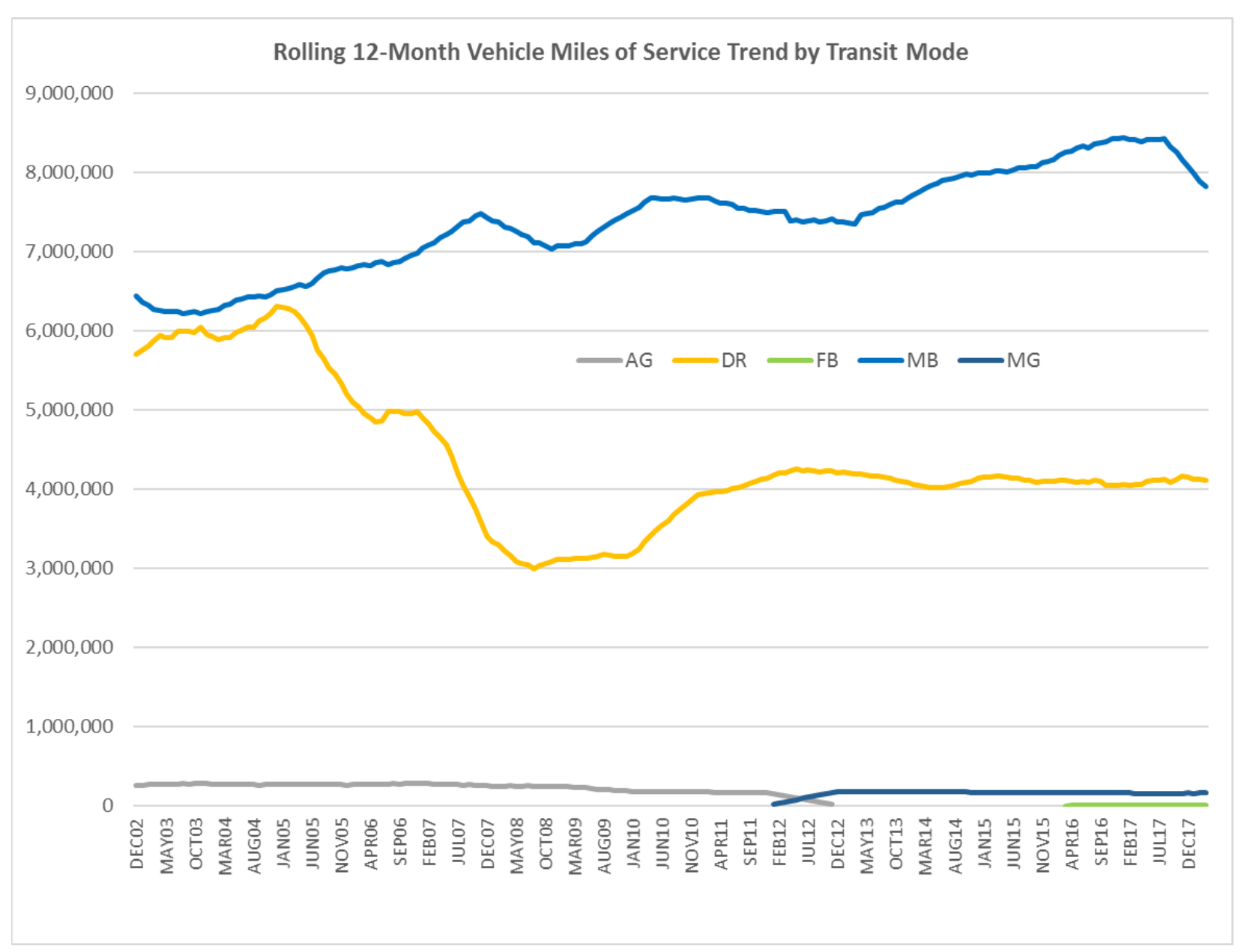


Pinellas County (Pinellas Suncoast Transit Authority, PSTA)

Ridership on the Pinellas

transit system has declined

Vehicle revenue miles of service has increased $3 \%$ in that same time period. The Pinellas transit system was most significantly impacted by declining ridership during the past two years.

Boardings per revenue mile has dropped $21 \%$ since its peak in 2014. Ridership per County resident has declined 22\% from its peak in 2014. 19\% since a peak in 2014.

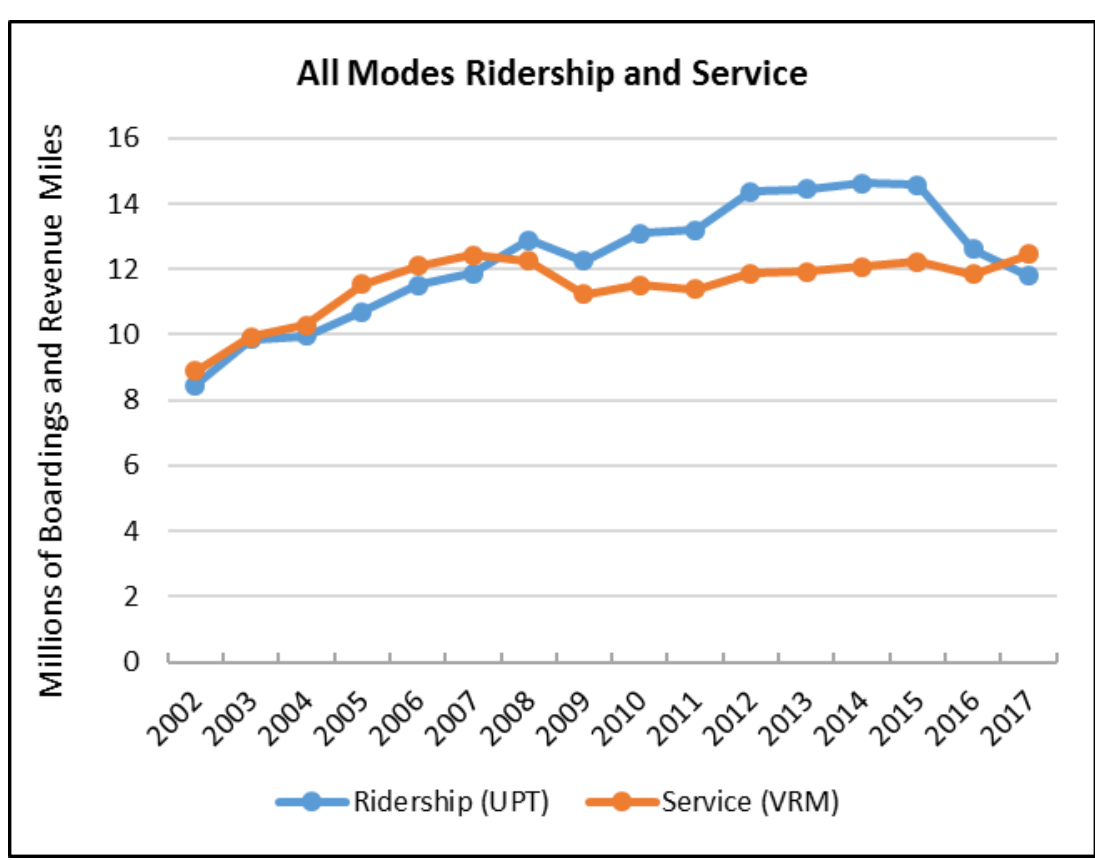

Average trip length on transit has declined through that period with fluctuations.

\begin{tabular}{|c|c|c|c|c|c|c|c|c|}
\hline \multicolumn{9}{|c|}{ Annual Trend Data, All Modes } \\
\hline Year & Ridership (UPT) & Service (VRM) & $\begin{array}{c}\text { Boardings } \\
\text { per Revenue } \\
\text { Mile }\end{array}$ & $\begin{array}{l}\text { AVG Fixed- } \\
\text { Route } \\
\text { Speed } \\
\text { (mph) }\end{array}$ & $\begin{array}{c}\text { County } \\
\text { Population }\end{array}$ & $\begin{array}{l}\text { Trips per } \\
\text { Capita }\end{array}$ & $\begin{array}{c}\text { Passenger } \\
\text { Miles of Travel }\end{array}$ & $\begin{array}{c}\text { Average } \\
\text { Trip } \\
\text { Length }\end{array}$ \\
\hline 2002 & $8,462,596$ & $8,883,373$ & 0.95 & 14.66 & 933,994 & 9.1 & $49,161,201$ & 5.81 \\
\hline 2003 & $9,858,096$ & $9,944,683$ & 0.99 & 14.62 & 939,864 & 10.5 & $49,610,513$ & 5.03 \\
\hline 2004 & $9,968,437$ & $10,281,776$ & 0.97 & 14.51 & 943,640 & 10.6 & $49,993,972$ & 5.02 \\
\hline 2005 & $10,705,025$ & $11,548,012$ & 0.93 & 14.71 & 947,744 & 11.3 & $50,097,925$ & 4.68 \\
\hline 2006 & $11,521,266$ & $12,098,763$ & 0.95 & 14.52 & 948,102 & 12.2 & $56,580,695$ & 4.91 \\
\hline 2007 & $11,875,422$ & $12,426,902$ & 0.96 & 14.68 & 944,199 & 12.6 & $57,835,087$ & 4.87 \\
\hline 2008 & $12,888,398$ & $12,257,844$ & 1.05 & 14.32 & 938,461 & 13.7 & $62,701,368$ & 4.86 \\
\hline 2009 & $12,243,962$ & $11,236,153$ & 1.09 & 14.33 & 931,113 & 13.1 & $63,471,767$ & 5.18 \\
\hline 2010 & $13,098,167$ & $11,518,623$ & 1.14 & 14.16 & 916,719 & 14.3 & $68,429,703$ & 5.22 \\
\hline 2011 & $13,198,099$ & $11,392,421$ & 1.16 & 14.33 & 918,496 & 14.4 & $73,452,254$ & 5.57 \\
\hline 2012 & $14,361,915$ & $11,872,558$ & 1.21 & 14.31 & 920,381 & 15.6 & $73,010,860$ & 5.08 \\
\hline 2013 & $14,440,250$ & $11,935,475$ & 1.21 & 14.23 & 926,610 & 15.6 & $71,543,214$ & 4.95 \\
\hline 2014 & $14,623,581$ & $12,088,624$ & 1.21 & 14.34 & 933,258 & 15.7 & $70,933,094$ & 4.85 \\
\hline 2015 & $14,573,879$ & $12,233,519$ & 1.19 & 14.34 & 944,971 & 15.4 & $69,787,144$ & 4.79 \\
\hline 2016 & $12,608,111$ & $11,836,712$ & 1.07 & 14.29 & 954,569 & 13.2 & $61,086,383$ & 4.85 \\
\hline 2017 & $11,793,282$ & $12,455,573$ & 0.95 & 14.01 & 962,003 & 12.3 & & \\
\hline
\end{tabular}


The monthly ridership decline impact from Hurricane Irma is evident in the monthly trend data. Ridership in the first third of 2018 was running behind the prior year by approximately $2 \%$.

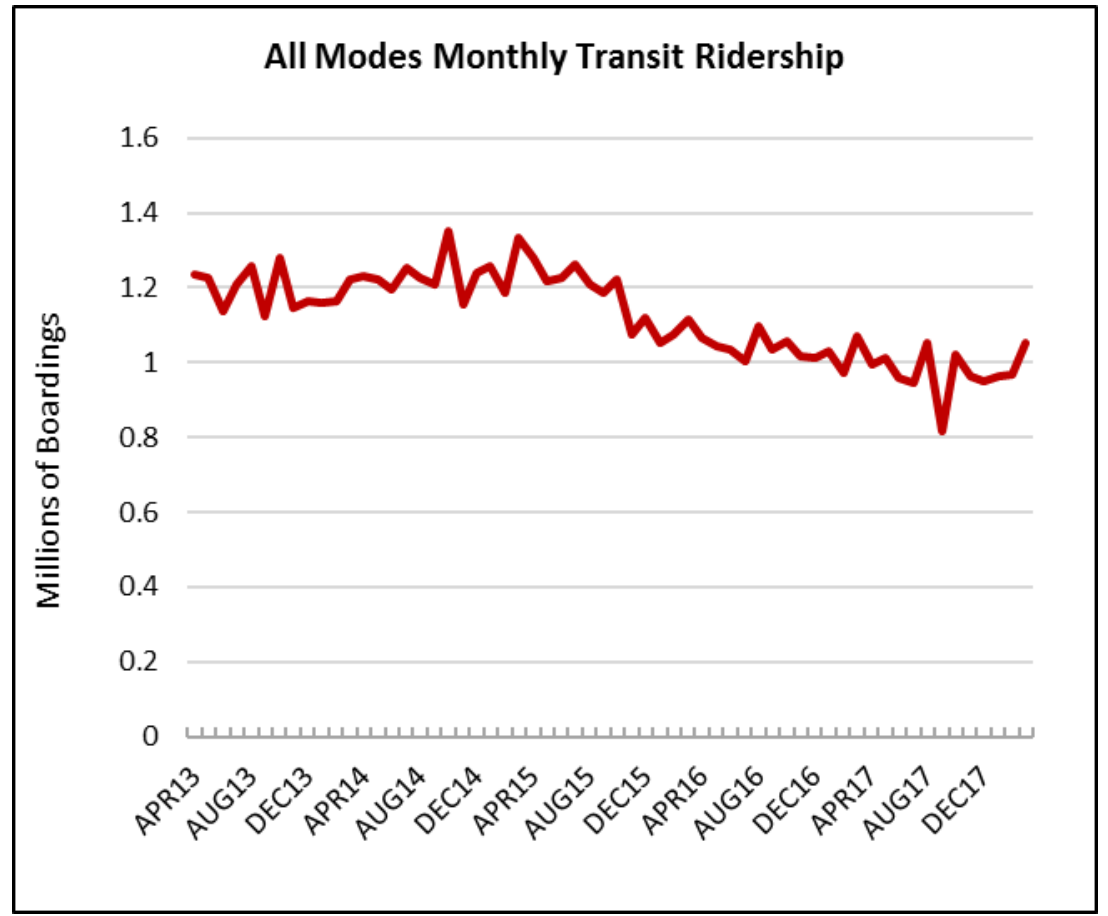

Average operating speed, defined as vehicle revenue miles divided by vehicle revenue hours, has declined very slightly and steadily since 2002 but remains faster that most urban systems with a speed over $14 \mathrm{mph}$.

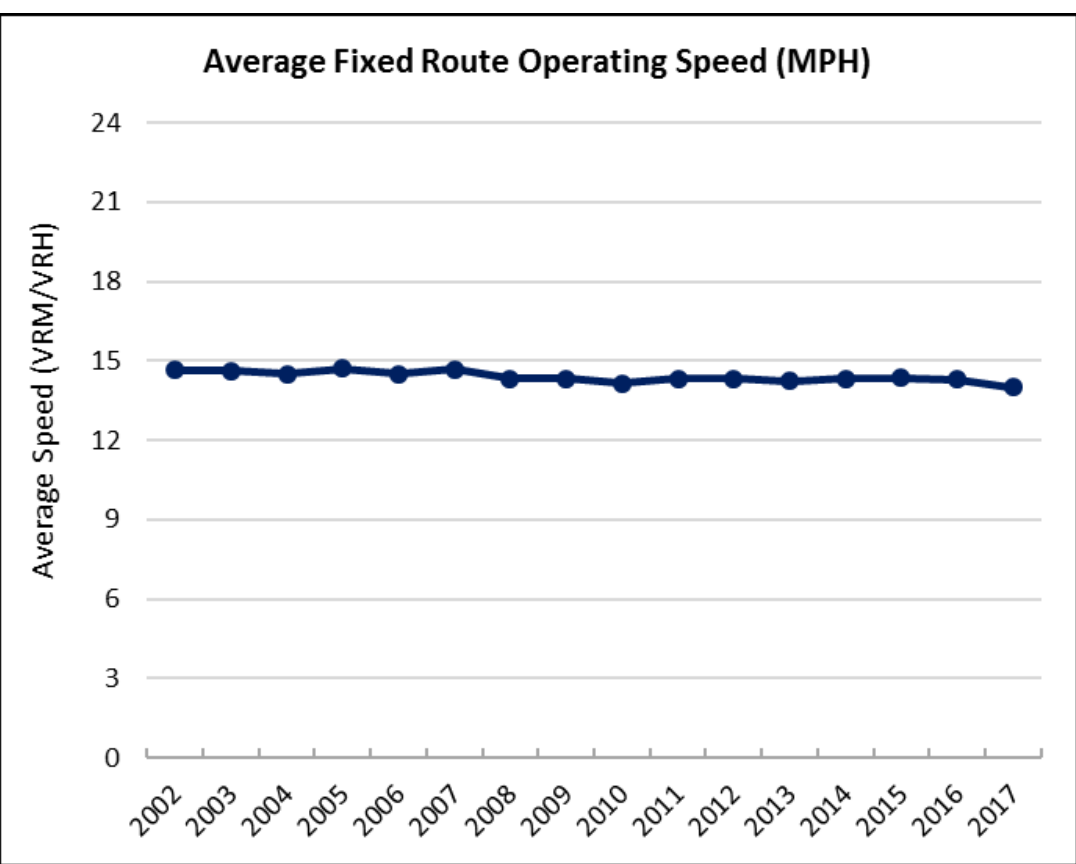


The adjacent graphic shows service

productivity. It has been increasing since 2002 until the recent two year dip.

The figures below provide the ridership trends and service supply trends by sub mode. This allows one to understand how the various component modes are performing. As visibly apparent, bus

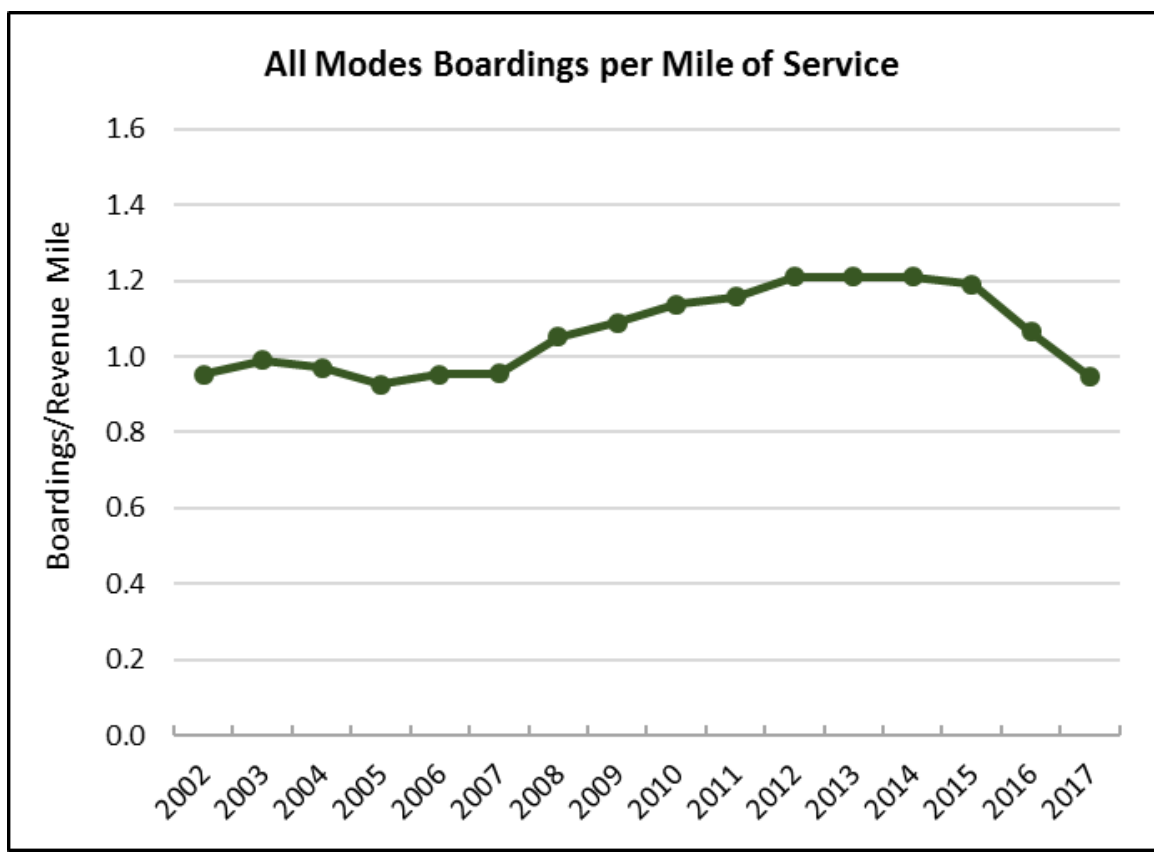

ridership dominates and has had the most pronounced decline in ridership. Bus ridership has

Rolling 12-Month Ridership Trend by Transit Mode

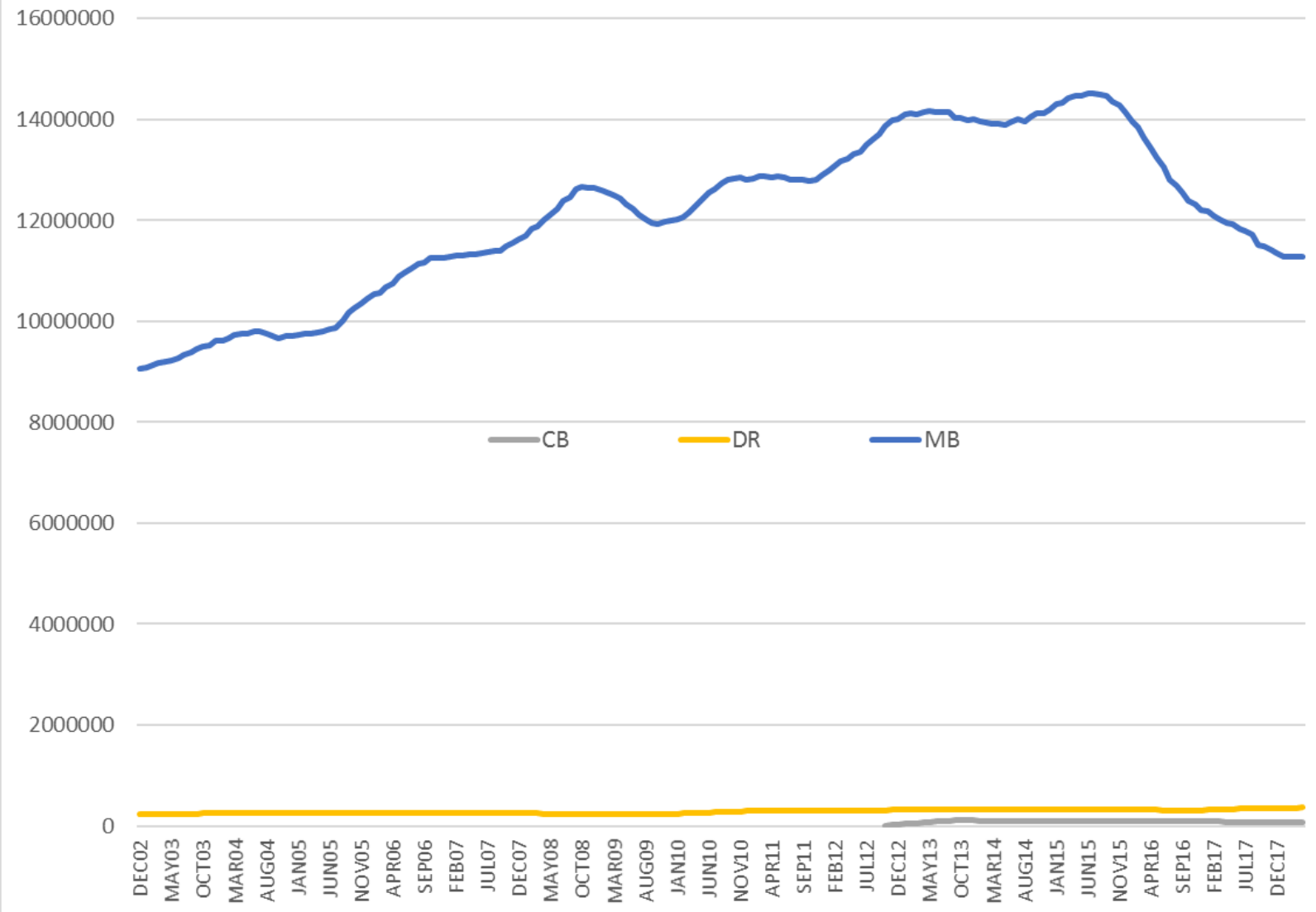


declined approximately $6 \%$ for the one year and $22 \%$ over three years. Demand responsive ridership increased $11 \%$ over the past year and $12 \%$ over the three-year period. Commuter bus service has declined $4 \%$ in the last year and $21 \%$ over three years.

The final graphic shows service supply as measured by revenue vehicle miles of service. As the graphical data communicates, bus service supply has been relatively stable over the years with dips post 2015 and service increases in 2017. Motorbus service has been steady over the past year and is down $5 \%$ over three years. Demand responsive service has increased $24 \%$ and $33 \%$

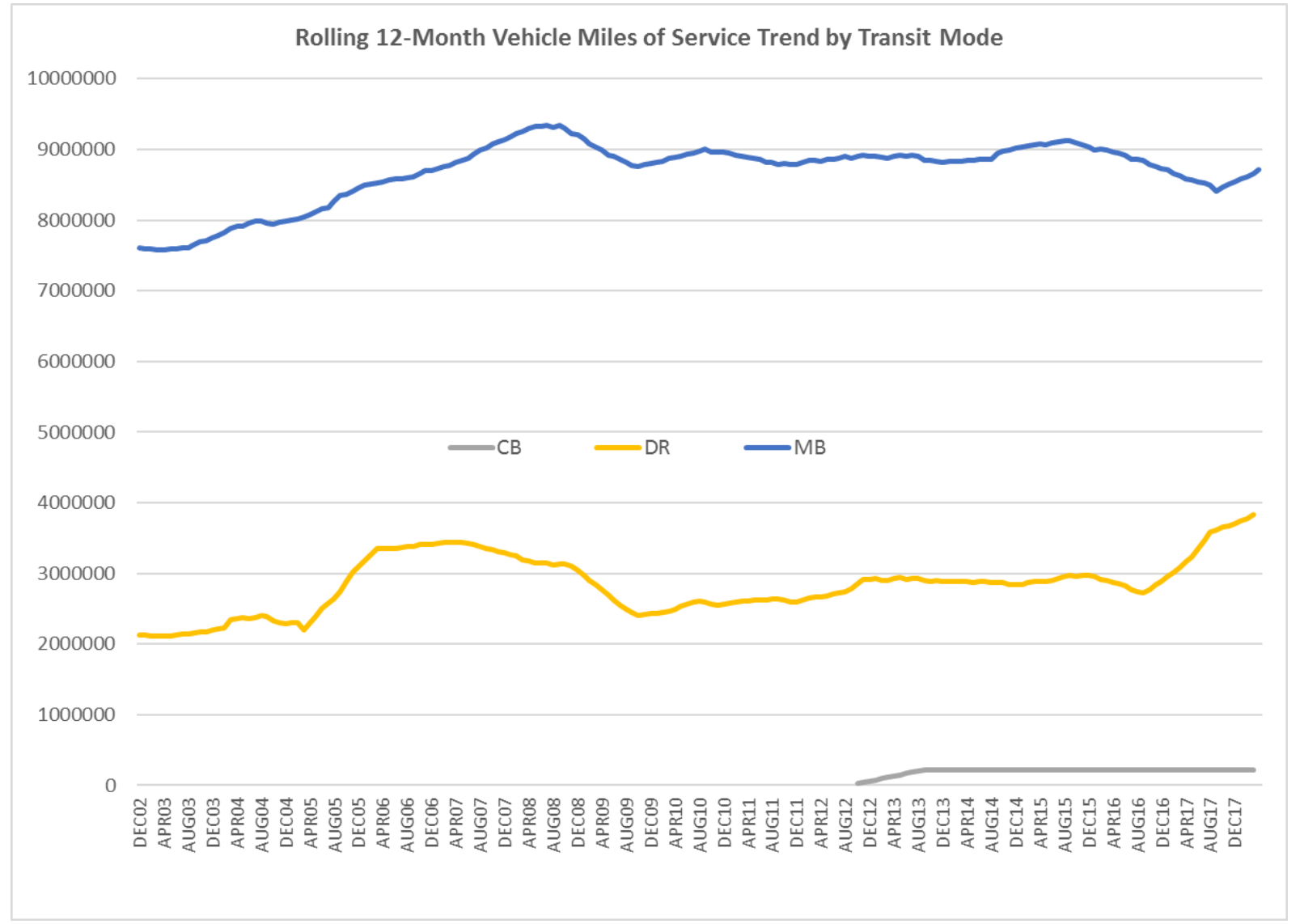

respectively over the past one in three years.

Jolley Trolley (Jolley Trolley Transportation of Clearwater, Inc.)

The Jolley trolley transit service reported independently from October 15 through September 17. Ridership during that time period totaled approximately 836,000 passengers. Data for the services has subsequently been integrated with the Pinellas County data submittals.

Accordingly, it is not treated independently here. 
Looper Group (The Looper Group, Inc.)

The Looper group operated service from October 15 through March 17 in Pinellas County and reported ridership through NTD. Total ridership during the period of operation was approximately 75,000 passengers. Subsequently this ridership has been subsumed within Pinellas County transit system. Accordingly, it is not treated independently here. 


\section{Palm Beach County (Board of County Commissioners, PalmTran)}

Ridership on the Palm Beach transit system has declined 23\% since a peak in 2013. Vehicle revenue miles of service has increased $2 \%$ in that same time period. The Palm Beach transit system was most significantly impacted by declining ridership during the past four years. Boardings per revenue mile has dropped $26 \%$ since its peak in 2015. Ridership per County resident has declined $27 \%$ from its peak in 2013.

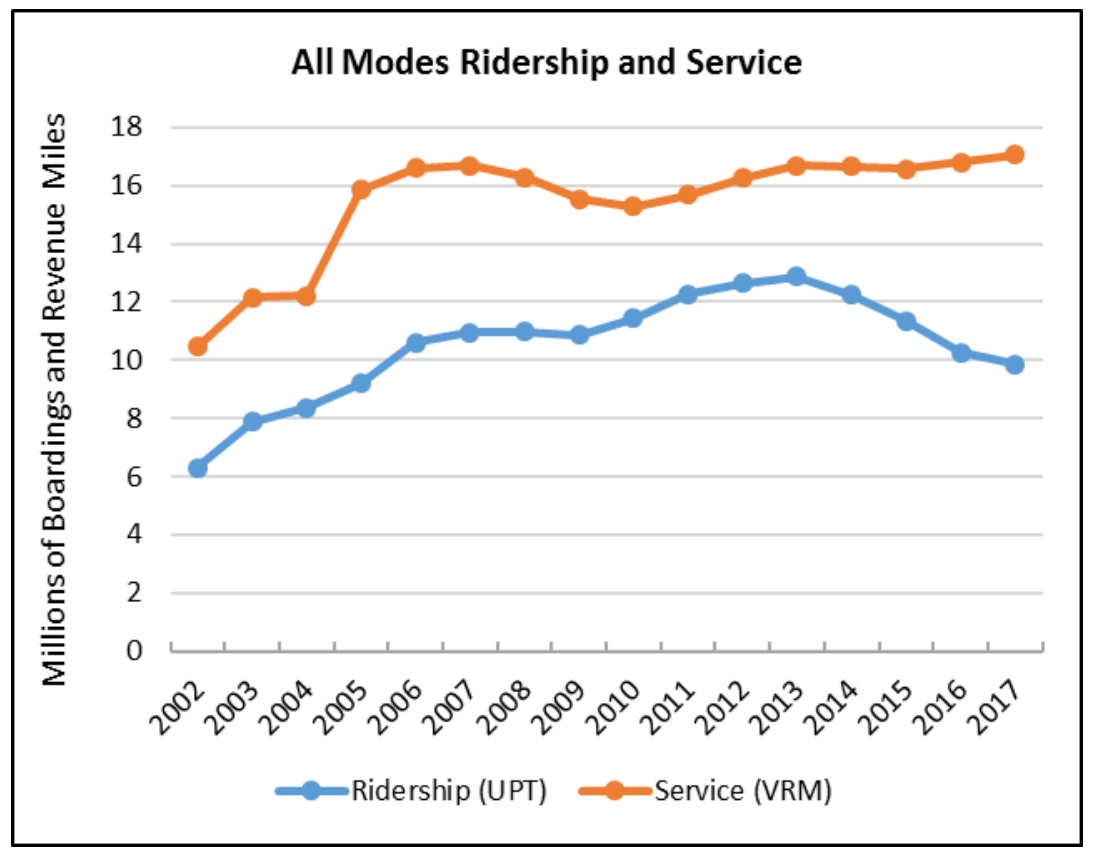

Average trip length on transit has fluctuated around 7 miles through that period with no resulting change.

\begin{tabular}{|c|c|c|c|c|c|c|c|c|}
\hline \multicolumn{9}{|c|}{ Annual Trend Data, All Modes } \\
\hline Year & Ridership (UPT) & Service (VRM) & $\begin{array}{c}\text { Boardings } \\
\text { per Revenue } \\
\text { Mile }\end{array}$ & $\begin{array}{l}\text { AVG Fixed- } \\
\text { Route } \\
\text { Speed } \\
\text { (mph) }\end{array}$ & $\begin{array}{c}\text { County } \\
\text { Population }\end{array}$ & $\begin{array}{l}\text { Trips per } \\
\text { Capita }\end{array}$ & $\begin{array}{l}\text { Passenger } \\
\text { Miles of } \\
\text { Travel }\end{array}$ & $\begin{array}{c}\text { Average } \\
\text { Trip } \\
\text { Length }\end{array}$ \\
\hline 2002 & $6,299,196$ & $10,447,751$ & 0.60 & 16.14 & $1,183,197$ & 5.3 & $42,814,006$ & 6.80 \\
\hline 2003 & $7,867,671$ & $12,144,809$ & 0.65 & 16.29 & $1,211,448$ & 6.5 & $49,406,949$ & 6.28 \\
\hline 2004 & $8,373,515$ & $12,212,766$ & 0.69 & 16.62 & $1,242,270$ & 6.7 & $52,281,485$ & 6.24 \\
\hline 2005 & $9,204,685$ & $15,866,022$ & 0.58 & 15.92 & $1,265,900$ & 7.3 & $58,187,999$ & 6.32 \\
\hline 2006 & $10,612,960$ & $16,597,582$ & 0.64 & 16.51 & $1,287,987$ & 8.2 & $60,742,809$ & 5.72 \\
\hline 2007 & $10,949,644$ & $16,682,230$ & 0.66 & 16.86 & $1,295,033$ & 8.5 & $69,402,664$ & 6.34 \\
\hline 2008 & $10,967,958$ & $16,288,465$ & 0.67 & 16.96 & $1,294,654$ & 8.5 & $67,465,129$ & 6.15 \\
\hline 2009 & $10,874,348$ & $15,540,472$ & 0.70 & 17.03 & $1,287,344$ & 8.4 & $61,266,013$ & 5.63 \\
\hline 2010 & $11,445,262$ & $15,272,658$ & 0.75 & 17.21 & $1,323,394$ & 8.6 & $66,609,404$ & 5.82 \\
\hline 2011 & $12,254,208$ & $15,675,007$ & 0.78 & 17.27 & $1,325,758$ & 9.2 & $73,661,708$ & 6.01 \\
\hline 2012 & $12,651,272$ & $16,264,691$ & 0.78 & 17.34 & $1,335,415$ & 9.5 & $77,568,482$ & 6.13 \\
\hline 2013 & $12,864,348$ & $16,695,472$ & 0.77 & 17.22 & $1,345,652$ & 9.6 & $86,678,305$ & 6.74 \\
\hline 2014 & $12,242,439$ & $16,654,822$ & 0.74 & 16.54 & $1,360,238$ & 9.0 & $86,811,205$ & 7.09 \\
\hline 2015 & $11,349,524$ & $16,580,748$ & 0.68 & 14.99 & $1,378,417$ & 8.2 & $80,945,257$ & 7.13 \\
\hline 2016 & $10,257,184$ & $16,811,979$ & 0.61 & 14.87 & $1,391,741$ & 7.4 & $69,434,906$ & 6.77 \\
\hline 2017 & $9,850,997$ & $17,056,542$ & 0.58 & 15.29 & $1,414,144$ & 7.0 & & \\
\hline
\end{tabular}


The monthly ridership decline impact from Hurricane Irma is evident in the monthly trend data. Ridership in the first third of 2018 was running approximately equivalent to the prior year.

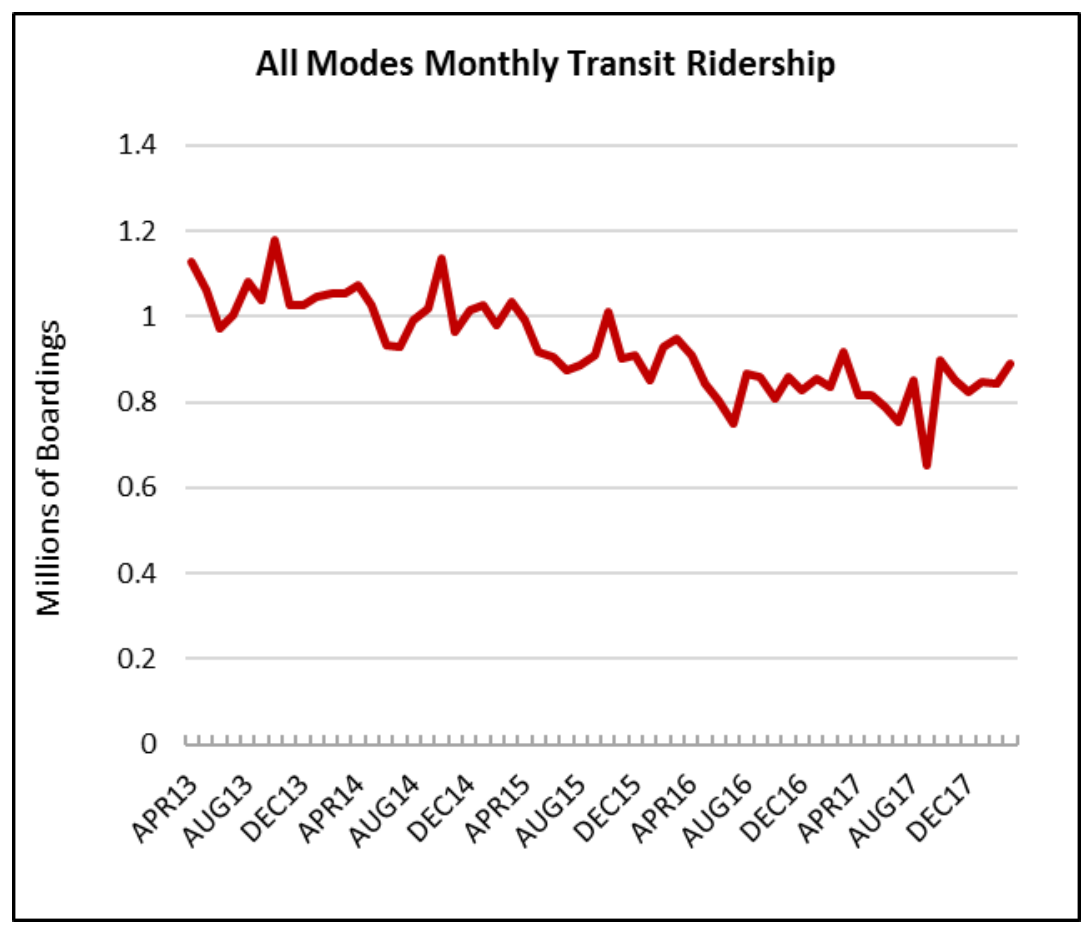

Average operating speed, defined as vehicle revenue miles divided by vehicle revenue hours, remain relatively steady through 2014 before declining reflecting greater congestion as the economy improved and perhaps other factors. The average operating speed is relatively high for urban transit systems reflecting the suburban character of Palm Beach County.

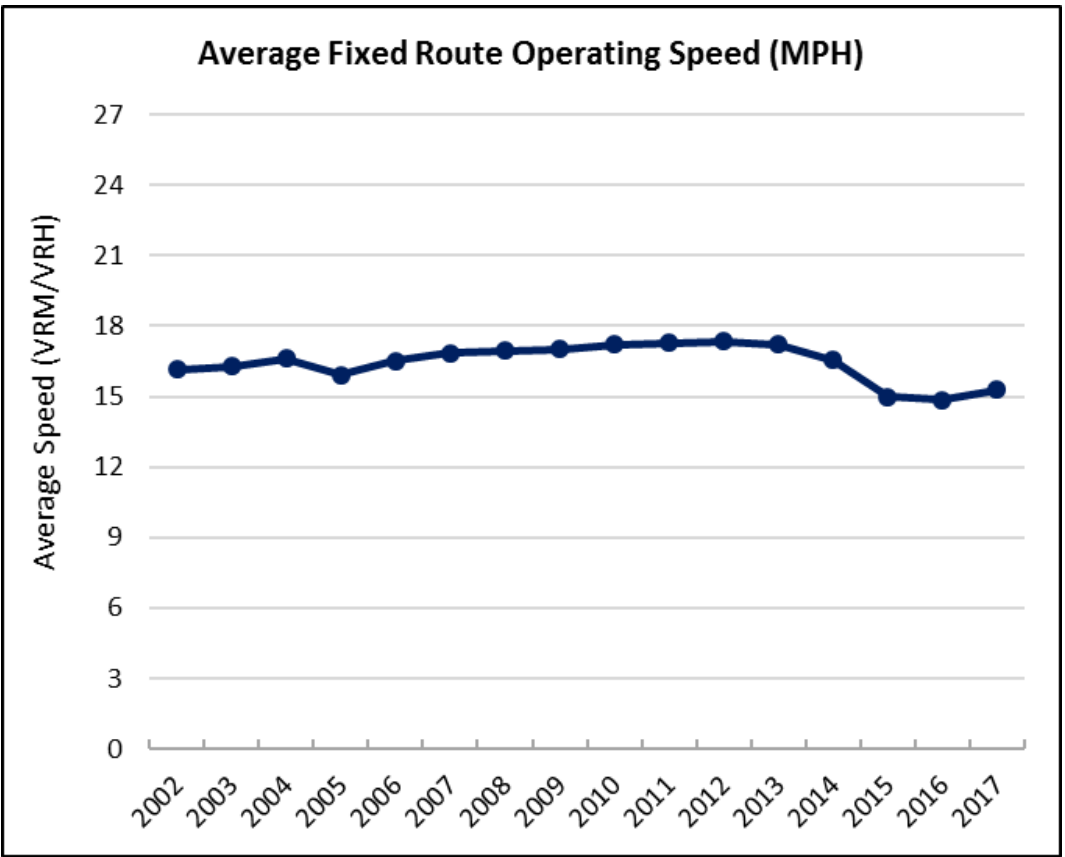


The adjacent graphic shows service productivity. It generally increased through 2011 before starting its multi-year decline.

The figures below provide the ridership trends and service supply trends by sub mode. This allows one to understand how the various component modes are performing. As visibly apparent, bus ridership dominates and has had the

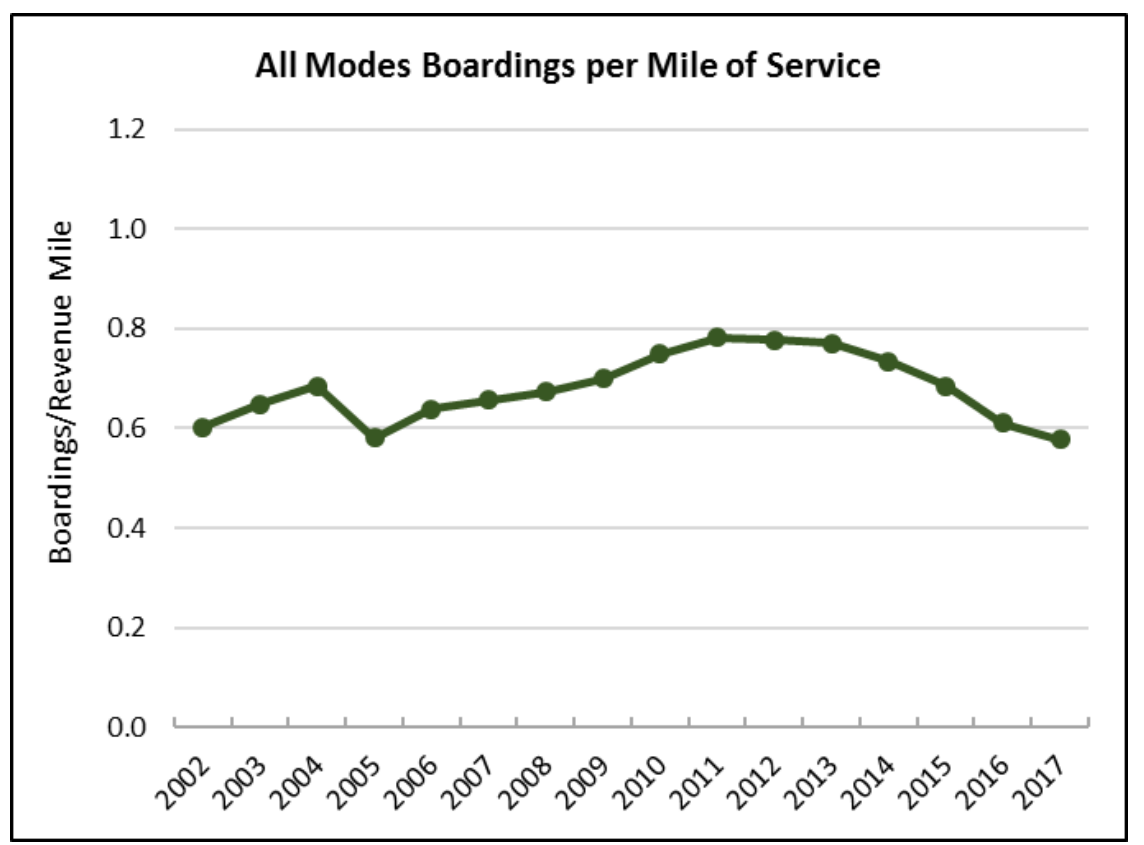

Rolling 12-Month Ridership Trend by Transit Mode

$14,000,000$

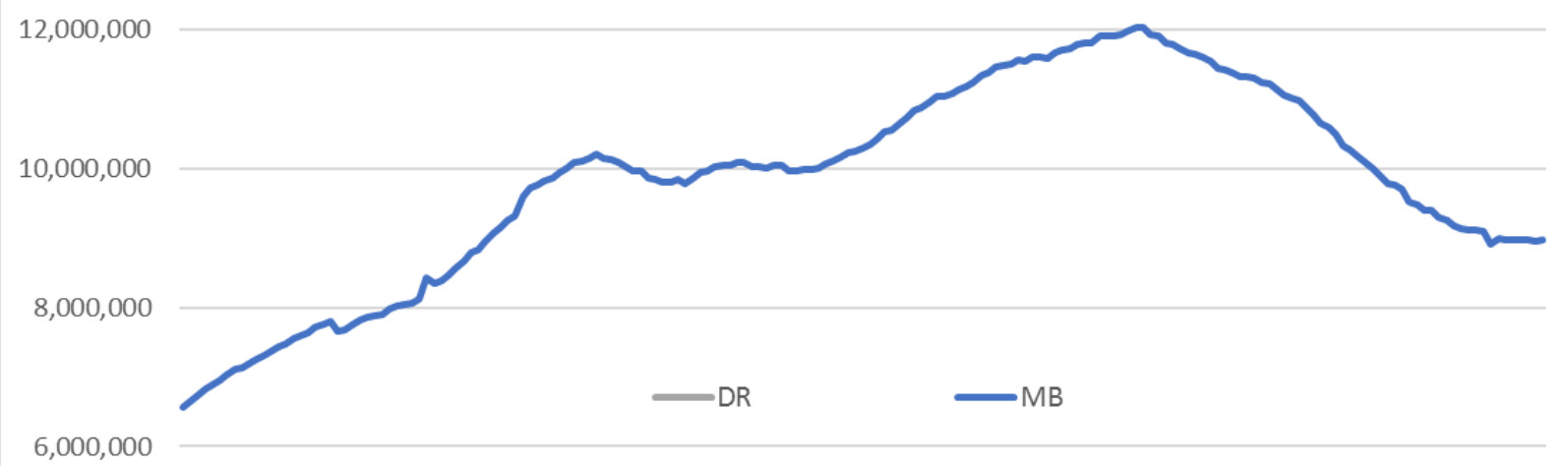

4,000,000

$2,000,000$

0

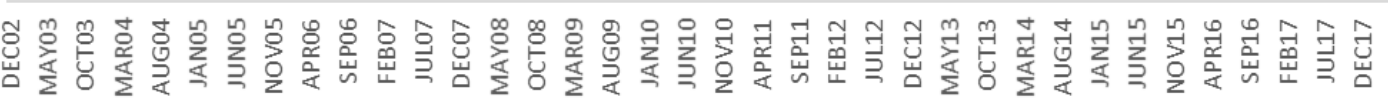


most pronounced decline in ridership. Bus ridership has declined approximately $3 \%$ for the one year and $20 \%$ over three years. Demand responsive ridership has been virtually flat during the past year and declined $4 \%$ over the three-year period.

The final graphic shows service supply as measured by revenue vehicle miles of service. As the graphical data communicates, bus service supply has been relatively stable over the years with dips post 2015. Bus service has declined 5\% over the past year and $7 \%$ over three years.

As vehicle miles of service for purchased demand responsive services is not included service supply for demand responsive services is not reflective of the total service provided.

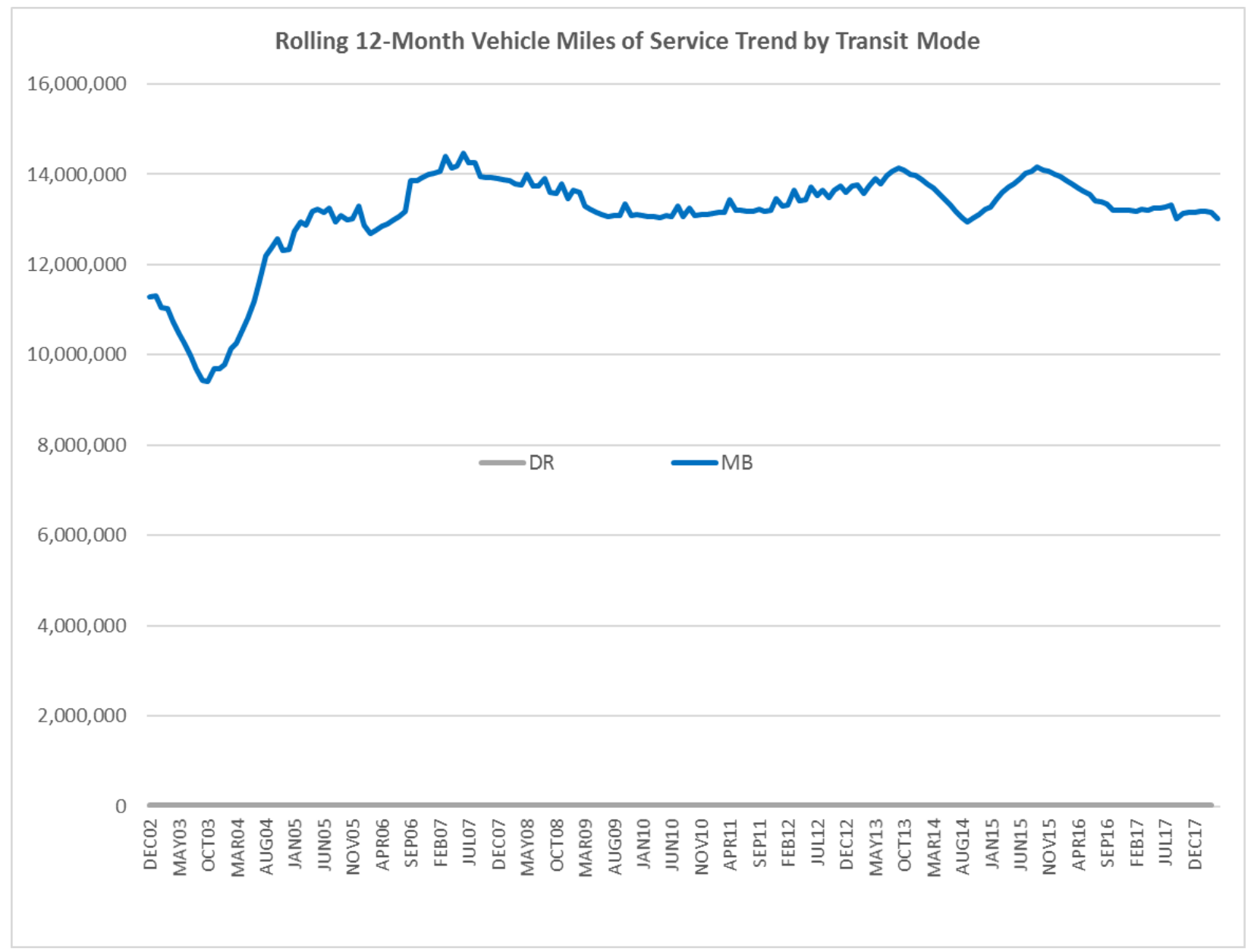

Note: Data on purchased demand responsive service not available. 
Gainesville (Gainesville Regional Transit System, RTS)

Ridership on the Gainesville transit system has declined $12 \%$ since a peak in 2013. Vehicle revenue miles of service has increased $17 \%$ in that same time period. The Gainesville transit system was most significantly impacted by declining ridership during the past three years. Boardings per revenue mile has dropped $28 \%$ since its peak in 2004. Ridership per County resident has declined $17 \%$ from its peak in

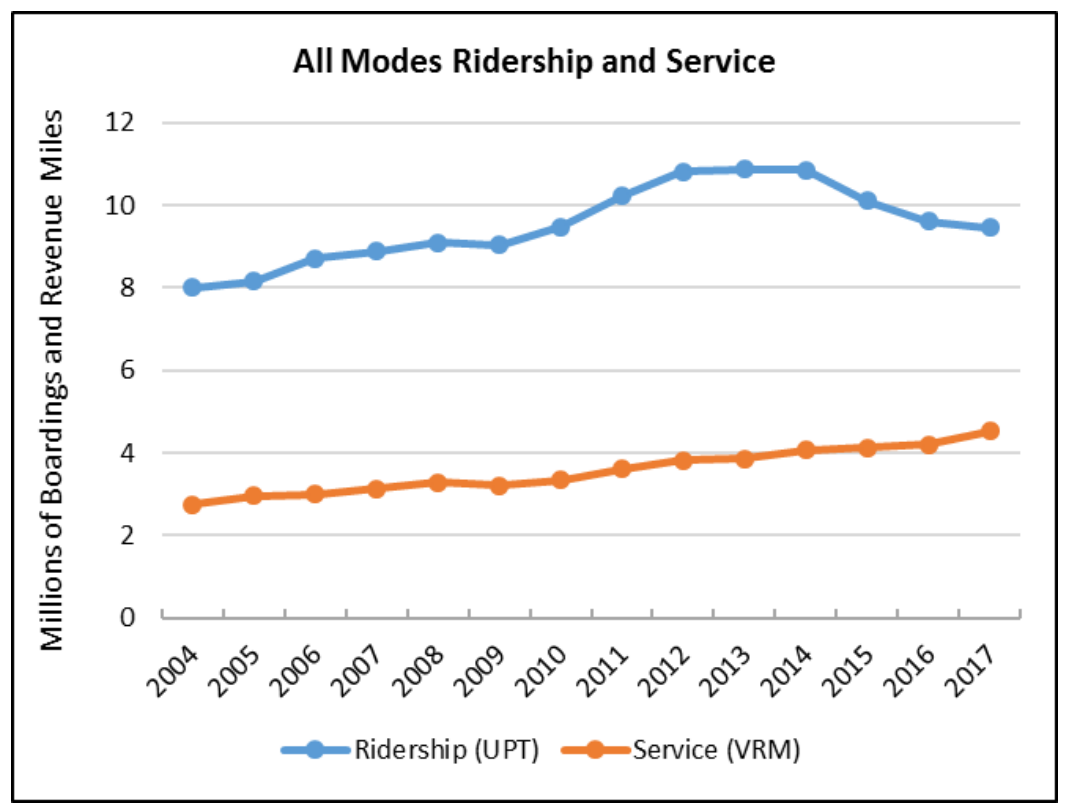
2013.

Average trip length on transit has fluctuated through that period with a modest decline. The trip length is under 3 miles and reflects the strong focus on University service.

\begin{tabular}{|c|c|c|c|c|c|c|c|c|}
\hline \multicolumn{9}{|c|}{ Annual Trend Data, All Modes } \\
\hline Year & Ridership (UPT) & Service (VRM) & $\begin{array}{c}\text { Boardings } \\
\text { per Revenue } \\
\text { Mile }\end{array}$ & $\begin{array}{l}\text { AVG Fixed- } \\
\text { Route } \\
\text { Speed } \\
\text { (mph) }\end{array}$ & $\begin{array}{c}\text { County } \\
\text { Population }\end{array}$ & $\begin{array}{c}\text { Trips per } \\
\text { Capita }\end{array}$ & $\begin{array}{l}\text { Passenger } \\
\text { Miles of } \\
\text { Travel }\end{array}$ & $\begin{array}{c}\text { Average } \\
\text { Trip } \\
\text { Length }\end{array}$ \\
\hline 2002 & 11,466 & 62,832 & 0.18 & & 228,607 & 0.1 & $17,218,905$ & \\
\hline 2003 & na & na & & & 231,296 & na & $27,556,248$ & \\
\hline 2004 & $8,000,076$ & $2,741,993$ & 2.92 & 11.69 & 236,174 & 33.9 & $27,406,381$ & 3.43 \\
\hline 2005 & $8,156,064$ & $2,963,694$ & 2.75 & 11.30 & 240,764 & 33.9 & $27,404,794$ & 3.36 \\
\hline 2006 & $8,705,537$ & $2,995,974$ & 2.91 & 11.44 & 243,779 & 35.7 & $29,156,774$ & 3.35 \\
\hline 2007 & $8,890,755$ & $3,119,064$ & 2.85 & 11.59 & 247,561 & 35.9 & $30,398,891$ & 3.42 \\
\hline 2008 & $9,094,667$ & $3,281,454$ & 2.77 & 11.67 & 252,388 & 36.0 & $25,529,505$ & 2.81 \\
\hline 2009 & $9,043,087$ & $3,211,964$ & 2.82 & 11.39 & 256,232 & 35.3 & $25,357,714$ & 2.80 \\
\hline 2010 & $9,481,298$ & $3,331,299$ & 2.85 & 11.55 & 247,497 & 38.3 & $26,605,532$ & 2.81 \\
\hline 2011 & $10,223,212$ & $3,605,861$ & 2.84 & 11.42 & 247,337 & 41.3 & $24,828,435$ & 2.43 \\
\hline 2012 & $10,809,471$ & $3,810,512$ & 2.84 & 11.56 & 246,770 & 43.8 & $26,553,266$ & 2.46 \\
\hline 2013 & $10,875,363$ & $3,847,440$ & 2.83 & 11.39 & 248,002 & 43.9 & $27,009,904$ & 2.48 \\
\hline 2014 & $10,849,268$ & $4,069,847$ & 2.67 & 11.57 & 250,730 & 43.3 & $28,862,080$ & 2.66 \\
\hline 2015 & $10,119,105$ & $4,120,125$ & 2.46 & 11.73 & 254,893 & 39.7 & $27,380,849$ & 2.71 \\
\hline 2016 & $9,608,877$ & $4,208,675$ & 2.28 & 11.92 & 257,062 & 37.4 & $25,952,503$ & 2.70 \\
\hline 2017 & $9,466,182$ & $4,523,977$ & 2.09 & 12.06 & 260,003 & 36.4 & & \\
\hline
\end{tabular}


The monthly ridership trend is dominated by the cyclical nature of dependency on student transportation. Ridership in the first two months of 2018 was running approximately $7 \%$ below year ago levels.

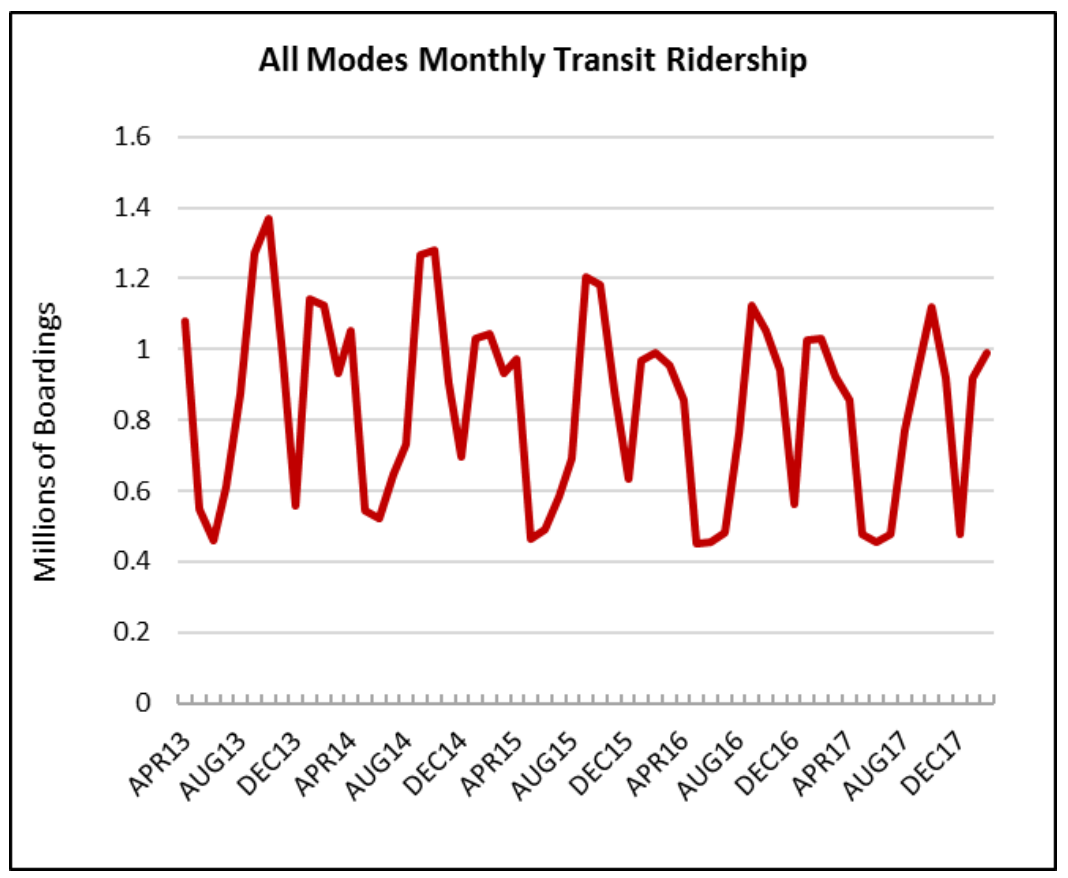

Average operating speed, defined as vehicle revenue miles divided by vehicle revenue hours, remain relatively steady around 12 miles per hour. The average operating speed is influenced by short trip length and relatively high boarding volumes.

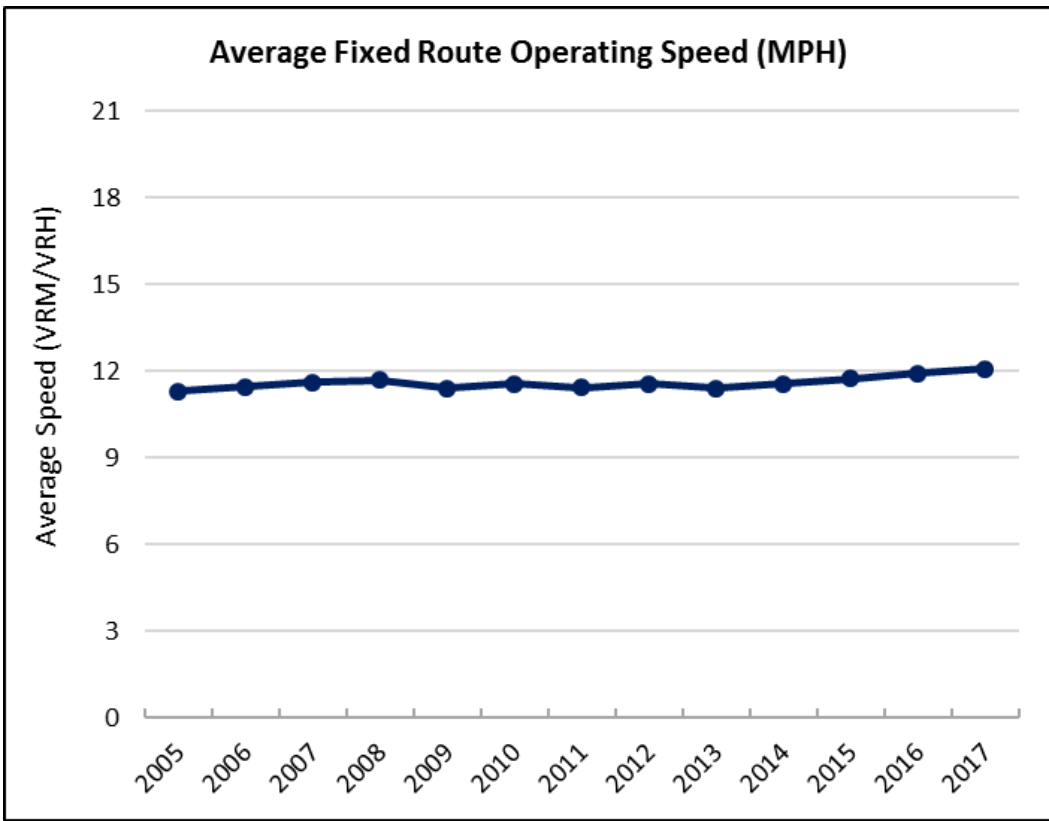


The adjacent graphic shows service productivity. It held steady for several years up until 2013 before starting its multi-year decline.

The figures below provide the ridership trends and service supply trends by sub mode. This allows one to understand how the various component modes are performing. As visibly apparent, bus ridership

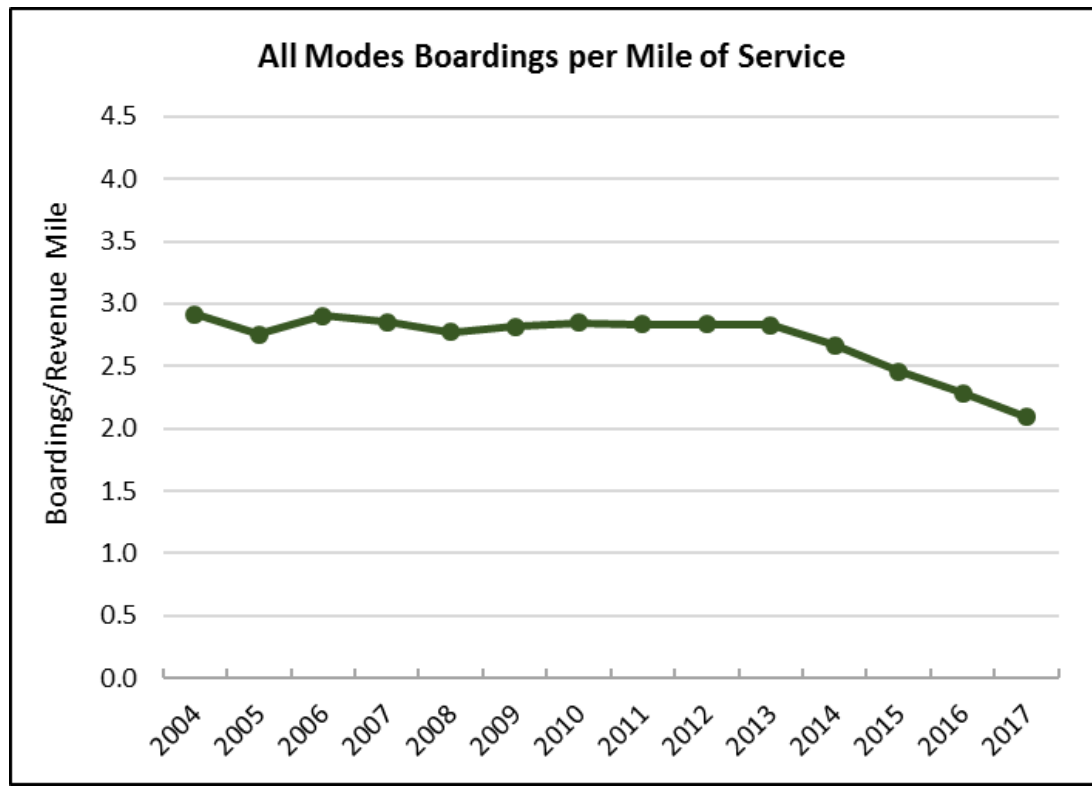
dominates and has had the most pronounced decline in ridership.

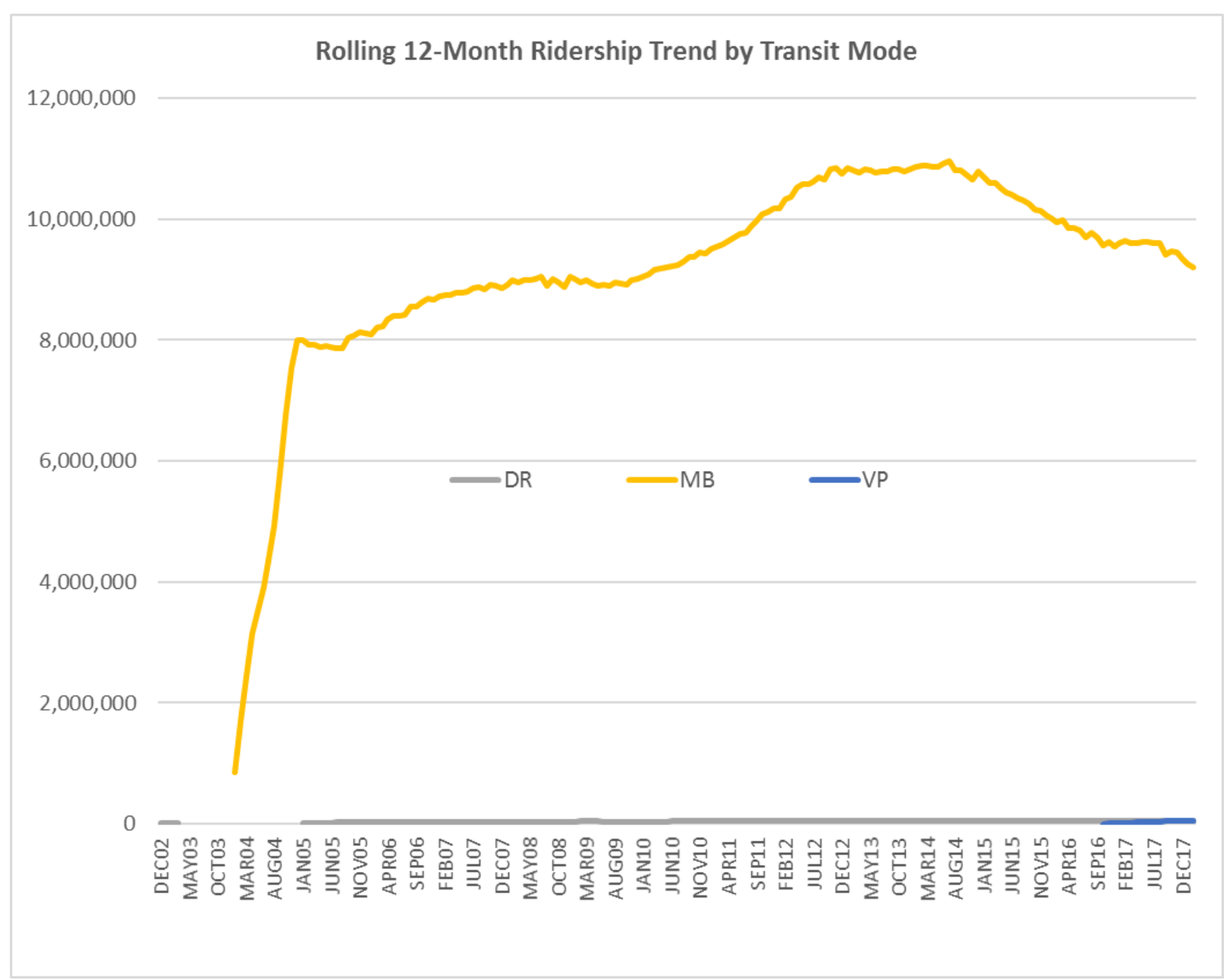


Bus ridership has declined approximately $5 \%$ for the one year and $13 \%$ over three years.

Demand responsive ridership has been up $18 \%$ in the last year and $14 \%$ in the last three years. Vanpool services not been in place a full year.

The final graphic shows service supply as measured by revenue vehicle miles of service. As the graphical data communicates, bus service supply has been growing steadily over the past several years, up $1 \%$ last year and $6 \%$ over three years. Demand response service increased $7 \%$ over one year and has declined $1 \%$ over three years.

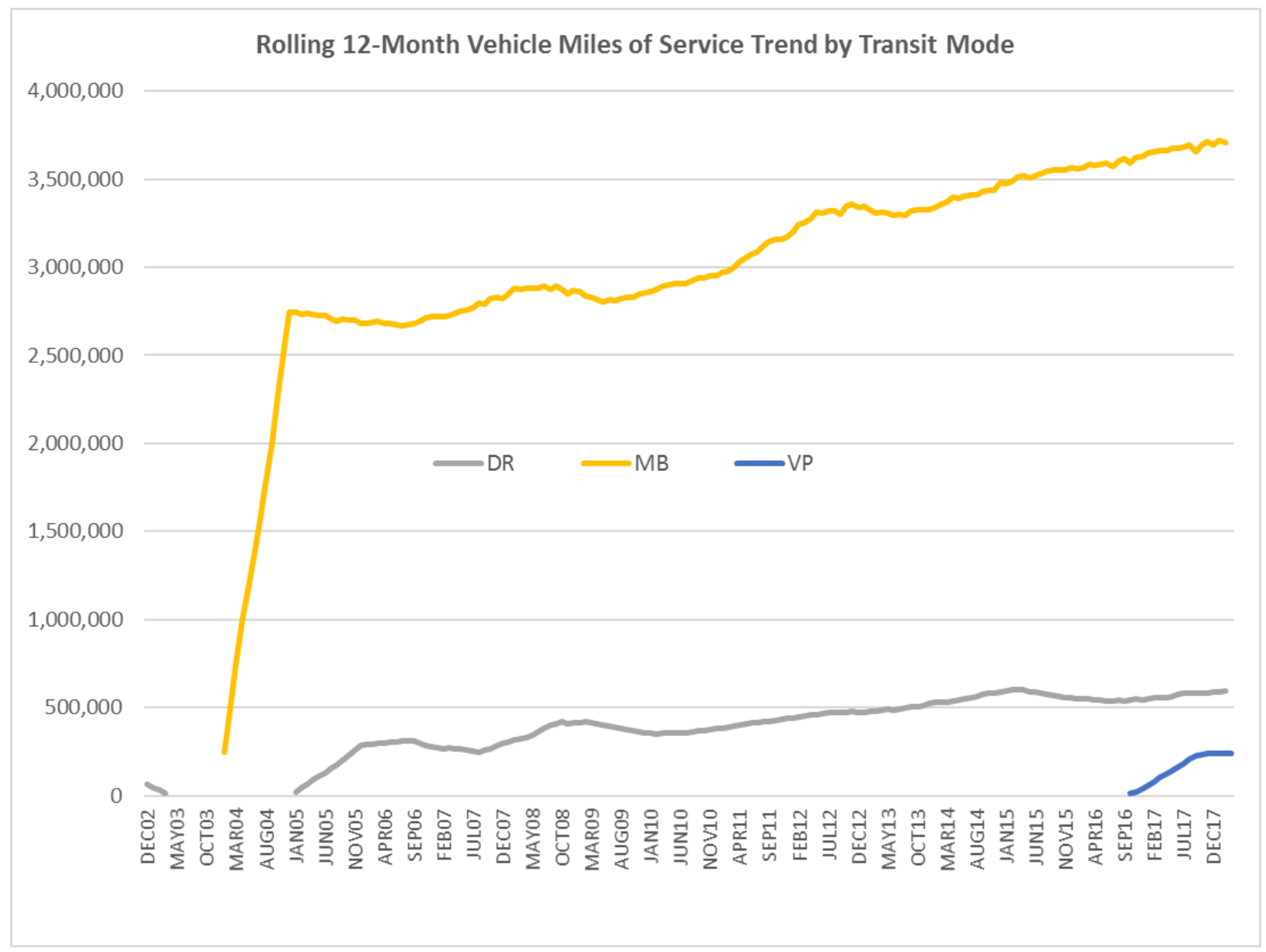


South Florida RTA (South Florida Regional Transportation Authority, SFRTA)

Ridership on the South

Florida RTA has declined

5\% since a peak in 2014.

Vehicle revenue miles of

service has remained

steady in that same time

period. The RTA transit

system was most impacted

by declining ridership

during the past three years.

Boardings per revenue mile

has dropped $73 \%$ since its

peak in 2002. Ridership per

three County resident has

declined $9 \%$ from its peak

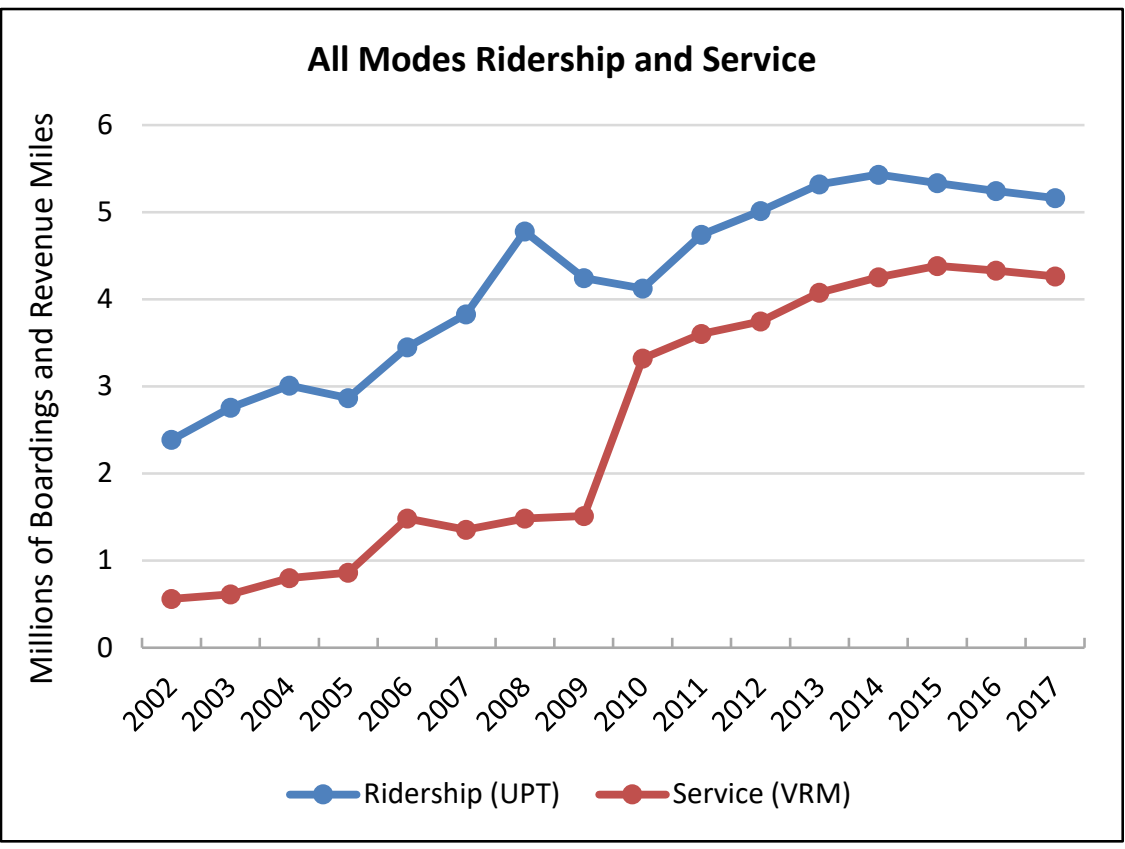

in 2014.

Average trip length on transit has declined significantly through that period with the current average trip length being approximately half of that from the 2003-2005 period and not much longer than a typical transit bus trip. The operating of supporting bus services and their increase over time contributes to this. Note that passenger miles of travel peaked in 2007 and has been lower since then.

\begin{tabular}{|c|c|c|c|c|c|c|c|c|}
\hline \multicolumn{9}{|c|}{ Annual Trend Data, All Modes } \\
\hline Year & Ridership (UPT) & Service (VRM) & $\begin{array}{c}\text { Boardings } \\
\text { per Revenue } \\
\text { Mile }\end{array}$ & $\begin{array}{l}\text { AVG Fixed- } \\
\text { Route } \\
\text { Speed } \\
\text { (mph) }\end{array}$ & $\begin{array}{l}3 \text { County } \\
\text { Population }\end{array}$ & $\begin{array}{c}\text { Trips per } \\
\text { Capita }\end{array}$ & $\begin{array}{c}\text { Passenger } \\
\text { Miles of } \\
\text { Travel }\end{array}$ & $\begin{array}{c}\text { Average } \\
\text { Trip } \\
\text { Length }\end{array}$ \\
\hline 2002 & $2,385,398$ & 560,623 & 4.25 & 20.63 & $5,164,828$ & 0.46 & $17,218,905$ & 7.22 \\
\hline 2003 & $2,755,778$ & 614,040 & 4.49 & 36.15 & $5,255,805$ & 0.52 & $27,556,248$ & 10.00 \\
\hline 2004 & $3,007,146$ & 800,277 & 3.76 & 21.57 & $5,345,219$ & 0.56 & $27,406,381$ & 9.11 \\
\hline 2005 & $2,867,481$ & 859,502 & 3.34 & 19.55 & $5,428,962$ & 0.53 & $27,404,794$ & 9.56 \\
\hline 2006 & $3,447,191$ & $1,485,385$ & 2.32 & 22.28 & $5,478,171$ & 0.63 & $29,156,774$ & 8.46 \\
\hline 2007 & $3,827,765$ & $1,353,047$ & 2.83 & 20.88 & $5,523,032$ & 0.69 & $30,398,891$ & 7.94 \\
\hline 2008 & $4,780,839$ & $1,481,994$ & 3.23 & 20.84 & $5,530,437$ & 0.86 & $25,529,505$ & 5.34 \\
\hline 2009 & $4,244,052$ & $1,513,747$ & 2.80 & 21.31 & $5,504,610$ & 0.77 & $25,357,714$ & 5.97 \\
\hline 2010 & $4,122,869$ & $3,320,608$ & 1.24 & 26.82 & $5,582,351$ & 0.74 & $26,605,532$ & 6.45 \\
\hline 2011 & $4,742,020$ & $3,603,977$ & 1.32 & 22.85 & $5,595,457$ & 0.85 & $24,828,435$ & 5.24 \\
\hline 2012 & $5,014,513$ & $3,744,061$ & 1.34 & 23.33 & $5,657,804$ & 0.89 & $26,553,266$ & 5.30 \\
\hline 2013 & $5,319,662$ & $4,077,505$ & 1.30 & 24.08 & $5,712,742$ & 0.93 & $27,009,904$ & 5.08 \\
\hline 2014 & $5,432,172$ & $4,255,182$ & 1.28 & 23.97 & $5,777,833$ & 0.94 & $28,862,080$ & 5.31 \\
\hline 2015 & $5,334,063$ & $4,384,380$ & 1.22 & 23.32 & $5,859,718$ & 0.91 & $27,380,849$ & 5.13 \\
\hline 2016 & $5,241,825$ & $4,328,153$ & 1.21 & 22.83 & $5,947,048$ & 0.88 & $25,952,503$ & 4.95 \\
\hline 2017 & $5,164,325$ & $4,263,537$ & 1.21 & 23.20 & $6,031,209$ & 0.86 & & \\
\hline
\end{tabular}


The monthly ridership trend relatively stable with the exception of the significant impact from Hurricane Irma. Ridership in the first four months of 2018 was running approximately $3 \%$ above year ago levels.

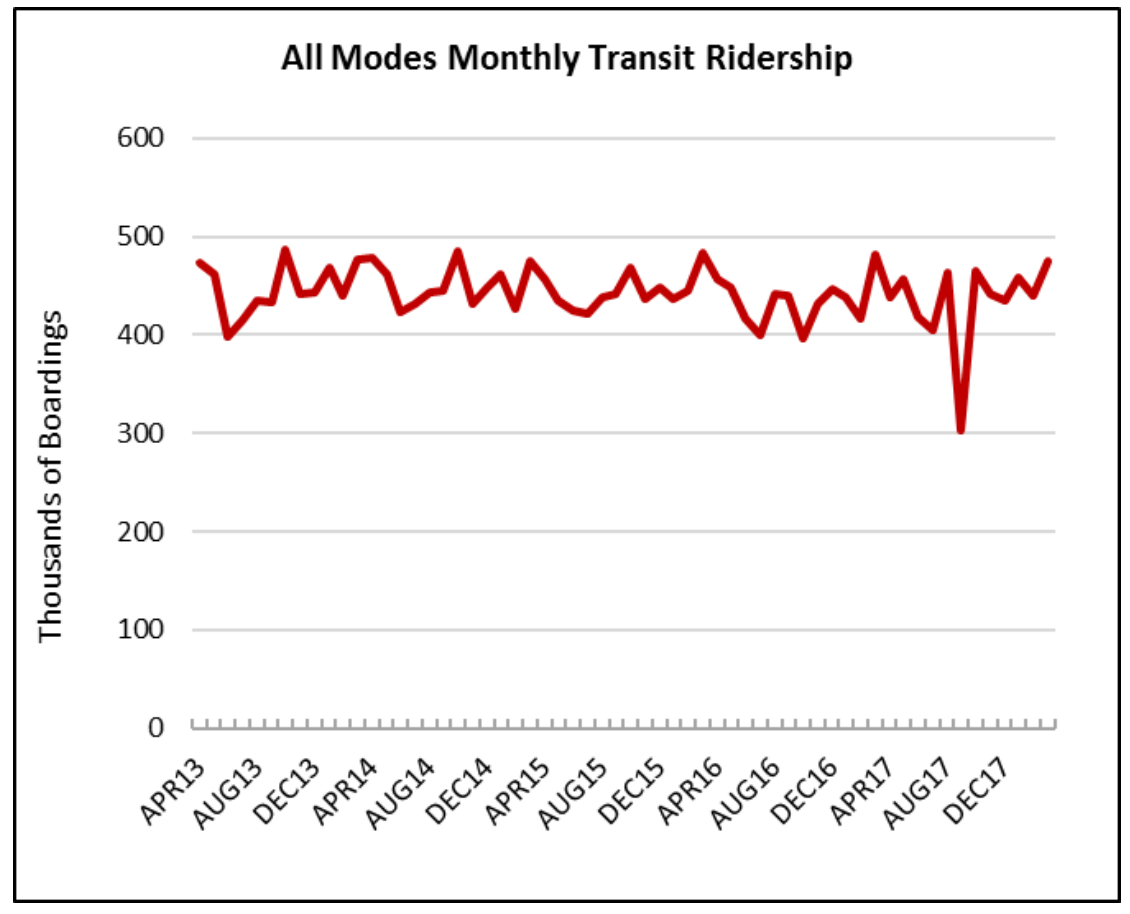

Average operating speed, defined as vehicle revenue miles divided by vehicle revenue hours, remain relatively steady around 23 miles per hour.

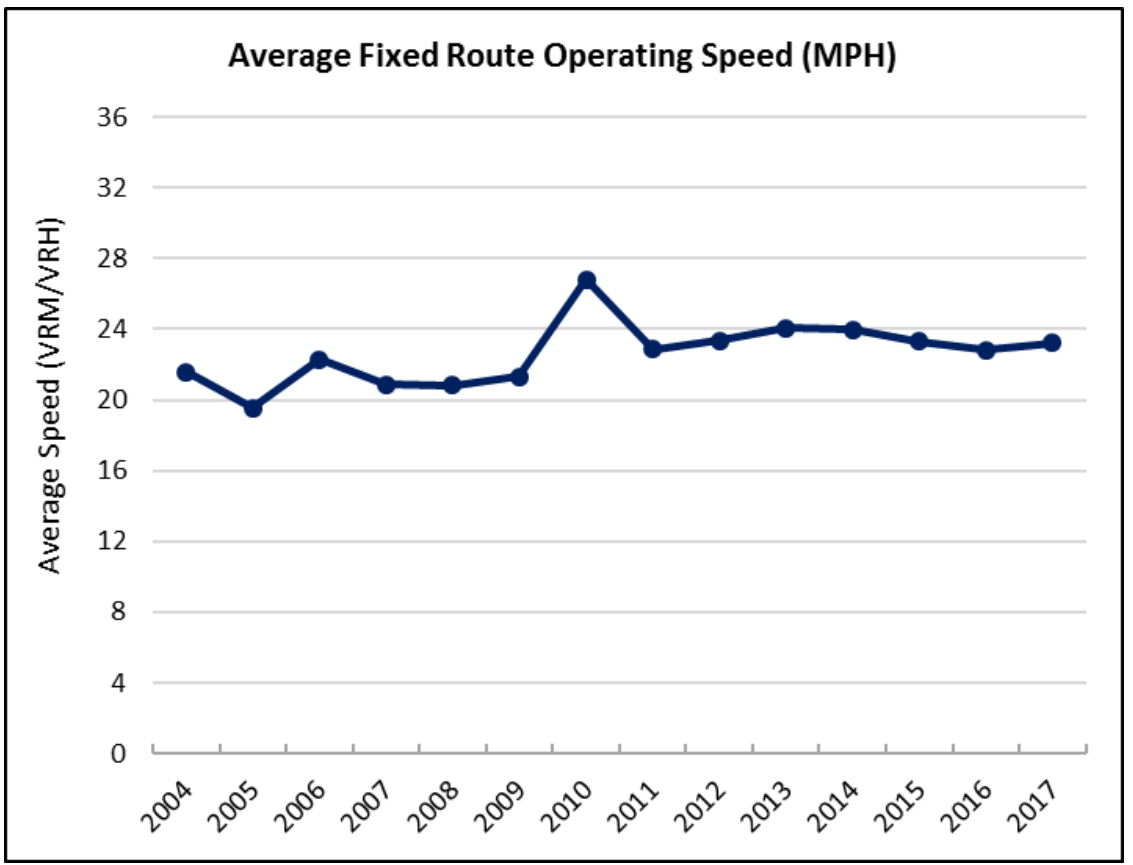


The adjacent graphic shows service productivity. After declines it has stabilized with a very slight downward trend since approximately 2010.

The figures below provide the ridership trends and service supply trends by sub mode. This allows one to understand how the various component modes are performing.

Rail ridership has grown

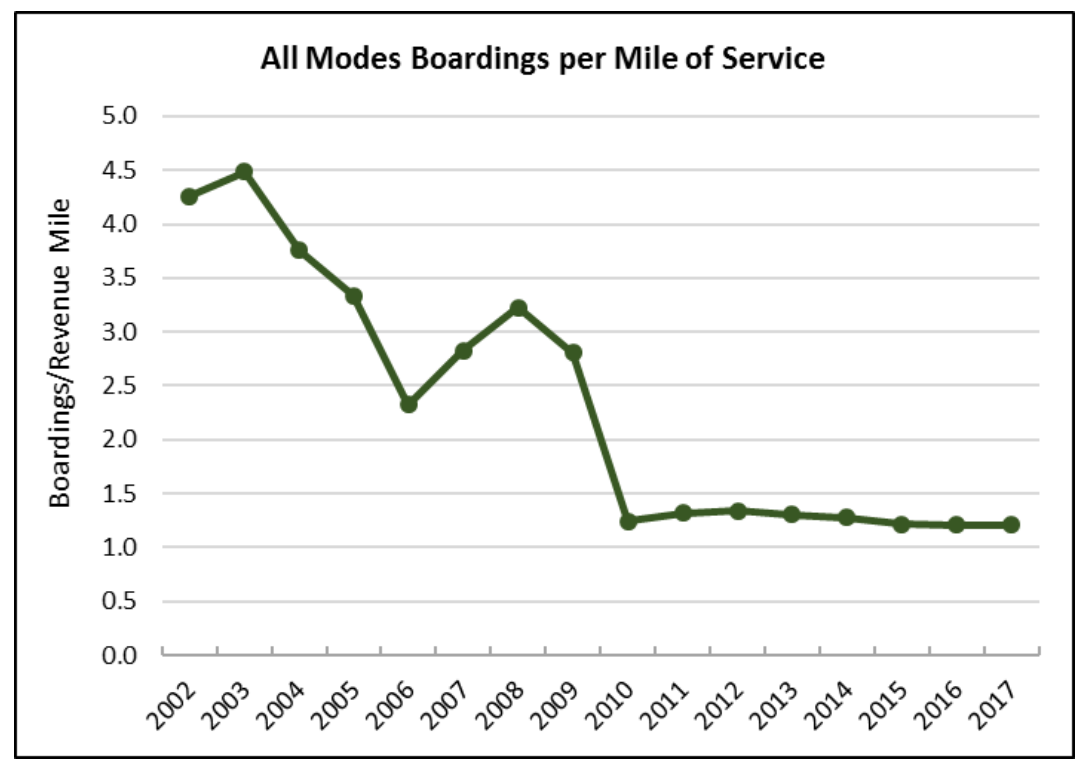
approximately $2 \%$ over one year and declined $1 \%$ over three years. Supporting bus ridership has declined $11 \%$ in the last year and $16 \%$ in the last three years. 


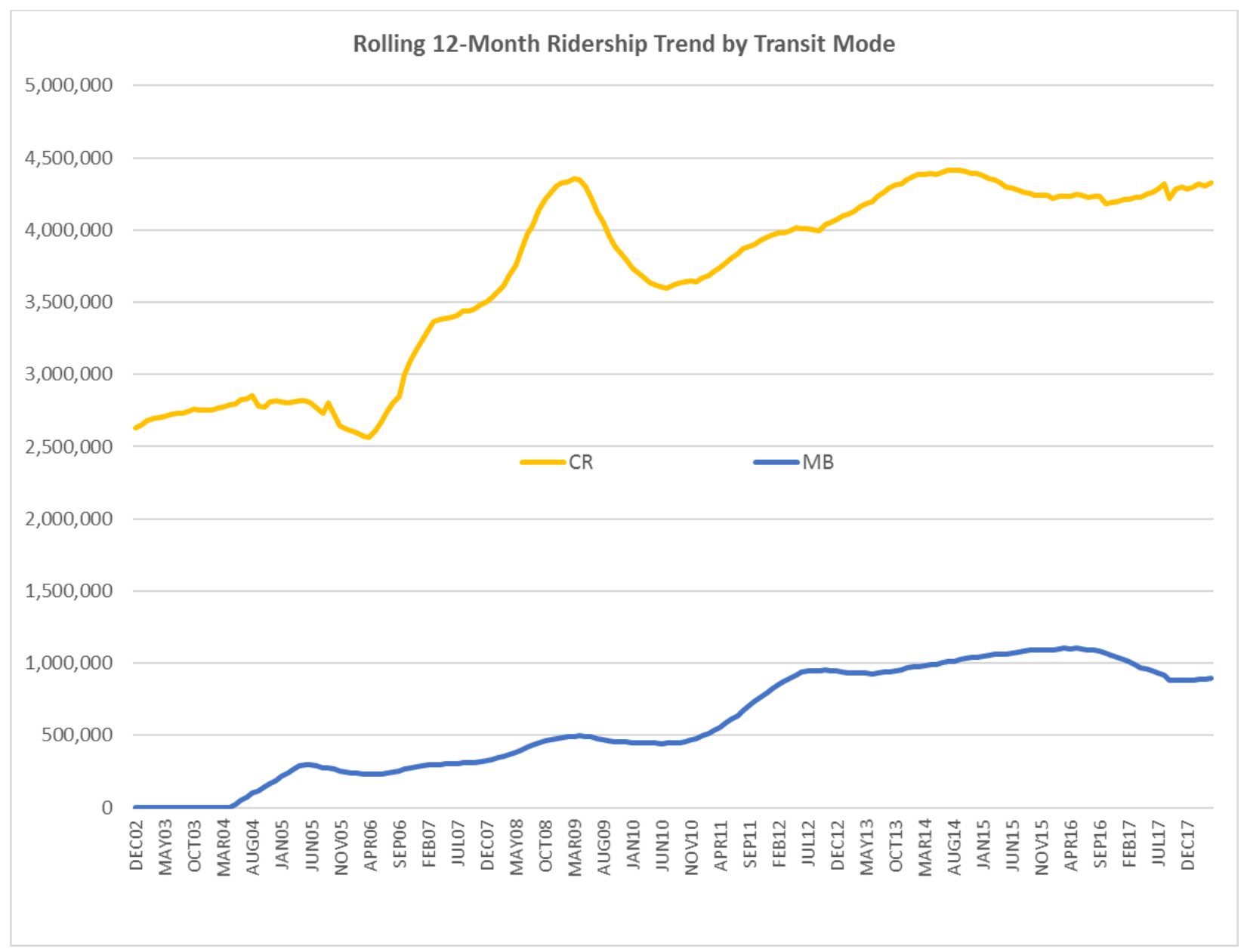


The final graphic shows service supply as measured by revenue vehicle miles of service. As the graphical data communicates, rail service supply has been growing in general but has been more stable in recent years. Supporting bus service increased since inception but has been modestly reduced since late 2016 . Rail service has increased $1 \%$ in the last year and $2 \%$ in the past three years. Supporting bus services has decreased $9 \%$ in the past year and $8 \%$ over three years.

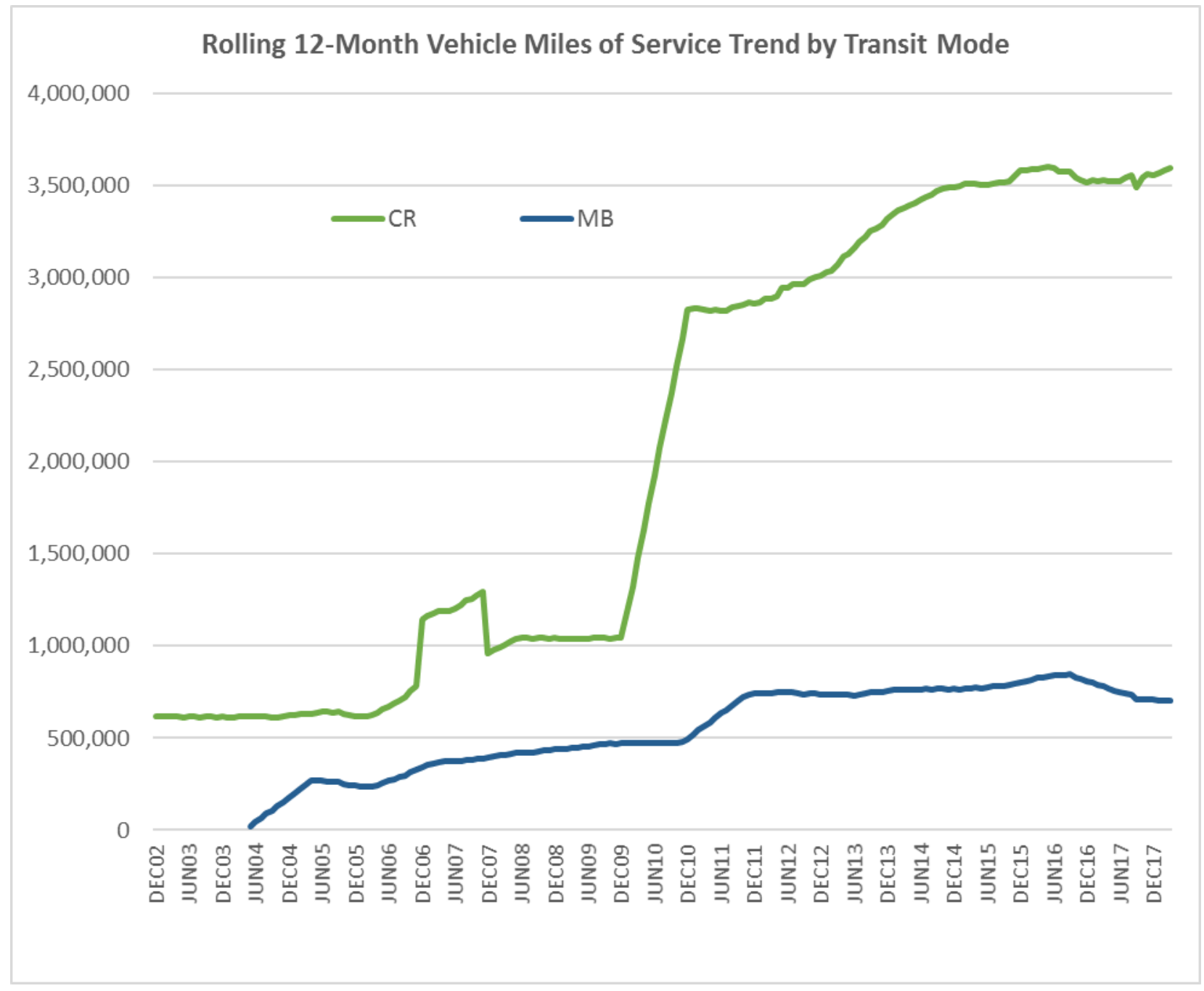


Volusia County (County of Volusia, VOTRAN)

Ridership on the Volusia transit system has declined $12 \%$ since a peak in 2013. Vehicle revenue miles of service has grown $10 \%$ in that same time period. The Volusia transit system was most impacted by declining ridership during the past four years with the past year showing a positive trend supported by expanded service. Boardings per revenue mile has dropped $20 \%$ since its peak in 2013. Ridership per

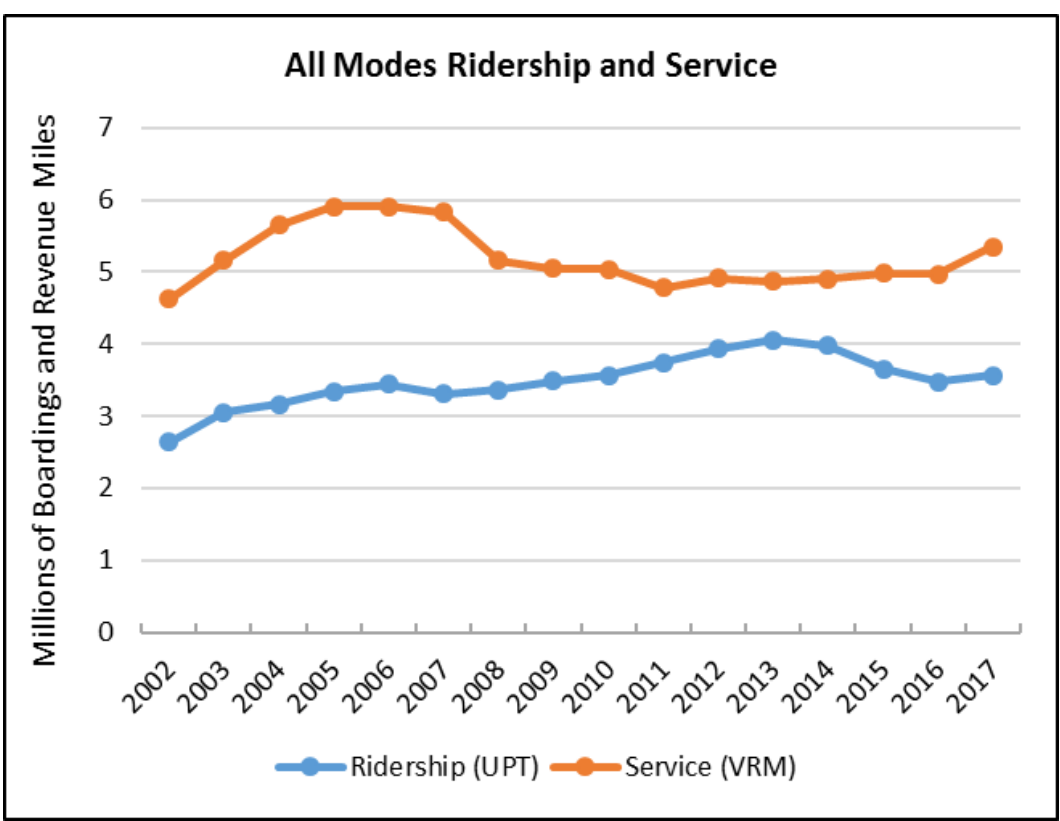
County resident has declined 16\% from its peak in 2013.

Average trip length on transit has declined significantly through that period with the current average trip length being approximately half of that from the 2003-2005 period and not much longer than a typical transit bus trip. The operating of supporting bus services and their increase over time contributes to this. Note that passenger miles of travel peaked in 2007 and has been lower since then.

\begin{tabular}{|c|c|c|c|c|c|c|c|c|}
\hline \multicolumn{9}{|c|}{ Annual Trend Data, All Modes } \\
\hline Year & Ridership (UPT) & Service (VRM) & $\begin{array}{c}\text { Boardings } \\
\text { per Revenue } \\
\text { Mile }\end{array}$ & $\begin{array}{l}\text { AVG Fixed- } \\
\text { Route } \\
\text { Speed } \\
\text { (mph) }\end{array}$ & $\begin{array}{c}\text { County } \\
\text { Population }\end{array}$ & $\begin{array}{c}\text { Trips per } \\
\text { Capita }\end{array}$ & $\begin{array}{c}\text { Passenger } \\
\text { Miles of } \\
\text { Travel }\end{array}$ & $\begin{array}{c}\text { Average } \\
\text { Trip } \\
\text { Length }\end{array}$ \\
\hline 2002 & $2,634,482$ & $4,629,657$ & 0.57 & 15.07 & 459,737 & 5.7 & $21,794,377$ & 8.27 \\
\hline 2003 & $3,049,097$ & $5,160,927$ & 0.59 & 15.46 & 470,770 & 6.5 & $20,394,242$ & 6.69 \\
\hline 2004 & $3,165,455$ & $5,655,464$ & 0.56 & 15.76 & 484,261 & 6.5 & $22,956,790$ & 7.25 \\
\hline 2005 & $3,338,332$ & $5,907,728$ & 0.57 & 15.62 & 494,649 & 6.7 & $23,503,961$ & 7.04 \\
\hline 2006 & $3,444,438$ & $5,905,810$ & 0.58 & 15.52 & 503,844 & 6.8 & $22,180,031$ & 6.44 \\
\hline 2007 & $3,307,294$ & $5,828,534$ & 0.57 & 15.39 & 508,014 & 6.5 & $20,427,445$ & 6.18 \\
\hline 2008 & $3,369,346$ & $5,159,193$ & 0.65 & 14.99 & 510,750 & 6.6 & $21,292,105$ & 6.32 \\
\hline 2009 & $3,487,510$ & $5,045,520$ & 0.69 & 14.99 & 507,105 & 6.9 & $20,731,955$ & 5.94 \\
\hline 2010 & $3,566,454$ & $5,035,850$ & 0.71 & 15.11 & 494,527 & 7.2 & $20,995,871$ & 5.89 \\
\hline 2011 & $3,740,824$ & $4,779,751$ & 0.78 & 15.61 & 495,400 & 7.6 & $18,889,436$ & 5.05 \\
\hline 2012 & $3,931,756$ & $4,912,503$ & 0.80 & 15.66 & 497,145 & 7.9 & $18,110,940$ & 4.61 \\
\hline 2013 & $4,056,608$ & $4,871,325$ & 0.83 & 15.57 & 498,978 & 8.1 & $17,938,903$ & 4.42 \\
\hline 2014 & $3,974,246$ & $4,908,828$ & 0.81 & 15.53 & 503,851 & 7.9 & $17,805,586$ & 4.48 \\
\hline 2015 & $3,657,990$ & $4,981,217$ & 0.73 & 15.56 & 510,494 & 7.2 & $16,584,047$ & 4.53 \\
\hline 2016 & $3,481,042$ & $4,975,379$ & 0.70 & 15.38 & 517,411 & 6.7 & $15,774,266$ & 4.53 \\
\hline 2017 & $3,565,970$ & $5,355,710$ & 0.67 & 15.57 & 523,405 & 6.8 & & \\
\hline
\end{tabular}


The monthly ridership trend relatively stable with a modest impact from hurricane Irma. Ridership in the first four months of 2018 was running approximately $2 \%$ below year ago levels.

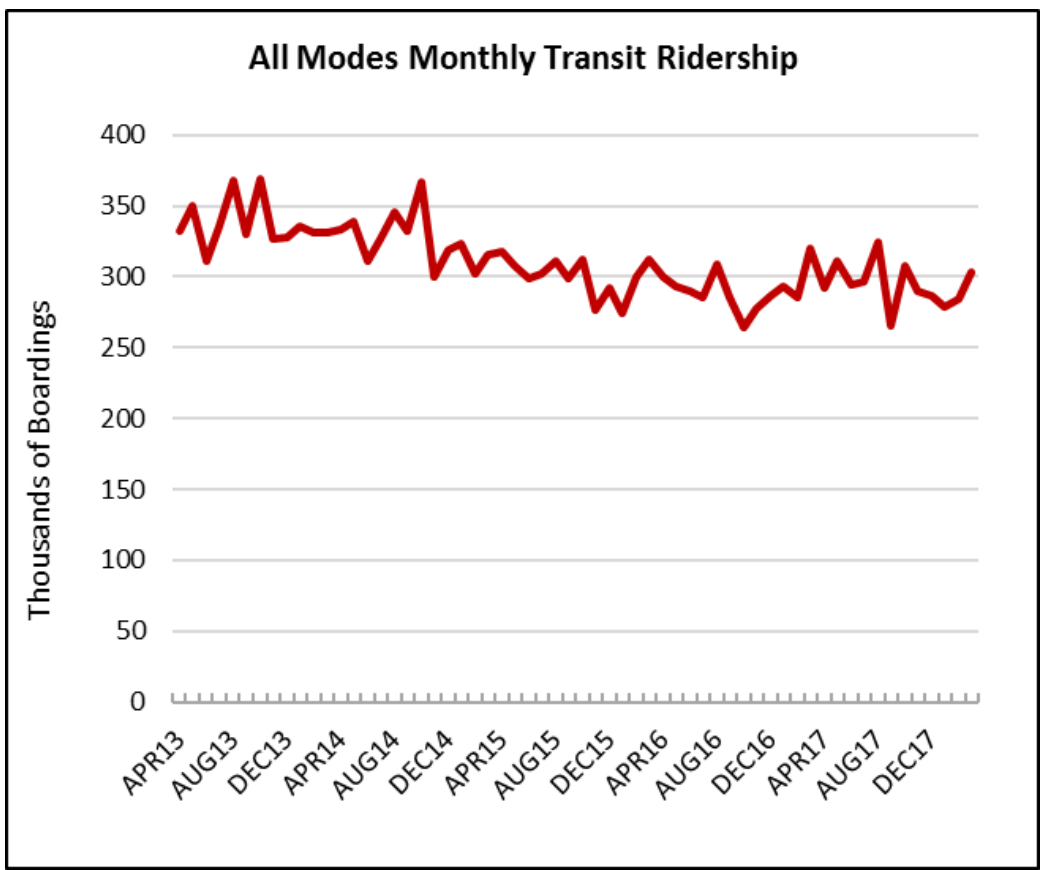

Average operating speed, defined as vehicle revenue miles divided by vehicle revenue hours, remain relatively steady around 15 miles per hour.

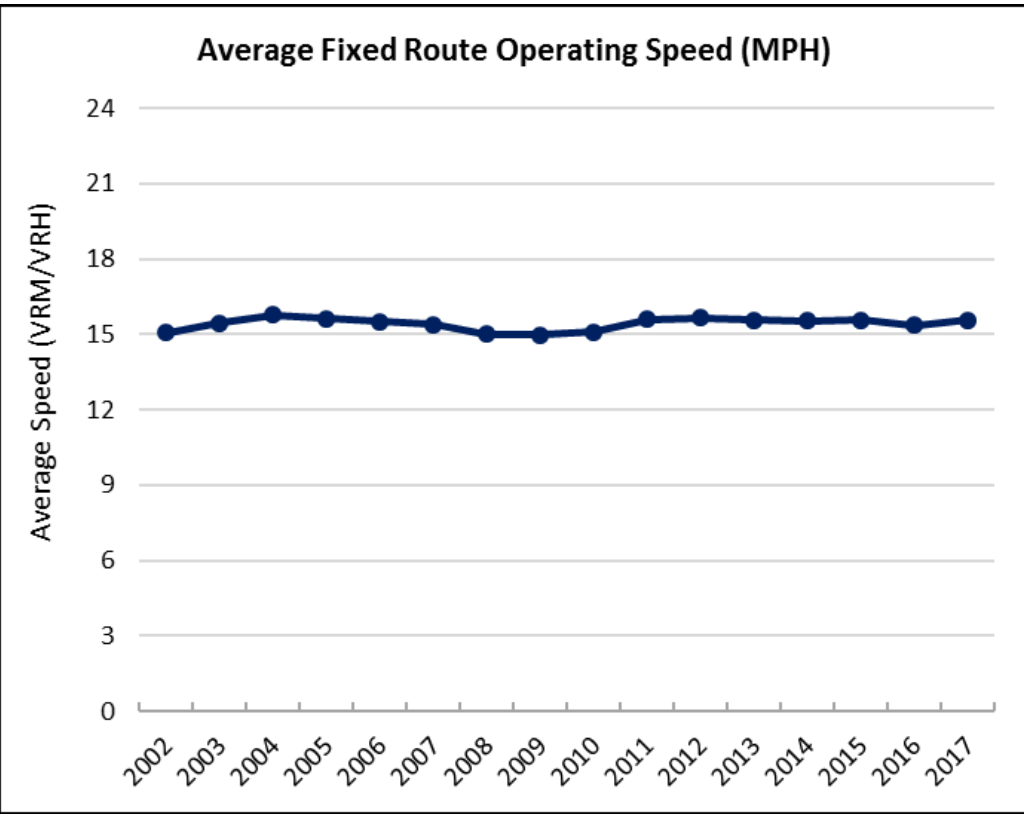


The adjacent graphic shows service productivity. After increasing from 2007 through 2013 productivity declined through 2017.

The figures below provide the ridership trends and service supply trends by sub mode. This allows one to understand how the various component modes are performing.

Bus ridership has grown

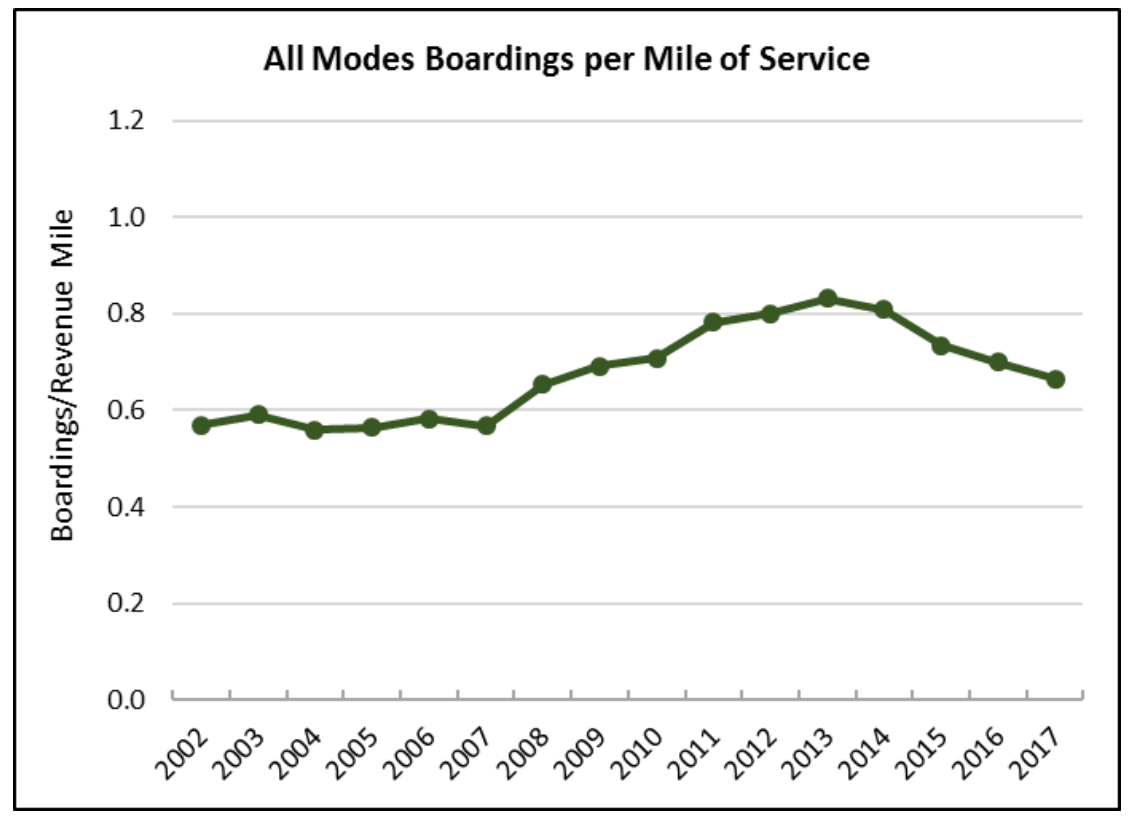
approximately $1 \%$ over one year and declined $11 \%$ over three years. Demand responsive

Rolling 12-Month Ridership Trend by Transit Mode

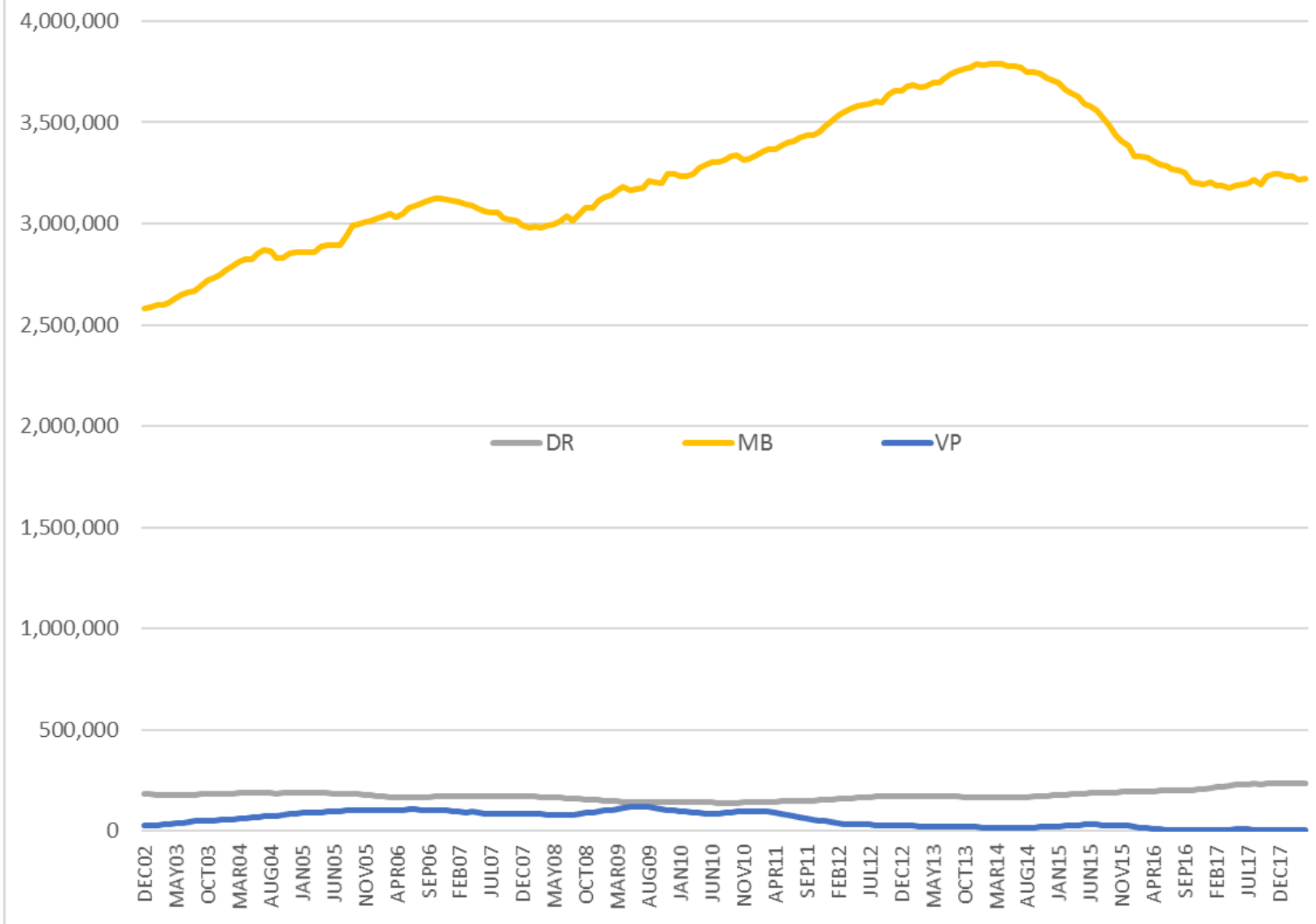


service has grown $5 \%$ in the last year and $27 \%$ over three years. Vanpool ridership have decreased $23 \%$ in the last year and $83 \%$ in the last three years

The final graphic shows service supply as measured by revenue vehicle miles of service. As the graphical data communicates, bus service supply has been growing, $8 \%$ in the past year and $11 \%$ over three years. Demand responsive service has grown $4 \%$ and $28 \%$ respectively and vanpool service has declined $37 \%$ and $18 \%$ respectively in the one in three year periods.

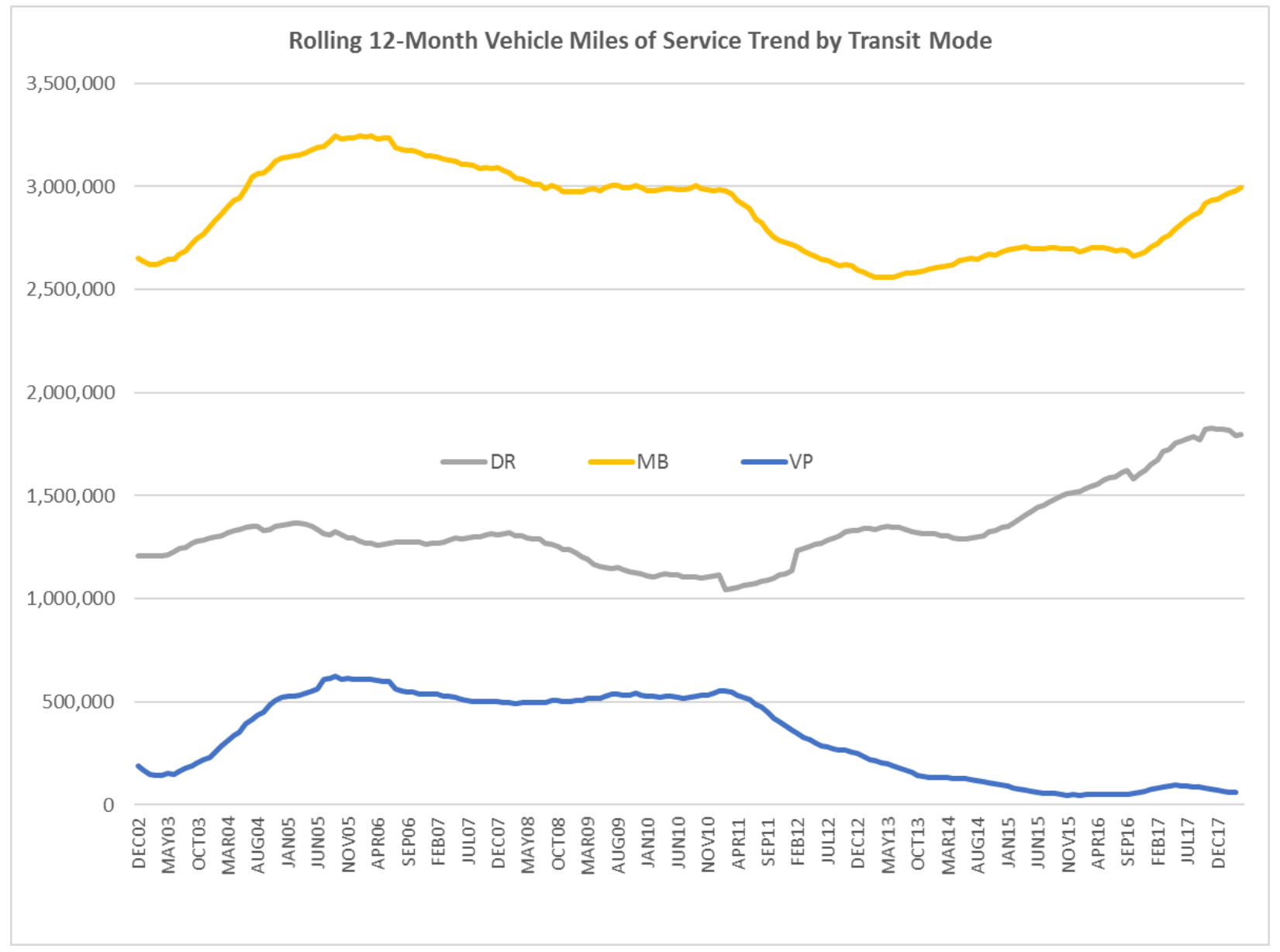




\section{Tallahassee (City of Tallahassee, StarMetro)}

Ridership on the Tallahassee transit system has declined 22\% since a peak in 2010. Vehicle revenue miles of service has grown $9 \%$ in that same time period. The Tallahassee transit system was most impacted by declining ridership during the past seven years.

Boardings per revenue mile has dropped $38 \%$ since its peak in 2010. Ridership per County resident has declined 35\% from its peak in 2010.

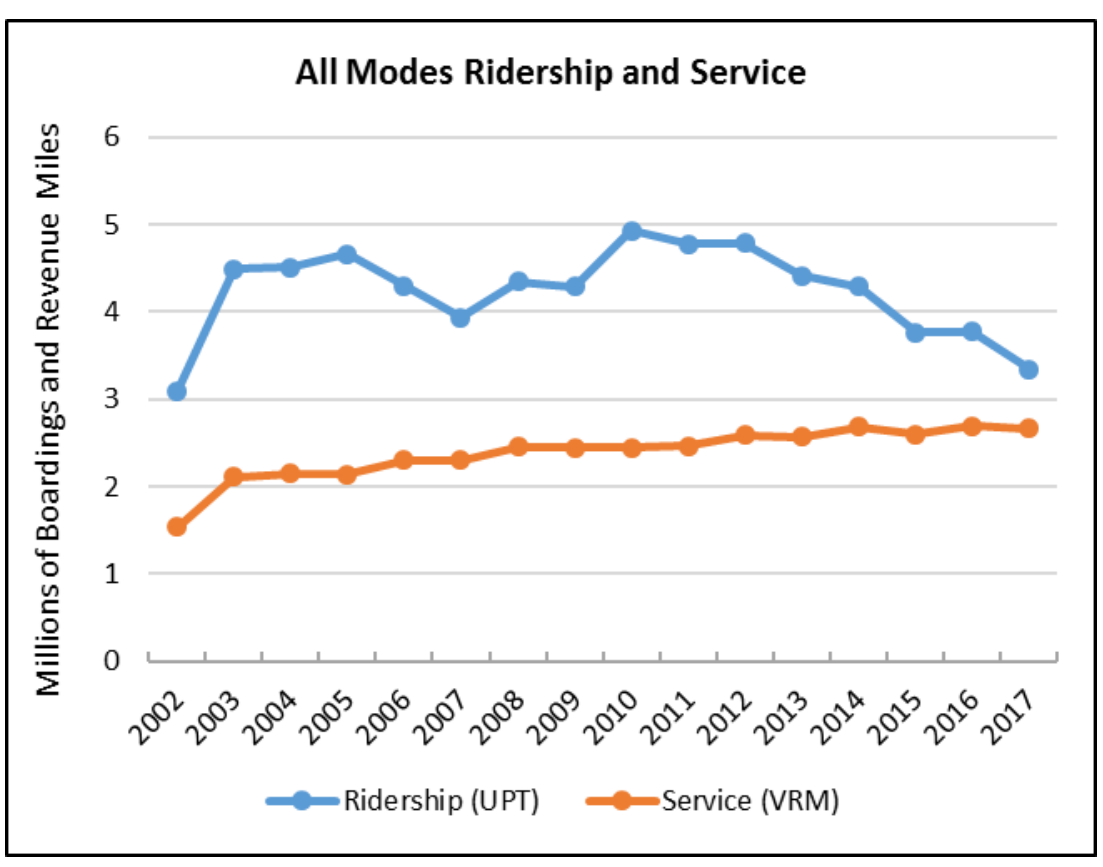

Average trip length on transit has been relatively stable and is short compared to other agencies at slightly over 3 miles.

\begin{tabular}{|c|c|c|c|c|c|c|c|c|}
\hline \multicolumn{9}{|c|}{ Annual Trend Data, All Modes } \\
\hline Year & Ridership (UPT) & Service (VRM) & $\begin{array}{c}\text { Boardings } \\
\text { per Revenue } \\
\text { Mile }\end{array}$ & $\begin{array}{l}\text { AVG Fixed- } \\
\text { Route } \\
\text { Speed } \\
\text { (mph) }\end{array}$ & $\begin{array}{c}\text { County } \\
\text { Population }\end{array}$ & $\begin{array}{l}\text { Trips per } \\
\text { Capita }\end{array}$ & $\begin{array}{l}\text { Passenger } \\
\text { Miles of } \\
\text { Travel }\end{array}$ & $\begin{array}{c}\text { Average } \\
\text { Trip } \\
\text { Length }\end{array}$ \\
\hline 2002 & $3,093,195$ & $1,534,808$ & 2.02 & 12.14 & 248,039 & 12.5 & $10,675,892$ & 3.45 \\
\hline 2003 & $4,487,759$ & $2,113,595$ & 2.12 & 12.12 & 255,500 & 17.6 & $10,502,085$ & 2.34 \\
\hline 2004 & $4,514,782$ & $2,150,040$ & 2.10 & 13.33 & 263,896 & 17.1 & $10,666,580$ & 2.36 \\
\hline 2005 & $4,665,607$ & $2,141,070$ & 2.18 & 12.73 & 271,111 & 17.2 & $11,000,927$ & 2.36 \\
\hline 2006 & $4,300,734$ & $2,303,103$ & 1.87 & 10.94 & 272,497 & 15.8 & & \\
\hline 2007 & $3,934,121$ & $2,300,173$ & 1.71 & 10.97 & 272,896 & 14.4 & $12,077,890$ & 3.07 \\
\hline 2008 & $4,351,201$ & $2,452,195$ & 1.77 & 9.78 & 274,892 & 15.8 & $12,265,111$ & 2.82 \\
\hline 2009 & $4,290,114$ & $2,442,472$ & 1.76 & 9.21 & 274,803 & 15.6 & $13,306,133$ & 3.10 \\
\hline 2010 & $4,933,682$ & $2,439,288$ & 2.02 & 9.06 & 276,058 & 17.9 & $13,962,966$ & 2.83 \\
\hline 2011 & $4,781,364$ & $2,460,041$ & 1.94 & 9.22 & 276,278 & 17.3 & $14,232,345$ & 2.98 \\
\hline 2012 & $4,786,792$ & $2,588,551$ & 1.85 & 9.18 & 277,670 & 17.2 & $14,597,604$ & 3.05 \\
\hline 2013 & $4,410,967$ & $2,564,053$ & 1.72 & 10.57 & 278,377 & 15.8 & $14,299,617$ & 3.24 \\
\hline 2014 & $4,291,927$ & $2,687,061$ & 1.60 & 9.89 & 281,292 & 15.3 & $14,107,019$ & 3.29 \\
\hline 2015 & $3,767,648$ & $2,594,194$ & 1.45 & 9.87 & 284,443 & 13.2 & $12,232,446$ & 3.25 \\
\hline 2016 & $3,769,872$ & $2,694,781$ & 1.40 & 10.10 & 287,671 & 13.1 & $12,086,737$ & 3.21 \\
\hline 2017 & $3,338,527$ & $2,663,613$ & 1.25 & 10.59 & 287,899 & 11.6 & & \\
\hline
\end{tabular}


The monthly ridership trend shows strong seasonal fluctuations as it often apparent in agencies highly dependent on college student riders. Ridership for the first three months of 2018 has been running approximately $16 \%$ behind last year.

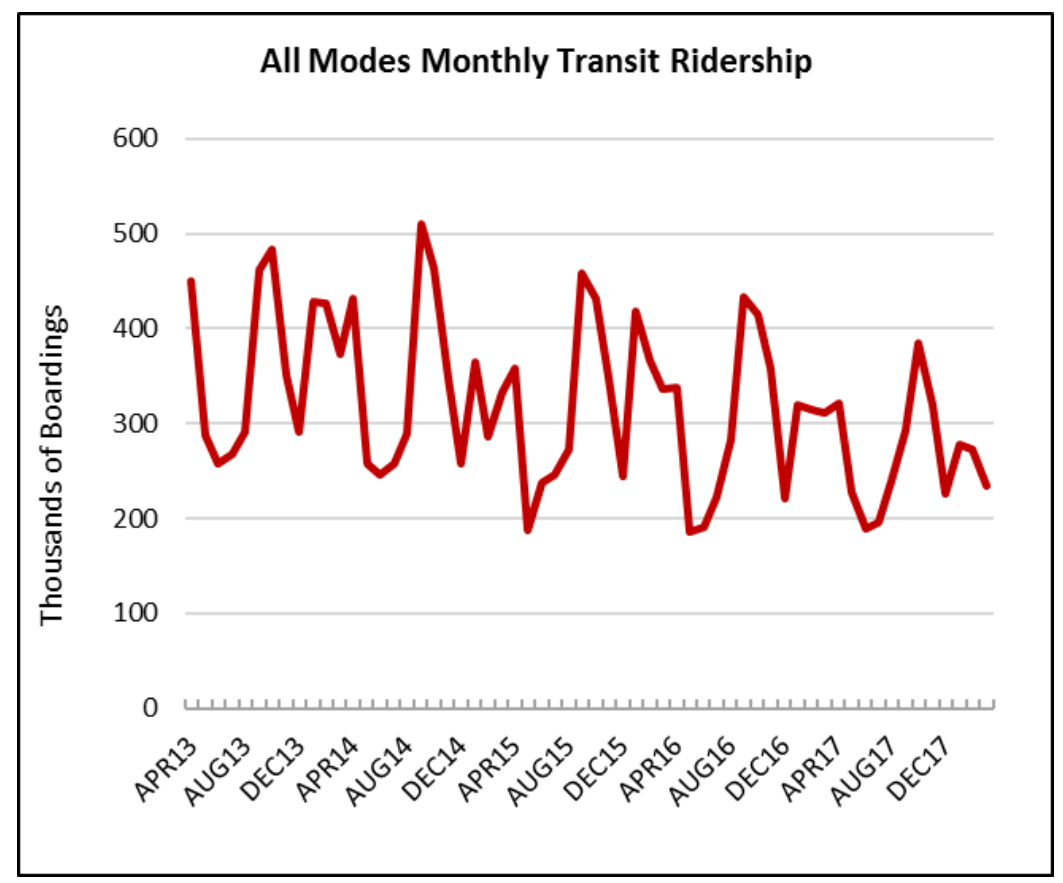

Average operating speed, defined as vehicle revenue miles divided by vehicle revenue hours, has ticked up slightly, now running over $10 \mathrm{MPH}$.

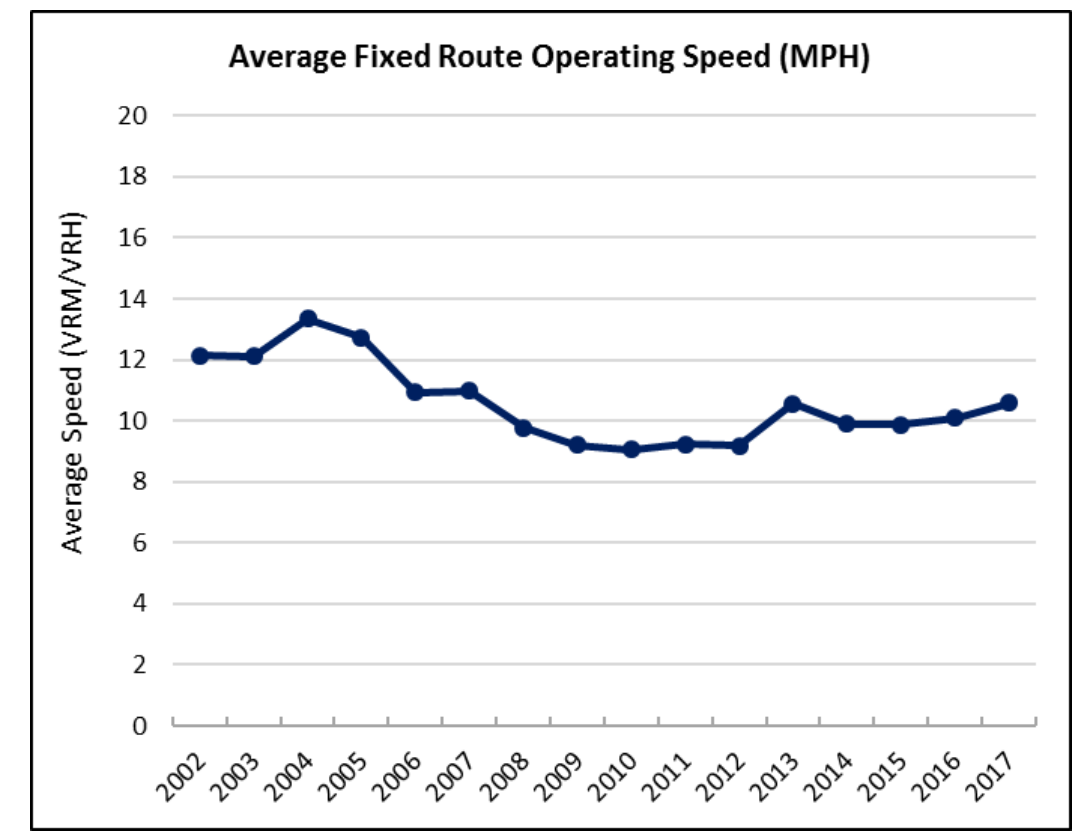


The adjacent graphic shows service productivity. Service productivity has declined steadily since 2010 .

The figures below provide the ridership trends and service supply trends by sub mode. This allows one to understand how the various component modes are performing.

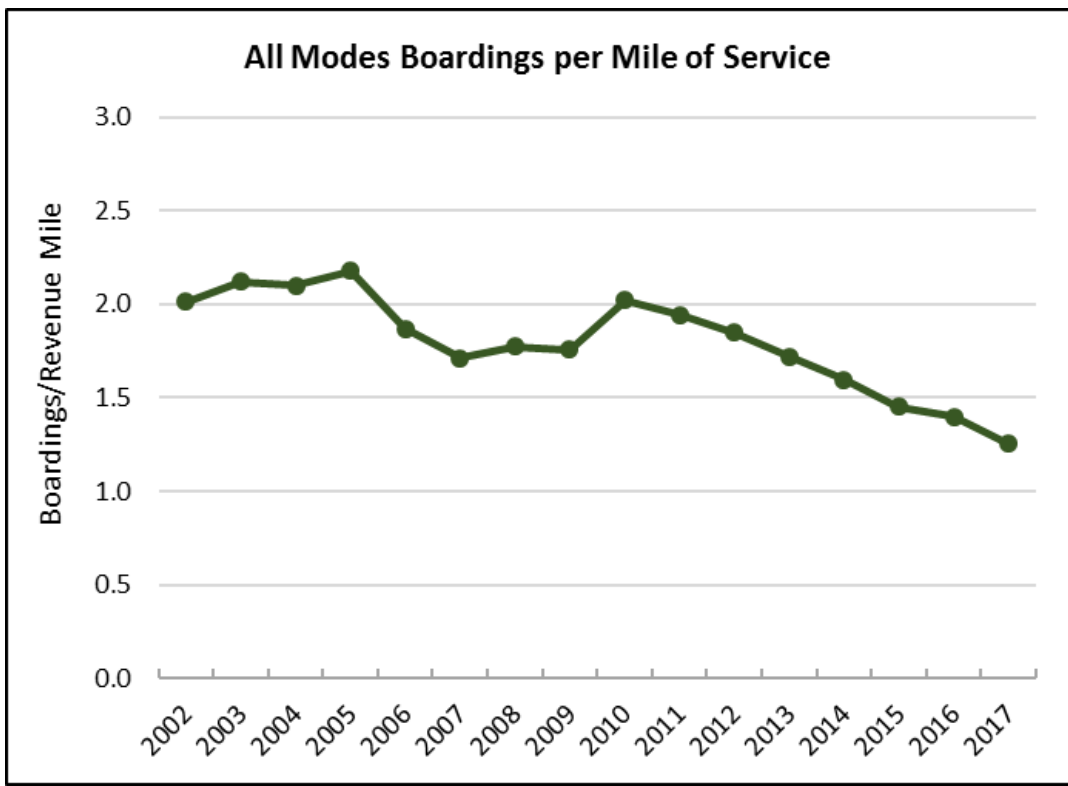

Bus ridership has declined approximately $12 \%$ over one year and declined $22 \%$ over three years. Demand responsive service has grown $4 \%$ in the last year and $18 \%$ over the past three.

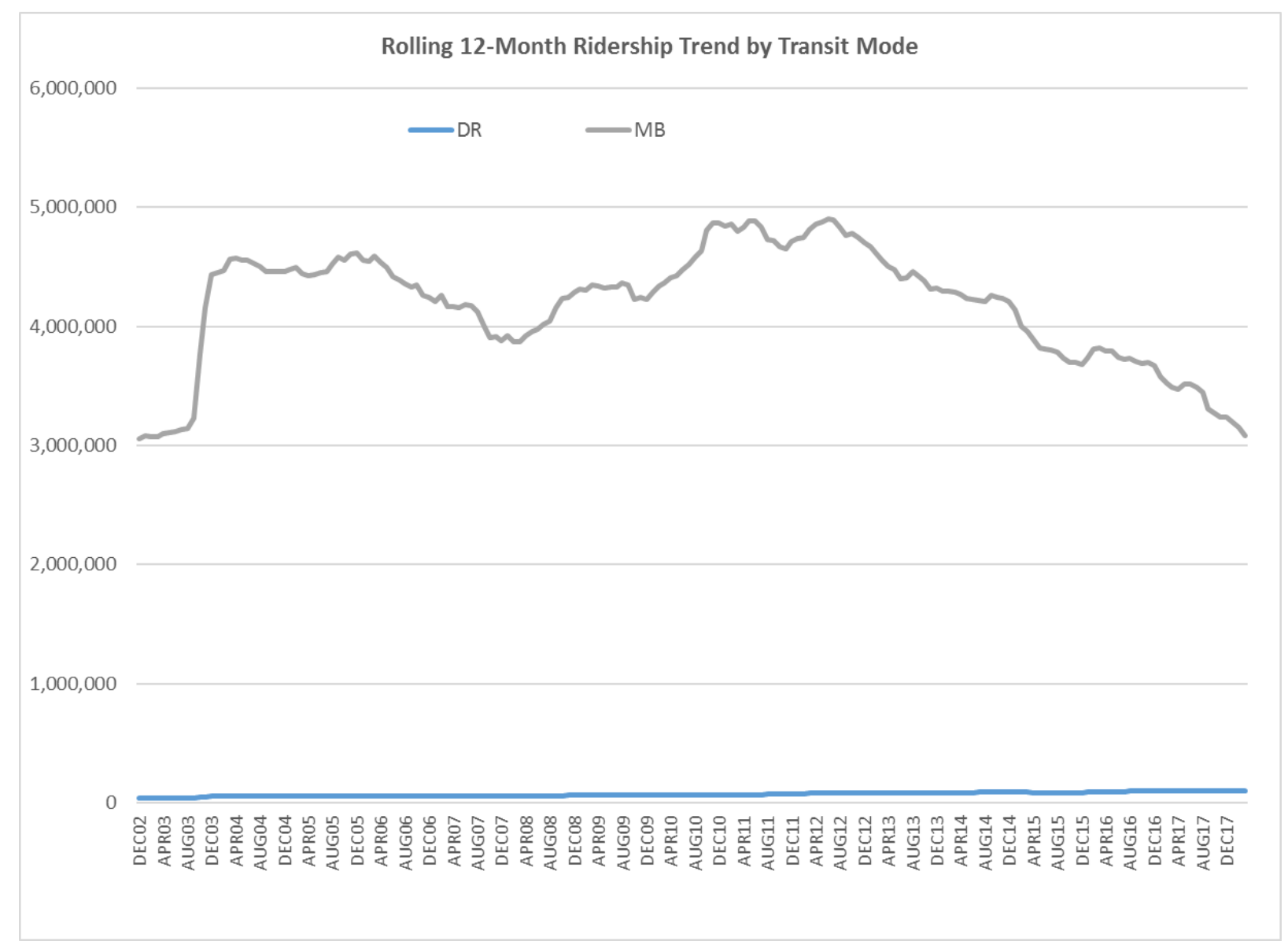


The final graphic shows service supply as measured by revenue vehicle miles of service. As the graphical data communicates, bus service supply has declined $2 \%$ in the past year and declined $2 \%$ over three years. Demand responsive service has grown $10 \%$ and $25 \%$ respectively in the one in three year periods.

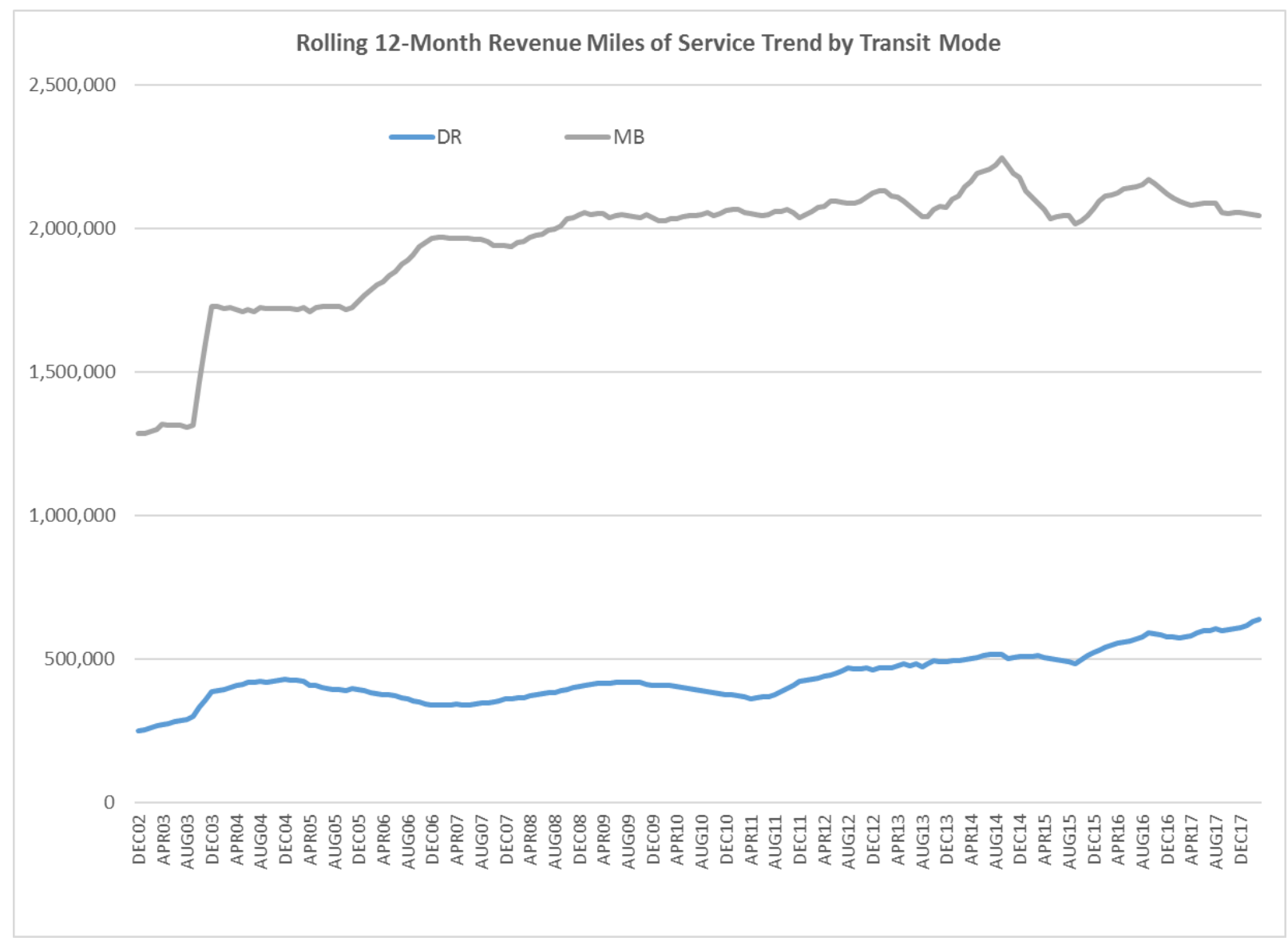


Lee County (Lee County Transit, LeeTran)

Ridership on the Lee County transit system has declined $23 \%$ since a peak in 2013. Vehicle revenue miles of service has grown $5 \%$ in that same time period. The Lee County transit system was most impacted by declining ridership during the past four years. Boardings per revenue mile has dropped $26 \%$ since its peak in 2013. Ridership per county resident has declined $29 \%$ from its peak in 2013.

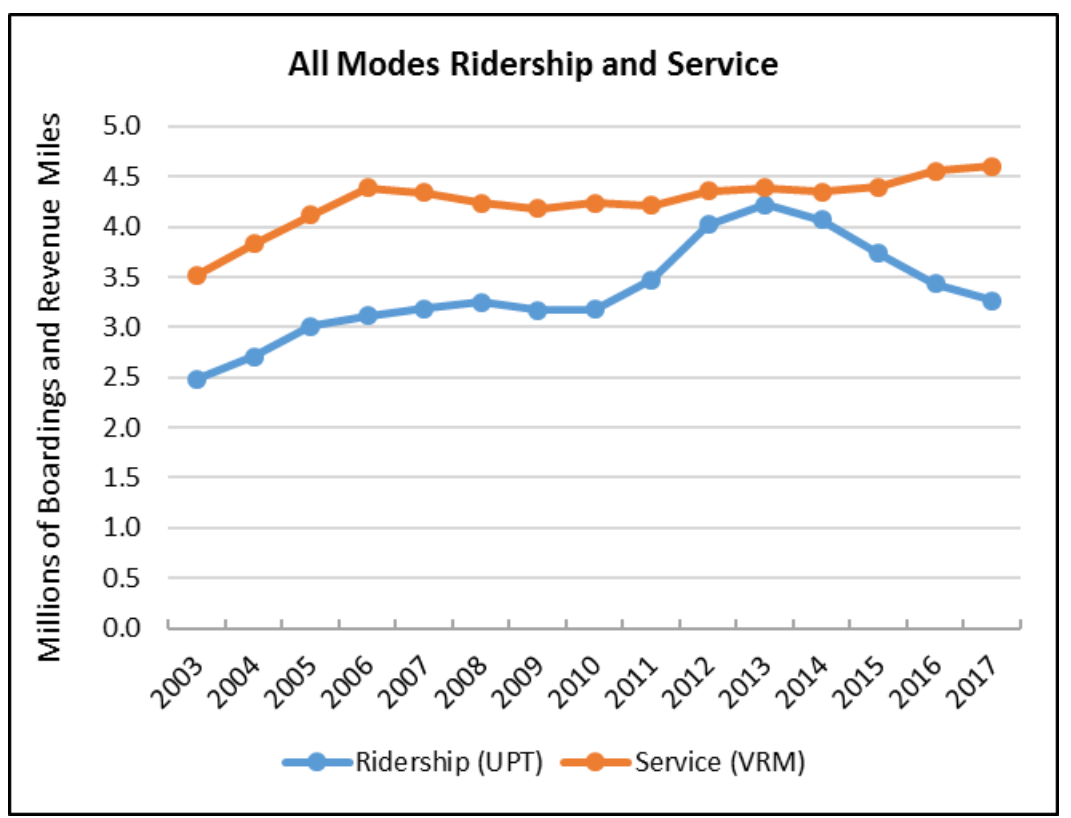

Average trip length on transit has generally increased through that period the average trip length being nearly 6 miles.

\begin{tabular}{|c|c|c|c|c|c|c|c|c|}
\hline \multicolumn{9}{|c|}{ Annual Trend Data, All Modes } \\
\hline Year & Ridership (UPT) & Service (VRM) & $\begin{array}{l}\text { Boardings per } \\
\text { Revenue Mile }\end{array}$ & $\begin{array}{l}\text { AVG Fixed- } \\
\text { Route } \\
\text { Speed } \\
\text { (mph) }\end{array}$ & $\begin{array}{c}\text { County } \\
\text { Population }\end{array}$ & $\begin{array}{c}\text { Trips per } \\
\text { Capita }\end{array}$ & $\begin{array}{c}\text { Passenger } \\
\text { Miles of Travel }\end{array}$ & $\begin{array}{c}\text { Average } \\
\text { Trip } \\
\text { Length }\end{array}$ \\
\hline 2002 & $2,143,871$ & $1,949,489$ & 1.10 & 14.50 & 475,073 & 4.5 & $11,253,588$ & 5.25 \\
\hline 2003 & $2,486,225$ & $3,516,430$ & 0.71 & 16.33 & 495,088 & 5.0 & $11,745,502$ & 4.72 \\
\hline 2004 & $2,709,843$ & $3,829,601$ & 0.71 & 16.15 & 521,253 & 5.2 & $12,825,164$ & 4.73 \\
\hline 2005 & $3,009,227$ & $4,119,666$ & 0.73 & 16.11 & 549,442 & 5.5 & $16,913,816$ & 5.62 \\
\hline 2006 & $3,114,494$ & $4,387,451$ & 0.71 & 17.12 & 585,608 & 5.3 & $17,738,014$ & 5.70 \\
\hline 2007 & $3,186,326$ & $4,338,189$ & 0.73 & 16.46 & 615,741 & 5.2 & $18,354,610$ & 5.76 \\
\hline 2008 & $3,250,001$ & $4,236,064$ & 0.77 & 16.26 & 623,725 & 5.2 & $18,303,247$ & 5.63 \\
\hline 2009 & $3,169,579$ & $4,178,317$ & 0.76 & 16.21 & 615,124 & 5.2 & $17,846,747$ & 5.63 \\
\hline 2010 & $3,175,855$ & $4,237,885$ & 0.75 & 16.17 & 620,151 & 5.1 & $17,498,483$ & 5.51 \\
\hline 2011 & $3,475,077$ & $4,210,737$ & 0.83 & 16.44 & 625,310 & 5.6 & $20,060,978$ & 5.77 \\
\hline 2012 & $4,020,837$ & $4,355,422$ & 0.92 & 16.07 & 638,029 & 6.3 & $23,519,620$ & 5.85 \\
\hline 2013 & $4,222,649$ & $4,391,868$ & 0.96 & 15.90 & 643,367 & 6.6 & $26,503,407$ & 6.28 \\
\hline 2014 & $4,070,448$ & $4,351,581$ & 0.94 & 15.68 & 653,485 & 6.2 & $22,996,804$ & 5.65 \\
\hline 2015 & $3,734,276$ & $4,395,587$ & 0.85 & 15.49 & 665,845 & 5.6 & $21,377,194$ & 5.72 \\
\hline 2016 & $3,428,452$ & $4,558,476$ & 0.75 & 15.37 & 680,539 & 5.0 & $19,791,447$ & 5.77 \\
\hline 2017 & $3,263,709$ & $4,605,332$ & 0.71 & 15.45 & 698,468 & 4.7 & & \\
\hline
\end{tabular}


The monthly ridership trend shows strong seasonal fluctuations and a significant impact from hurricane Irma. Ridership for the first four months of 2018 has been running approximately $2 \%$ ahead of last year.

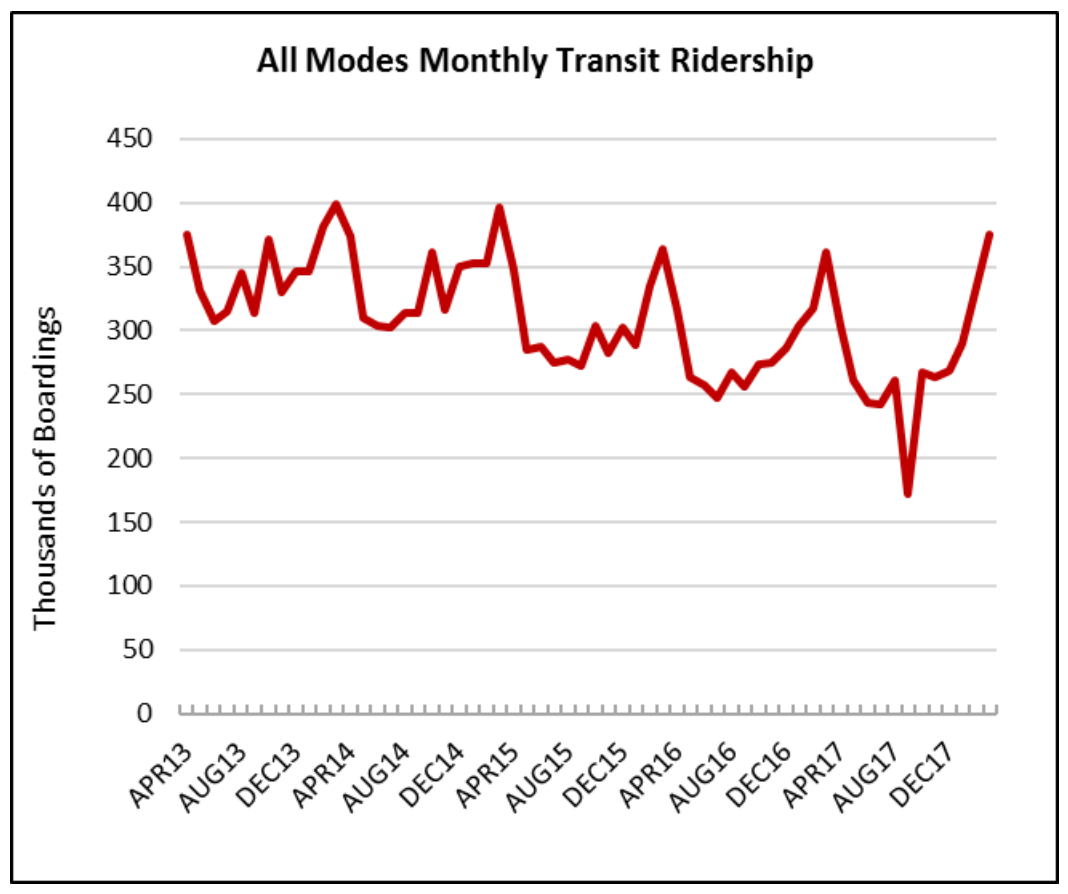

Average operating speed, defined as vehicle revenue miles divided by vehicle revenue hours, has been declining slightly from above to modestly below $16 \mathrm{mph}$.

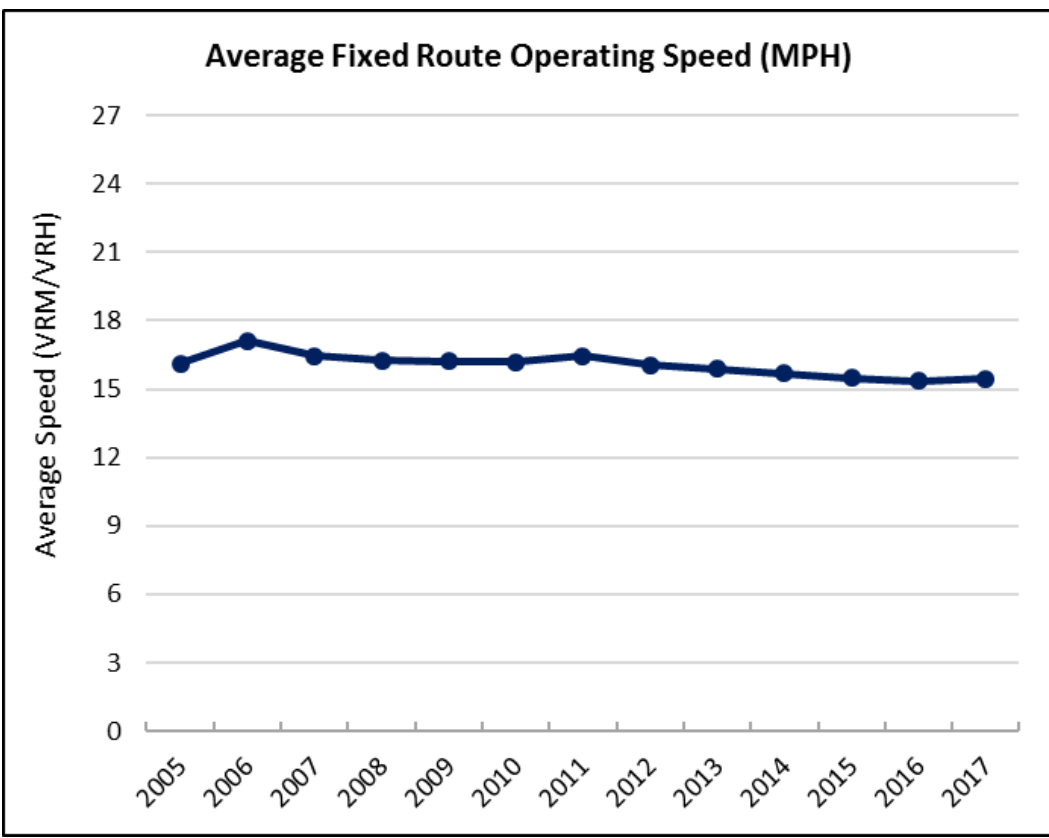


The adjacent graphic shows service productivity. After increasing from 2010 through 2013 productivity declined through 2017.

The figures below provide the ridership trends and service supply trends by sub mode. This allows one to understand how the various component modes are performing.

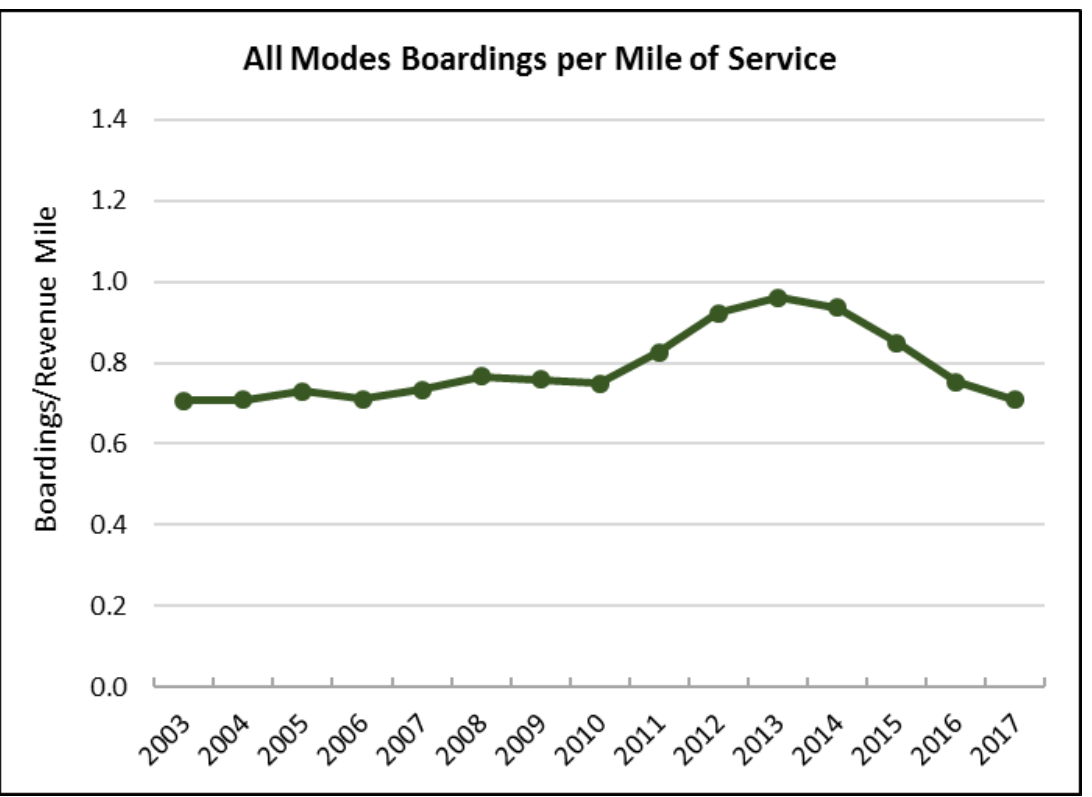

Bus ridership has declined approximately $5 \%$ over one year and declined $20 \%$ over three years. Demand responsive service has grown $3 \%$ in the last year and $12 \%$ over the past three years

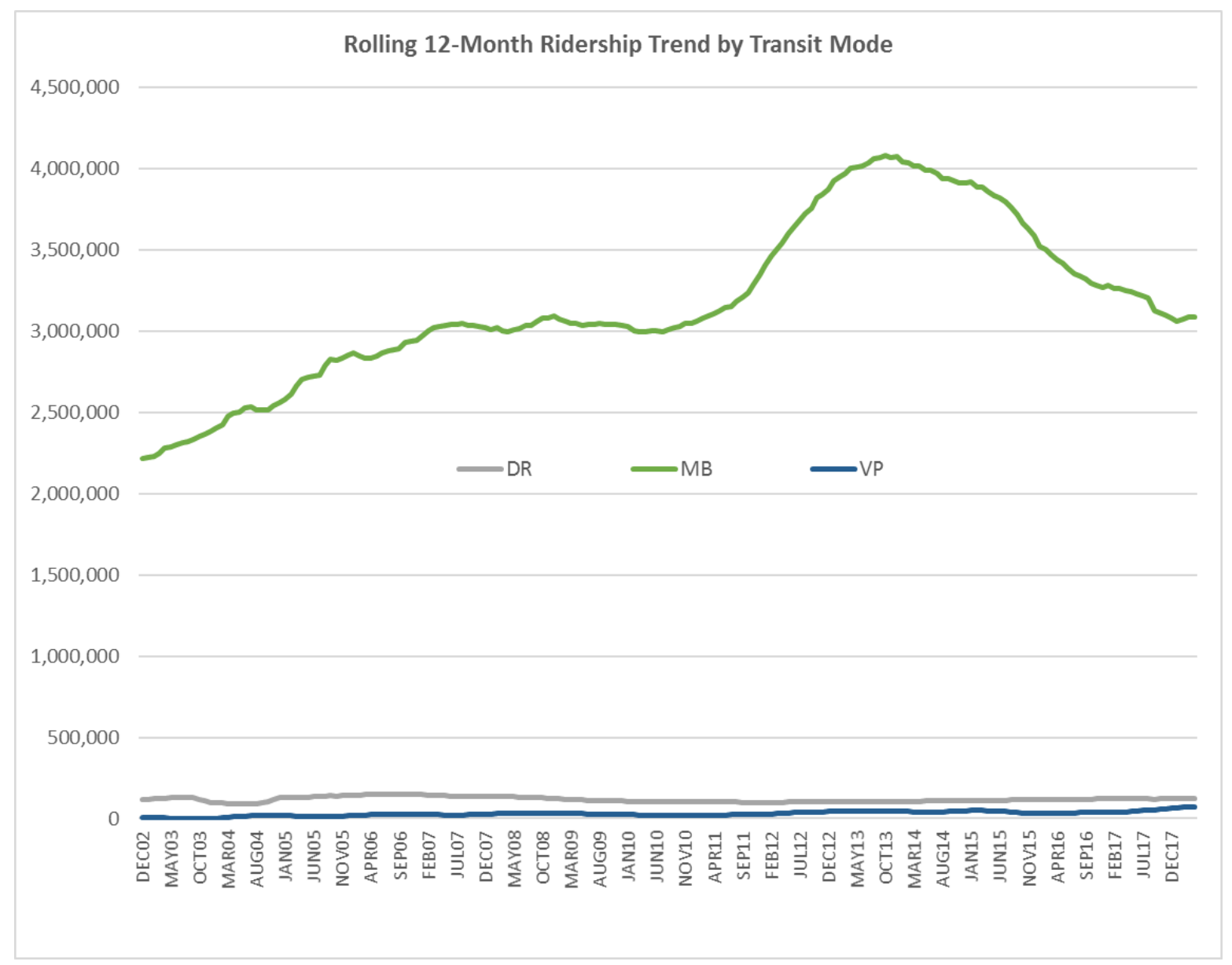


with similar levels of expanded vehicle miles of service. Vanpool ridership has expanded $85 \%$ in the past year and $54 \%$ in the past three years.

The final graphic shows service supply as measured by revenue vehicle miles of service. As the graphical data communicates, bus service supply has declined $1 \%$ in the past year and grown $2 \%$ over three years. Demand responsive service has grown $3 \%$ and $13 \%$ respectively and vanpool service has grown $54 \%$ and $25 \%$ respectively in the one in three year periods.

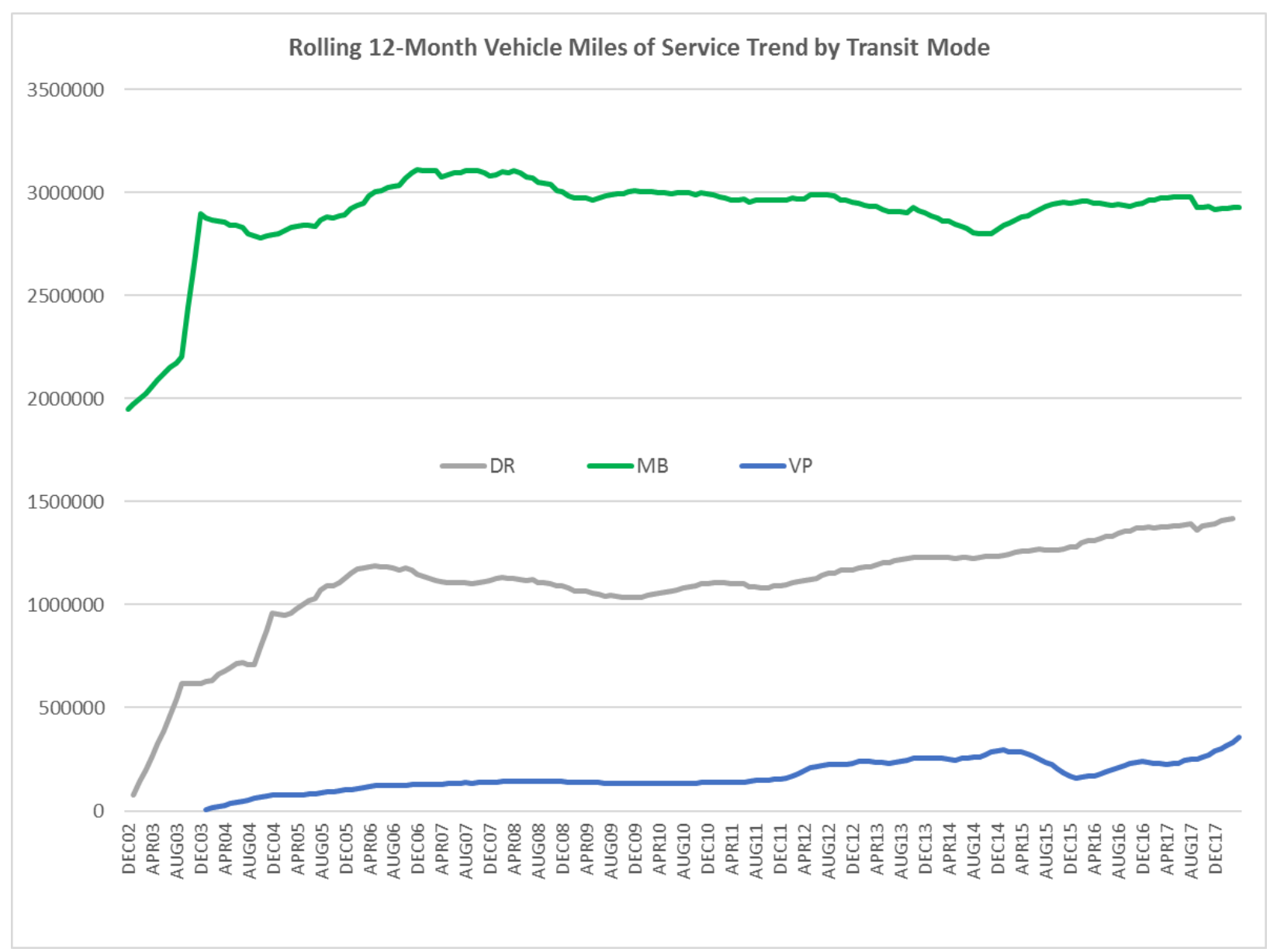


Space Coast (Space Coast Area Transit)

Ridership on the Space Coast transit system has declined 13\% since a peak in 2013. Vehicle revenue miles of service has declined $8 \%$ in that same time period. The Space Coast transit system was most impacted by declining ridership during the past three years. Boardings per revenue mile has dropped 6\% since its peak in 2011. Ridership per County resident has declined $16 \%$ from its peak in 2014.

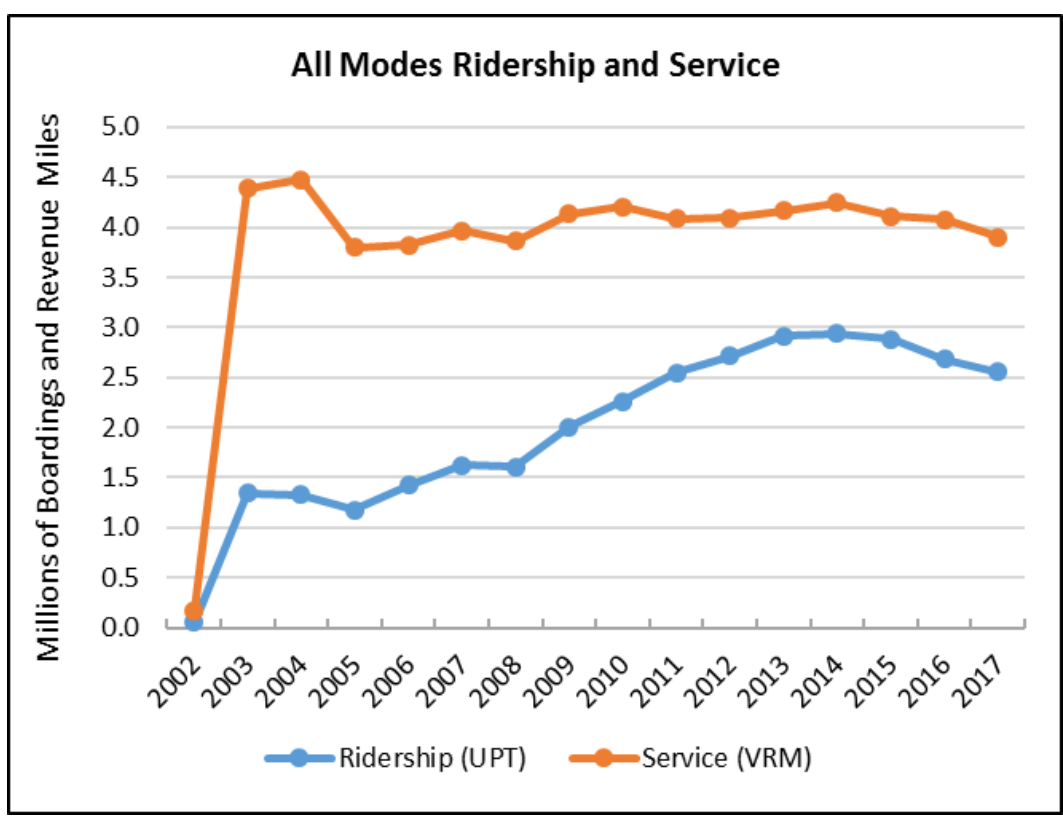

Average trip length on transit has been relatively stable since 2005 Under 6 miles.

\begin{tabular}{|c|c|c|c|c|c|c|c|c|}
\hline \multicolumn{9}{|c|}{ Annual Trend Data, All Modes } \\
\hline Year & Ridership (UPT) & Service (VRM) & $\begin{array}{c}\text { Boardings } \\
\text { per Revenue } \\
\text { Mile }\end{array}$ & $\begin{array}{l}\text { AVG Fixed- } \\
\text { Route } \\
\text { Speed } \\
\text { (mph) }\end{array}$ & $\begin{array}{l}\text { County } \\
\text { Population }\end{array}$ & $\begin{array}{c}\text { Trips per } \\
\text { Capita }\end{array}$ & $\begin{array}{c}\text { Passenger } \\
\text { Miles of Travel }\end{array}$ & $\begin{array}{l}\text { Average } \\
\text { Trip } \\
\text { Length }\end{array}$ \\
\hline 2002 & 51,311 & 169,048 & 0.30 & 18.53 & 494,102 & 0.1 & $20,433,650$ & 398.23 \\
\hline 2003 & $1,341,151$ & $4,385,582$ & 0.31 & 20.62 & 507,810 & 2.6 & $21,139,925$ & 15.76 \\
\hline 2004 & $1,328,404$ & $4,472,012$ & 0.30 & 20.18 & 521,422 & 2.5 & $20,674,327$ & 15.56 \\
\hline 2005 & $1,172,225$ & $3,795,870$ & 0.31 & 21.41 & 531,970 & 2.2 & $21,683,130$ & 18.50 \\
\hline 2006 & $1,421,591$ & $3,819,131$ & 0.37 & 21.90 & 543,050 & 2.6 & $21,924,441$ & 15.42 \\
\hline 2007 & $1,620,041$ & $3,964,220$ & 0.41 & 22.34 & 552,109 & 2.9 & $23,381,999$ & 14.43 \\
\hline 2008 & $1,603,354$ & $3,862,375$ & 0.42 & 18.64 & 556,213 & 2.9 & $22,251,575$ & 13.88 \\
\hline 2009 & $2,006,182$ & $4,132,272$ & 0.49 & 19.06 & 555,657 & 3.6 & $20,416,472$ & 10.18 \\
\hline 2010 & $2,256,476$ & $4,207,931$ & 0.54 & 19.03 & 543,573 & 4.2 & $20,699,448$ & 9.17 \\
\hline 2011 & $2,545,203$ & $4,084,340$ & 0.62 & 18.55 & 545,184 & 4.7 & $22,807,495$ & 8.96 \\
\hline 2012 & $2,714,554$ & $4,089,887$ & 0.66 & 18.69 & 545,625 & 5.0 & $23,661,724$ & 8.72 \\
\hline 2013 & 2,911,099 & $4,161,187$ & 0.70 & 18.32 & 548,424 & 5.3 & $25,902,092$ & 8.90 \\
\hline 2014 & $2,938,196$ & $4,245,355$ & 0.69 & 18.44 & 552,427 & 5.3 & $26,873,487$ & 9.15 \\
\hline 2015 & $2,881,056$ & $4,105,781$ & 0.70 & 18.83 & 561,714 & 5.1 & $24,836,601$ & 8.62 \\
\hline 2016 & $2,680,147$ & $4,078,172$ & 0.66 & 18.57 & 568,919 & 4.7 & $23,198,942$ & 8.66 \\
\hline 2017 & $2,555,367$ & $3,904,534$ & 0.65 & 18.69 & 575,211 & 4.4 & & \\
\hline
\end{tabular}


The monthly ridership trend shows the influence of hurricane Irma. Ridership for the first three months of 2018 has been running approximately $5 \%$ behind last year.

Average operating speed, defined as vehicle revenue miles divided by vehicle revenue hours, has been averaging nearly $19 \mathrm{mph}$, a relatively fast speed for transit service.
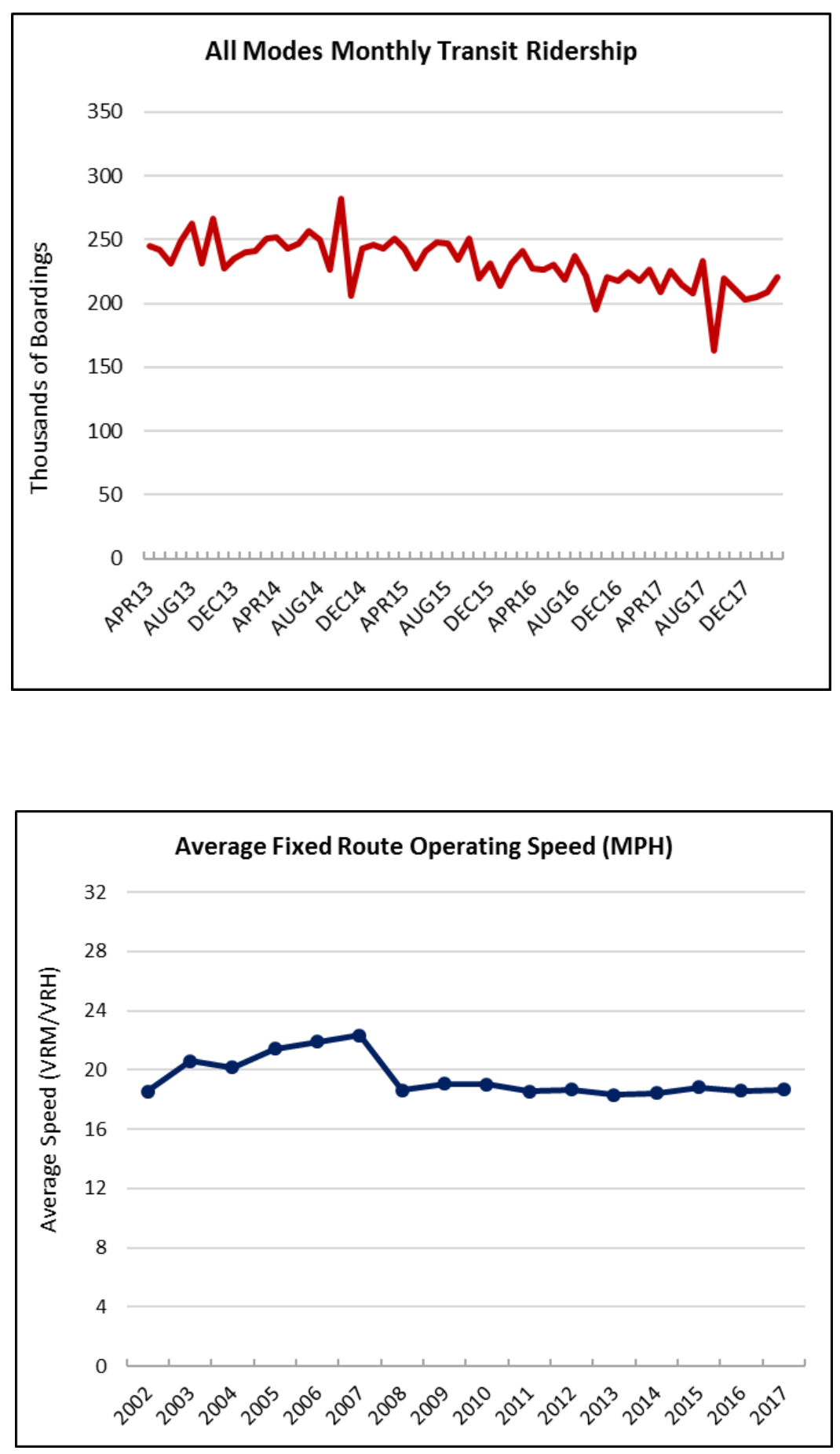
The adjacent graphic shows service productivity. Service productivity has declined modestly since 2015.

The figures below provide the ridership trends and service supply trends by sub mode. This allows one to understand how the various component modes are performing.

Bus ridership has declined

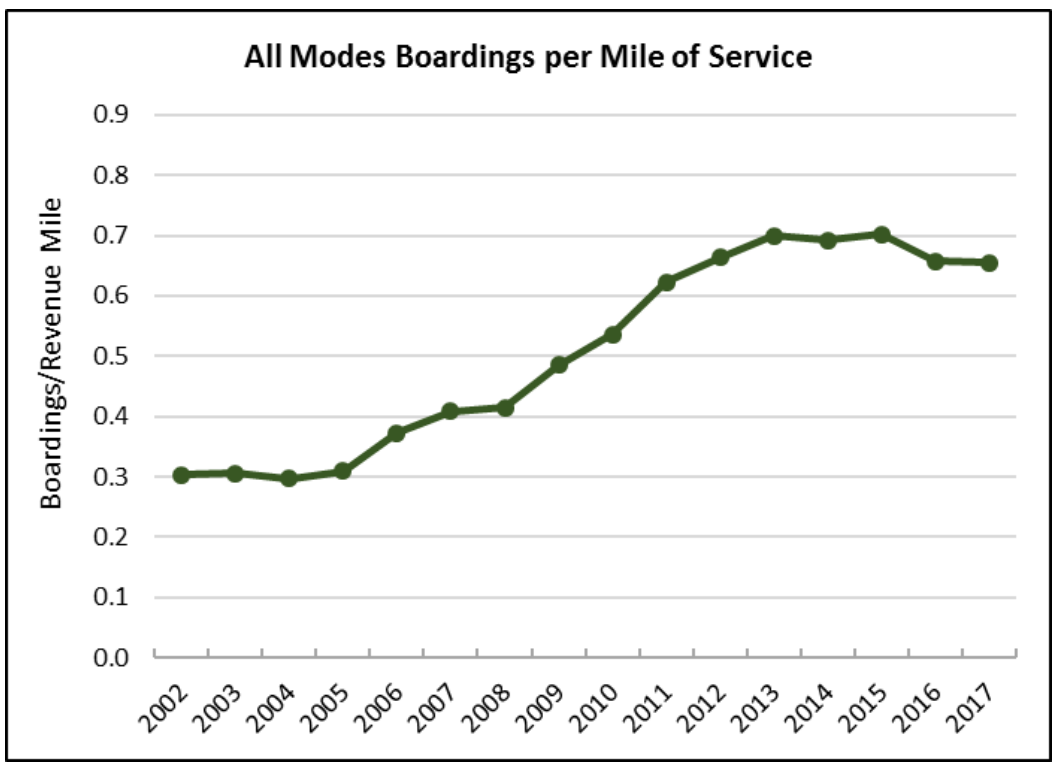
approximately $4 \%$ over one year and $11 \%$ over three years. Demand responsive service has declined $7 \%$ in the last year and declined $23 \%$ over the past three. Van pool service declined

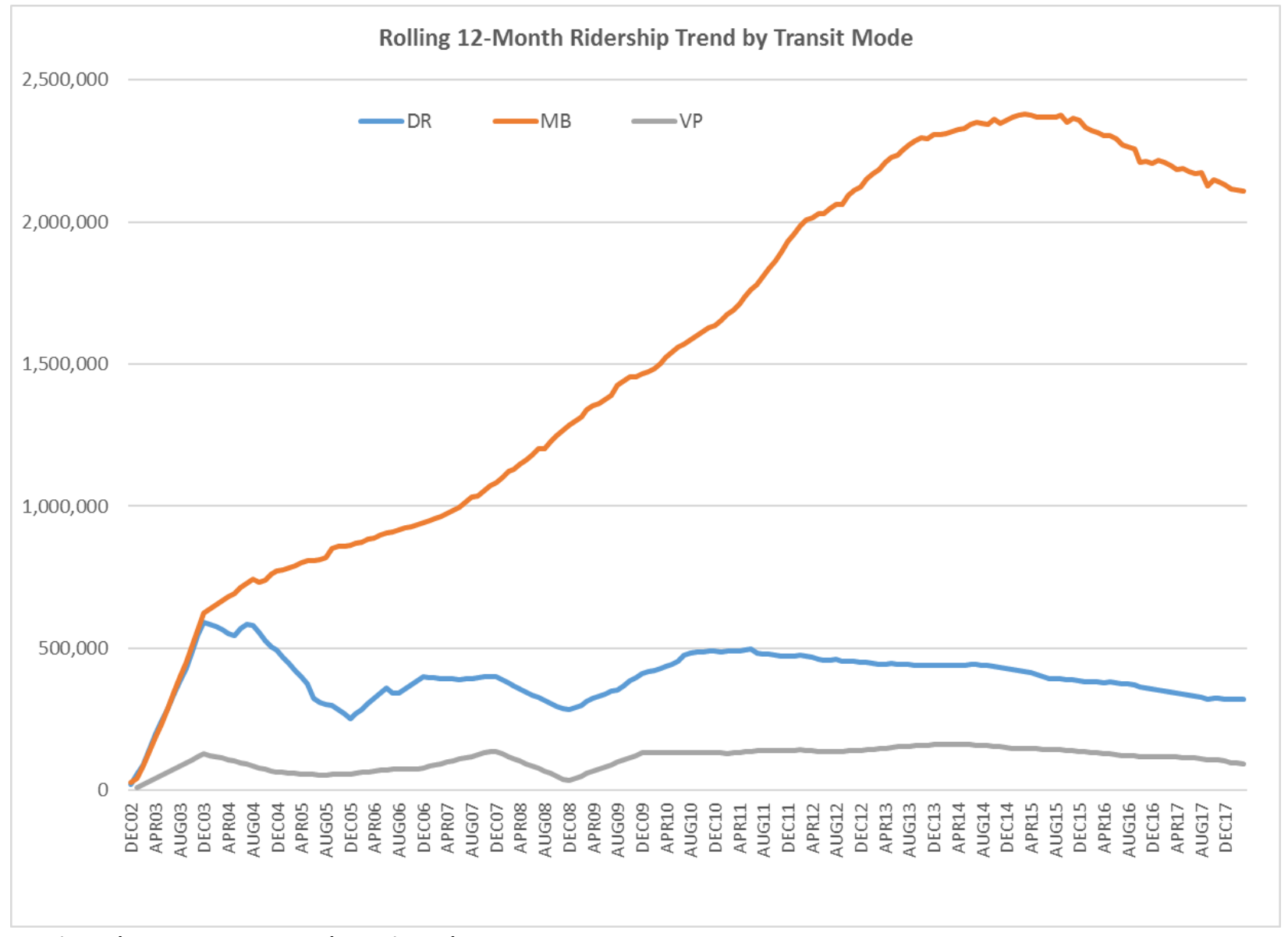

$22 \%$ in the past year and $38 \%$ in three years. 
The final graphic shows service supply as measured by revenue vehicle miles of service. As the graphical data communicates, bus service supply has increased $2 \%$ in the past year and $9 \%$ over three years. Demand responsive service has declined $2 \%$ and $8 \%$ respectively in the one in three year periods. And vanpool service has declined $27 \%$ in the past year and $37 \%$ over three years.

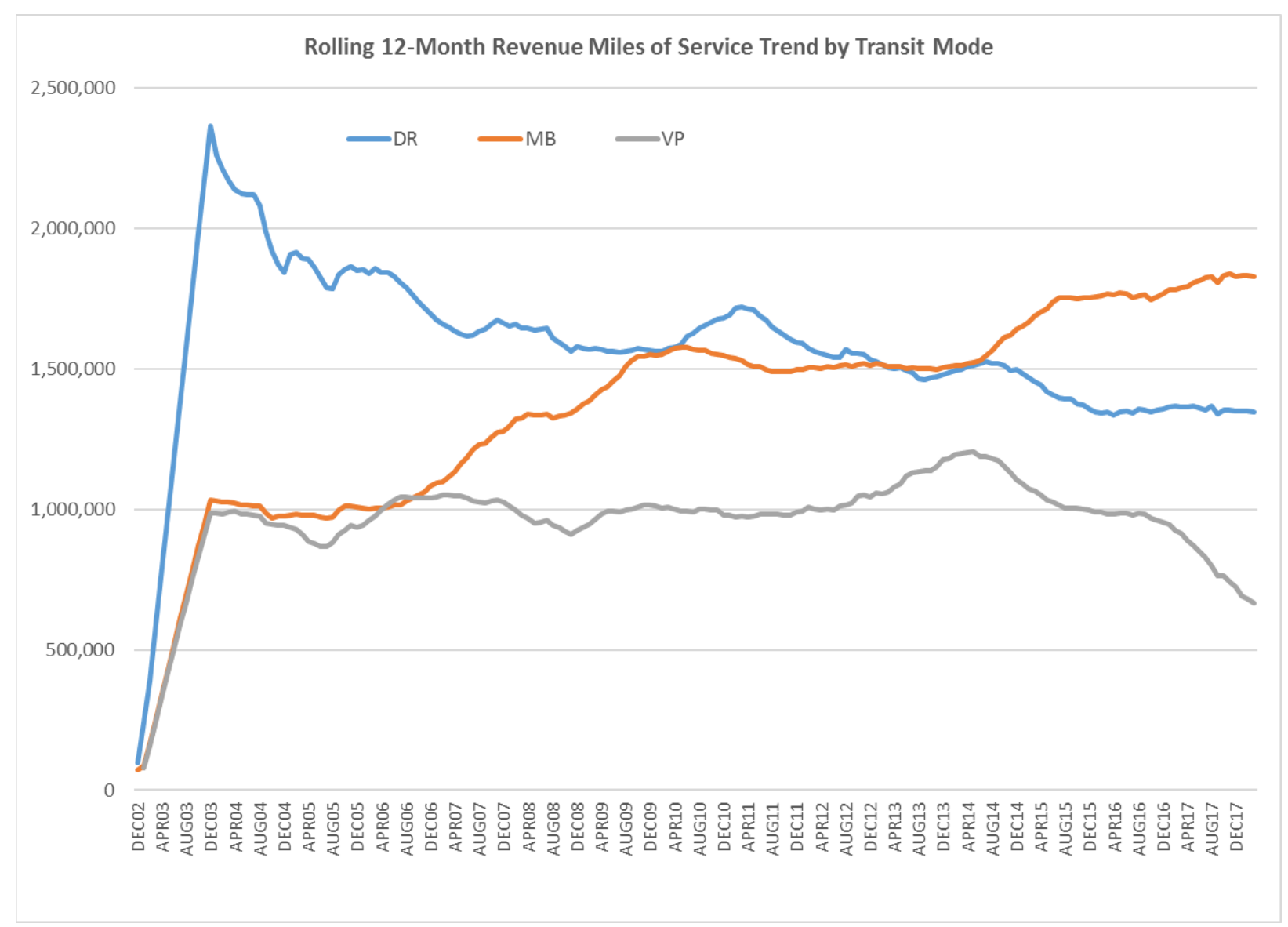




\section{Sarasota County (Sarasota County Area Transit, SCAT)}

Ridership on the Sarasota transit system has declined 18\% since a peak in 2011. Vehicle revenue miles of service has declined $4 \%$ in that same time period. The Tallahassee transit system was most impacted by declining ridership during the past seven years. Boardings per revenue mile has dropped $27 \%$ since its peak in 2011. Ridership per County resident has declined $23 \%$ from its peak in 2011.

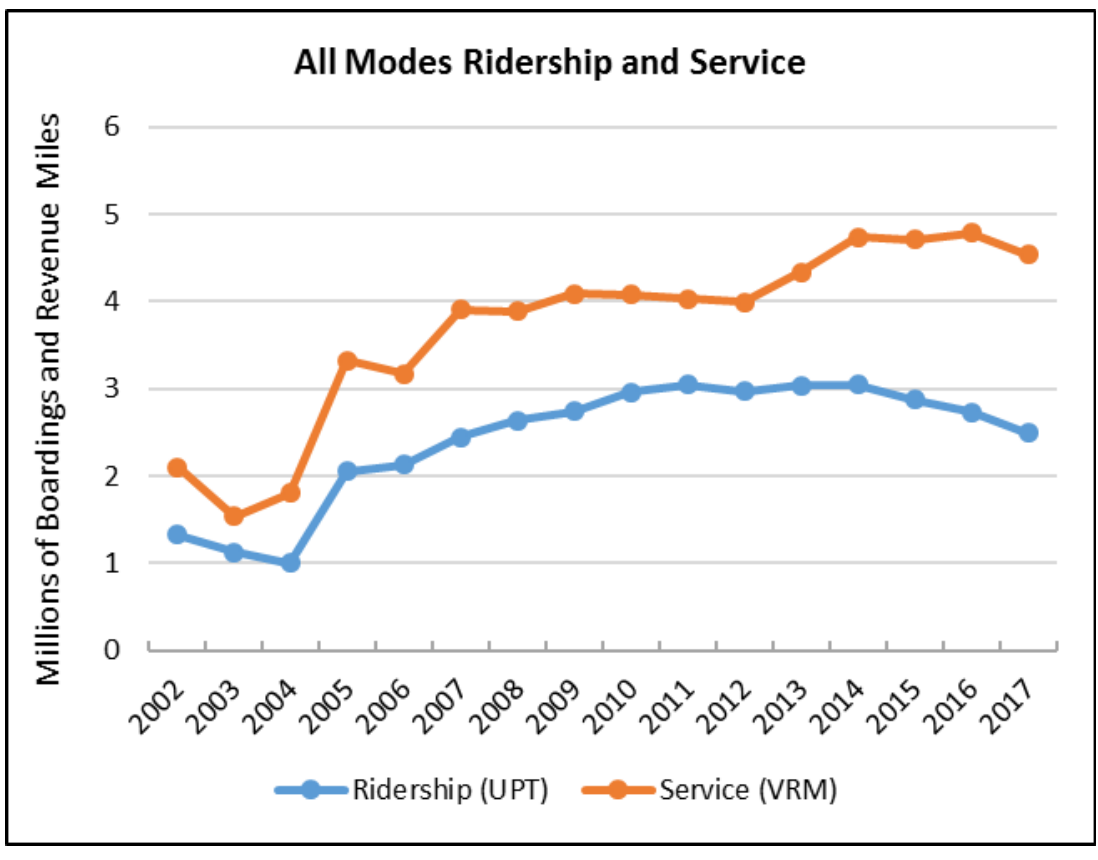

Average trip length on transit has been relatively stable since 2005 Under 6 miles.

\begin{tabular}{|c|c|c|c|c|c|c|c|c|}
\hline \multicolumn{9}{|c|}{ Annual Trend Data, All Modes } \\
\hline Year & Ridership (UPT) & Service (VRM) & $\begin{array}{l}\text { Boardings per } \\
\text { Revenue Mile }\end{array}$ & $\begin{array}{l}\text { AVG Fixed- } \\
\text { Route } \\
\text { Speed } \\
\text { (mph) }\end{array}$ & $\begin{array}{c}\text { County } \\
\text { Population }\end{array}$ & $\begin{array}{l}\text { Trips per } \\
\text { Capita }\end{array}$ & $\begin{array}{c}\text { Passenger } \\
\text { Miles of } \\
\text { Travel }\end{array}$ & $\begin{array}{c}\text { Average } \\
\text { Trip } \\
\text { Length }\end{array}$ \\
\hline 2002 & $1,320,639$ & $2,096,117$ & 0.63 & 15.37 & 339,684 & 3.9 & $12,399,996$ & 9.39 \\
\hline 2003 & $1,120,817$ & $1,537,024$ & 0.73 & 15.32 & 348,761 & 3.2 & $11,551,702$ & 10.31 \\
\hline 2004 & 999,822 & $1,798,651$ & 0.56 & 16.05 & 358,307 & 2.8 & $11,355,315$ & 11.36 \\
\hline 2005 & $2,053,510$ & $3,328,738$ & 0.62 & 17.33 & 367,867 & 5.6 & $10,934,144$ & 5.32 \\
\hline 2006 & $2,127,150$ & $3,167,400$ & 0.67 & 14.06 & 379,386 & 5.6 & $11,703,236$ & 5.50 \\
\hline 2007 & $2,442,445$ & $3,908,061$ & 0.62 & 14.78 & 387,461 & 6.3 & $13,061,665$ & 5.35 \\
\hline 2008 & $2,638,582$ & $3,885,856$ & 0.68 & 14.64 & 393,608 & 6.7 & $15,391,446$ & 5.83 \\
\hline 2009 & $2,742,935$ & $4,087,311$ & 0.67 & 14.68 & 389,320 & 7.0 & $16,113,563$ & 5.87 \\
\hline 2010 & $2,958,830$ & $4,079,455$ & 0.73 & 14.78 & 379,874 & 7.8 & $16,958,847$ & 5.73 \\
\hline 2011 & $3,045,016$ & $4,034,636$ & 0.75 & 14.94 & 381,319 & 8.0 & $16,793,682$ & 5.52 \\
\hline 2012 & $2,969,716$ & $3,997,002$ & 0.74 & 15.26 & 383,664 & 7.7 & $16,636,194$ & 5.60 \\
\hline 2013 & $3,040,794$ & $4,341,880$ & 0.70 & 15.67 & 385,292 & 7.9 & $16,941,813$ & 5.57 \\
\hline 2014 & $3,049,780$ & $4,739,429$ & 0.64 & 15.48 & 387,140 & 7.9 & $17,230,378$ & 5.65 \\
\hline 2015 & $2,876,284$ & $4,715,704$ & 0.61 & 15.06 & 392,090 & 7.3 & $16,483,471$ & 5.73 \\
\hline 2016 & $2,726,505$ & $4,785,988$ & 0.57 & 14.58 & 399,538 & 6.8 & $15,402,333$ & 5.65 \\
\hline 2017 & $2,491,676$ & $4,539,203$ & 0.55 & 14.33 & 407,260 & 6.1 & & \\
\hline
\end{tabular}


The monthly ridership trend shows the influence of Hurricane Irma and has remained weak since that time. Ridership for the first three months of 2018 has been running approximately $18 \%$ behind last year.

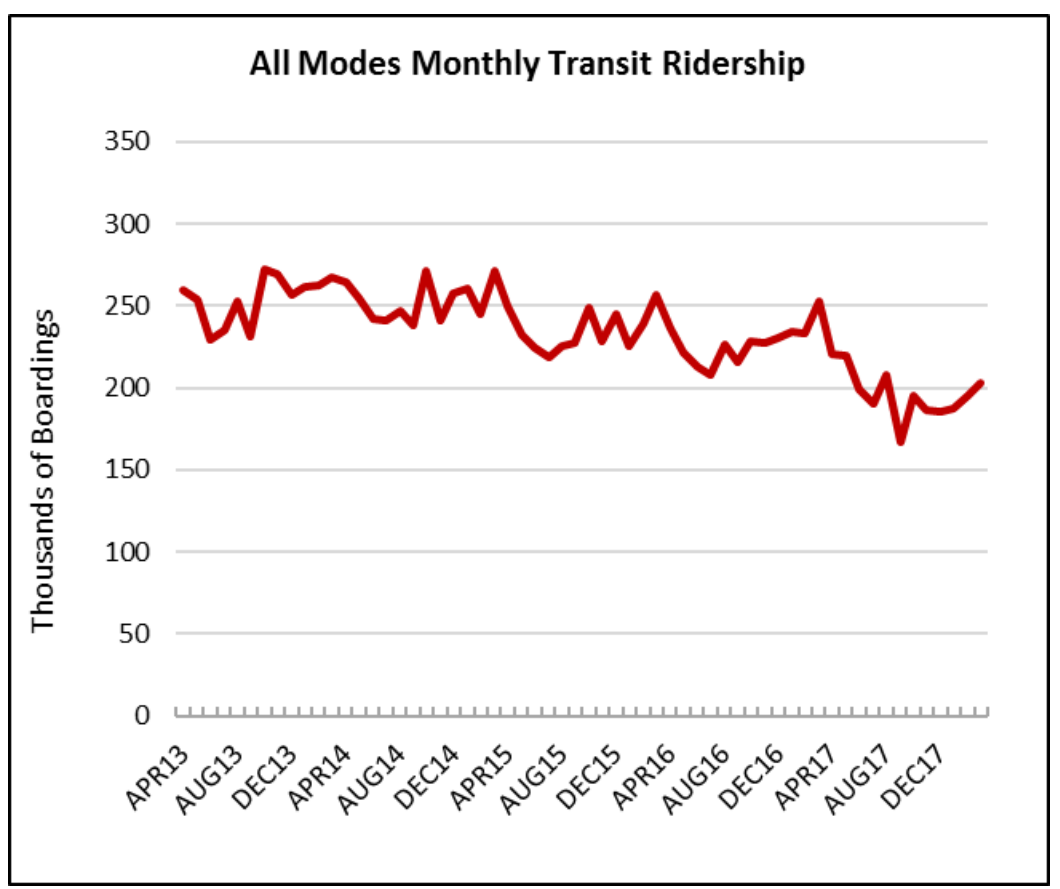

Average operating speed, defined as vehicle revenue miles divided by vehicle revenue hours, has ticked up slightly, now running over 10 $\mathrm{MPH}$.

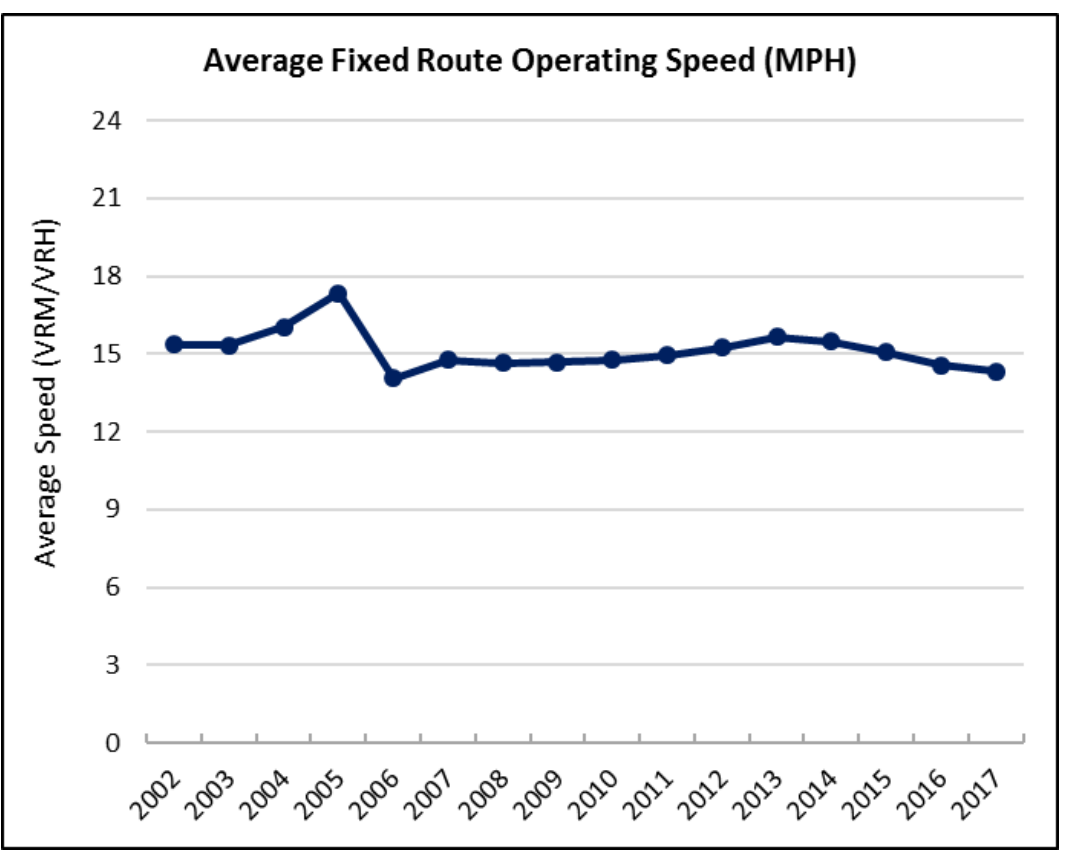


The adjacent graphic shows service productivity. Service productivity has declined steadily since 2010 .

The figures below provide the ridership trends and service supply trends by sub mode. This allows one to understand how the various component modes are performing. The irregularities in the rolling

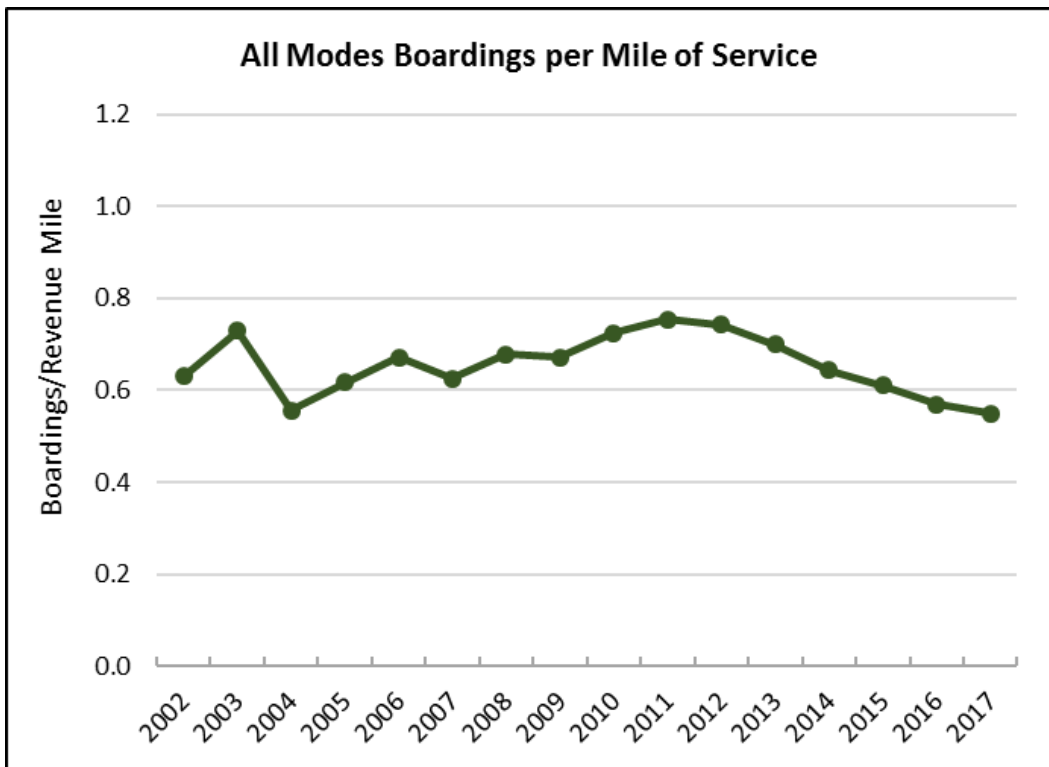
average are the result of missing data in 2002 and 2003.

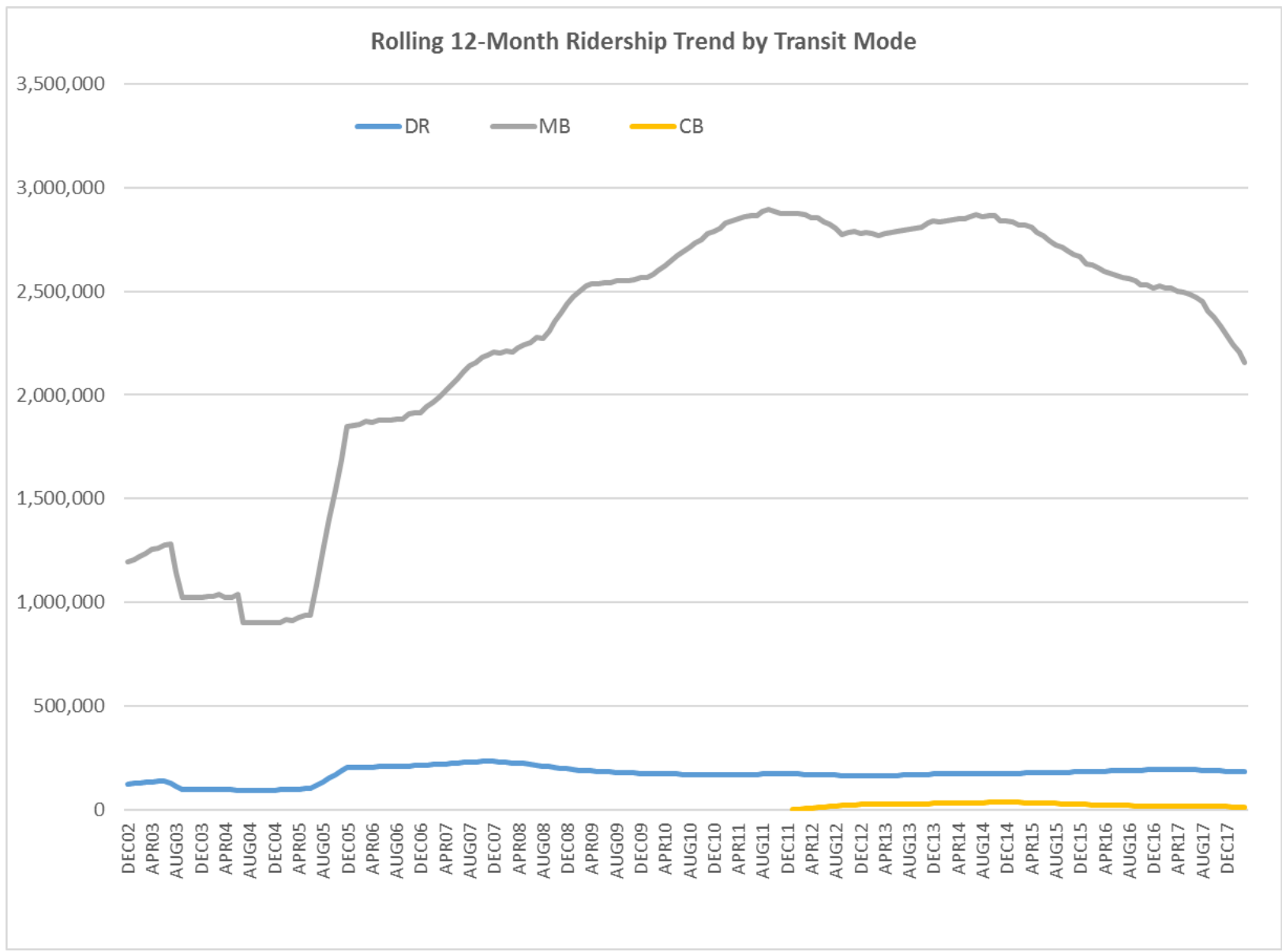


Bus ridership has declined approximately $14 \%$ over one year and $24 \%$ over three years. Demand responsive service has grown $4 \%$ in the last year and declined $4 \%$ over the past three.

The final graphic shows service supply as measured by revenue vehicle miles of service. As the graphical data communicates, bus service supply has declined $8 \%$ in the past year and declined $6 \%$ over three years. Demand responsive service has declined $5 \%$ and $1 \%$ respectively in the one in three year periods.

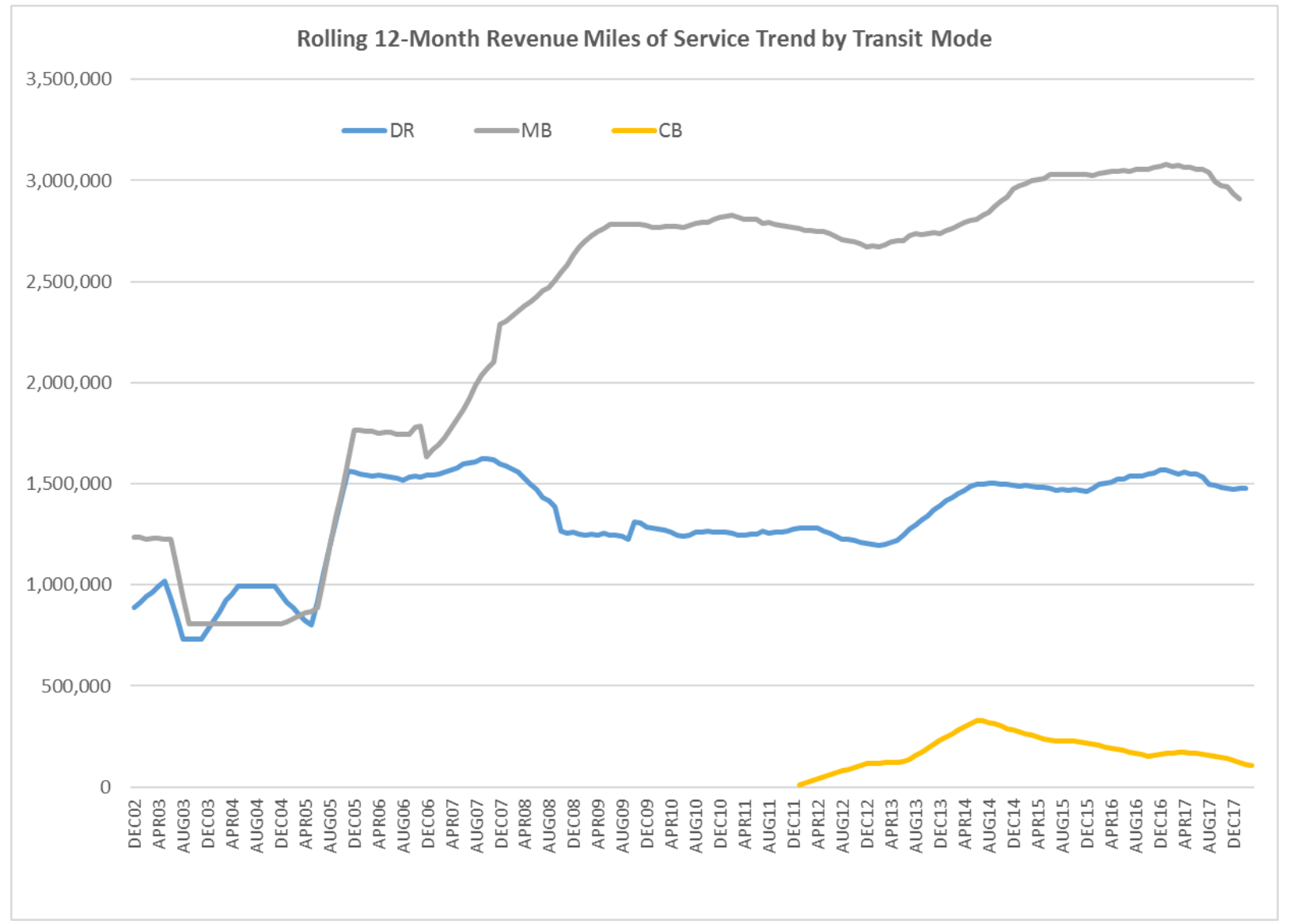


Escambia County (Escambia County Area Transit, ECAT)

Ridership on the Escambia transit system has declined $1 \%$ since a peak in 2013. Vehicle revenue miles of service has increased $35 \%$ in that same time period.

Boardings per revenue mile has dropped $27 \%$ since its peak in 2013. Ridership per County resident has declined 4\% from its peak in 2013.

Average trip length on transit has been increasing and is over $6 \mathrm{mph}$.

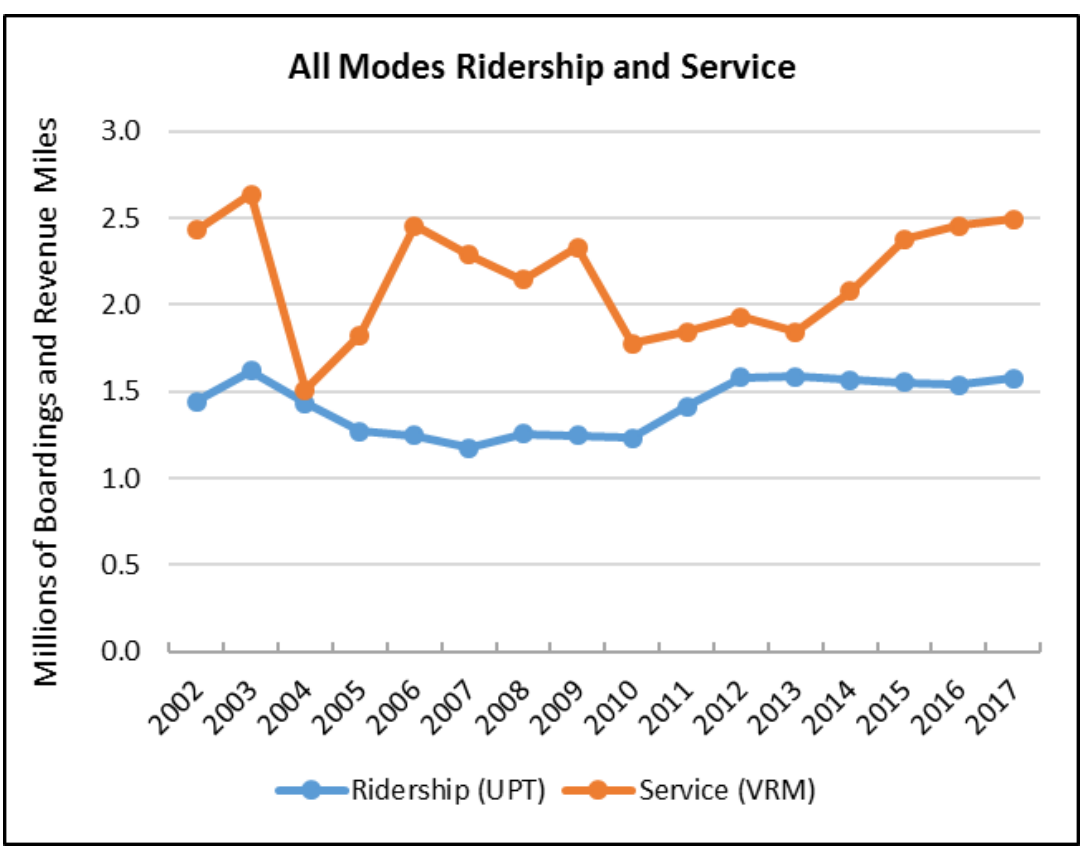


The monthly ridership trend shows the seasonality of ridership. Ridership for the first four months of 2018 is running $5 \%$ below year ago levels.

Average operating speed, defined as vehicle revenue miles divided by vehicle revenue hours, has been averaging around $15 \mathrm{mph}$, a relatively fast speed for transit service.
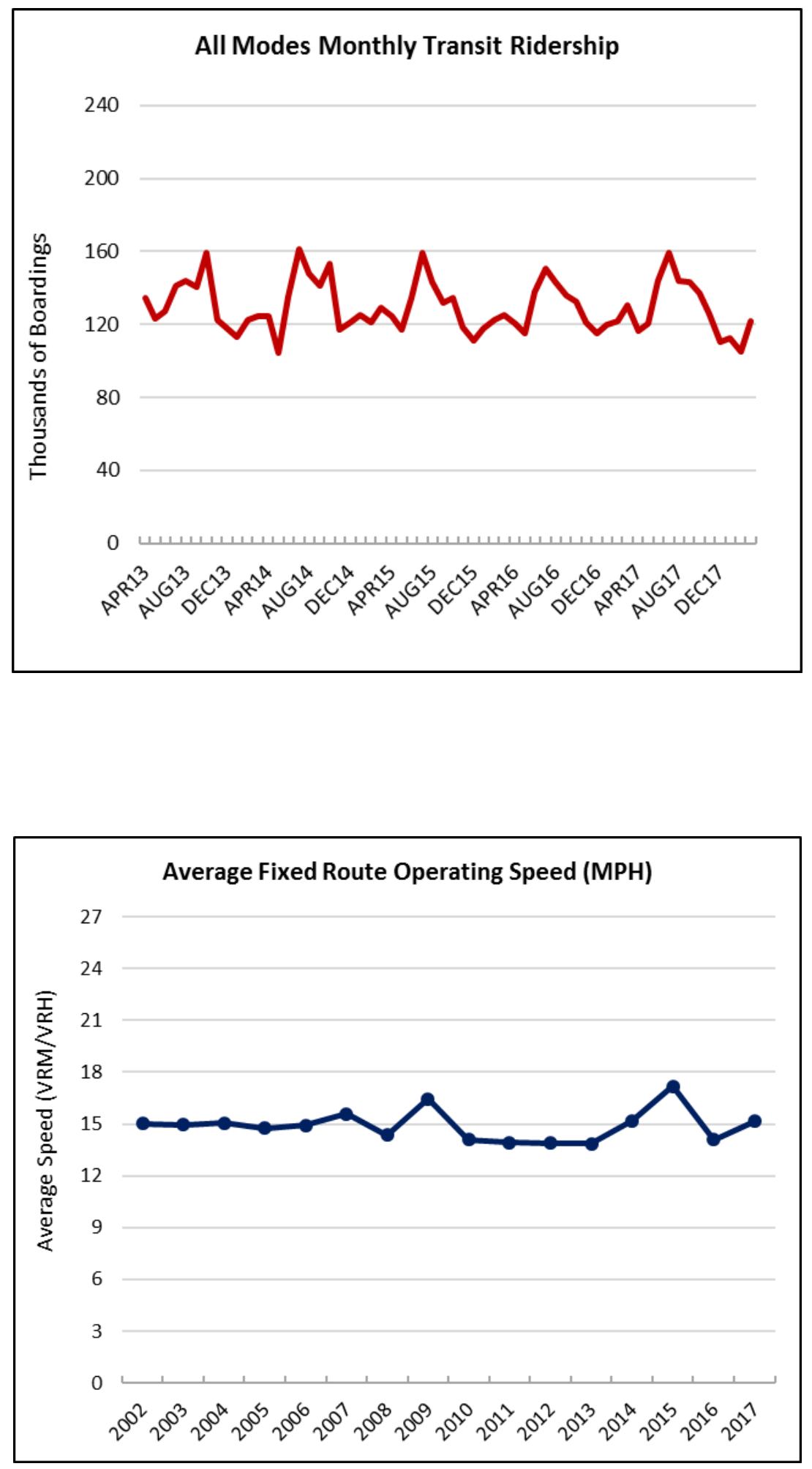
The adjacent graphic shows service productivity. Service productivity has declined since 2013.

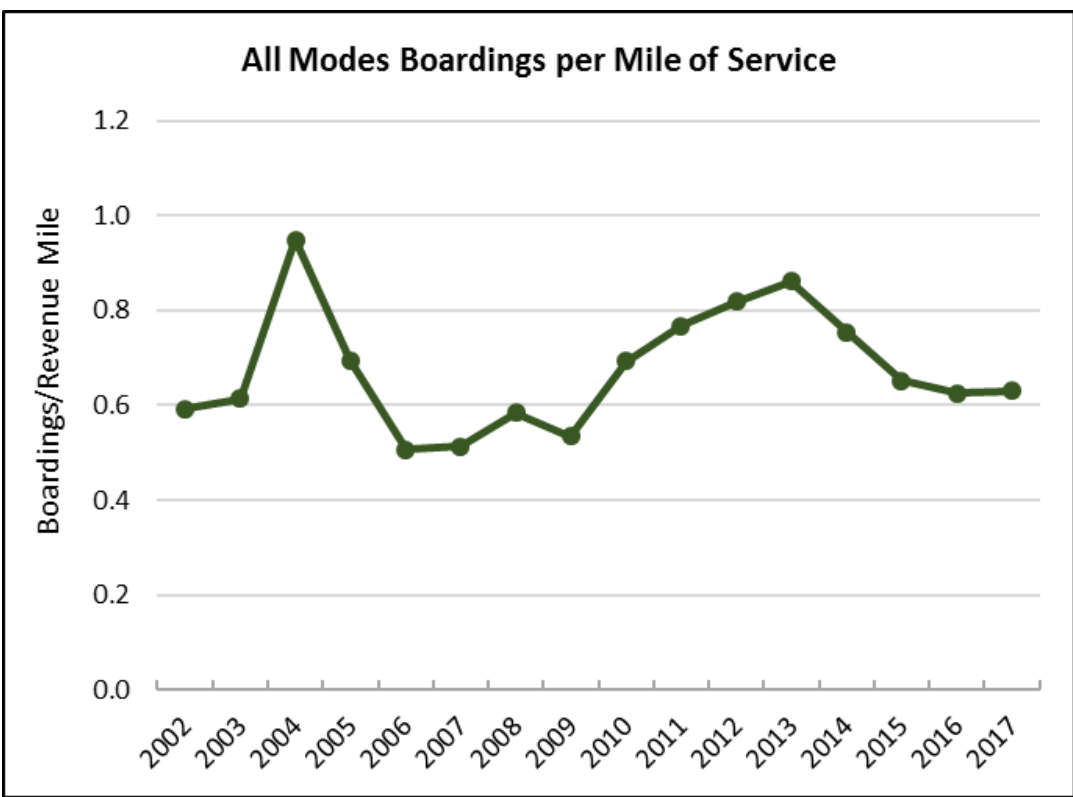

The figures below provide the ridership trends and service supply trends by sub mode. This allows one to understand how the various component modes are performing. 
Bus ridership has declined $1 \%$ over one year and declined $4 \%$ over three years. Demand responsive service has grown $11 \%$ in the last year and $20 \%$ over the past three.

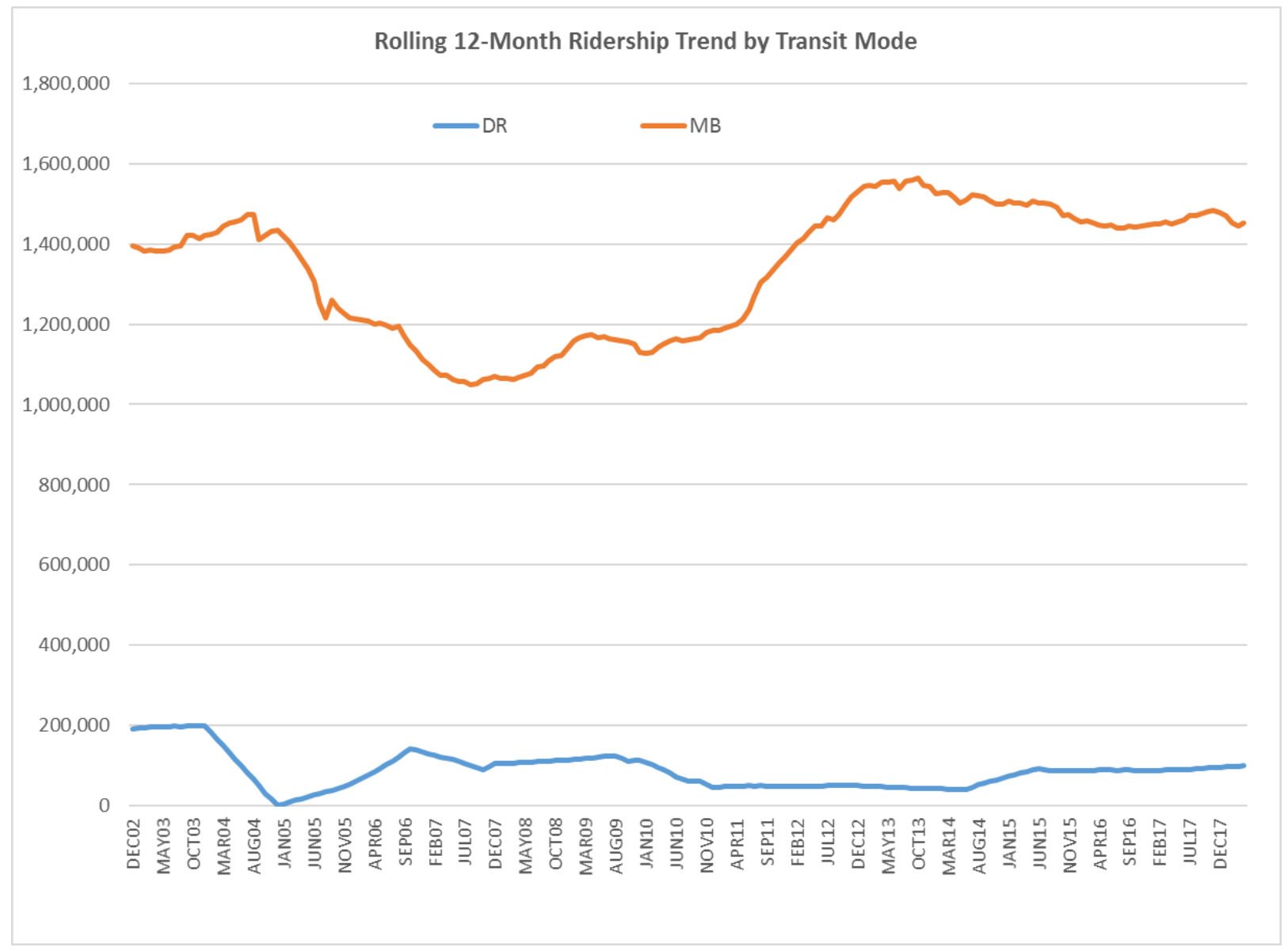

The final graphic shows service supply as measured by revenue vehicle miles of service. As the graphical data communicates, bus service supply has increased $3 \%$ in the past year and $7 \%$ over three years. Demand responsive service has grown $1 \%$ over the last year and grown $23 \%$ in the three year periods. Note, dramatic fluctuations in demand responsive service reflect on available data for select time periods. 


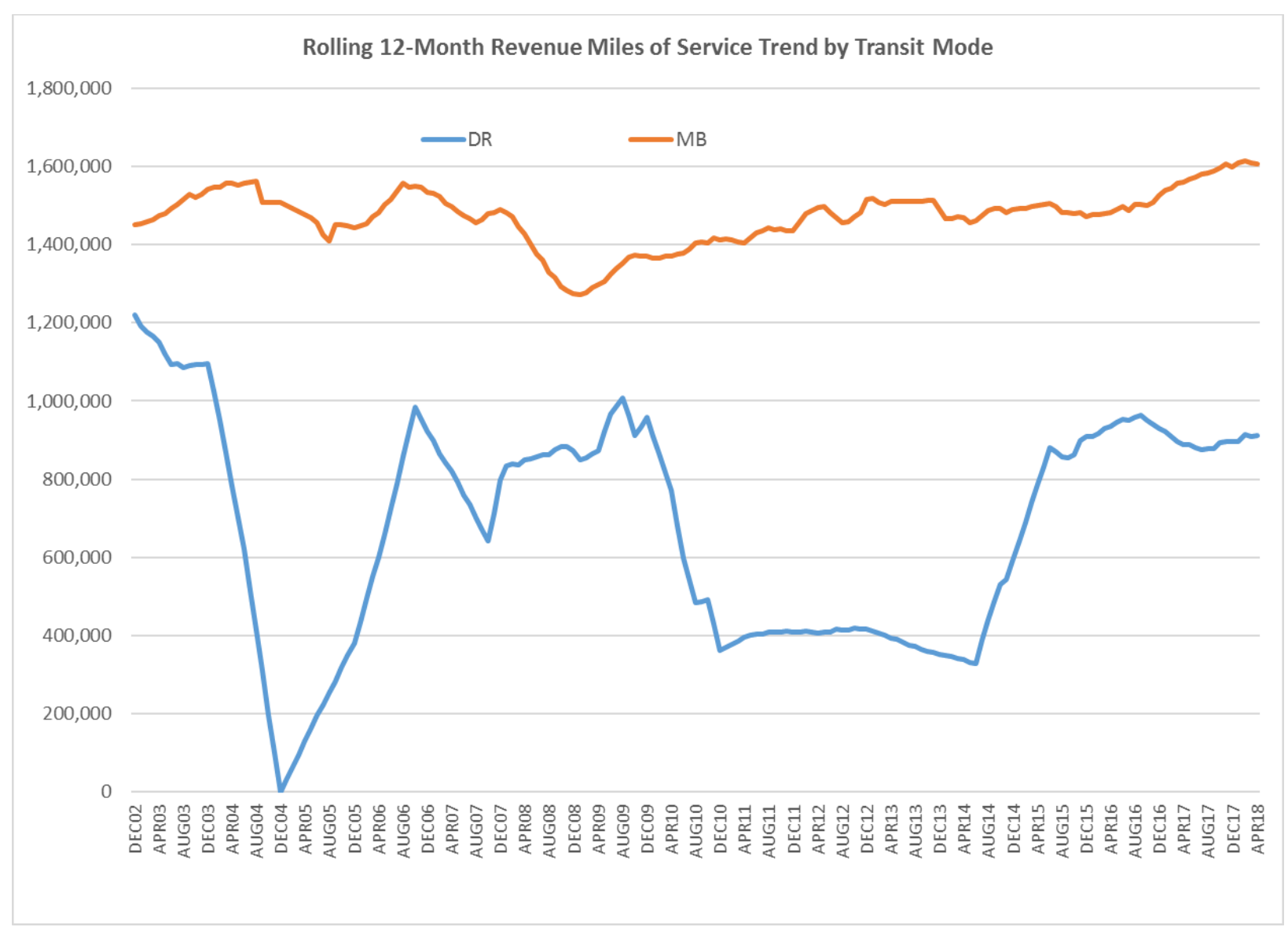


Manatee County (Manatee County Area Transit, MCAT)

Ridership on the Manatee transit system has declined $18 \%$ since a peak in 2014. Vehicle revenue miles of service has increased $6 \%$ in that same time period. The Manatee system was most impacted by declining ridership during the past three years. Boardings per revenue mile has dropped $23 \%$ since its peak in 2013. Ridership per County resident has declined $25 \%$ from its peak in 2014.

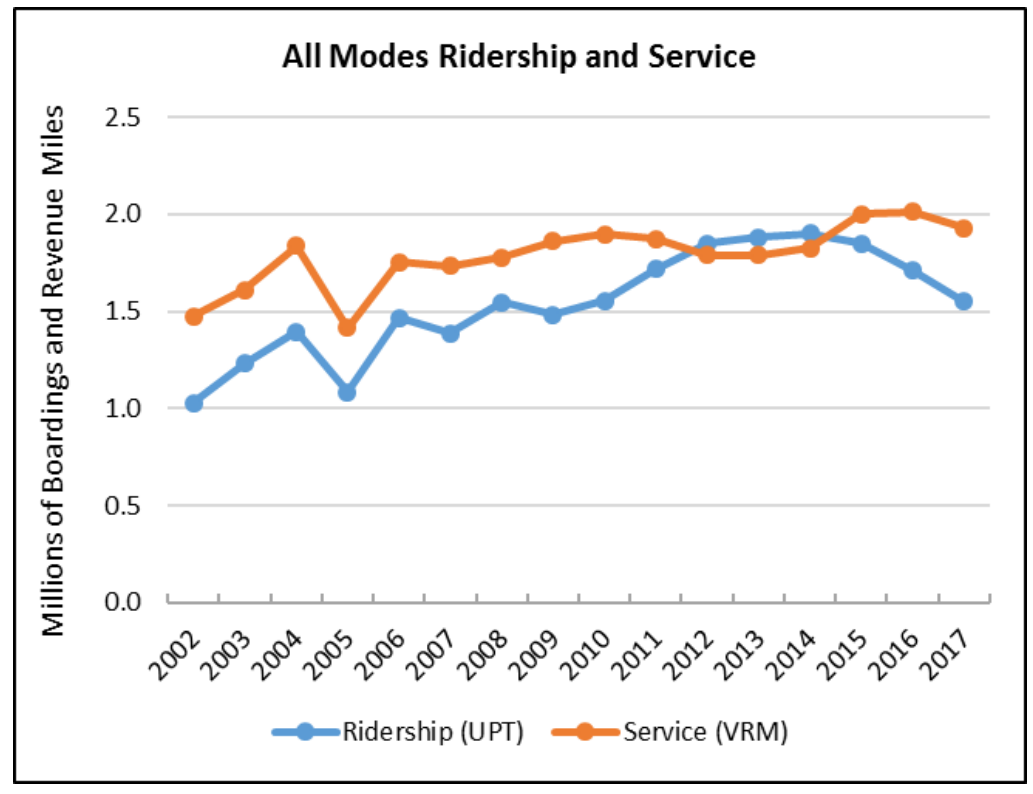

Average trip length on transit has fluctuated from 4 to 5 miles.

\begin{tabular}{|c|c|c|c|c|c|c|c|c|}
\hline \multicolumn{2}{|c|}{ Annual Trend Data, All Modes } \\
\hline Year & Ridership (UPT) & Service (VRM) & $\begin{array}{c}\text { Boardings } \\
\text { per Revenue } \\
\text { Mile }\end{array}$ & $\begin{array}{c}\text { AVG Fixed- } \\
\text { Route } \\
\text { Speed } \\
\text { (mph) }\end{array}$ & $\begin{array}{c}\text { County } \\
\text { Population }\end{array}$ & $\begin{array}{c}\text { Trips per } \\
\text { Capita }\end{array}$ & $\begin{array}{c}\text { Passenger } \\
\text { Miles of } \\
\text { Travel }\end{array}$ & $\begin{array}{c}\text { Average } \\
\text { Trip } \\
\text { Length }\end{array}$ \\
\hline 2002 & $1,029,658$ & $1,475,153$ & 0.70 & 15.08 & 277,362 & 3.7 & $5,264,409$ & 5.11 \\
\hline 2003 & $1,232,899$ & $1,610,180$ & 0.77 & 12.91 & 286,884 & 4.3 & $5,477,332$ & 4.44 \\
\hline 2004 & $1,396,253$ & $1,837,589$ & 0.76 & 16.40 & 295,242 & 4.7 & $2,201,450$ & 1.58 \\
\hline 2005 & $1,085,123$ & $1,414,276$ & 0.77 & 15.69 & 304,364 & 3.6 & $2,287,452$ & 2.11 \\
\hline 2006 & $1,465,020$ & $1,753,052$ & 0.84 & 17.42 & 308,325 & 4.8 & $7,492,920$ & 5.11 \\
\hline 2007 & $1,388,373$ & $1,735,147$ & 0.80 & 14.59 & 315,890 & 4.4 & $7,343,038$ & 5.29 \\
\hline 2008 & $1,545,397$ & $1,776,710$ & 0.87 & 18.32 & 317,699 & 4.9 & $6,642,378$ & 4.30 \\
\hline 2009 & $1,480,914$ & $1,860,990$ & 0.80 & 18.40 & 318,404 & 4.7 & $7,441,572$ & 5.02 \\
\hline 2010 & $1,556,005$ & $1,897,766$ & 0.82 & 15.35 & 323,435 & 4.8 & $7,514,788$ & 4.83 \\
\hline 2011 & $1,717,335$ & $1,871,609$ & 0.92 & 15.48 & 325,905 & 5.3 & $8,085,412$ & 4.71 \\
\hline 2012 & $1,850,636$ & $1,791,591$ & 1.03 & 14.81 & 330,302 & 5.6 & $8,697,358$ & 4.70 \\
\hline 2013 & $1,881,608$ & $1,790,308$ & 1.05 & 14.28 & 333,880 & 5.6 & $9,481,637$ & 5.04 \\
\hline 2014 & $1,902,730$ & $1,824,554$ & 1.04 & 14.28 & 339,545 & 5.6 & $9,515,789$ & 5.00 \\
\hline 2015 & $1,848,290$ & $2,001,950$ & 0.92 & 14.35 & 349,334 & 5.3 & $8,318,739$ \\
\hline 2016 & $1,710,245$ & $2,013,071$ & 0.85 & 14.49 & 357,591 & 4.8 & $8,150,157$ & 4.50 \\
\hline 2017 & $1,551,586$ & $1,929,368$ & 0.80 & 14.57 & 368,782 & 4.2 & 4.77 \\
\hline
\end{tabular}


The monthly ridership trend shows the influence of hurricane Irma. Ridership for the first three months of 2018 has been running approximately $11 \%$ behind last year.

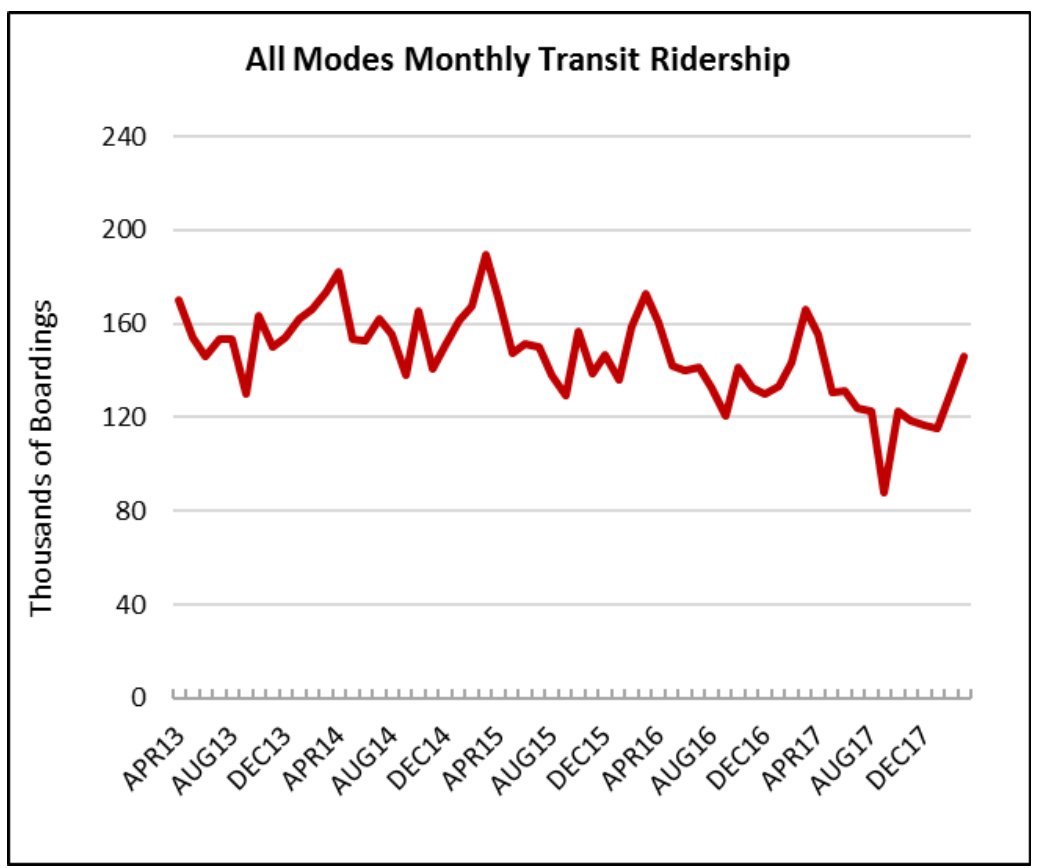

Average operating speed, defined as vehicle revenue miles divided by vehicle revenue hours, has been averaging over $14 \mathrm{mph}$.

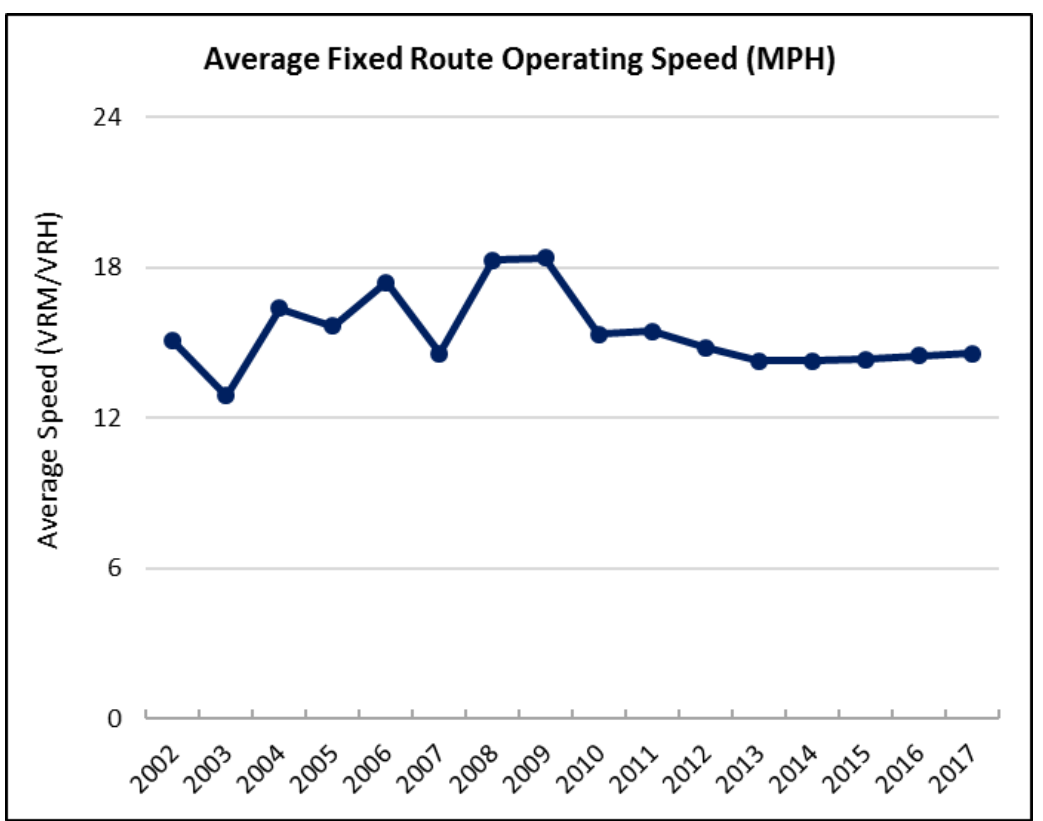


The adjacent graphic shows service productivity. Service productivity has declined modestly since 2015 .

The figures below provide the ridership trends and service supply trends by sub mode. This allows one to understand how the various component modes are performing.

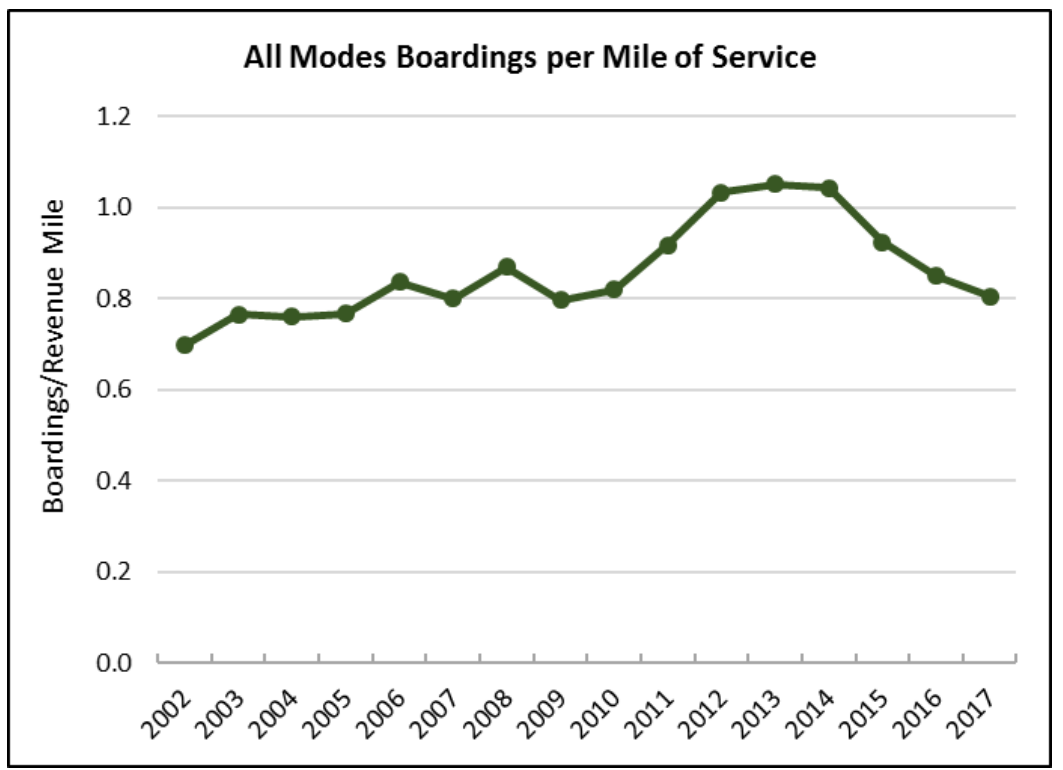

Bus ridership has declined approximately $11 \%$ over one year and $23 \%$ over three years. Demand responsive service has declined $2 \%$ in the last year and grown $3 \%$ over the past three. Van pool service are no longer offer thru the agency.

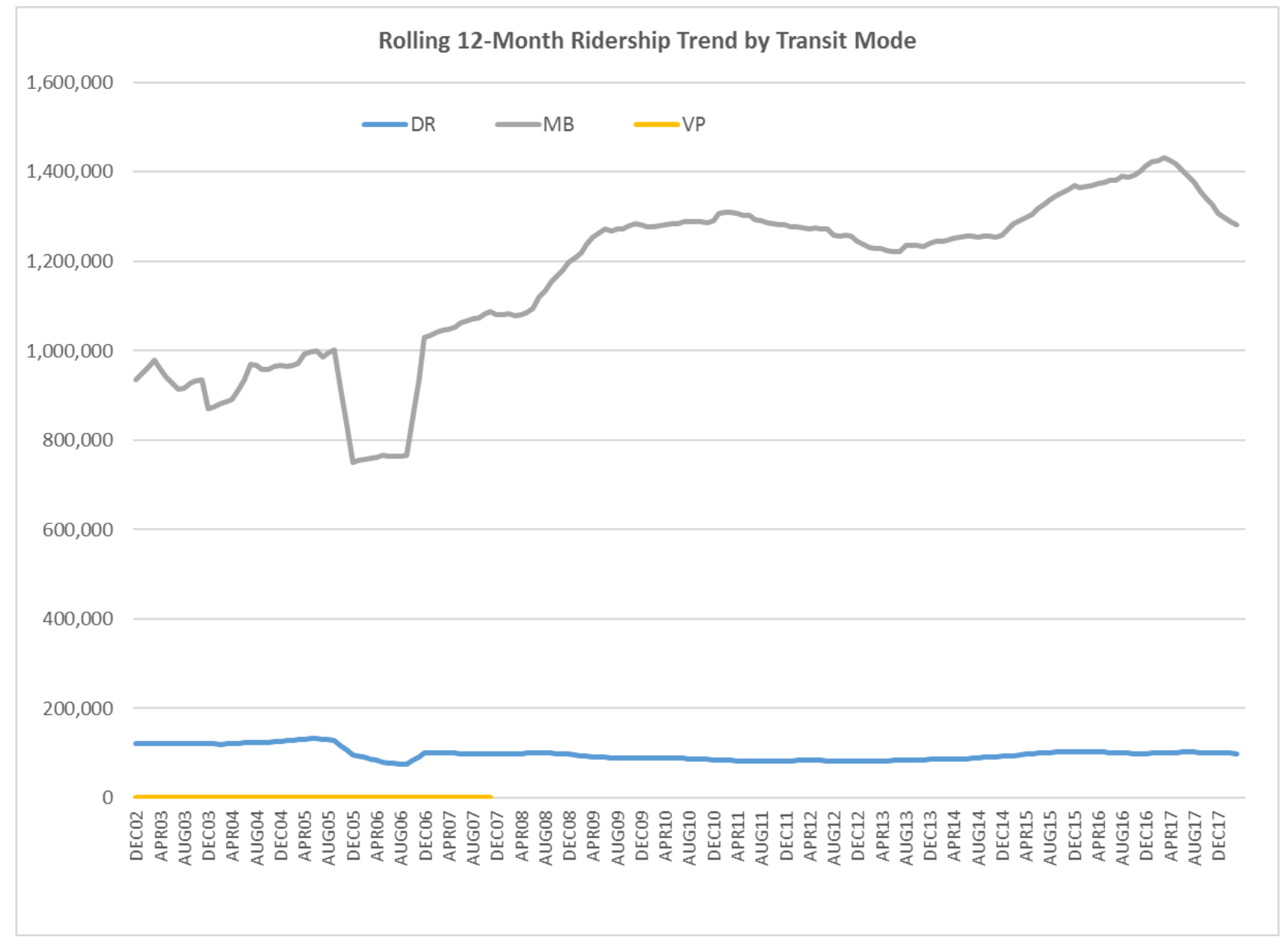


The final graphic shows service supply as measured by revenue vehicle miles of service. As the graphical data communicates, bus service supply has decreased $10 \%$ in the past year and $1 \%$ over three years. Demand responsive service has grown $3 \%$ and $7 \%$ respectively in the one in three year periods.

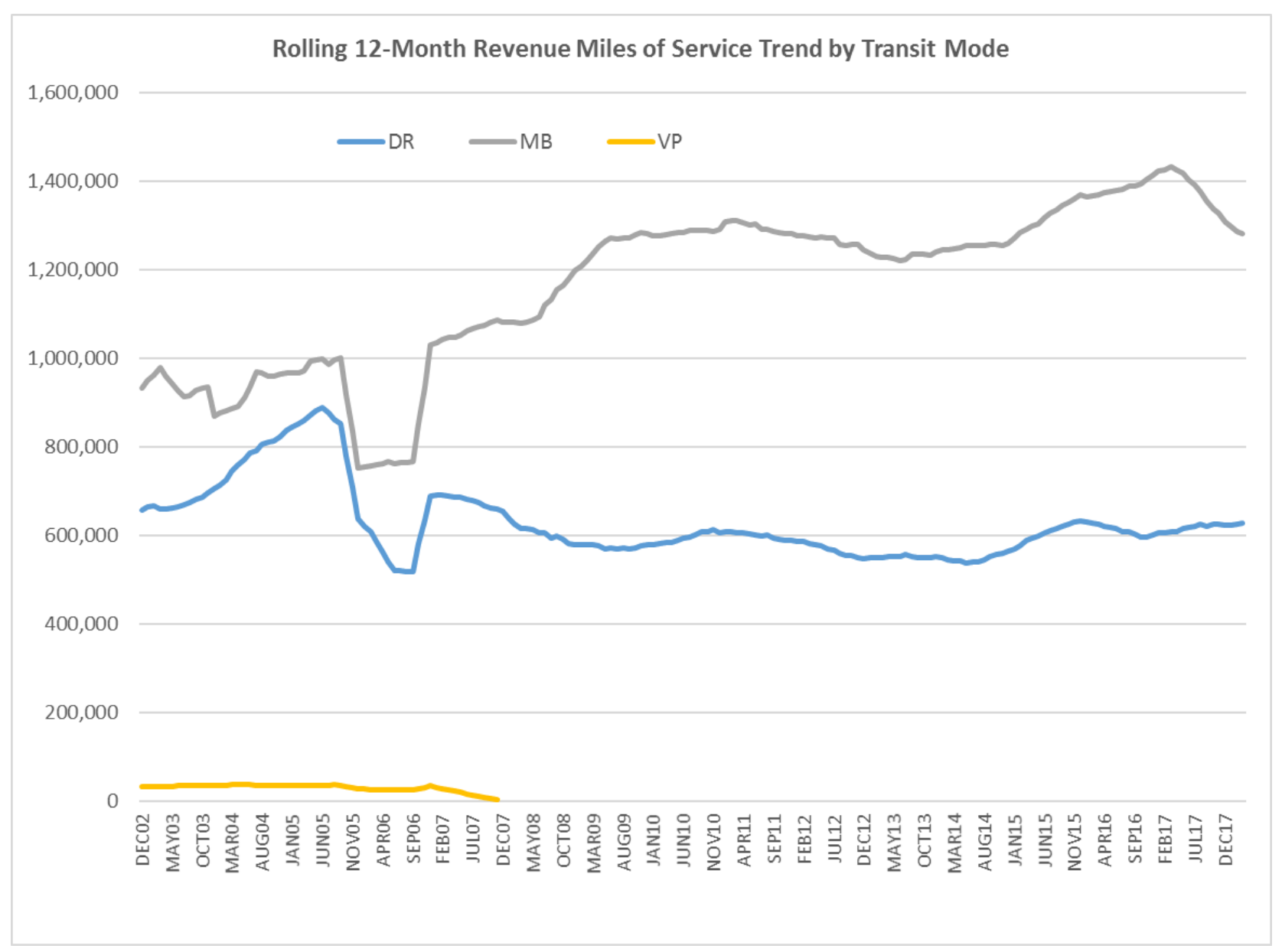




\section{Lakeland (Lakeland Area Mass Transit District, CitrusConnection)}

Ridership on the Lakeland transit system has declined $17 \%$ since a peak in 2014. Vehicle revenue miles of service has declined $24 \%$ in that same time period. The Lakeland system was most impacted by declining ridership during the past three years. Boardings per revenue mile has dropped $34 \%$ since its peak in 2014. Ridership per County resident has declined $22 \%$ from its peak in 2014.

Average trip length on transit has from five to over 6 miles.

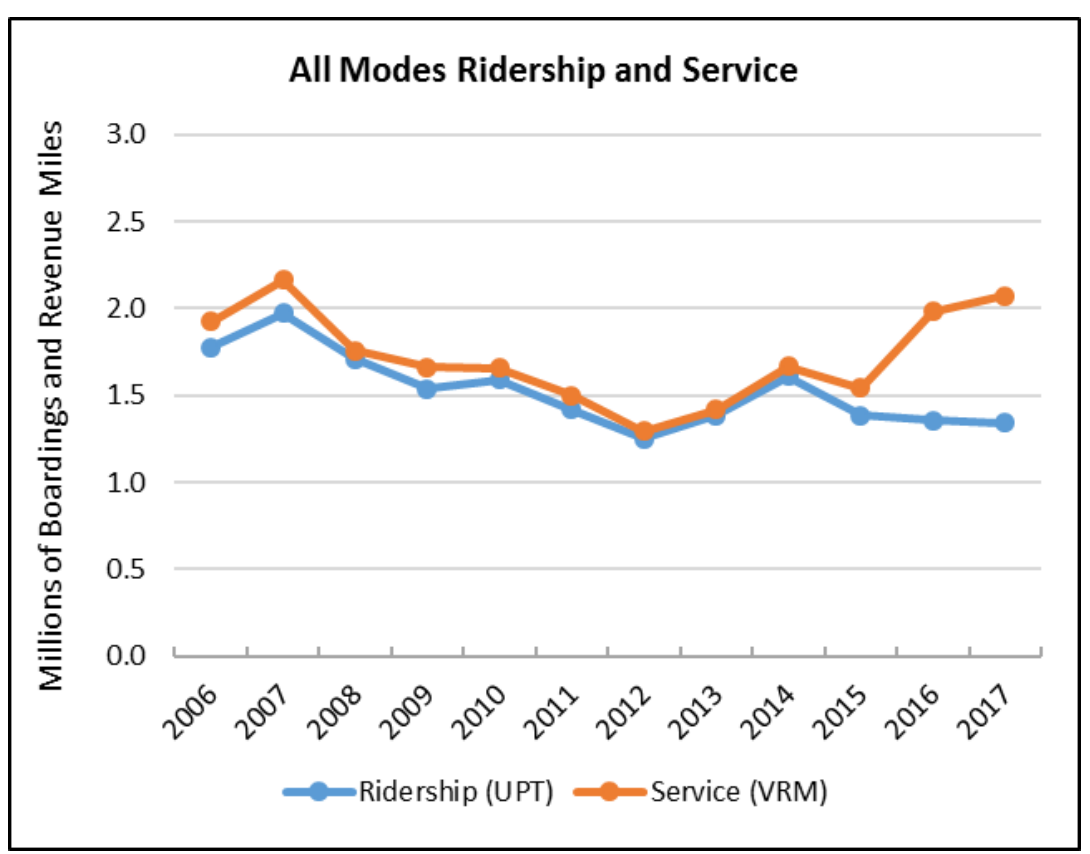

\begin{tabular}{|c|c|c|c|c|c|c|c|c|}
\hline \multicolumn{9}{|c|}{ Annual Trend Data, All Modes } \\
\hline Year & Ridership (UPT) & Service (VRM) & $\begin{array}{l}\text { Boardings per } \\
\text { Revenue Mile }\end{array}$ & $\begin{array}{l}\text { AVG Fixed- } \\
\text { Route } \\
\text { Speed } \\
\text { (mph) }\end{array}$ & $\begin{array}{c}\text { County } \\
\text { Population }\end{array}$ & $\begin{array}{l}\text { Trips per } \\
\text { Capita }\end{array}$ & $\begin{array}{c}\text { Passenger } \\
\text { Miles of } \\
\text { Travel }\end{array}$ & $\begin{array}{c}\text { Average } \\
\text { Trip } \\
\text { Length }\end{array}$ \\
\hline 2002 & na & na & & & & & $6,580,546$ & \\
\hline 2003 & na & na & & & & & $6,635,011$ & \\
\hline 2004 & na & na & & & & & $7,348,866$ & \\
\hline 2005 & na & na & & & & & $7,348,866$ & \\
\hline 2006 & $1,775,231$ & $1,927,274$ & 0.92 & 16.26 & 565,049 & 3.1 & $9,472,930$ & 5.34 \\
\hline 2007 & $1,975,167$ & $2,162,491$ & 0.91 & 16.31 & 581,058 & 3.4 & $9,245,605$ & 4.68 \\
\hline 2008 & $1,709,109$ & $1,756,034$ & 0.97 & 16.53 & 585,733 & 2.9 & $8,879,248$ & 5.20 \\
\hline 2009 & $1,539,440$ & $1,663,732$ & 0.93 & 15.56 & 584,343 & 2.6 & $8,068,044$ & 5.24 \\
\hline 2010 & $1,590,911$ & $1,657,107$ & 0.96 & 15.64 & 602,788 & 2.6 & $8,172,244$ & 5.14 \\
\hline 2011 & $1,416,514$ & $1,499,292$ & 0.94 & 15.21 & 604,792 & 2.3 & $8,298,927$ & 5.86 \\
\hline 2012 & $1,250,430$ & $1,295,461$ & 0.97 & 13.48 & 606,888 & 2.1 & $6,341,769$ & 5.07 \\
\hline 2013 & 1,386,194 & $1,420,098$ & 0.98 & 13.88 & 613,950 & 2.3 & $6,962,739$ & 5.02 \\
\hline 2014 & $1,610,827$ & $1,668,529$ & 0.97 & 15.57 & 623,174 & 2.6 & $9,447,808$ & 5.87 \\
\hline 2015 & $1,383,500$ & $1,542,947$ & 0.90 & 14.94 & 633,052 & 2.2 & $8,458,715$ & 6.11 \\
\hline 2016 & $1,353,975$ & $1,981,954$ & 0.68 & 15.20 & 646,989 & 2.1 & $8,731,148$ & 6.45 \\
\hline 2017 & $1,339,562$ & $2,071,244$ & 0.65 & 15.34 & 661,645 & 2.0 & & \\
\hline
\end{tabular}


The monthly ridership trend shows the influence of hurricane Irma. Ridership for the first three months of 2018 has been running approximately $5 \%$ behind last year.

Average operating speed, defined as vehicle revenue miles divided by vehicle revenue hours, has been averaging 15 $\mathrm{mph}$, a relatively fast speed for transit service.
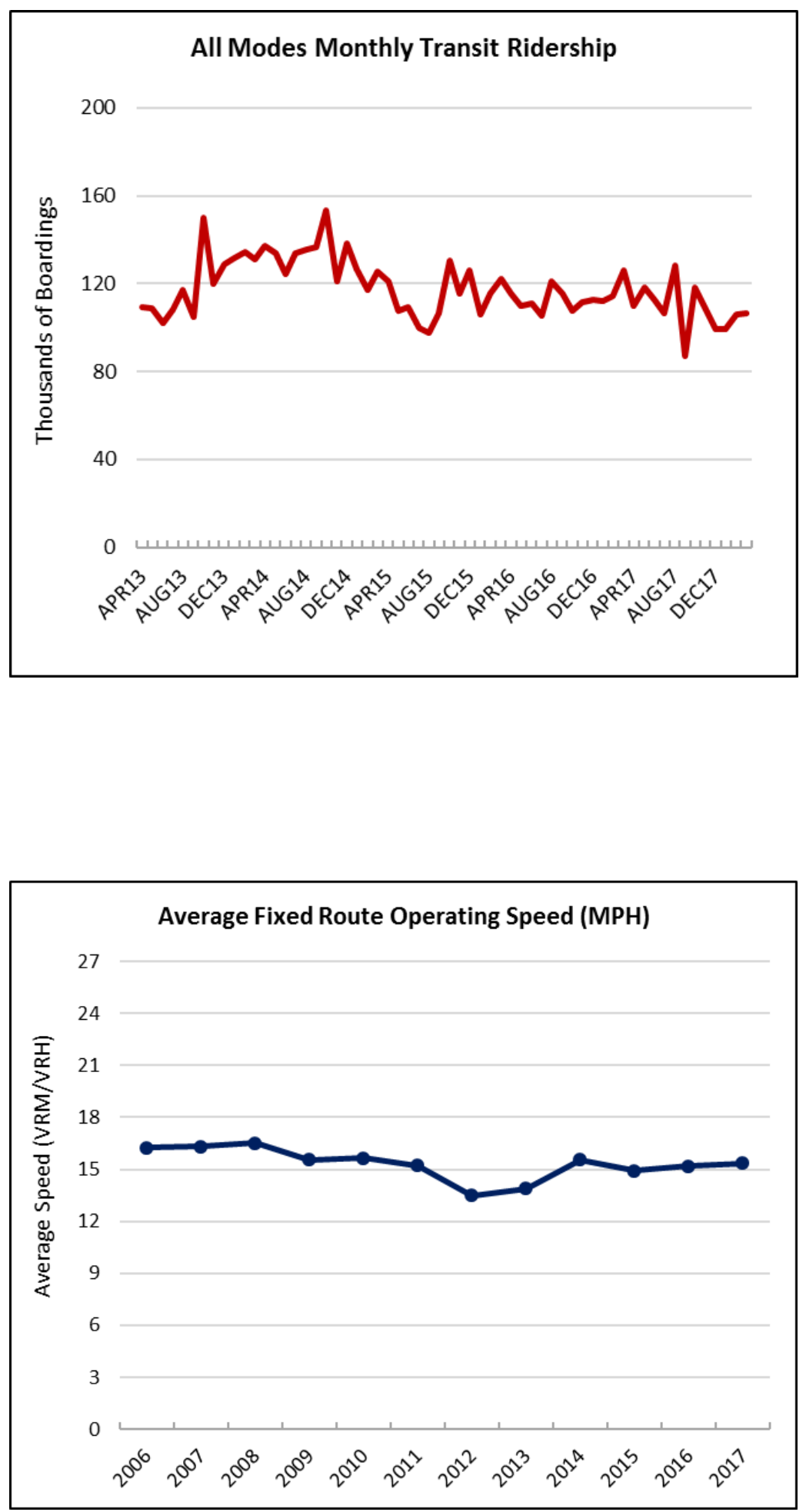
The adjacent graphic shows service productivity. Service productivity has declined modestly since 2015 .

The figures below provide the ridership trends and service supply trends by sub mode. This

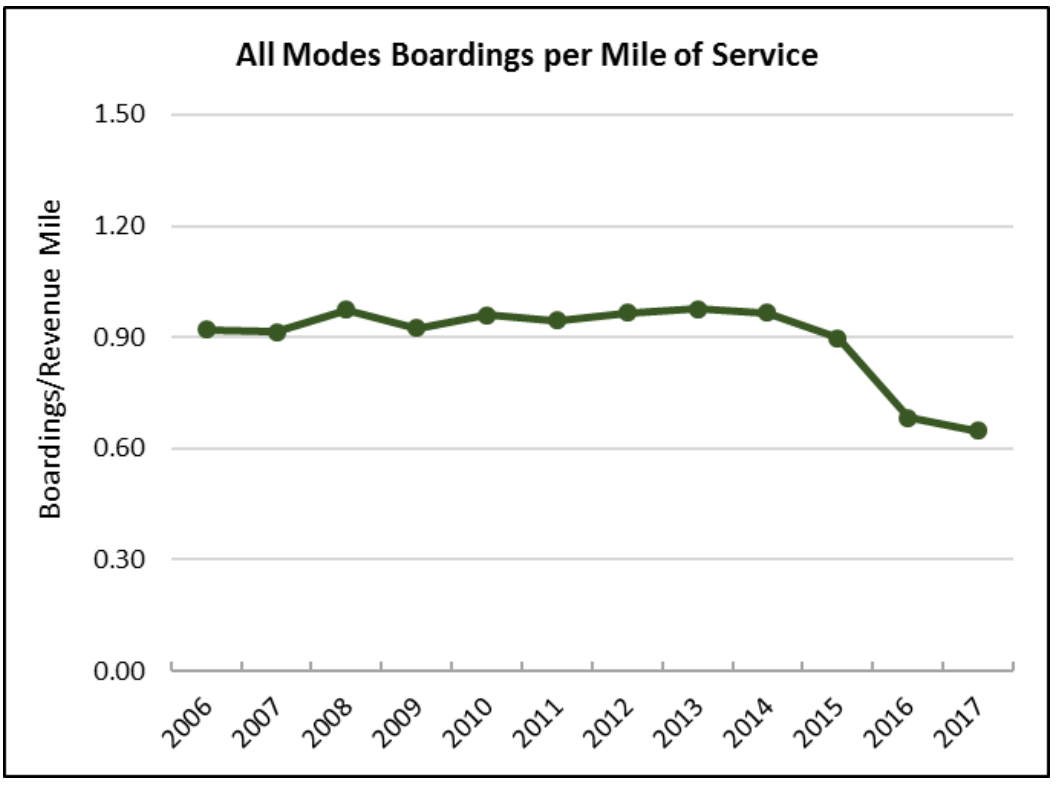
allows one to understand how the various component modes are performing.

Bus ridership has declined approximately $6 \%$ over one year and $20 \%$ over three years. Demand responsive service has grown $14 \%$ in the last year and $30 \%$ over the past three.

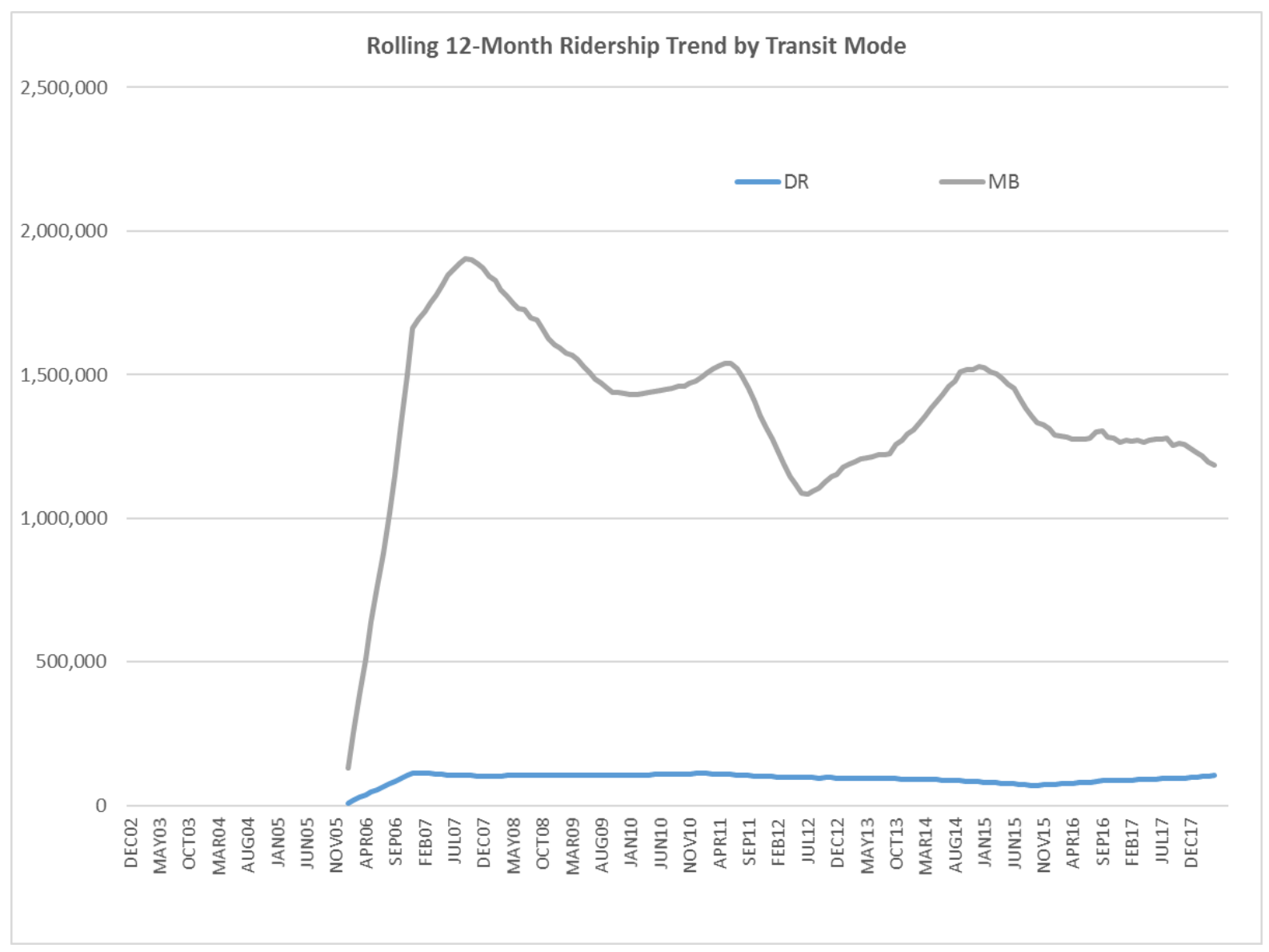


The final graphic shows service supply as measured by revenue vehicle miles of service. As the graphical data communicates, bus service supply has increased $6 \%$ in the past year and $10 \%$ over three years. Demand responsive service has $4 \%$ in the past year and $110 \%$ over three years.

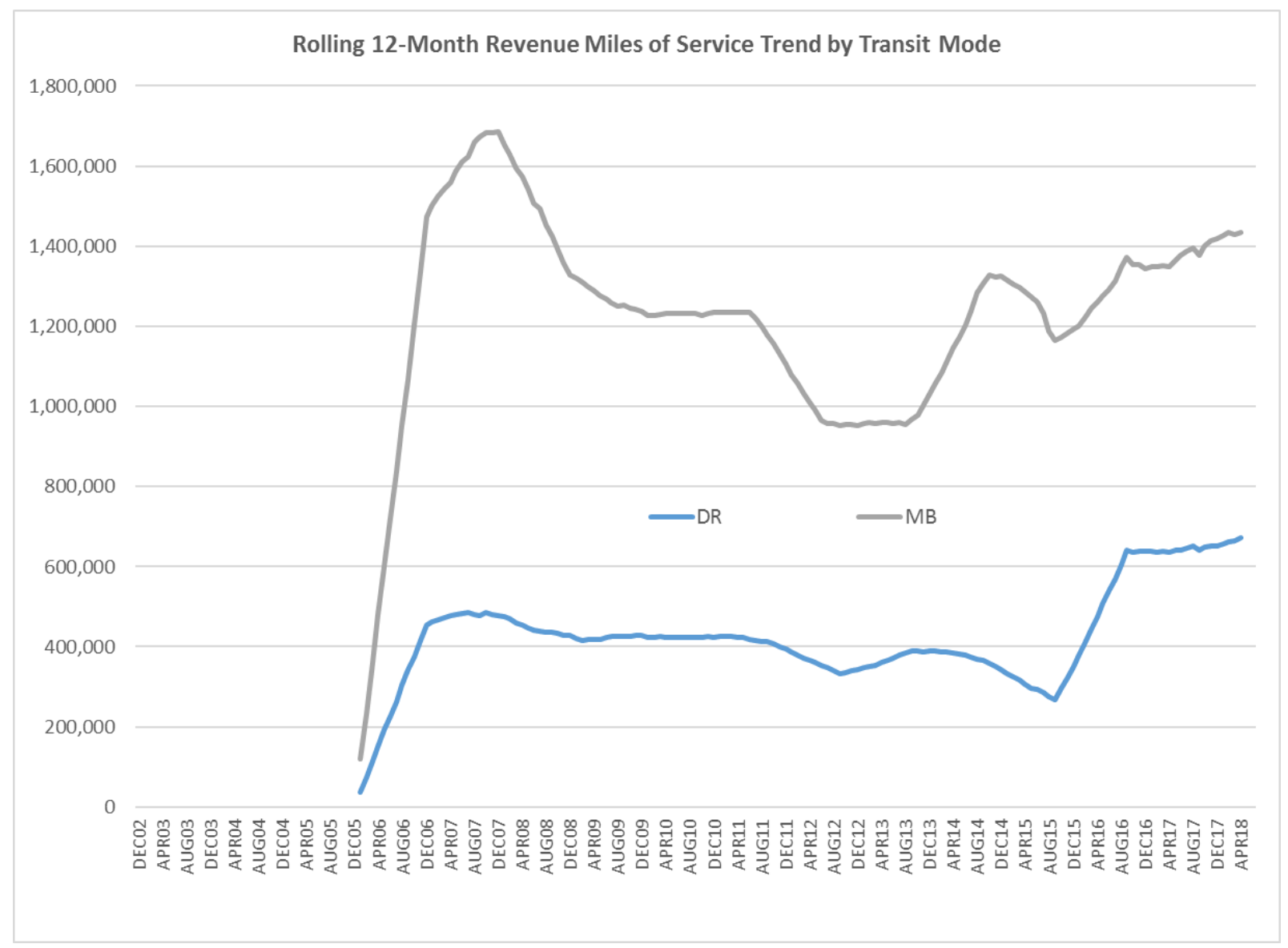


Indian River County (Indian River County, GoLine)

Ridership on the Indian River transit system is unique in that it has had growing ridership over the past several years. 2017 ridership was 7\% ahead of the prior year. Service supply increased $1 \%$.

Boardings per revenue mile has dropped $10 \%$ since the peak in 2012. Ridership per County resident has risen consistently having grown $5 \%$ in the past year.

Average trip length on transit

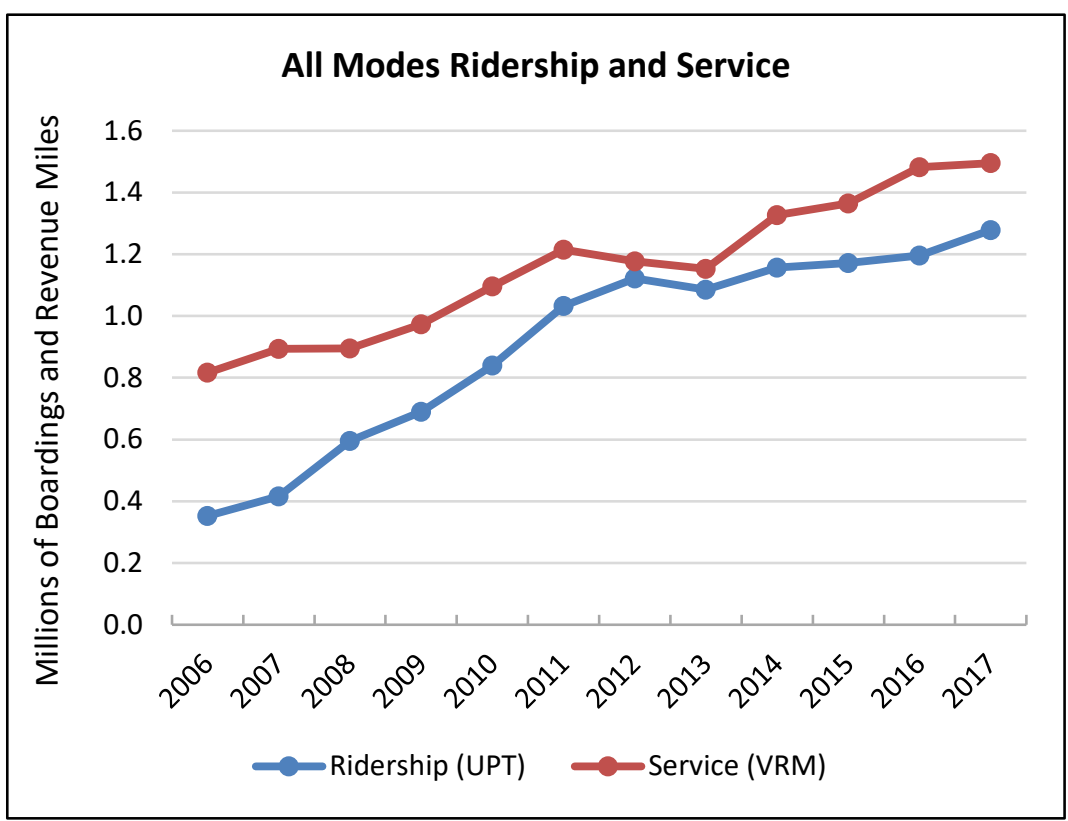
has been growing quite steadily and currently exceeds 5 miles.

\begin{tabular}{|c|c|c|c|c|c|c|c|c|}
\hline \multicolumn{9}{|c|}{ Annual Trend Data, All Modes } \\
\hline Year & Ridership (UPT) & Service (VRM) & $\begin{array}{c}\text { Boardings } \\
\text { per Revenue } \\
\text { Mile }\end{array}$ & $\begin{array}{l}\text { AVG Fixed- } \\
\text { Route } \\
\text { Speed } \\
\text { (mph) }\end{array}$ & $\begin{array}{c}\text { County } \\
\text { Population }\end{array}$ & $\begin{array}{c}\text { Trips per } \\
\text { Capita }\end{array}$ & $\begin{array}{c}\text { Passenger } \\
\text { Miles of } \\
\text { Travel }\end{array}$ & $\begin{array}{c}\text { Average } \\
\text { Trip } \\
\text { Length }\end{array}$ \\
\hline 2002 & 192,530 & 547,430 & 0.35 & 1.12 & 118,149 & 1.6 & 623,543 & 3.24 \\
\hline 2003 & na & na & & & 121,174 & na & 711,701 & \\
\hline 2004 & na & na & & & 126,829 & na & 826,342 & \\
\hline 2005 & na & na & & & 130,043 & na & na & \\
\hline 2006 & 352,581 & 816,326 & 0.43 & 18.43 & 135,262 & 2.6 & 815,073 & 2.31 \\
\hline 2007 & 415,852 & 894,000 & 0.47 & 16.35 & 139,757 & 3.0 & $1,822,886$ & 4.38 \\
\hline 2008 & 595,558 & 894,964 & 0.67 & 16.32 & 141,667 & 4.2 & $2,568,834$ & 4.31 \\
\hline 2009 & 690,190 & 973,964 & 0.71 & 14.60 & 141,634 & 4.9 & $3,126,241$ & 4.53 \\
\hline 2010 & 840,283 & $1,095,479$ & 0.77 & 15.65 & 138,268 & 6.1 & $3,305,161$ & 3.93 \\
\hline 2011 & $1,032,725$ & $1,215,087$ & 0.85 & 17.02 & 138,694 & 7.4 & $4,296,049$ & 4.16 \\
\hline 2012 & $1,121,295$ & $1,177,149$ & 0.95 & 16.87 & 139,446 & 8.0 & $6,323,449$ & 5.64 \\
\hline 2013 & $1,085,918$ & $1,152,773$ & 0.94 & 18.73 & 139,586 & 7.8 & $5,620,117$ & 5.18 \\
\hline 2014 & $1,156,651$ & $1,326,591$ & 0.87 & 19.83 & 140,955 & 8.2 & $6,003,584$ & 5.19 \\
\hline 2015 & $1,171,478$ & $1,364,667$ & 0.86 & 18.76 & 143,326 & 8.2 & $7,884,691$ & 6.73 \\
\hline 2016 & $1,195,786$ & $1,481,938$ & 0.81 & 18.02 & 146,410 & 8.2 & $6,280,462$ & 5.25 \\
\hline 2017 & $1,278,399$ & $1,495,029$ & 0.86 & 17.71 & 148,962 & 8.6 & & \\
\hline
\end{tabular}


Ridership for the first four months of 2018 has been running approximately $3 \%$ ahead of last year.
Average operating speed, defined as vehicle revenue miles divided by vehicle revenue hours, has been averaging near $18 \mathrm{mph}$, a relatively fast speed for transit service.
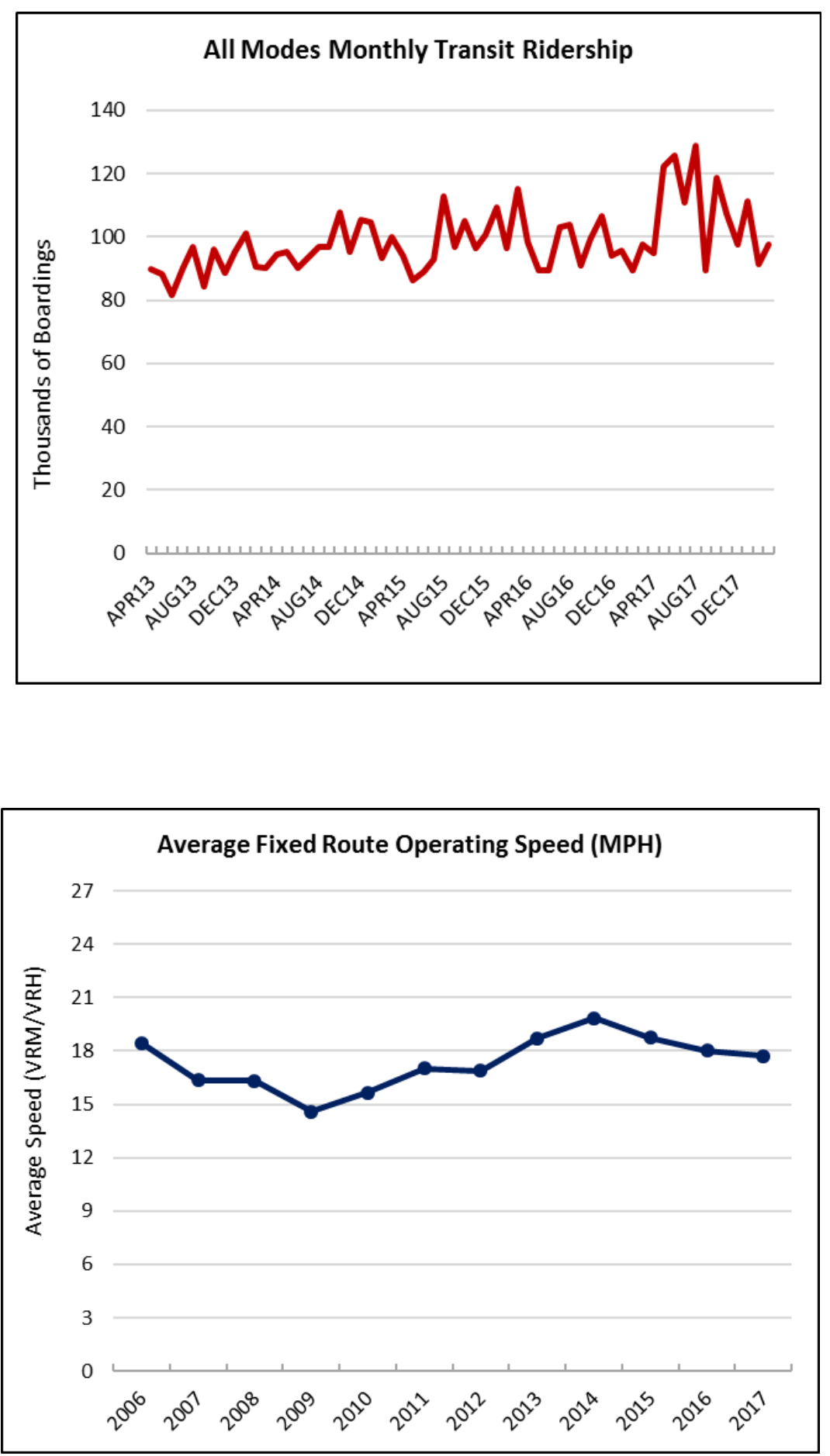
The adjacent graphic shows service productivity. Service productivity has declined modestly since 2012.

The figures below provide the ridership trends and service supply trends by sub mode. This allows one to understand how the various component modes are performing.

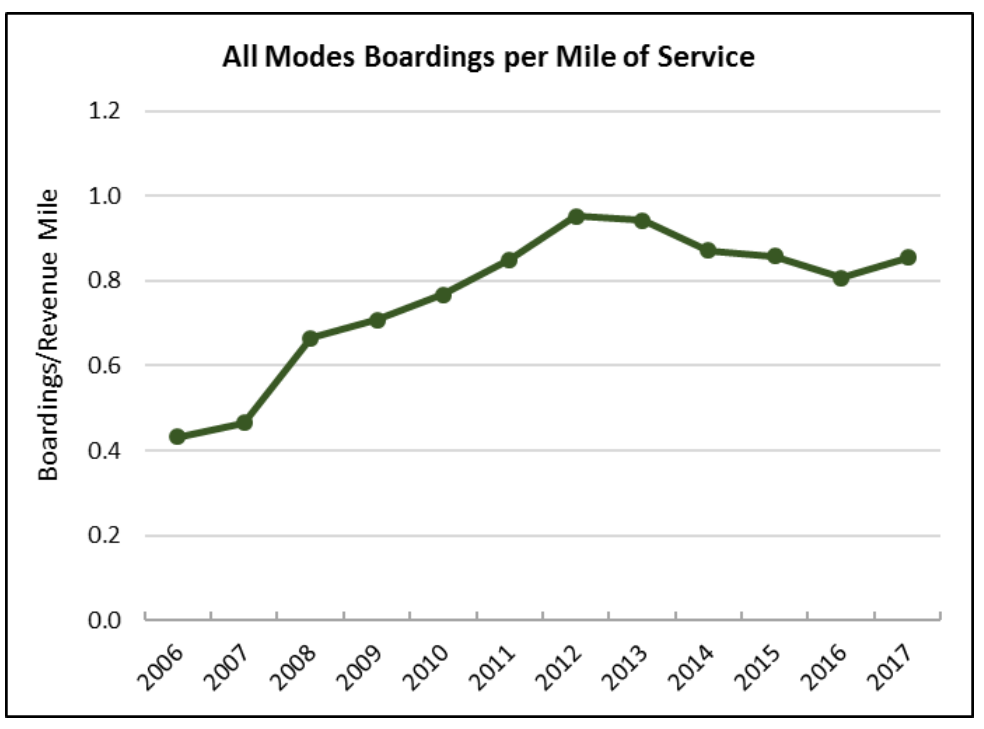

Bus ridership has grown approximately $12 \%$ over one year and $10 \%$ over three years. Demand responsive service has been stable over one year and grown $43 \%$ over three years.

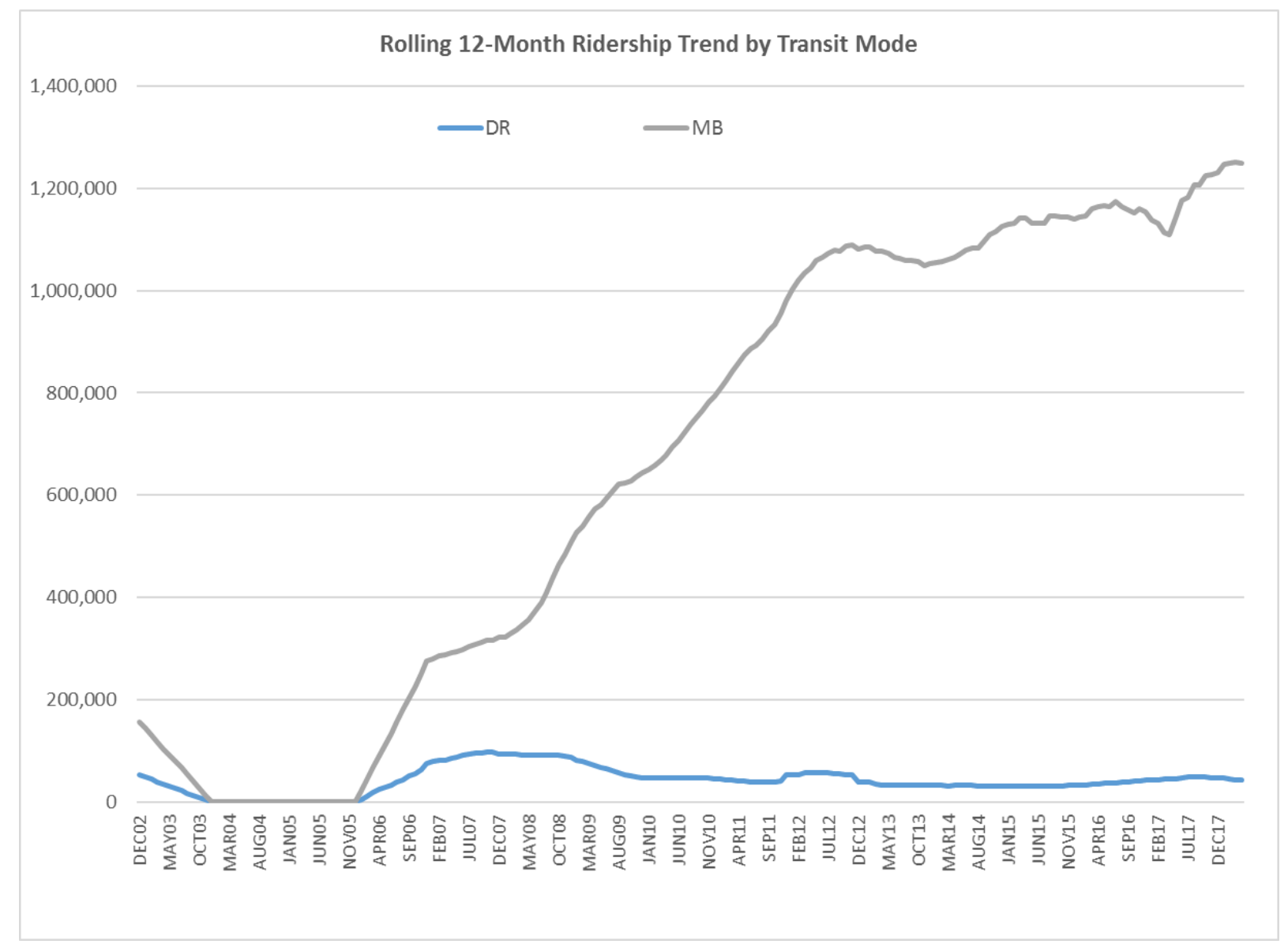


The final graphic shows service supply as measured by revenue vehicle miles of service. As the graphical data communicates, bus service supply has decreased $5 \%$ in the past year and $8 \%$ over three years. Demand responsive service has grown $1 \%$ and $71 \%$ respectively in the one in three year periods.

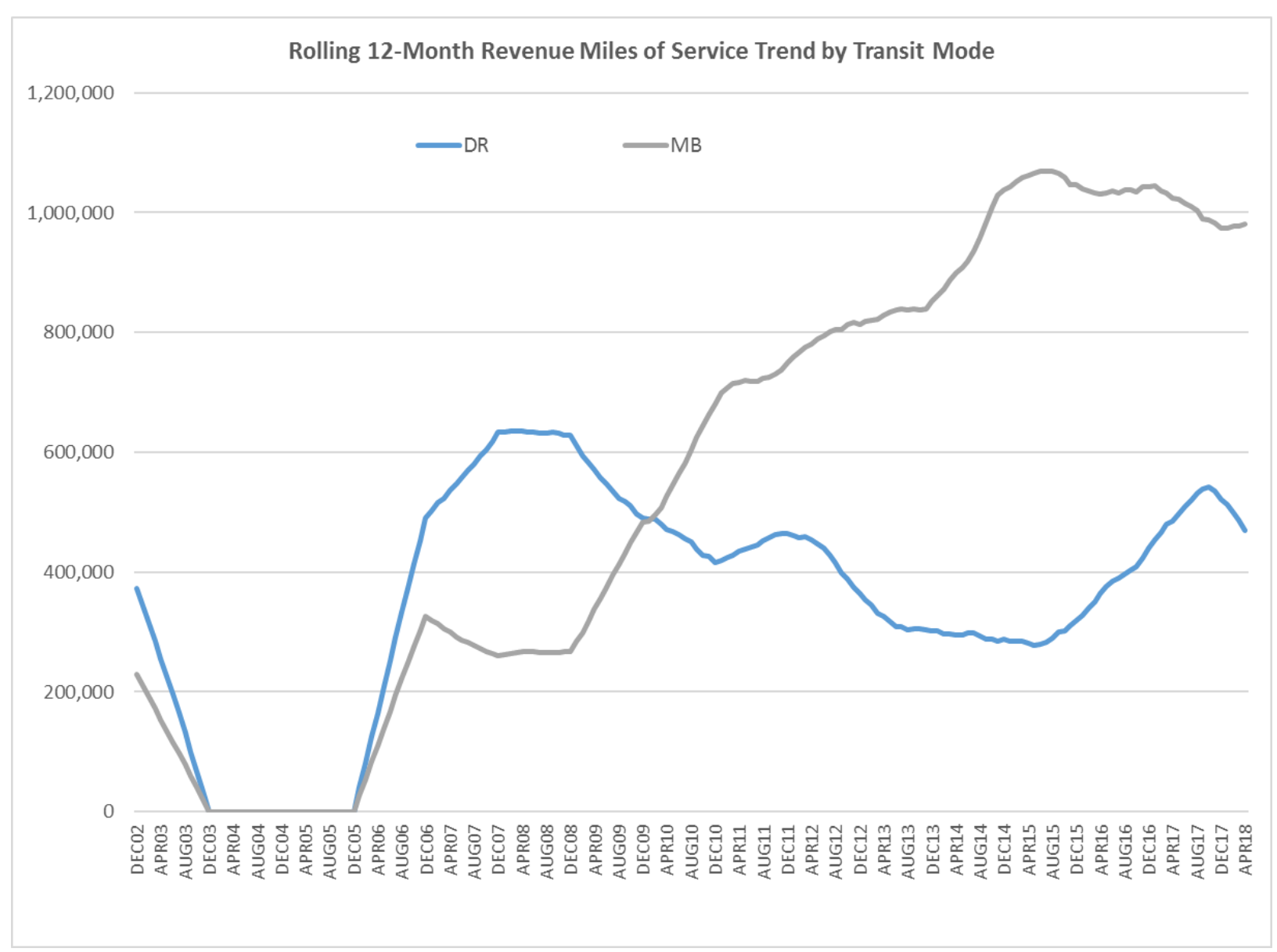


Collier County (Collier Area Transit, CAT)

Ridership on the Collier transit system has declined $31 \%$ since a peak in 2013. Vehicle revenue miles of service has increased $10 \%$ in that same time period. Collier system was most impacted by declining ridership during the past four years. Boardings per revenue mile has dropped $37 \%$ since its peak in 2013. Ridership per County resident has declined $36 \%$ from its peak in 2013.

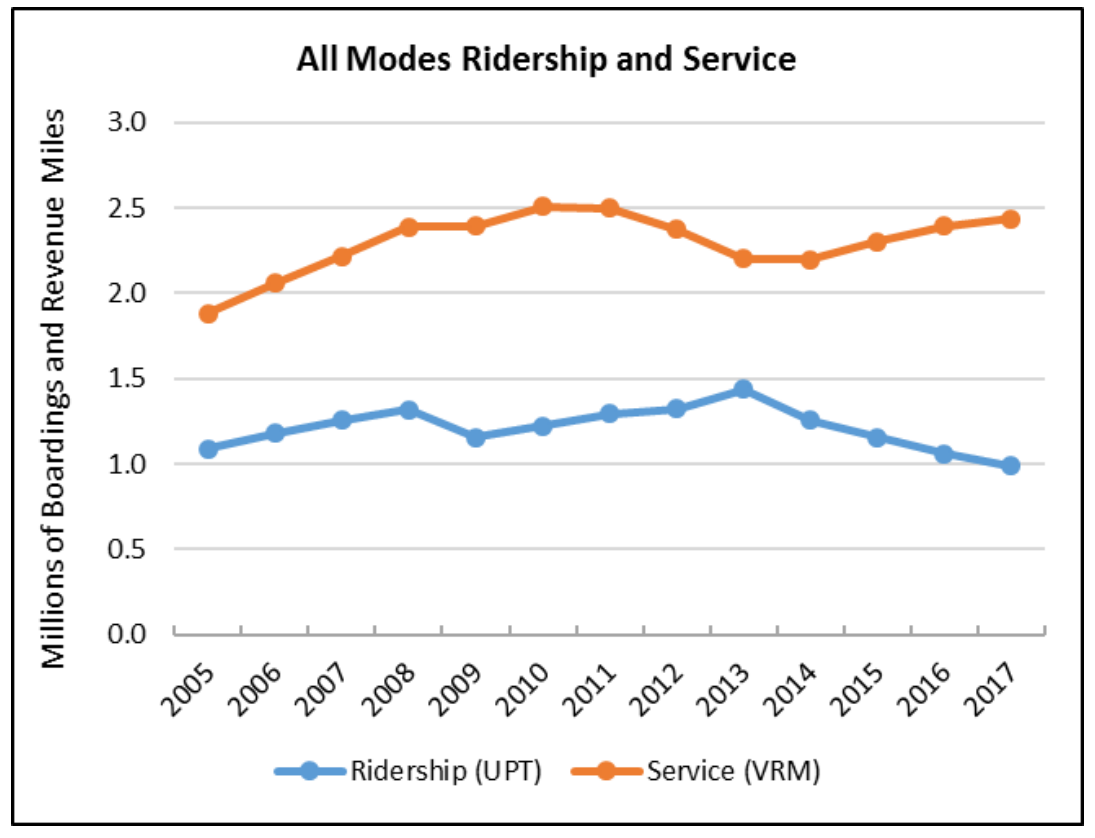

Average trip length on transit has been has been increasing and exceeds 9 miles.

\begin{tabular}{|c|c|c|c|c|c|c|c|c|}
\hline \multicolumn{9}{|c|}{ Annual Trend Data, All Modes } \\
\hline Year & Ridership (UPT) & Service (VRM) & $\begin{array}{l}\text { Boardings per } \\
\text { Revenue Mile }\end{array}$ & $\begin{array}{l}\text { AVG Fixed- } \\
\text { Route } \\
\text { Speed } \\
\text { (mph) }\end{array}$ & $\begin{array}{c}\text { County } \\
\text { Population }\end{array}$ & $\begin{array}{l}\text { Trips per } \\
\text { Capita }\end{array}$ & $\begin{array}{c}\text { Passenger } \\
\text { Miles of } \\
\text { Travel }\end{array}$ & $\begin{array}{c}\text { Average } \\
\text { Trip } \\
\text { Length }\end{array}$ \\
\hline 2002 & na & na & & & & & & \\
\hline 2003 & na & na & & & & & & \\
\hline 2004 & na & na & & & & & & \\
\hline 2005 & $1,085,995$ & $1,883,958$ & 0.58 & 18.29 & 317,788 & 3.4 & $6,628,401$ & 6.10 \\
\hline 2006 & $1,179,218$ & $2,057,676$ & 0.57 & 18.50 & 326,658 & 3.6 & $2,198,978$ & 1.86 \\
\hline 2007 & $1,255,566$ & $2,217,879$ & 0.57 & 18.34 & 333,858 & 3.8 & $2,448,473$ & 1.95 \\
\hline 2008 & $1,318,658$ & $2,388,633$ & 0.55 & 18.44 & 332,854 & 4.0 & $10,184,778$ & 7.72 \\
\hline 2009 & $1,154,925$ & $2,394,026$ & 0.48 & 18.59 & 333,032 & 3.5 & $10,140,265$ & 8.78 \\
\hline 2010 & $1,219,679$ & $2,508,872$ & 0.49 & 18.47 & 322,472 & 3.8 & $9,778,607$ & 8.02 \\
\hline 2011 & $1,295,998$ & $2,499,423$ & 0.52 & 18.30 & 323,785 & 4.0 & $11,179,382$ & 8.63 \\
\hline 2012 & $1,320,628$ & $2,372,560$ & 0.56 & 18.30 & 329,849 & 4.0 & $11,372,395$ & 8.61 \\
\hline 2013 & $1,436,488$ & $2,201,441$ & 0.65 & 18.30 & 333,663 & 4.3 & $12,451,828$ & 8.67 \\
\hline 2014 & $1,253,941$ & $2,199,058$ & 0.57 & 18.59 & 336,783 & 3.7 & $10,030,892$ & 8.00 \\
\hline 2015 & $1,153,440$ & $2,302,592$ & 0.50 & 18.60 & 343,802 & 3.4 & $10,504,755$ & 9.11 \\
\hline 2016 & $1,058,006$ & $2,391,484$ & 0.44 & 18.29 & 350,202 & 3.0 & $10,324,757$ & 9.76 \\
\hline 2017 & 986,946 & $2,435,441$ & 0.41 & 17.86 & 357,470 & 2.8 & & \\
\hline
\end{tabular}


The monthly ridership trend shows the influence of hurricane Irma. Ridership for the first three months of 2018 has been running approximately $10 \%$ behind last year.

Average operating speed, defined as vehicle revenue miles divided by vehicle revenue hours, has been averaging nearly $18 \mathrm{mph}$, a relatively fast speed for transit service.
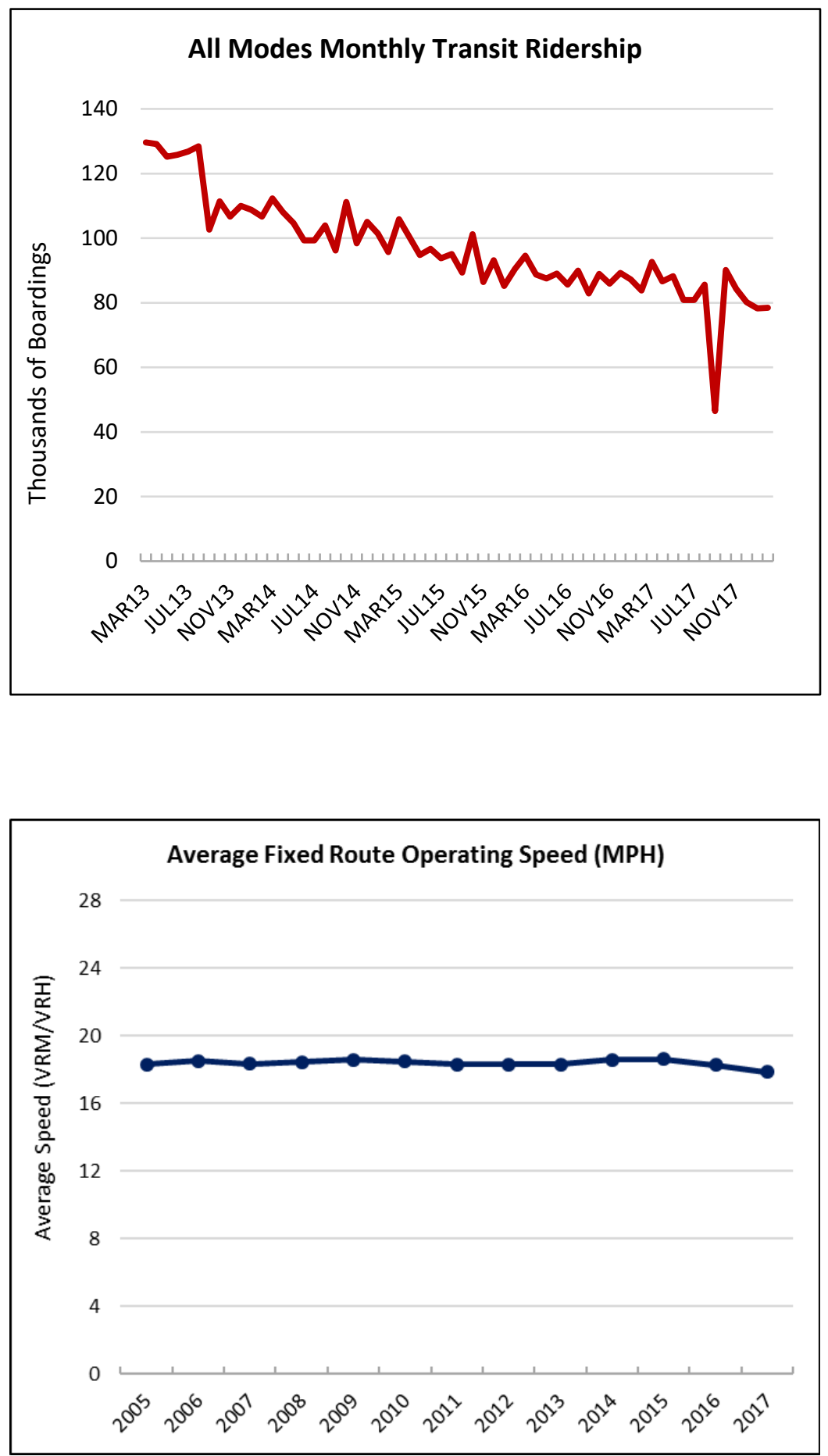
The adjacent graphic shows service productivity. Service productivity has declined sharply since 2013.

The figures below provide the ridership trends and service supply trends by sub mode. This allows one to understand how the various component modes are performing.

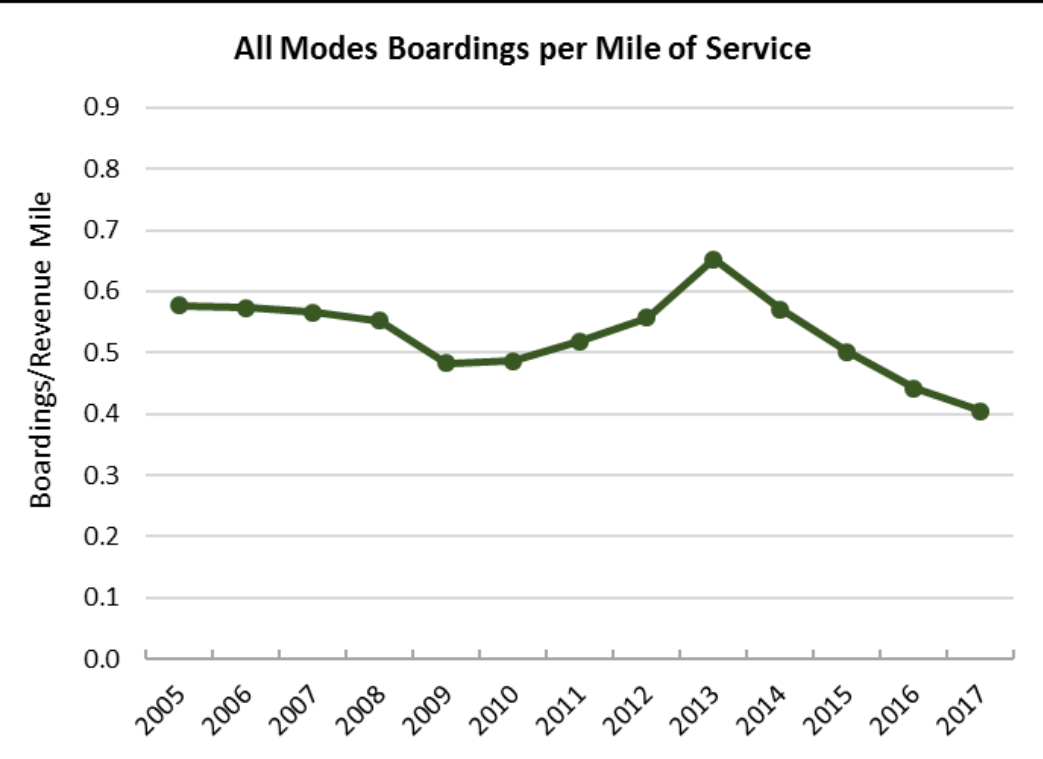

Bus ridership has declined approximately $10 \%$ over one year and $25 \%$ over three years. Demand responsive service has grown $1 \%$ in the last year and $13 \%$ over the past three.

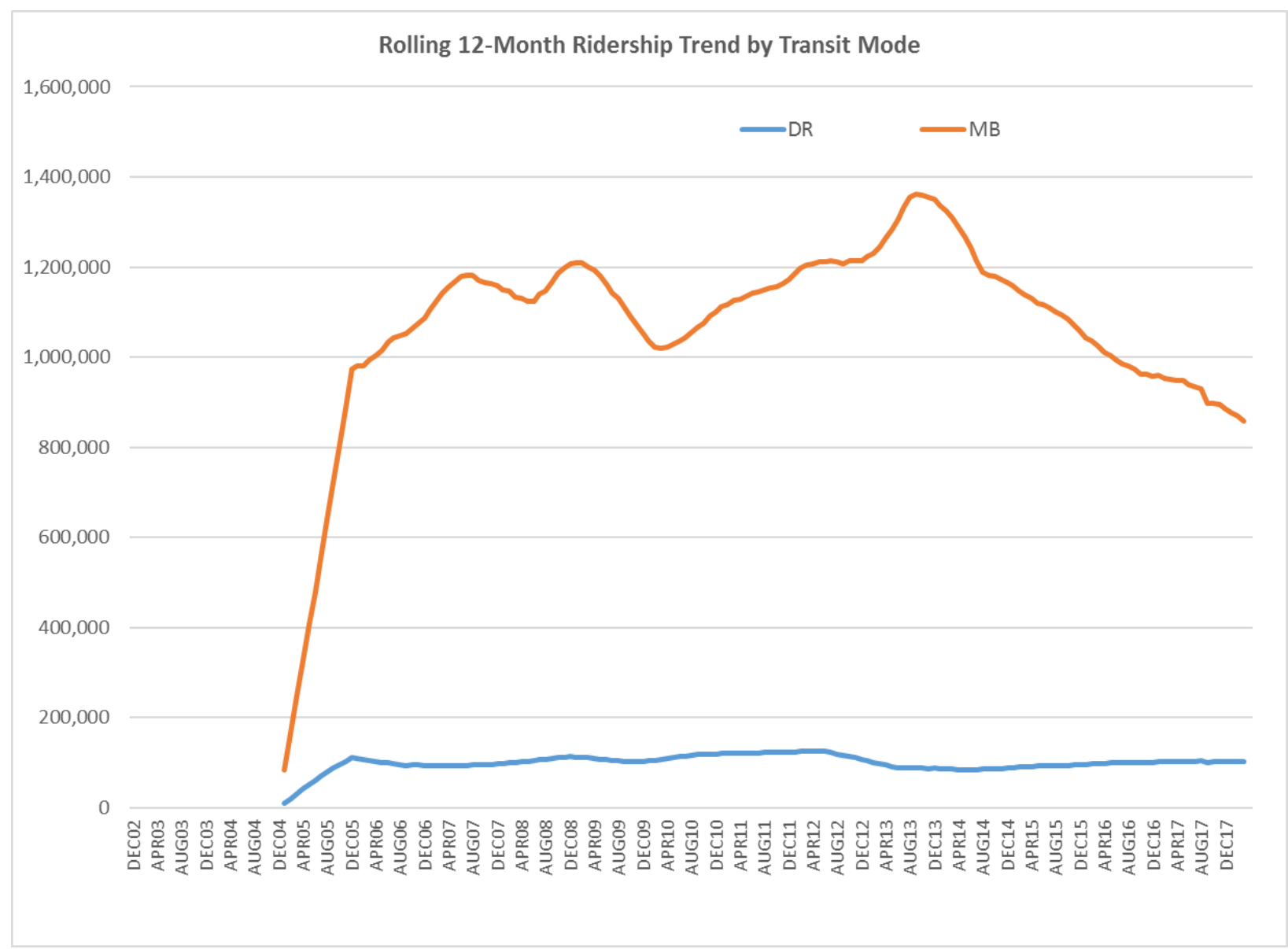


The final graphic shows service supply as measured by revenue vehicle miles of service. As the graphical data communicates, bus service supply has declined $4 \%$ in the past year and been steady over three years. Demand responsive service has grown $7 \%$ and $22 \%$ respectively in the one in three year periods.

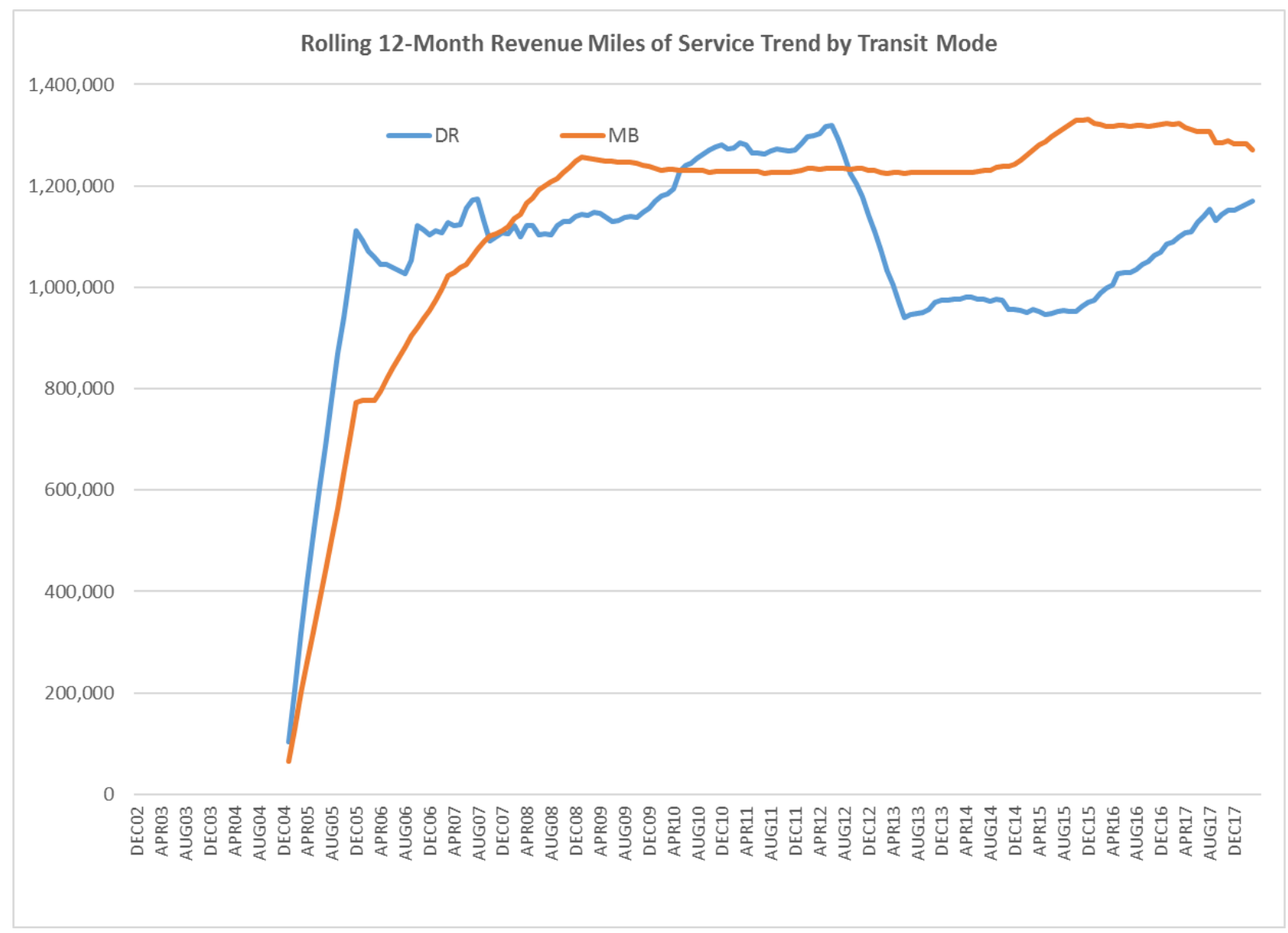


Pasco County (Pasco County Public Transportation, PCPT)

Ridership on the Pasco transit system has declined $19 \%$ since a peak in 2013. Vehicle revenue miles of service has increased $18 \%$ in that same time period. The Pasco system was most impacted by declining ridership during the past three years. Boardings per revenue mile has dropped $48 \%$ since its peak in 2007. Ridership per County resident has declined $31 \%$ from its peak in 2007.

Average trip length on transit has been in the 6-8 mile range.

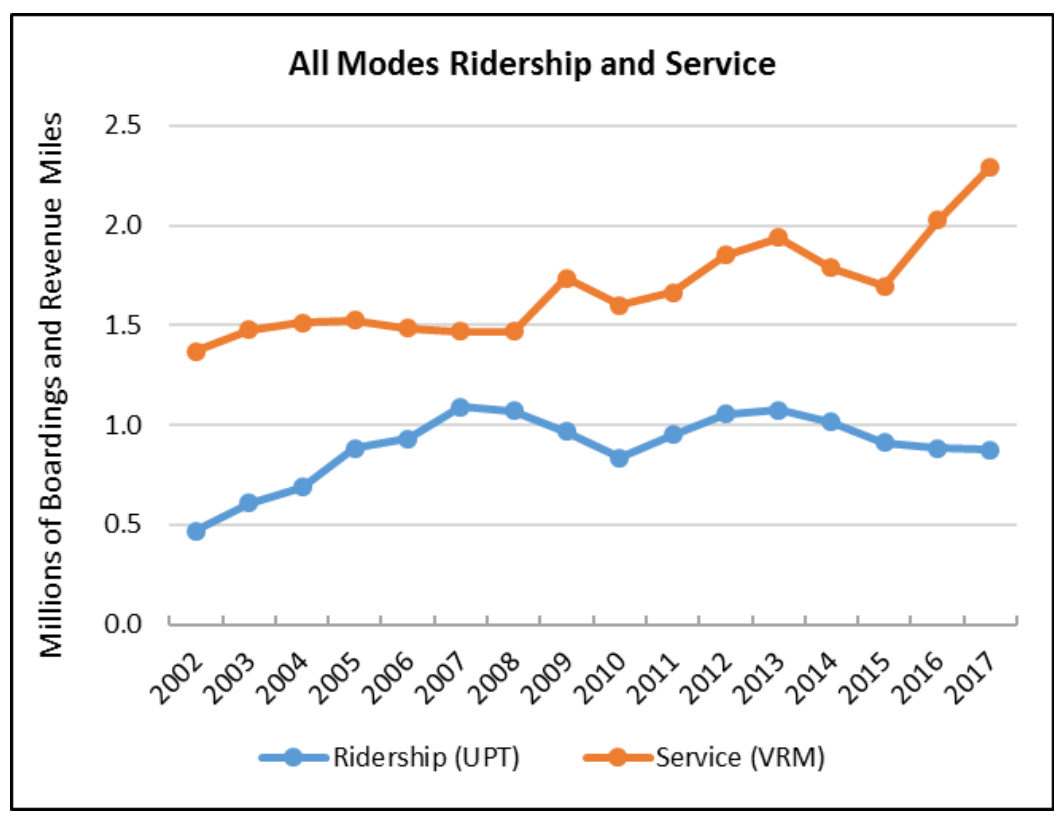

\begin{tabular}{|c|c|c|c|c|c|c|c|c|}
\hline \multicolumn{9}{|c|}{ Annual Trend Data, All Modes } \\
\hline Year & Ridership (UPT) & Service (VRM) & $\begin{array}{l}\text { Boardings per } \\
\text { Revenue Mile }\end{array}$ & $\begin{array}{l}\text { AVG Fixed- } \\
\text { Route } \\
\text { Speed } \\
\text { (mph) }\end{array}$ & $\begin{array}{c}\text { County } \\
\text { Population }\end{array}$ & $\begin{array}{c}\text { Trips per } \\
\text { Capita }\end{array}$ & $\begin{array}{c}\text { Passenger } \\
\text { Miles of } \\
\text { Travel }\end{array}$ & $\begin{array}{c}\text { Average } \\
\text { Trip } \\
\text { Length }\end{array}$ \\
\hline 2002 & 468,953 & $1,370,091$ & 0.34 & 17.93 & 361,468 & 1.3 & $2,977,208$ & 6.35 \\
\hline 2003 & 608,230 & $1,476,670$ & 0.41 & 18.04 & 375,318 & 1.6 & $3,994,259$ & 6.57 \\
\hline 2004 & 687,204 & $1,510,693$ & 0.45 & 17.75 & 389,776 & 1.8 & $4,182,884$ & 6.09 \\
\hline 2005 & 882,376 & $1,525,582$ & 0.58 & 16.99 & 406,898 & 2.2 & $5,372,642$ & 6.09 \\
\hline 2006 & 930,570 & $1,486,395$ & 0.63 & 16.65 & 424,355 & 2.2 & $6,091,632$ & 6.55 \\
\hline 2007 & $1,090,475$ & $1,469,352$ & 0.74 & 16.73 & 434,425 & 2.5 & $6,970,891$ & 6.39 \\
\hline 2008 & $1,068,306$ & $1,468,435$ & 0.73 & 16.72 & 438,668 & 2.4 & $7,468,644$ & 6.99 \\
\hline 2009 & 968,196 & $1,735,562$ & 0.56 & 16.72 & 439,786 & 2.2 & $6,601,384$ & 6.82 \\
\hline 2010 & 833,256 & $1,598,305$ & 0.52 & 16.75 & 465,543 & 1.8 & $5,726,015$ & 6.87 \\
\hline 2011 & 949,036 & $1,664,272$ & 0.57 & 17.07 & 466,533 & 2.0 & $6,551,669$ & 6.90 \\
\hline 2012 & $1,053,280$ & $1,850,806$ & 0.57 & 17.83 & 468,562 & 2.2 & $7,564,443$ & 7.18 \\
\hline 2013 & $1,074,266$ & $1,938,381$ & 0.55 & 18.29 & 473,566 & 2.3 & $8,419,724$ & 7.84 \\
\hline 2014 & $1,013,234$ & $1,787,322$ & 0.57 & 18.34 & 479,340 & 2.1 & $7,578,044$ & 7.48 \\
\hline 2015 & 909,426 & $1,697,038$ & 0.54 & 17.36 & 487,588 & 1.9 & $6,486,806$ & 7.13 \\
\hline 2016 & 882,208 & $2,026,259$ & 0.44 & 17.36 & 495,868 & 1.8 & $6,062,308$ & 6.87 \\
\hline 2017 & 875,027 & $2,293,290$ & 0.38 & 19.95 & 505,709 & 1.7 & & \\
\hline
\end{tabular}


The monthly ridership trend shows a modest influence of hurricane Irma. Ridership for the first three months of 2018 has been running approximately even with last year.

Average operating speed, defined as vehicle revenue miles divided by vehicle revenue hours, has been averaging in the high teens and jumped to nearly $20 \mathrm{mph}$, a relatively fast speed for transit service.
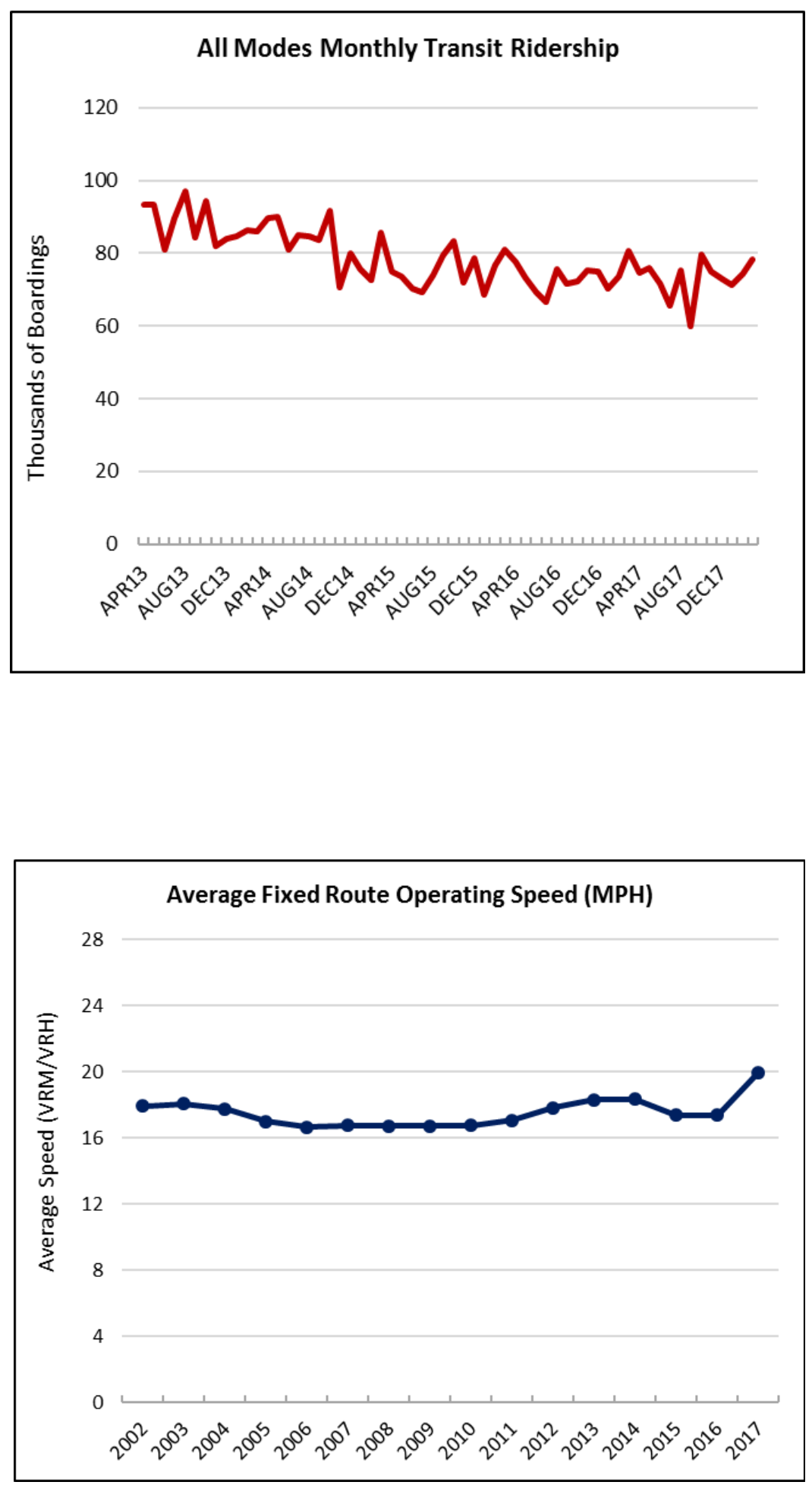
The adjacent graphic shows service productivity. Service productivity declined sharply from 2008 to 2010 and again post 2014.

The figures below provide the ridership trends and service supply trends by sub mode. This allows one to understand how the various component modes are performing.

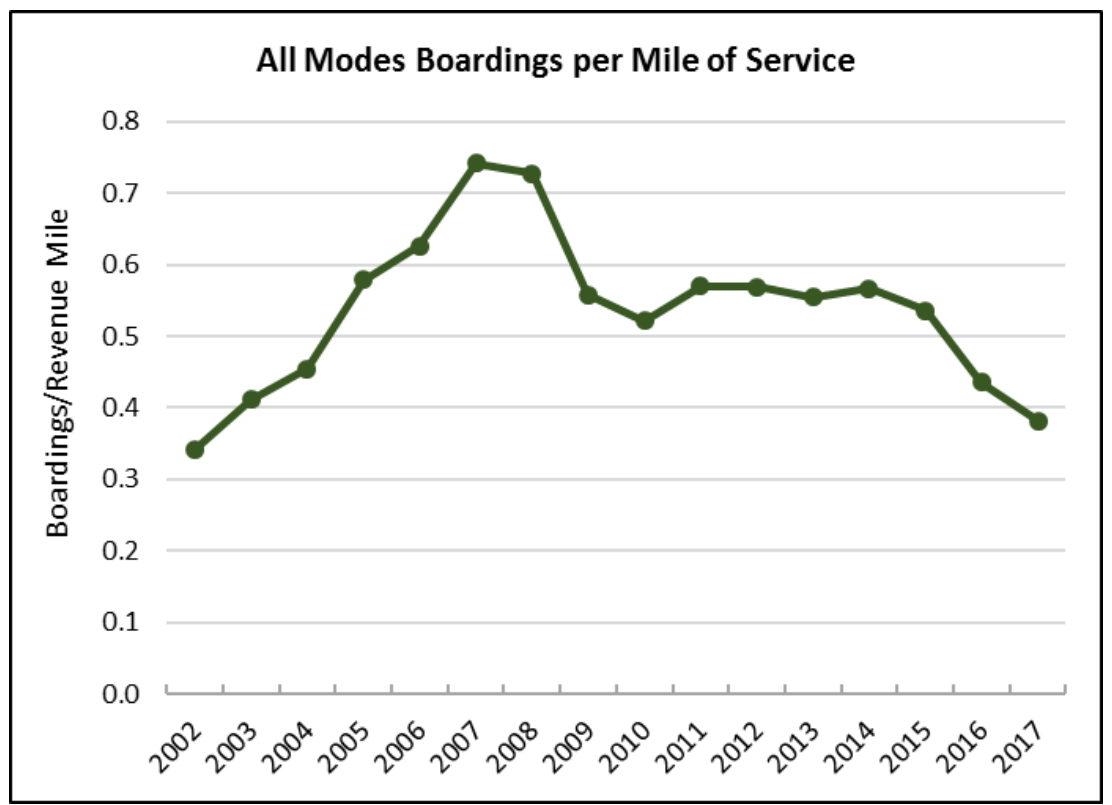

Rolling 12-Month Ridership Trend by Transit Mode

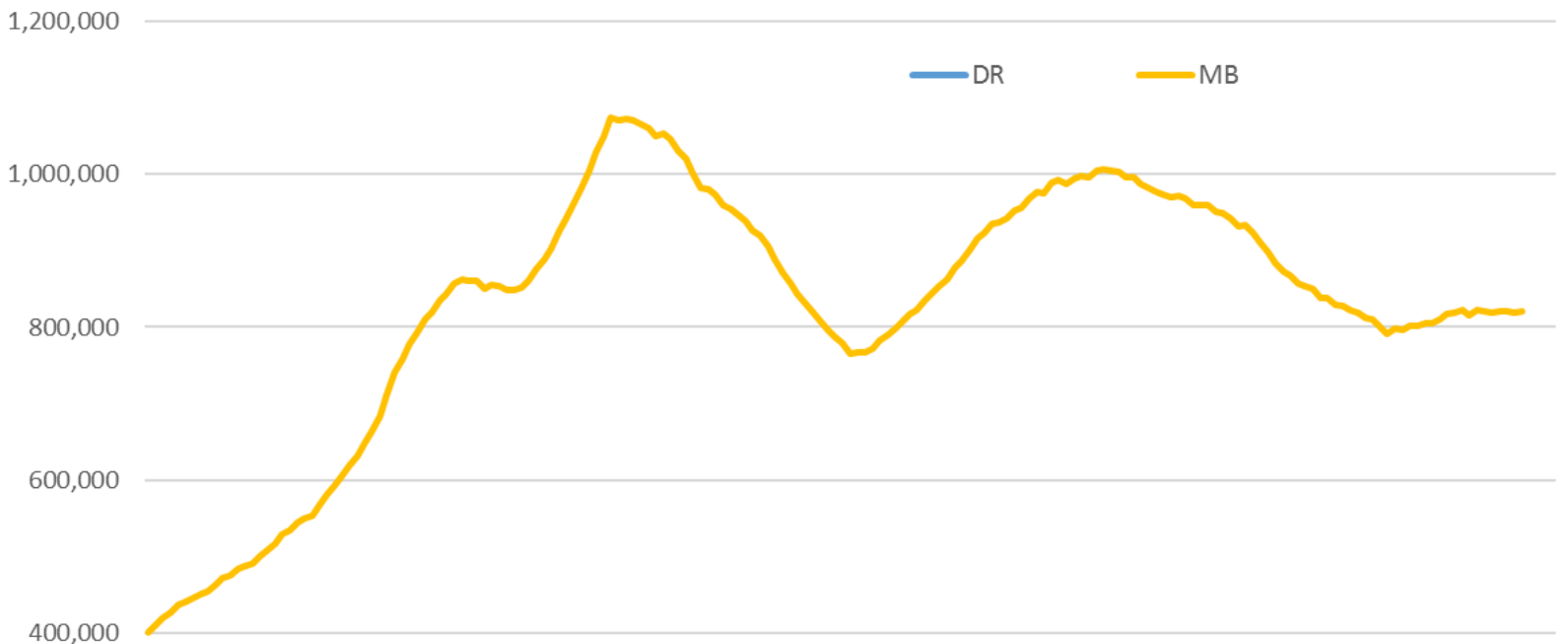

200,000

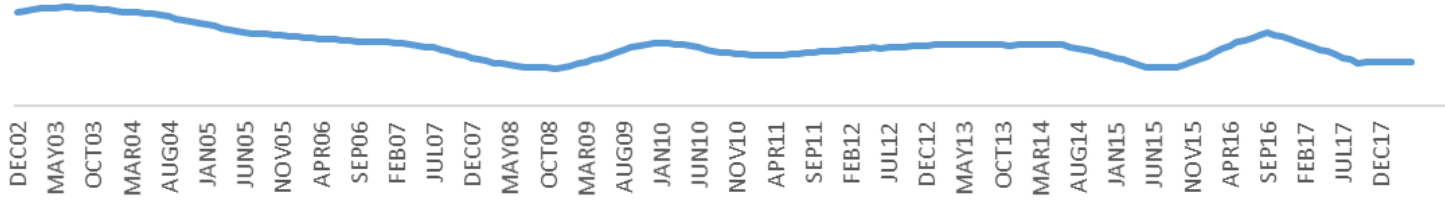


Bus ridership has grown approximately $2 \%$ over one year and declined $12 \%$ over three years. Demand responsive service has declined $26 \%$ in the last year and declined $1 \%$ over the past three.

The final graphic shows service supply as measured by revenue vehicle miles of service. As the graphical data communicates, bus service supply has increased $7 \%$ in the past year and $30 \%$ over three years. Demand responsive service has declined $5 \%$ and grown $33 \%$ respectively in the one in three-year periods.

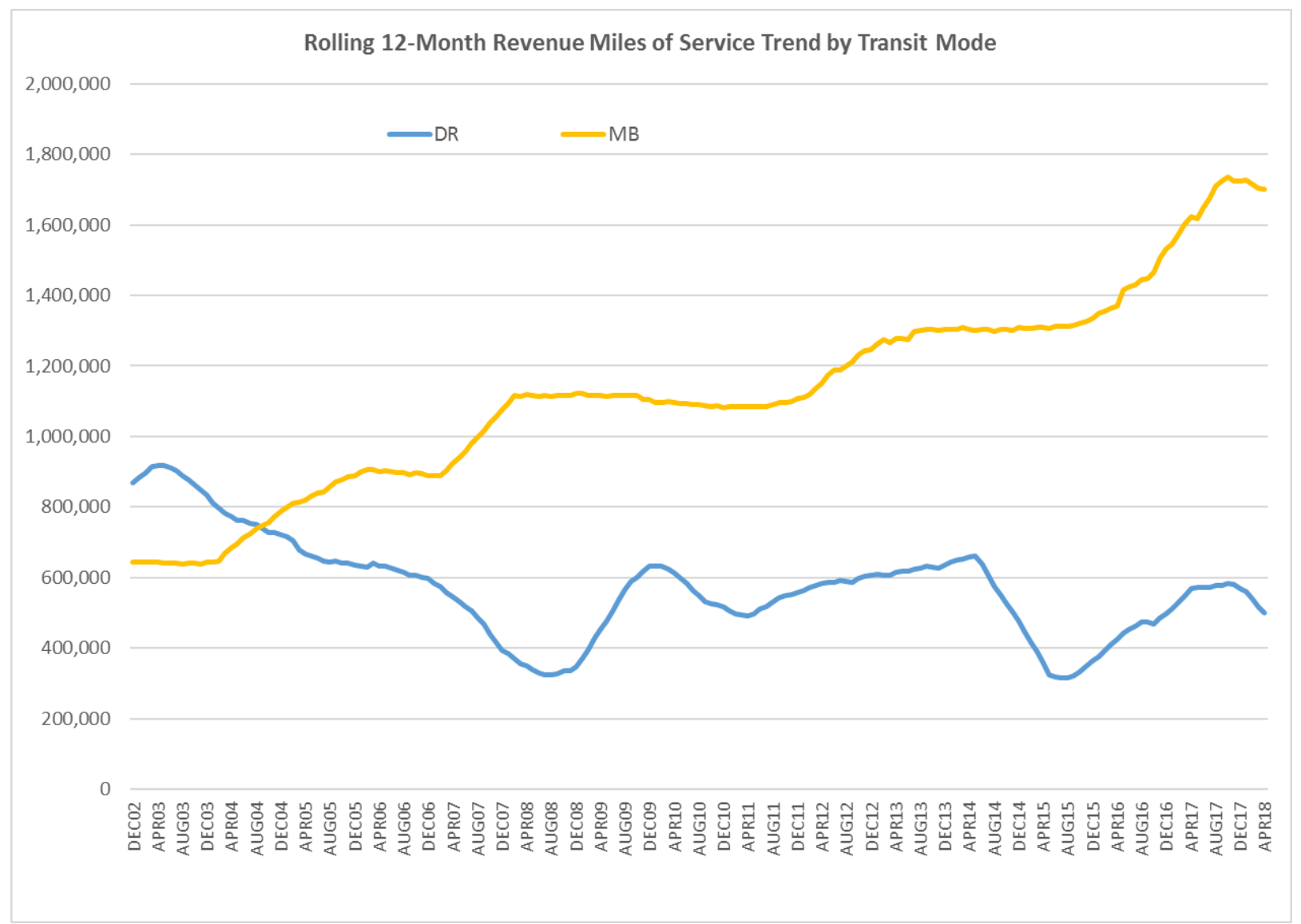


Central Florida CR (Central Florida Commuter Rail, SunRail)

The central Florida commuter rail system began service in May 2014. Ridership on the Central Florida Commuter Rail system has declined $12 \%$ since a peak in 2015. Vehicle revenue miles of service has declined $4 \%$ in that same time period. The Central Florida Commuter Rail system has shown declining ridership each year since it opened. Boardings per revenue mile has dropped $8 \%$ since its peak in

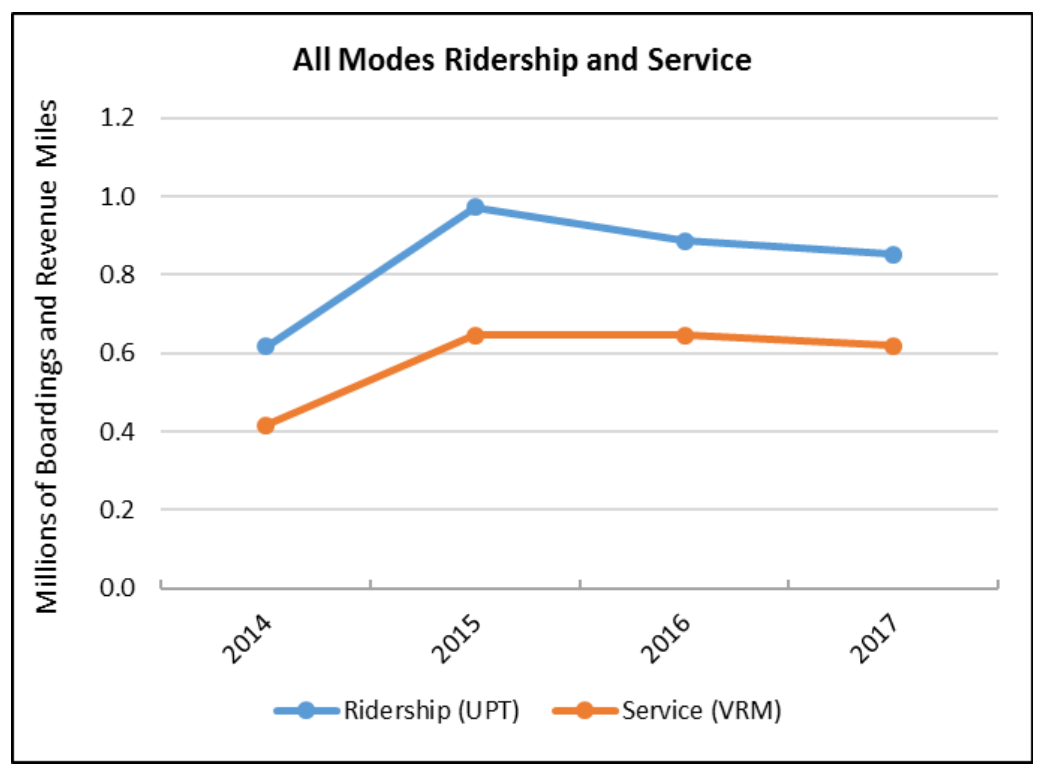
2015. Ridership per County resident has declined 16\% from its peak in 2015.

Average trip length on transit has been relatively stable since 2005 Under 6 miles.

\begin{tabular}{|c|c|c|c|c|c|c|c|c|}
\hline \multicolumn{9}{|c|}{ Annual Trend Data, All Modes } \\
\hline Year & Ridership (UPT) & Service (VRM) & $\begin{array}{l}\text { Boardings per } \\
\text { Revenue Mile }\end{array}$ & $\begin{array}{l}\text { AVG Fixed- } \\
\text { Route } \\
\text { Speed } \\
\text { (mph) }\end{array}$ & $\begin{array}{c}\text { County } \\
\text { Population }\end{array}$ & $\begin{array}{l}\text { Trips per } \\
\text { Capita }\end{array}$ & $\begin{array}{c}\text { Passenger } \\
\text { Miles of } \\
\text { Travel }\end{array}$ & $\begin{array}{c}\text { Average } \\
\text { Trip } \\
\text { Length }\end{array}$ \\
\hline \multicolumn{9}{|l|}{2002} \\
\hline \multicolumn{9}{|l|}{2003} \\
\hline \multicolumn{9}{|l|}{2004} \\
\hline \multicolumn{9}{|l|}{2005} \\
\hline \multicolumn{9}{|l|}{2006} \\
\hline \multicolumn{9}{|l|}{2007} \\
\hline \multicolumn{9}{|l|}{2008} \\
\hline \multicolumn{9}{|l|}{2009} \\
\hline \multicolumn{9}{|l|}{2010} \\
\hline \multicolumn{9}{|l|}{2011} \\
\hline \multicolumn{9}{|l|}{2012} \\
\hline \multicolumn{9}{|l|}{2013} \\
\hline 2014 & 616,411 & 417,026 & 1.48 & 30.70 & $1,227,995$ & 0.5 & $2,611,853$ & 4.24 \\
\hline 2015 & 972,546 & 646,527 & 1.50 & 31.41 & $1,252,396$ & 0.8 & $14,058,081$ & 14.45 \\
\hline 2016 & 887,224 & 646,445 & 1.37 & 28.29 & $1,280,387$ & 0.7 & $13,104,921$ & 14.77 \\
\hline 2017 & 851,881 & 618,888 & 1.38 & 25.41 & $1,313,880$ & 0.6 & & \\
\hline
\end{tabular}


The monthly ridership trend shows the influence of hurricane Irma. Ridership for the first four months of 2018 has been running approximately $6 \%$ behind last year.

The Average operating speed, defined as vehicle revenue miles divided by vehicle revenue hours, has declined from an excess of $30 \mathrm{mph}$ to above $25 \mathrm{mph}$.
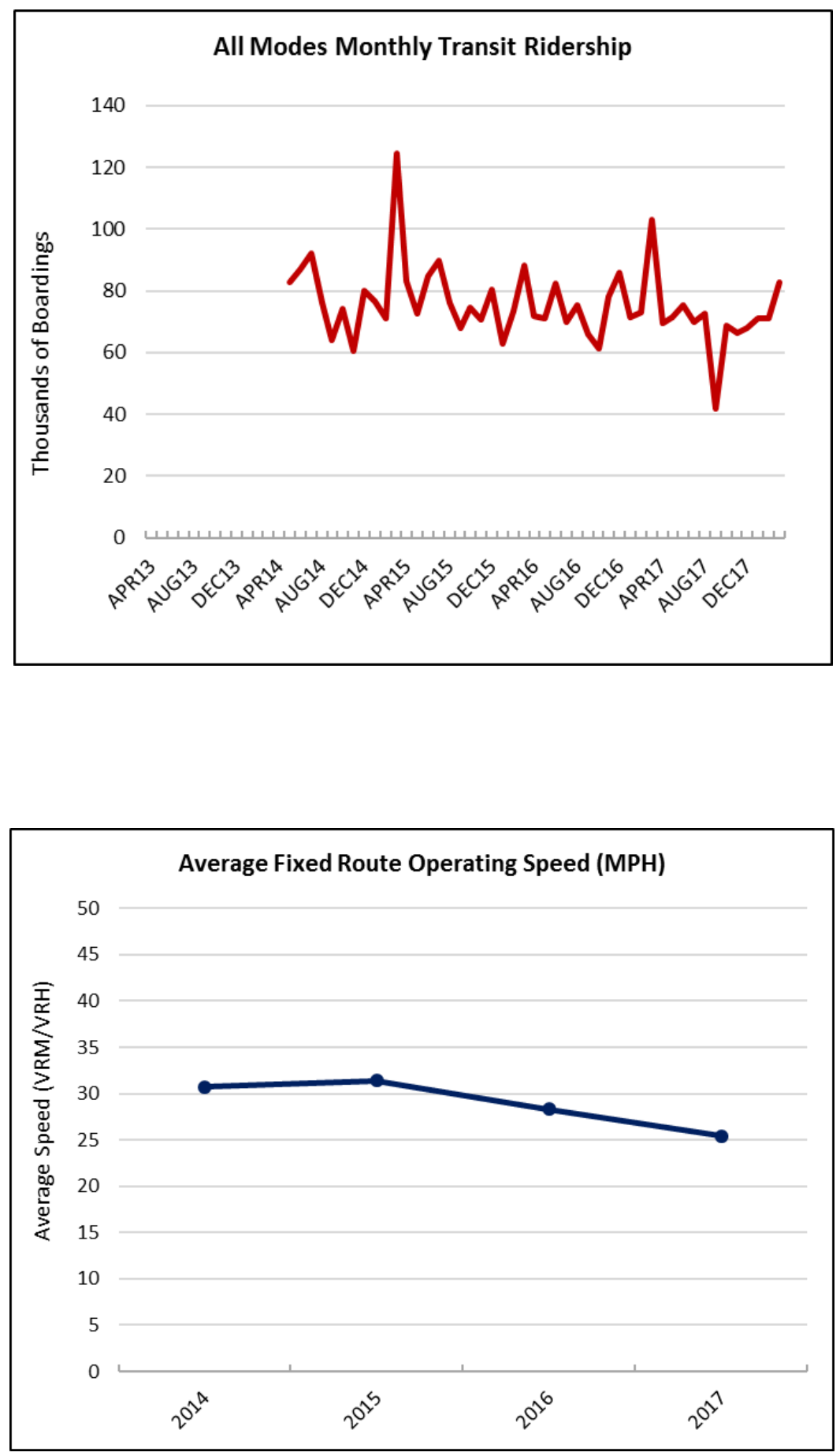
The adjacent graphic shows service productivity. Service productivity has declined modestly since 2015 .

The figures below provide the ridership trends and service supply trends by sub mode. This allows one to understand how the various component modes are performing.

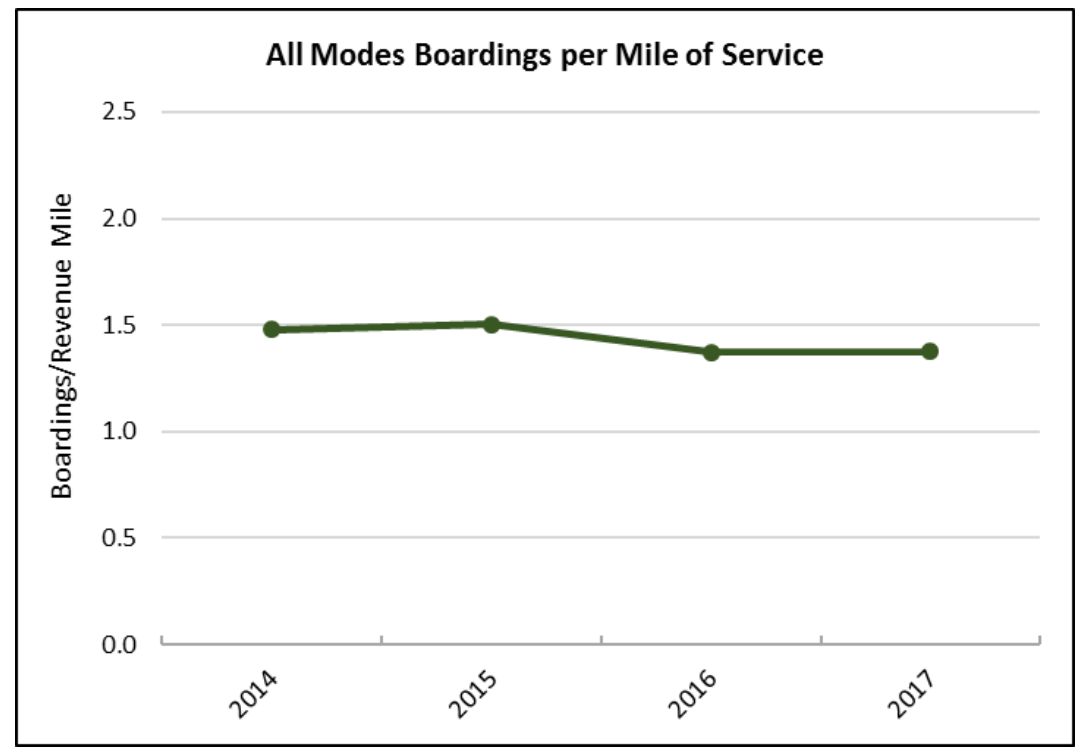

Rail ridership has declined approximately $9 \%$ over one year and $13 \%$ since the first year of service.

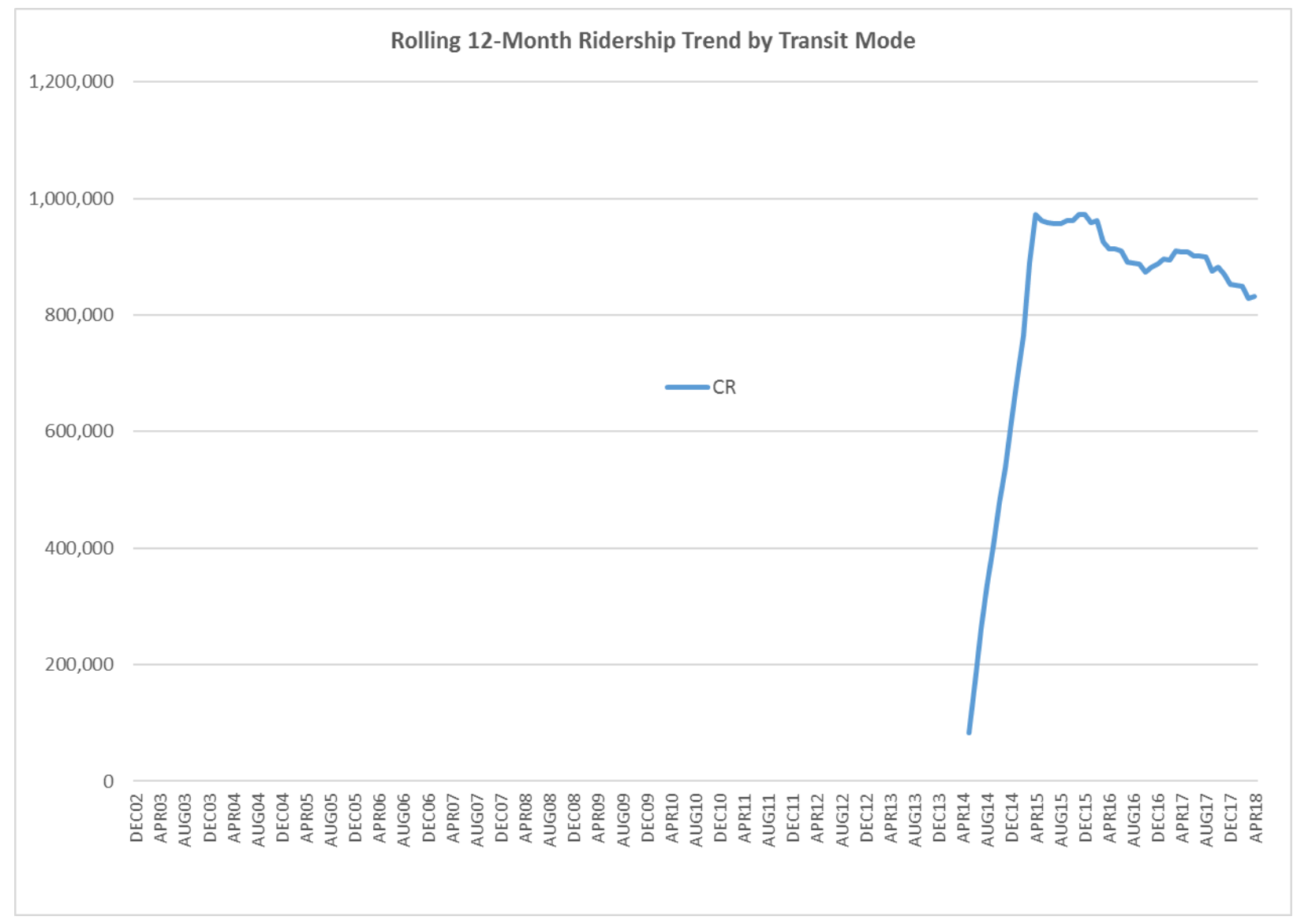


The final graphic shows service supply as measured by revenue vehicle miles of service. As the graphical data communicates, rail service supply has declined $7 \%$ in the past year and $3 \%$ since its first year of service.

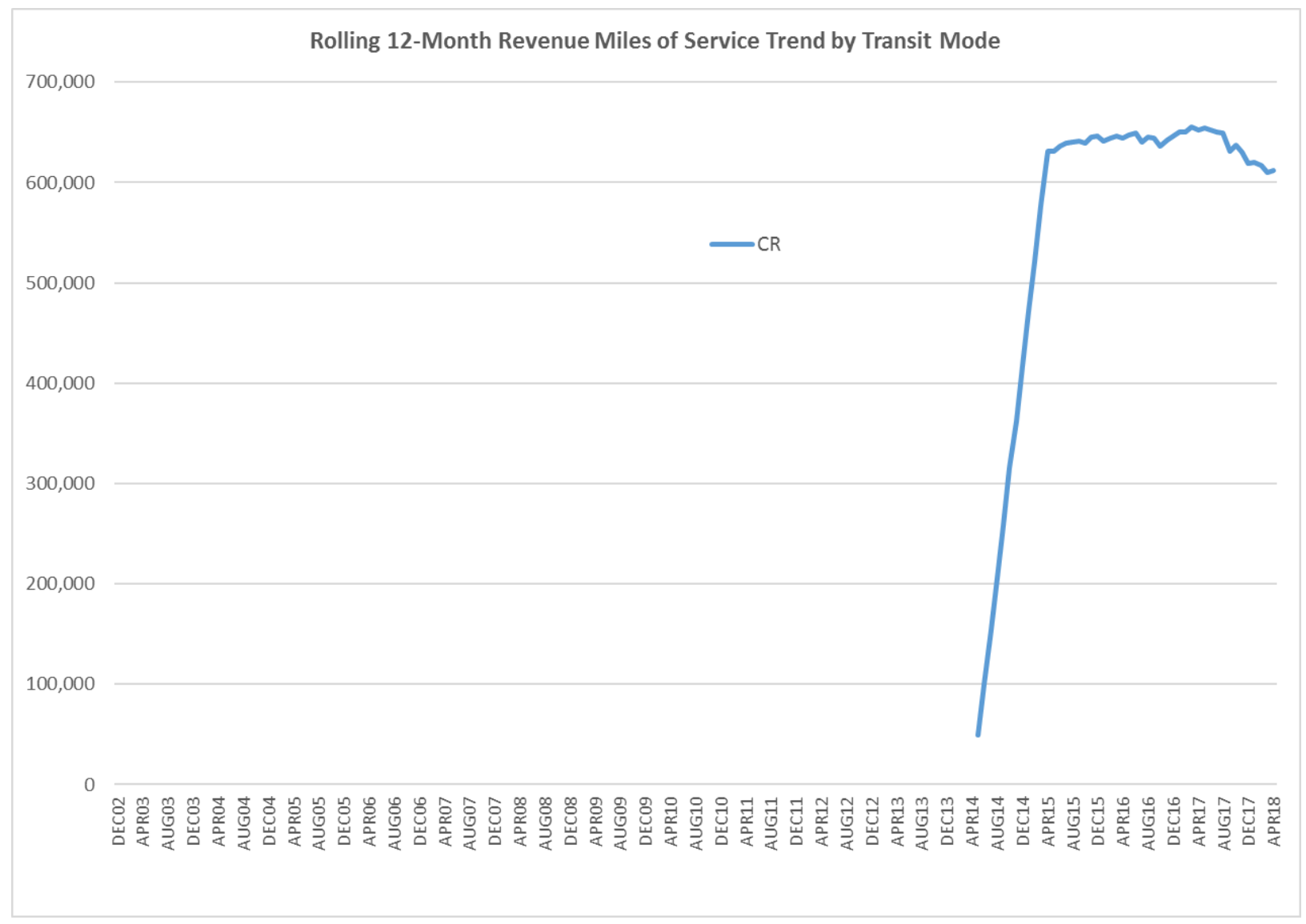


Miami vRide (Miami Lakes -vRide, Inc.)

Ridership on the Miami vRide transit system has declined 13\% since a peak in 2013. Vehicle revenue miles of service has declined $8 \%$ in that same time period. The Miami vRide system was most impacted by declining ridership during the past three years. Boardings per revenue mile has dropped $6 \%$ since its peak in 2011. Ridership per County resident has declined 16\% from its peak in 2014.

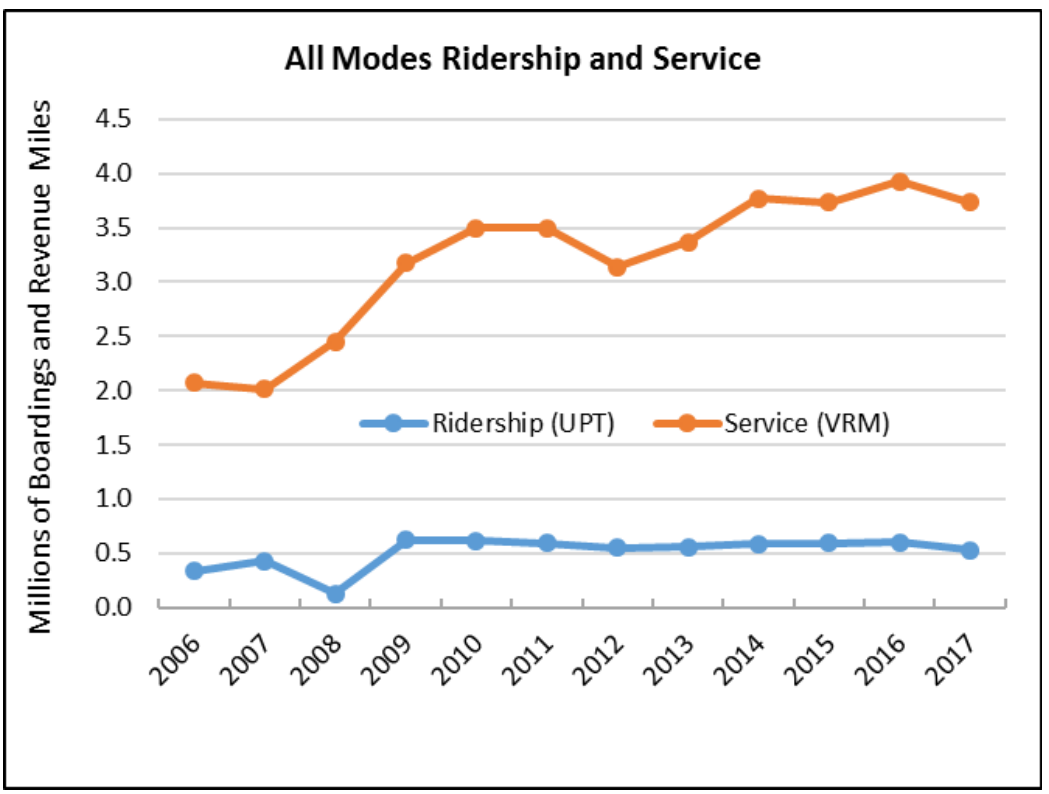

Average trip length on transit has been relatively stable since 2005 Under 6 miles.

\begin{tabular}{|c|c|c|c|c|c|c|c|c|}
\hline \multicolumn{9}{|c|}{ Annual Trend Data, All Modes } \\
\hline Year & Ridership (UPT) & Service (VRM) & $\begin{array}{l}\text { Boardings per } \\
\text { Revenue Mile }\end{array}$ & $\begin{array}{l}\text { AVG Fixed- } \\
\text { Route } \\
\text { Speed } \\
\text { (mph) }\end{array}$ & $\begin{array}{c}\text { County } \\
\text { Population }\end{array}$ & $\begin{array}{l}\text { Trips per } \\
\text { Capita }\end{array}$ & $\begin{array}{c}\text { Passenger } \\
\text { Miles of } \\
\text { Travel }\end{array}$ & $\begin{array}{c}\text { Average } \\
\text { Trip } \\
\text { Length }\end{array}$ \\
\hline \multicolumn{9}{|l|}{2002} \\
\hline \multicolumn{9}{|l|}{2003} \\
\hline \multicolumn{9}{|l|}{2004} \\
\hline \multicolumn{9}{|l|}{2005} \\
\hline 2006 & 331,012 & $2,070,947$ & 0.16 & & $2,437,022$ & 0.14 & $10,546,494$ & 31.86 \\
\hline 2007 & 423,319 & $2,011,450$ & 0.21 & & $2,462,292$ & 0.17 & $10,787,420$ & 25.48 \\
\hline 2008 & 126,972 & $2,448,155$ & 0.05 & & $2,477,289$ & 0.05 & $13,108,683$ & 103.24 \\
\hline 2009 & 621,268 & $3,177,142$ & 0.20 & & $2,472,344$ & 0.25 & $13,489,380$ & 21.71 \\
\hline 2010 & 610,001 & $3,498,115$ & 0.17 & & $2,505,379$ & 0.24 & $14,183,978$ & 23.25 \\
\hline 2011 & 590,013 & $3,500,589$ & 0.17 & & $2,516,537$ & 0.23 & $14,476,587$ & 24.54 \\
\hline 2012 & 547,820 & $3,139,984$ & 0.17 & & $2,551,290$ & 0.21 & $15,940,745$ & 29.10 \\
\hline 2013 & 554,081 & $3,369,737$ & 0.16 & & $2,582,375$ & 0.21 & $15,960,462$ & 28.81 \\
\hline 2014 & 583,036 & $3,768,611$ & 0.15 & & $2,613,692$ & 0.22 & $15,915,643$ & 27.30 \\
\hline 2015 & 592,262 & $3,736,383$ & 0.16 & & $2,653,934$ & 0.22 & $20,056,371$ & 33.86 \\
\hline 2016 & 598,696 & $3,928,217$ & 0.15 & & $2,700,794$ & 0.22 & $16,601,580$ & 27.73 \\
\hline 2017 & 529,754 & $3,732,755$ & 0.14 & & $2,743,095$ & 0.19 & & \\
\hline
\end{tabular}


The monthly ridership trend shows the influence of hurricane Irma. Ridership for the first three months of 2018 has been running approximately $5 \%$ behind last year.

Average operating speed, defined as vehicle revenue miles divided by vehicle revenue hours, has been averaging nearly $19 \mathrm{mph}$, a relatively fast speed for transit service.

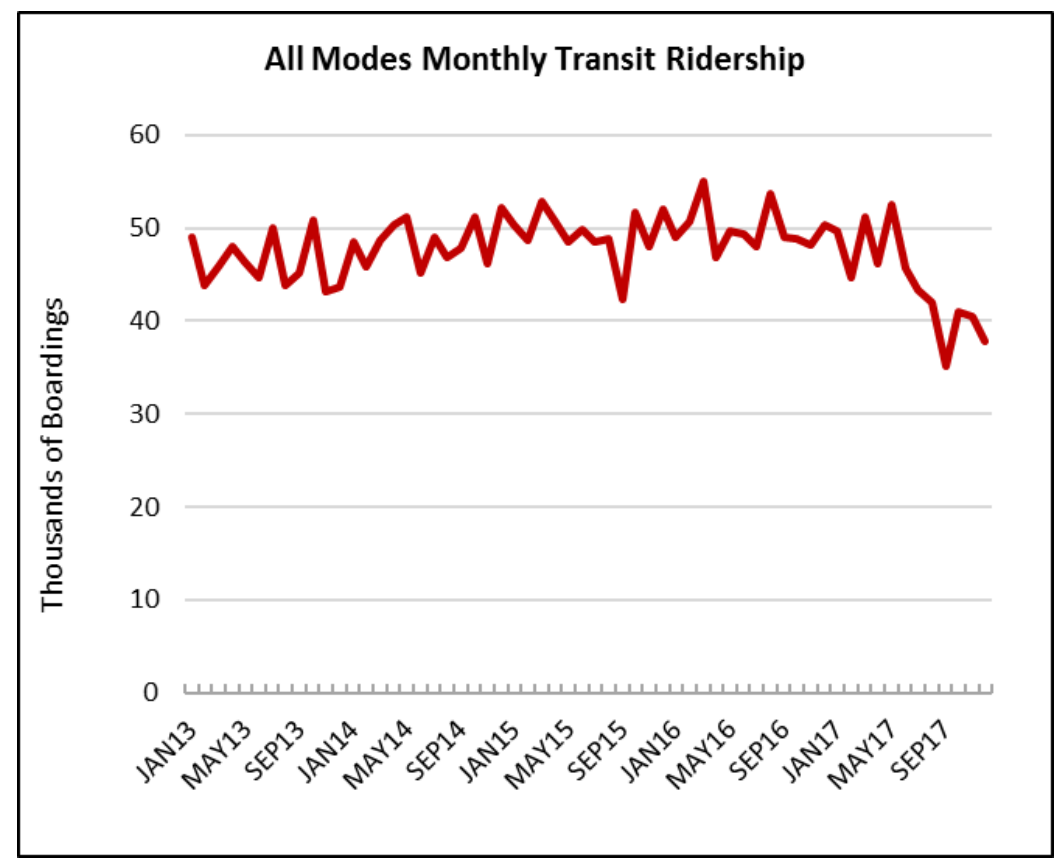

The adjacent graphic shows service productivity. Service productivity has declined modestly since 2015 .

The figures below provide the ridership trends and service supply trends by sub mode. This allows one to understand how the various component modes are performing.

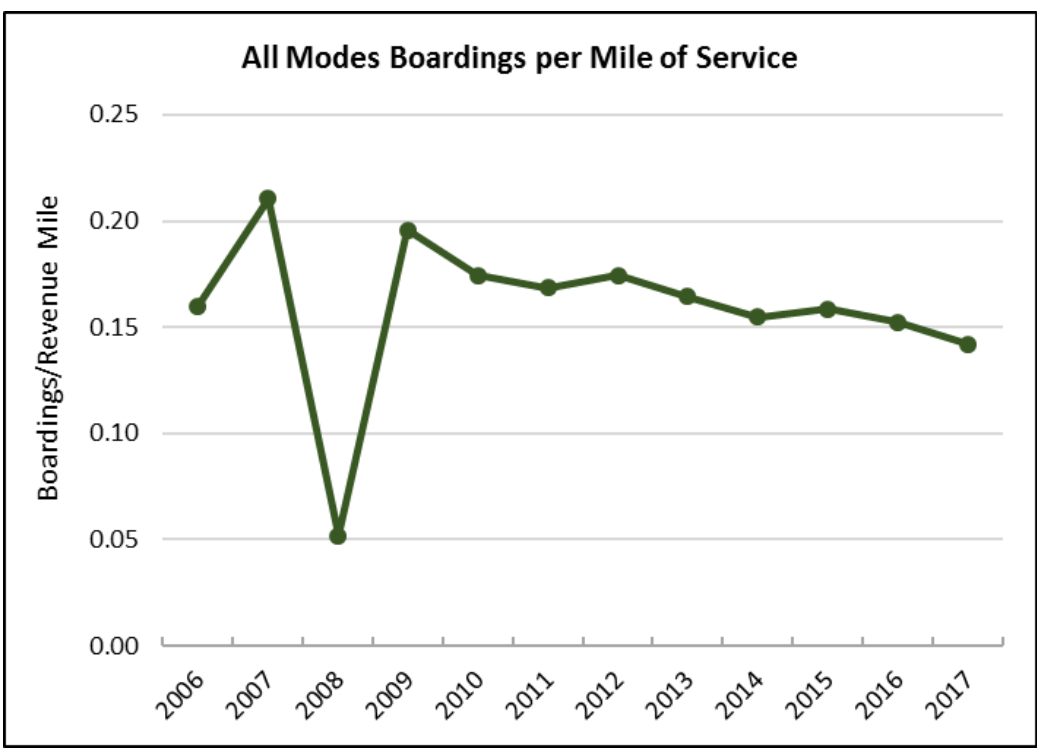

Van ridership has declined approximately $11 \%$ over one year and $9 \%$ over three years.

The final graphic shows service supply as measured by revenue vehicle miles of service. As the graphical data communicates, vanpool service has declined $5 \%$ in the past year and $1 \%$ over three years. 

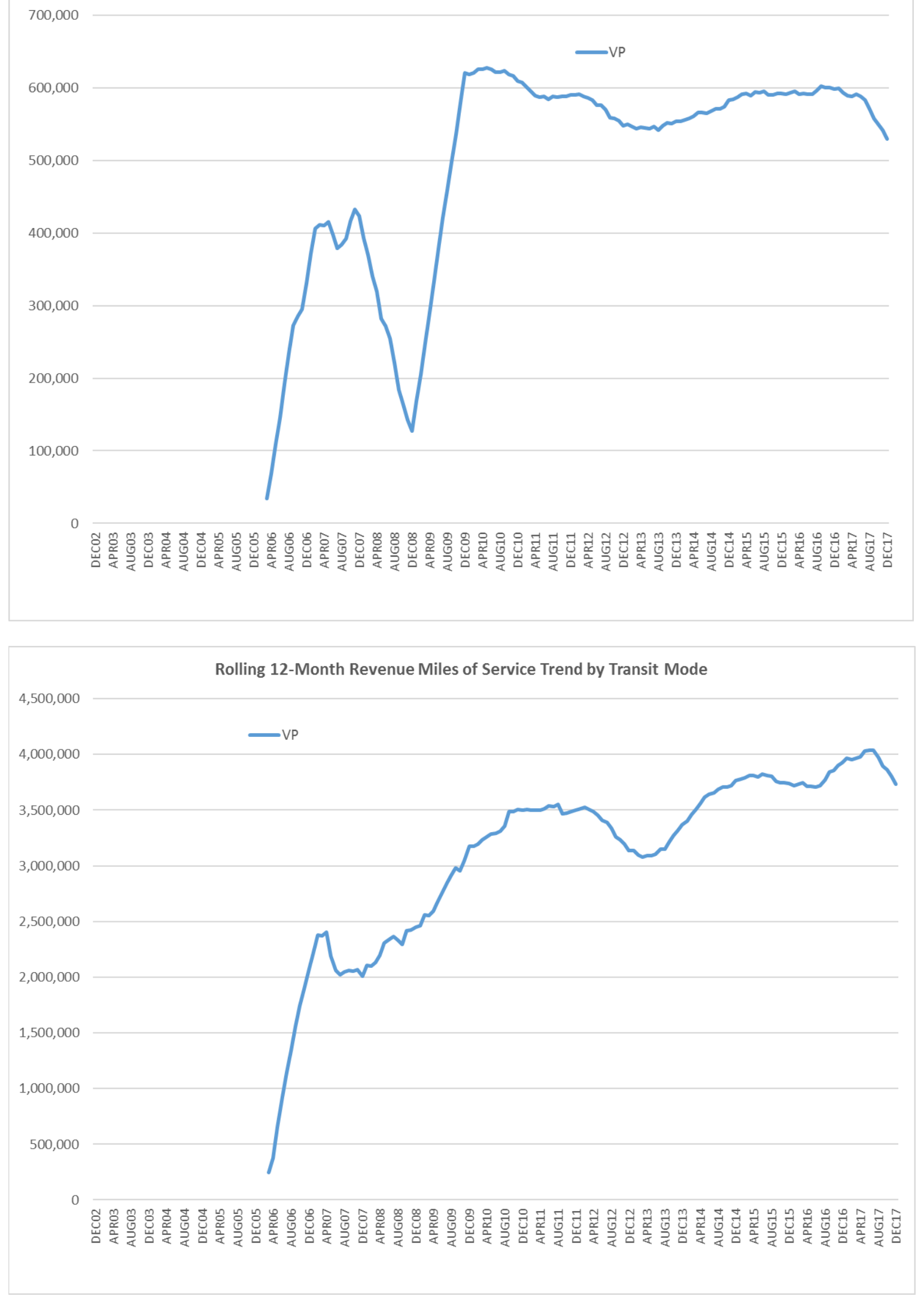
Lake County (Lake County Board of County Commissioners, Lake Transit)

Ridership on the Lake County transit system has declined $8 \%$ since a peak in 2012. Vehicle revenue miles of service has declined $18 \%$ in that same time period. The Lake County system has had stable ridership during the past three years. Boardings per revenue mile was at its highest level in 2017. Ridership per County resident has declined $17 \%$ from its peak in 2012.

Average trip length on transit

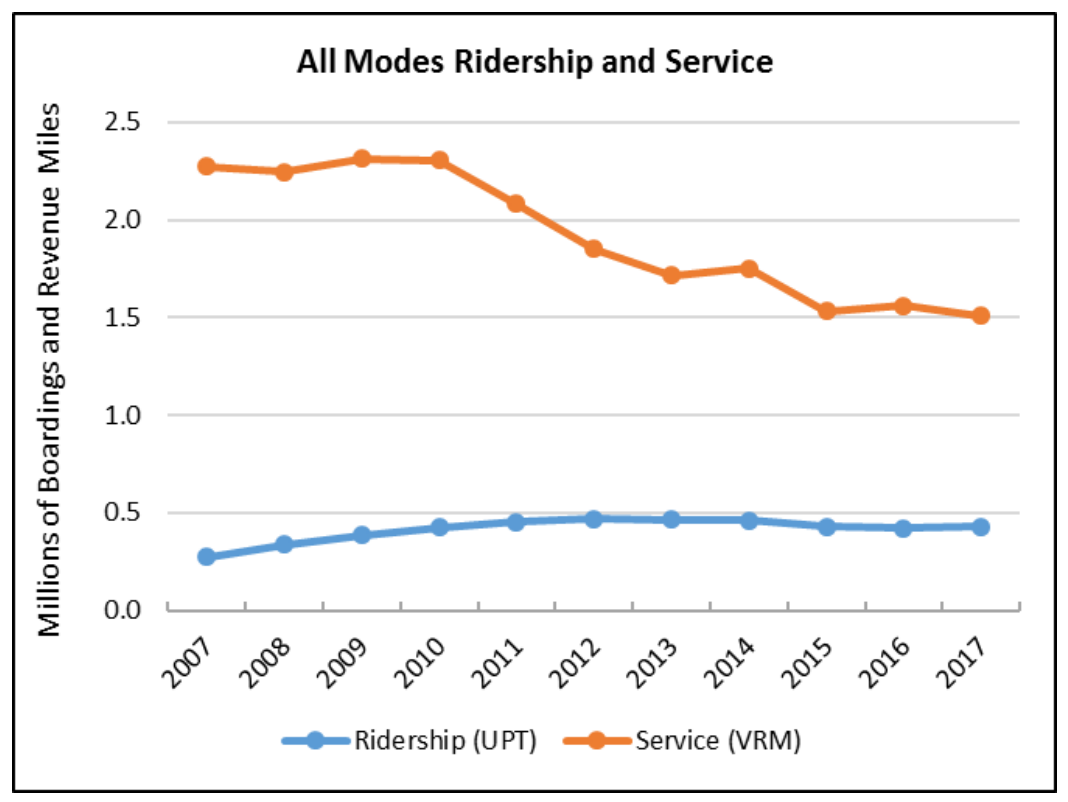
has been relatively stable since 2005 Under 6 miles.

\begin{tabular}{|c|c|c|c|c|c|c|c|c|}
\hline \multicolumn{9}{|c|}{ Annual Trend Data, All Modes } \\
\hline Year & Ridership (UPT) & Service (VRM) & $\begin{array}{l}\text { Boardings per } \\
\text { Revenue Mile }\end{array}$ & $\begin{array}{l}\text { AVG Fixed- } \\
\text { Route } \\
\text { Speed } \\
\text { (mph) }\end{array}$ & $\begin{array}{c}\text { County } \\
\text { Population }\end{array}$ & $\begin{array}{c}\text { Trips per } \\
\text { Capita }\end{array}$ & $\begin{array}{c}\text { Passenger } \\
\text { Miles of } \\
\text { Travel }\end{array}$ & $\begin{array}{c}\text { Average } \\
\text { Trip } \\
\text { Length }\end{array}$ \\
\hline \multicolumn{9}{|l|}{2002} \\
\hline \multicolumn{9}{|l|}{2003} \\
\hline \multicolumn{9}{|l|}{2004} \\
\hline \multicolumn{9}{|l|}{2005} \\
\hline \multicolumn{9}{|l|}{2006} \\
\hline 2007 & 272,878 & $2,272,532$ & 0.12 & 15.68 & 286,499 & 1.0 & $1,952,995$ & 7.16 \\
\hline 2008 & 336,740 & $2,247,039$ & 0.15 & 15.72 & 288,379 & 1.2 & $5,428,903$ & 16.12 \\
\hline 2009 & 386,332 & $2,313,883$ & 0.17 & 14.21 & 291,993 & 1.3 & $5,737,036$ & 14.85 \\
\hline 2010 & 425,304 & $2,306,825$ & 0.18 & 16.66 & 297,950 & 1.4 & $5,027,060$ & 11.82 \\
\hline 2011 & 452,035 & $2,082,371$ & 0.22 & 17.25 & 298,265 & 1.5 & $4,819,753$ & 10.66 \\
\hline 2012 & 466,756 & $1,849,344$ & 0.25 & 17.50 & 299,677 & 1.6 & $4,848,499$ & 10.39 \\
\hline 2013 & 462,571 & $1,717,770$ & 0.27 & 17.58 & 303,317 & 1.5 & $4,546,039$ & 9.83 \\
\hline 2014 & 460,567 & $1,751,982$ & 0.26 & 17.59 & 309,736 & 1.5 & $4,488,988$ & 9.75 \\
\hline 2015 & 428,847 & $1,533,892$ & 0.28 & 17.62 & 316,569 & 1.4 & $4,034,590$ & 9.41 \\
\hline 2016 & 420,486 & $1,561,725$ & 0.27 & 17.60 & 323,985 & 1.3 & $3,482,854$ & 8.28 \\
\hline 2017 & 429,213 & $1,507,507$ & 0.28 & 17.32 & 331,724 & 1.3 & & \\
\hline
\end{tabular}


Ridership for the first three months of 2018 has been running approximately $4 \%$ ahead of last year.

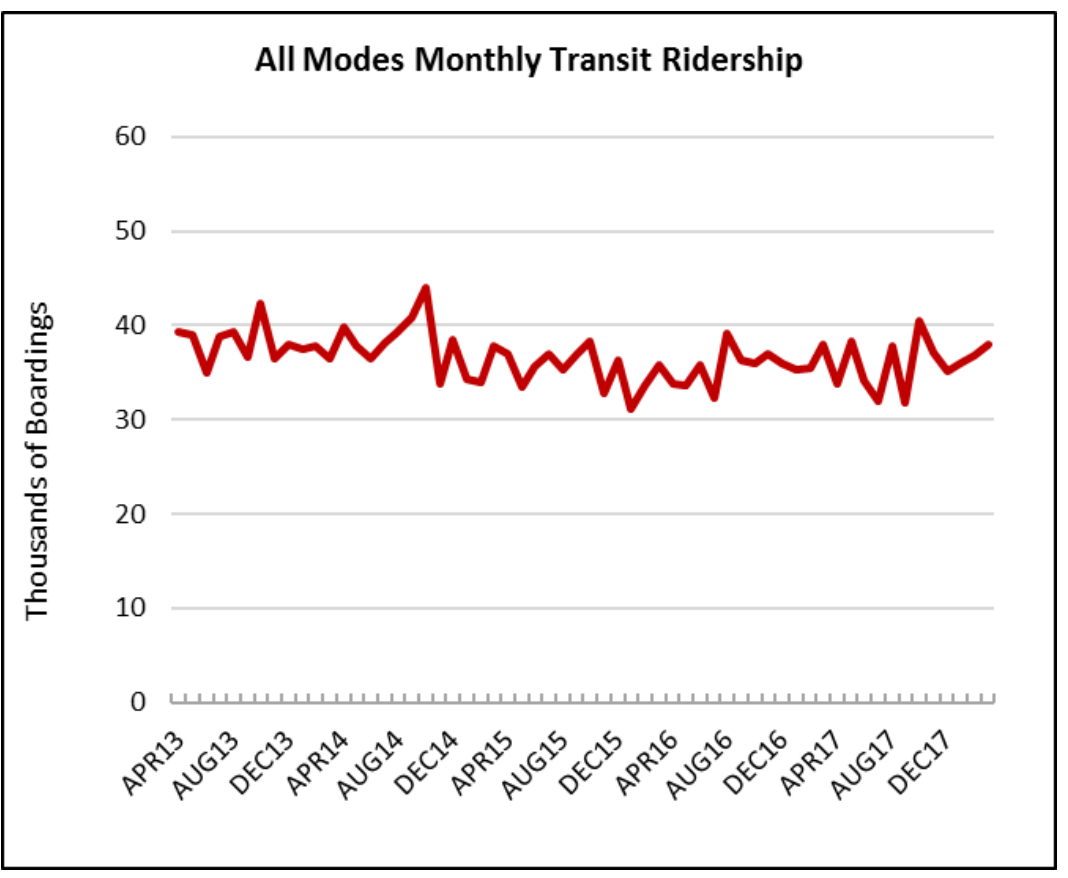

Average operating speed, defined as vehicle revenue miles divided by vehicle revenue hours, has been averaging nearly $19 \mathrm{mph}$, a relatively fast speed for transit service.

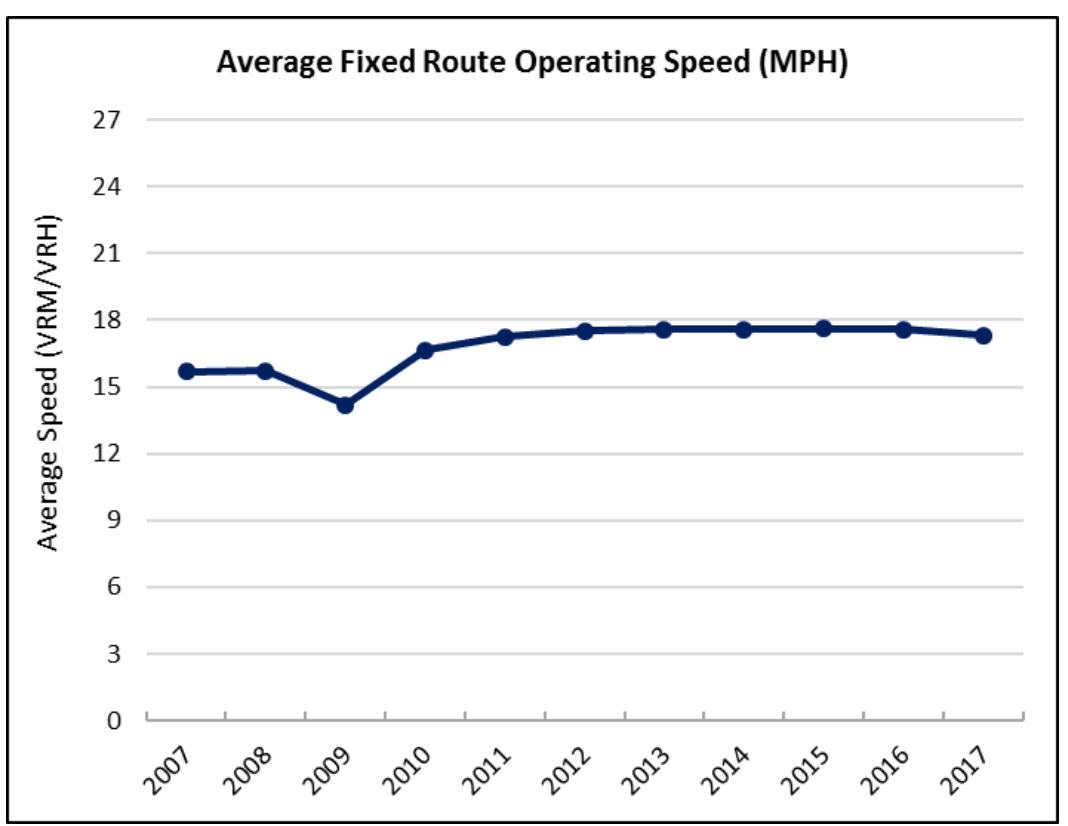


The adjacent graphic shows service productivity. Service productivity has declined modestly since 2015.

The figures below provide the ridership trends and service supply trends by sub mode. This allows one to understand how the various component modes are performing.

Bus ridership has grown

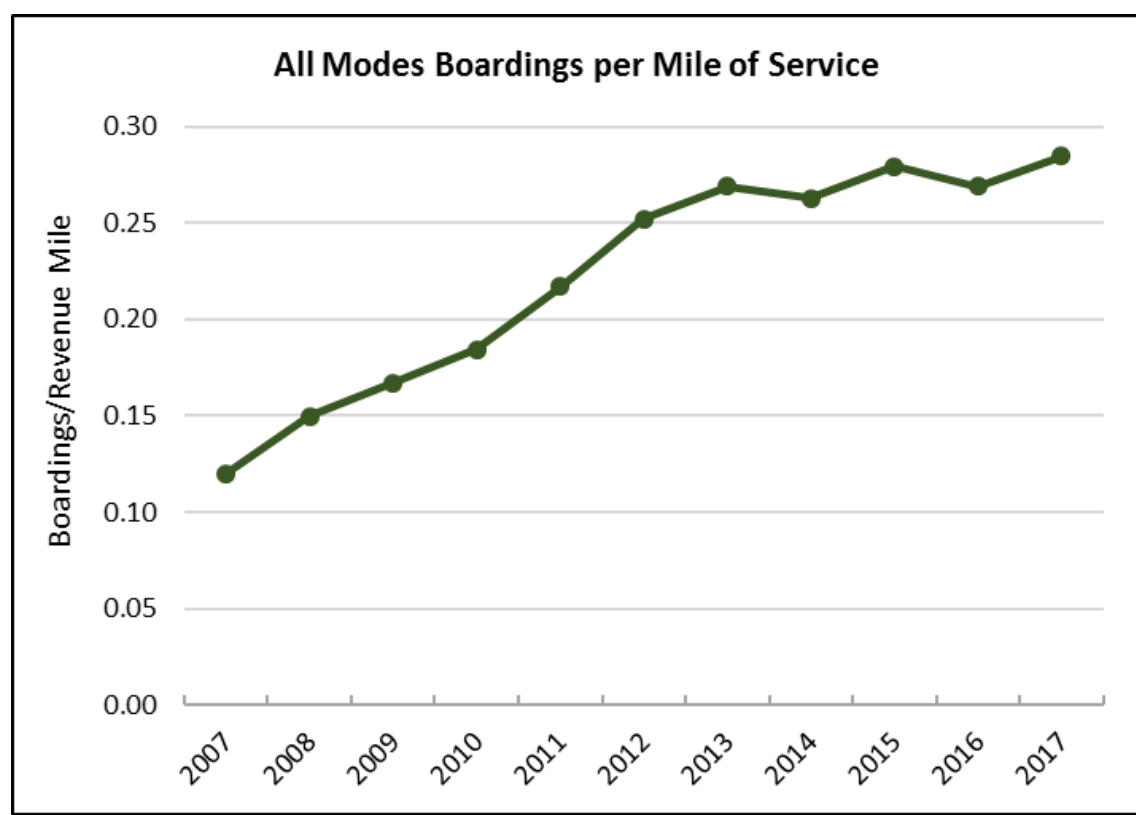
approximately $2 \%$ over one year and $6 \%$ over three years. Demand responsive service has declined $4 \%$ in the last year and declined $30 \%$ over the past three.

Rolling 12-Month Ridership Trend by Transit Mode

\section{0,000}

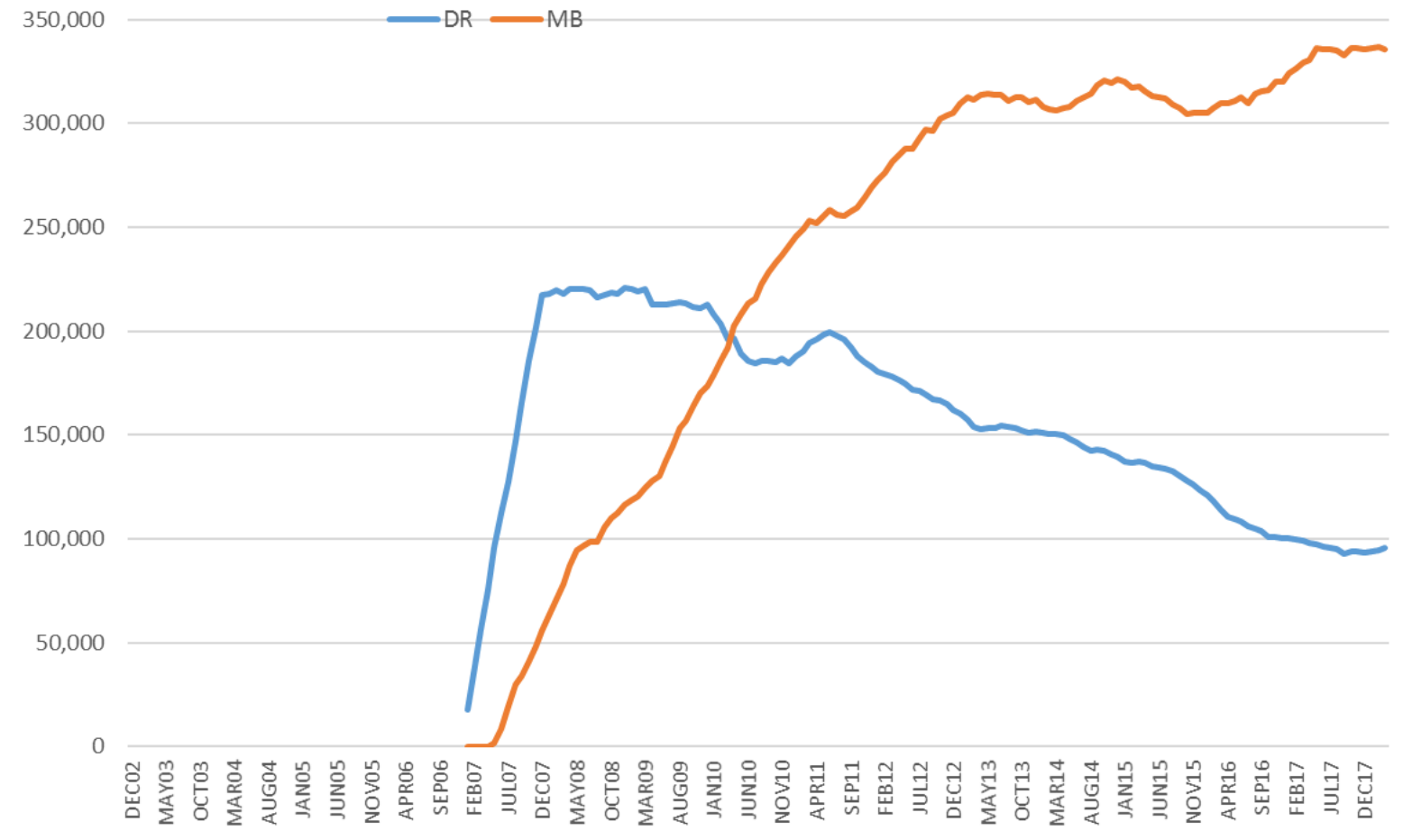


The final graphic shows service supply as measured by revenue vehicle miles of service. As the graphical data communicates, bus service supply has remained stable over the past year and grown $43 \%$ over three years. Demand responsive service has declined $5 \%$ and $30 \%$ respectively in the one in three year periods.

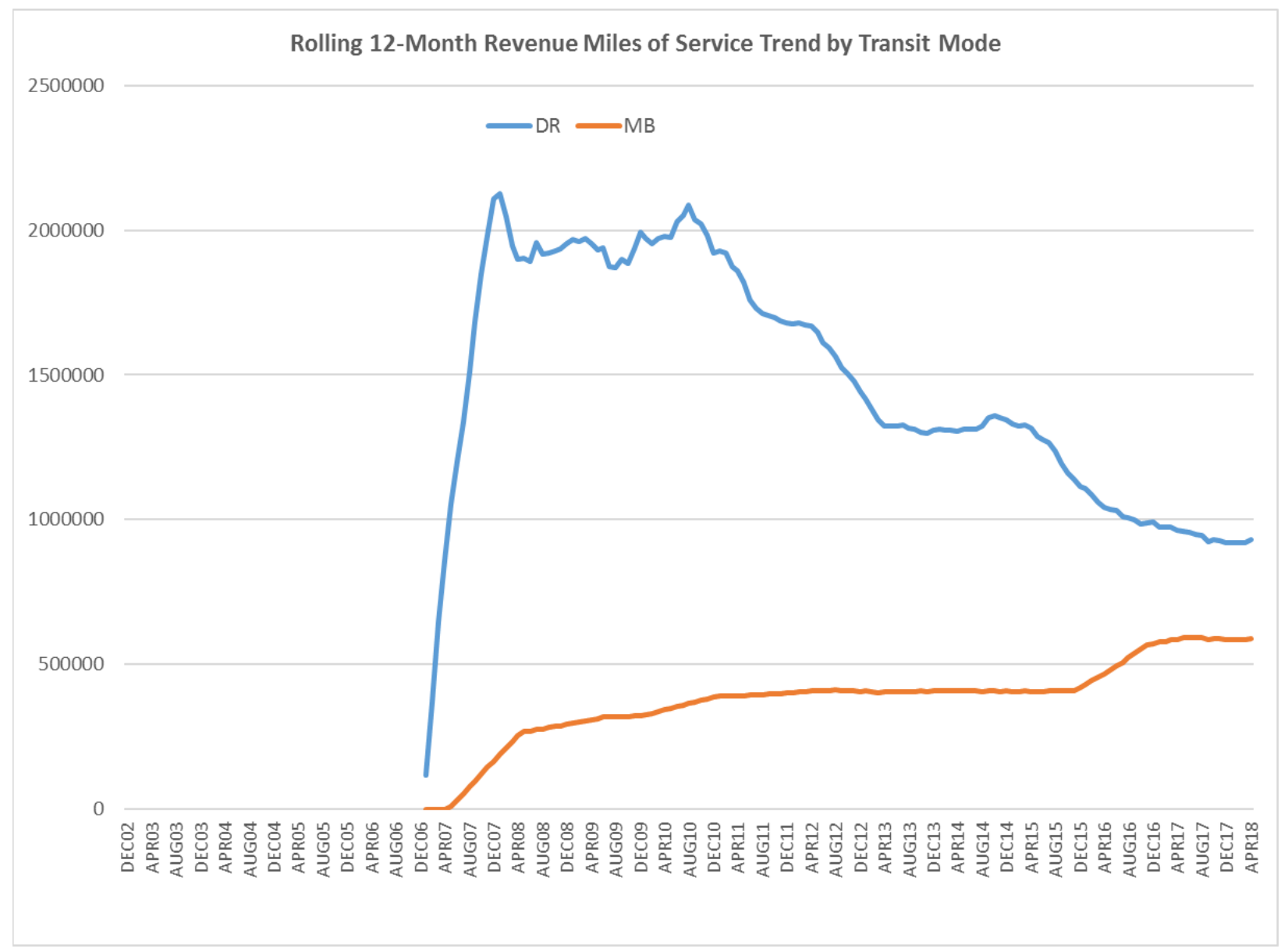


Ocala (City of Ocala, SunTran)

Ridership on the Ocala transit system has declined $5 \%$ since a peak in 2014. Vehicle revenue miles of service has declined $2 \%$ in that same time period. Boardings per revenue mile has dropped $14 \%$ since its peak in 2011. Ridership per County resident has declined $8 \%$ from its peak in 2014.

\section{Average trip length on transit} has been 5 to 6 miles in length.

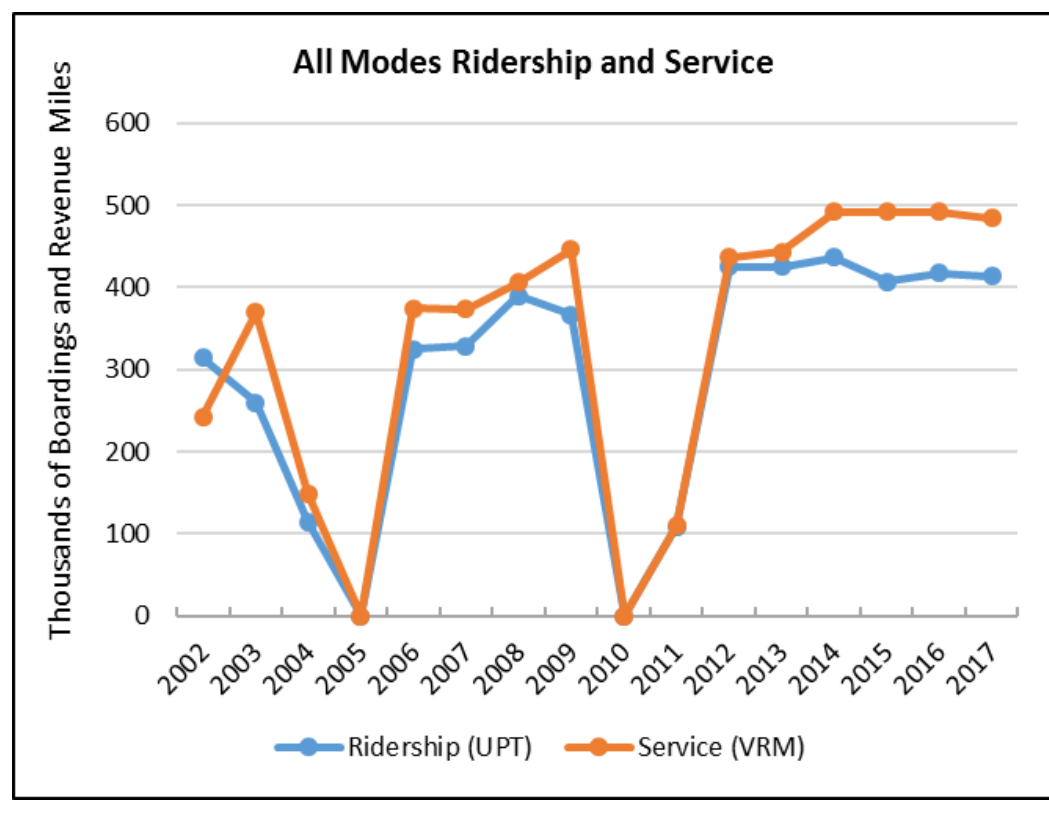

\begin{tabular}{|c|c|c|c|c|c|c|c|c|}
\hline \multicolumn{9}{|c|}{ Annual Trend Data, All Modes } \\
\hline Year & Ridership (UPT) & Service (VRM) & $\begin{array}{l}\text { Boardings per } \\
\text { Revenue Mile }\end{array}$ & $\begin{array}{l}\text { AVG Fixed- } \\
\text { Route } \\
\text { Speed } \\
\text { (mph) }\end{array}$ & $\begin{array}{c}\text { County } \\
\text { Population }\end{array}$ & $\begin{array}{l}\text { Trips per } \\
\text { Capita }\end{array}$ & $\begin{array}{c}\text { Passenger } \\
\text { Miles of } \\
\text { Travel }\end{array}$ & $\begin{array}{l}\text { Average } \\
\text { Trip } \\
\text { Length }\end{array}$ \\
\hline 2002 & 313,789 & 242,508 & 1.29 & 16.77 & 271,096 & 1.2 & $1,080,245$ & 3.44 \\
\hline 2003 & 259,819 & 369,742 & 0.70 & 15.84 & 281,966 & 0.9 & $1,324,281$ & 5.10 \\
\hline 2004 & 114,605 & 148,675 & 0.77 & 14.86 & 293,317 & 0.4 & $1,441,338$ & 12.58 \\
\hline 2005 & na & na & & & 304,926 & na & $1,490,590$ & \\
\hline 2006 & 324,537 & 374,278 & 0.87 & 15.65 & 315,074 & 1.0 & $1,178,993$ & 3.63 \\
\hline 2007 & 328,628 & 373,887 & 0.88 & 15.58 & 325,023 & 1.0 & $1,079,877$ & 3.29 \\
\hline 2008 & 390,108 & 405,968 & 0.96 & 15.65 & 329,418 & 1.2 & na & na \\
\hline 2009 & 366,707 & 446,016 & 0.82 & 15.97 & 330,440 & 1.1 & na & na \\
\hline 2010 & na & na & & & 331,290 & na & na & na \\
\hline 2011 & 108,803 & 109,576 & 0.99 & 15.81 & 331,745 & 0.3 & na & na \\
\hline 2012 & 425,402 & 436,904 & 0.97 & 15.70 & 332,989 & 1.3 & $2,234,935$ & 5.25 \\
\hline 2013 & 425,457 & 443,297 & 0.96 & 15.74 & 335,008 & 1.3 & $2,250,998$ & 5.29 \\
\hline 2014 & 436,636 & 492,268 & 0.89 & 15.62 & 337,455 & 1.3 & $2,469,956$ & 5.66 \\
\hline 2015 & 406,958 & 492,185 & 0.83 & 15.62 & 341,205 & 1.2 & $2,453,325$ & 6.03 \\
\hline 2016 & 417,834 & 492,127 & 0.85 & 15.67 & 345,749 & 1.2 & $2,351,090$ & 5.63 \\
\hline 2017 & 413,892 & 484,246 & 0.85 & 15.63 & 349,267 & 1.2 & & \\
\hline
\end{tabular}


The monthly ridership trend shows some influence from hurricane Irma. Ridership for the first four months of 2018 has been running approximately $1 \%$ ahead of last year.

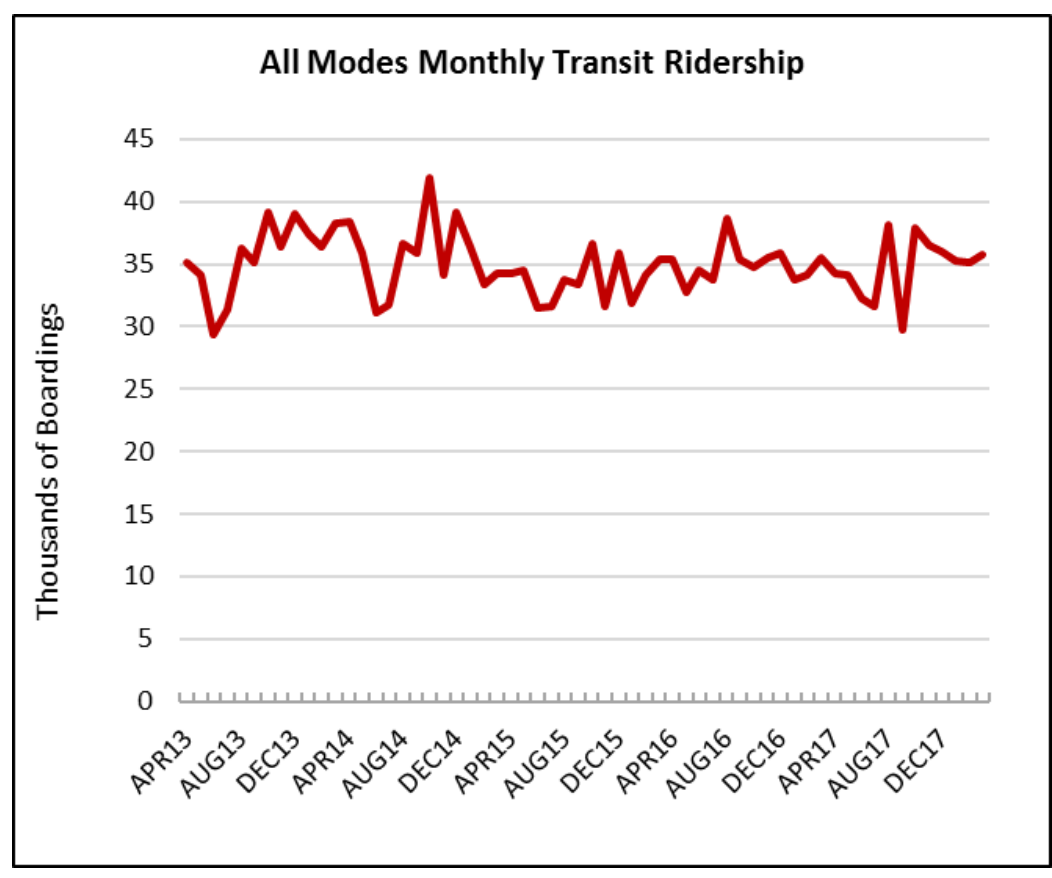

Average operating speed, defined as vehicle revenue miles divided by vehicle revenue hours, has been averaging nearly $16 \mathrm{mph}$, a relatively fast speed for transit service.

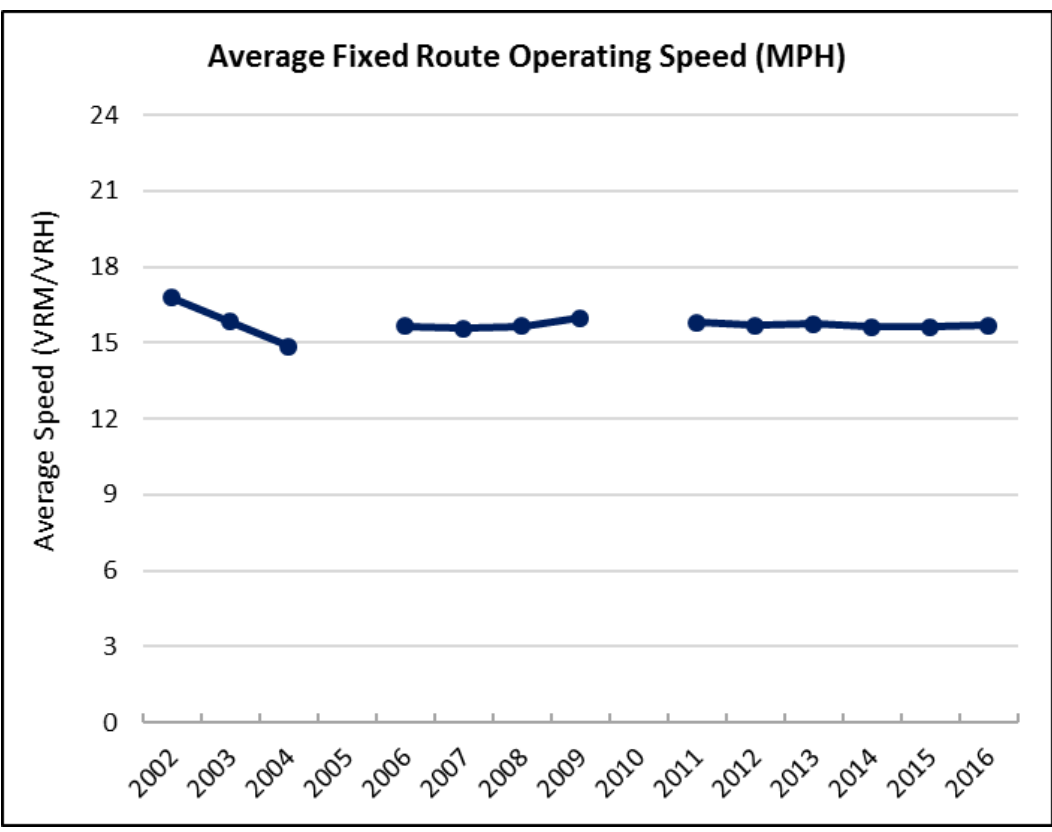


The adjacent graphic shows service productivity. Service productivity has declined modestly since 2015 .

The figures below provide the ridership trends and service supply trends by sub mode. This allows one to understand how the various component modes are performing.

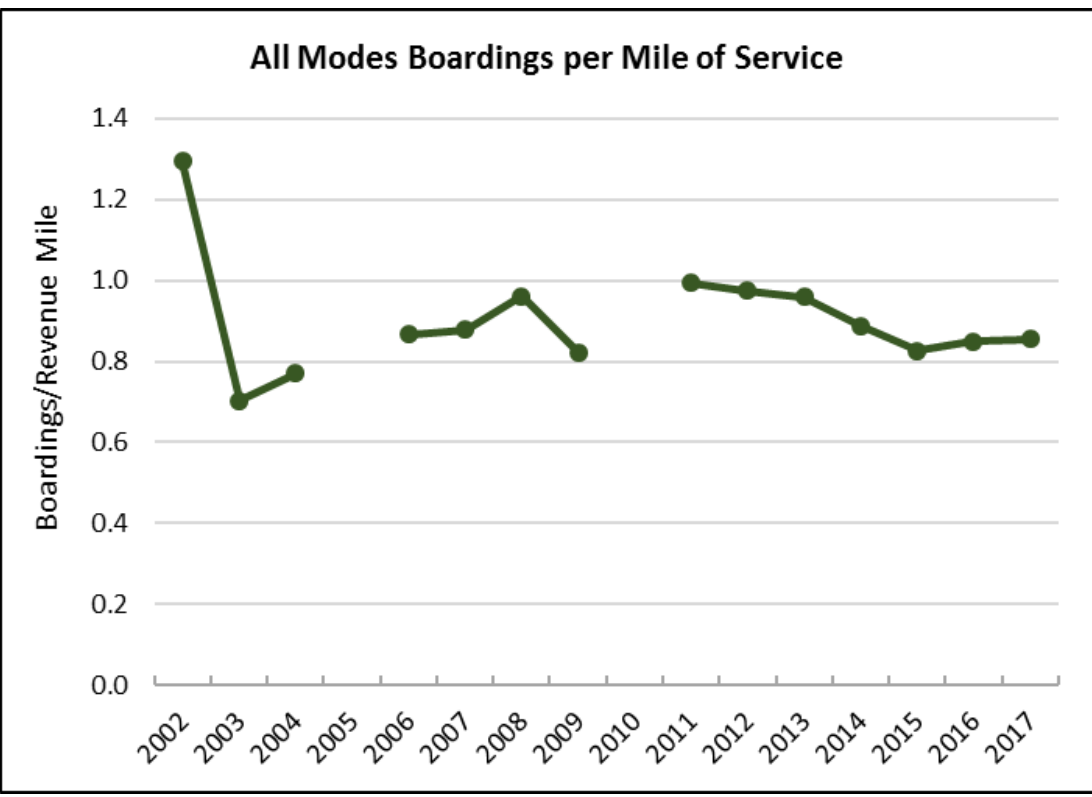

Bus ridership has declined approximately $1 \%$ over one year and $3 \%$ over three years. The graphics irregularities are due to missing data.

\section{Rolling 12-Month Ridership Trend by Transit Mode}

\section{0,000}

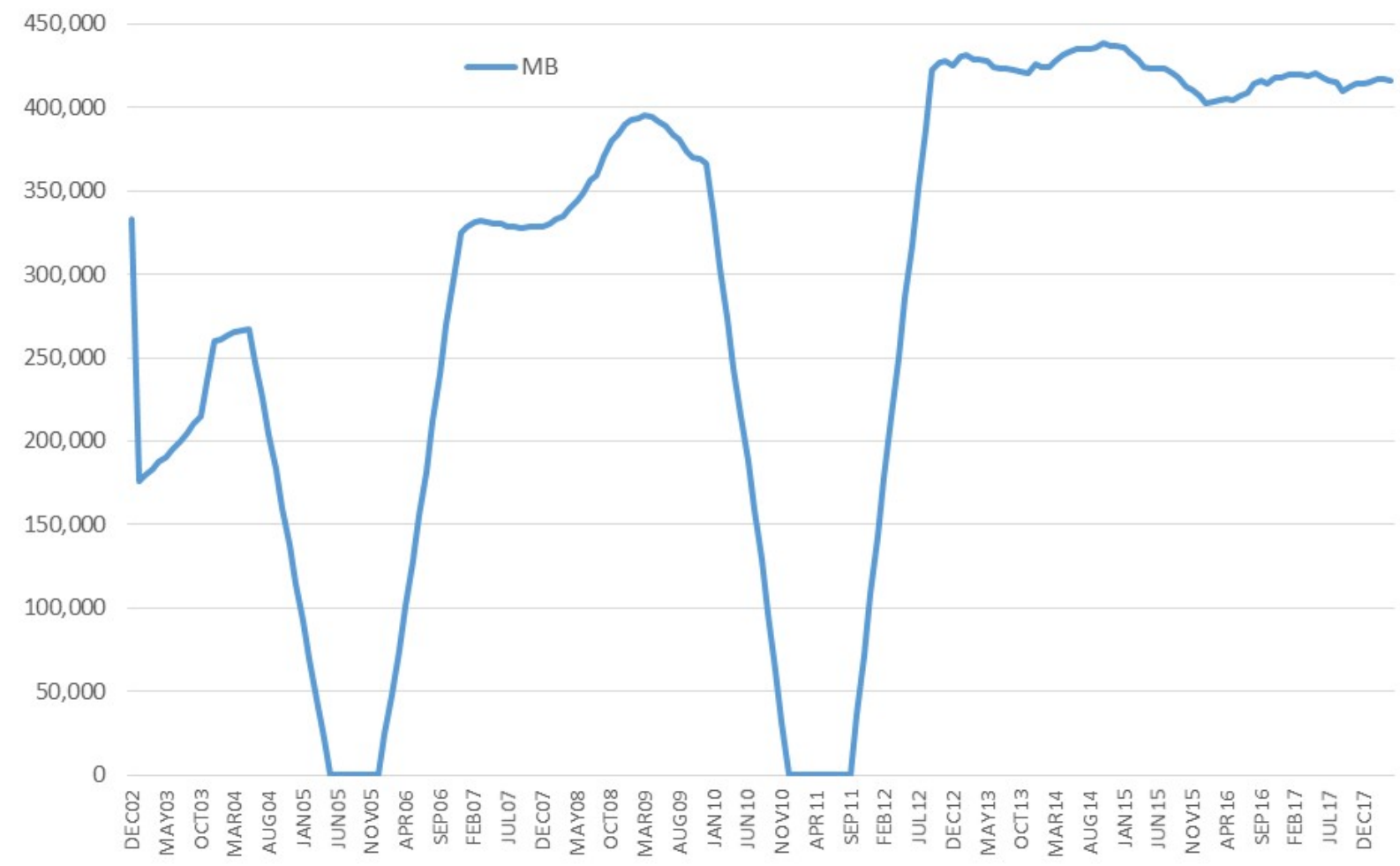


The final graphic shows service supply as measured by revenue vehicle miles of service. As the graphical data communicates, bus service supply has declined $1 \%$ in the past year and $1 \%$ over three years..

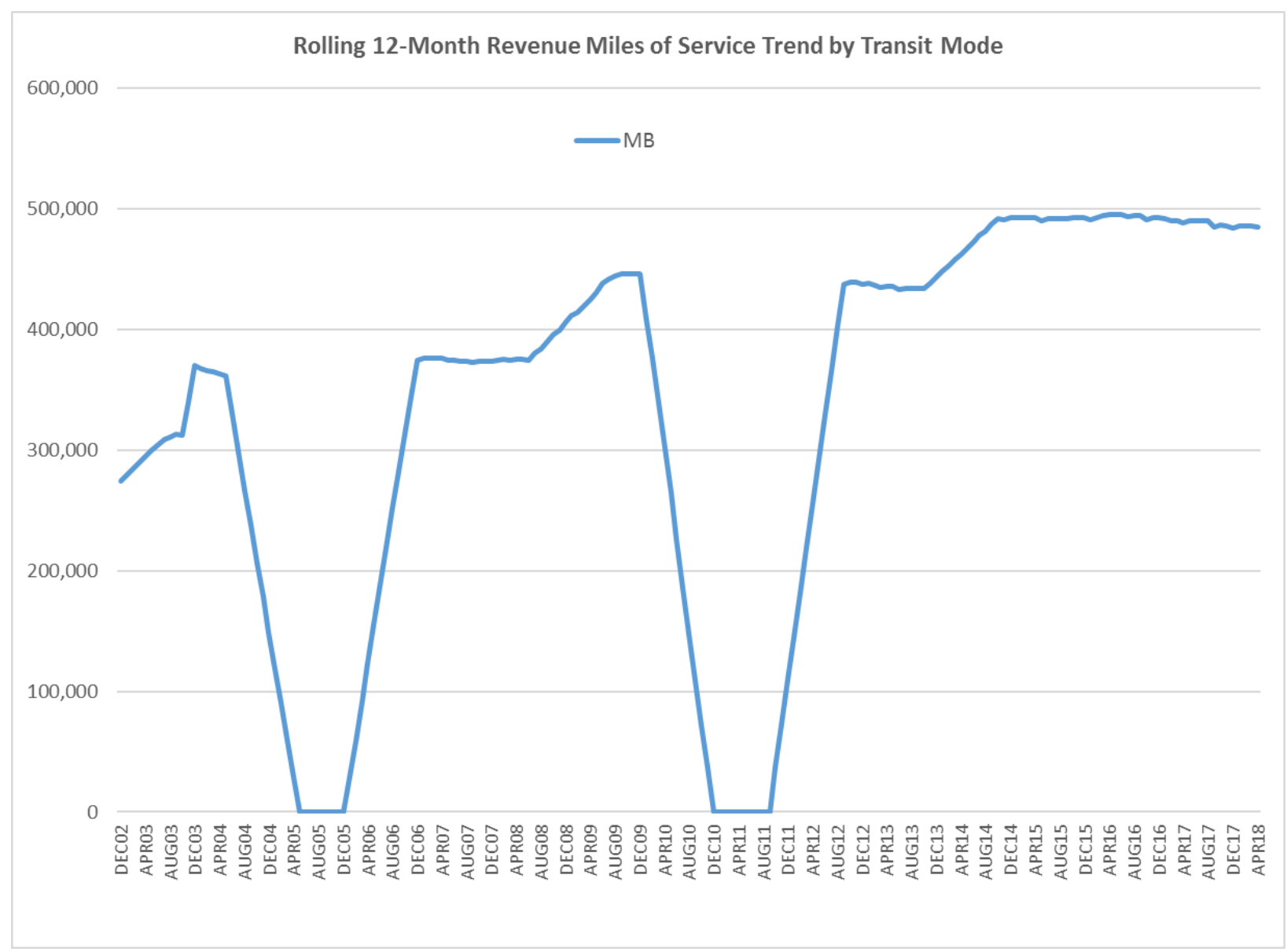


St. Lucie County (Council on Aging of St. Lucie, Inc., Treasure Coast Connector)

Ridership on the St. Lucie transit system has grown since 2011 with a peak ridership in 2017. Vehicle revenue miles of service has similarly increased. All performance metrics including service productivity and utilization per capita were at their peaks in 2017.

Average trip length on transit has

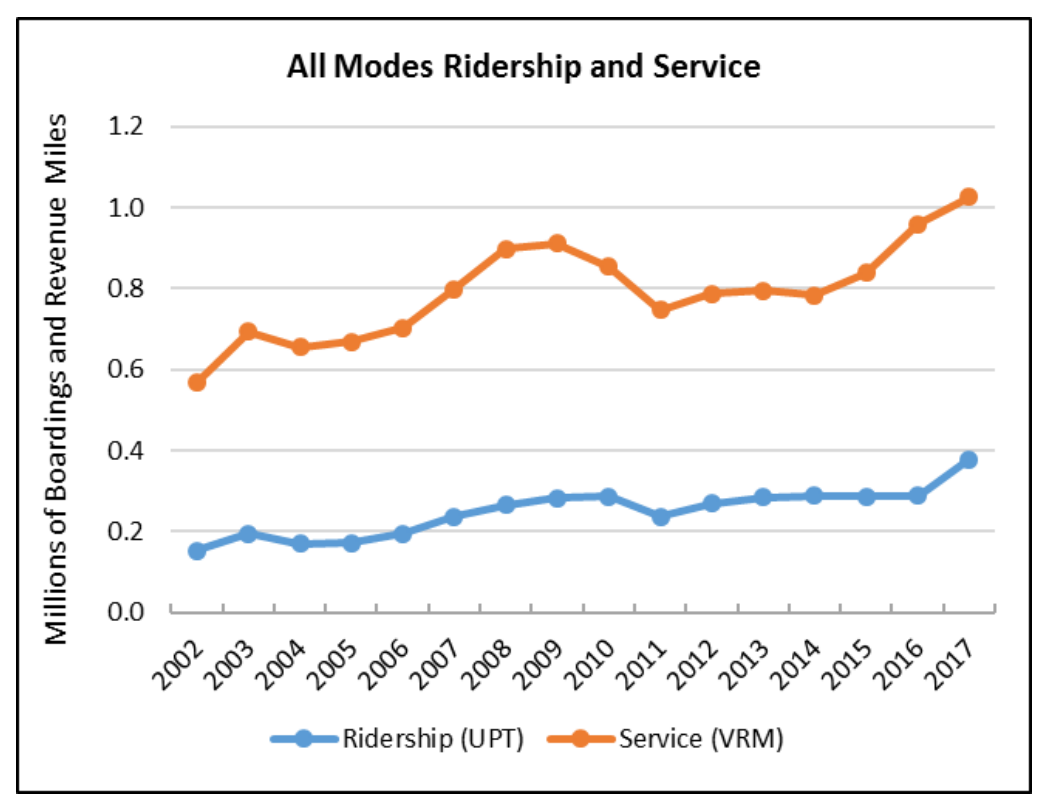
been relatively stable in the past three years at nearly 11 miles.

\begin{tabular}{|c|c|c|c|c|c|c|c|c|}
\hline \multicolumn{9}{|c|}{ Annual Trend Data, All Modes } \\
\hline Year & Ridership (UPT) & Service (VRM) & $\begin{array}{l}\text { Boardings per } \\
\text { Revenue Mile }\end{array}$ & $\begin{array}{l}\text { AVG Fixed- } \\
\text { Route } \\
\text { Speed } \\
\text { (mph) }\end{array}$ & $\begin{array}{c}\text { County } \\
\text { Population }\end{array}$ & $\begin{array}{c}\text { Trips per } \\
\text { Capita }\end{array}$ & $\begin{array}{c}\text { Passenger } \\
\text { Miles of } \\
\text { Travel }\end{array}$ & $\begin{array}{c}\text { Average } \\
\text { Trip } \\
\text { Length }\end{array}$ \\
\hline 2002 & 152,143 & 567,059 & 0.27 & 16.01 & 203,360 & 0.7 & 681,466 & 4.48 \\
\hline 2003 & 194,759 & 692,849 & 0.28 & 16.07 & 211,898 & 0.9 & 758,061 & 3.89 \\
\hline 2004 & 169,598 & 655,849 & 0.26 & 15.31 & 226,216 & 0.7 & 740,439 & 4.37 \\
\hline 2005 & 171,616 & 668,348 & 0.26 & 9.97 & 240,039 & 0.7 & 683,920 & 3.99 \\
\hline 2006 & 194,800 & 702,814 & 0.28 & 10.18 & 259,315 & 0.8 & $1,088,919$ & 5.59 \\
\hline 2007 & 236,291 & 799,571 & 0.30 & 11.53 & 271,961 & 0.9 & $1,220,106$ & 5.16 \\
\hline 2008 & 264,068 & 897,700 & 0.29 & 13.55 & 276,585 & 1.0 & $1,264,585$ & 4.79 \\
\hline 2009 & 282,522 & 911,163 & 0.31 & 13.40 & 272,864 & 1.0 & $1,573,630$ & 5.57 \\
\hline 2010 & 286,382 & 854,247 & 0.34 & 13.98 & 278,689 & 1.0 & $1,929,055$ & 6.74 \\
\hline 2011 & 236,472 & 747,306 & 0.32 & 14.34 & 279,696 & 0.8 & $1,655,012$ & 7.00 \\
\hline 2012 & 268,009 & 786,617 & 0.34 & 14.15 & 280,355 & 1.0 & $1,994,743$ & 7.44 \\
\hline 2013 & 283,931 & 795,576 & 0.36 & 14.18 & 281,151 & 1.0 & $2,539,723$ & 8.94 \\
\hline 2014 & 288,559 & 784,355 & 0.37 & 14.11 & 282,821 & 1.0 & $3,096,472$ & 10.73 \\
\hline 2015 & 286,043 & 839,544 & 0.34 & 14.24 & 287,749 & 1.0 & $2,945,576$ & 10.30 \\
\hline 2016 & 287,679 & 958,720 & 0.30 & 14.83 & 292,826 & 1.0 & $3,153,473$ & 10.96 \\
\hline 2017 & 377,949 & $1,027,117$ & 0.37 & 15.98 & 297,634 & 1.3 & & \\
\hline
\end{tabular}


The monthly ridership trend shows a steep ridership months. Ridership for the first four months of 2018 has been running approximately $95 \%$ ahead of last year. increase over the past several

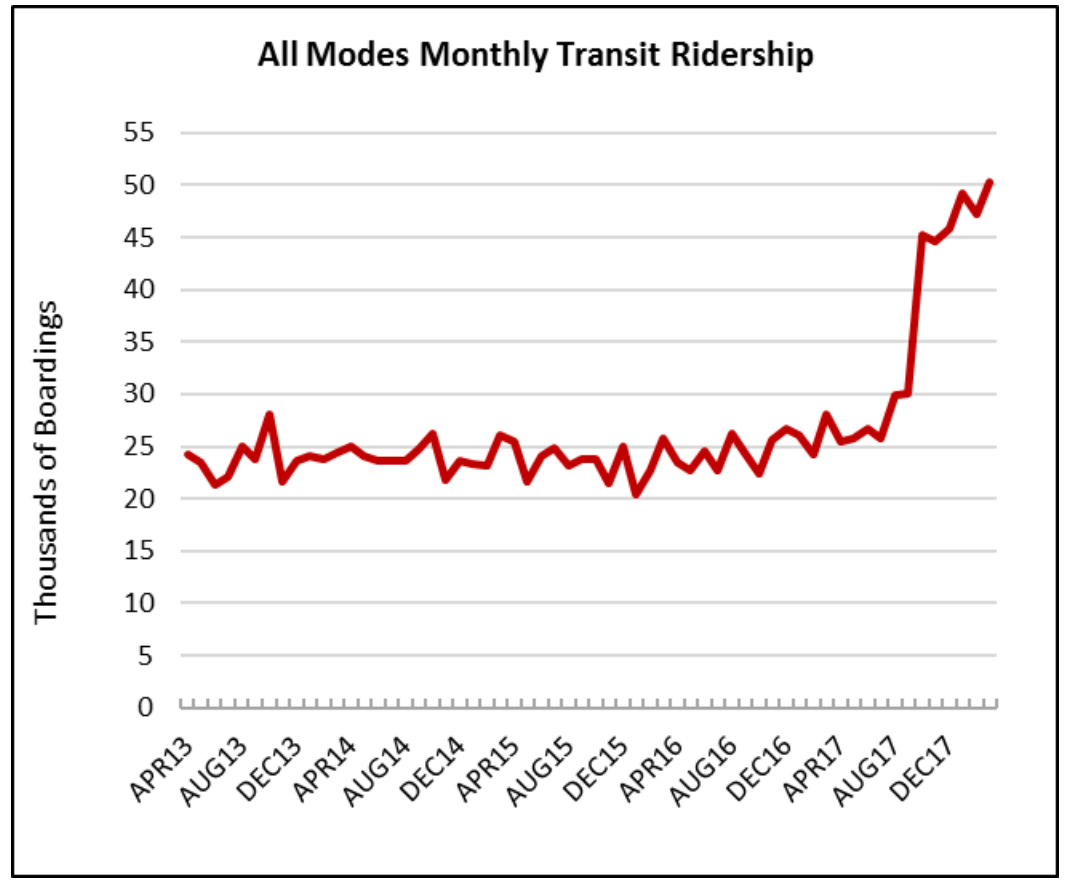

Average operating speed, defined as vehicle revenue miles divided by vehicle revenue hours, has been increasing to nearly $16 \mathrm{mph}$, a relatively fast speed for transit service.

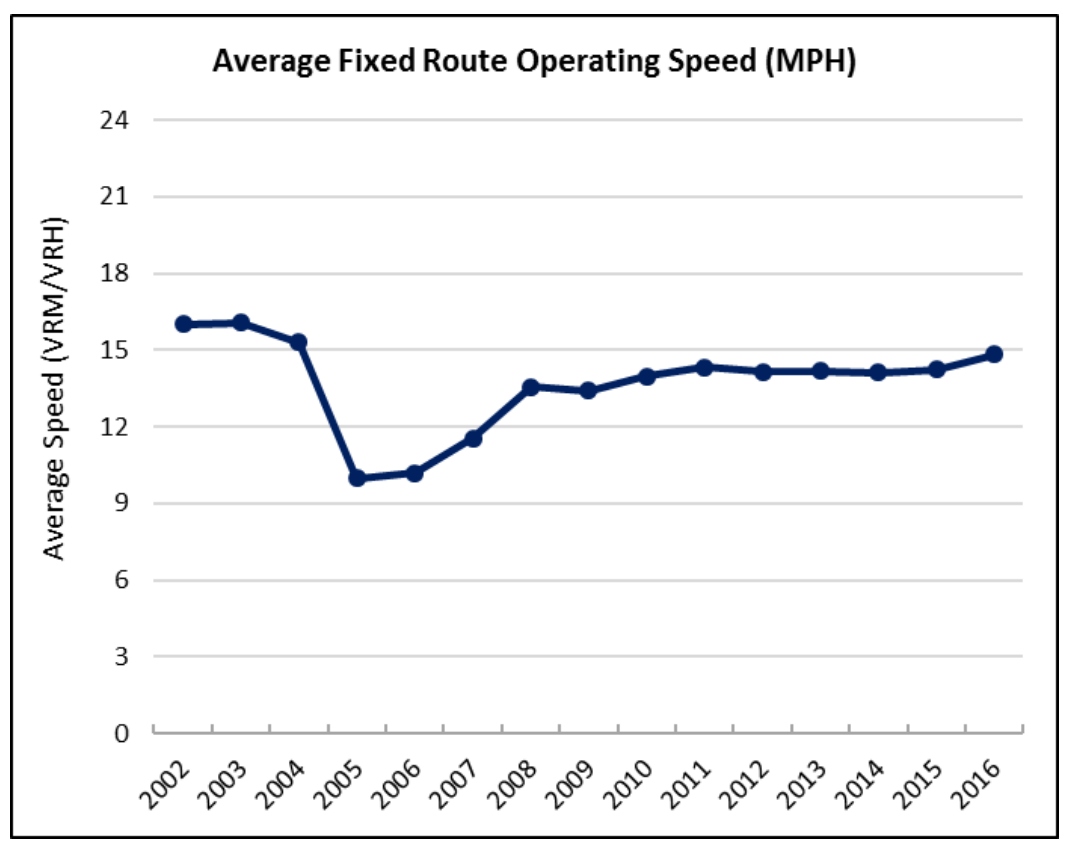


The adjacent graphic shows service productivity. Service productivity has generally trended upward with a dip in 2016 and bounce back in 2017.

The figures below provide the ridership trends and service supply trends by sub mode. This allows one to understand how the various component modes are performing.

Bus ridership has increased

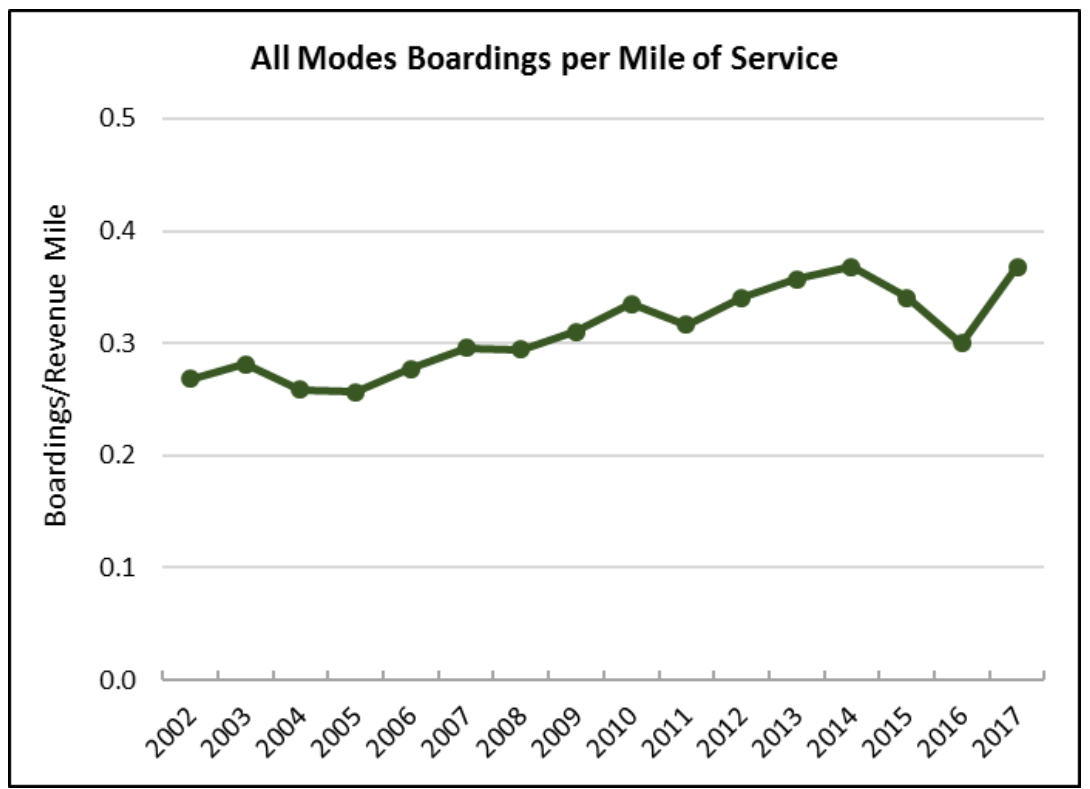
approximately $74 \%$ over one year and $83 \%$ over three years. Demand responsive service has increased $2 \%$ in the last year and $1 \%$ over the past three.

\section{Rolling 12-Month Ridership Trend by Transit Mode}

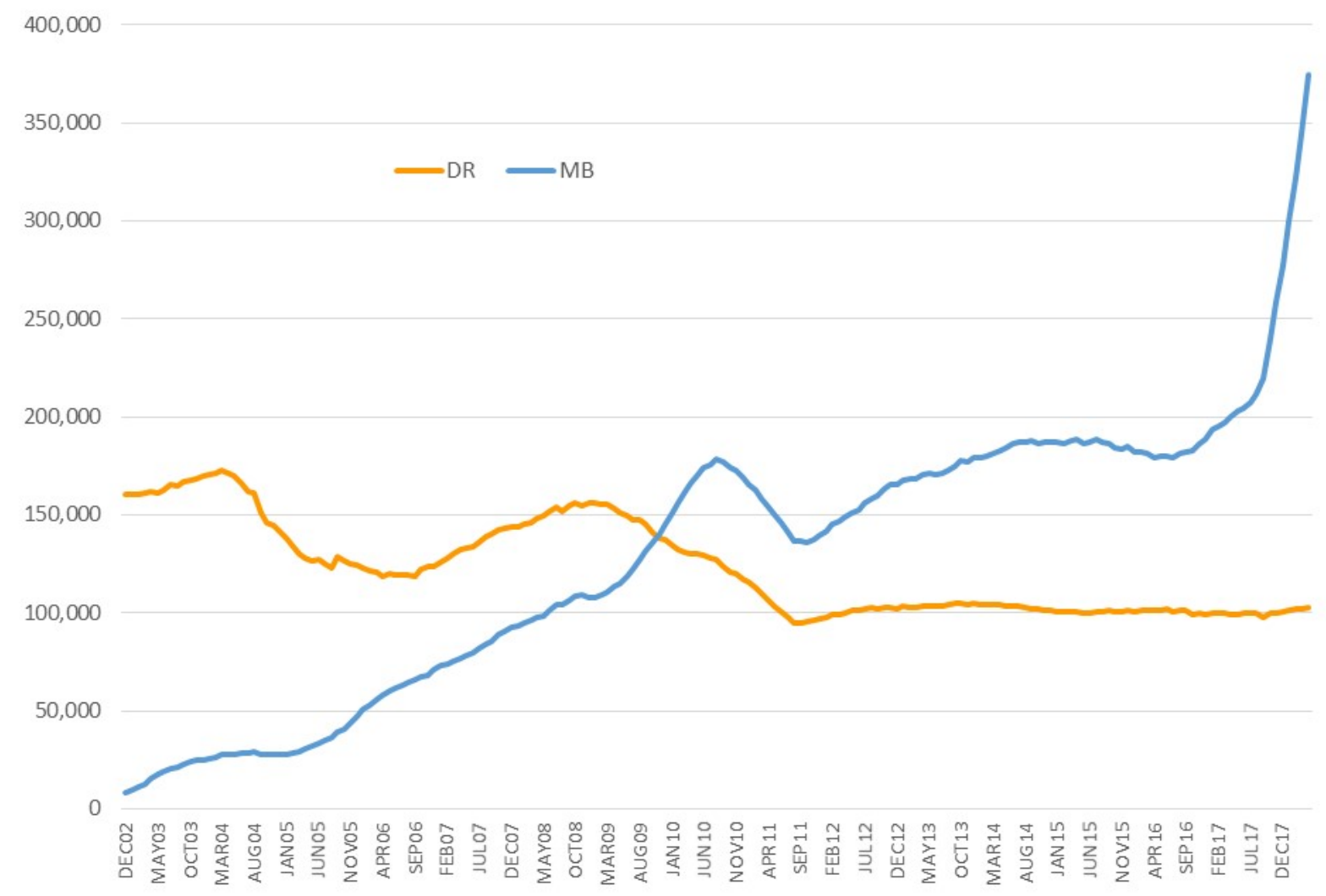


The final graphic shows service supply as measured by revenue vehicle miles of service. As the graphical data communicates, bus service supply has increased $14 \%$ in the past year and $61 \%$ over three years. Demand responsive service has declined $2 \%$ and $8 \%$ respectively in the one in three year periods. And vanpool service has been stable over the past year and grown $12 \%$ over three years.

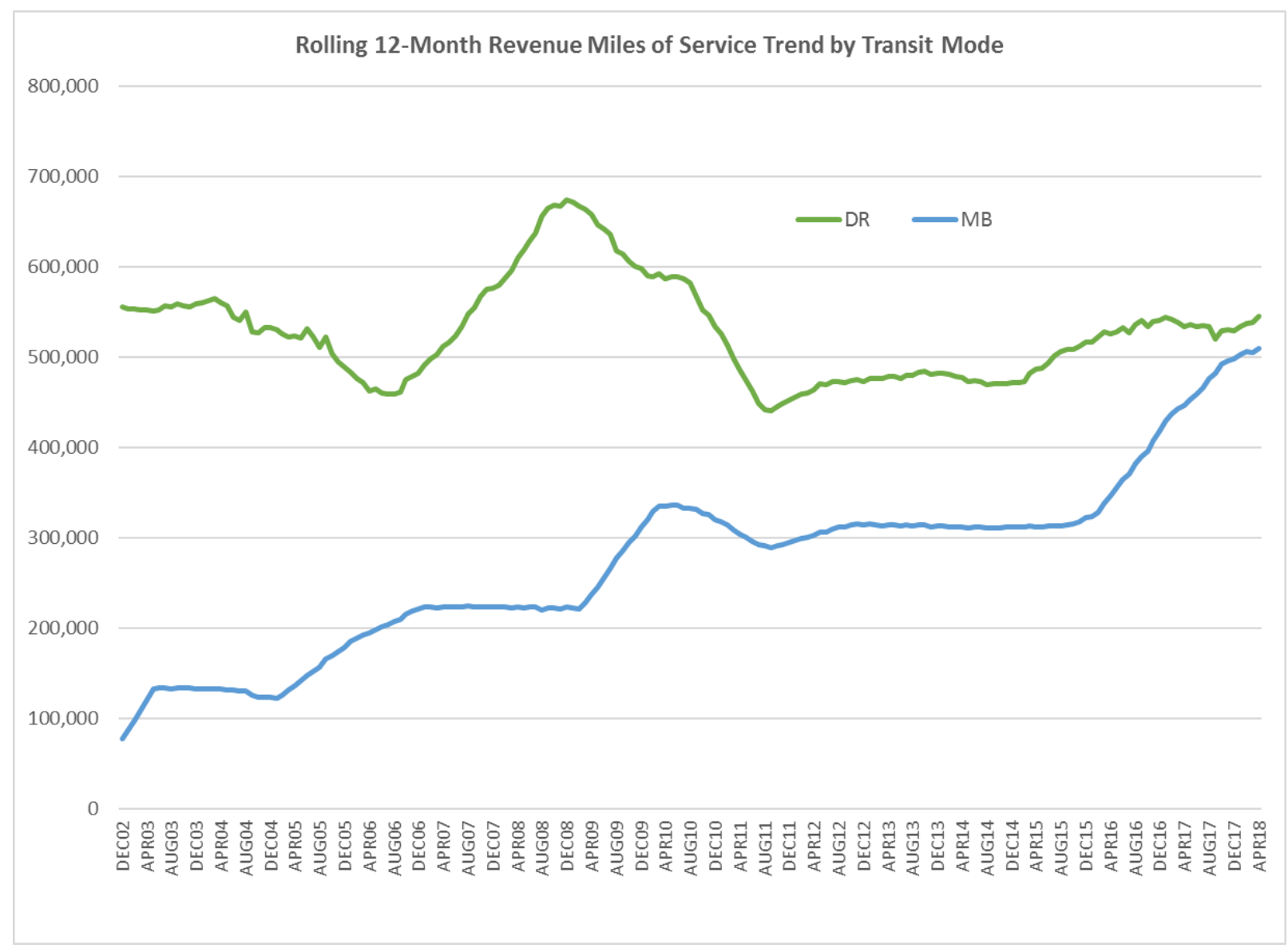


Fort Lauderdale (City of Fort Lauderdale Transit)

Fort Lauderdale City reported ferry boat and motor bus service independently from October 2014 through present. Ridership on the system has declined $18 \%$ since a peak in 2016. Vehicle revenue miles of service has been steady in that same time period.

Boardings per revenue mile has dropped $31 \%$ since its peak in 2015. Ridership per County resident was .23 trips

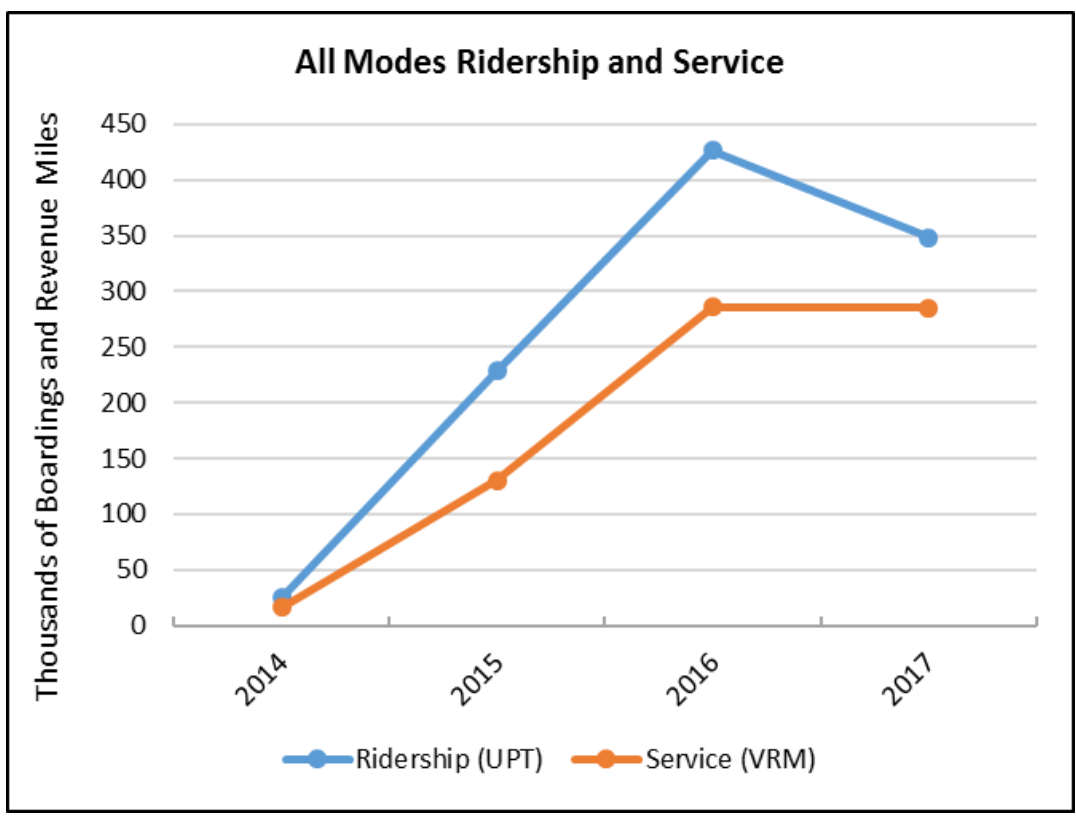
per capita in 2016.

Average trip length on transit has been is 3 miles based on 2016 data.

\begin{tabular}{|c|c|c|c|c|c|c|c|c|}
\hline \multicolumn{9}{|c|}{ Annual Trend Data, All Modes } \\
\hline Year & Ridership (UPT) & Service (VRM) & $\begin{array}{l}\text { Boardings per } \\
\text { Revenue Mile }\end{array}$ & $\begin{array}{l}\text { AVG Fixed- } \\
\text { Route } \\
\text { Speed } \\
\text { (mph) }\end{array}$ & $\begin{array}{c}\text { County } \\
\text { Population }\end{array}$ & $\begin{array}{c}\text { Trips per } \\
\text { Capita }\end{array}$ & $\begin{array}{c}\text { Passenger } \\
\text { Miles of } \\
\text { Travel }\end{array}$ & $\begin{array}{c}\text { Average } \\
\text { Trip } \\
\text { Length }\end{array}$ \\
\hline \multicolumn{9}{|l|}{2002} \\
\hline \multicolumn{9}{|l|}{2003} \\
\hline \multicolumn{9}{|l|}{2004} \\
\hline \multicolumn{9}{|l|}{2005} \\
\hline \multicolumn{9}{|l|}{2006} \\
\hline \multicolumn{9}{|l|}{2007} \\
\hline \multicolumn{9}{|l|}{2008} \\
\hline \multicolumn{9}{|l|}{2009} \\
\hline \multicolumn{9}{|l|}{2010} \\
\hline \multicolumn{9}{|l|}{2011} \\
\hline \multicolumn{9}{|l|}{2012} \\
\hline \multicolumn{9}{|l|}{2013} \\
\hline 2014 & 24,931 & 15,882 & 1.57 & 8.32 & $1,803,903$ & 0.01 & & 0.00 \\
\hline 2015 & 228,717 & 130,043 & 1.76 & 8.80 & $1,827,367$ & 0.13 & 155,006 & 0.68 \\
\hline 2016 & 426,692 & 285,652 & 1.49 & 9.33 & $1,854,513$ & 0.23 & 1,333,012 & 3.12 \\
\hline 2017 & 348,037 & 285,369 & 1.22 & 9.49 & $1,873,970$ & 0.19 & & \\
\hline
\end{tabular}


The monthly ridership trend shows the influence of hurricane Irma. Ridership for the first four months of 2018 has been running will approximately $10 \%$ behind last year.

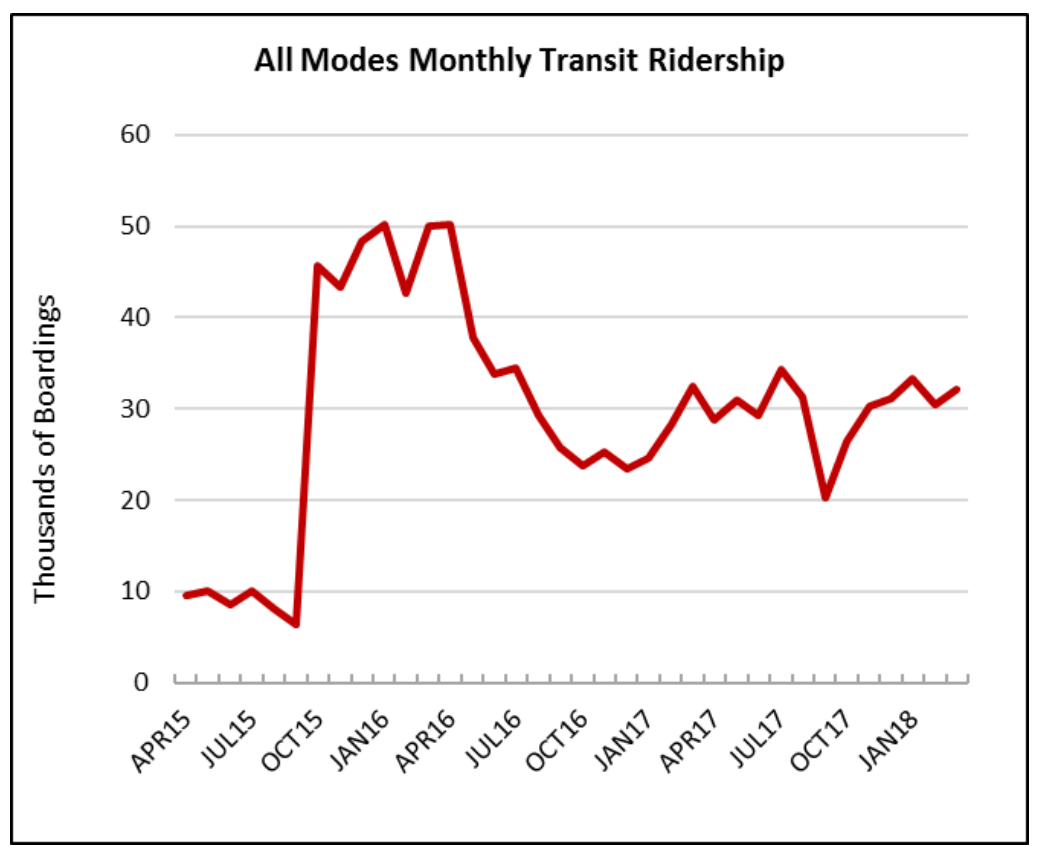

Average operating speed, defined as vehicle revenue miles divided by vehicle revenue hours, has been averaging nearly $19 \mathrm{mph}$, a relatively fast speed for transit service.

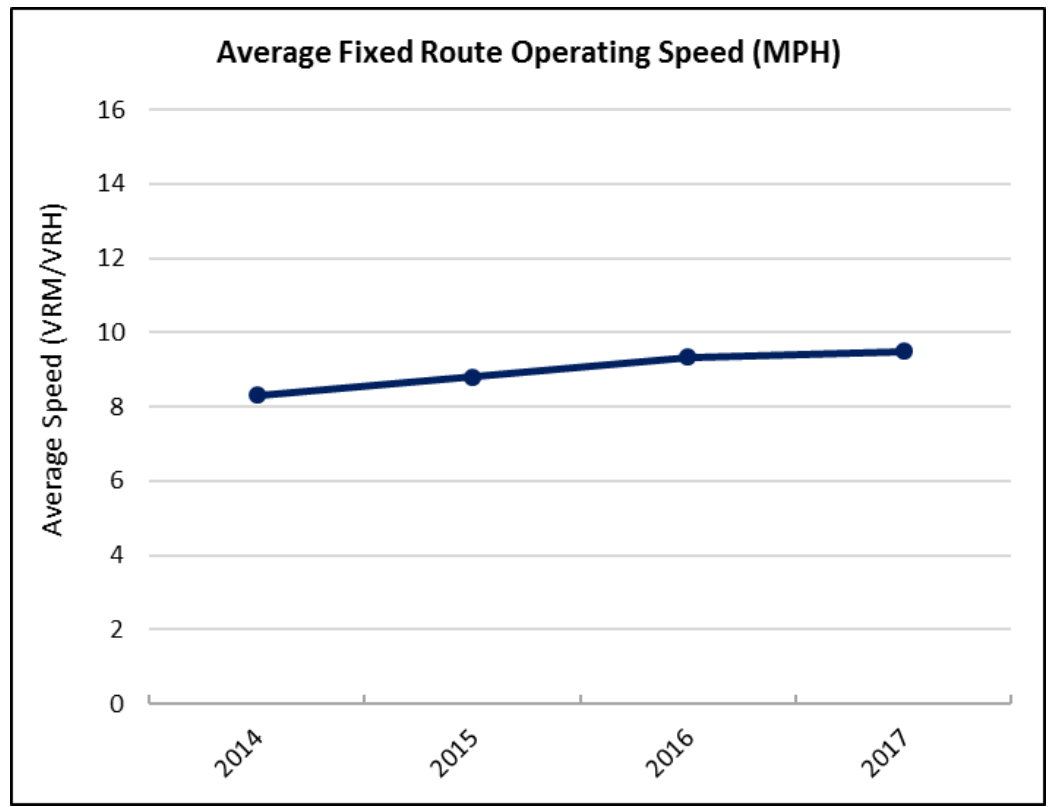


The adjacent graphic shows service productivity. Service productivity has declined modestly since 2015.

The figures below provide the ridership trends and service supply trends by sub mode. This allows one to understand how

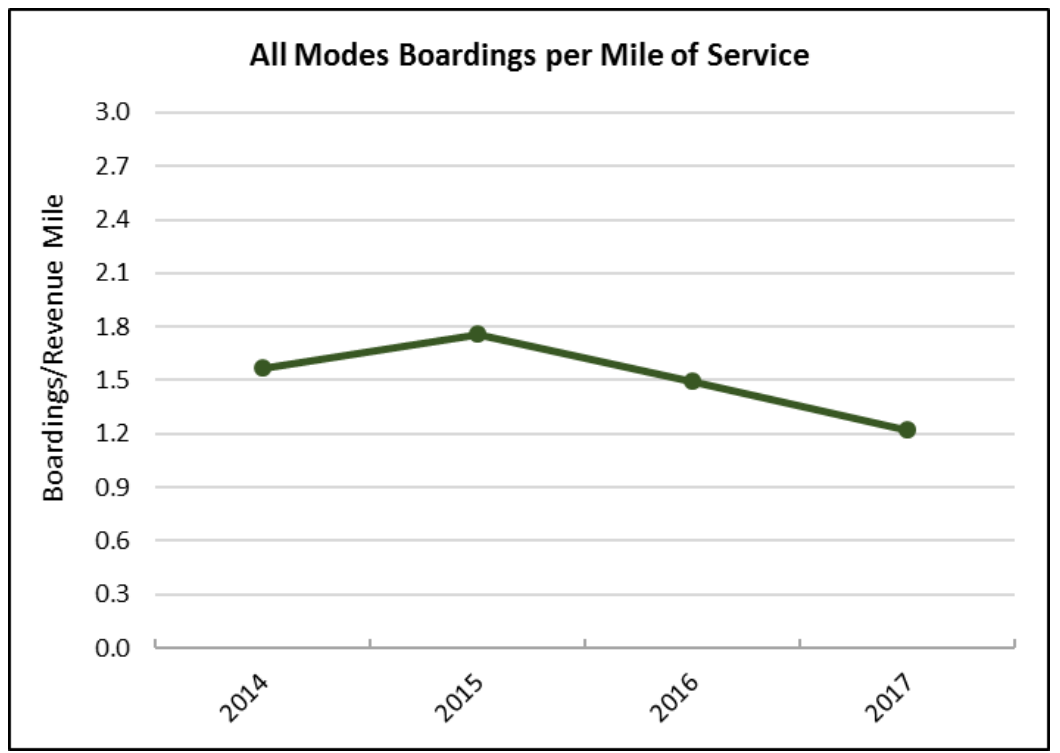
the various component modes are performing.

Bus ridership has increased approximately 5\% over one year and has increased $120 \%$ over three years. Ferryboat service has declined 33\% in the last year and grown $22 \%$ over the past three.

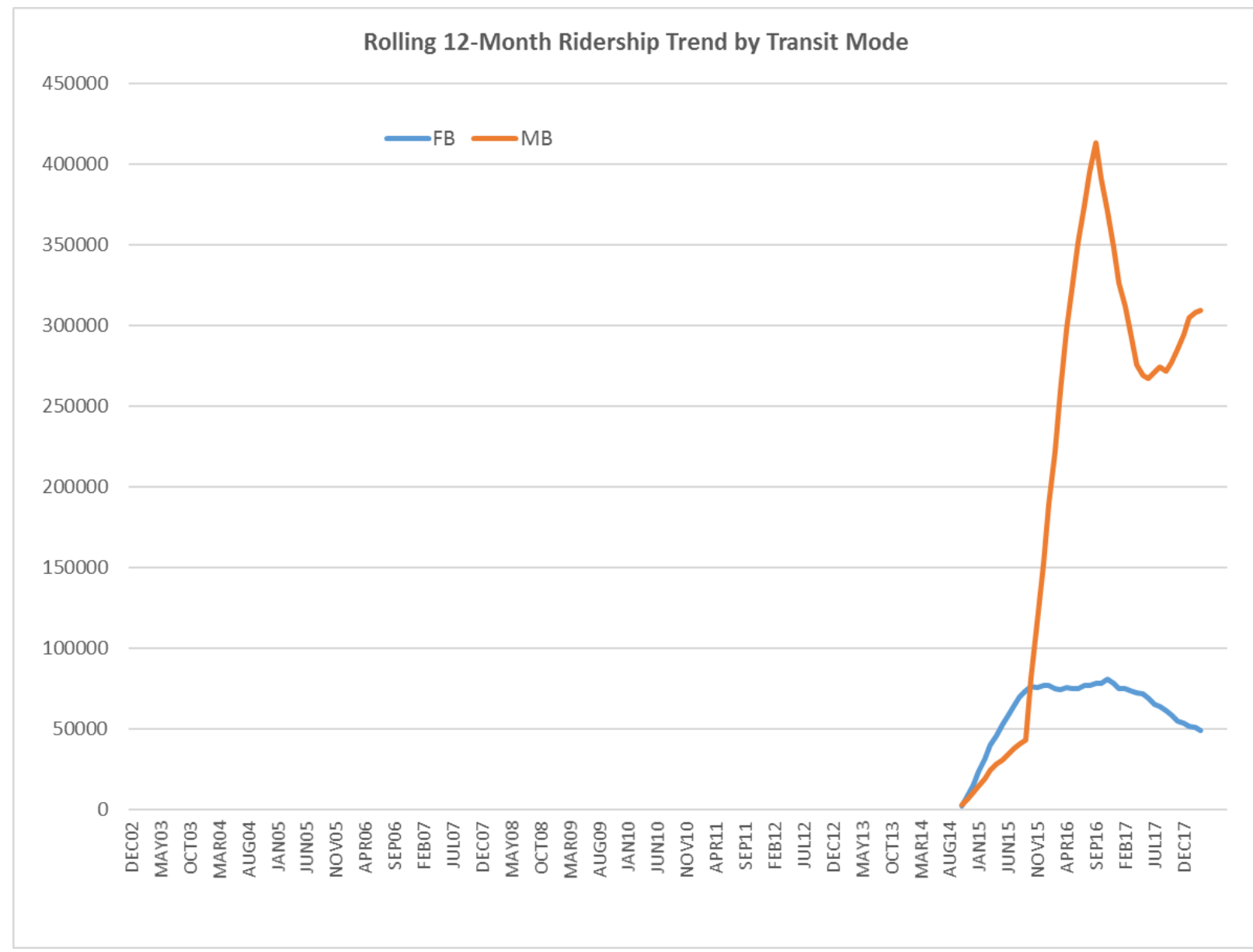


The final graphic shows service supply as measured by revenue vehicle miles of service. As the graphical data communicates, bus service supply has increased $10 \%$ in the past year and increased over $900 \%$ over three years. Ferryboat service has declined $17 \%$ in the past year but grown $92 \%$ in the three year periods.

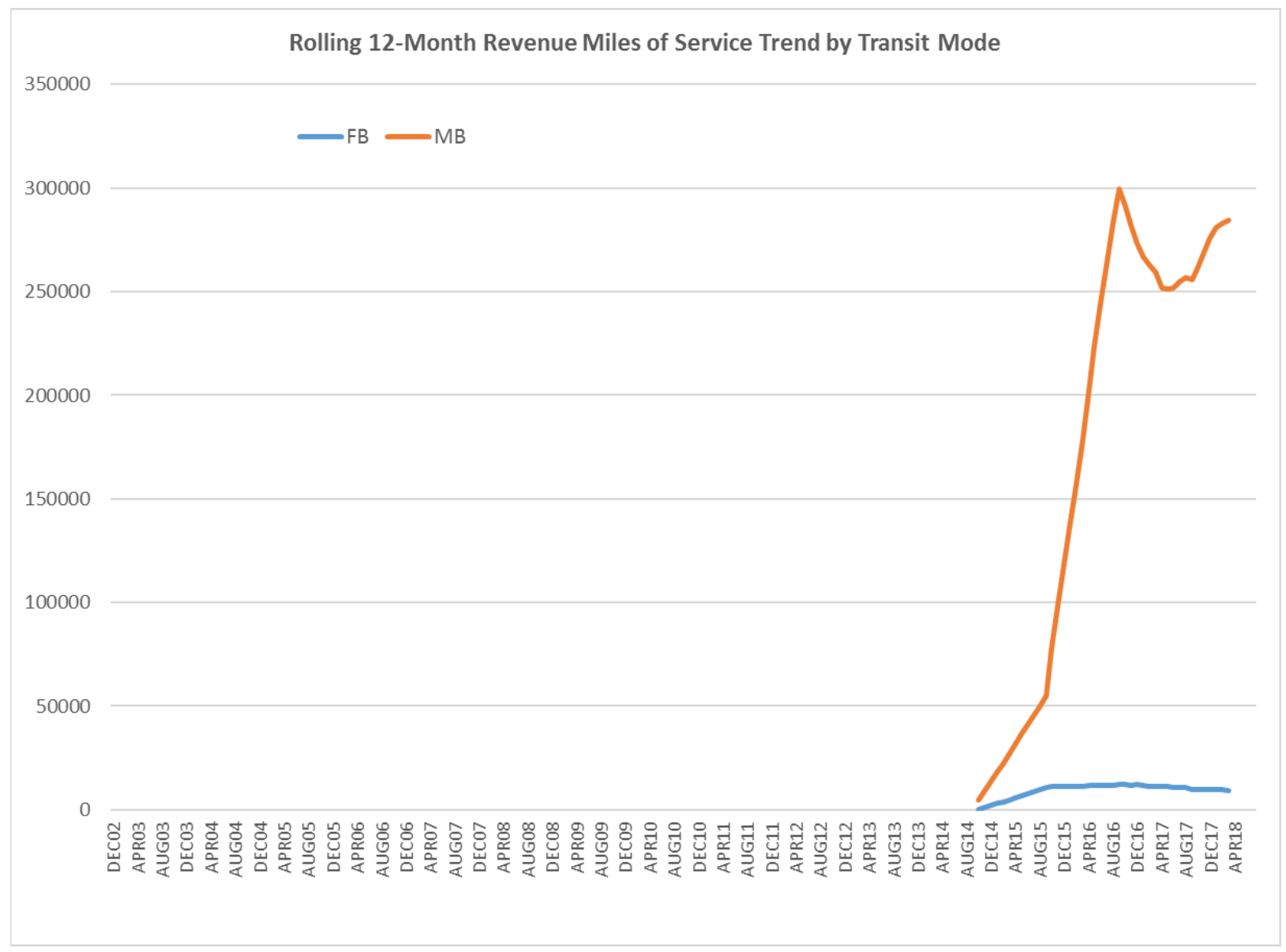


Okaloosa County (Okaloosa County Board of County Commissioners, EC Rider)

Ridership on the Okaloosa transit system has declined 24\% since a peak in 2013. Vehicle revenue miles of service has declined $24 \%$ in that same time period. The Okaloosa system was impacted by declining ridership during the past four years. Boardings per revenue mile has dropped $49 \%$ since its peak in 2008. Ridership per County resident has declined $16 \%$ from its peak in

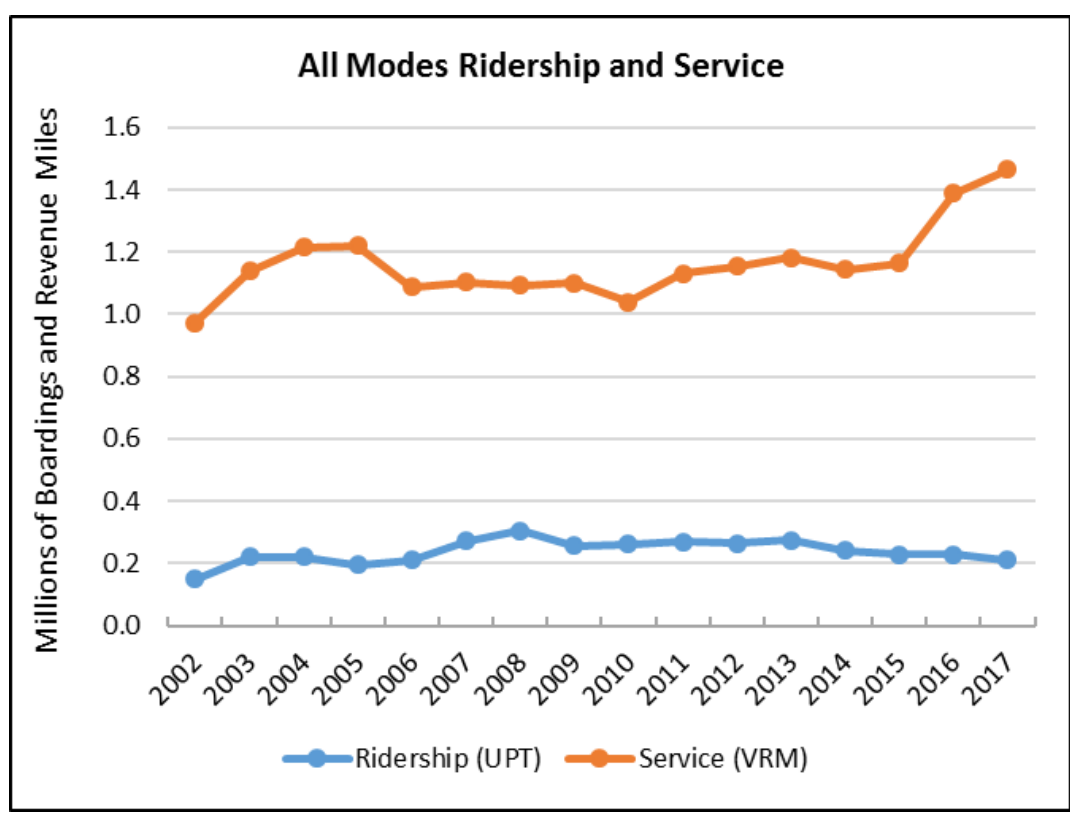
2014.

Average trip length on transit is about 6 miles.

\begin{tabular}{|c|c|c|c|c|c|c|c|c|}
\hline \multicolumn{9}{|c|}{ Annual Trend Data, All Modes } \\
\hline Year & Ridership (UPT) & Service (VRM) & $\begin{array}{l}\text { Boardings per } \\
\text { Revenue Mile }\end{array}$ & $\begin{array}{l}\text { AVG Fixed- } \\
\text { Route } \\
\text { Speed } \\
\text { (mph) }\end{array}$ & $\begin{array}{c}\text { County } \\
\text { Population }\end{array}$ & $\begin{array}{l}\text { Trips per } \\
\text { Capita }\end{array}$ & $\begin{array}{c}\text { Passenger } \\
\text { Miles of } \\
\text { Travel }\end{array}$ & $\begin{array}{c}\text { Average } \\
\text { Trip } \\
\text { Length }\end{array}$ \\
\hline 2002 & 150,386 & 974,054 & 0.15 & 15.35 & 176,971 & 0.8 & $1,301,212$ & 8.65 \\
\hline 2003 & 220,556 & $1,140,117$ & 0.19 & 13.06 & 181,102 & 1.2 & $1,507,108$ & 6.83 \\
\hline 2004 & 221,136 & $1,214,770$ & 0.18 & 4.85 & 185,778 & 1.2 & $1,491,435$ & 6.74 \\
\hline 2005 & 194,266 & $1,220,618$ & 0.16 & 14.04 & 188,939 & 1.0 & $1,327,517$ & 6.83 \\
\hline 2006 & 210,110 & $1,087,134$ & 0.19 & 13.01 & 192,672 & 1.1 & $1,166,626$ & 5.55 \\
\hline 2007 & 272,121 & $1,103,341$ & 0.25 & 13.87 & 196,540 & 1.4 & $1,426,027$ & 5.24 \\
\hline 2008 & 305,699 & $1,093,332$ & 0.28 & 13.49 & 197,597 & 1.5 & $1,756,693$ & 5.75 \\
\hline 2009 & 255,225 & $1,099,469$ & 0.23 & 14.40 & 196,237 & 1.3 & $1,537,153$ & 6.02 \\
\hline 2010 & 260,447 & $1,039,793$ & 0.25 & 11.76 & 180,728 & 1.4 & $1,479,508$ & 5.68 \\
\hline 2011 & 268,166 & $1,131,721$ & 0.24 & 12.62 & 181,679 & 1.5 & $1,449,914$ & 5.41 \\
\hline 2012 & 262,842 & $1,154,897$ & 0.23 & 12.58 & 187,280 & 1.4 & $1,522,052$ & 5.79 \\
\hline 2013 & 273,593 & $1,182,703$ & 0.23 & 12.53 & 188,349 & 1.5 & $1,519,664$ & 5.55 \\
\hline 2014 & 241,280 & $1,145,039$ & 0.21 & 12.63 & 190,666 & 1.3 & $1,478,241$ & 6.13 \\
\hline 2015 & 229,455 & $1,165,221$ & 0.20 & 13.68 & 191,898 & 1.2 & $1,345,702$ & 5.86 \\
\hline 2016 & 229,229 & $1,387,774$ & 0.17 & 13.67 & 192,925 & 1.2 & $1,424,365$ & 6.21 \\
\hline 2017 & 209,197 & $1,464,708$ & 0.14 & 12.96 & 195,488 & 1.1 & & \\
\hline
\end{tabular}


The monthly ridership trend shows the influence of hurricane Irma. Ridership for the first four months of 2018 has been running approximately $17 \%$ ahead of last year.

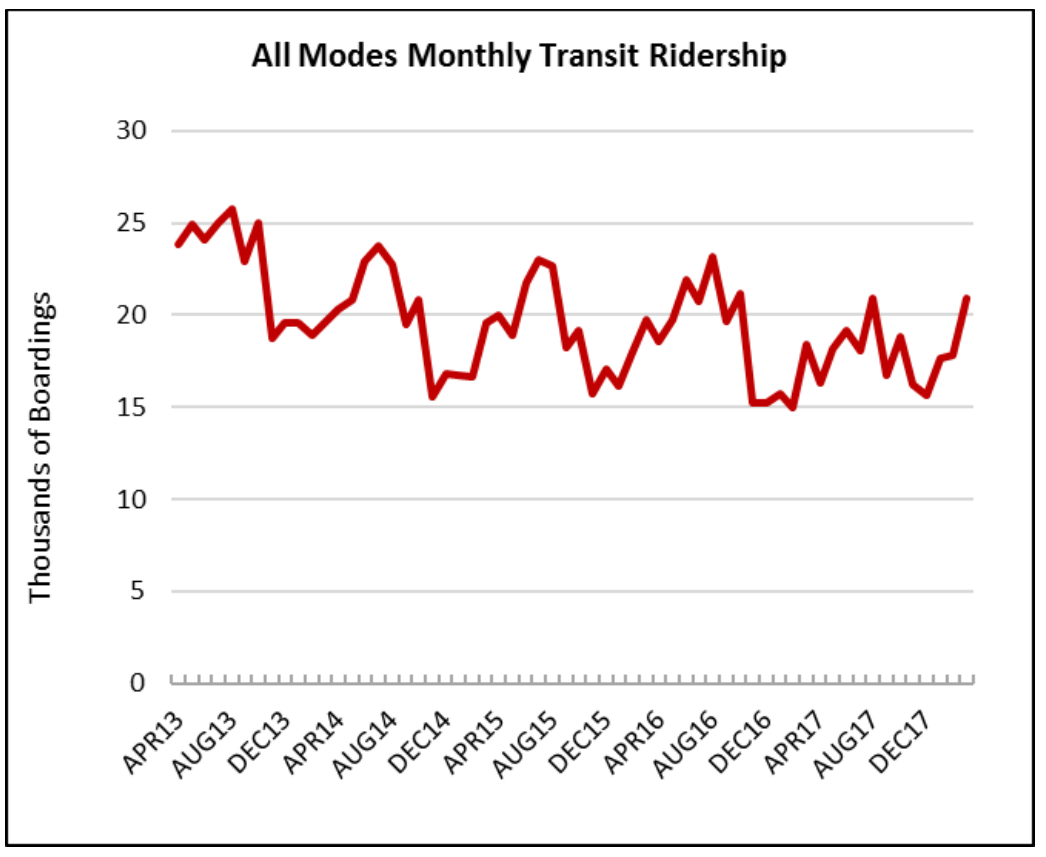

Average operating speed, defined as vehicle revenue miles divided by vehicle revenue hours, has been averaging nearly $19 \mathrm{mph}$, a relatively fast speed for transit service.

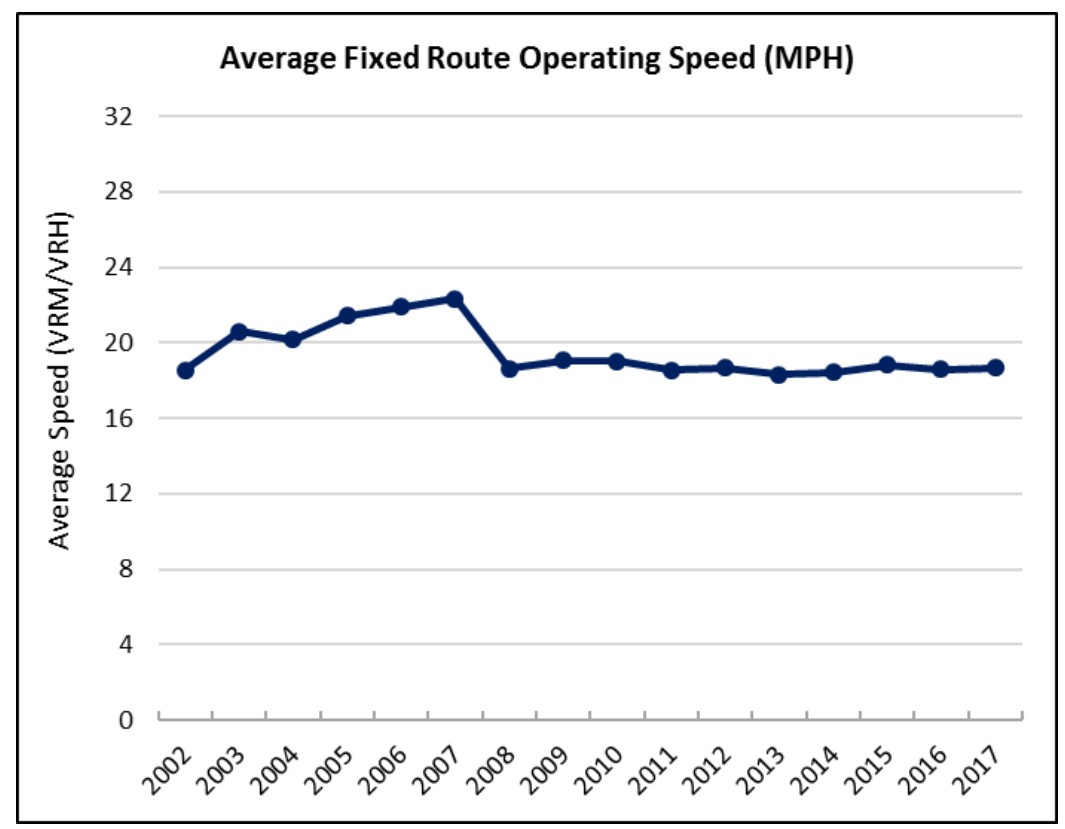


The adjacent graphic shows service productivity. Service productivity has declined since 2008.

The figures below provide the ridership trends and service supply trends by sub mode. This allows one to understand how the various component modes are performing.

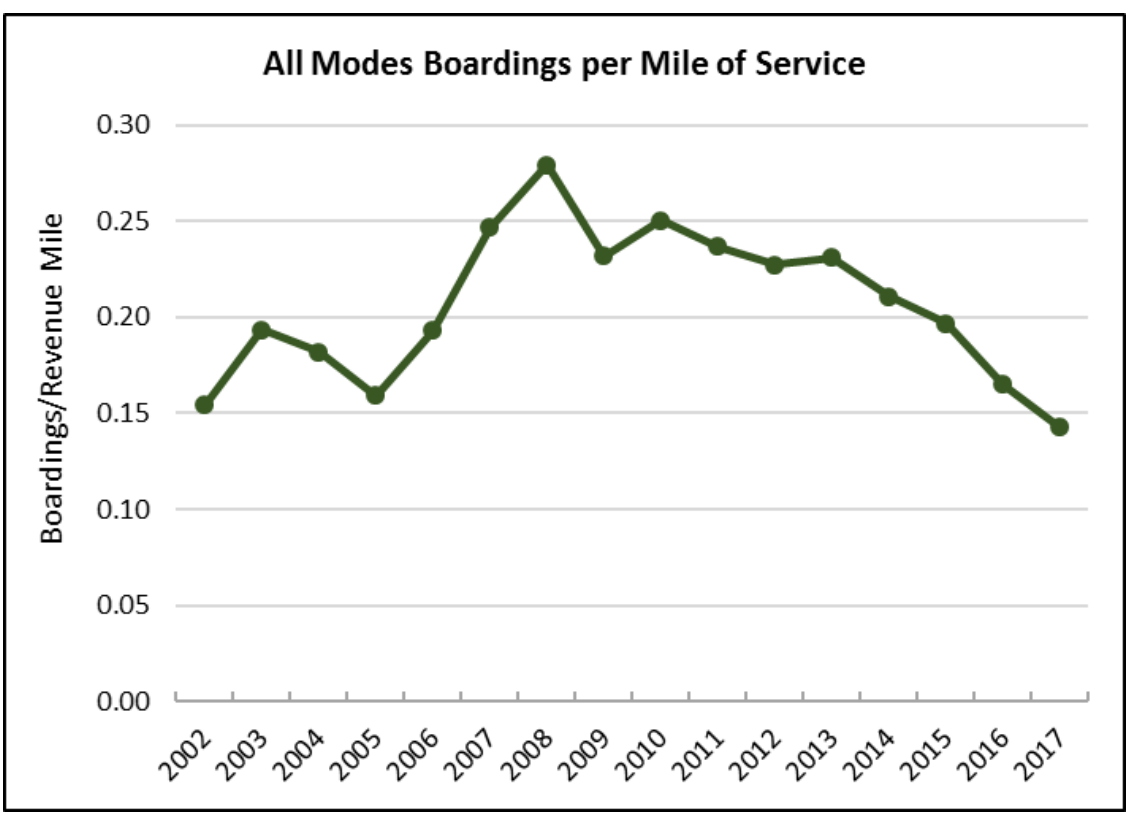

Bus ridership has declined approximately $13 \%$ over one year and $19 \%$ over three years. Demand responsive service has grown $10 \%$ in the last year and grown $8 \%$ over the past three.

Rolling 12-Month Ridership Trend by Transit Mode

250,000
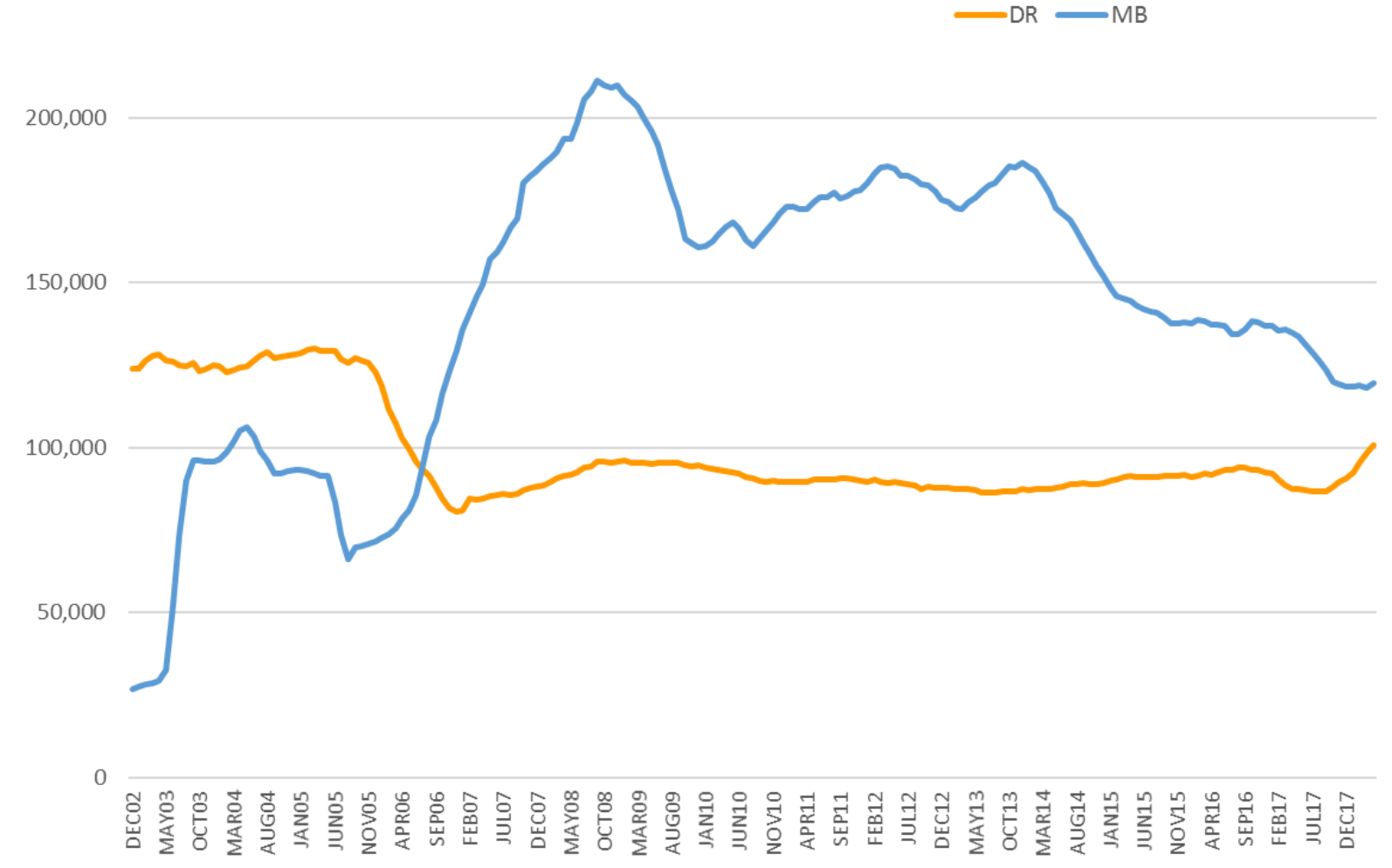
The final graphic shows service supply as measured by revenue vehicle miles of service. As the graphical data communicates, bus service supply has declined $8 \%$ in the past year and $1 \%$ over three years. Demand responsive service has grown $19 \%$ and $49 \%$ respectively in the one in three-year periods.

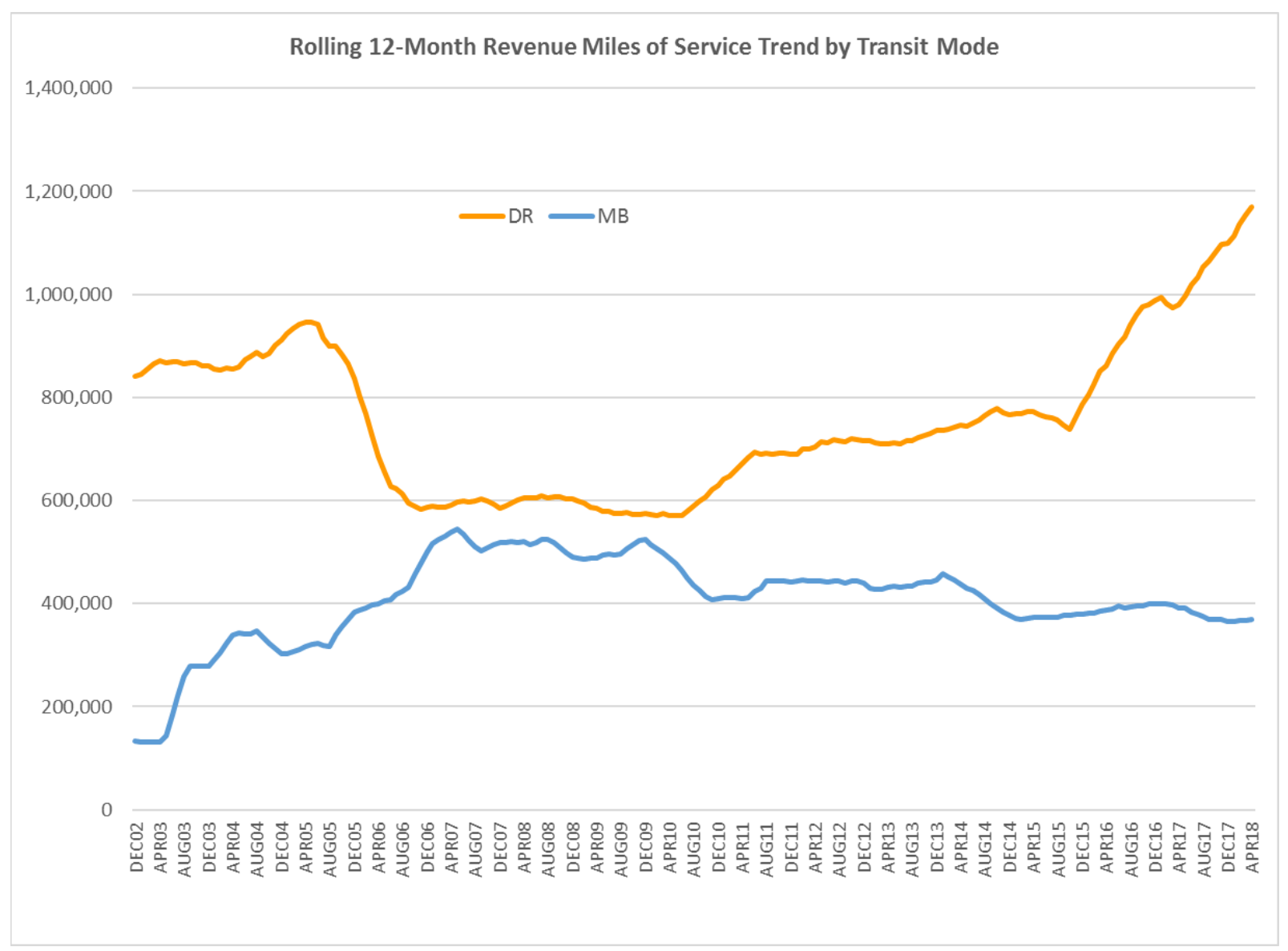


TBARTA (Tampa Bay Area Regional Transportation Authority)

TBARTA operates vanpool services in the Tampa Bay area. Ridership on the TBARTA services has declined $9 \%$ since a peak in 2012. Vehicle revenue miles of service has declined $5 \%$ in that same time period. Boardings per revenue mile has dropped $8 \%$ since its peak in 2014. Ridership per County (Hillsborough) resident has declined $14 \%$ from its peak in 2013.

Average trip length on van service has been approximately 34 miles.

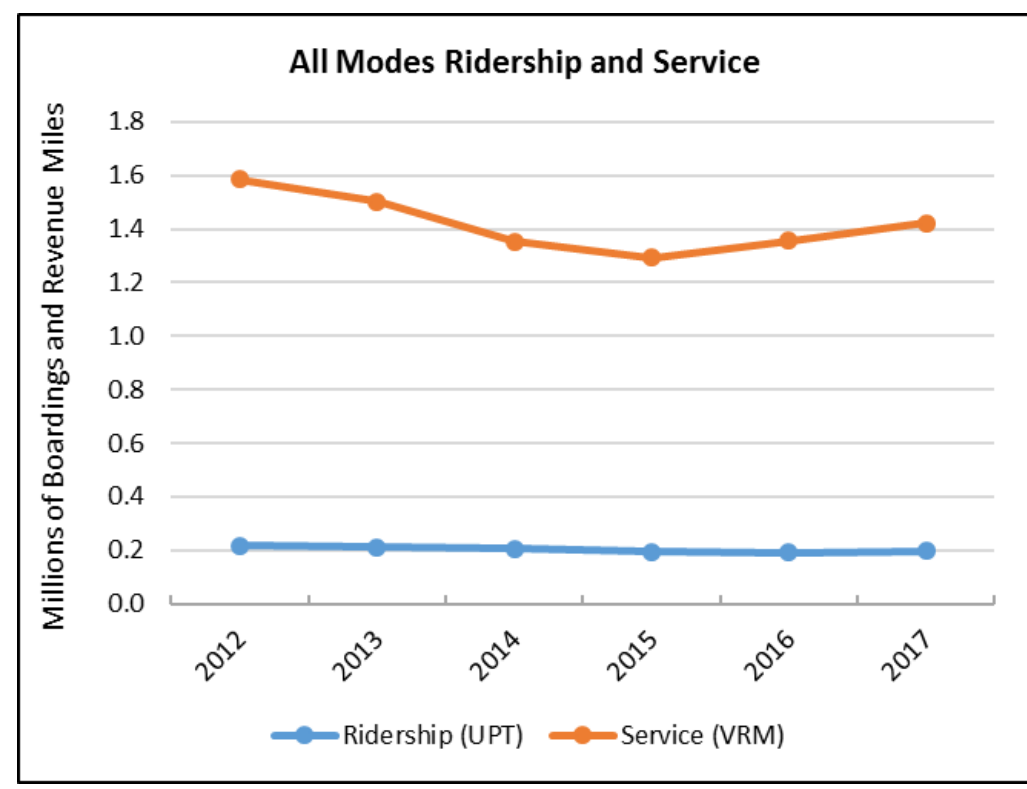

\begin{tabular}{|c|c|c|c|c|c|c|c|c|}
\hline \multicolumn{9}{|c|}{ Annual Trend Data, All Modes } \\
\hline Year & Ridership (UPT) & Service (VRM) & $\begin{array}{l}\text { Boardings per } \\
\text { Revenue Mile }\end{array}$ & $\begin{array}{l}\text { AVG Fixed- } \\
\text { Route } \\
\text { Speed } \\
\text { (mph) }\end{array}$ & $\begin{array}{c}\text { County } \\
\text { Population }\end{array}$ & $\begin{array}{l}\text { Trips per } \\
\text { Capita }\end{array}$ & $\begin{array}{c}\text { Passenger } \\
\text { Miles of } \\
\text { Travel }\end{array}$ & $\begin{array}{c}\text { Average } \\
\text { Trip } \\
\text { Length }\end{array}$ \\
\hline \multicolumn{9}{|l|}{2002} \\
\hline \multicolumn{9}{|l|}{2003} \\
\hline \multicolumn{9}{|l|}{2004} \\
\hline \multicolumn{9}{|l|}{2005} \\
\hline \multicolumn{9}{|l|}{2006} \\
\hline \multicolumn{9}{|l|}{2007} \\
\hline \multicolumn{9}{|l|}{2008} \\
\hline \multicolumn{9}{|l|}{2009} \\
\hline \multicolumn{9}{|l|}{2010} \\
\hline \multicolumn{9}{|l|}{2011} \\
\hline 2012 & 216,154 & $1,584,581$ & 0.136 & & $1,256,118$ & 0.17 & $8,606,208$ & 39.82 \\
\hline 2013 & 212,040 & $1,503,664$ & 0.141 & & $1,276,410$ & 0.17 & $8,166,577$ & 38.51 \\
\hline 2014 & 204,169 & $1,354,126$ & 0.151 & & $1,301,887$ & 0.16 & $6,961,152$ & 34.10 \\
\hline 2015 & 193,264 & $1,293,345$ & 0.149 & & $1,325,563$ & 0.15 & $6,492,089$ & 33.59 \\
\hline 2016 & 191,022 & $1,356,873$ & 0.141 & & $1,352,797$ & 0.14 & $6,522,472$ & 34.15 \\
\hline 2017 & 196,377 & $1,421,004$ & 0.138 & & $1,379,302$ & 0.14 & & \\
\hline
\end{tabular}


The monthly ridership trend shows the influence of hurricane Irma. Ridership for the first three months of 2018 has been running approximately $5 \%$ behind last year.

Operating speeds for vanpool services are not reported.

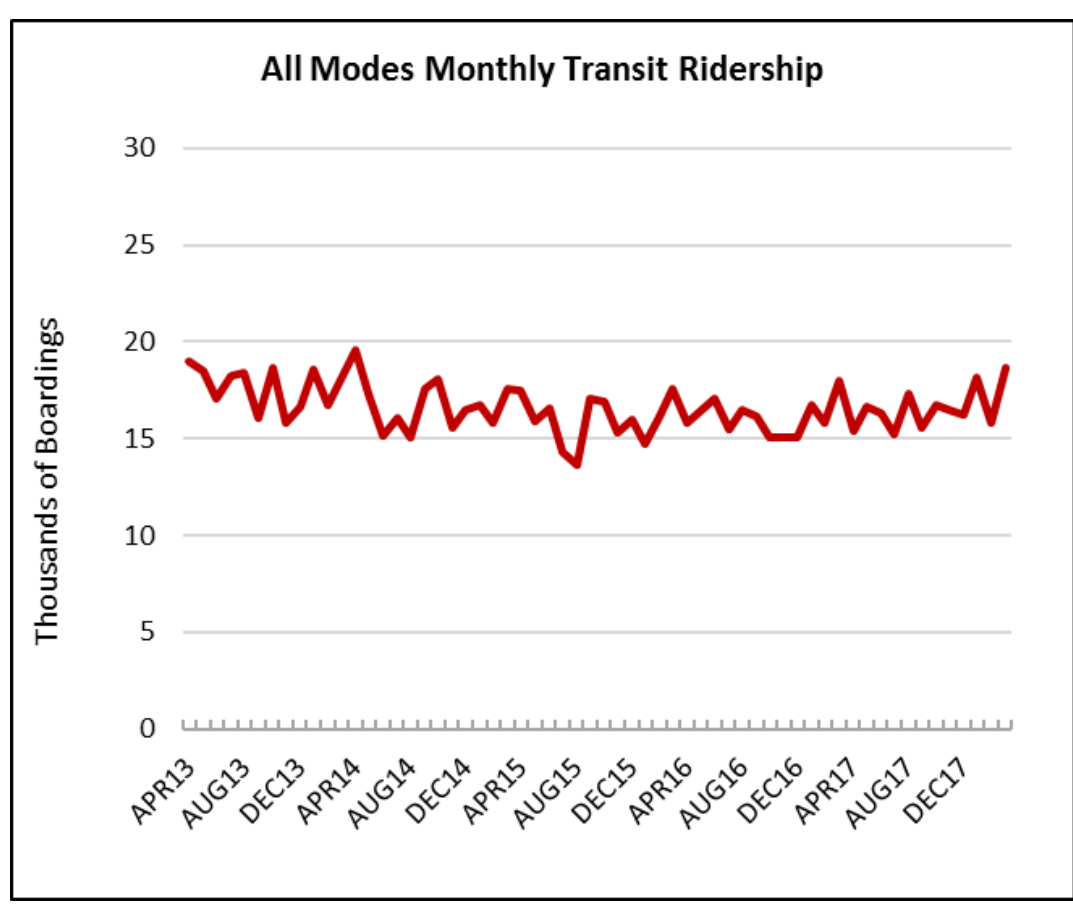

The adjacent graphic shows service productivity. Service productivity has declined modestly since 2015 .

The figures below provide the ridership trends and service supply trends by sub mode. This allows one to understand how the various component modes are performing.

Vanpool ridership has grown

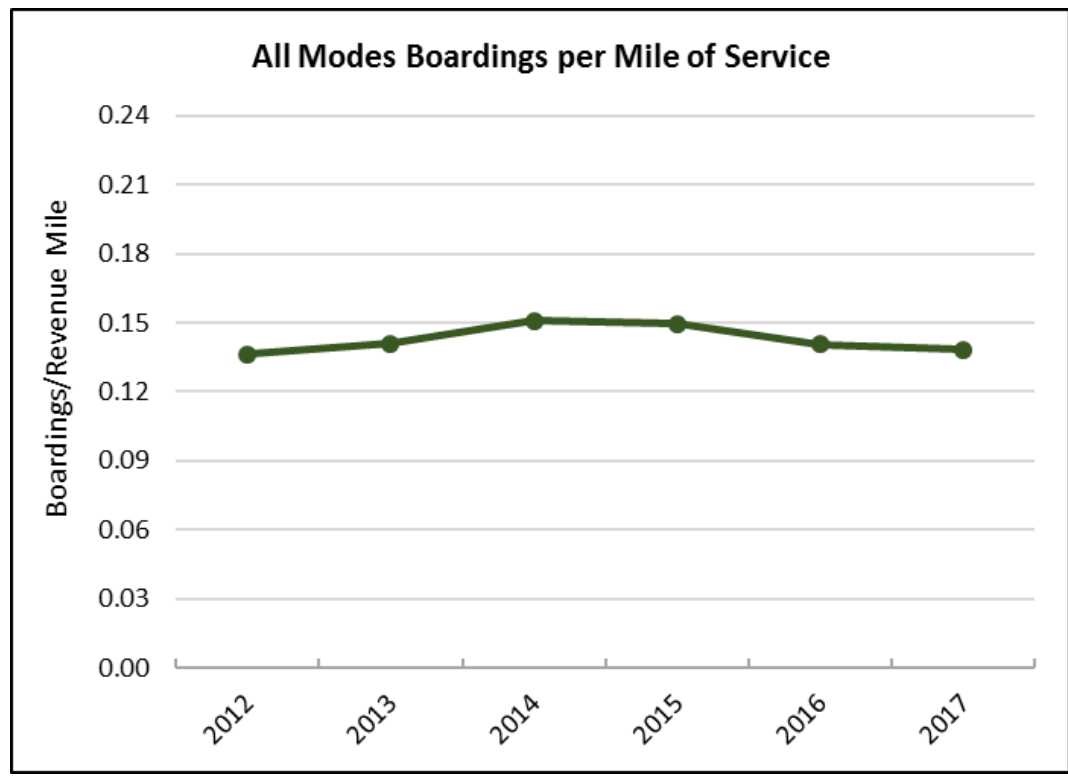
approximately $3 \%$ over one year but declined $1 \%$ over three years.

The final graphic shows service supply as measured by revenue vehicle miles of service. Vanpool service supply has increased $7 \%$ in the past year and $10 \%$ over three years. 
250,000

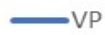

200,000

150,000

100,000

50,000

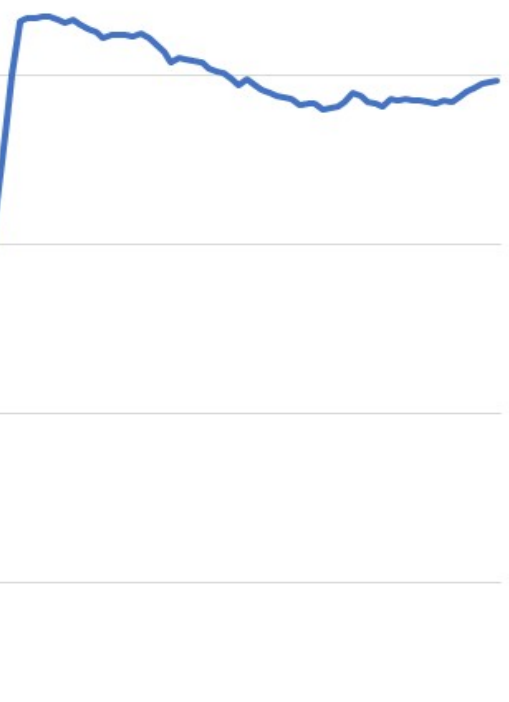

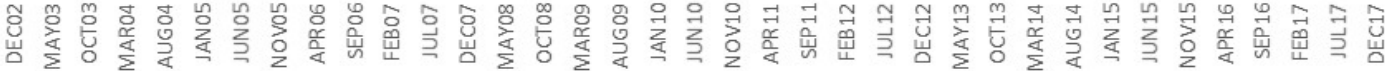

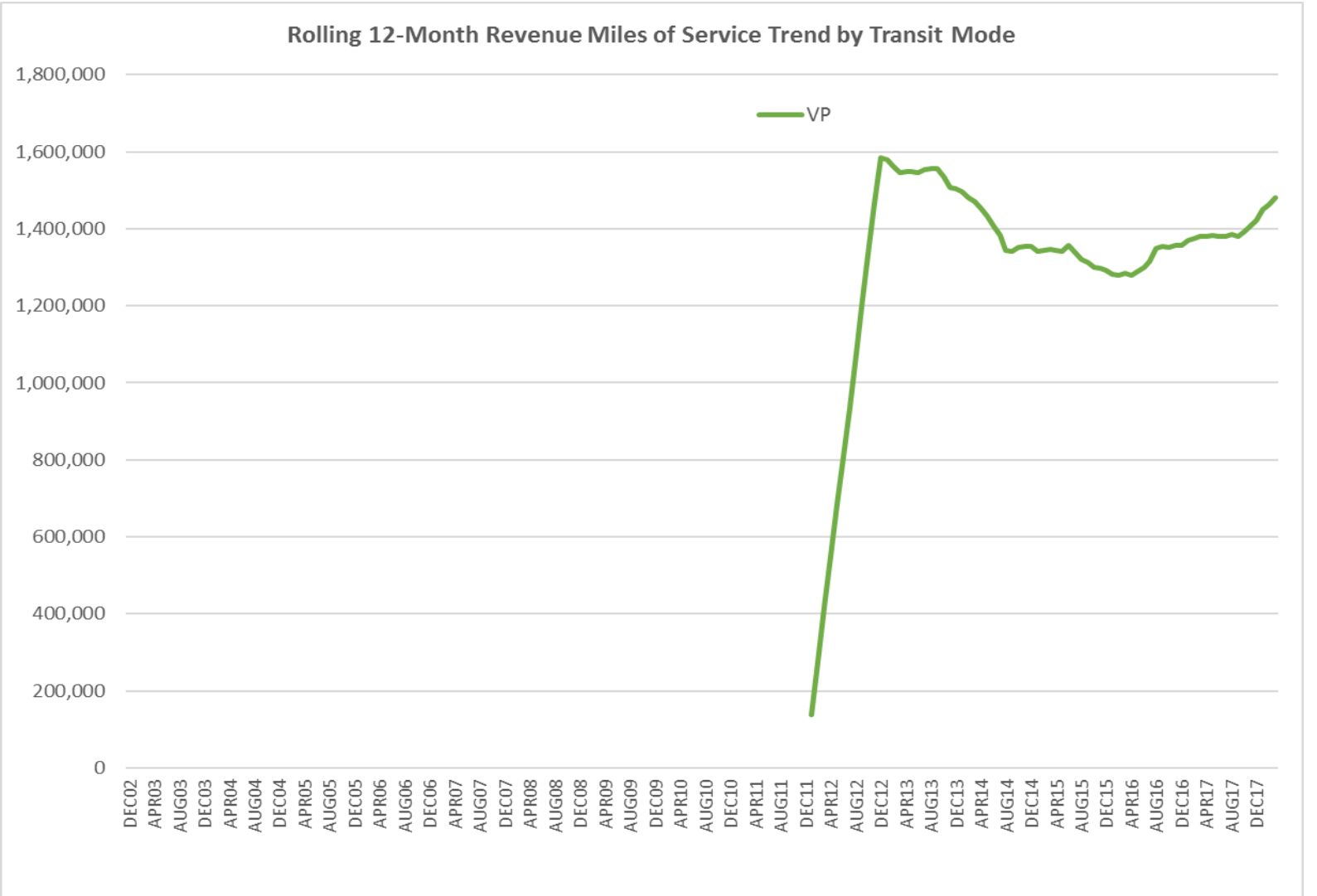




\section{Bay County (Bay County Transportation Planning Organization, Transit Division)}

Ridership on the Bay County since a peak in 2014. Vehicle revenue miles of service has declined $67 \%$ in that same time period. The Bay County system was most impacted by declining ridership during the past three years. Boardings per revenue mile has dropped $35 \%$ since its peak in 2012. Ridership per County resident has declined 81\% from its peak in 2012. transit system has declined $79 \%$

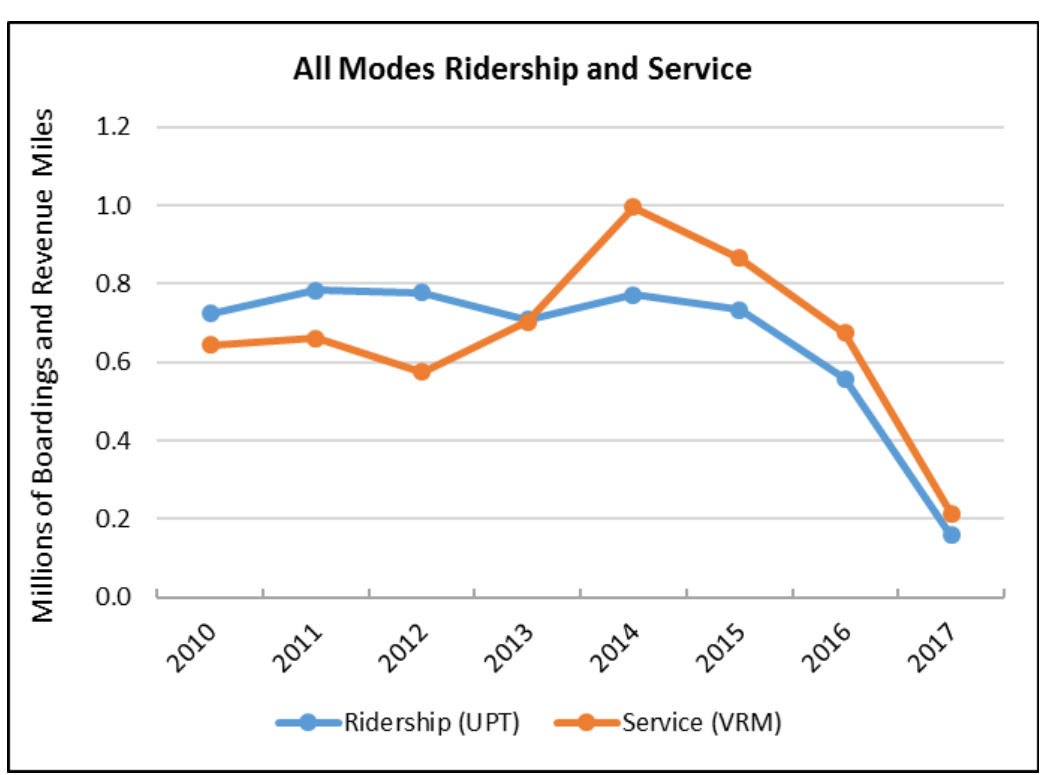

Average trip length on transit has been relatively around 5 miles.

\begin{tabular}{|c|c|c|c|c|c|c|c|c|}
\hline \multicolumn{9}{|c|}{ Annual Trend Data, All Modes } \\
\hline Year & Ridership (UPT) & Service (VRM) & $\begin{array}{l}\text { Boardings per } \\
\text { Revenue Mile }\end{array}$ & $\begin{array}{l}\text { AVG Fixed- } \\
\text { Route } \\
\text { Speed } \\
\text { (mph) }\end{array}$ & $\begin{array}{c}\text { County } \\
\text { Population }\end{array}$ & $\begin{array}{l}\text { Trips per } \\
\text { Capita }\end{array}$ & $\begin{array}{c}\text { Passenger } \\
\text { Miles of } \\
\text { Travel }\end{array}$ & $\begin{array}{c}\text { Average } \\
\text { Trip } \\
\text { Length }\end{array}$ \\
\hline \multicolumn{9}{|l|}{2002} \\
\hline \multicolumn{9}{|l|}{2003} \\
\hline \multicolumn{9}{|l|}{2004} \\
\hline \multicolumn{9}{|l|}{2005} \\
\hline \multicolumn{9}{|l|}{2006} \\
\hline \multicolumn{9}{|l|}{2007} \\
\hline \multicolumn{9}{|l|}{2008} \\
\hline 2009 & & & & & & & $3,315,512$ & \\
\hline 2010 & 724,141 & 644,470 & 1.12 & 16.50 & 169,272 & 4.3 & $3,579,588$ & 4.94 \\
\hline 2011 & 783,758 & 661,396 & 1.19 & 16.45 & 169,278 & 4.6 & $3,870,145$ & 4.94 \\
\hline 2012 & 777,225 & 574,692 & 1.35 & 15.57 & 169,392 & 4.6 & $3,861,896$ & 4.97 \\
\hline 2013 & 709,300 & 703,405 & 1.01 & 13.79 & 169,866 & 4.2 & $3,862,467$ & 5.45 \\
\hline 2014 & 771,647 & 995,723 & 0.77 & 12.85 & 170,781 & 4.5 & $3,289,564$ & 4.26 \\
\hline 2015 & 734,261 & 864,766 & 0.85 & 12.95 & 173,310 & 4.2 & $3,023,093$ & 4.12 \\
\hline 2016 & 558,397 & 673,914 & 0.83 & 12.99 & 176,016 & 3.2 & $2,906,459$ & 5.21 \\
\hline 2017 & 156,982 & 212,416 & 0.74 & 13.36 & 178,820 & 0.9 & & \\
\hline
\end{tabular}


The monthly ridership trend is impacted by missing monthly data in 2017. Ridership for the first three months of 2018 has been running approximately 3\% behind 2016.

Average operating speed, defined as vehicle revenue miles divided by vehicle revenue hours, has been averaging around $13 \mathrm{mph}$.
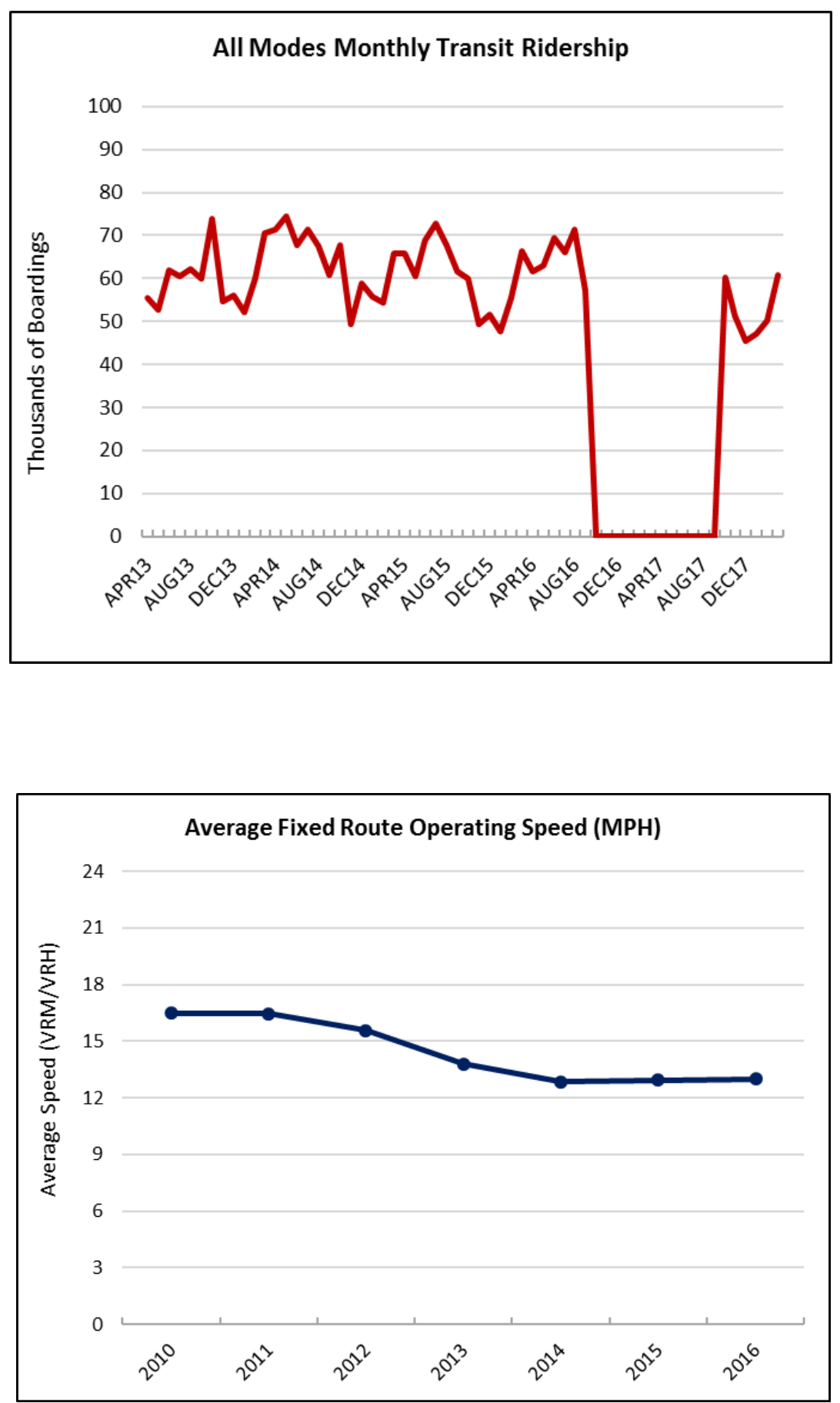
The adjacent graphic shows service productivity. Service productivity declined from 2012 through 2014 and has been relatively stable since then.

The figures below provide the ridership trends and service supply trends by sub mode. This allows one to understand how the

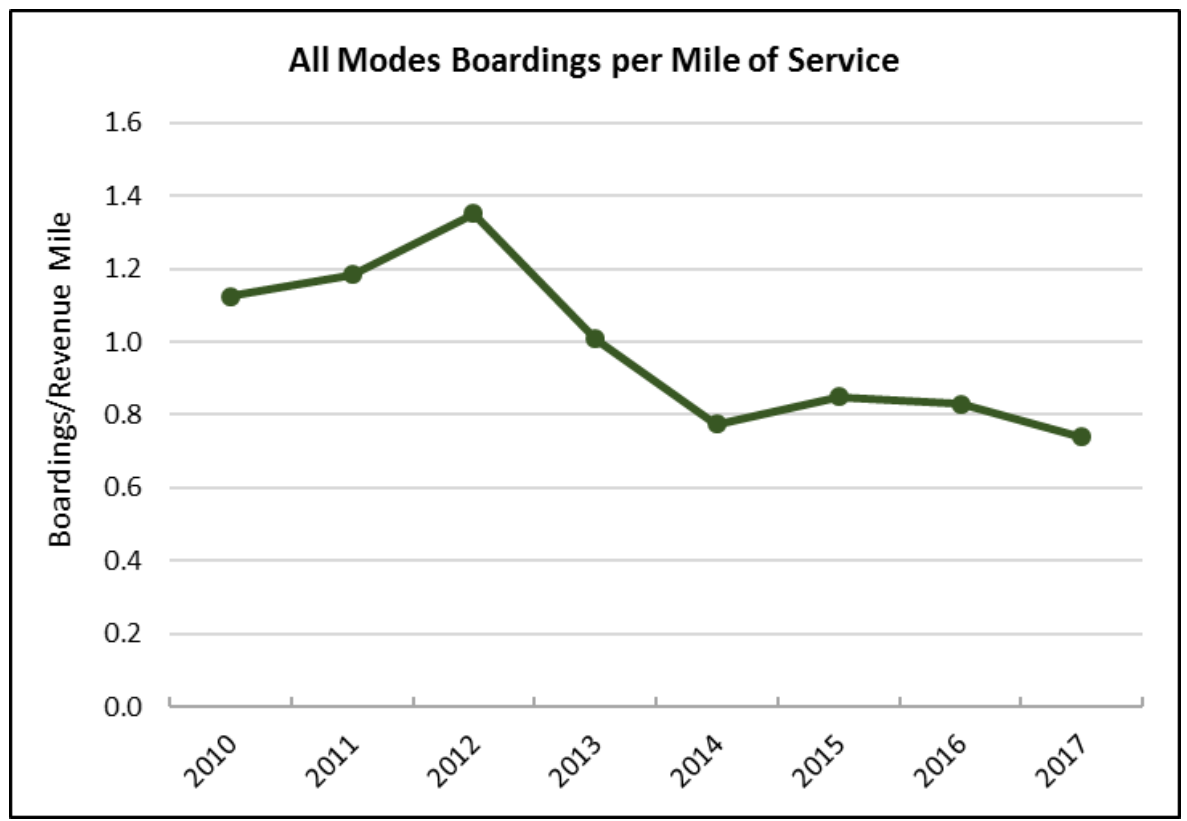
various component modes are performing.

Missing monthly data makes it impossible to do one and three year comparisons based on monthly data.

Rolling 12-Month Ridership Trend by Transit Mode

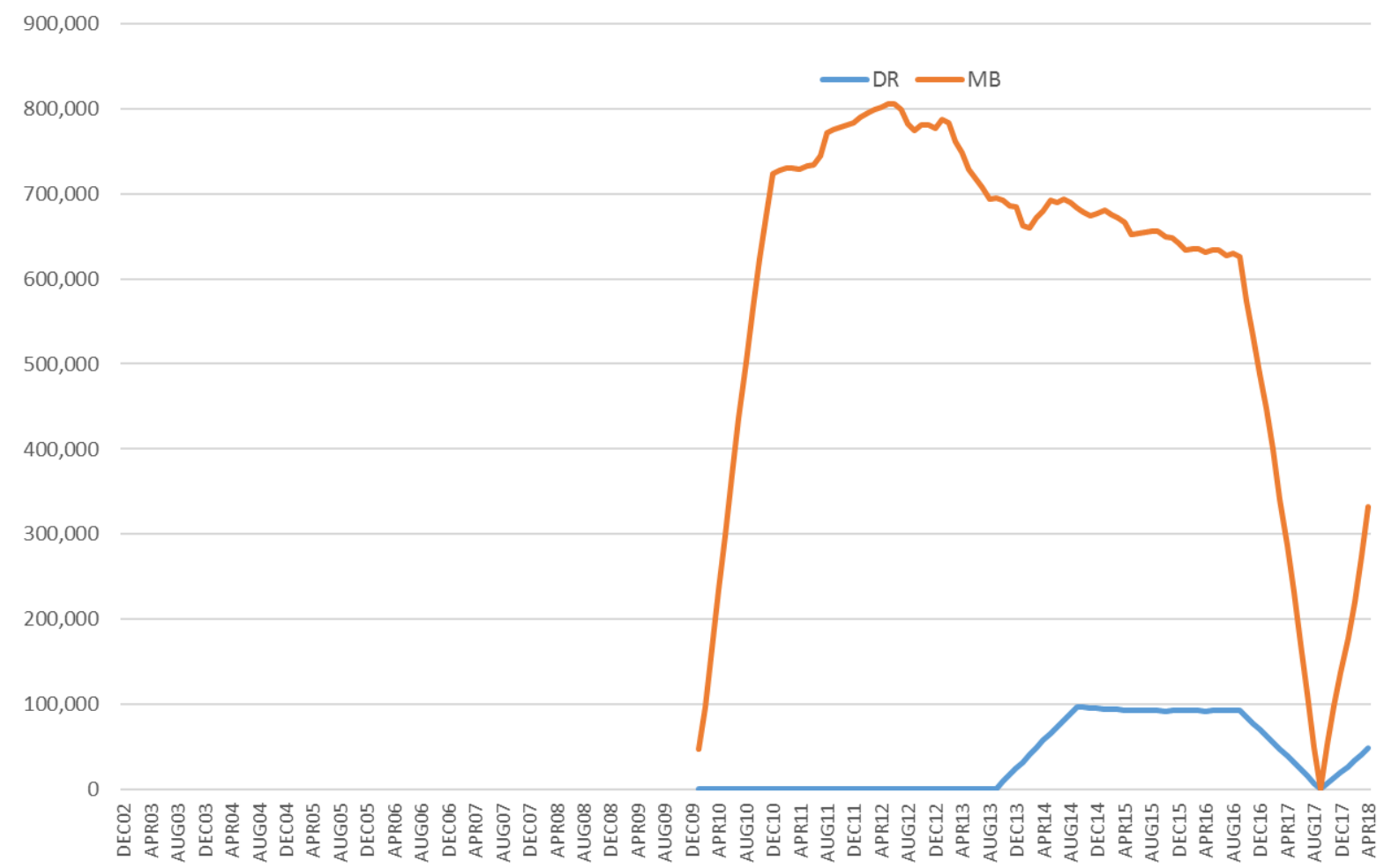


The final graphic shows service supply as measured by revenue vehicle miles of service. Demand responsive service has declined $2 \%$ and $8 \%$ respectively in the one in three year periods.

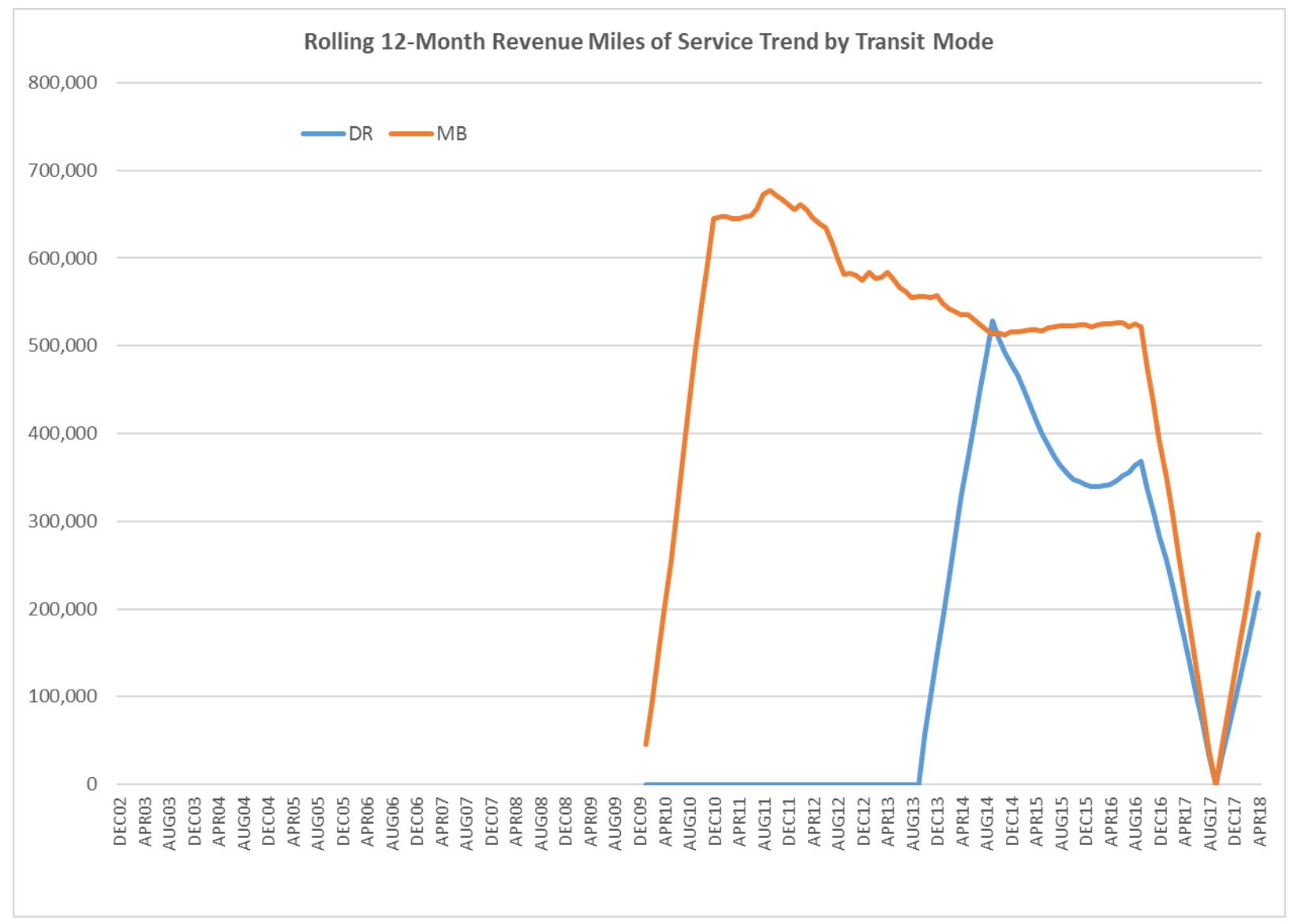




\section{Charlotte County (Charlotte County Transit)}

Ridership on the Charlotte demand responsive and vanpool services has declined 4\% since a peak in 2013. Vehicle revenue miles of service has declined $13 \%$ in that same time period. The Boardings per revenue mile was at its highest level in 2017. Ridership per County resident has declined $9 \%$ from its peak in 2013.

Average trip length on transit

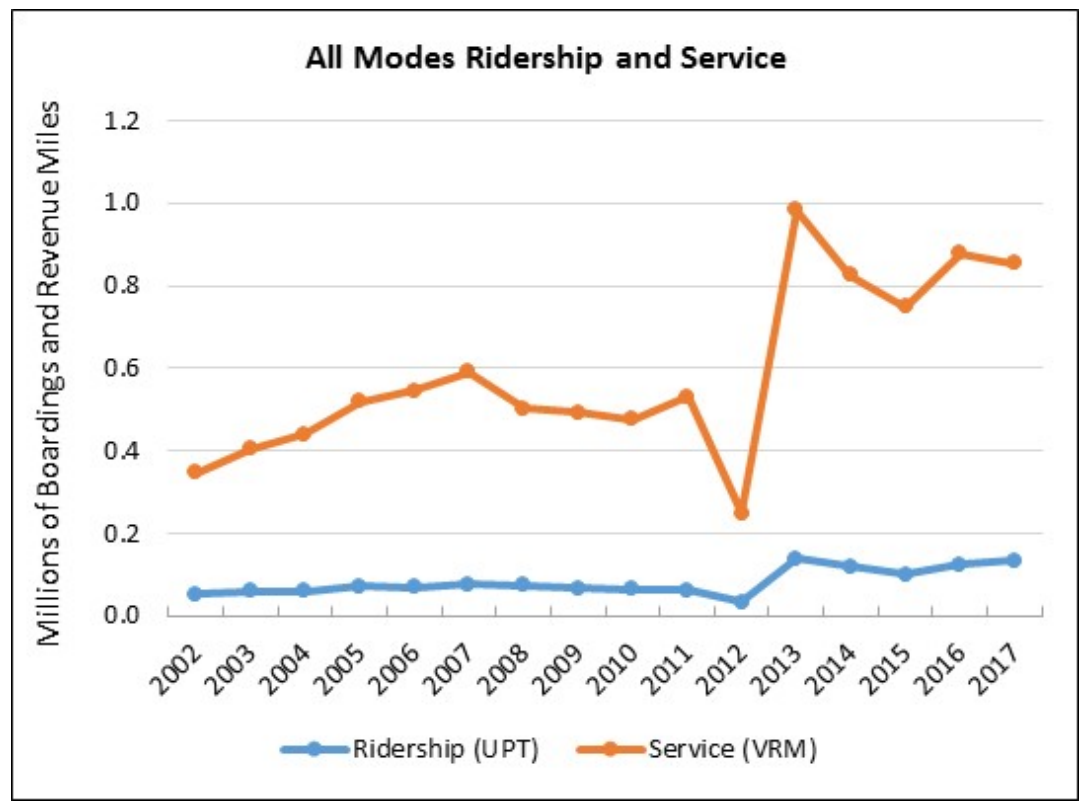

is about 6 miles.

\begin{tabular}{|c|c|c|c|c|c|c|c|c|}
\hline \multicolumn{9}{|c|}{ Annual Trend Data, All Modes } \\
\hline Year & Ridership (UPT) & Service (VRM) & $\begin{array}{l}\text { Boardings per } \\
\text { Revenue Mile }\end{array}$ & $\begin{array}{l}\text { AVG Fixed- } \\
\text { Route } \\
\text { Speed } \\
\text { (mph) }\end{array}$ & $\begin{array}{c}\text { County } \\
\text { Population }\end{array}$ & $\begin{array}{c}\text { Trips per } \\
\text { Capita }\end{array}$ & $\begin{array}{c}\text { Passenger } \\
\text { Miles of } \\
\text { Travel }\end{array}$ & $\begin{array}{c}\text { Average } \\
\text { Trip } \\
\text { Length }\end{array}$ \\
\hline 2002 & 53,876 & 347,225 & 0.16 & & 148,521 & 0.4 & 338,671 & 6.29 \\
\hline 2003 & 60,472 & 403,744 & 0.15 & & 151,994 & 0.4 & 361,757 & 5.98 \\
\hline 2004 & 59,770 & 439,917 & 0.14 & & 156,985 & 0.4 & 406,293 & 6.80 \\
\hline 2005 & 72,153 & 520,597 & 0.14 & & 154,030 & 0.5 & 524,408 & 7.27 \\
\hline 2006 & 70,463 & 546,905 & 0.13 & & 160,315 & 0.4 & 559,884 & 7.95 \\
\hline 2007 & 77,048 & 591,038 & 0.13 & & 164,584 & 0.5 & 591,661 & 7.68 \\
\hline 2008 & 75,860 & 501,831 & 0.15 & & 165,781 & 0.5 & 538,422 & 7.10 \\
\hline 2009 & 68,159 & 493,756 & 0.14 & & 165,455 & 0.4 & 536,422 & 7.87 \\
\hline 2010 & 64,559 & 476,326 & 0.14 & & 159,990 & 0.4 & 542,508 & 8.40 \\
\hline 2011 & 63,466 & 531,613 & 0.12 & & 160,463 & 0.4 & & \\
\hline 2012 & 33,068 & 250,547 & 0.13 & & 163,357 & 0.2 & $1,765,140$ & 53.38 \\
\hline 2013 & 139,884 & 983,823 & 0.14 & & 163,679 & 0.9 & $1,477,468$ & 10.56 \\
\hline 2014 & 119,121 & 826,007 & 0.14 & & 164,467 & 0.7 & $1,420,325$ & 11.92 \\
\hline 2015 & 100,314 & 750,161 & 0.13 & & 167,141 & 0.6 & $1,651,947$ & 16.47 \\
\hline 2016 & 126,117 & 878,275 & 0.14 & & 170,450 & 0.7 & $1,997,155$ & 15.84 \\
\hline 2017 & 134,785 & 853,998 & 0.16 & & 172,720 & 0.8 & & \\
\hline
\end{tabular}


Ridership for the first four months of 2018 has been running approximately $6 \%$ behind last year.

Speeds for the van pool and demand responsive service are not reported.

The adjacent graphic shows service productivity. Service productivity has declined remained relatively steady as would be expected for demand responsive and vanpool services.

The figures below provide the ridership trends and service supply trends by sub mode. This allows one to understand how the various component modes are performing.

Demand responsive has grown $2 \%$ in the past year and $19 \%$ in the past three years. Utilization of the vanpool service has declined $17 \%$ in the last year
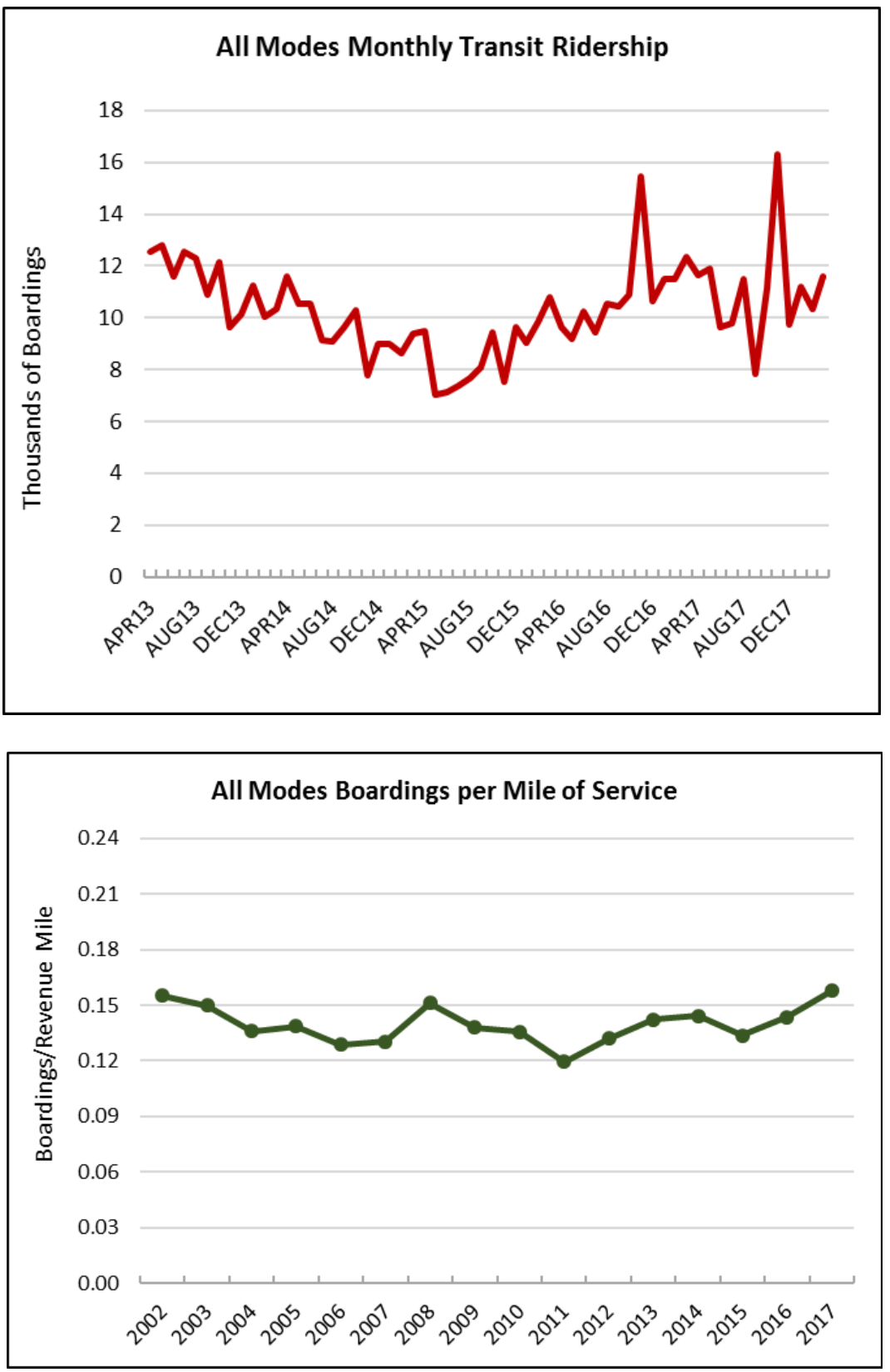
and $21 \%$ over the last three years

The final graphic shows service supply as measured by revenue vehicle miles of service. As the graphical data communicates, demand responsive service supply has declined $2 \%$ in the past year and $12 \%$ over three years. Vanpool service has declined $28 \%$ and $39 \%$ respectively in the one in three year periods. 

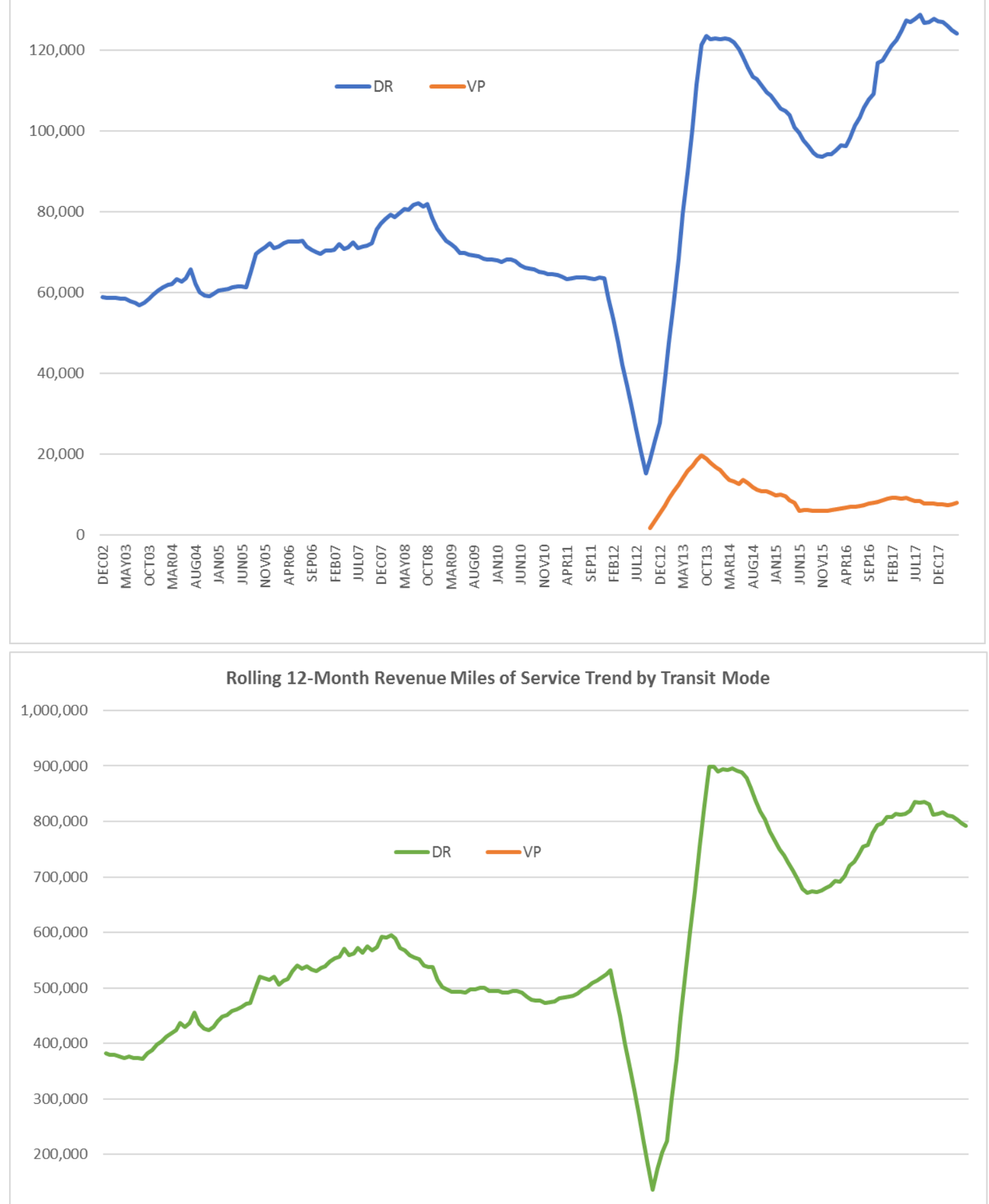

100,000

0

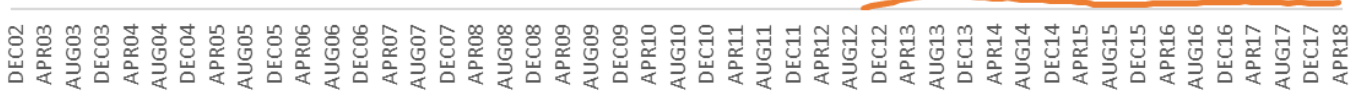


Clay County (Clay County Council on Aging, Inc., Clay Transit)

Clay began reporting service data in January 2015. Ridership on the Clay transit system has declined $12 \%$ since a peak in 2016. Vehicle revenue miles of service has declined $7 \%$ in that same time period.

Boardings per revenue mile has dropped 5\% since 2016.

Ridership per County resident has declined $16 \%$ from its peak in 2016.

Average trip length on transit

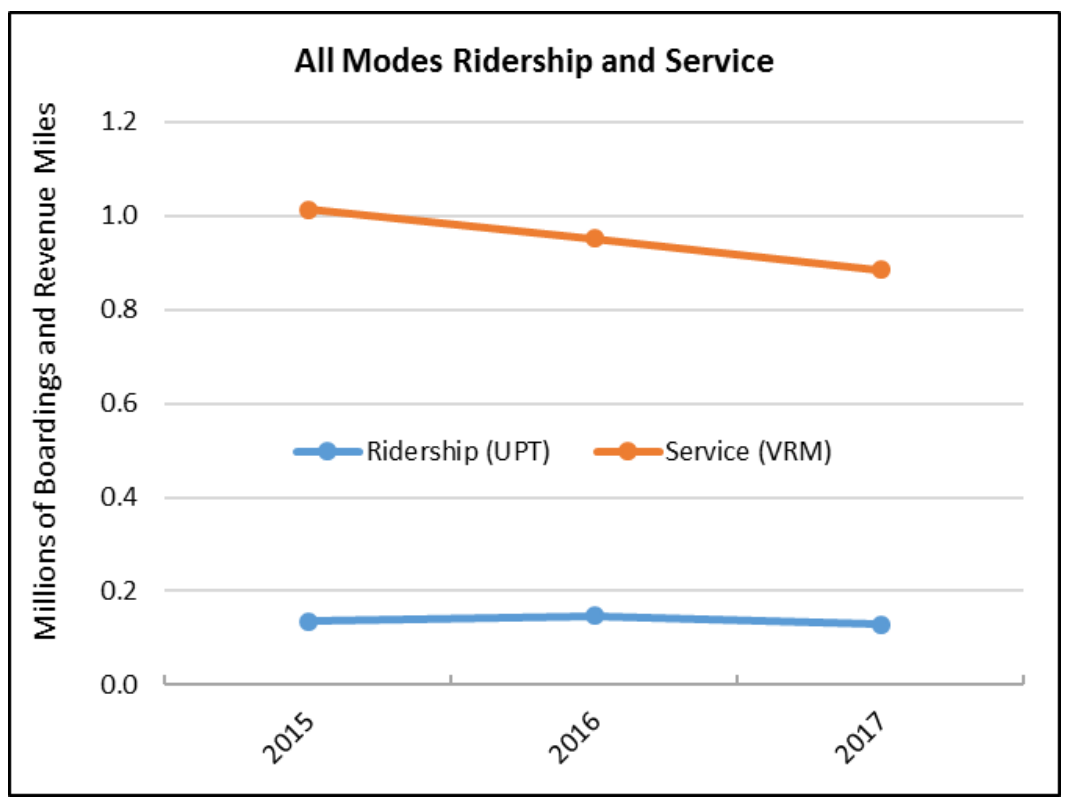
was reported as over 15 miles in 2015 and over 10 miles in 2016.

\begin{tabular}{|c|c|c|c|c|c|c|c|c|}
\hline \multicolumn{9}{|c|}{ Annual Trend Data, All Modes } \\
\hline Year & Ridership (UPT) & Service (VRM) & $\begin{array}{l}\text { Boardings per } \\
\text { Revenue Mile }\end{array}$ & $\begin{array}{l}\text { AVG Fixed- } \\
\text { Route } \\
\text { Speed } \\
\text { (mph) }\end{array}$ & $\begin{array}{c}\text { County } \\
\text { Population }\end{array}$ & $\begin{array}{c}\text { Trips per } \\
\text { Capita }\end{array}$ & $\begin{array}{c}\text { Passenger } \\
\text { Miles of } \\
\text { Travel }\end{array}$ & $\begin{array}{c}\text { Average } \\
\text { Trip } \\
\text { Length }\end{array}$ \\
\hline \multicolumn{9}{|l|}{2002} \\
\hline \multicolumn{9}{|l|}{2003} \\
\hline \multicolumn{9}{|l|}{2004} \\
\hline \multicolumn{9}{|l|}{2005} \\
\hline \multicolumn{9}{|l|}{2006} \\
\hline \multicolumn{9}{|l|}{2007} \\
\hline \multicolumn{9}{|l|}{2008} \\
\hline \multicolumn{9}{|l|}{2009} \\
\hline \multicolumn{9}{|l|}{2010} \\
\hline \multicolumn{9}{|l|}{2011} \\
\hline \multicolumn{9}{|l|}{2012} \\
\hline \multicolumn{9}{|l|}{2013} \\
\hline \multicolumn{9}{|l|}{2014} \\
\hline 2015 & 135,458 & $1,013,387$ & 0.134 & 18.17 & 201,277 & 0.67 & $2,088,119$ & 15.42 \\
\hline 2016 & 146,857 & 951,363 & 0.154 & 17.83 & 205,321 & 0.72 & $1,530,058$ & 10.42 \\
\hline 2017 & 129,415 & 884,676 & 0.146 & 17.30 & 208,549 & 0.62 & & \\
\hline
\end{tabular}


The monthly ridership trend shows the influence of hurricane Irma. Ridership for the first four months of 2018 has been running approximately $17 \%$ ahead of last year.

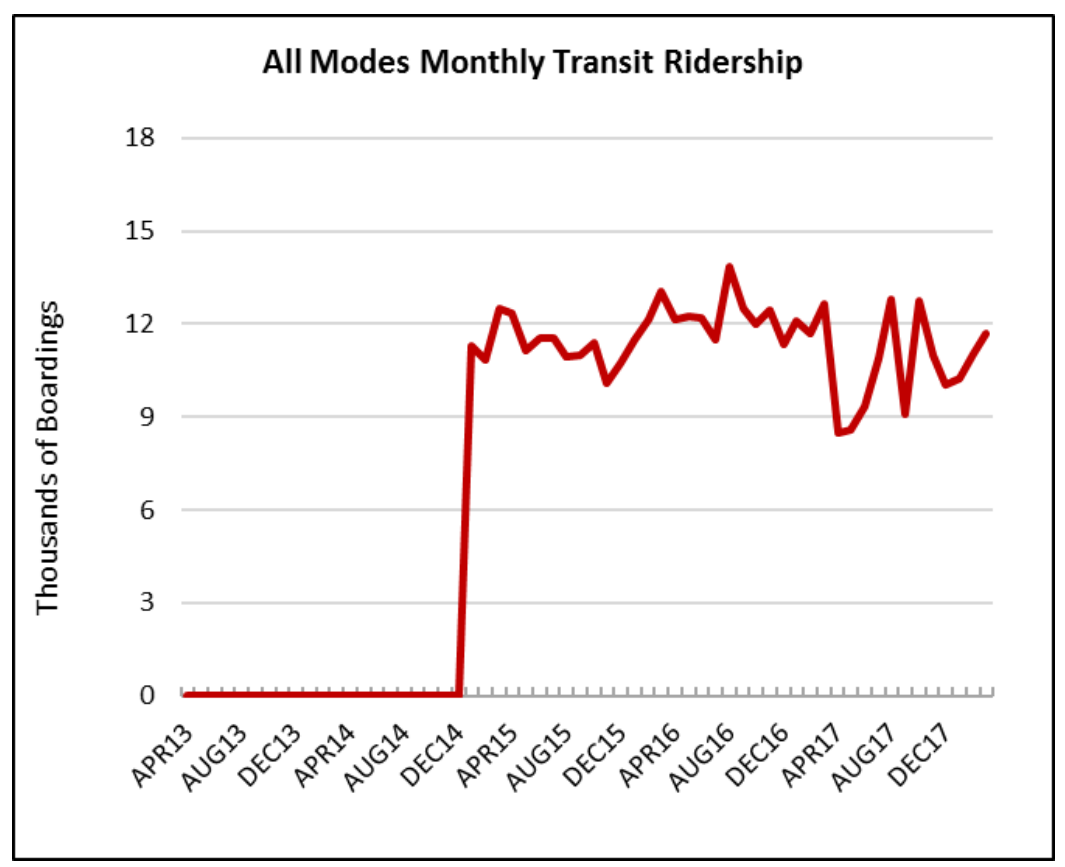

Average operating speed, defined as vehicle revenue miles divided by vehicle revenue hours, has been averaging 17-18 $\mathrm{mph}$, a relatively fast speed for transit service.

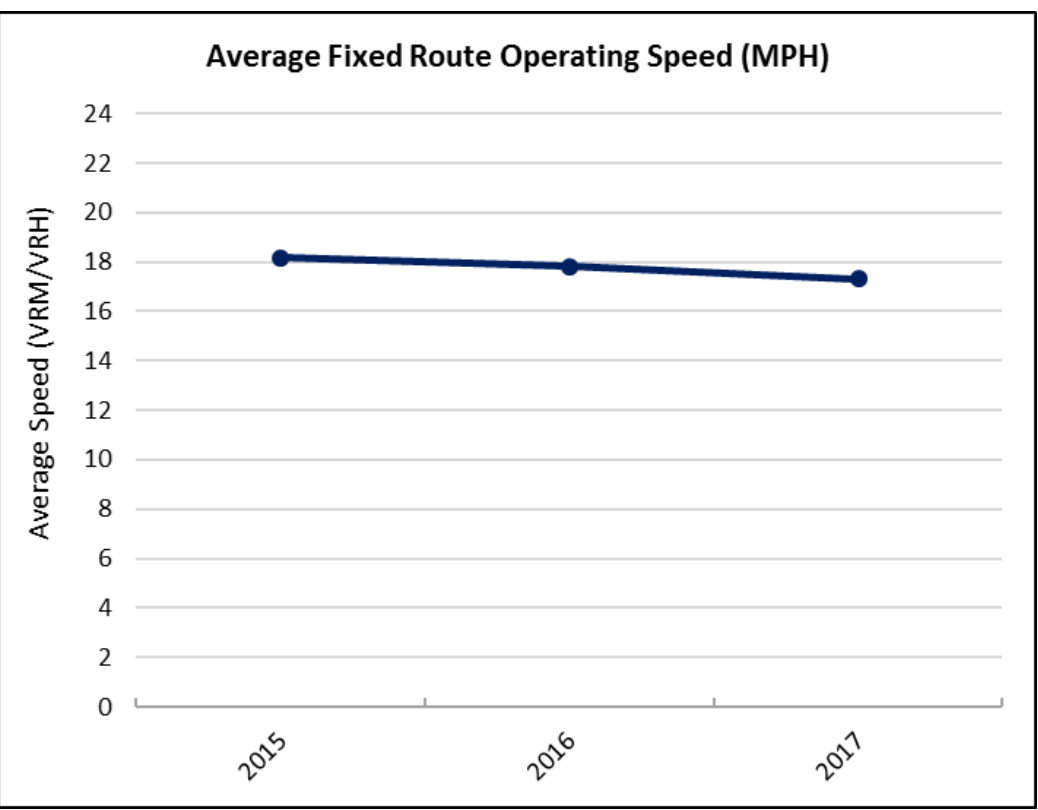


The adjacent graphic shows service productivity. Service productivity has declined since 2008.

The figures below provide the ridership trends and service supply trends by sub mode. This allows one to understand how the various component modes are performing.

Bus ridership has declined approximately $17 \%$ over one

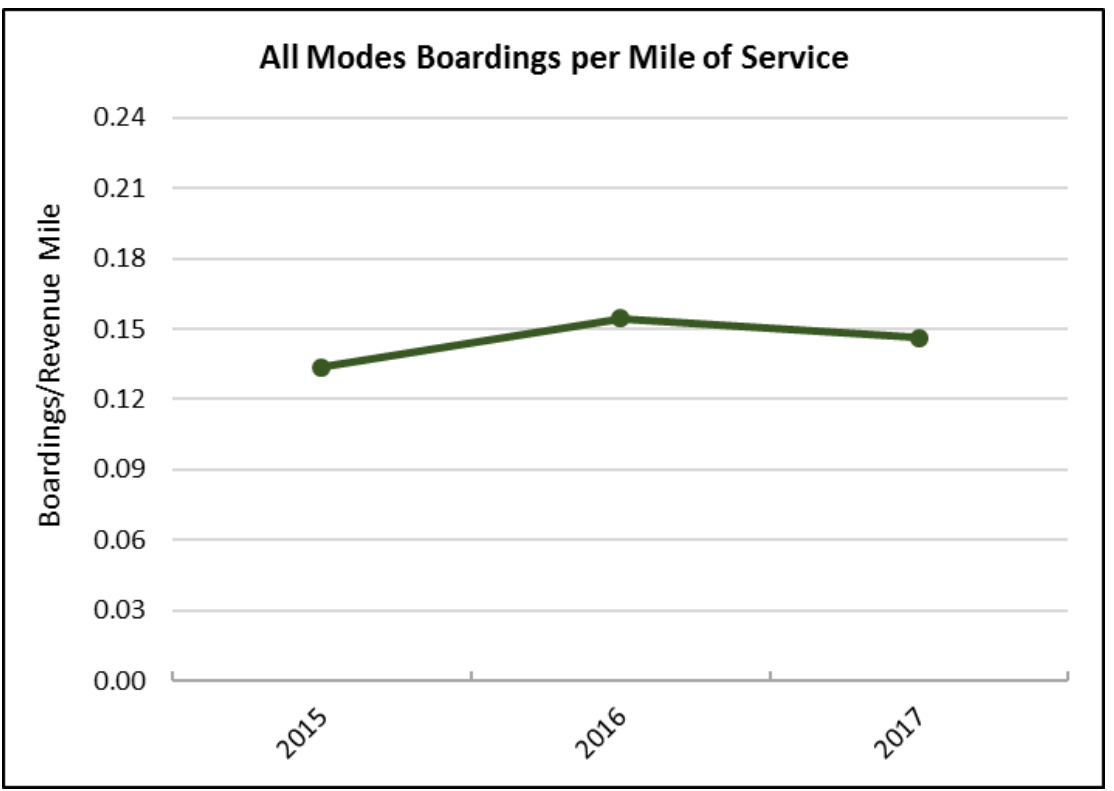
year and has not been reporting data for three full years. Demand responsive ridership has declined $13 \%$ in the last year.

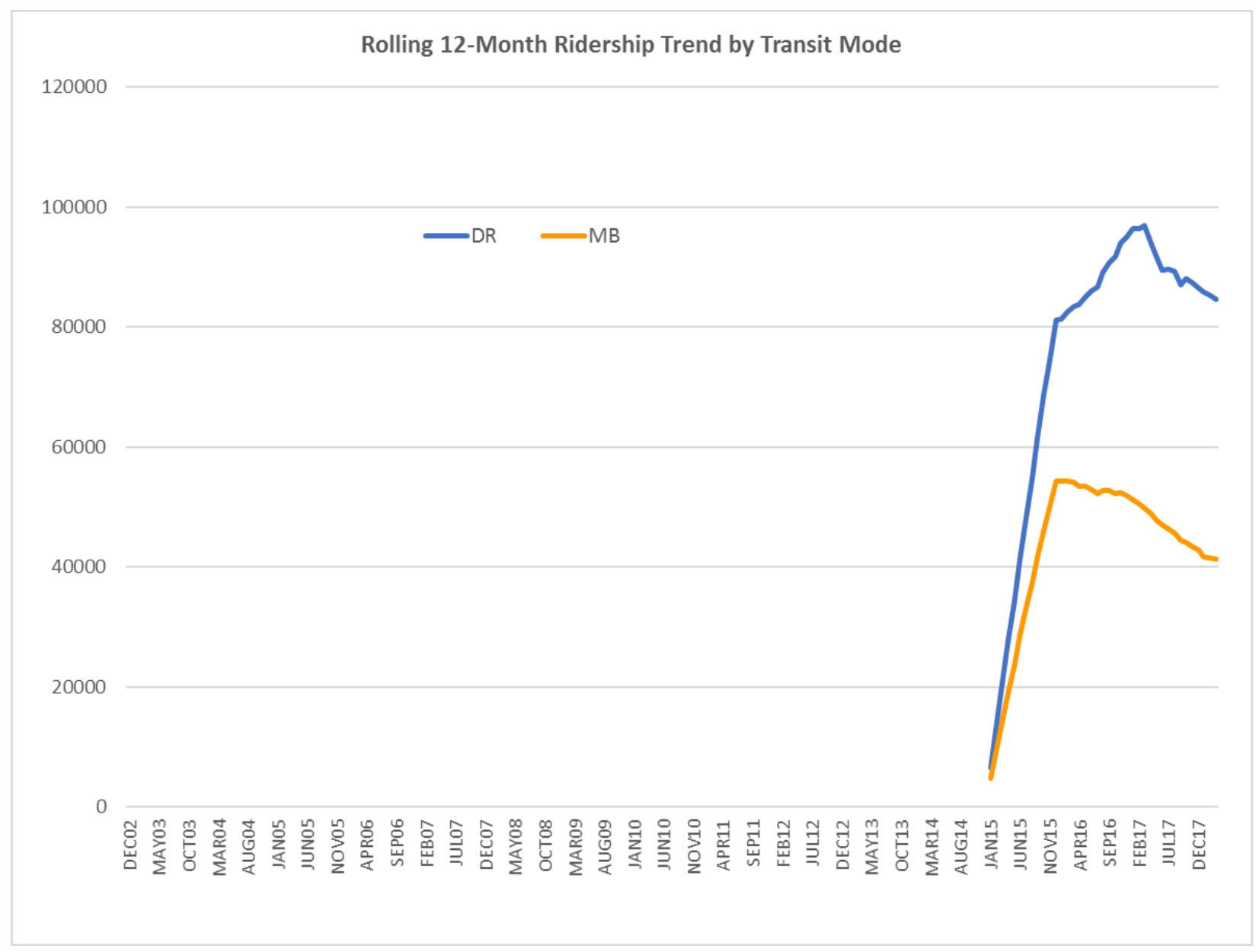


The final graphic shows service supply as measured by revenue vehicle miles of service. As the graphical data communicates, bus service supply has declined $6 \%$ in the past year. Demand responsive service has declined $8 \%$.

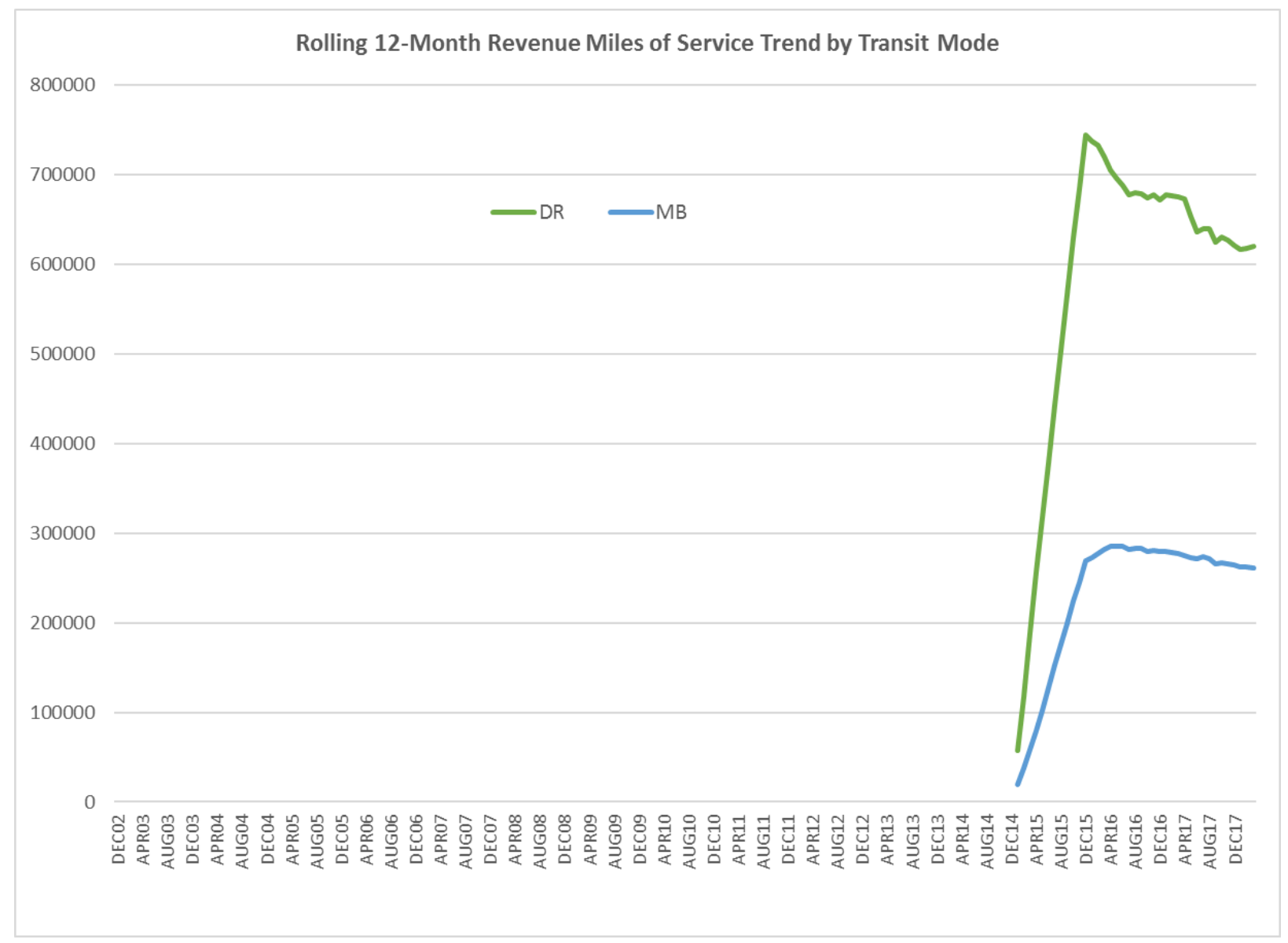


Flagler County (Flagler County Public Transportation, FCPT)

Flagler County began reporting demand responsive service in October 2014. Ridership on the Flagler service has increased modestly since inception. Vehicle revenue miles of service has similarly increased modestly.

Boardings per revenue mile have been stable to slightly increasing. Ridership per County resident has similarly been stable.

Average trip length on demand

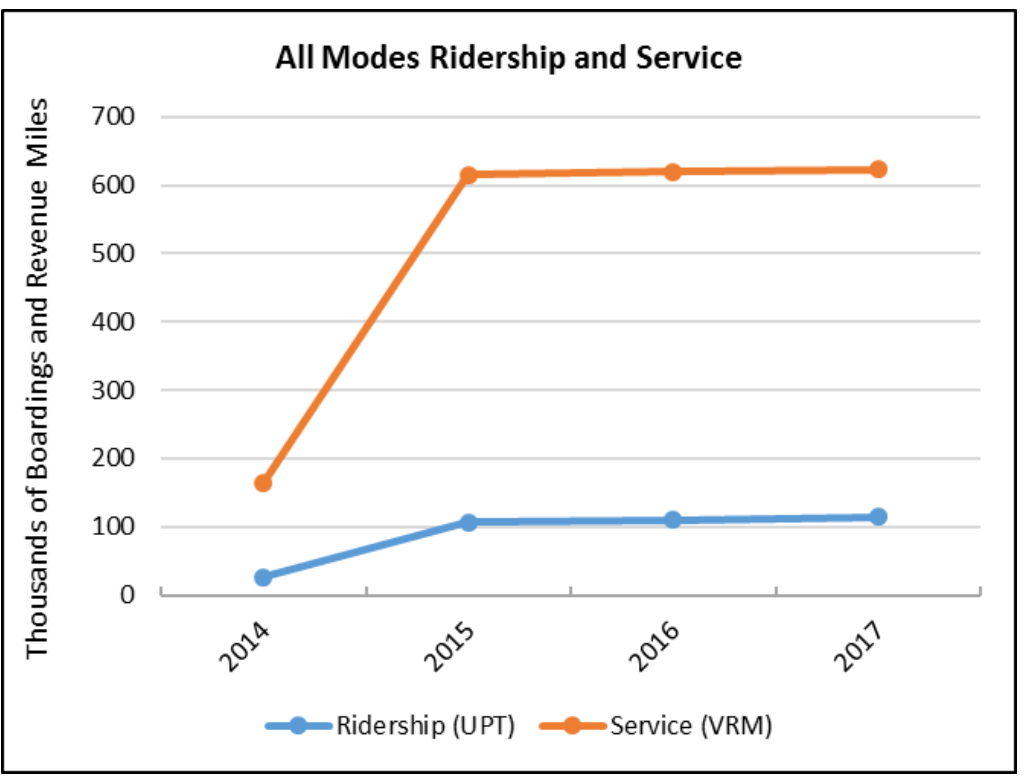
responsive service is about 6 miles.

\begin{tabular}{|c|c|c|c|c|c|c|c|c|}
\hline \multicolumn{9}{|c|}{ Annual Trend Data, All Modes } \\
\hline Year & Ridership (UPT) & Service (VRM) & $\begin{array}{l}\text { Boardings per } \\
\text { Revenue Mile }\end{array}$ & $\begin{array}{l}\text { AVG Fixed- } \\
\text { Route } \\
\text { Speed } \\
\text { (mph) }\end{array}$ & $\begin{array}{c}\text { County } \\
\text { Population }\end{array}$ & $\begin{array}{c}\text { Trips per } \\
\text { Capita }\end{array}$ & $\begin{array}{c}\text { Passenger } \\
\text { Miles of } \\
\text { Travel }\end{array}$ & $\begin{array}{c}\text { Average } \\
\text { Trip } \\
\text { Length }\end{array}$ \\
\hline \multicolumn{9}{|l|}{2002} \\
\hline \multicolumn{9}{|l|}{2003} \\
\hline \multicolumn{9}{|l|}{2004} \\
\hline \multicolumn{9}{|l|}{2005} \\
\hline \multicolumn{9}{|l|}{2006} \\
\hline \multicolumn{9}{|l|}{2007} \\
\hline \multicolumn{9}{|l|}{2008} \\
\hline \multicolumn{9}{|l|}{2009} \\
\hline \multicolumn{9}{|l|}{2010} \\
\hline \multicolumn{9}{|l|}{2011} \\
\hline \multicolumn{9}{|l|}{2012} \\
\hline \multicolumn{9}{|l|}{2013} \\
\hline 2014 & 26,313 & 164,285 & 0.16 & & 99,121 & 0.3 & & 0.00 \\
\hline 2015 & 106,609 & 615,349 & 0.17 & & 101,353 & 1.1 & 642,596 & 6.03 \\
\hline 2016 & 109,444 & 619,942 & 0.18 & & 103,095 & 1.1 & 627,341 & 5.73 \\
\hline 2017 & 114,693 & 623,028 & 0.18 & & 105,157 & 1.1 & & \\
\hline
\end{tabular}


Ridership for the first four months of 2018 has been running approximately $6 \%$ below last year.

Average operating speed is not reported for demand responsive services.

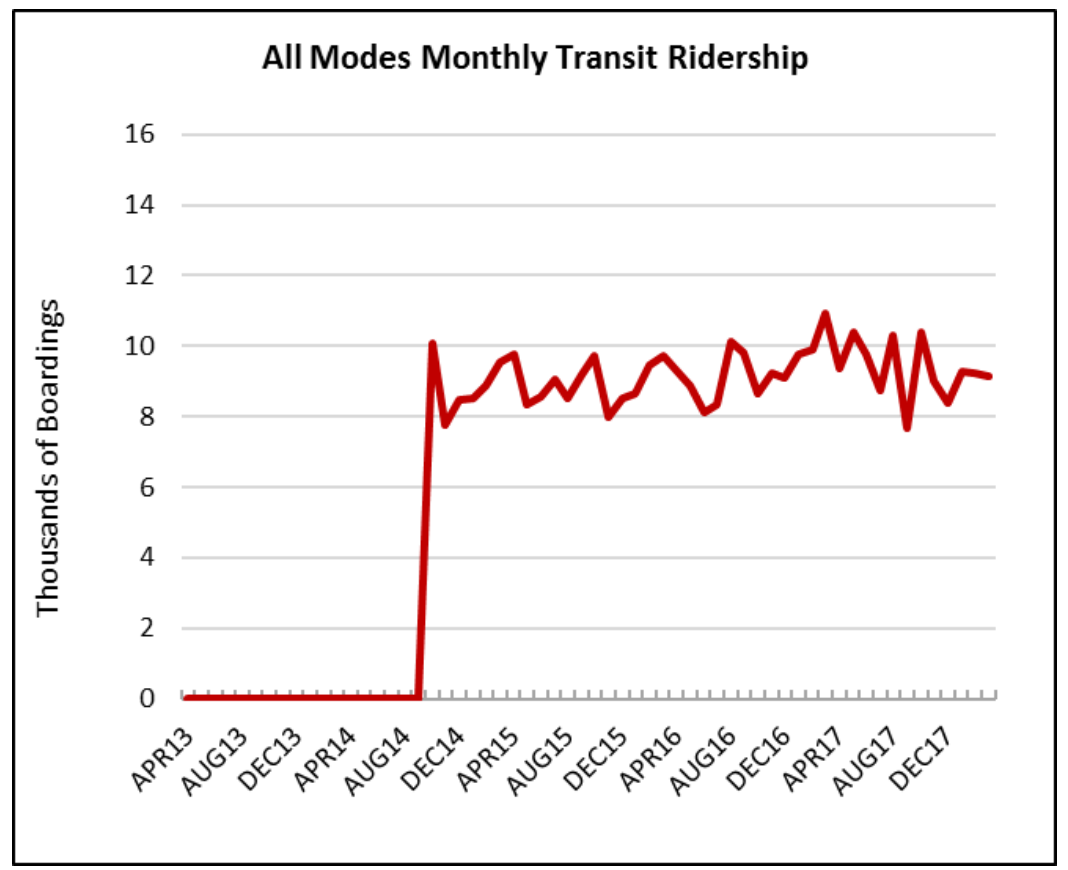

The adjacent graphic shows service productivity. Service productivity has increased slightly since inception.

The figures below provide the ridership trends and service supply trends by sub mode. This allows one to understand how the various component modes are performing.

Demand responsive service ridership has been steady over

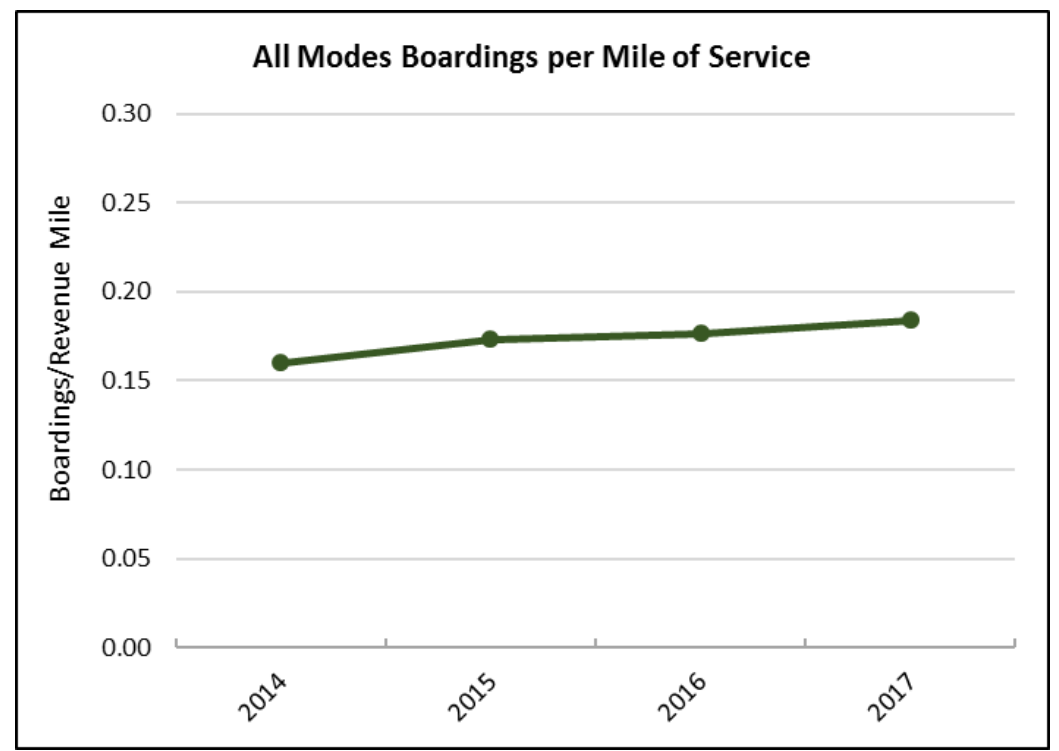
the past year and a three-year trend is not available.

The final graphic shows service supply as measured by revenue vehicle miles of service. As the graphical data communicates, demand responsive service supply has declined $5 \%$ in the past year. 
140,000
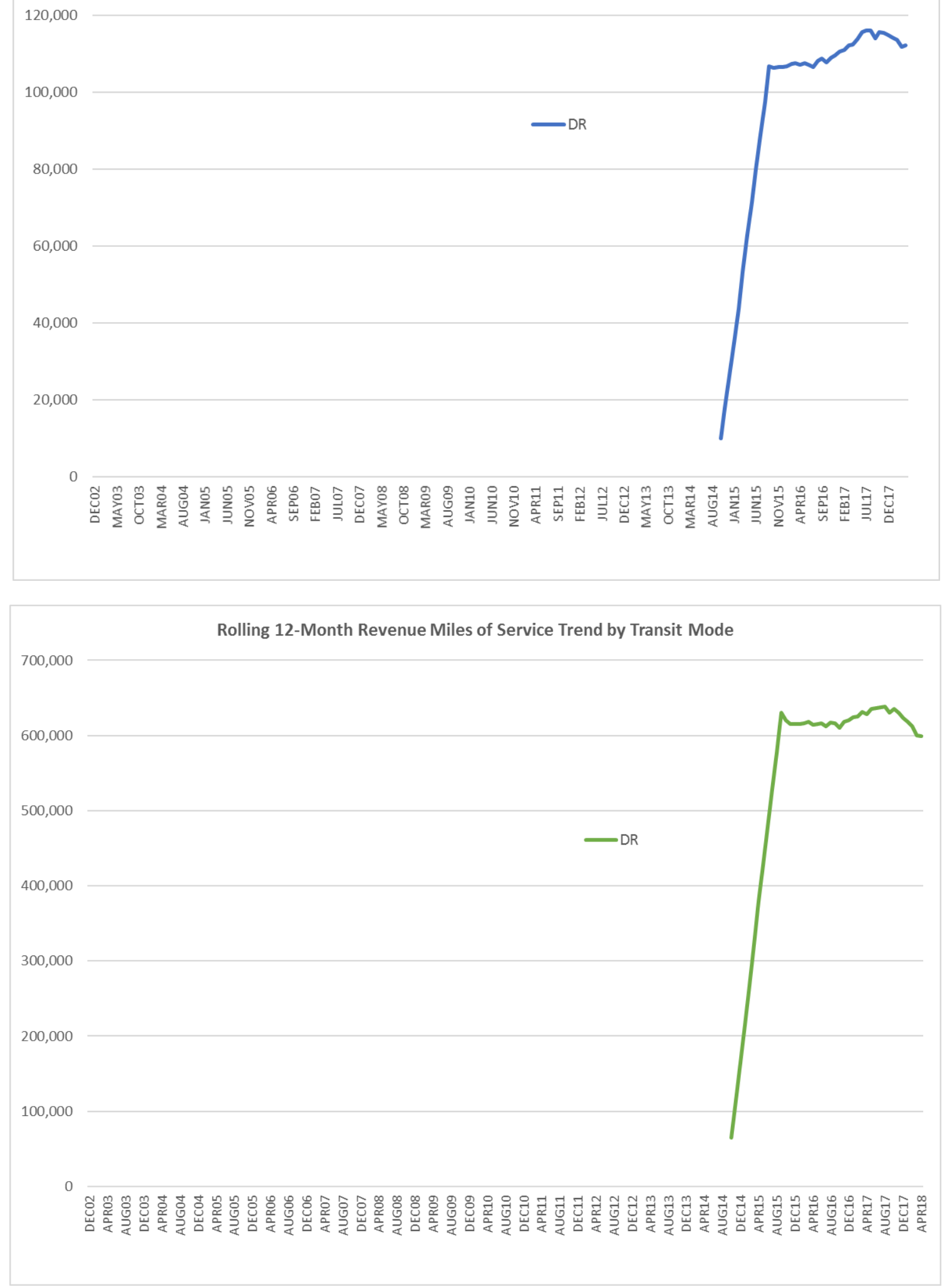
Martin County (Martin County Transit, Marty)

Martin County added

commuter bus service in

November 2015 to complement

their motorbus and demand responsive services. Ridership on the Martin County transit system has grown $80 \%$ since a peak in 2015. Vehicle revenue miles of service has declined $24 \%$ in that same time period.

Boardings per revenue mile has dropped $50 \%$ since its peak in 2012. Ridership per County resident has declined $14 \%$ from

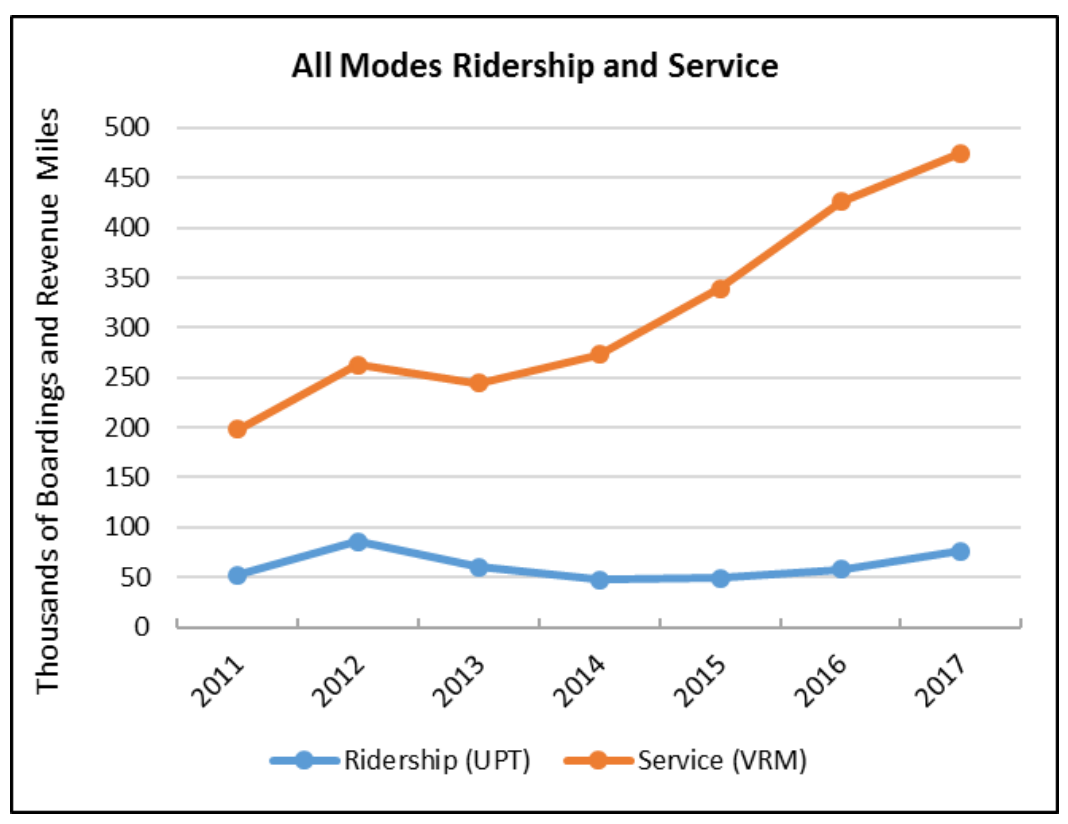
its peak in 2012.

Average trip length on transit has fluctuated significantly and more recently been approximately 8 miles.

\begin{tabular}{|c|c|c|c|c|c|c|c|c|}
\hline \multicolumn{9}{|c|}{ Annual Trend Data, All Modes } \\
\hline Year & Ridership (UPT) & Service (VRM) & $\begin{array}{l}\text { Boardings per } \\
\text { Revenue Mile }\end{array}$ & $\begin{array}{l}\text { AVG Fixed- } \\
\text { Route } \\
\text { Speed } \\
\text { (mph) }\end{array}$ & $\begin{array}{c}\text { County } \\
\text { Population }\end{array}$ & $\begin{array}{l}\text { Trips per } \\
\text { Capita }\end{array}$ & $\begin{array}{c}\text { Passenger } \\
\text { Miles of } \\
\text { Travel }\end{array}$ & $\begin{array}{c}\text { Average } \\
\text { Trip } \\
\text { Length }\end{array}$ \\
\hline \multicolumn{9}{|l|}{2002} \\
\hline \multicolumn{9}{|l|}{2003} \\
\hline \multicolumn{9}{|l|}{2004} \\
\hline \multicolumn{9}{|l|}{2005} \\
\hline \multicolumn{9}{|l|}{2006} \\
\hline \multicolumn{9}{|l|}{2007} \\
\hline \multicolumn{9}{|l|}{2008} \\
\hline \multicolumn{9}{|l|}{2009} \\
\hline \multicolumn{9}{|l|}{2010} \\
\hline 2011 & 52,534 & 198,360 & 0.26 & 13.90 & 146,689 & 0.4 & 118,400 & 2.25 \\
\hline 2012 & 85,414 & 262,717 & 0.33 & 11.84 & 147,203 & 0.6 & 368,637 & 4.32 \\
\hline 2013 & 60,228 & 244,389 & 0.25 & 13.53 & 148,077 & 0.4 & 382,234 & 6.35 \\
\hline 2014 & 47,102 & 273,053 & 0.17 & 13.97 & 148,585 & 0.3 & 407,030 & 8.64 \\
\hline 2015 & 48,734 & 338,873 & 0.14 & 16.01 & 150,062 & 0.3 & 471,091 & 9.67 \\
\hline 2016 & 57,728 & 426,400 & 0.14 & 18.92 & 150,870 & 0.4 & 440,100 & 7.62 \\
\hline 2017 & 76,472 & 475,052 & 0.16 & 19.05 & 153,022 & 0.5 & & \\
\hline
\end{tabular}


The monthly ridership trend shows the influence of hurricane Irma. Ridership has generally been increasing since mid-2013. For the first four months of 2018 ridership is approximately $32 \%$ ahead of last year.

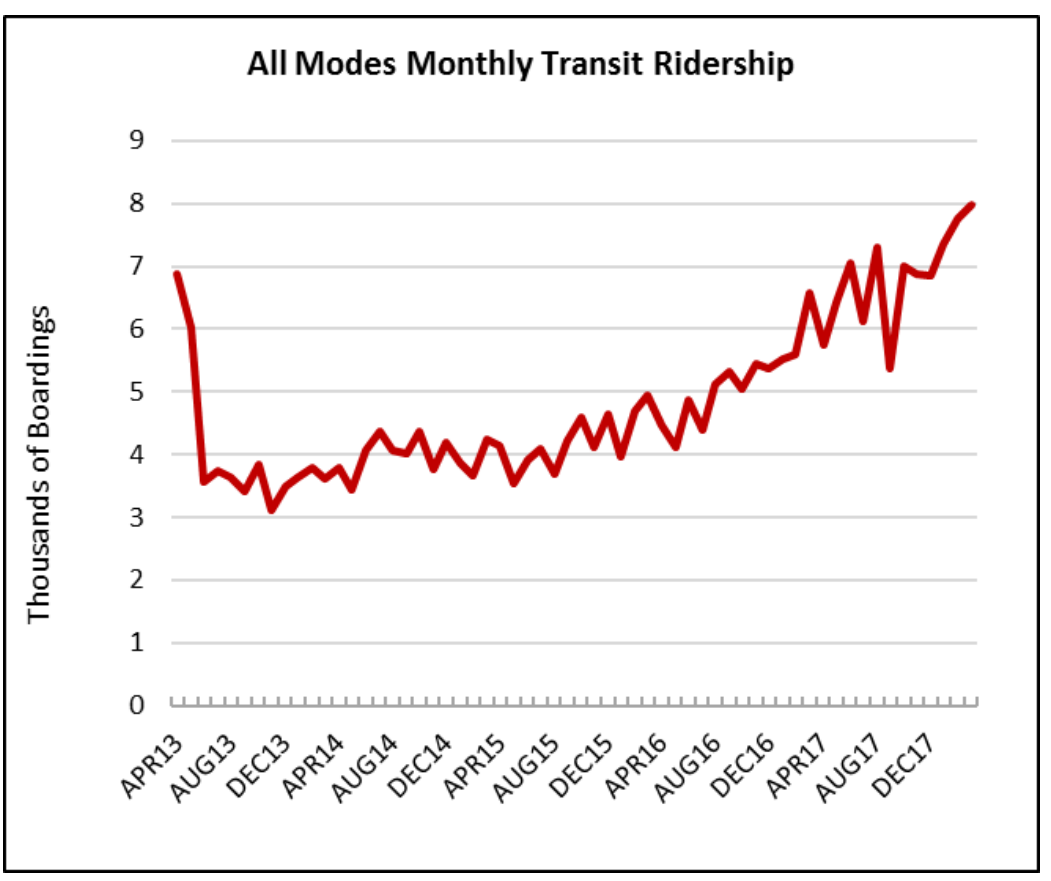

Average operating speed, defined as vehicle revenue miles divided by vehicle revenue hours, has increased to over 19 $\mathrm{mph}$, a relatively fast speed for transit service.

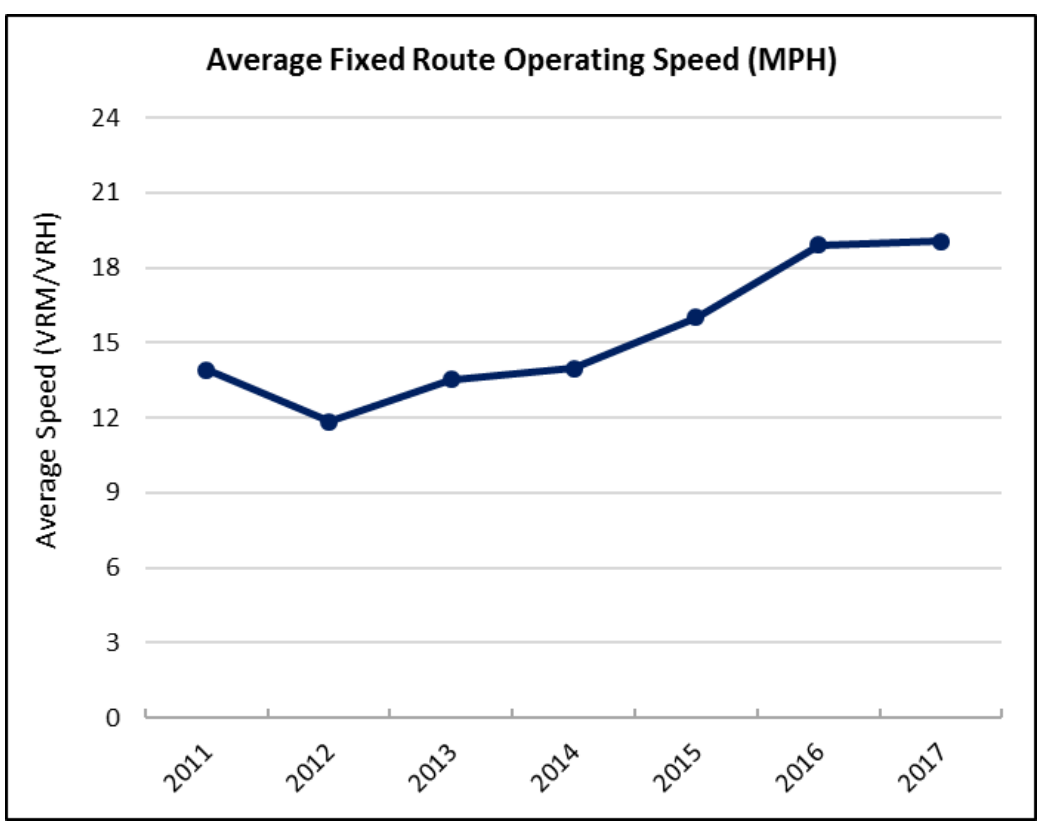


The adjacent graphic shows service productivity. Service productivity has declined since 2012 before increasing from 2016 to 2017.

The figures below provide the ridership trends and service supply trends by sub mode. This allows one to understand how the various component modes are performing.

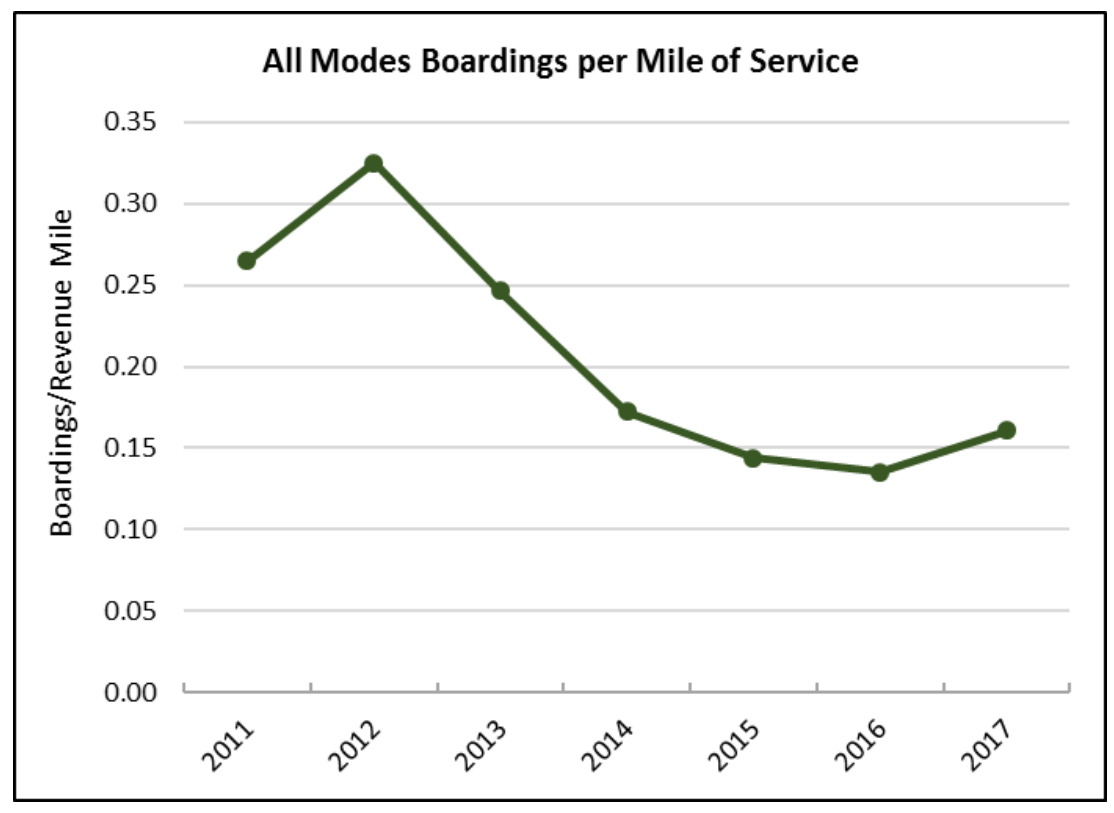


Bus ridership has grown approximately $33 \%$ over one year and $81 \%$ over three years. Demand responsive service has grown $7 \%$ in the last year and declined $29 \%$ over the past three. Commuter bus service has grown $59 \%$ in the last year.

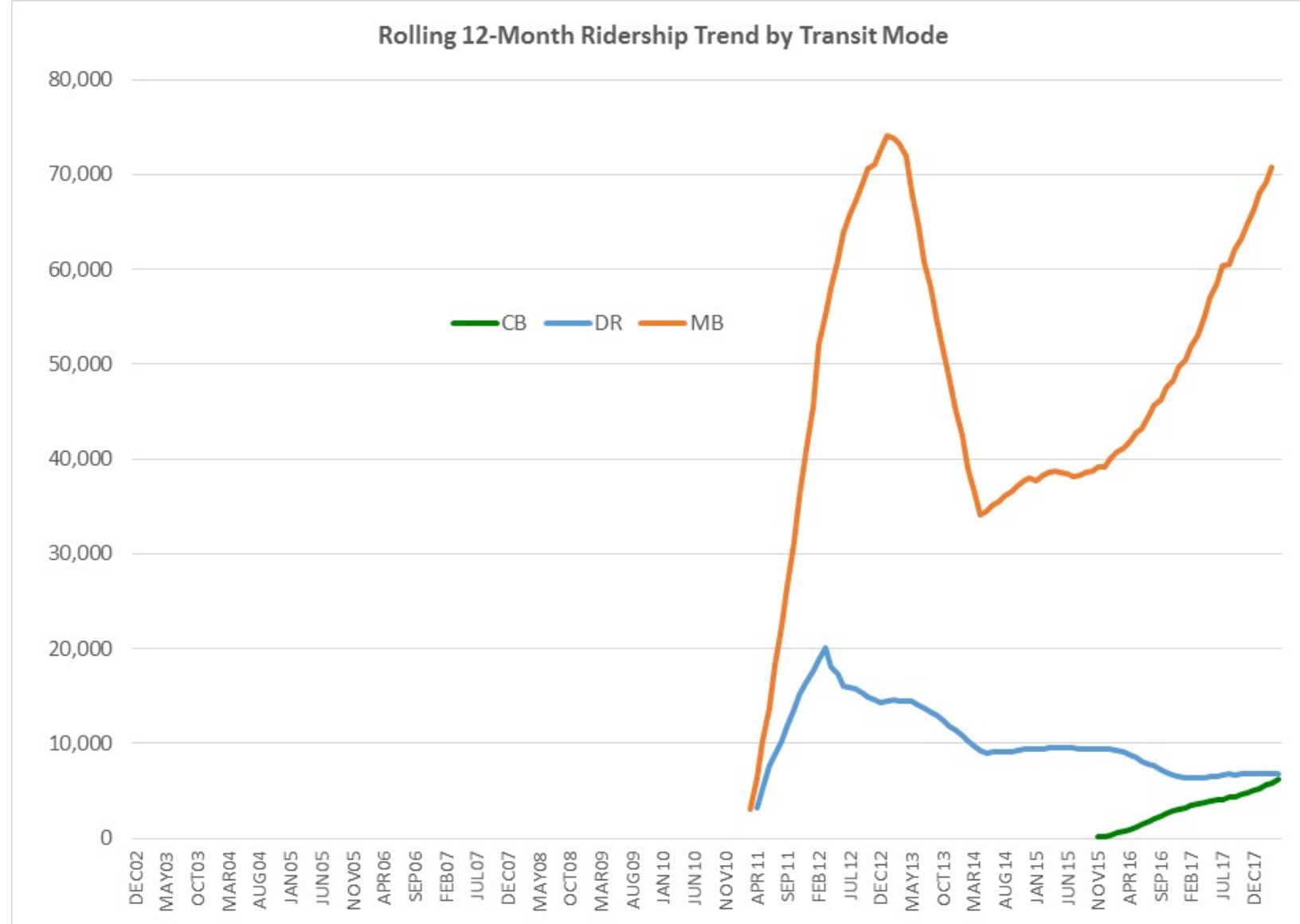

The final graphic shows service supply as measured by revenue vehicle miles of service. As the graphical data communicates, bus service supply has declined $8 \%$ in the past year and $1 \%$ over three years. Demand responsive service has grown $19 \%$ and $49 \%$ respectively in the one in three year periods. 
Rolling 12-Month Revenue Miles of Service Trend by Transit Mode

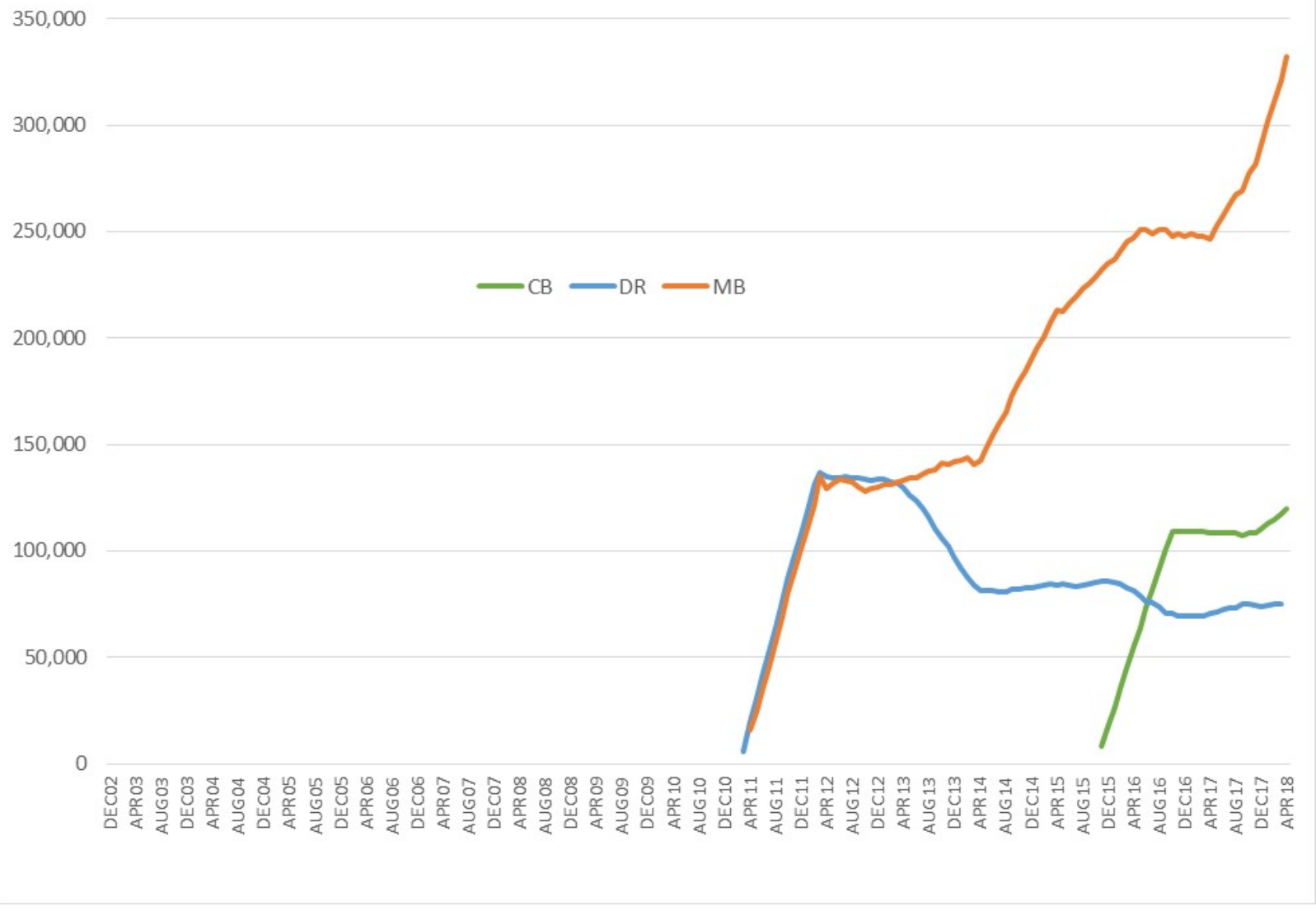




\section{Polk County (Polk County Transit Services Division)}

\section{Polk County ceased reporting}

transit ridership in September 2015 when service was integrated throughout the County. This historical peak ridership level occurred in 2006. Ridership trended downward from 2012 until the service was redesigned in Polk County.

Average trip length on transit had been running in excess of 10 miles.

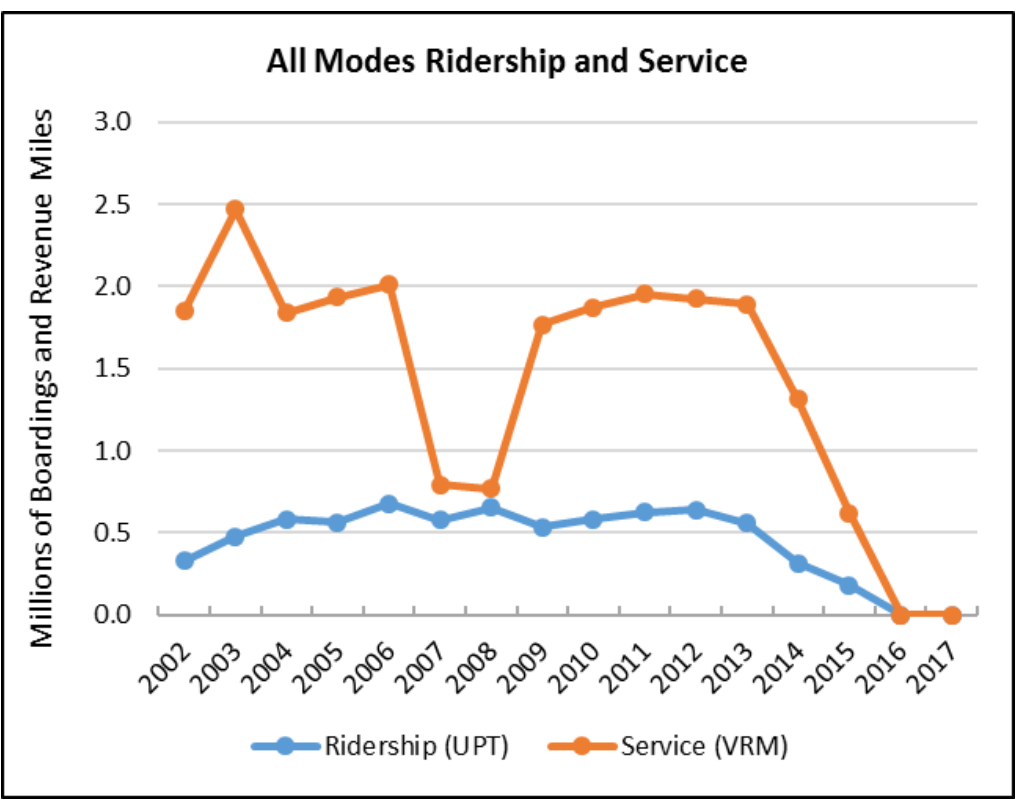

\begin{tabular}{|c|c|c|c|c|c|c|c|c|}
\hline \multicolumn{9}{|c|}{ Annual Trend Data, All Modes } \\
\hline Year & Ridership (UPT) & Service (VRM) & $\begin{array}{l}\text { Boardings per } \\
\text { Revenue Mile }\end{array}$ & $\begin{array}{l}\text { AVG Fixed- } \\
\text { Route } \\
\text { Speed } \\
\text { (mph) }\end{array}$ & $\begin{array}{c}\text { County } \\
\text { Population }\end{array}$ & $\begin{array}{c}\text { Trips per } \\
\text { Capita }\end{array}$ & $\begin{array}{c}\text { Passenger } \\
\text { Miles of } \\
\text { Travel }\end{array}$ & $\begin{array}{c}\text { Average } \\
\text { Trip } \\
\text { Length }\end{array}$ \\
\hline 2002 & 326,797 & $1,846,554$ & 0.18 & 18.65 & 502,385 & 0.7 & $2,149,019$ & 6.58 \\
\hline 2003 & 474,633 & $2,471,280$ & 0.19 & 19.10 & 511,929 & 0.9 & $2,446,362$ & 5.15 \\
\hline 2004 & 582,941 & $1,838,282$ & 0.32 & 17.29 & 528,389 & 1.1 & $2,015,753$ & 3.46 \\
\hline 2005 & 562,112 & $1,935,641$ & 0.29 & 18.55 & 541,840 & 1.0 & $2,205,109$ & 3.92 \\
\hline 2006 & 674,778 & $2,010,935$ & 0.34 & 18.40 & 565,049 & 1.2 & $1,303,489$ & 1.93 \\
\hline 2007 & 576,214 & 791,014 & 0.73 & 18.72 & 581,058 & 1.0 & $1,412,596$ & 2.45 \\
\hline 2008 & 653,621 & 765,690 & 0.85 & 18.88 & 585,733 & 1.1 & $3,268,668$ & 5.00 \\
\hline 2009 & 533,774 & $1,768,738$ & 0.30 & 21.54 & 584,343 & 0.9 & $4,063,522$ & 7.61 \\
\hline 2010 & 581,386 & $1,871,012$ & 0.31 & 21.59 & 602,788 & 1.0 & $4,036,165$ & 6.94 \\
\hline 2011 & 626,245 & $1,955,169$ & 0.32 & 21.38 & 604,792 & 1.0 & $6,714,109$ & 10.72 \\
\hline 2012 & 640,312 & $1,926,820$ & 0.33 & 20.68 & 606,888 & 1.1 & $6,522,069$ & 10.19 \\
\hline 2013 & 555,279 & $1,893,120$ & 0.29 & 19.50 & 613,950 & 0.9 & $6,472,268$ & 11.66 \\
\hline 2014 & 313,171 & $1,311,993$ & 0.24 & 17.79 & 623,174 & 0.5 & $3,107,371$ & 9.92 \\
\hline 2015 & 180,362 & 620,006 & 0.29 & 17.48 & 633,052 & 0.3 & $2,221,917$ & 12.32 \\
\hline 2016 & & & & & 646,989 & 0.0 & & \\
\hline 2017 & & & & & 661,645 & 0.0 & & \\
\hline
\end{tabular}


Monthly ridership had trended down for two years prior to the service redesign.

Average operating speed, defined as vehicle revenue miles divided by vehicle revenue hours, has been averaging between 17.5 and $20.5 \mathrm{mph}$, a relatively fast speed for transit service.
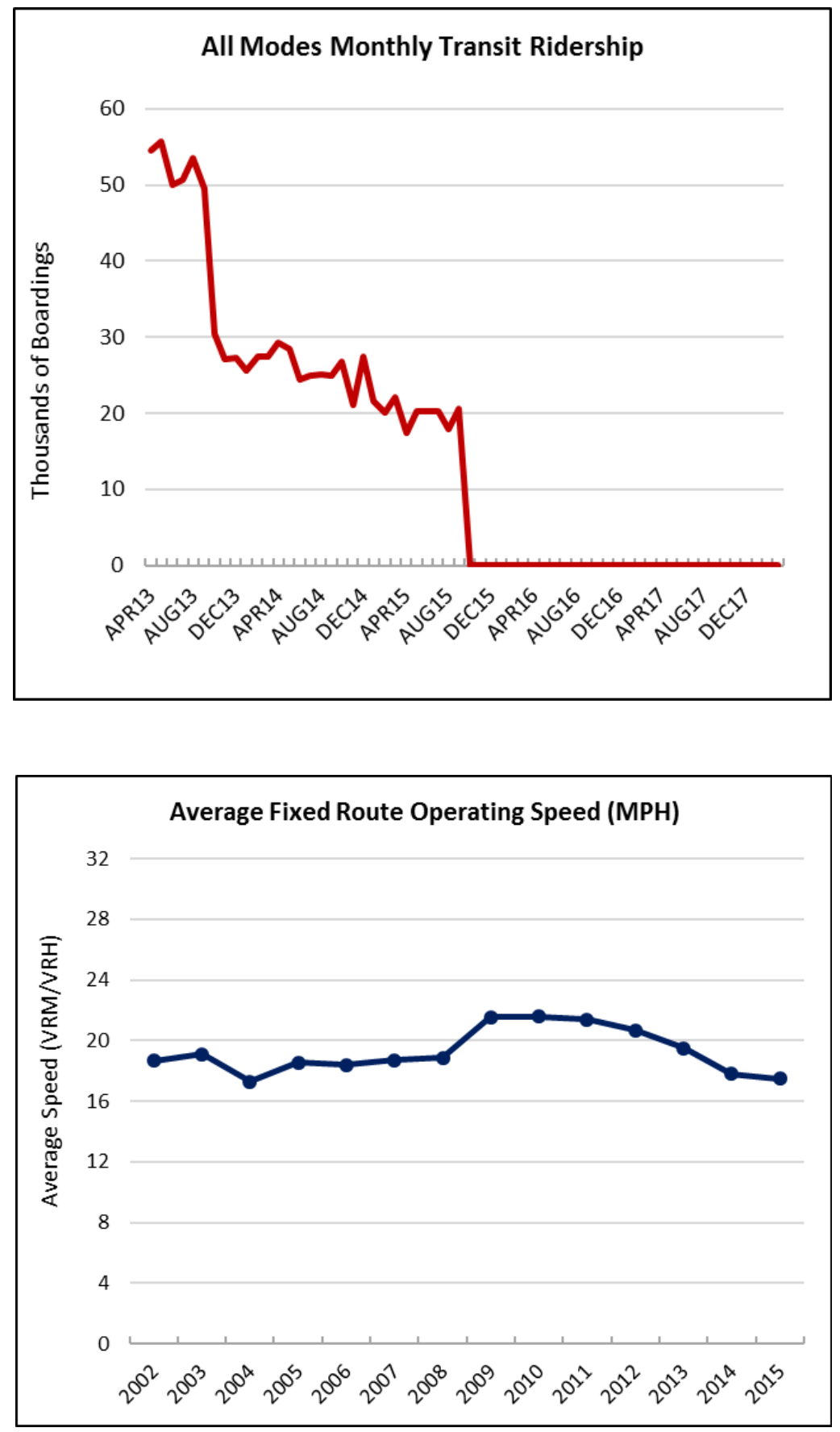
The adjacent graphic shows service productivity. The shape of the curve is influenced by incomplete reporting of mileage in 2007 and 2008.

The figures below provide the ridership trends and service supply trends by sub mode. This allows one to understand how the various component modes are performing.

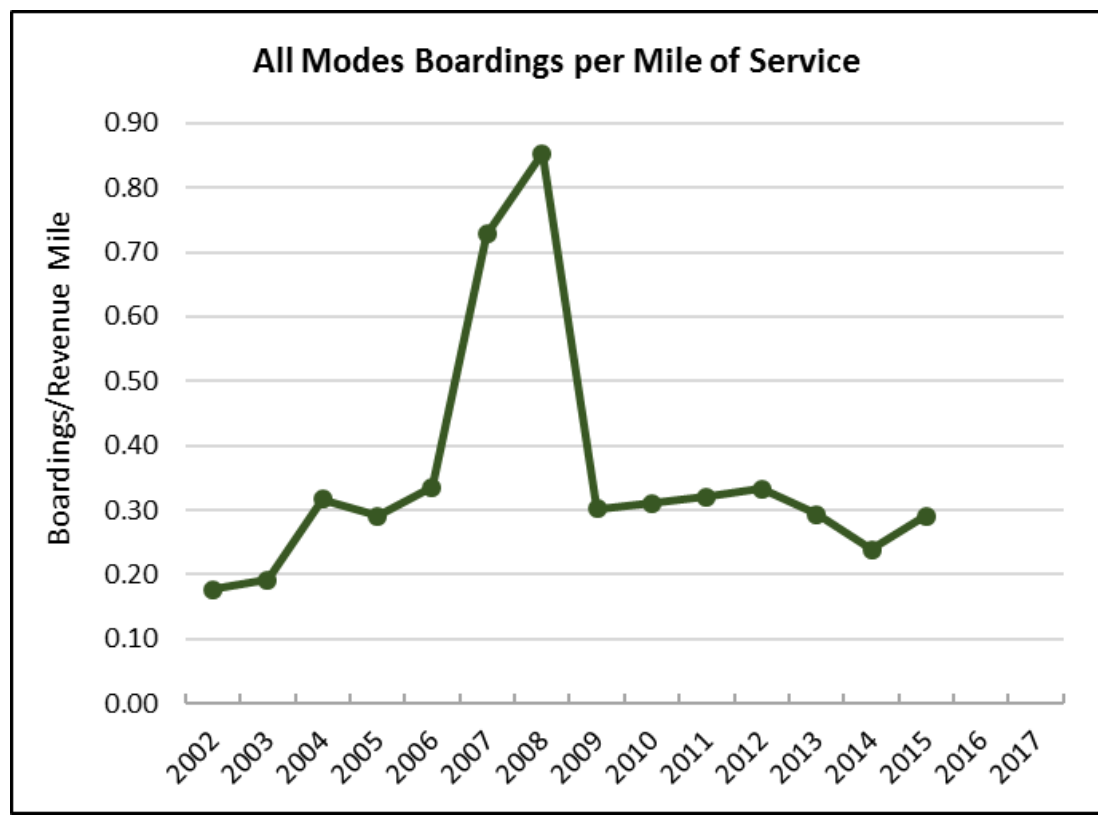

Missing data and discontinuation of the service make comparative metrics inappropriate.

Rolling 12-Month Ridership Trend by Transit Mode

\section{0,000}

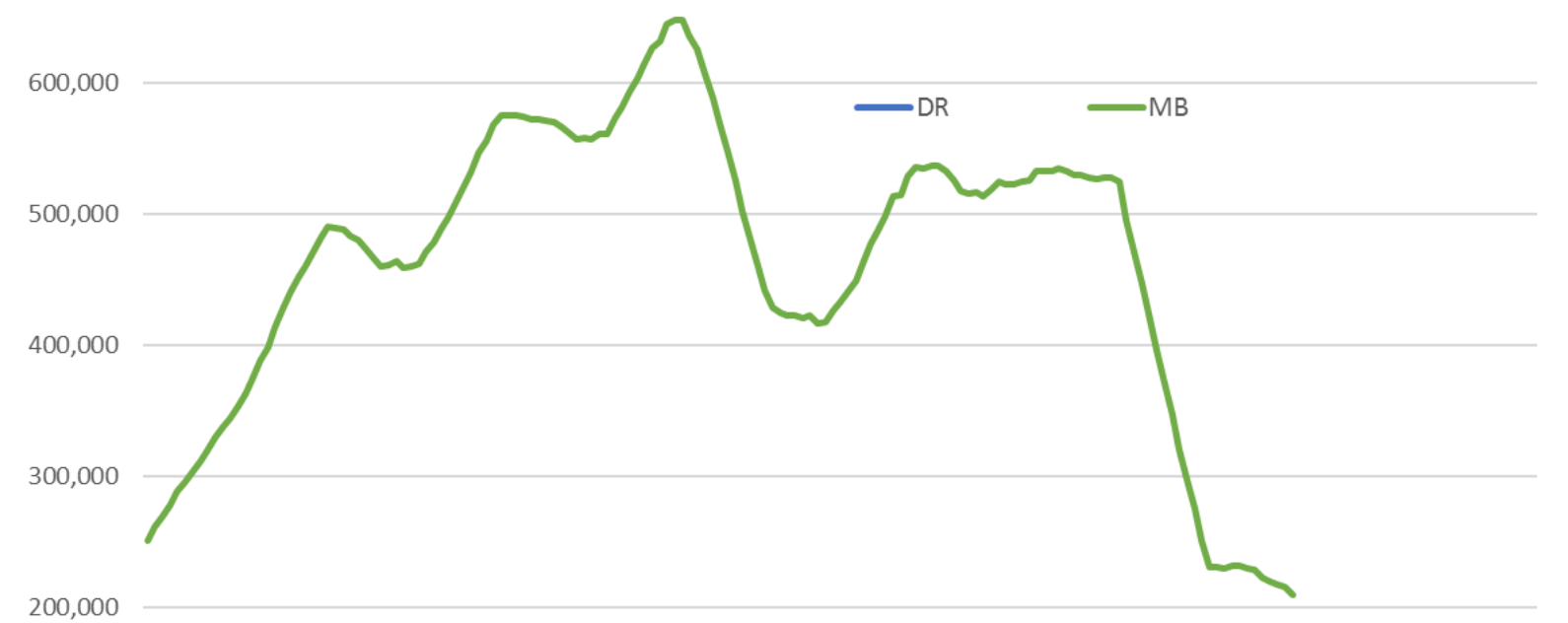

100,000

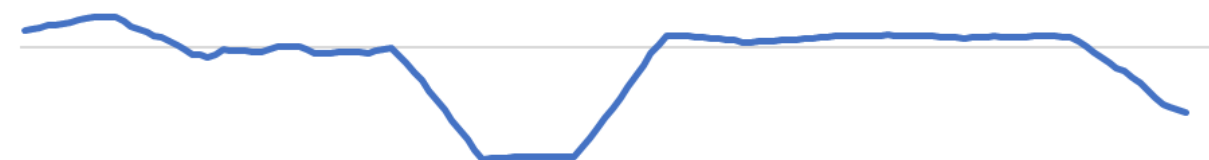

0 


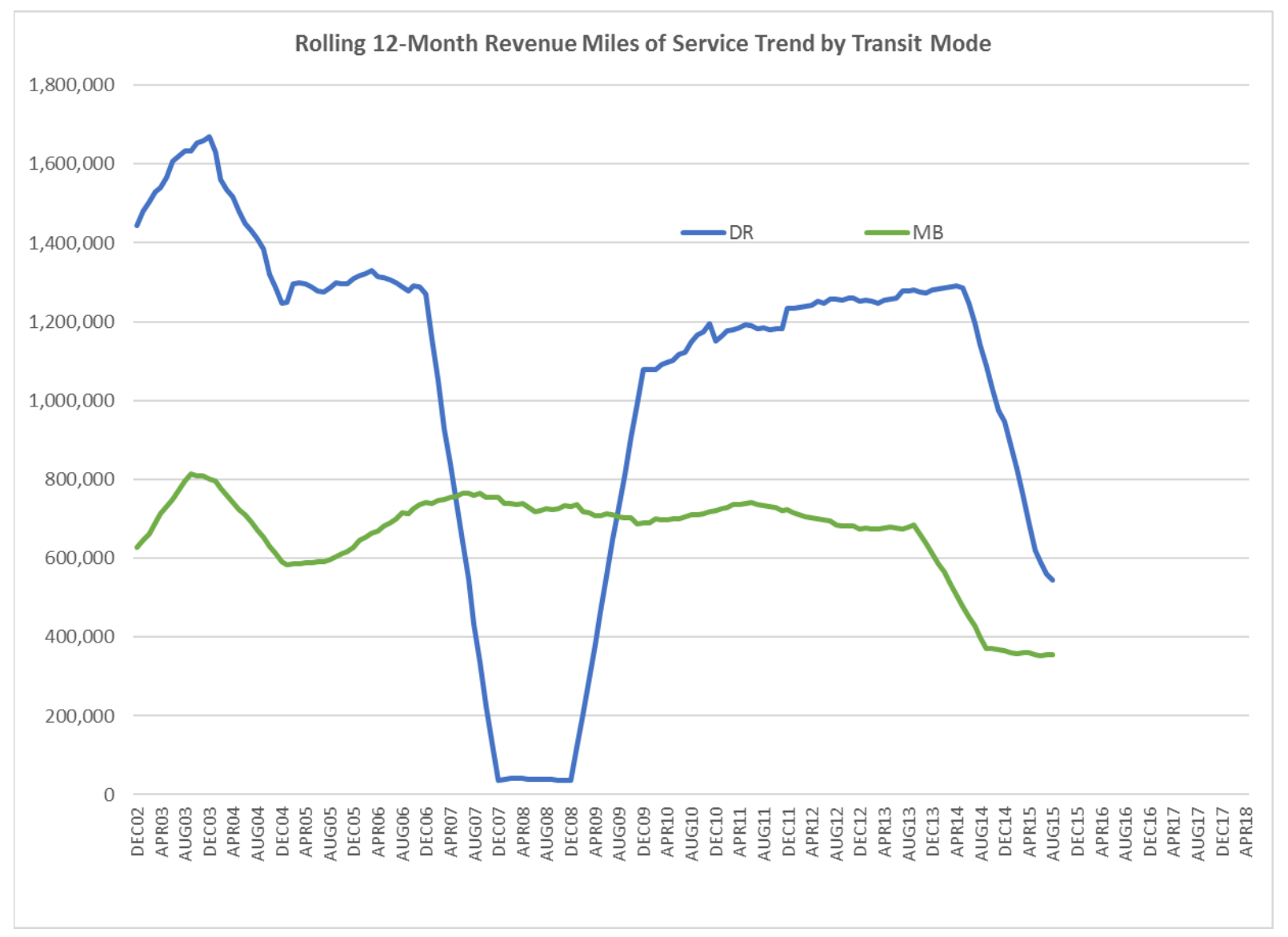




\section{Appendix B Stakeholder Interaction}

This research initiative called for communications with stakeholders. The intention was both to solicit input and access to data as well as to share findings and results. These interactions took a number of different forms.

Early in the project a set of stakeholders was identified. This included identifying contact individuals for Florida transit properties as well as identifying other stakeholders including district representatives of FDOT, representatives of professional associations that represented the transit industry, and select other practitioners and interested parties. Transit agencies in particular were communicated with, generally the email but occasionally with follow-up phone calls, to identify a contact person with whom to communicate. A list of contacts was identified and reviewed by FDOT.

After affirming a representative for each transit agency, a web-based survey was disseminated to solicit information. That survey content is shown below. Multiple follow-up emails were sent to non-respondents and phone calls were used in select instances. Survey results included answers to the narrative questions and the identification of data for use in subsequent phases of the analysis. Survey results responses are shown in the text box below the questionnaire.

\section{Transit Ridership Issues Questionnaire}

Name:

Affiliation/agency:

Email:

Phone:

As we explore transit ridership trends, we would appreciate your assistance in answering the following questions that are relevant to your situation. Please attach any supporting documentation to your questionnaire response.

Given changing transit ridership, has your agency engaged in any of the following:

1. Initiated new data collection to more fully understand ridership changes?

$\square$ No $\quad \square$ Yes. Please describe

2. Initiated staff efforts or procured support for a more detailed analysis of ridership changes?

$\square$ No $\quad \square$ Yes. Please describe 
3. Modified service (frequency, span, operating hours) specifically in response to changing ridership? $\square$ No $\quad \square$ Yes. Please describe

4. Explored strategic responses relating to longer-term service and capital needs?

$\square$ No $\quad \square$ Yes. Please describe

5. Other activities specifically in response to ridership changes?

$\square$ No $\quad \square$ Yes. Please describe

Do you have any information, observational or quantitative, regarding the following possible changes in your transit ridership?

6. Changes in the demographic characteristics of your transit passengers (changes in age, income, gender, race/ethnicity, household vehicle availability, etc.)?

$\square$ No $\quad \square$ Yes. If yes, are there any documents or data available (for example sequential on-board surveys)?

7. Changes in the distribution of trip purposes of transit riders?

$\square$ No $\quad \square$ Yes. If yes, are there any documents or data available (for example sequential on-board surveys)?

8. Changes in temporal pattern of demand for transit (peak, midday, evening, weekends)?

$\square$ No $\square$ Yes, If yes, (for example APC or fare box data)? 
9. Changes in ridership patterns across transit service types (local, express, circulator, crosstown, etc.)? $\square$ No $\quad \square$ Yes, If yes, (for example APC or fare box data)?

10. Changes in ridership by fare payment category, etc.?

$\square$ No $\square$ Yes, If yes, (for example APC or fare box data)?

11. Based on observations or feedback from passengers, employees, or the community, what factors do you feel have been contributing to changing ridership in your community? Please describe.

12. Do you have any specific questions about changing ridership trends that we might address in this study?

Return to: Steven Polzin, polzin@cutr.usf.edu, 


\section{Online Survey of Florida Transit Properties}

Florida transit properties were communicated with both to share existing NTD data sets for verification and to solicit additional data to help in the analysis. After multiple follow-up email and telephone calls. We have received 20 responses to the online survey. In addition, we have received data and communications from some agencies. Provided data will be used in the analysis and we may continue to approach select agencies for more detailed analysis. As one would note from a review of figure 1, a significant share of the total statewide decline in transit ridership occurred in Miami Dade and Broward counties. Accordingly, we will be paying particular attention to data available from those locations in our analysis.

Table 6. Preliminary Results from Survey

\section{Has your agency:}

$\begin{array}{ll}\text { No } & \text { Yes } \\ 12(63 \%) & 7(37 \%) \\ 9(47 \%) & 10(53 \%) \\ 6(32 \%) & 13(68 \%) \\ 8(44 \%) & 10(56 \%) \\ 8(42 \%) & 11(58 \%)\end{array}$

initiated any other activities specifically in response to ridership changes?

Do you have any information, observational or quantitative,

No

Yes regarding:

Changes in the distribution of demographic characteristics of your 13 (76\%) transit passengers (changes in distribution of age, income, gender, race/ethnicity, household vehicle availability, etc.)?

Changes in the distribution of trip purposes of transit riders?

Changes in temporal pattern of demand for transit (peak, midday,

$13(76 \%)$

4 (24\%) evening, weekends)?

Changes in ridership patterns across transit service types (local,

13 (76\%)

$4(24 \%)$ express, circulator, crosstown, etc.)?

Changes in ridership by geography? (Urban core, city, suburb,

$13(76 \%)$

$4(24 \%)$ fringe, etc.)

Changes in ridership by fare payment category, etc.?

15 (88\%)

2 (12\%) 
As a follow-up to questionnaire, communications with several transit agencies were carried out to secure copies of surveys of customers for use in the technical analysis. In addition, consultants actively engaged in transit planning were similarly supportive in providing documents.

During the course of the research effort there were initiatives carried out to share observations and findings with various stakeholders. Four specific sets of interactions were significant in terms of the number of industry/stakeholder participants. CUTR hosted three webinars addressing transit ridership issues. The first of those webinars was presented on March 29, 2018. 105 IP addresses were logged into the webinar including many from Florida. Some parties had multiple attendees at each IP address. PowerPoint materials were presented and subsequently made available to participants. Similarly, the webinar he was recorded and available for download. To date 216 additional parties have viewed the webinar online. The recording of the webinar can be accessed at https://www.cutr.usf.edu/2018/03/cutr-webcasttrends-in-travel-behavior-and-transit-ridership/.

A subsequent webinar was held on April 12, 2018 to continue educating stakeholders with respect to factors influencing transit ridership. This webinar presented work developed independent of this project but complementary. Online attendance included 51 live IP address participants and 137 subsequent downloads of the saved webinar. The recording to the webinar can be accessed at https://www.cutr.usf.edu/2018/04/cutr-webcast-socio-economic-factorsridership-trends/.

A third webinar was held on Thursday, November 8, 2018 specifically presenting findings and observations regarding this project. This presentation had 60 IP attendees and as of December 10,2018 , it has had 59 subsequent views. The recording to the webinar can be accessed at https://www.cutr.usf.edu/2018/11/cutr-webcast-understanding-florida-transit-ridershipdeclines-and-how-we-can-respond/.

Question and answer opportunities Incorporated in these seminars provided a chance for attendees to have their questions addressed. Presented materials as well as participant evaluations were provided to FDOT.

In addition to these communications, project investigator Steven Polzin presented information on transit ridership trends and associated issues as the luncheon keynote speaker at the 2018 FPTA/FDOT/CUTR Professional Development Workshop \& Transit Safety and Operations 
Summit, on Wednesday, June 6, 2018. This presentation titled, Making Transit Great Again, was attended by in excess of 180 workshop participants.

An additional stakeholder outreach occurred in the form of communications with the select group of individuals actively engaged in transit planning. They are insights were sought regarding issues associated with how public transportation planning might need to change in response to ridership trends. 